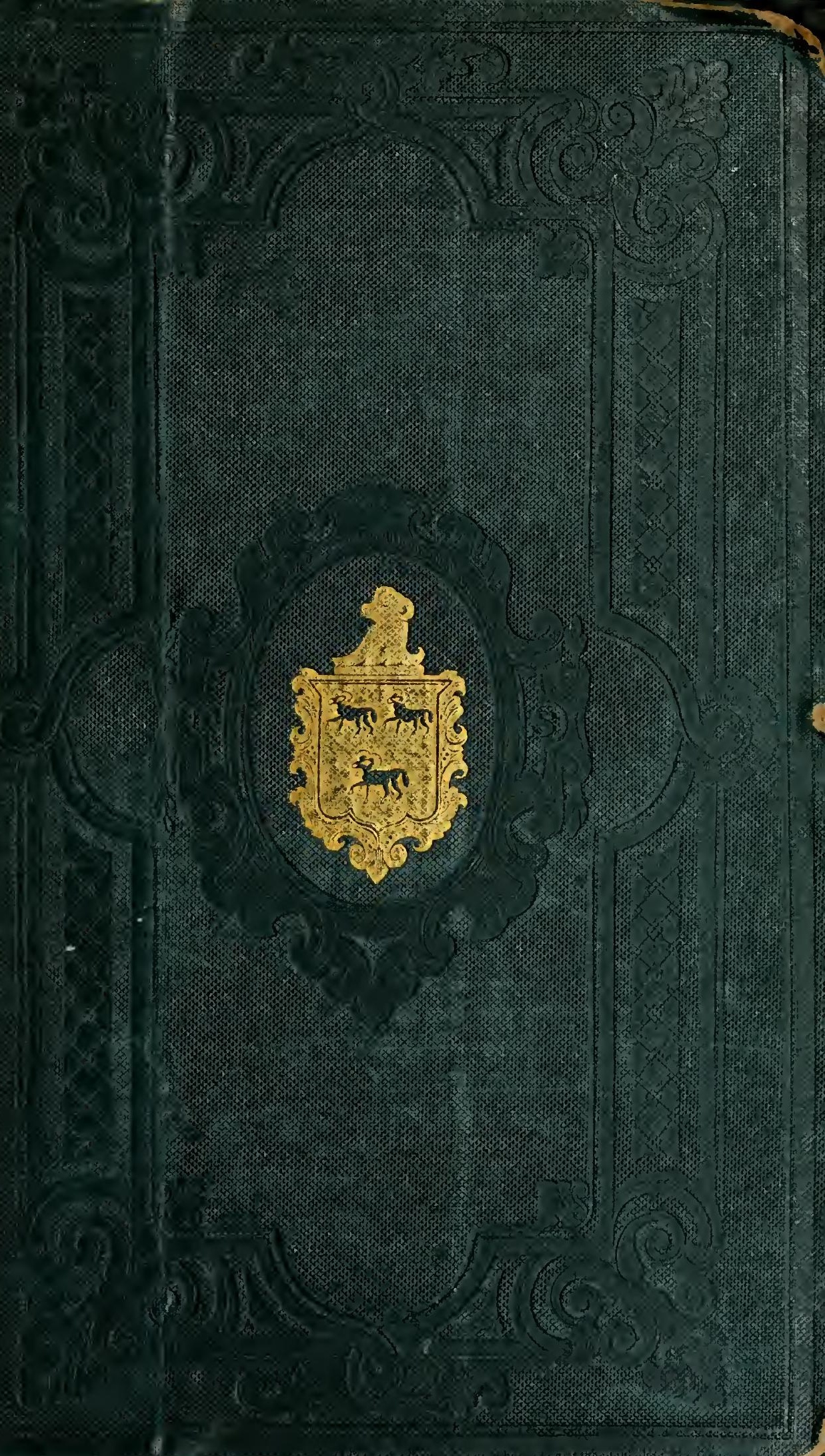




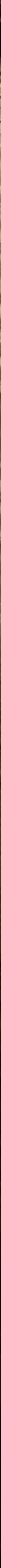


(59) 
Digitized by the Internet Archive in 2008 with funding from Microsoft Corporation 
II A N U A L

of

ANIMAL AND VEGETABLE PARASITES. 



\title{
ANIMAL AND VEGETABLE PARASITES
}

OF THE

\author{
H U M A N B O D Y,
}

A M A N A L

OF THEIR

NATURAL HISTORY, DIAGNOSIS, AND TREATMEN'T.

B Y

DR. FREDERICH K ÜCHENMEISTER,

PIISICIAN TO HIS SERENE HIGHNESS THE DUKE OF SAXE MEININGEN; CORRESPONDING MEMBER

OF THE ISIS SOCIETY $\triangle N D$ OF THE NATCRAL HISTORY AND MEDICAL SOOIETY OF DRESDEN ; THE IMPERIAI, SOCIETY OF PHYSICIANS AT VIENNA, ETC. ETC.

THANSLATED FROI THE SECOND GERMAN EDITION, BT

E D W N LA N K E T ER, M.D., F.R.S.

VOL. I.

ANIMAL PARASITES BELONGING TO THE GROUP ENTOZOA.

WITH EIGHT COPPER-PLATES.

\section{LON DON :}

PRINTED FOR THE SYDENHAM SOCIE'TY.

M D C C I, VII.

[The right of Reproduction and Translation is reserved.] 


$$
\begin{aligned}
& \frac{13086}{1191^{91}} \\
& R C \\
& 119 \\
& k 843 \\
& 1854 \\
& 61
\end{aligned}
$$




\section{THE}

\section{S YDENHA M SOCIETY,}

INSTITUTED

MnReCXLIII

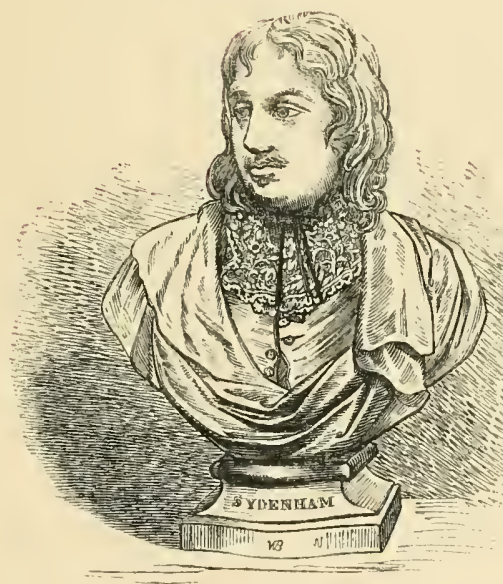

LONDON

MDCCCIVIJ. 



\section{PREFACE TO THE GERMAN EDITTON. ${ }^{1}$}

Tнь knowledge of Parasites, a knowledge which interests the medical practitioner, as well as the pathological anatomist, is usually treated of either in larger or smaller fragments, both in manuals of pathology and therapeutics, as well as text-books of pathological anatomy. The conviction that, notwithstanding the admirable contributions of various writers, much still remains to be done; the attempts of recent pathological anatomists, as, for instance, Förster, to get rid of this branch of science entirely from the text-books of pathological anatomy; the necessity which has been felt at different periods for special works upon the human parasites, such as have been produced by Bremser, Delle Chiaje, and others ; the opinion, which is certainly shared by all, that these last-mentioned works are antiquated; and, finally, the individuality which this branch of natural listory has acquired of late years, induce me to furnish the public, whether interested practically or theoretically in the subject, with a textbook and manual treating of the parasites of the human body, in a manner corresponding to the requirements of the present day, and illustrated with explanatory plates.

The plan of the book itself is as follows:- In the first division I shall treat of the Animal Parasites, and this will be founded, as far as it was possible in my native country, upon my own investigations; I shall begin with the Cestoidea, upon which I shall

- This preface appcared in the first German edition of the work, and was published with the first part of the first lialf of the work. 
communicate in more detail those observations which I sent at the time, in nuce, to the Academy of Sciences in Paris, and in consequence of which the academy decreed me an "honorable mention," togrether with a medal of the value of 1500 francs, whilst I was requested by the French sarants to proceed with my communications. At the same time those experiments will be reported upon, which the Saxon ministry of the interior, at my request, allowed to be made at its expense, by Professor Haubner at the Veterinary School at Dresden, under my instructions; as also the experiments made, principally with materials forwarded by me, at Berlin, Copenhagen, Giessen, Lourain, Stuttgart, Vienna, Weyhenstephan, and recently by M. Kind, of Kleinbautzen, and myself, at the charge of the Agricultural Society of Saxon Lusatia.

This will be followed by the section on the Trematoda, with views as to the mode in which man and animals are infected with these parasites, and with this the first half of the first division will conclude.

The second division will contain the natural history of the Nematoidea, with ideas and experiments upon the progenitors of the Trichinc; that of the parasitic insects, such as Linguatule (Pentastoma), Mites, Lice, and Fleas, in which an examination of the eggs (nits) of the lice upon Perurian mummies and the heads of New Zealanders will be referred to; and that of the pseudoparasites. An appendix, consisting of an account of experiments not yet concluded, and other recent materials, with a catalogue of rorks upon the subject, will conclude this part of the work.

A second independent division will be formed by the Vegetable parasites; with these I shall give a few special introductory remarks.

In each separate cliapter I shall give both the treatment and the scientific description of the parasites. Most of the figures hare been made from specimens prepared by myself; but when perfectly good figures existed, and I could make no preparations myself, I have giren copies, always naming the author. I have, however, omitted giving copies of those parasites which have only 
once been found by others, or which, in other respects, are deficicnt in interest.

The animals employed in experiments by myself and at my own cost were, rabbits, cats, dogs, and a few sheep. The greater part of the pigs and sheep employed, were procured at the expense of the Saxon ministry of the Interior, by Professor Haubner; a great number of sheep were also provided at the expense of the Agricultural Society of Saxon Lusatia, and by the kindness of individual agriculturalists. Larger animals were not at my command, and I was obliged to console myself by the adrice of Saint Francis Xavier, who thought that the wisdom and greatness of the Creator might be recognised even from the cousideration of the "pecora minora:"- "si thure non licet, farre litandum est."

Larger animals (oxen) were employed for rearing Conuri by Professor May, in Weyhenstephan, who has had the kindness to inform me of the favorable result.

It still remains for me to return my public thanks for kind assistance in my endearours, to the Saxon Ministry of the Interior ; to the Agricultural Society of Saxon Lusatia; to MM. Kind, Von Magnus, Baron ron Uckermann, of Lutteritz, Ton Mucke, of Niederrennersdorf, and Pastor Kärmsen, of Drausendorf, for furnishing me with animals for experiment, and for sending me all sorts of materials for investigation with regard to sereral animal parasites; to Dr. Gurlt, of Berlin, for forwarding two female Strongyli for examination, as well as for other desirable Helmintha; to Professors Luschka and Richter, for sending me Trichina spiralis; to Professor Griesinger, for Distoma hamatobium; to Professor Leuckart, of Giessen, and Dr. G. R. Wagener, of Berlin, for preparations of Tania, which have been made use of in part on Pl. IV; to M. Kinne, apothecary of Herrnhut, for the communication on the Tania from the Cape of Good Hope; and to Madame Heller, of Hamburg, for furnishing me with several specimens of Tania mediocanellata and Bothriocephalus latus; also for literary assistance of various kinds to Dr. von Ammon, body-surgeon to his Majesty the King of Saxony, 
Professor H. L. Richter, of Dresten, and Dr. A. vou Graefe, of Berliı. But above all, I must thank my fricud Dr. F. A. 'Zenker', of Dresden, for sending fresh specimens of Trichina spiralis, fresh intestinal mucus, with living males and females of Oxyuris vermicularis, and spirit specimens of Trichocephalus. Lastly, I may also express my best thanks beforehand to all those who will have the goodness to assist me by forwarding rare parasites, especially living Trichocephati, which may be sent long distances in white of egg, and will remain alive for six or eight days; I must also beg all who are interested in this branch of science, to assist me by sending me rare parasites, especially those found on the human body (in spirit or white of egg), for examination and future use, eitlier as loans or gifts.

Finally, I shall be thankful for any sound criticisms or corrections founded apon personal study.

And thus I present to the public this book, with its preface (vorreden), which deserves the name of a preface more than most productions of the kind which, in homage to the fashion of the day, are written after works have been published in parts, and which might rather be called postscripts (naclureden). The postscript I leave to others, - may it be a good one. 


\section{TRANSLA'TOR'S PREFACE.}

Is introducing a translation of Küehenmeister's work on the Parasites affeeting Man to the members of the Sydenham Soeiety, I wish to say first a few words on the history of the undertaking; and, seeond, to make some remarks on the general scientifie theory involved in the history of the ereatures treated of in this first volume. In offering to translate the work, I was induced to do so by the interest I took in the subjeet from a natural history point of view; and as I had not been unused to translation, I hoped to have found time to eomplete the task myself. I had not got far with my work before I found that it would be utterly impossible for me, without assistance, to aceomplish the translation in the time desired by the Couneil of the Sydenham Society, I therefore seeured the serviees of my friend, Mr. W. S. Dallas, whose aequaintanee with the German language, and eompetent knowledge of natural history, rendered him peeuliarly qualified to aid me. And I would here express my thanks to that gentleman for his advice and assistanee in overcoming the difficulty of translating a large number of new terms into the English language. The work was placed in my hands in Mareh, 1856 , and by the following Deember the whole of the first volume, and the greater part of the second were translated, and ready for the press. About this time, the Couneil of the Sydenham Society were informed by Dr. Küchenmeister that he was preparing a second German edition, and that he was willing to plaee his notes and alterations at the disposal of the Society for the use of his translator. This offer was gladly aecepterl, and 
the manuscript and alterations of the anthor were placed in my liands. The additions and emendations were so numerons as to extend in the first volume alone to eleven sheets of the translated work. The labour of translating this quantity of new matter was, of course, considerable, but this labour was greatly increased from its having to be done from the author's manuscript. Nearly the whole of the already completed manuscript had also to be revised, for the insertion of the author's corrections. Whilst this labour was going on, in the spring of the year, an attack of illness compelled me to forego for some weeks all literary labour. These circumstances will explain the delay that has occurred in bringing out the first volume of this work.

I had at first wished to have added notes and explanations; but, as the work progressed, I found these might be made very numerous, and would not only increase the size of the work, but delay its publication. I have, however, added some matter in the form of an Appendix, relating to the subject. For this matter I am indebted to several friends. Mr. Rainey, Lecturer on Anatomy at St. Thomas's Hospital, has kindly forwarded to me a proof of his unpublished 'Memoir on Cysticercus cellulosa,' from which I have made several extracts. Professors Busk and Owen have kindly permitted me to use their manuscripts in the cases recorded in Appendix B. I am also obliged to Mr. Curling for his communications on the subject of the worm referred to in Appendix C.

As is usual, I have left all Latin descriptions as in the original. I have also done this in the case of prescriptions occurring where the treatment is referred to. Some of the abbreviations, as well as the remedies, will undoubtedly be as puzzling to the reader as to myself, but I preferred allowing them to stand rather than to rum the hazard of giving a wrong interpretation to that which laid out of the province of the translator.

I now turn to the scientific theory involved in some parts of this book. Although written by a medical man, engaged in practice, and with a thoroughly practical aim, some of the most 
practical parts involve questions of the highest scientific interest, and of a purely theoretical character. They afford, indeed, a beautiful illustration of the fact, that there are no questions so profound and theoretical in the physiology and natural history of man, that are not intimately connected with the efficient performance of the daily duties of the medical man. They teach, that though scientific theories may be sometimes barren of immediate practical results, they cannot fail to disencumber the mind of those prejudices which lead to erroncous practice by the medical man, and disastrous results to the patient. On this ground I may, perhaps, be excused for referring to some of the least apparently practical parts of this rolume, not with a view of adding any new matter to that already accumulated with so much labour by the author, but with the hope of assisting the reader to understand those generalisations which the subject of the book involves, but which are necessarily not bronght prominently forward by the author.

The history of the Entozoa has ever been supposed to involve some of the most interesting questions relative to the generation and reproduction of organic beings. Although it was easy to account for the presence of worms in the stomach and intestines by the ready explanation of the swallowing of the eggs, a difficulty always presented itself in the case of those creatures called hydatids, which evidently had an independent animal existence. They exhibited no sexes, they produced no eggs, and the readiest theory was that of spontaneous or equivocal generation. Eren as this theory was successively driven from every other part of the animal and vegetable kinglom, it found a refuge amongst the strange and paradoxical creatures imbedded in the tissues of man and other animals, far removed from any external influences.

The time has, lowever, at length arrived, when it can be dcmonstrated, that the cystic worm is no longer to be regarded as the result of a "fortuitous concourse of atoms," but that it is the offspring of the tape-worm, undergoing one stage of its growth, through which it must pass before it can attain to the more dig- 
nified development of its parent. From this point of view we may compare the cystic worm to the caterpillar, or chrysalis stage in the development of the insect. It differs, however, in this, that in many cases the cystie worm has the power of developing, at this stage of its growth, a large number of creatures resembling itself, and these have, each of them, the power of developing themselves into tape-worms, as though the caterpillar had the power of producing in its interior any number of young caterpillars, each of which would grow into a perfect butterfly.

It is here that the history of our Entozoa becomes interesting from another point of view. They are illustrations of Steenstrup's theory of the "Alternation of Generations." The eystic-wormlet it be an Echinococcus-has originated from the egg of a tapeworm, the embryo of which has found its way from the stomach and intestines through their walls, into the tissues of the body. This worm consists of a vesicle, or bag, to which is attached a head, called the "scolex." In Cysticercus, the hydatid of the pig, there is but one scolex, but in Echinococcus there are many scolices. Now this scolex, or scolex-head, as it is sometimes called, is the stock or germ-the head-from which all the segments of a tape-worm proceed. The eyst of Echinococcus, then, has the power of producing a large number of these heads, each of which may grow into a tape-worm. The cyst, the original cyst of the worm, is, in the language of Steenstrup, "a nurse." Küchenmeister and the Germans call it a mother-cyst. But this cyst will not only produce scolex-lieads, but other cysts like itself. These are "daughter-cysts," and these secondary cysts will also produce scolex-heads. They are also "nurses;" and in virtue of their existence the mother-cyst becomes, in the language of Steenstrup, a "parent-nurse." The second cyst

1 This word "scolex" was originally employed by Müller to designate generically some imperfectly developed forms of tape-worm. The head was the most characteristic part of these creatures, and gradually the term "scolex" was applied to the heads of all forms of cystic and tape-worms. The tern scolex has now no generic signification, as the creatures to which it was applied were immature forms of other genera. 
may contain, as it frequently does in the Echinococcus altricipariens of Küchenmeister, a third cyst, a "granddaughter-cyst," which is also a "nurse," and thus on.

Anotlier curious point about all these creatures is, that they are sexless. Neither cyst nor scolex-head has any sex. Nor do they acquire sexuality as long as they remain in the flesh in the hydatid condition. It is to this condition of the worm that Professor Huxley proposes to apply the term "Agamozooid." The objection to this term is, that it is equally applicable to all sexless forms of reproduction amongst animals as to those to which Steenstrup has applied the term "nurses."

In order to acquire the conditions necessary to the derelopment of sexual organs, the cystic, or asexual form of the worm must be swallowed and digested by another animal. The scolex-head then becomes in its turn truly a "nurse," and this of a most prolific kind, for the cyst below being displaced, the numerous segments ("proglottides," as they have been called) begin to make their appearance. The conditions are now such, that sexes appear ; each segment is merely a capsule containing a male and female generative apparatus, and nothing else. Eggs, the result of the union of sperm-cells and germ-cells, are now produced in myriads. These pass into the external world, and being swallowed and digested, set free the embryos, which again become cystic worms as above described.

Now these phenomena are not peculiar to Entozoa. Steenstrup pointed out that they had been observed in the Medusce, the Claviform Polypes, the Salpæ, and the Trematode Entozoa." Professor Owen, in the exposition of his views on "Parthenogenesis,"2 a general term lie applied to the phenomena of asexual reproduction, has also given a large number of cases of the same kind. One of the forms examined by Professor Owen,

1 'On the Alternation of Generations,' by J. J. S. Steenstrup, translated for the Ray Society Ly George Busk.

2 "On l'artlenogenesis; or the suecessive production of procreating Individuals from a siugle Ovum,' by Richard Owen, F.R.S. 
in his work, is peculiarly interesting, on account of its occurring in a family where such phenomena were regarded as highly exceptional. This case was first pointed out by Bonnet, and was the production of young aphides for several successive generations without any union of the sexes. The rirgin-aphides, however, thus producing viviparous young, were not true females. These eventually appear, producing eggs, from which proceed the virgin generation. These virgin-aphides are truly "nurses," according to Stecnstrup's theory. But a further derelopment of this strange history remains. Not only have we the lower animals in their various stages of development, capable of producing buds, or individuals like themselves, without sexual union, and embryo-bearing eggs, but we have also amongst the Articulata, both in Crustacea and Insects, females producing eggs, which proceed to the derelopment of perfect animals without any sexual intercourse or union of sperm-cells and germ-cells. ${ }^{1}$ Such a phenomenon is so opposed to the unirersally accepted dogma of the necessity of sexual intercourse for the development of the embryo, amongst the higher animals, that many physiologists of the present day have not hesitated to express their unqualified dissent. Regarding, howerer, the phenomena of reproduction from the point of view afforded us by the Entozoa, and other forms of lower animals, we must receire the facts in both cases equally cautiously, and judge according to the eridence. Von Siebold, in his work on 'True Parthenogenesis,' affords good evidence for beliering that the queen-bee deposits two kinds of eggs, the one of which has come under the influence of the sperm-cells of the male, and the other not. A rery curious point in this history, is the fact that, whilst both eggs produce roung bees, the impregnated eggs produce worker or female bees, whilst the unimpregnated eggs produce male or drone bees. In a recent

1 'On a true Parthogenesis in Moths and Bees; a contribution to the History of Reproduction in Animals,' by Carl Theodor Ernest ron Siebold, translated from the German by William S. Dallas, F.L.S., London, 1857. 
communication $^{1}$ read to the Royal Society, Mr. Lubbock has shown that species of the Entomostracous crustaceous genus Daphnia produce living young in all respects like their parent without any sexual intercourse. It would appear, then, that up as high as the most developed forms of articulate animals, we have evidence that there is no real difference between the functions of reproduction and generation.

If we turn now to the regetable kingdom, we find perfectly analogous phenomena presenting themselves. In fact, the modifications of the reproductive function, which have recently excited so much surprise, in the animal kingdom, are the normal forms of the function among plants. In the roots and branches of a tree we have a gigantic "nurse," and the buds are its progeny. Just as we find the same secondary products called "gemmæ," in animals either remaining adherent to their parent-stocks, as in the Sertularian and other Zoophytes, or floating off, as in Hydra and many others, so we find the buds of plants remaining attached to the tree, or bccoming separated from it. Just too as we find a different form assumed by the secondary offspring of the "nurse," as in the scolex-head of the cystic-worm, so we find in such cases as those presented by the "bulbillus," the "bulb," and the "sporule," different forms assumed by parts having the same relations in the plant as in the animal. So likewise in the plant we find a greater cliange of the secondary offspring taking place, when sexes are developed and flowers are produced, and the hermaphrodite flower with its stamens and pistils is the representative of the segments (proglottides) of the tape-worm, with its male and female apparatus in a common envelope. We may go yet further with our analogies in the vegetable kingdom. Here also we have numerous cases, in which the germ-cell, the ovule, is produced, ${ }^{2}$ and developes within itself an embryo, quite independent of the influence of the

1 'An account of two methods of Reproduction in Daphnia, and of the structure of the Ephippium,' by John Lubbock, Esq., F.G.S. Read January 29th, 1857.

¿ See 'Quarterly Journal of Mieroscopical Science,' 1. 228 ; also Lubbock, loc. cit. 
sperm-cell-the pollen. The eases seem to me to have a strict analogy, and no more simple way could be found of mastering the details of the reproductive phenomena of animals, than by studying those in plants.

Perhaps these general remarks will be better understood by the aid of the following diagram :

\section{GENESIS.}

Growth-Reproduction-Generation.

\section{HoMOgENESIS}

(Reproductive force acting through - similar cells.)

It is represented in-

A. Plants by Phytoids.

1. Isophytoids. Buds.

2. Allophytoids.

Bulbilli.

Bulbs.

Sporules, \&c.

B. Animals by Zooids.

1. Isozooids.

Gems, or buds.

2. Allozoids.

"Nurses" (Steenstrup).

"Agamozooids" (Huxley).

"Virgin Aphides" (Owen).

"Agamic eggs" (Lubbock).

"Drone bees" (Siebold).
Heterogenesis

(Reproductive force acting through dissimilar cells, sperm-cells and germ-cells.)

It is represented in-

A. Plants by

1. Gynophỵtoids.

Female flowers.

Pistillidia, \&c.

2. Androphytoids.

Male flowers.

Antheridia, \&c.

3. Androgynophytoids.'

Hermaphrodite flowers.

B. In animals-

1. Gynozooids.

Females.

2. Androzooids.

Males.

3. Androgynozooids.

Hermaphrodites.

8, Savile Row,

August 24th, 1857. 


\section{CONTENTS OF VOLUME I.}

Autlor's Preface

Translator's Preface

Introduction

\section{Animal Parasites.}

First Group.--Parasites whose muscles exhibit no transverse striæ

First Class.-INFUSORIA

Trichomonas vaginalis

Denticola hominis

Second Class.-VERMES, HELMLNTHA

A. Platyelmia

PAGE 
A. Mature state

B. Ora and embryos

1. Tenia solium

A. Tænia matura

B. Scolex of $T$. solium $=$ Cysticercus cellulosa

2. Tania mediocanellata

Tænia from the Cape of Good Hope

3. Tania nana

1. Cysticercus cellulosa (p. 113.)

2. Cysticercus tenuicollis

3. Echinococci

a. Echinococcus scolicipariens $=E$. veterinorum

b. Echinococcus altricipariens $=E$. hominis

4. Cysticercus vesica hominis

Appendix. On the hydatid disease of Iceland

1. Monostomum lentis

Fam. II. Distoma

1. Distoma hepaticum

2. Distoma lanceolatum

3. Distomum heterophyes

B. Nematelma 
P'AGE

3. Stronyylus gigas . . . . . . . 376

4. S. longevaginatus . . . . . . . . 381

5. Ancylostomum duodenale . . . . . . . . 384

6. Ascaris lumbricoides . . . . 410

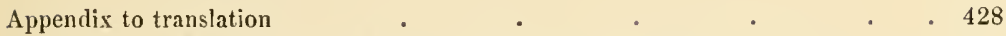

Appendix A. Mr. Rainey's researches on Cysticercus cellulose in the pig . 428

Appendix B. Additional cases of the uccurrence of species of Distoma in the

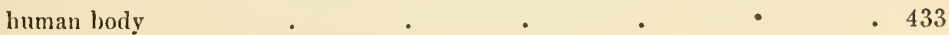

Appendix C. Case of the occurrence, and description of a nematoid worm, Dactylius aculeatus, and account of Spiroptera hominis 



\section{INTRODUCTION.}

Parasites are independent organized beings, descended from peculiar animal or vegretable parents, which require, in order that they may be enabled to complete their development, growth, or reproduction, to take up their abode either constantly or temporarily in or upon a second animal or vegetable organism of a different kind, from which they also derive their nourishment.

Human parasites are those which select the human body as this second organism.

These parasites are usually divided, according to the place to which they attach themselves, and the kingdom of nature (Animal or Vegetable) to which they belong, into animal and vegetable parasites-Epi- and Ento-zoa, and Epi- and Entophyta. We shall adopt the division into animal and vegetable parasites, and endeavour to give a natural historical description and classification of the different species, leaving it to the reader himself, from the description of the habitation of these creatures, to detcrmine whether those under his consideration be Ento- or Epi-zon, or Ento- or Epi-phyta.

The meaning of the term pseudo-parasites is easily understood from the foregoing. These are animals or plants, which, either in a living or dead state, reach the intestinal canal in consequence of impurities in food or drink, or get into the air-passages, or upon the surface of the body; but, even when this takes place during the life of the animal, can only continue their existence for a short time on the human body, are soon subjected to the laws of organic decomposition, and are never capable of continuing their species there. 


\section{ANIMAL PARASITES.}

"WHenever au animal," says Leuckart, " is too small and too imperfectly armed to overcome and destroy another living being upon which its instincts direct it to seck for nourishment, it must be contented with robbing it, by feasting upon its blood, juices, and solid parts." The only animals which occur as parasites in or apon the human body belong to the classes of Insects and Worms, and perhaps also to the Infusoria. As far as we yet know, these parasites of man are not subject to the attacks of secondary parasites. Many of them are common to Man and other Mammalia, whilst others are peculiar to him. From the presence or absence of transverse strix in the muscles they may be divided into two large groups.

\section{FIRST GROUP.}

PARASITES WhOSE MUSClEs EXHIBIT NO TRANSVERSE STRIATION.

This group, with the exception of the still questionable Infusoria, is composed of the true Helmintha of authors. We will first take into consideration the peculiarities in the mode of life of these animals in general, and afterwards in detail.

The Infusoria are destitute of all high organization. They are simple, vitalised, membranous structures, which live by mere endosmose.

The other parasites of this division also, or the true Helmintha, are destitute of many of the organs possessed by the higher animals. Thus, they have no separate respiratory organ, and the oxygen necessary to their existence, as to that of all organized beings, must always be taken up in a dissolved state, simultaneously with their fluid food. Hence they are enabled to exist within the human body, either in its closed or open cavities, or in its tissues. They constitute the true Entozoa, and furnish no representatives to the series of human Epizoa, although some of them

I Vierordt's 'Archiv,' 1852, article "Parasiten und Parasitismus." 
may be destined, in the course of their development, to pass a portion of their lives in water, or perhaps (as in the case of the Cercarice) as Epizoa upon other animals. Sexual organs may always be detected in those specimens of these animals which have attained their last grade of development. Although Oscar Schmidt states that he has recently discovered a production of the six-hooked brood in the Trenia dispar of the frog, without being able to find sexual organs in the segments of this animal, yet this statement requires a more careful revision, especially as these organs, and particularly the male ones, are so delicate that they are very easily overlooked.

The senses of sight, smell, and taste are wanting to all these animals, but their general sense of touch appears to be highly developed, although no undoubter proof of the existence of a special nervous system in the Helmintha has yet been obtained, except in the Oxyurides, in which George Walter has recently discovered a lighly developed nerrous system. The intestinal canal is wanting in the Cestoidea. In the Trematoda it forms a crecal canal, in which the moutl also performs the functions of the anus; whilst in the Nematoida it becomes a complete alimentary canal, with a mouth, œsophagus, stomach, intestine, and anus. In the tissues of the Cestoidea the tenderrey to the formation of a bouy envelope makes its appearance, in the deposition of calcareous salts, which have been recently regarded as siliceous by Esehricht, but certainly incorrectly; in the Trematoda we generally look for these in vain, and in the Nematoidea they are always deficient. If we bring together the particulars which are characteristic of all these three kinds of true Helmintha, we find them to comprise (besides the greatly developed general sense of touch) the vascular system, consisting, in the Cestoidea, of four longitudinal, lateral canals, and in the Trematoda of a fine network of vessels, which is less distinctly marked only in the Nematoidea; the muscular system, composed of transverse and longitudinal museles, vithout transverse strix; the structure of the epidermis, which consists of a homogencous, more or less finely checked substance, which is, perhaps, composed of chitine, but at all events of a substance which closely approaches chitine in its chemical reactions; the property of sooner or later giving off a strongly refractive, albuminons substance, in oleayinous drops, when in contact with water, and the circumstance that they can scarcely ever effect their development 
without a passive and active migration of the embryos and immature youny.

This migration itself is passive during the embryonal state, and as long as the embryos are still enclosed in the egg-shells or egg-envelopes, during which period they usually cmigrate once, passively, into the exterual world, gencrally with the excrements of the hosts, ${ }^{1}$ of their parents, and then again, passively in general, into the intestinal canal of the animal in which they are to acquire a ligher development. From the latter moment commences their active migration, by which they seek the situations, usually exterior to the intestinal canal, in which they are to undergo their metamorphosis into the next ligher step or steps of development, which is generally accompanied by an encysting process.

Finally, as a general rule, at least as regards the trematode and cestoid worms, they must afterwards migrate passively once more into the intestine of the animal in which they are to attain maturity; that is to say, they must pass with the food of their new and final host into its intestine.

The general etiology proves that a spontaneous generation (generatio aquivoca) never takes place, but that there is always a reproduction from sexual parents, either directly or by indirect channels. 2

The general pathology shows that the worms do not effect their

1 [" Host" is a literal translation of the Germau "Wirth," and although not perhaps previously used in the above sense in the English language, I have adopted it to prevent a somewhat tedious circumlocution. E. L.]

2 Very recently we have obtained much new information relating to the theory of reproduction. In the first place, the discovery of the male generative organs in the earth-worms by Hering, of Leipzig, has proved these animals to be lermaphrodite; aud we have perhaps some reason to hope that we may find this hermaphrodism more widely diffused orer other sections of animals than has hitherto been the case; for example, amongst the insects. Whether there really are creatures amongst insects which produce young without any sexual union, in the manner of uurse-production, is a question of the day raised by Von Siebold's theory of Parthenogenesis in Psyche helix, Solenobia clathrella and lichenella, Bombyx mori, and Apis mellifica. However, even in this case it will be seen that there is no reference to a generatio requivoca. (See Hering, in Siebold and Kölliker, 'Zeitsch. fur Wiss. Zool.,' viii, p. 400, and Von Siebold's 'Parthenogenesis, Leipzig, 1856, transl. by Dallas Van Voorst, 1857.) Czenkowsky's statements, which amount to a true generatio aquivoca, however, appear to us to be quite incredible; he professes to have seen swarm-spores furuished with two cilia produced by a peculiar metamorplosis from the starch-grains of decomposing potatoes. Must not this isolated fact be a mistake? For our part, we believe that the theory of the generatio aquivoca cannot be considered as supported or proved by this statement. 
active migration without some irritation of the regions of the body through which they pass, whether this migration is performed by the youngest brood, which is the usual course, or by the mature or nearly mature animal, which takes place but rarely, and that amongst the Nematoidea. Nature, with rare exceptions, endeavours to render those immature grades of development, which are passed through by these animals out of the intestinal canal, innocuous, by the process of encysting, and in these stages symptoms of pressure especially prevail. The passive nnigration, however, of all still-immature parasites into the human intestine takes place without any perceptible morbid symptoms.

The general prognosis follows naturally from the observations just recorded, and it is easily seen that the most dangerous individuals for the moment are the youmg animals engaged in their migration. Next to these the migrating, mature individuals, which inhabit the intestinal canal, produce the most dangerous symptoms. The encysted states, or those in which the animals reside in closed cavities, can only become dangerous to life by their presence when they attain an enormous size, but when smaller may be present without doing any mischief. Lastly, most of the mature individuals are more accessible to curative processes than those of the lower stages, which live outside the intestinal canal.

The general therapeutics will have to keep a double object in view :

1. The removal and destruction of the mature individuals with their progeny.

2. The observation of the mode of life and migration of the immature individuals; and, in places where such plagues are endemic, of the habits and mode of life of the people, which facilitate this migration - so as to found a rational prophylaxy upon these observations.

\section{First Class-Infusoria.}

As the Vibriones (PI. I, fig. 1) and their allies, such as Bursarice, Monades, and Bodones, are a peculiar attribute of formenting and putrefying fetid animal substances, or always presuppose a half-dead soil, and do not derive their nourishment so much from living substances as from matters which the living 
body has expelled, or is in the course of expelling as fureign to it, they are properly only to be regarderl as indirectly parasitic upon the luman body. We shall, thercfore, refer to them superficially here, and only devote a closer attention to two species. How widely diffused they are in the body is shown by the fact that Ficinus, for example, found sluggish, bear-shaped Infusoria, $\frac{1}{1000}-\frac{1}{1500}$ inch, and sometimes double this size, of a globular form, in the perspiration of the feet, on the places where the epidermis separated in caseous crumbs, as well as in the moist walls of the folds of skin in little children; and that others have met with them in purulent and foul secretions from the vagina, urethri, and bladder, putrescible urine, \&c.

\section{Trichomonas vaginalis. (Pl. I, fig. 2.)}

Diesing has placed this animalcule in his Subclassis I, Achethelmintha; Sectio 1, Ach. mollia; Ordo I, Prothelmintha ; Subordo, Aprocta; Nibus, Atricha; Familia II, Monadinece; Subfam. III, Cercomonadinere; Genus XIV, Trichomonas (Duj.) ; and described it as follows:

Animalcula solitaria, libera. Corpus nudum, loricâ dcstitutum, subglobosum, brevicaudatum, mollitie sua mutabile, hyalinum, divisione spontanea simplici bipartitum v. indivisum. Os (?) obliquoterminale, limbo ciliatum. Flagellum simplex, terminale. Ocellus nullus. Endoparasita.

Trichomonas vaginalis: Corpus nodulosum (gelatinosum) lacteum; cauda brevis; flagellum corpore triplo longius. Motus vacillans. Longit. $\frac{1}{222 .}$ "' (Duj., 'Hist. Nat. Inf.,' 300 tab., iv, fig. 13.)

Notwithstanding that Dujardin, who also describes a Trichomonas in the intestine of Limax agrestis, recognised the animal nature of this structure, it has hitherto been unable in Germany to establish its title to a place amongst the true independent parasites of man. Some regarded this parasite as ciliated epithelium (compare Ecker's figure of the ciliated epithelium of the auditory organ of Petromyzon marinus, in Müller's 'Archiv,' 1814, Taf. xvi, figs. 1, 2). Other's considered the animal as a mite. Recently, however, Kölliker and Scanzoni (see Scanzoni's 'Beiträge zur Geburtskunde,' \&c., Band ii) have confirmed Donné's statements ('Rech. microsc. sur la nature du Mucus,' Paris, 1837; and 'Cours de Microscopie,' Paris, 1815, pp. 157- 
161, fig. 33). Trichomonas vaginalis only occurs in women with gonorrhœal discharge, or with an abundant vaginal secretion mixed with mucus- and pus-corpuscles; never in a normal and healthy vaginal secretion, but only in pathological conditions. The mucus, however, need not be frothy, as Donné supposes, so long as it is not quite normal. Kölliker and Scanzoni found it in the vaginal (never in the cervical) mucus of both pregnant and unimpregnated women, especially in the yellowish, creamy, and acid mucus; sometimes in neutral, but never in alkaline mucus. From their granulated appearance, their form, size, and structure, the mucus-corpuseles closely resemble this Infusorium; they both also generally lie in masses together. All these things, with the very sluggish movements of the parasite, liave caused it hitherto to be very commonly overlooked, and confounded with the mueuscorpuscles. The prolongation at the anterior end, which is even sometimes drawn out into an elliptical form, and furnished with a delicate, long filament (flagellum), distinguishes the parasite from the epithelium. The body of the parasite is 0.01 millim. (Duj.), or 0.02-0.01 millim. $=0.008-0.018^{\prime \prime \prime}$ (Köll. and Scanz.), in length; the flagellum, 0.028-0.033 millim. (Duj.), or 0.040.08 millim. $=0.015-0.030^{\prime \prime \prime}$ (Köll. and Scauz.), in lengtl, sometimes double or triple, and furnished with several ( $7-8$ according to Dujardin, $4-5$ according to Domné) short cilia in continual movement, which greatly facilitate the recognition of the animal. A mouth, which Donné states he saw under the flagellum, was found neither by Dujardin nor by Kölliker and Scanzoni, who sometimes saw, heneath the cilia, a delicate furrow running obliquely. The vacuoles observed by Dujardin in the body of the animalcule were only seen by Kölliker and Scanzoni, during its contact with water or weak sugar and water, in which the animals swell up into a globnlar form and soon become motionless, and then closely resemble ciliated cells. Then examined in pure vaginal mucus, the parasites exhibit a very lively infusorial swarming; and those who speak of similarity to ciliated epithelium must have made use of water in their investigations. Kölliker and Scanzoni observed no leech-like movements, true contractions and expansions of the body, or adhesion by the so-called posterior extremity, which is produced into a delicate, but still rather thick, stiff, immoreable, and rather long process. Unfortunately they did not attempt to transfer vaginal mucus with Trichomonads to the liealthy vagina of women which were not 
infested by Trichomonas, so as to obtain information as to their capability of infection. According to this, the statements of Donné, Dujardin ('Infusoires,' Paris, 1844, p. 299), Leblond, ('Traité Zool. et Physiol. sur les vers intestinaux de l'homme'), and Froriep ('Nene Notizen,' ii, p. 40), are correct. But those of Von Gluge ('Untersuchungen,' Heft i, ciliated epithelinm), Talentin, Julius Vogel ('Pathol. Anat.', i, p. 10t, and 'Erlauterungstafeln zur patl. Anat.'), Von Siebold (Wagner's 'Handwörterbuch der Phỵs.,' ii, p. 660), Rokitansky ('Pathol. Anat., 3 Aufl., i, p. 367), Lebert ('Physiol. Pathol.,' Paris, 1845, i, p. 230), Raspail ('Nouv. Syst.', ii, p. 102, according to which the animal is identical with Cercaria syrinus), and Ehrenberg and Froriep (1. c., p. 88, by whom Trichomonas is referred to the Ascarides), are to be corrected.

We have above referred to the slow morement of these parasites. Morements of this kind, or the formation of prominences, processes, \&c., occurring in the lower sections of the auimal kingdom, are called amaboid movements. From these re must distinguish the movements of individual nicroscopic constituent parts of the human body, which we may denominate pseudo-amaboid. Such morements are met with, according to Lieberkühn (Tab. I, fig. 3), in the tenacious fluid of dropsical ovaries, in the colourless blood-corpuscles of animals and of man (Tab. I, fig. 4), for which reason they are met with most frequently in leucrmia of the human subject, and in the isolated cells of the human lirer (Leuckart). All these corpuscles with amæboid motion are diaphanous, homogeneous globules, which by slow morement give off all sorts of processes, sometimes like tails. These last are not animals; some of them, perhaps, are lymph-corpuscles, consisting of Ecker's contractile substance. The true Amabc, according to Wragener and Lieberkühn, stand in a certain developmental connection with Psorospermice and Gregarince, of which we cannot speak here.

\section{Denticola hominis (Ficinus)?}

Genus valde dubiosum (Tab. I, fig. 2').

In 1772, in his 'Arcana Naturæ detecta,' p. 40, Leeurenhoek figured animalcules resembling Bacillarice, which he had discorered 
in the mucus of the teeth. Lebeaume described the tartar of the teeth as the habitation and product of these Infusoria, and considered the tartar as a polypary; and Mandl even ('Comptes rendus de l'Acad, des Sciences,' tome xvii, p. 213) supposed the tartar to be produced by the aggregation of calcareous remains of bacillar Vibriones (Leenwenhoek's Bacillaria) from the mucus of the mouth. The latter were said to occur in large quantities, especially in the coating of the tongue, when the diet was hard and non-stimulant, as well as in cases of deranged digestion, but to be destroyed by heat, muriatic acid, and spirituous beverages. R. Ficinus makes the following statement ('Journ. der Chirurgie und Augenheilkunde ron Walther und Ammon,' Bd. 36, or new series, Bd. 6, 1817, p. 4) regarding the animal structures in the dental mucus. In the yellowish-white dental mucus, amongst the peculiar filaments of Leeuwenhoek and Bühlmann (Müller's 'Archiv,' 1840), closely aggregated, very small granules, epithelial cells, and mucus-globules, make their appearance in various quantities, and sometimes single Infusoria which have accidentally got into the mouth with food and drink. In the interstices remaining between the granular substance, especially on the addition of water or saliva, we see an extraordinary quantity of small, roundish, and longish corpuscles, which are only visible with high magnifying porrers, which move about briskly with a revolving motion, remain restlessly on particular granules or filaments, or move about upon them, lay themselves on one side, or vibrate, attaching themselves by one end, and acquire a conical form. These are automatic morcments of an animal nature, independent of currents or molecular movements, and perfectly resemble morements in search of nourishment. 'The form of the body of these animalcules appears to be an ellipsoid, divided in the middle by a slight constriction, like a bean. Their transverse diameter amounts to $0.00005-8$, and their longitudinal diameter to $0.00016-20^{\prime \prime}$ Par. The animalcule is met with particularly in the vertical position, when it appears as a globule of $\frac{1}{1200}-\frac{1}{1500}$ "' Par., and on account of this figure it was regarded by Eisenmann as a Monas Lens. Nore rarely it is seen in a horizontal position. When moving quietly the form of its body may be more distinctly recognised, when it has approached objects which offer it nourishment. Then we sometimes see, in the constriction at the middle of the body, a lip-like elevation, below which Ficimus supposed the oral opening to be situated, if the animalcule be not destitute of a mouth. 
The animal is an aciliated Infusorium, with the mouth on the ventral surface, and probably furnished with a carapace, resembling the Purumecia and Kolpodo, but which Ficinus prefers regarding as a distinct genus, standing near the Monudes and Vibriones. The species, aceording to him, are numerous, as almost every mammal has its peeuliar species. Dogs and horses, which, next to man, suffer most from tartar, exhibit these Infusoria in abundance, and the species are partieularly like those of man.

Ehrenberg also referred to these Infusoria, but could not confirm Leeuwenhoek's statements.

Ficinus found his Denticola in all persons having teeth, especially in the interstices of the molars. He met with it more rarely on the mucous membrane of the month, searcely at all in the saliva, but especially when the teeth were neglected, and in immense numbers in hollow teeth. In teeth which are kept moist, and between glass plates, the animaleules live for days. In spirituous and acid fluids, and fluids mixed with eigar smoke and spices they do not live in the superficial strata, but exist still in the lower ones.

Two, three, four, or more of these animals adhere together by their longitudiual axis, become more sluggish, then push themselves about from place to place, and, lastly, penetrate with one end into a mass of Bühlmann's filaments, and become motionless, when, according to Ficiuus, these filameuts, which appear darker, are produced from them. The satin-like surface of the tartar of the teeth is elosely set with these filaments. If fragments be prepared in muriatic acid, the groups of filaments, arranged in the form of mucedinous fungi, are seen in them; by concentrated sulphuric acid these are broken up into the above-mentioned small, bean-shaped corpuseles; that is to say, iuto Denticolc. Where the parts are quiet, as on the edges of the gums, and especially in the lower jaw, these filaments are deposited, and gradually increase in number; they constantly cake together more and more firmly, cover the lateral surfaces of the teeth, push back the gum, penetrate between this and the cement of the roots of the teeth, destroy their union, and loosen and ruin the teeth. To cure this disorder the incrustations must be removed, and fresh deposits and the aceess of the Infusoria must be prevented; this is effected by aromatic, spiritwous remedies, eleaning the teeth with lamp-black, washing the mouth with vinegar or dilute mineral acids, from time to time, and fastening the loose teeth to their neighbours. 
It appears to me that there is a confusion here of the animalcule with the buccal Alga, their spores, \&c. An error lias certainly slipped in witl regard to the production of Bühlmann's filaments (bnccal Alga) from Infusoria. This metamorphosis is impossible. Nevertheless I do not venture to decide whether this particular Denticola exists amongst them.

\section{Second Class-Vermes, Helmintha (Diesing).}

The animals of which we have now to treat belong to Diesingr's first sub-class, - Helmintha achathelminthica : animalia evertebrata, inarticulata (i. e., extremitatibus articulis nullis predita), nunc mollia, ant elastica, ebranchiata, setis retractilibus nullis; whilst we find no representatives of Diesing's second sub-class, the Helmintha chathelminthica, i. e., animalia evertebrata, inarticulata, nunc mollia, ebranchiata, vel branchiis externis munita, setis retractilibus instructa.

In the consideration of the different classes, however, we prefer following, as Virchow has done, Vogt's division into-

A. Platyelmia $=$ Flat worms.

B. Nematelnia $=$ Round or Thread-worms.

And, like Vogt, again dividing the first section into two subdivisions. At the same time we would put it for consideration whether it would not be better to adopt the new denominations added at the end.

^. 1. Cestoidea, Vogt $=$ Cephalocotylea, Diesing $=$ Flat-worm colonies, or Platyelmia colonias exhibentia, Küchenmeister.

2. Trematoidea, Vogt $=$ Myzelmintha, Diesing $=$ Isolated Flat-worms, or Platyelmia isolata, Küch.

It will scarcely be possible to do anything further towards the union of these two subdivisions than is here done, that is to say, placing them together in the system in one great division. Virchow represents Van Beneden as referring all the cestode worms to the Trematoidea, and I myself felt compelled to attribute to Vail Beneden the same views, judging from the hitherto imperfectly known opinion of that illustrions naturalist; but his 
replies to my inquiries, expressing doubts as to the existence of a trausition from the cestode to the trematode worms, have enabled me to come to the conclusion that Van Beneden does not appear to aim at much more than what Vogt and Virchow have done, namely; to show that Rudolphi's classification of the worms, founded merely upon differences of form, and not upon the history of the development, was no longer tenable, and to introduce a division into the system, which should place the relationship between the cestode and trematode worms in a clearer light. I shall hereafter combat the belief in an actual transition between the Cestoidec and Trematoidea, and have endeavoured to give here a classification which may perhaps furnish a more exact representation of the affinities of these two kinds of worms, and reconcile the contradictory statements of authors, and which closely approaches the views maintained years ago by Valisneri and others, and more recently by Eschricht, Leuckart, \&c.

\section{A. platyelita.}

Entozoa solitaria aut composita, androgyna. Corpus depressum vel teretiusculum, molle, organis ad fixandum aptis preditum. Anus nullus; canalis cibarius aut divisus (rarissime simplex), aut nullus. Cavitas corporis non distincta. Metamorphosis in plerisque; larva gemmipare aut sporuliparce. (Leuckart, in Van der Hoeven.)

\section{First Sub-class.}

Cestoidea $=$ Cephalocotylea $($ Diesing $)=$ Bandwürmer $(=$ Tapeworms $)=$ Platyelmia composita ant colonias extibentia = Plattwurmcolonien (mihi), Flat-worm-colonies (incl. Cysticis).

Animalia tomotoca, per longum plerumque tempus larve nutrici juncta et una cum ea corpus elongatum, articulatum, polymorphum formantia. Larva (Scolex, vulgo caput) pyriformis, foveis aut osculis suctoriis 4 vel 2 instructa, sepissime uncinata. Proles sexualis (Proglottides, vulgo articuli) organis externis destituta, embryones nucinulis armatos gignentes. Canalis cibarius nullus. (Leuckart, in Vau der Hoeven.) 
5-varia inveniuntur in is metamorphoses: 1. Animal maturum (proglottis). 2. Embryones uncinulati (Grand-nurse; Grossamme). 3. Scolex passivam vitam agens sub forma vermis cystici seu Cysticerca, sub forma Platycerca et sub forma Acerca. 4. Scolex activane vitam agens (Nurse, Amme). 5. Strobila.

Before proceeding to the closer examination of this subject in detail, I will here give a historical summary of the remarkable attempts which have been made at its explanation. We shall thus see that it is only very recently that the Cystici have been got rid of as a distinct family amongst the Helmintha, and united with the Trenice.

The embryos were seen and fignred, but not explained by Goeze as early as 1782. The correct recognition and signification of these structures commences with Von Siebold (Burdach's 'Physiologie' ii, p. 201).

The most important steps of development, in a historical point of view, are the cystic worms (vermes cystici), and we therefore begin with their history.

The explanation of these hydatid structures has undergone the most varied treatment. As I lave mentioned in another place (see my book, 'Ueber die Cestoden im Allgemeinen,' Zittau 1853), it is not improbable that the Mosaic prohibition of swine's-flesh has been caused by the circumstance that the measly disease of pork which appears to be particularly rife in the East, even in the present day, was very well known to Moses. To the naturalist, at least, it must appear remarkable that in Lev. xi, verses 5 to 7 , Muses has mentioned as unclean, immediately after each other, threz animals, the pig, the hare, and the shaphan, which are still universally known as bearers of Cysticerci. Even if we do not consider the animal "shaphan" to be the rabbit, as the old commentatcrs have done, yet hitherto in all attempts at explaining this word in modern times only animals have been referred to which belong to families particularly characterised by their harbouring Cysticerci. From the point of view above indicated it is a matter of perfect indifference to us whether, in this passage of Scripture, we have to do with a Mus or Scirteles Jaculus, or with a species of Pedetes (of which as yct only one species, Pedetes Caffer, the Jumping IIarc, is known), or with Hyrax Syriacus (a species of the family Lamnunguia). All that matters to us is, that both the Rodentia, to which the first two specics belong, and the Pachydermata, to 
which, like the pig, the Hyrax belongs, as is universally known, harbour Cysticerci in particular abundance. ${ }^{1}$

This view finds further support from the fact that Aristotle, in his ' Historia Animalium,' lib. viii, $\$ 21$, speaks of the Cysticerci of the pig ( $\chi{ }^{\prime} \lambda a \zeta_{\eta}=$ grando) as a disorder of the pig which had beein known for ages, and which he mentions, together with two other diseases in swine, namely, the scurvy in the gums ( $\left.\beta \rho c^{\prime} \gamma \chi^{\circ}{ }^{\prime}\right)$ and

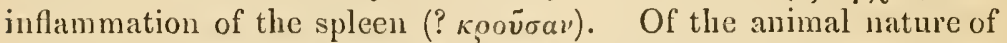
this disease nothing was known either amongst the Aneients or in the Middle Ages. Even before Aristotle, Hippocrates regarded the Cysticerci as hydatids, and the example of both was followed up to the time of the celebrated Redi, surgeon to Cosmo III, in 1684, and the Konigsberg surgeon, Hartmann, in 1685. Whatever produced a swelling similar to the cystic worms was men-

1 In attempts at the zoological determination of the animal "shaphan," the following particulars must be taken into consideration:

1. The uncloren hoofs.

2. The rumination, or a movement of cutaneous and muscular parts of the face similar to rumination; as it is well known that many Rodentia liave the habit of clean* ing themselves sitting up on their hind legs, whilst at the same time they distort the face (the upper lips and cheeks), or as we say "make faces," a movement which in such animals may easily be taken for rumination by those who only judge by appearances, and do not inquire into anatomical structure.

3. The occurrence of Cysticerci or encysted Helmintha of other kinds in the liver, the abdomen, or the muscles of the animal in question, and-

4. The occurrence of this animal in Egypt, Syria, \&c., but especially in the vicinity of and upon the monntains Ioreh and Sinai.

The linguistic knowledge of the author, who was once destined for the theological profession, is not sufficient to enable him to determine whether in the words

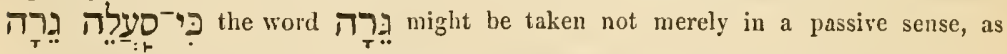
"that which is bitten, or the morsel," but also in an active sense, as "that which bites; the masticating organs, or the lips and cheeks," so that these verses might also be translated "nam ascendens facit id, quod disserat," $i$. e., " by the movement of the upper lip and the cntaneous and muscular parts of the face it nakes faces," whilst, according to the ortinary translation, they run, "nam ascendens facit id, quod jamjan dissecatum erat." Although in a linguistic point of view there is nothing to object against this attempt to restore the ancient Moses in integrum, yct M. Michaël, teacher of Hebrew in the Gymnasium of Zittau, from whom I made inquiries on this subject, thought that the words

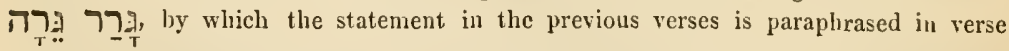
7 , as well as the parallel passage in Deuteronomy, chap. xiv, v. 8 , were in opposition to this attempted interpretation. In the latter place we shonld not then read "it cheweth not the cud" (that is, "rumination is not given to it"), but, "ruminating organs are not given to it," by which the possession of lips would be denied to the pig. Whether my attempted interpretation be possible may be decided by linguists! If it be impossible, we must suppose that the making of faces has been confounded with runination. 
tioned at that time under the name of hydatids, which were then considered sometimes as enlarged and degenerated glands (Ruysch); sometimes as accumulations of pus and mucus mixed with serum (Piso, Malpighi, Boerhave, Haller); sometimes as the ends of blood-vessels which had changed their nature (Spiegel, Bartholin, Diemerboock, Portal, Brandes, Grashuis); sometimes, soon after the discovery of the lymphatic vessels by Aselli in the seventeenth century, as enlarged lymphatic vessels or varices of these vessels (Wharton, Bidloo, Nuck, Lettsom, Cruickshank, and down to Sömmering and Hufeland); and sometimes as tumours produced by the accumulation of serum between the laminæ of the cellular tissue, which obliterated the vessel lying in their vicinity by pressure (Ruysch and Schacher); and lastly, as degenerated mucus-sacs (Tode). Although it may generally be difficult from these opinions amongst the learned surgeons of the Middle Ages to know, when they speak of hydatids, whether true liydatids or cystic worms were observed by them, yet in some cases it may be proved with certainty that the old surgcons really had cystic worms before them. Thus according to Möller (see 'Bibliothek for Laeger,' July, 1856; 'Ueber' die Entwickclung: der Blasenwürmer zu Bandwürmern im Allgemeinen und über die Lintw. des Cystic. tenuicoll. zu 'T. tenuicoll. im Besonderen,' \&c.) Aretreus speaks of vesicles which, in paracentesis of the abdomeu, stopped up the punctured opening and hindered the operation (a circumstance which would indicate the puncture of an Echinococcus-sac with daughter-vesicles). R. Lenckart, however (see 'Die Blasenbandwürmer und ihre Entwicklung,' Giessen, 1856), has above all taken the trouble of collecting some of these very scattered materials. For this purpose, according to him, we should consult the celebrated compilation of Bonetus ('Sepulchretum sive Anatomia practica,' Geneva, 1697), especially lib. iii, sect. $\mathrm{xx}$, de cachexia, anasarca, \&c., and sect. xxi, de ventri tumore, hydropse, and lib. iv, sect. iii, de tumoribus. There we shall find the case of a soldier infested with Cysticercus cellulose from Wharton (1. c., p. 1541), who was covered with Cysticerci (ylandul. adventitice, plane suna) under the skin of the arms and thighs (a case analogous to that observed by Stich in the Hospital of Romberg). Here also, as in Platerus (Obs., lib. iii, p. 635), we find indications of cases of Cysticercus tenuicollis in. the liver and peritoneum of dropsical human bodies, and the occurrence of these tumours (Cysticerci) in apes and pigs was 
very well known to Plater, as also in the latter to Bartholin ('Hist. Anat. rar.,' sect. ii, obs. 67) as early as 1653, and in Plater's time even to the butchers as somethiug very common. Bartholiu (l. c., obs. 4.9) was aware of their occurrence in goats; and lastly Stcno ('Act. Barthol. med.,' i, p. 135), aud Harder ('Apiai.' obs. 3), recognised their occurrence in Ruminants almost as a matter of course. Besides the above-mentioned cases, others of Echinococcus hominis (nutricipariens, Küch.) are also known as occurring at this period, namely, that of Riverus (Bonetus, l, c., lib. iii, sect. 21, p. 1505), in which, after the opening of an abseess in the liver, more than 200 vesicles fell out, and a cure followed; that of Joachim Camerarius ('ibicl.,' p. 1532), in which, after the abscess was opened below the processus ensiformis, an immense number of resicles, of the size of hens' and pigeons' eggs and smaller, passed out, and the patient lived for a year. Pallas ('Nene Nord. Beitr.,' i, p. 81) also subsequently reported a case of Echinococcus hominis. Even at this early period it was known that the lyyclatids, as they were called, presented certain pecularities. Bartholin speals of a "substantia flava in the interior of the vesicle," Steno of a "grisea quædam materies pisi mole" (by which, in both cases, the head retracted into the sheath is indicated), and Harder lastly mentions "Hydatides in duplicatura omenti libere fluctuantes," and also of those which adhere to the neighbouring parts of the body by cellular tissue and blood-ressels ; but, as already observed, the animal nature of these lydatids remained entirely unknown until the years $168 \pm$ and 1685 .

In 1681, Redi first united these hydatids with other encysted animal parasites, as "glaudulette o resichette verminose," and mentions ('Opere di Redi,' Venezia, i, p. 21), as examples of such rorm-sacs, a Cysticercus of the marten (Cyst. cordatus? Leuck.), and at p. 110, the Cysticercus pisiformis of the rabbit. Redi's "lumbrichetto" is the retracted neck of the $C$. cordatus; but in $C$. pisiformis he distinctly recognised the connection of the "lumbrichetto" (from the time of Pliny "lumbrici" was the common denomination of all intestinal worms) with the caudal vesicle. Redi, indeed, gives no further reasons for the animal nature of these hydatids, but speaks of the independent morements of these animals, and regards them as probably the embryos of the Distoma found in the liver of the rabbit. Apparently, independently of Redi, the surgeon Hartmann, of Königsberg ('Misc. cur. seu Ephem. Acad. Nat. Cur.,' decur. ii, ann. 
iv, p. 152, with a plate), speaks, in the year 1685, of the Vermes vesiculares seu hydatidodes from the peritoneum of the goat (Cysticercus tenuicollis); in 1688 (l. c., decur. ii, ann. vii, p. 58), of the animal nature of the Cysticercus of the pig, as two years afterwards Wepfer did that of the Cysticercus fasciolaris. It is true that the head, the suckers, and the circlet of hooks were unknown to Hartmann, but he very distinctly saw the movements of the worms in warm water, regarded the caudal vesicle as "corpus utriculare," the imperfectly exserted neck as an appendage (proboscis), and called the bands proceeding from the neck in the interior of the vesicle the "fi'ustulım."

In 1688, when he discovered the Cysticercus fasciolaris, Wepfer at the same time recognised its similarity with the tapeworms (latis lumbricis intestinorum), and he was the first author who did this. Even in 1675, Wepfer had also discovered the hydatids in the brain of vertiginous sheep ('De apoplexia,' p. 56), withont, however, recognising their animal nature, which seems to have been first done by Leske.

These opinions as to the animal nature of cystic worms remained unknown to authors, as, for instance, Peyer and Brumer in 1689 and 1694 ('Misc. Cur.,' dec. ii and iii), and for this reason, Tyson, who in 1691 again discovered the animal nature of the Cysticercus tenuicollis ('Phil. 'Trans.,' No. 193, p. 506, and 'Act. erud.,' Lips., 1692, p. 435), is often regarded as the original discoverer of this fact. Tyson considered the caudal vesicle as the stomach, to which the nourishment flowed from the mouth through the joints, but he added nothing at all to Hartmann's statements, except perhaps the unfortunate name of "Lumbricus hydropicus," iustead of Hartmann's "Vermis vesicularis = hydatidodes," or in English, "cystic worm." Besides Tyson, Malpighi (1694) is also often mentioned as the discoverer of the animal nature of the cystic worms, but certainly unjustly; his merit consists in having admirably described the Cysticercus of the pig ("Oper. posth.,' edit. Londin., 1698), and spoken of the head of the cystic worms; and he also speaks of a prohibition of the flesh of the "Sues verminosi = Lazaroli."

$\mathrm{U}_{\mathrm{p}}$ to the sixtieth year of the eighteenth century this theory stood still, or even retrograded; Ruysch, Frysch, Onymos, with Doeveren, and Daubenton, with Buffon, like Wepfer, only regarded the Cysticercus fasciolaris as an encysted tape-worm.

In 1760, Pallas ('Dissert. inaug. de infest. vivent. intra viven- 
tia') went over the statements of the ancients, and gave a natural history of these creatures as different species of the Trenia hydatigena (1766, 'Misc. Zool.,' p. 157); in 1769 ('Stralsund. Magaz.,' i, p. 64), he described the Cysticercus tenuicollis from the abdomen of Ruminants, and remarks that the watery vesicles in question all agree in structure with the common tape-worms, especially in the liead, circlet of hooks, and sucking pits. They are only less developed in the joints following the head, and they also bear a larger or smaller vesicle of water at the caudal extremity. Accordiug to him all cystic worms are forms of tape-worms, and belong to a single species, "Trenia hydutigena= Cystic tape-worm," which only presents some differences, especially in the caudal vesicle, according to the animal it inhabits. He was atso aware of the agreement of the head of the Cysticercus of the monse with that of the Tenia crassicollis of the cat (his Tenia cncumerina, tab. ii, fig. 2). But neither Pallas nor Tyson, by the denominations Tenia hydatigcna, or Lumbricus hydropicus, introduced by them for the cystic worms, wished to express any opinion as to the genesis of these worms, or their derivation from the ordinary tape-worms, however much we may be inclined to suppose so. The originator of the unlucky theory of the dropsical degeneration of the vesicular worms-a theory which Pallas does not once mention--must have been Hartmann, who appears to have referred to a dropsical degeneration from other intestinal worms (Lumbrici) when he says, "An natura loci, non sinens longos formari lumbricos, corpns reliquum ob abundantiam alimenti non concoqueudam in utriculos extendit?"

As regards Pallas, he considers the Comurus of the sheep, which was well known to him as a many-headed tape-worm, and the Echinococcus, as nearly related to, if not identical with it; and at the same time thiuks that the lieads of Conurus in the former case are only a further development of the globules observed in the Echinococcus. Pallas also ('Neu. Nord. Beitr.,' i, p. 58) states that he introduced the small red eggs of the Tcenia cucumerina of the dog through a small wound into the abdominal cavity of a young dog, and after the lapse of a month found there small tapeworms less than au inch long, and with very short segments. This is very improbable, and, I think, a complete mistake.

Besides Pallas, Statius Müller and Otto Fabricus, to whom the discovery of the animal nature of the Cysticercus of the pig is sometimes erroneously ascribed, introduced more system into 
the observation of the intestinal worms in general. But the most powerful stimulus to the development of helminthology in general, and for some time to that of the theory of the cystic worms, was given to science by the proposition, in the year 1780, on the part of the Academy of Sciences of Copenhagen, of the following prize essay: "Ueber die Samen der Eingeweidewürmer; ob die Trenien u. s. w. den Thieren angeboren sind, oder ob sie von aussen in sie kommen. Diess ist mit Erfahrungen und Gründen zu beweisen, und es sind Mittel gegen sic vorzuschlagen." In his prize memoir, 'Abhandlung von der Erzeugung der Eingeweidewürmer,' Berlin, 1782, Bloch established a peculiar genus, "Vermis vesicularis," which rather approached the Echinorhynchi than the Tanice, but Bloch's work did no other essential service to the elabolation of our probiem. For the most important contribution to this object we are indebted to Goeze, although the observations scattered through his works have remained up to our own day neglected and even misunderstood. Goeze, although he still believed in the zoological independence of the cystic worms, nevertheless reckoned them amongst the Tanice, distinguished them as $T$, viscerales from the intestiual tape-worms, $T$. intestinules and referred to several species of his T. vesiculares hydatigence (Cysticercus, Zeder; Vesicaria, Schrank; Hydatula, Abilgaard), such as T. hydatig. orbicularis (Cystic. tenuicollis, Rud.), T. hydatig. pisiformis and utriculenta (both probably C. pisiformis), T. hydat. fasciolaris (C. fasciolaris, Rud.), T. hydat. vesicul. multiceps, from the brain of the sheep (Ccemurus cerebralis, Rud.), and $T$. visceralis socialis granulosa (Echinococcus, Rud.) He was thoroughly aware of the similarity of the heads of the cystic worms and Trenice, which he was the first to discover with regard to Echinococcus, and like Pallas he recoynised the perfect similarity of the head of $T$. crassicollis (his T. serrata of the cat) with that of Cysticercus fasciolaris. This appears most distinctly from a passage in his ' Versuch einer Naturgeschichte der Ningeweidewürmer,' 1782, to which Eschricht first called attention. At page 310 of this work, he says, "The size, form, and structure of its head are perfeetly identical with those of the head of the articulated cystic tapeworm in the liver of the mouse; for this also has no neck, but its head sits immediately upon the first segment. But who can say why these two species are so similar as regards the head, and so heterogeneous in the rest of their economy?" - and also, at p. 222, in the description of his "lan'ge-headed, band- 
like, jointer cystic tape-worm from the liver of the mouse" (i. e., Cystic. fasciuluris), he says, "It has no inarticulated neck at all; it may elongate itself as much as it likes, but the first segment is immediately attached to the head, \&c. The size of its head agrees perfectly with that of the tapeworm with notched segments (T'. serrata)." The passage just quoted has been so completely ignored that Von Siebold regarded himself as the person who had called attention to the identity of these two animal forms, which was already known to Pallas and Wepfer even before Goeze's time, and commenced his article, "Ueber die Umwandlung des Cysticercus pisiformis in Trenia scrrata" ("Zeitschr. fuir Wiss. Zool.,' iv., 1853), with the words, "As early as the year 1844 I first called attention to the similarity of the head of the Cysticercus fasciolaris of rats and mice to that of Trenia crassicollis," \&c. The above passage had fallen into such complete oblivion that others also admitted this priority of Von Siebold's without dispute ; amongst others, Kölliker writes, in 1850, in the report of his travels, to Von Siebold, "Lastly, Thompson, of Glasgow, and his prosector, showed us drawings from which it appears that these savans had also observed the conformity of the Cysticercus of the mouse and the tape-worm of the cat, and that they have arrived at the same result with yourself, without knowing anything of your observations." Goeze's most important contributions, however, are his statements regarding the development of Cysticercus fasciolaris (1. c., p. 245). He says, "On the 13th March, 1780, I found in the liver of the mouse two clear, crystal vesicles, in each of which there was a pisiform vesicle, but on this as yet no body. I believe that as regards the production and development of this kind of worm, I have surprised nature in the act. In the interior of the inner vesicle there was a small white process or body of about $1^{\prime \prime \prime}$ in length. This was firmly attached by its base to the interior of the vesicle, and the white point at which it was affixed could be seen from the outside. When the vesicle was placed in such a position that the white point to which it was attached was at the bottom, it stood upright in the interior of the resicle, like the light in a lantern, reacling about to the middle of the vesicle, so that it was completely surrounded by the vesicle. From this it follows-

1. That this was the first stage of growth of the cystic tapeworm in its proper vesicle.

2. The first thing that comes out of the egg must therefore be 
the caudal vesicle, and this because the worm must first care for its habitation, and prepare this in proportion to the growth of its caudal vesicle.

3. In the vesicle the body sits, but internally, and, as it were, turned inside out. It must therefore live upon its own juices in the vesicle, until it is time to reverse itself, because it already has the four suckers and the circlet of hooks upon the head. (See his figure, tab. xix.) The caudal vesicle thus serves it as a reservoir of nourishment.

4. When its body has attained the necessary degree of development, and the vesicle over it is large erough ${ }^{1}$ for its habitation, the body reverses itself by the agency of its folds and segments, from within outwards, and then constantly grows until it reaches its perfect form and size, such as we procure it from the cysts of the liver.

5. The body here sits still in the vesicle, exactly in the same way that the numerous bodies of the cystic tape-rworm of the sheep sit in the interior of their common vesicle in the manner of a colony."

Goeze, or, more correctly, his friend Wagler, also proposes (l. c., p. 292) that the Tania of cold-blooded animals should be trausferred (by feerling) into cold- and warm-blooded animals, and those of warm-blooded animals into warm- and coldblooded ones, and watched to see whether they remained the same or became degenerated, and acquired other properties from the difference of their host, from what they had in their original situation, like certain cultivated plants. Lastly, like Pallas, he recommended the administration of the eggs of Tanice to animals (1. c., p. 290). The views of Pallas and Goeze were also followed by Steinbuch and Fiscber.

With this the progress of the theory of the cystic worms ceases for more than half a century, and with Zeder and Rudolphi a general retrogression commences. Zeder, in 1803, in his 'Naturgeschichte der Eingeweidewürmer,' formed a distinct family of the cystic worms; Rudolphi constituted them a separate order ('Entoz. Synops.,' 1819, p. 536), and thus, although he pointed out the resemblance between certain species of cystic worms and the Tanice, separated them in point of

1 This seems to be a misprint; it should probably bc "the vesicle is no longer large enough." 
fact from the Tenie, against which, as an unnatural separation, Nitzsch ('Lrsch and Gruber's Encyclop.', art. Anthocephlulus), T. S. Leuckart, and F. Müller' ('Archiv,' 1836, p. criii) contended in vain, in opposition to the great authority of Rudolphi. This long interval only furnished the knowledge that even in cestode worms, which were generically distinct from the Trenia, states resembling vesicular worms occurred, namely, the resicnlar genus Anthocephalus, Rud. (= Floriceps, Cuv.), which, as was subsequently ascertained, belonged to the Tetrarhynchi, and the Cysticercus Lucii, Zeder, which the latter states he has found with the remains of the caudal vesicle, and which was subsequently found to belong to Tricuspidaria nodosa (Rhytis tricuspidala, Zeder).

At list, in 181:2, Stecnstrup's theory of the Alteruation of Generations made its way here also. Steenstrup conjectured that the cystic worms were early steps in the development or generations of Helmintha which were unknown to him (Redi had erroneously supposed that they belonged to Distoma of the liver, and Tyson had also raised the same supposition, but only to contradict it), and that they must be banished from the system as a peculiar group, just as much as the asexual Tiemutoda (e. g., Cercaria, Leucochloridion, \&c.) It is the more remarkible that the Hclmintha appertaining to the cystic worms shonld have remained unknown to this distingnished zoologist, as from the statements of Pallas and Goeze the relationship of Tenia crassicollis to Cysticercus fasciolaris was easy to be seen, and Nitzsch, F.'S. Leuckart, and F. Müller had already recommended the abandonment of the separation of the cystic worms from the tape-worms, because it was umatural. It appears to have been a peculiar fate which prevented the earlier solution of this zoological problem; naturalists either could not correctly comprehend the true direction of progress, or, for reasons which it is difficult to perceive, they ignored the labours of their predecessors, which perhaps can only he realised when we consider how universally the recognition of the truth takes place slowly, and before it "a thousand years are as one day."

In 1845, in consequence of Steenstrup's discovery, Dujardin ('Hist. Nat. des Helm.' pp. 544, 633) first asserted that the cystic worms were undeveloped animal-forms and young states of tape-worms; and, indeed, that they were produced from those germs of tape-worms, which, instearl of the intestine, had got into the parenchyma of the body of their host, and under the 
infuence of this unnsual dwelling-place, had advanced to the abnormal state of development which we call "a cystic worm."

Simultaneously with Dujardin (whose work, as Lenckart says, was frequently made use of in Von Siebold's article "Parasiten," in R. Wagner's 'Handwörterbuch der Physiol.,' Band ii, which, although it bears the date 1844, did not appear until 1845), Von Siebold expressed the same opinions in Germany, which were supported by Dujardin on the other side of the Rhine. At first, howerer (see 'Lehrbuch der vergleichenden Anatomie,' p. 111), Von Siebold inclined towards Steenstrup's view, and said, "In its form, its suckers, and its circlet of hooks, the head of the asexual cystic worms possesses such a striking similarity to the heads of certain tape-worms, that one is tempted to believe that the eystic worms are nothing else than undeveloped and lave-form tape-worms." Had Ton Siebold adhered to this view, had he not allowed himself to be led, probably by Dujardin's suppositions, to give up this simple idea, he would have saved himself and science from a most unpleasant dispute. As he himself says (art. "Parasiten," pp. 650 and 676), however, he subsequently arrived "at the most decided conviction that the cystic worms are strayed tape-worms which have remained undeveloped and become degencrated, and of which the body grew ont in the foreign soil into a vesicle, without developing sexual orgaus."

Independently of the authority of Dujardin, in France, and of Von Siebold, in Germany, this view obtained the more acceptance, because Vou Siebold, in proving his opinions, employed as an example the fact, already known to the old helminthologists, of the identity of the Cystic. fusciolaris of the mouse with the Tceniu crassicollis of the cat, and (as Creplin had previously observed a metamorphosis of the asexual Schistocephalus dimorphus from the intestine of the stickleback, or from the liver of the pike ('Zeder's Cystic. Lucii, vide supra), into the sexual Tricuspidaria nodosa in the intestine of certain water-birds) expressed the opinion that the cystic worm of the mouse, which, according to him, was a strayed and degenerated tape-worm of the cat, would be transformed into the $T$. crassicollis in the intestine of the latter animal. "It is certain," says he (l.c., art. "Parasiten," p. 650), "that single individuals of the brood of Tania crassicollis frequently stray into rodent animals, and here degrenerate into Cysticercus fusciolaris, but when their 
host lias been devoured by a cat, and they themselves thus transplanted to their proper soil, they may cast off their degenerated segments, return to the normal form of $T$. crassicollis, and arrive at sexual maturity. By a similar degeneration, young individuals of the Tania plicata, when they stray from the intestine into the abdominal cavity of the horse, become deformed into Cysticercus fistularis. ${ }^{1}$ I am also convinced that the vesicular worms, referred by Rudolphi to the genus Anthocephalus, are nothing but Bothriocephali or Tetrarhynchi which have strayed in their migrations and become degenerated."

Subsequently also ('Zeitschr. für wiss. Zool.,' 1850, p. 220), in the revision of the Tetrarhynchi, Von Siebold repeatedly says, "that the cystic worms are really only (strayed) tape-worms, engaged in their migration, which have remained undeveloped and become dropsically degenerated, but which, on getting into favorable circumstances (i.e., into the intestine of an animal), become perfectly healthy and mature, and are even destined to wait for this act of swallowing." At last he even breaks out into the words, "I have reason to believe that, with the exception of the Cysticercus fasciolaris, and perhaps the C.crispus, no other cestode-uurse which has degenerated into a cystic worm can so far return to its normal condition, from its dropsical state, as to become fit for the production of sexual individuals. This is shown by the fact that the high degree of dropsical swelling causes such a great extension of the body, that, even from this, we may conclude that these tape-worms can no longer acquire the faculty of producing sexual individuals by the formation of segments, and the cestode-nurses, which have become degenerated into Cysticerci, perish without descendants, as is proved by the empty Cysticercuscysts with their remains." This proposition was refuted by experiments in the administration of cystic worms of all kinds, and the principal evidence upon which Vou Siebold supported his opinion was destroyed, but the proposition itself was still upheld by him, as we shall soon see.

The production of the cystic worms, according to Von Siebold and Dujardin, does not take place directly from the embryos, but in this way,--that tape-worms already developed,

I It is only possible to place together the T. plicata and Cystic. fistularis, and thus regard them as belonging to one and the same species, if we regard the mode of life of the animal infested, as of no value at all in the discrimination of species amongst the Tanice ('Leuckat t, Die Blasenbandwürmer,' p. 38). 
that is to say, furnished with the armature of the head of mature Trenice, and also with the commencement of segmentation, have reached some place exterior to the intestine of a certain animal, and become dropsical by the accumulation of water in the posterior, otherwise jointed part of the body. R. Leuckart himself calls his views put forward in 1818 in Wiegmann's 'Archiv' (xiv 'Th., i, p. 7), and subsequently in 1852 (in Vierordt's 'Archir für physiol. Heilkunde,' xi, p. 401, art. "Parasiten und Parasitisuus"), nothing but a paraphrase of the assertions of Dujardin and Von Siebold. In his most recent work ("Dic Blasenbandwürmer', p. 2l) he regrets having supported this theory, from ignorance, both of Goeze's statements with regard to the production of Cysticercus fasciolaris (vide supra) and of Guido Wagener's discoveries ('Euthelminthica, Dissert. inaug.,' Berol., 1848 , p. 30), by regarding the flat bands (frustula of the older writers) which hang down freely into the vesicle of Cysticercus tenuicollis as the remains of the previous body of the tape-worm, separated by the increasing dropsical disease.

In 1850, the celebrated Belgian zoologist, Van Beneden ('Les Vers Cestoïdes on Acotyles,' Bruxelles, pp. 83 and 81), declared the vesicular worms to be larva-like young states (scolices) of Tanice, and compared them with the larvæ of Tetrarhynchus (that is, with the Anthocephali of the older writers), without supporting this assertion empirically. According to hirn, the head of the tape-worm (scolex) is prodnced from the egg of the tape-worm. If an egg of a tape-worm reaches the intestinal canal of an animal in which it may be further developed witlout interruption, the jointed mature tape-worm (strobila) immediately grows from the egg in uninterrupted succession; but if it does not reach an intestine of this kind, a longer or shorter period of rest ensues in the further development, as soon as it has arrived at the evolution of the head of the tape-worm (scolex) ; in this case the anterior part of the head (scolex) then sinks into its inflated hinder part, and it becomes a Cysticercus, or a cysticercal animal-form.

Here, however, we find two errors-1, it is by no means proved that a tape-worm can pass through all the separate phases of its development in the intestine of its host; 2, and just as little as the caudal vesicle is produced subsequently by dropsical degeneration (Dujardin and Von Sichold) does the ready-formed lead sink into its inflated hind part, in order to become a Cysti- 
cercus, a view which has also been erroneously supported by Huxley, in the 'Annals of Natural History,' vol, xiv, p. 383.

'This was the aspect of affairs when, in the year 1851, the thought already expressed, although with other views, by Goeze, which, however, was still unknown to ne, suggested itself to my mind, of purposely administering various cystic worms to different animals. For this purpose, I selected one of the most easily accessible cystic worms, which Von Siebold had expressly omitted from amongst those which he supposed to be capable of becoming converted into maturc Tanie, or, as he said, "again becoming liealthy," namely, the Cysticercus pisiformis of the rabbit, and also the C. fascioluris ('Prager Vierteljahrsschrift,' 1852, "Ueber die Umwandlung der Finnen in Tienien"). In this way I succeeded in rearing Tenice, rapidly approaching maturity, from Cysticercus pisiformis in the intestine of the dog, and from C. fusciolaris in that of the cat. Supported by these facts, I expressed the following opinions with regard to the nature of the cystic worms ('Ueber den Cestoden im Allgemeinen,' \&c., Zittau, 1853).

1. If the caudal vesiche were a morbid structure, this would say little for the wise arrangement of Nature, in undertaling nothing without an object.

2. The similarity of the dwelling-place of millions of cystic worms indicates a general plan, and the idea of a systematic infliction of disease is too unnatural to be admitted.

3. The caudal vesicle occurs in all individuals, of all species of cystic worms, even though they live in the most various zones and different animals. Even in the greatest epidemics and epizootics some individuals and districts are spared, but here none.

4. The universal loss of the caudal vesicle has its analogue in the metamorphoses of many animals.

5. It would be a forced assertion to say that the dropsy is cured simply by casting off the caudal resicle; sometling like curing ovarian dropsy by extirpation.

6. In the cystic worms, there is no mutritive fluid between the worm and the cyst, which, however, is never deficient in encysted Helmintha of other classes. (Sec Luschka, 'Ueber' Tr.ichina spiralis.')

7. All cystic worms, in the earliest period of their existence, have the head constantly inverted towards the caudal vesicle.

8. The state of rest in which the cystic worms must live 
in the interior of their caudal vesicle, in order to their development, would be inconceivable, if they had to collect the nutritive fluid for themselves, and did not contain it in them.

9. Dropsy in its nature is an anomaly of secretion and excretion ; the cysticercal vesicle is the product of resorption.

10. We introduce artificial separations where science must and will unite, and thus disturb our comprehension of the process of development in the Trenia.

11. The cystic worms are not strayed dropsical tape-worm nurses, but tape-worm larva furnished with a provisional organ (caudal vesicle), probably acting as a reservoir of nourishment, and incapable of sexual multiplication, for which there is neither room nor sufficient nutritive material.

12. The cystic worms constitute a necessary step in the development of the Trenice.

13. We cannot speak of dropsy or degeneration (for, as I afterwards pointed out, we can only speak of degeneration, and I might add of disease, when we are acquainted with the different normal or healthy states), and not even of straying, because we do not yet clearly perceive how the blood could get to the dwelling-place of the cystic worm. (Leuckart has recently put forward the opinion with regard to the straying hypothesis, that in this case we must also regard the young brood of a frog, in a pond which is drying up, as strayed.)

At the same time, I proved that the Cysticerci administered, when transferred to the intestines of other animals (as, for instance, the Cysticercus pisiformis in the intestine of the cat, \&c.), did not become developed into jointed tape-worms, but bore behind the head a long, inarticulated appendage, and died in a short time, without being any further developed; and that every species only thrives in a particular species of animal.

In the course of the year 1852 Von Siebold had repeated these experiments, partly himself and partly by his pupil Lewald; and was thus, as he said, convinced of the possibility of the conversion of the eystic worms into Tenice. In the first supplement, No. 200, of the 'Breslauer Zeitung,' of the year 1852, lie reported upon the experiments proving this metamorphosis with Cysticercus pisiformis, C. fasciolaris, and Cenurus; and upon the commencement of experiments with Echinococcus veterinorum, and by Lewald, in his dissertation 'De Cystiscercorum in Trenias 
metamorphosi,' Wratislavia, upon the conversion of C'ysticercus pisiformis into Tenia seriuta; he also amplified these confirmatory observations in his 'Zeitschrift' for' 1853, Band iv, p. 400.'

At the same time Von Siebold had administered the Cysticerci of rabhits to rabbits, and reared in their intestine a developmental form similar to that which I had obtained by the administration of the Cysticerci of rabbits to cats, which I have just mentioned. The forms with band-like, inarticulate appendages, reared, according to Von Siebold, from the Cysticerci of the rabbit in the intestine of that animal, were made use of by myself to transfer them through an incision into the abdominal cavity of rabbits, in order to test the opinion of Von Siebold and Van Benerlen as to the production of the vesicular worms from the ready-formed tape-worm lieads. The result was, that I could not confirm the opinion of these two zoologists, as the worms thus transferred into the abdominal cavity retained the form which they possessed at their introduction, or, if any change could be said to take place, instead of an inflation of the abdomen, a dimimution of the bandlike appendage was rather observed.

Subsequently, I also obtained a peculiar tape-worm (T. ex Cysticerco tenuicolli) by the administration of Cysticercus tennicollis to dogs. This is probably the same which Von Siebold supposed he had reared from Cysticercus cellulosce in the dog; but I never snceeded in rearing a mature Tania from the latter cystic worm in dogs, which, however, as we know by experience, must take place in the human subject, and which, indeed, did take place according to an experiment of Leuckart's.

In the meantime Von Siebold, who appears to have felt personally injured and affronted because 1 had attacked his notions upon the nature of the Cysticerci in the 'Prager Vierteljahrschrift,' and at the same time made an ironical remark about the theory of dropsy and recovery, was led to make personal attacks on me, in the 'Breslauer Zeitung;' and, amongst other things, was induced to remark that if he had not come to my assistance by his determination of the species, the whole theory of the process of metamorphosis would have been thrown by me into a state of confusion which could lardly be corrected, as I was not in a position to determine the particular species of Tenice and Cysticerci. I of course admitted this, but at the

1 [See a translation in 'Quarterly Journal of Microscopical Scienee,' vol. ii, p. 255.] 
same time I cast back upon Von Sicbold the reproaches which he liad made against me. Immediately after I stated in various places, especially in some numbers of Gurlt's 'Magazin für 'Thierheilkunde,' for the year's 1854 and 1855, that I had distinguished a $T$. serrata vera (Cystic. pisiformis), a T. Conurus (Ccenurus), a T. ex. Cystic. tenuicolli (Cystic. tennicollis), a $T$. solium (Cystic. cellulose), a T. medio-canellata (hookless Cysticercus?), a $T$. litterata (cysticercal state?), a $T$. crassiceps, Rud. (Cystic.? subsequently recognised by Leuckart as Cystic. longicollis), a $T$. crassiceps, Dıj. = T. polyacantha, Lenckart (Cysticercus?), and a $T$. intermediu (Cysticercus?). I certainly, up to that time, did not know low to distinguish these Trenice correctly, but had learnt to do this. Von Siebold, as he himself was not in a position to determine and discriminate the species, had done me an injustice in that reproach; and whoever admits the distinction of species in zoology would be obliged to agree with my statements, when he had liad some little practice in the microscopical examination of the lieads of tape-worms. I had preserved the principal proof of the correctness of my specific distinctions, partly on Plate IV of this Text-book, and partly in my prize essay, "Ueber' die Entwicklung der Blasenwürmer zu Bandwürmern im Allgemeinen und die des Cysticercus tenuicollis im Besonderen.'

In the first volume of Moleschott's 'Untersuchmmgen' for 1856, the attempt to answer this question was laid before the general public.

During the last five years the most celebrated German zoologists have made raluable investigations upon this whole subject, and these, with the exception of Von Siebold, have only furnished a confirmation of my statements, extended them, and given them a better foundation.

G. R. Wagener proved (Froriep's 'Tagesber. Zool.,' iii, p. 65, 1852, and 'Verhandl. der Kais. L. C. Acad.,' xxiv, Suppl., 1854), that every cestode worm, and not merely the Tenice, pass through a cysticercal state; that the cysticercal larva lives in various parenchymatous organs, and the free scolex (strobila) usually in the intestiue of a different host; and lastly, that the tape-wormhead (scolex) is produced in the interior of the previous embryonic body (i.e., the caudal vesicle), and remains enveloped by this until it gains the situation for which it is ultimately destined.

Stein ('Zeitschrift für' wiss. Zool.,' iv, p. 211) still clings to 
Von Siebold's viers, just as Von Siebold himself has done repeatedly. In the fourth volume of his 'Zeitschrift,' p. 407, the lattcr let fall the expression, "cystic worms are diseased dropsical tape-worms," but only in order to maintain the more firmly that they are degenerated tape-worm larre, and he also perscvered in the same course in his memoir, "Ueber Band- und Blasenwürmer,' 185t, p. 6t, in which he at the same time throws together nearly all the large-hooked tape-worms of man, the dog, the fox, and the marten, and regards them as different races of a single species.

After the greater part of the zoologists of Germany and other countries, with the exception of Von Siebold, Diesing ('Ber. der Wiener Acad.', 1853, p. 4.21), Valenciennes ("Comptes rendus,' 1855, xl, p. 1000), and, amongst others, even the Commission for the examination of the Danish prize essay (Eschricht, Steenstrup, and Hannover), had acceded to my riews; $R$. Leuckart especially, in his most recent work, confirmed all that I had said on the production and nature of the cystic worms, as well as on the metamorphosis of the Trenia. Leuckart. recalls his previous statements, and shows that Von Sicbold differed from me only in words, but not in any real difference of opinion and facts; that Ton Siebold's riews had become essentially different in the course of the year, and, as Von Siebold said, not a little modified, as he supposes that the cystic worms are of an embryonic nature, that their caudal vesicle is founded in the plan of development of the cestoid worms, and not produced by a pathological process. In short, Leuckart agrees essentially with all my statements and views.

But to place it beyond all doubt that the cystic worms were necessary steps in the development of the Tanice, it was also requisite to prove their production from the embryos of the tapeworm-brood. It is true that the six characteristic embryonal hooklets have not yet been detected upon true vesicular worms, but we shall shortly see that the laws of aualogy, as well as experiment, afford us a glance into this process. Thus Stein (Siebold and Kölliker's 'Zeitschr.,' ir, p. 203) saw the embryos of a species of tape-worm, after their transfer to the intestine of an animal (the mealworm-beetle), break out of their eggshells, penetrate the walls of the intestine, become encystcd, as he erroneously says, with the loss of their six hooklets, outside 
the intestine, and, increasing in size, give origin in their interior to the head of the tape-rorm (scolex), whilst the portions of the embryonal body which were not employed in the formation of the head, remained attached to the head in the form of a caudal vesiclc. With him, therefore, the cysticercal state is the second stage of development immediately following the embryonal state. Meissner also afterwards found (Siebold and Kölliker's 'Zeitschr.,' v, p. 380) the six embryonal hooklets on the Cysticercus of Arion empiricorum, but did not explain the nature of the caudal vesicle correctly. Without discorering the much smaller embryonal looklets of those tapeworm-embryos which pass through a true resicular state, Goeze (loc. cit.) had already seen how the future tapeworm-liead is developed in the interior of the cauchal vesicle; G. R. Wagener (loc. cit.) had proved the occurrence of this process within the enlarged embryonal body (caudal vesicle); and I myself had set about the experinental solution of this problem, by the administration of the ora of tape-worms. In order to arrive at a peculiarly convincing result by these administrations, I selected the $\operatorname{dog}$ as an experimental animal, in July, 1853, and even previously, - and this may, at the same time, serve the reviewer of $m y$ book, 'Ueber die Cestoden in Allgemeinen,' in Schmidt's 'Jahrbuch der Medizin,' as an answer to lis astonish.. ment on this account, - and administered mature segments of Trenia solium to several of these animals. Gurlt had previously stated that he had found a dog with Cysticercus cellulose, and I thonght that, from the rarity of the occurrence, the experiment would be most convincing in ease I succeeded in infecting the dog with Cyst. cellulose. In this, however, I did not succeed, any more than in infecting rabbits with the same Cysticercus by the administration of $T$. solium. The attempt, also, to produce cysticercal forms in the meal-worm, by the administration of Tenia angulata of the missel thrush, and of a Teria from the starling,-an experiment upon which I lave hitherto forgotten to report,-did not succeed; but for about four years I liave been unable to find the Tenire of the rat and mouse, which I regard as the Trenia belonging to the cysticercal forms of the meal-worm. In the meanwlile I resolved to resume these experiments with the Tenia Conurus, in order to obtain the remarkable phenomena of the vertigo in sheep. On the 15th of May, 1853, I at last obtained the cystic Cenuri; on the 25th of July mature proglottides of this Tania were passed by the $\log$ to which the Conuri were adminis- 
tered, and these, in order to make the experiment under the most unfavorable circumstances, were administered to a perfectly healthy two-year-old wether, a description of sheep which is usually free from Conuri. On the 10th of August the sheep was affected with vertigo; on the 13th the disorder had advanced so far as to necessitate the killing of the animal. Herr Kärmsen, of Drausendorf, near Zittau, a very intelligent agriculturist, who harl furnished the animal for experiment, unfortunately only sent me the head for examination; the rest of the body was kept to be eaten by the people on the farm, so that I was prevented from observing the immigration of the brood of the Trenia into the other parts of the borly. In the brain I found yellow stria from exuclation-passages, at the ends of which small vesicles of the size of a grain of millet were situated. I found fifteen young vesicles of Ccenurus, partly on the surface of the brain, which was reddened by inflammation, partly in the substance of the brain, and even in the ventricles. I then reported this result to the Saxon Ministry of the Interior, from which Professor Haubner, of the Veterinary School of Dresden, was commissioned to test my results; but I communicated the result of this first experiment to the scientific public in the November number of Günsburg's 'Zeitschrift für Klinische Medizin' for 1853. By a mistake of the editors, a heading was given to this article from which it appears as if the first experiment was made under the commission of the Saxon Government, whilst the text itself shows that only a subsequent commission could be spoken of. The impossibility of immediately obtaining a mature Ccenurus cerebralis delayed the making of the experiment at the cost of the Government, and it was only in the middle of November that I procured a Conurus cerebralis, with which I fed a dog. I killed him on the 9 th of January, 1854, and immediately afterwards six lambs in all were fed with the Tenice, both by myself in Drausendorf and by Professor Haubner in Dresden. Of these, five became vertiginous in about eleven days. The experiment has since been repeated so frequently, that this conversion of the brood of Trenia Ccenurus into Conuri in the brain of the sheep is an ascertained fact. I shall only remark, that vertigo was produced with proglottides of Tcenia Conurus sent by me in white of egg, in lambs, by Gurlt in Berlin, by Eschricht in Copenhagen, by Van Beneden in Louvain, by Leuckart in Giessen, and by Röll in Vienna, and in young cattle by May in Weishenstephan. The Agricultural 
Society of Saxon Lusatia, also, has repeatedly tested this subject by experiment, especially the Society at Klix, and its president, M. Kind, of Kleiubantzen.

Four months after I liad made my first experiment, Leuckart fed a colony of white mice with $T$. crassicollis. This appears to have been in October, 1853. His experiment was forgotten until the results obtained by Haubner and myself, in January, 1854, were communicated to him by letter. When, upon this, he examined his white mice, he found them infested by cystic worms. (See Siebold and Kölliker's 'Zeitschr. für Wiss. Zool.,' vii, p. 139.)

It still remained to be tried whether it was possible also to produce the other cystic worms artificially, and Haubner and myself, as well as Leuckart subsequently, employed the experiments made with this view, for the purpose of proving at the same time the specific determinations undertaken by me. I myself also proved that, by the administration of the abovementioned mature species of Tenia as far as they were accessible to me, to suitable animals, only the cystic worms belonging to these species can be reared, but not any kind of cystic worm at pleasure. In his most recent and excellent work Leuckart has proved that every one of these species presents such essential differences, even by the first processes in the conversion of the brood into the forms in questicn, that we can only speak of their identity if we are willing to give up altogether the idea of species in zoology, or not to see the differences.

Very recently, in Gurlt's 'Magazin für Tlïerheilkunde,' Professor May, of Weishenstephan, has made known some experiments from which it might appear as if such specific distinctions did not exist. But an exact criticism, such as I have given in the appendix to the work upon Cysticercus tenuicollis, proves the inadmissibility of May's statements, the deficiency of his knowledge of systematic determination, and the faultiness of the mode in which his experiments were made. To cite only one circumstance in support of these assertions, I may mention that May believes he reared Tcenia solium in the intestine of the dog, from Cysticerci cellulose which he had preserved for ten days in water at a temperature of about $10^{\circ} \mathrm{R}$. $\left(=48^{\circ} \mathrm{F}\right.$.) Although I regarded this experiment as contradictory to nature, merely because the infected mouse which a cat is about to devour, or the rabbit which a dog is going to eat, is not laid by these animals 
in water for ten days, but is usually devoured by them at once, I nevertheless undertook the direct investigation of this question. I laid Cystic. pisiformes with their enveloping cysts in water, and as the temperature was that of a hot summer I placed them in an ice-cellar, in which an average temperature of $8^{\circ} \mathrm{R} .\left(=45^{\circ} \mathrm{F}\right.$.) was shown by the thermometer. A stay of a few days in this place was sufficient to render all the Cysticerci pisiformes incapable of development in the intestine of the dog, although this vesicular worm thrives in that situation much more readily than the Cysticercus cellulose employed by May, even if this ever finds a suitable dwelling-place in the intestine of the dog.

From the concordant experiments of Haubner and myself, of Leuckart, Tan Beneden, and Möller, this much is established:

1. Mature Tenice have hitherto been reared successfully from all vesicular worms administered when a suitable host was selected; thus from Cysticercus pisiformis the Tania serrata vera was obtained; from Cyst. tenuicollis the Tania ex Cyst. tenuicolli (erroneously named $T$. tenuicollis by Möller and the Danish committee of examination, this name having been already em. ployed by Rudolphi for a Tenic of the marten and weasel, the Cysticercus belonging to which I found in the liver of the fieldmouse and mole $=$ Cysticercus innominatus Hyperdcei, Leuckart); and from Conurus cerebralis the Tania Conurus, all three in the intestine of the dog; from Cyst. fasciolaris the Tania crassicollis, in the intestine of the cat; from Cyst. cellulose the Trenia solium, in the human intestine; from Echinococcus veterinorum (scolicipariens, Küch.) a Trenia Echinococcus, in the intestine of the dog; and from Cysticercus longicollis Hyperdai, the Trenia crassiceps, Rud., in the intestine of the dog (Leuckart). Möller in vain swallowed Cysticerci tenuicolles with the view of infecting himself with a Tania, and Zenker and myself administered Echinococcus altricipariens to dogs; in the latter case, however, it is possible that the individual scolices were already dead.

2. From the eggs of Tania solium in pigs, from those of $T$. Conurus in sheep and cattle, of $T$. serrata vera in rabbits, of $T$. crassicollis in rats and mice, of $T$. ex Cysticercus temuicolli in sheep and lambs, the corresponding vesicular worms have been reared. The experiments with the eggs of the Trenia of Echinococcus have hitherto remained unsuccessful.

The phenomena which occur after the different administrations are so constant that we may almost predicate by days and 
weeks what state of growth will be found. I should advise any one wishing to repeat the latter experiments to administer the eggs of $T$. serrata vera to young rabbits, even from motives of economy.

It only remains now to refer to the opinions which have been entertained regarding the developed tape-worm-chains, as they are called. $\mathrm{U}_{\mathrm{p}}$ to a very recent time it was the most general opinion, still entertained by some, that this tapeworm-chain was a simple animal, with numerous segments. But, nevertheless, even some of the older physicians and naturalists correctly perceived that the tape-worms were not simple but compound animals. By many of the older medical men the isolated segments of tape-worms were regarded as separate individual worms; and what Dujardin has recently called proglottides, are described by them in the tape-worms of the human subject as "Vermes cucurbitini." Valisneri and Coulet, who were subsequently followed by Blumenbach, to the horror of his age, even described the tape-worms as animals composed of these "Vermes cucurbitini." At the same time they fell into the great error of not regarding this chain as produced by a successive formation of joints placed one behind the other from the head, but expressed the remarkable opinion that the tapeworm was produced by the adhesion of the individual "Vermes cucurbitini" one after the other, by which means the manyjointed body of the tape-worm was formed. The idea that the tape-worm was a compound animal was so completely repudiated that $\mathrm{S}$. Leuckart only ventured to express himself in the following words: "I was almost iuclined to think that I must also regard the jointed tape-worms as organisms in which each joint was to be considered an individual animal, and the whole, therefore, as an 'animal compositum,' as indeed was previously supposed by many distinguished zoologists." Eschricht first, and after him Steenstrup, expressed this opinion more distinctly; and Van Beneden proved it more clearly by examples aud figures; after Dujardin, as already observed, had described the segments of tape-worms which occur isolated as peculiar animals under the name of Proglottis. The Trematode-like appearance of these last had already introduced errors in regard to their signification. Thus Diesing described a proglottis of the Trenia fimbriata of the Brazilian deer first as a Trematode, under the name of Thysanosoma actinoides. Pallas, who had seen an 
isolated proglottis of $T$. serrata creeping upon the wall of a room at a lieiglit of several feet, named them Ovaria ambulantia. When they still contain eggs the presence or absence of the six-hooked embryos in these renders it easy to avoid error and distinguish the proglottides from the true Trematoda. From the considerable similarity of form of the two animals, it has recently becn attempted to regard all these proglottides as Trematoda; nay, many have even expressed the hope that it would some day be possible to prove that the final destiny of the proglottides was to become converted into Trematoda. Against this notion I declare myself unconditionally, and even Vau Beneden appears only to intend to call attention to the mere relation of form of the two animals, which, even in the time of Rudolphi, must liave sufficed to cancel the separation of the two forms into Cestodea and Trematoda in Rudolphi's system. The experiments of De la Talette upon the production of the Trematoda, which will be mentioned by me hereafter, and the observation that in the outer world, as in the intestinal canal of other animals, the proglottides die rapidly, support the above refutation of an intimate relationship between the Cestodea and Trematoda, founded upon their development and not merely upon form. By the advice of J. Müller, I administered to three different young dogs mature proglottides of the characteristic $T$. ex Cysticerco tenuicolli. But on dissecting the animals eight, ten, and fourteen days after the different administrations, I never found the slightest trace of these proglottides, or of any trematode forms. The proglottides had totally disappeared (by digestion), and the very same thing had taken place in the intestine of the rabbit when I had administered proglottides of $T$. serrata to rabbits. Moreover, if we look more closely at the essentially different anatomical structure of the two kinds of animals, for, besides the different form and colour of the eggs, and the different form of the embryos, the want of calcareous corpuscles, the presence of a pair of lateral aquiferous vessels with a pulsating tube at the posterior extremity of the body in the Trematoda, in opposition to the four lateral longitudinal vessels of the Cestodea, the pulsating tube (communicating ressel) of which, should rather be sought in their cephalic than in their abdominal extremity, and the want of an alimentary canal in these animals, will prevent us unconditionally from placing these two animal forms 
together, and from supposing that there is anything more than an affinity of form between them. Even the proglottides of the Bothriocephali, which are, perhaps, still more similar to the Trematoda in their form, cannot constitute an exception to this rule. If we would regard the Cestodea and Trematoda as creatures standing in an intimate developmental commection, we must finally inquire also from what species of cestode worm a certain trematode worm is derived? What cestode proglottis have we before us in any particular trematode worm? With those Trematoda which dwell in the blood (Distoma hamatobium, Bilharz), it would be difficult to discover what mature cestode proglottis liad been able to penetrate into the vascular system of the liuman subject, and there become transformed into a Distoma. All that we can regard as justifiable in this case is a union of the Trematoda and Cestodea as two independent subclasses in the class of the flat worms (Platreluia), as we have done in the Introduction.

After this historical, critical, and systematic summary, I turn to trace the subject in its details.

\section{The mature animal, or the Proglottis.}

From the moment when the hindmost segment or segments of a tape-ivorm colony have become so far developed as to contain the six-liooked brood ready formed and encloser in the egg-capsules, this segment seeks to break loose either by itself or in company with several others, in order to continue an independent existence, either in the same place (the intestine of its previous host), or in a different one (in the external world). All this varies according to the species. In Tania, Tetrarhynchus, \&c., each joint usually breaks loose; in Bothriocephalus a series of joints. In those cases in which no regular formation of segments occurs, (in Trianophorus, there are merely lateral notches representing the commencement of segmentation, in Ligula nothing but groups of hermaplurodite brood-places occur,) no single proglottides or series of segments can break loose, but only single brood-places or fragments of the body of the cestode worm with such broodplaces; or the eggs must escape singly. In the same way, as Möller has strikingly pointed out, in certain polype-stocks the mature individuals scparate from the parent, sometimes in a more, 
sometimes in a less independent form. It is only in a few species that the eggs, whether singly or enclosed in the segments, must cscape outwards in a state in which the formation of the embryo is not yet completed, so that it exists for a time in the exterual world, as in otlier Helmintha.

Some Bothriocephali, which are themselves unarmed, have hookless embryos. In this case either the formation of the hooklets must take place subsequently outside the intestine of the animal infested, or the brood (II, p. 40) is nerer capable of active migration into another host. Perhaps they may pass through their further development behind the villi and in the more sheltered pyloric appendages of the same animal, or in those of lower animals of the sea and land, and find in such situations the repose necessary for this purpose. As a matter of course, when the brood bears the same form of head as the mature cestode worm whilst still in the egg.shell (for example, that of Phyllobothrium tridax, Van Ben., with four bothridia and an unarmed rudimentary bulb between them), the intestine of the same animal would be sufficient for its dwelling-place, and such brood would require no migration for its development. The latter two forms, however, do not come under our consideration amongst the Cestodea of the human subject. The proglottides to be noticed here have, for the most part, a flat, quadrangular form, very similar to the Trematoda, and usually a white, or yellowish, rarely a reddish or brownish colour (cansed by the coloration of the eggs); they have neither mouth, anus, nor intestime. With regard to the vessels, nerves, muscular system, and skin, the description of the strobila form may be consulted. Of the sexual organs referred to in the same place, some of the parts have undergone a retrograde metamorphosis, and we can only distinctly find the genital pore situated on the lateral margin in the middle of the segment, with the seminal cord and the male genital opening towards the anterior end of the proglottis, and with the vagina towards its hinder margin, and lastly the uterus, with semen, eggs, and sixhooked embiyos.

As the eggs possess a much greater diameter than the vagina, they cannot pass through this; they cannot, therefore, be deposited in this way, but can only escape ont of the proglottis when the latter acquires a larger opening in some way, by tearing, \&c. The latter takes place sometimes even in the intestine of the first host, and the eggs escape separately into the outer 
world with the excrements, which then appear as if sprinkled with fine white sand; or immediately without the intestine, where, as was even stated by Dujardin, the progress of the progiottis is seen indicated by a white, milky streak. Sometimes the pro. glottis does not burst in either of the above-mentioned places, but gets uninjurer into the intestine of a new host, in which case it only distributes its brood after it has been destroyed by digestion. According as the eggs reach the intestine of their host in this way separately, or enclosed in the proglottis, and therefore in a mass, solitary or numerous specimens of a cystic worm, or of the analogous state, are produced within one and the same host. With regard to the duration of the existence of the proglottides, which are passed sometimes with, and sometimes without, frecal matter, we know nothing ; moist soils, upon which they creep about, keep them alive longer than dry grouud, and they live more than eight days in carefully-renewed white of egg. The capability of evolution of the enclosed brood is of longer duration than the life of the proglottides, as the putridity and mouldiness of the proglottides do not destroy this faculty in the brood.

In consequence of their power of independent motion, they quit the places in which they have been deposited with or without excrementitious matter, creeping away from the dung upon all sorts of moist objects in the meadows (such as stalks of grass, clover, low plants, roots, salad, windfalls, \&c.), and upon the foliage of trees, when they have been dropped upon the latter with the excrements of birds. In this way they are devoured by vertebrate and invertebrate animals which feed upon grass, raw fruit, roots, leaves, \&c. If they get into water they burst and disseminate their brood in that fluid, where it may reach the stomachs of other animals with their drink. In cesspools and drains the Tenice of the human subject evacuate their eggs, and are then thrown upon salad, grass, roots, \&c., as liquid manure, or swallowed by pigs which wallow in such filth. In predaceous fishes which live upon their own species, the mature Cestodea of the smaller specimens get into the stomachs of the larger ones, when they disseminate their eggs, and thus infect the latter with Cysticerci. On a dry soil their vitality may only last for a few hours.

The proglottides, therefore, in the first place, perform an active migration from within the intestine of their previous host and are thus passively transferred into the intestinal canal of a new host. 
Arrived in the stomach, they are entirely or partially digested, diffuse their brood there, and sometimes even pass in a half-digested state into the intestine. With this the functions of the proglottides come to an end, even if this be not the case previonsly, on their escape into the onter world and the dissemination of their eggs there. That proglottides cannot pass the stomach of an animal without being digested, has already been stated. But even if particular proglottides, after bursting in the intestine of an animal, should be capable of healing up again and living for a Ionger period, it would certainly be impossible that such proglottides should again produce brood as the genitulia for the production of germs are in course of retrogression. With the dissemination of the brood their function ceases.

\section{The six-hooked brood, enclosed in separate egg-capsules.}

These are called eggs, although their developmental history differs greatly from that of ordinary eggs. The embryos enclosed in the egg-shells are globular, naked vesicles, mnlike their parents; the smallest of them measure only 0.022 mill., and the largest as much as 0.05 ; they are destitute of any organs, scarcely furnished with an oil-drop, possess an epidermis with a double outline, and usually bear six, but in the Tetrarhynchi only four, very small, microscopic hooklets, on their anterior extremity, so that they carry their destination, that of boring forward through the tissues, as it were, written upon their foreheads. The bodies of these small, but very dangerous vesicles, whether armed or unarmed, are always capable of motion. The embryos which are destined to migrate into cold-blooded animals are in general larger, possess larger hooks, and exhibit tolerably-distinet movements, even at the ordinary temperature of a room. Those destined to migrate into warm-blooded animals are much smaller, have smaller hooklets, and only, exhibit pretty-distinct movements at an elevated temperature (at the temperature of the stomach). We may easily suppose that according to the greater or less size of the vesicle which is to move forward through the tissues the boring apparatus of the vesicle will also be larger or smaller. Perhaps, some day, we shall discover some small, coustant distinctions in the embryonal hooklets of the different species; but in general these distinctions are hardly to be called essential, and in the embryos with very small hooklets they disappear entirely. 
These smallest forms are not only similar in all the species in which they occur, but all the six hooklets are also similar to each othel. In the smaller vesicles these hooklets are about 0.0095 millim. in length, and have a crescent of 0.0038 ; in the larger ones they are about 0.020 millim. long, with a crescent of 0.009. They are placed in pairs (two pairs latcrally, and one pair in the mirldle), with all their points directer outwards; there are no muscles at their base, their movements are produced by the displacement of the neighbouring parenchyma of the body, and take place in the same direction with all the hooks, as may be seen distinctly in the Trenie of birds. The enbryos generally liave a small clear space between them and their envelope.

The shells or envelopes of these embryos (egg-shells) are very different in the different species; they are larger or smaller, ${ }^{1}$ simple or multiple, smooth or rough, clear or dark, round or oval, or furnished with appendages, \&c. The eggs of the Tanice of the human subject, like those of the others which pass through a vesicular stage, are brown or yellow, thick and firm, rough externally, or, as was formerly said, beset with pits (foveoli). Leuckart, lowever, shows that, according to Welcker's statements regarding the microscopic relief-picture, we must admit the existence of numerous, perpendicular, stiff bacilla or hairs which are separated by confluent crevices or chinks. In those cases in which, as in Trenia solium, it has been supposed that a concentric stratification and radiate arrangement is to be seen in the shells, an optical illusion takes place. The supposed radii are strongly refractive bacilla; the concentric strata are the optical product of the projection of particular bacilla; nothing of them is seen in isolated fragments of shells. The clefts between the bacilla appear sometimes even to have penetrated through the inner layer. The size of the bacilla varies according to the species; the shortest are those of $T$. Echinococcus. Both the bacilla and the inner smooth layer of the shells are chitinous. The former appear to be destined partly to give the shells greater firmness and partly to increase the surface exposed to digestion.

1 The smaller the eggs the more easily will they, on the one hand, escape the dangers to which they are exposed in the outer world, and the forces which may act upon them; whilst, on the other hand, we may suppose that a greater number of them may be destroyed without any injurious effect on the continuance of the species; as also that, for the latter reason, nature has endeavoured to produce the smallest, or, according to the proportions of space, the most numerous eggs in the largest proglotides. 
The thinner the shells are the more readily do the eggs alter their form. Thus the eggs of $T$. solium acquire a funnel-shaped or cup-like hollow when placed in strong spirits (by extraction of water); this I had overlooked in previous investigations, as Leuckart has pointed ont. The mode of formation of these shells will be subsequently described.

We have now, in the first place, to speak of the subsequent fate of the egg-envelopes or shells and the embryos enclosed in them, and for this reason refer to what has been said (Section I) with regard to the migration of the proglottides and their subsequent fate in the outer world, and respecting the exclusion of the eggs from the intestine and the eggs which occur isolated in nature. The next thing that happens to the eggs, whether enclosed in the proglottides or freely disseminated, is that they are swallowed with the above-mentioned grasses, with roots and fruits which are eaten without peeling, or lastly with drink, by different herbivorous or omnivorous animals (including man). They thus pass the mouth and œsophagus, and then reach the stomach, in most cases certainly uninjured; here the egg-shells, which have become softened in the cligestive fluid, partly in consequence of the cligestive process, which acts first of all and principally upon the inner stratum of the egg-shell, and partly in cousequence of friction, burst against other solid alimentary substances, by which means, of course, the embryo is set free. Artificial experiments made by Leuckart on the digestion of proglottides and eggs, by introducing them into the stomachs of animals kept at a hatching heat, gave, as their ordinary result, after the digestion of the proglottis itself, only a greater brittleness of the eggs; it was very rarely, and only in a few eggs, that Lenckart saw a breaking up of the egg-shell; but he only observed this once in greater abundance in eggs of the Tania crassicollis, which he had exposed to a hatching heat in an emulsion of the mucous membrane of the stomach. But, on the contrary, if we examine the contents of the stomach of a rabbit four or five hours after the administration of proglottides or eggs (the animal should have fasted previously for more than twenty-four hours), we find amongst the contents of the stomach, uninjured, but extremely brittle eggs, together with various remains of broken egg-shells, and, under farorable circumstances, perhaps a free embryo here and there. The rupture of the egg-shells, therefore, appear's to be, as already remarked, a consequence of the chemical action of the fluids of 
the stomach, and consequently of digestion; but also, at the same time, of the mechanical influence of the friction of the walls and contents of the stomach, in consequence of its peristaltic movements. It is to be ohserved at the same time that the processes last described may be produced not only in the stomach of the rabbit, but also in that of any other animal experimented on, and with the proglottides or eggs of all species of Trenice. The latter at least applies to the Tcenice, which pass through a vesicular state and to the stomachs of the Mammalia.

We have now to discuss the question whether the stomach is the only place in the alimentary caual in which the rupture of the eggs and exclusion of the embryos takes place, so that every embryo set free must once have passed the stomach of an animal before it can attain a higher development. I have formerly expressed the opinion that I regarded such an exclusion of the brood as possible, in consequence of the mastication and rupture of proglottides and eggs which had just entered the moutl of the animal, observing at the same time that it now appeared to be established by observation that the brood may sometimes escape in the upper part of the alimentary canal and before reaching the stomach, as in the pig we met with the Cysticerci very abundantly in the tongue and osophagus, although I freely admit that the brood may reach these parts from the stomach.

That the animal heat alone is insufficient to cause the exclusion of the brood is proved by an experiment made upon a pig at my request by Haubner. Uninjured eggs of Tania solium were introduced beneath the conjunctiva of a pig, without producing Cysticercus cellulose in the eye. It is true that to arrive at a definite result in this case the experiment must be made again with crushed eggs, from which the embryos liave been completely or partially set free. For as the fresh eggs of Tanice, when placed in large numbers between two glasses, may be crushed, so as to set free at least some of their embryos, without the latter being destroyed, or even injured in any way, the egg-shells, notwithstanding the minnteness of the eggs, may just as casily be crushed during mastication by the teeth of the pig, without the necessary occurrence of any injury to the embryo. I am perfectly convinced that an embryo which has been set free in any part of the alimentary canal of a warm-blooded animal, will commence its migration even from this spot, the animal leat exciting its activity. Therefore, until I am convinced of the contrary by 
the last-mentioned experiment, I must maintain this opinion in opposition to Leuckart, who seems to think that when the eggs are masticated the embryo must necessarily be always destroyed, or clse that, from their small size, all the eggs must pass uninjured through the teeth. It appears that eggs which have passed the stomach and reached a portion of the intestine below the stomach in an uninjured state, may still give issue to their six-hooked embryos, from the discovery by Leuckart of a free embryo in the intestinal mucus of a part of the small intestine; and $I$ also consider that this riew is supported by an experiment of Leuckart's, which will be mentioned hereafter, according to which the caudal vesicle of those Cysticerci which are left for a time in contact witl the fluid of the stomach in experiments in artificial digestion, and then enclosed in a piece of the small intestine, is readily digested; whilst when the Cysticerci are enclosed at once in the small intestine, no digestion of the proglottis takes place. We may consequently suppose with some probability that the temporary sojourn of the eggs in the stomach of an animal at least facilitates the exclusion of the brood materially. This question is especially important for the theory of the production of Cysticercus cellulose in the human body. If we consider, on the one hand, that it cannot be denied that Tenia solium is the producer of the germs of Cyst. cellulosce; and on the other that, in many cases of Cysticerci in the human body, the simultaneous or previous existence of $T$. solium in the same subject has been established beyond all doubt (as in the case of Cyst. cellulose in the brain of a person of weak intellect, from whom Günsburg had previously expelled a Tania solium; in one of the cases of C'ysticercus cellulose in the eye, described by Von Graefe, in which the woman suffered from $T$. solium; and in the case narrated by Möller, in which a woman who had been epileptic for many years, and who had, twenty year's before, visited the hospital at Hamburgh, to get a tape-worm expelled, and who exhibited Cyst. cellulose in the brain); and if at the same time we do not forget how often the patient is quite unaware of his being infested by a tape-worm, we may certainly come, without much reflection, to the idea that it is by no means improbable that in such a case the bearer of the tape-worm may have infected himself with the C'ysticerci.

There are various ways in which this infection may take place. The infested person, when the proglottides have fallen into his 
clothes, wishes to remore these moist, cool bodies, and if he does not go about this in a peculiarly eleanly fashion, but seizes the proglottides with his fingers, he might have contaminated the latter with eggs. Or in the examination of the Trenice expelled by medical treatment, in pulling away those hanging down from the anus, or in tonching the vessels in which the tape-worms lie, and on the margins of which their white eggs are very often found, the patient, or those around him (servants), may contaminate their fingers with these eggs. This I have seen only too often, and always warned those interested against such an oecurrence. Now, if the last-mentioned individuals have not washed their hands perfectly clean, or if they have forgotten to wash them altogether, and then incautiously put them to the mouth, their infection with eggs, and consequently with Cysticerci, is rendered possible. In the examination of freshly-expelled Tenie, especially $T$. solium, I lave always made it a rule to take the most anxious preeautions; in seeking the heads of the expelled worms, I always disentangle the latter by means of two pairs of forceps, of whieh I hold one in each hand, at as great a distanee from their tips as will still allow me to hold objeets firmly. On the other hand, I by no means hesitate, when pressed for time, to disentangle Tenice which have been long preserved in spirits, even with my fingers in case of necessity, and I regard the fact mentioned by Möller, that Cystic. cellulose have been reared in Paris from eggs of Tania solium preserved in spirits, as quite impossible, and evidently a mistake. (Vide 'Gazette Médicale,' 1854.) Moreover, a transfer of the eggs of tape-worms into the mouth might take place unconseiously with persons infested witl these worms, or their bedfellows; sueh persons grasping with their hands whilst asleep after the proglottides moving about upon their bodies, and produeing an unpleasant sensation in eonsequence of their moisture; or scratehing themselves on the places passed over by the proglottides, and then carrying the hands thus employed to the mouth. In all these eases, however, the infection would take place by the introduetion of the eggs from without into the mouth and stomach, and therefore in the ordinary way.

But the person infested by Trenice may also infect himself with Cysticerci, without the previous eseape of the proglottis from the intestine, when the proglottis itself, instead of progressing downwards, passes upwards in the intestine, and therefore towards the stomach; or when it is carried there forcibly during vomiting, by 
the antiperistaltic movements of the intestine. That this passagc of the proglottides from the duodenum into the stomach is possible is slown by those cases in which (as is rot unfrequently the case in dogs and cats) tape-worms are vomited, and hang out from the mouth; and perhaps, also, by the occurrence, which does not appear to be rare, of Cysticerci (e.g. in the eye) at a period when the individuals are suffering remarkably from vomiting. Thus, two of Graefe's patients complained, during pregnancy, of the appearance of Cysticercus cellulose, and women in general appear to suffer particularly from this Cysticercus, and indeed from Tenia solium. If we admit this mode of self-infection of tapevorm patients with Cysticerci, the exclusion of the brood would only take place when the eggs arrive in the stomach of the host, cxactly as in other cases.

The question still remains, whether, when the eggs are set frec in the small intestine by the rupture of the proglottis, the embryos can escape from them, so as never to pass through the stomach of an animal. In this case, also, I am firmly convinced, that if an embryo be freed from its egg-shell anywhere in the small intestine, it must migrate forward, although this case will certainly be of very rare occurrence, as Leuckart has only met with a free embryo onee in the duodenum and once in the small intestine, but never with uninjured eggs or numerous remains of egg-shells. Leuckart denies the possibility of the exclusion of the brood from eggs thus set free immediately in the small intestine of their host, and, at the same time, thinks that if the intestine possessed the faculty of setting free the brood, there would hardly be a tape-worm patient without Cysticerci. Uufortunately, Leuckart did not succeed in testing this question by experiment, in the way recommended by me. Thus, the establishment of fistulie in the small intestine, and the subsequent introduction of the eggs of Tcenice through these into the intestine, did not succeed for a sufficiently long time, as all the animals experimented on died immediately. As soon as I have sufficient material by me, I shall again test this question experimentally, by tying up a portion of the small intestine in the living rabbit, and introducing eggs and proglottides of Tcenia serrata into this portion of intestine. The result will show whether an exclusion of the brood will take place, or whether this is effected only when the brood has passed once through the stomach. Until then, however, I must, in opposition to Leuckart, regard the supposition 
of a direct exclusion of the brood in the small intestine as possible, and not as, ̀̀ priori, improbable.

As to how long the eggs can be preserved free externally, witlout their embryos losing the faculty of life, we do not yet possess any certain eviclence. It appears to me that there is a certain limit, and that not a very wide one; at least I am convinced by my own experiments, which are confirmed by a statement of Leuckart's, that when the eggs of Tcenia Conurus and T. serrata are preserved in water, the vitalizability of the brood is extinguished in two months. I do not know whether a constant renewal of white of egg may preserve their vitalizability for a longer period, but such a preservation in white of egg is of but little value in practice, or even in itself. It is, consequently, at present an hypothesis quite destitute of proof, to think, as I did formerly, that the eggs might lie through the winter in ice and snow, be carried about in the waters for months by the stormy weather of spring, and yet, at the expiration of this period, develop their brood as soon as they arrive at a suitable intestine. A moderate humidity is certainly favorable to the brood. Desiccation kills the embryos pretty quickly. After 14-24 days Haubner and I did not succeed in producing the evolution of the brood of Tenia Conurus, and Leuckart is even of opinion that complete dryness for twenty-four hours is probably sufficient to destroy the vitalizability of the brood.

With regard to the fate of the brood of tape-worms, therefore, we now know-that the six-hooked brood contained in the swallowed eggs of Truir is set free in the alimentary canal of animals after the rupture of the egg-shells; that this mipture, and of course the simultaneous exclusion of the brood, takes place principally in the stomach, and therefore the egg of the tape-worm has usually once passed the stomach of the animal in question, either fiom the pyloric or cardiac orifice.

A question still open is, whether this rupture and exclusion is possible before reaching the stomach by the assistance of the masticatory organs, or whether it may occur even in the interior of the small intestine in which the brood was produced? even when it had never reached the stomach. There is a possibility, but no certainty of the two latter. That segments disseminate their eggs, even in the small intestine, appears from the occurrence of those shrivelled segments of a tape-worm colony, furnished with scars, which are followed posteriorly by still uninjured segments. 
With this we come to the end of the passive migration of the eggs of the Cestodea, and of the brood in the eggrs.

\section{The destiny of the six-hooked brood when set fiee.}

This subject must be divided into two sections:

1. What is the fate of this brood until it reaches its settled dwelling place external to the intestinal canal?

2. What becomes of it in this dwelling place?

1. As soon as the embryo has become free in any part of the body (especially, therefore, in the stomach) of an animal which suits it, the instinct of active migration awakens in it. For this purpose, according to Van Beneden, it brings together the central pair of its embryonal hooklets like a wedge (Tab. I, fig. 5), and at the same time, by thrusting and twisting, begins to force them forward. Having in this way made a little progress, it assists itself further with the two lateral pairs of hooklets, and pushes itself forward therewith, just as a person who wishes to spring out of a low window rests his elbows against the window-frames, and drives himself forward with a swing.

According to Möller, the central spines, which are the longest, and also straight, move exactly as described by Van Beneden; they lay themselves together in the form of a stile and only move forwards and backwards. The other two lateral pairs liave small hooks at the apex. All the six have their roots directed towards the same point, by which means they pretty nearly touch each other at the base. Möller, however, compares their movements with those of a watch, on the face of which he imagines three pairs of hands all pointing to twelve. The central hooks are driven directly for'wards, whilst the other pairs go back, the one to three and the other to nine, so as at last to form a right angle with the central ones. I have always described the movements of these hooklets according to Van Beneden, but I have never been able to arrive at a perfectly clear idea of the movement of those embryos in which the central spines do not form straight stiles, but are also curved in front in the form of a claw, although perhaps somewhat less strongly than the lateral hooks. Such spines occur especially amongst the large-hooked Tenice of birds, as well as in the small-hooked embryos of the Trenia of the human subject. Leuckart is of opinion that the morements are 
by no means effected right and left in all the hooks in the same direction, but that "whilst the two lateral pairs move dowuwards from the vertex in the lateral plane nearly simultancously, this movement only takes place somewhat later in the central pair, and then in the median plane." Thus, sometimes one pair of hooks (the central one), appears to rest, and to hold the embryo firmly in its place whilst the other two lateral pairs are in motion, and sometimes the cental pair appears to be actire whilst the other two pairs hold the embryo and preserve it from slipping back, which certainly appears to be most in accordance with nature. By its boring movements the little embryo then penetrates with considerable rapidity through the tissues in its vicinity, and conse urently through the wall of the alimentary canal, and especially of the stomach. This act is the same in all embryos, but as soon as the walls of the alimentary canal are penctrated the case becomes different. The embryos which efiect their further development in cold-blooded animals, may probably arrive at once and directly by their boring activity (active migration), at the place where they propose to take up their abode, in order to pass there into the next higher stage of development. But those embryos which are to effect this in warm-blooded animals present a complication of conditions. First of all the migration, as in the former, is an active one, but it must soon become passive, although probably, in most cases, only for a time. Leuckart's careful investigations certainly appear to contradict the assumption made by Haubner and myself as regards the greater part of the embryos which subsequently take up their abode in the abdominal cavity and the orgaus there situated; namely, that the migration of most of the embryos of Tenia takes place through the ductus choledochus. Lenckart never succeeded in finding free embryos in this canal. It may perhaps even be disagreeable to them, because in it they would have to struggle agaiust a stream of bile flowing down, and not only to bore, which, according to the previous observations, they like to do, but also by alternately adhering and letting go their hold, to move along by creeping. I now admit that what appeared to me to be the easiest, as it offered an open way to the embryos, would rather be very difficult to them. The passage by the ductus choledochus, therefore, can be selected by them, if ever, only in very rare, exceptional cases. I believe also, that (as these animals do not appear to be particularly fond of creeping without horing) 
the immigration of the greater part of them into the liver, \&c., probably takes place very rarcly by their first of all piercing through the walls of the stomach, then moving upon the serous coat of the peritoneum in the free abdominal cavity, and only penetrating through this into the parenchyma of the organ selected, for example, the liver. It is true, the latter has not as yet been completely refuted by the fact that Leuckart found no embryos upon the serous coat of the liver. From the size of the surface under examination, he might have orerlooked them.

I also return again to my original supposition, which I afterwards gave up, that the active migration is probably followed by a passive one in the stream of the blooch By the careful investigations of Leuckart, who found free embryos four times in the main branch of the vena porta at its entrance into the liver (whilst he never succeeded in discovering free embryos in the mesenteric and gastric veins, in the lacteals, or on the serous coat of the stomach and liver), I feel convinced that the brood is introduced into the circulation of the blood by the active penetration of the tissues, and then a passive migration with the blood is commenced. In this way the immigration of the brood into the liver would be easily explained, the embryos getting into the vena porta, and remaining fixed in the finest ramifications of the capillary system of the liver; and into the brain and other parts situated more peripherically, by the embryos making their way into blood-vessels (e.g., the vena cava, the capillaries of the liver, and especially those of the lungs), which couduct the blood, aud with it the brood, towards distant regions of the body. Nay, I even go a step further, and perceive in the small size of the brood of the last-mentioned Trenice, as compared with the size [of that] of the allied Cestodea in the bodies of cold-blooded animals, an indication of the fact that nature has positively prepared this smallest brood for migration through or into the capillaries, and destined them to this purpose. Lastly, it is perhaps not venturing too far, if, in the pigment on the heads of certain Cysticerci, we should recognise an additional proof of the previous migration of these specimens through the blood of man, or of certain mammalia.

Moreover, I also subscribe to Leucliart's assumption that, in the choice of its dwelling-place in the body of its new host, the immigrant embryo is not driven to it by a certain 
instinct. But when Leuckart goes on "where the embryo cannot go further, there it remains seated," I only adopt this view if we add "for the present, for" an iudeterminate (probably very short) time." Here, indeed, I must for the present differ from Leuckart, for various reasons. I suppose that as soon as the embryo becomes fixed [in the capillaries], it, as it were, awakens again, and again sets about migratiug actively through the walls of the capillaries, or if it remains stuck in the capillaries, it rather dies, or by thrombus-formation and thrombous diseases thereby produced, very rapidly causes the death of its host. Every one will admit that the extraordinarily speedy death of the animals experimented on may be best explained by the supposition that death is produced by the tearing away of blood-coagulum (Thrombose). The immediate active exit of the little brood, appears to me to be supported by the circumstance that the desire of active migration in these little creatures, as is shown by the formation of passages upon the liver and in the brain, still exists at a period when they have already become developed into resicles which may be very clearly perceived with the naked eye, and is proved by the fact that even ten or eleven days after administration, sucl visible Conurusvesicles are found free upon the convolutions of the brain. From the considerable extensibility usually possessed by the walls of vessels, we may well suppose that with this bulk these walls would not be burst, but that a greater dilatation of the vesicle would be necessary for this purpose. It is also remarkable that we do not usually meet with effusion of blood so much as mere plastic exudations. All this is most easily explained by the supposition that the smallest brood, when scarcely or inconsiderably dilated, emigrates at once directly from the bloodvessels. Moreover, Lenckart has not succeeded by his experiments in injection, in proving that the Cystic. pisiformes remained fixed in the interior of the finest ramifications of the venu porta. As he says himsclf, the mass of the injection only reached the position of the Cystictrei after the rupture of the capillaries. 'The question can only be finally settled by the rediscovery of the six small embryonal hooklets upon the Cysticercus. If Leuckart's statement-that these six embryonal looklets are discoverable upon Cysticerci pisiformes seated free in the liver-be confirmed, these hooklets, by which "its destiny to wander is written upon the forehead of the embryo," furnish 
us with an important support for the assumption of a new active migration of the brood from the capillaries.

If the Cysticercus bears no embryonal hooklets, and loses them in the current of the blood, as a matter of course it cannot escape from the blood-ressels unless the vessel in which it is seated bursts at last. At any rate, the fact that the embryos still possess their hooklets at the commencement of the vena porta does not prove that these hooklets are not subsequently lost by the friction of the stream of the blood in the narrower vessels, and then these hookless creatures would remain seated in the interior of the ressels. As regards those Cysticerci or Echinococci in the walls of which the histological constituents of vascular tubes are recognised, no one will doubt that we have to do with embryos which have remained sealed in the interior of the vascular tubes; but when these indications are wanting (and this is certainly the general rule, with extremely few exceptions), we must suppose that there is a further emigration out of the ressels, either indirect and secondary, or primary and direct; the latter, howerer, especially, if the six hooklets still exist upon the young vesicular worm.

To sum up the whole briefly, the migration of the young of the Cestodea to the places where we meet with them as resicular worms, or in analogous states, takes place in the following way:

1. A portion of the six-hooked brood in all species of Cestodea (whether they take up their abode in cold- or warm-blooded animals, whether they possess small or large embryonal hooklets, and whether they do or do not pass through a true resicular state,) may reach their dwelling-place directly and by active migration.

2. Another portion, after a longer or shorter active migration, reaches the vascular system of the new host (the blood-ressels, and perhaps also the lymphatic system, as, according to Virchow, is the case with the Echinococci), is subjected to a passive migration here with the fluid, remains fixed in the smallest ramifications, and-

a. Becomes further developed in the vascular tube, making use of the walls of the vessel as an envelope (cyst), so as to remain there permanently, or-

b. Migrates passively into the neighbouring tissues, after the rupture of the walls of the vessel, in consequence of the swelling of the body of the embryo, or- 
c. After sticking in the finest vascular ramifications, enters anew upon an active migration by means of its six small hooklets, passing through the walls of the vessels into the neighbouring tissues, and often continuing its wanderings for some time in closed cavities of the body or in the soft parenchyma of organs, even when it has already attained a certain size, so as to be visible to the naked eye.

In the vicinity of the dwelling-place preferred by it the young embryo becomes stationary, after the completion of an active, or an active-passive, or an active-passive-active migration, and establishes its habitation there, or wanders through the selected organ for a time. By these active migrations, which undoubtedly take place at a certain time, in the interior of the selected organ of the host, the organ is irritated by the intruder, brought into an inflammatory condition, and excited to produce exudations, which, by their yellow colour, indicate the course of the wanderer, and form passages (streaks), either in the interior or on the surface of the organ, which is also disturbed in its functions; nay, if the number of the immigrants be very large, or the organ selected of great importance to life, the whole organism sympathises, and functional disturbances, and more or less dangerous disorders are produced in organs of particular importance to the individual.

The question, what further takes place with the embryos when they have come to rest in their new dwelling-place? Ieads us to the consideration of the-

Third stage in the development of the Cestodea.-This consists of the so-called vesicular worms and their analogous asexual forms, which, in accordance with the alteration which the embryonal vesicle undergoes in the different species of tape-norms, and with the different animals infested, may be divided into cysticercal (vesicular worms), platycercal (forms with a flat, inarticulate, tail-like appendage), and acercal (or tail-less) forms.

It is a common peculiarity of all the three forms here mentioned, that they are cestode-heads produced from the embryonal vesicle, which occur still in the interior of the embryonal vesicle, or upon it in a state of rest. We may therefore best comprehend this step under the name of resting scolices.

It is true that on account of the extremely small size of the embryonal hooklets in the species of Cestodea with which we are here especially occupied, we have not yet succeded in proving the direct transition from the embryos to the resting, and usually cysticercal scolices, by the re-discovcry of the six embryonal hook- 
lets, if we except a single case by Leuckart; but we may revertheless regard this metamorphosis as proved, partly by experiment and partly by analogy with the platycercal cestode-forms of this stage of development in cold-blooded animals, as Stein and Meissner have actually seen on the latter forms, the pretty large hooklets of the embryos of the mature Cestodea in question.

The details of the processes of this metamorphosis are as follows: the embryo, still furnished with its six hooklets, begins to swell by the reception of fluid (liquid nourishment), which is secreted from the place in which it has established itself; this is at first a fluid similar to protoplasm; but after the formation of the enveloping cyst, or after the cessation of inflammation, when the creature lives free in the interior of serous cavities, it does not agree so much in its composition with the serum of the blood, as with the ordinary products of the secretion of serous membranes (Luschka).

"By carefully stripping off the inner surface of the cyst of a Cysticercus tenuicollis from a he-goat," writes Luschka, "I obtained objects, amongst which numerous roundish cells of an average diameter of 0.016 mill. were remarkable. These contained, in their interior, clear, roundish, larger or smaller portions of fluid, which were partly separated by a fine molecular mass (Pl. I, fig. $10 a, b$ ), and partly converted for the most part into a clear mass of the same nature (fig. $10 \mathrm{c}$ ). In certain of these cells I was able to convince myself of the escape of hyaline drops from their walls, and of their coagulation on the addition of acetic acid. For my own part I entertain no doubt that these cells are of a secretory nature, and that by their complete fusion, or by the escape of their contents through the uninjured walls, the fluid which surrounds the worm within its cyst is produced. I have recently fuund exactly similar cells in the Graafian vesicles of man and various mammalia, and attribute to them a similar connection with the formation of the liquor folliculorum Graafii. In true epithelial laminæ I have only seen scattered romdish and polygonal cells, of which some were without nuclei, whilst other's possessed a distinct uucleus. It is more than probable that these secretory cells are nothing but metamorphosed epithelial formations." From this it appears distinctly that Luschka has observed the same processes in this case that he had previously noticed in the production of the Anid of serous cavities, and we must accordingly suppose that 
the fluid contents of the caudal vesicle of the cystic worms also is not a direct ready formed transudation from the blood-vessels, but that it corresponds with the normal secretion of serous cavities. This also explains how the worm can thrive, living freely in closed serous cavities of the body, as well as when enclosed in cysts, which, as we have said, are to be regarded as analogous to these serous cavities, and also why this fluid should not be so rich in albumen as is commonly supposed. I have convinced myself that the nature of the fluid scraped off the inner surface of the enveloping cyst exactly correspouds with that of the synovia furnished by the serous synovial membranes.

Besides the larger clear bodies, of which Luschka speaks, I also found a considerable number of small, clear, pellucid bodies, which resemble the calcareous corpuscles of the Cestodea. Are these structures a regular product of the serous membranes, which, if we bear in mind the occurrence of calcareous concretions in the articular cavities, must at all events be rich in lime?

In the Echinococci, in the fluid of which Heintz found succinic acid, the process is not so readily intelligible, as in these a very intimate and nearly organic connection takes place between the worm and the cyst. Iu this case we must suppose either that the inner wall of the enveloping cyst continues imperceptibly to perform the functions of a serous membrane, or that the innermost layer of the Echinococcus itself takes the place and performs the function of a serous membrane. It is true that the structure of the walls of this cystic worm gives no support to this view, to which, however, Eschricht's statements upon the structure of the innermost layer in Echinococcus scolicipariens may, perhaps, have some relation. Perhaps the fact here referred to may furnish us with a further explanation of the circumstance that cystic worms do not occur so much in cold-blooded as in warm-blooded animals, when we have acquired some more certain knowledge of the functions of the serous membranes in these two groups of animals. I must, therefore, request that in the discussion of the question why cystic worms only occur in warm. blooded animals, besides the reasons which I have endcaroured to adduce in my little work, 'Uber die Cestoden im Allgemeinen und die des Menschen im Besonderen, Zittau,' 1853, the fact here mentioned may also be tested. In this way the swelling of 
the young embryo is materially facilitated and its further developmeut favoured. ${ }^{1}$

As soon as it has in this way rather rapidly enlarged to a certain size, and arrived at a state of repose, the round vesicle thus formed, when it does not project freely into a serous cavity of the body and has not fallen into one, surrounds itself with a peculiar envelope, which protects it from external pressure, and assists it in procuring its necessary repose. These erveloping cysts, as is proved even by the relations of the finer structure of the cyst, constitute an absolute new formation, which commences around the germ of the resicular worm from the same masses of exudation which are deposited around the youngest brood during its migrations; this new formation acquires a structure analogous to that of the subjacent tissues, in this case, therefore, analogous to that of the serous membranes, and con. stantly increases in size with the growth of the young Cestode vesicle.

These enveloping cysts always exhibit the same chemical reactions as other serous membranes; they dissolve in caustic potash, with the exception of a very small rolled up membranous film, which, however, is not chitine, as may be ascertained by the employment of Von Bibra's method for the detection of chitine.

As regards the histological structure, we rery clearly find all those elements which Luschka describes and figures, ('Ueber Structura der seröseu Häute,' Taf. I, fig. 4), which make their appearance with particular distinctness after treatment with cold caustic potash. Besides the elastic fibres and cellular fibres, we find those formerly called by Luschka " serous fibres," but subsequently denominated by him "plastic fibres of the areolar tissue." It is indeed in these enveloping cysts that we may trace the various steps in the development of the cells of ligamentous tissue into fibres, and the formation of the so widely diffused plastic fibres by the direct splitting of plastic striæ. Thus we see-1. Cells of ligamentous tissue which pass from an

1 It may also be possible that besides the structure, a difference of function may also occur in the enreloping cysts in cold and warm-blooded animals. It is a universally admitted observation that in warm-blooded animals the secretion furnished by the serous memhranes is reabsorhed by them with great difficulty. Should this take place with greater ease iu cold-blooded animals we should have in this a further explanation of the variations of the caudal vesicle in true cystic worms. 
oval through a spindle-shaped form, to the complete cellular fibre. 2. Plastic fibres, partly still in the form of broad plastic striæ, partly as very fine fibrillæ, repeatedly crossed, but at the same time always attaining a considerable length. 3. Elastic tissue in all pliases of development, from the so-called ligamentous corpuscles of Virchow, up to fully developed elastic fibres (Luschka). For my own part I have never been able clearly to detect epithelium. Of the secretory cells of these serous cysts and their prodnct, I have already spoken in the preceding pages (Pl. I, fig. 10).

When, however, the brood of a cestoid worm gets freely into serous cavities, it either never attains to this formation of an enveloping cyst, as already remarked, or does so at a rather late period, and at a time when the young embryo has become a vesicle of very considerable size, and often exlibits the Trenia-liead in an adranced state of development. At any rate, in these cases, and in places where the young cystic worm again falls into repose, a fresh exudation of plastic masses adapted to the formation of cysts, takes place. The walls of the cyst, moreover, are rich in blood-vessels.

Having disposed of this subject, we turn, without further interruption to the consideration of the subsequent development of the brood.

It might have been quite impossible to prove definitively the metamorphosis of the brood, had not Stein succeeded in discovering the six hooklets of the young embryo, together with the armature of the head, upon the embryos when increasing in size by the reception of fluid nutriment, and also on the cestoid vesicle when developed to the resicular stage. This has been done with perfect certainty hitherto only in the Cestodea of the cold-blooded animals, and once, although doubtfully, by Leuckart in Cysticercus pisiformis. For the history of the earliest days of the development of the Cestodea, therefore, we must refer especially to those of the cold-blooded animals, and of these the following may be said. By the reception of the secretion of the serous membranes the young Cestoid vesicle swells up. At its anterior end, and therefore at the point where the six embryonal hooklets are situated, a funnel-shaped pit is probably formed first of all, and this gradually penetrates more deeply into the parenchyma of the embryonal body. In the bottom of this pit the first traces of the head then make their appearance, whilst 
the lateral walls of this impression become converted into the body (central body) of the future crstic worm, and the remaining portion of the embryonal vesicle, which is not inverted, or which is not implicated in the individual metamorphosis, becomes the so-called caudal vesicle. That the inversion and the first formation of the head must frequently commence at the anterior surface of the vesicle, is seen distinctly in the Cestodea of Arion empiricorum, for in these the six small hooks are placed in pairs at the point of transition of the borly or central body just mentioned into the caudal vesicle of the worm, and indeed at a distance of 0.02 millim. from each other. Their apices are often turned away (Leuckart). ${ }^{1}$ But for this rery reason, as these hooklets are situated upon the central body, and this is lost during the conversion of the cystic worm into a tapeworm, they will necessarily be sought in vain on the last segment of the future tape-worm colony, which Meissner supposed would be the case. The central body and the head are always developed in the interior of the embryonal vesicle, and during the whole period of the resicular state the head always has its apex directed towards the caudal vesicle, even when the central body, which encloses the head in the form of a hollow canal, has not

1 Although this description and mode of comprehension differ from those adopted by Stein and Meissner, yet I even previously understood the processes in the way just indicated, which has now been confirmed by R. Leuckart's independent observations upon the Cestodea of the lungs of Arion empiricorum var. rubra, which I have songht for in vain in my locality. Stein supposes the embryonic hooklets to be lost and taken up by the formative materials of the enveloping cyst, but Meissner had already ascertained that they remain. It is true that IIeissner misplaces them on the last third or fourth part of the bods. But at the same time we must bear in mind that in all Meissner's investigations the true caudal resicle was usually torn away by pressure, and entirely orerlooked by him. According to Leuckart, when the entire worm, freed from its envelopes, is laid in water, it is observed to protrude its head. The head, central body, and caudal resicle are then preserred; the latter is spherical, pisiform, rery thick, rich in fat-corpuscles, and rery clearly distinguished from the central body. Lastly, Von Siebold has also understood Stein's Cestodea from Tenebrio molitor in a different way from Stein. He regards the so-called cystic tail, spoken of by Stein, as belonging to the body of the embryo. I might also adopt this notion. If we do this, we must assume1. That Stein has erroneously described the enreloping crst instead of the caudal resicle. 2. That the agreement in the histological nature of the enveloping cyst with that of the parenchyma of the body of the Tenebrio, described by Stein, cannot be so remarkable as he supposes; and 3 . That there are also cestoid embryos which produce the tænioid head on their hinder and not on the anterior part. As matters stand, no definite opinion can be formed, and a new investigation of the cestoid worm of Tenebrio molitor would be very desirable. 
sufficient room in the embryonal vesicle, but is pushed out of it. The same thing is seen in the Cysticercus fasciolaris of the mouse, except that in this the central body is jointed. However, I will by no means assert that there may not be cestoid embryos which proliferate at the hinder part. It is possible, as we saw in the preceding note, that Von Siebold's notion of Stein's cestoid worm is correct, and then, in this case, the embryonal hooklets would not have been cast off, but have remained seated upon the anterior part of the body, whilst the development of the head would have taken place at the posterior extremity, and the anterior part of the body of the embryo become converted into that sterile appendage which we usually denominate the caudal vesicle. In this case, it is true, the embryo must have turned itself round, and, after taking firm hold, have pushed its abdomen forward towards the ventral cavity, and retracted the anterior part of its body towards the intestine. However, even in this case, the hooklets would not be transmitted to the trenioid period of existence.

Proliferation on the posterior part of the body of the cestoid embryo will, however, be regarded as impossible by no one who takes into consideration the multiple proliferation of the Canuri and Echinococci. The latter takes place on such various parts, that we cannot say it occurs on the anterior or on the posterior part, but it takes place everywhere in the body of the embryo, which consequently cannot arrive at the formation of a true caudal vesicle.

Unfortunately, we can state nothing more definite regarding the spot in the embryonal vesicle on which it proliferates the Tanice, called by Lenckart bladder-tape-worms, in which we are here especially interested. The hooklets are so small that they are overlooked, or small folds of the skin easily imitate them. Even here, however, it is most probable that they are not cast off and imbedded in the enveloping cyst. If Leuckart's statement, that the small hooklets could be found in the vicinity of the anterior extremity of the body, at a distance of 0.1 millim. from the cephalic pit, in a Cysticercus pisiformis of 2 millim. in diameter, should be confirmed, then the Cystic. pisiformis, and perhaps the other true Cysticerci, would belong to that first kind in which the proliferation takes place at the head.

If, from the experiments made by Haubner and myself, by Leuckart, Röll, Van Beneden, Eschricht, Gurlt, May, and others, 
with the most various Tonia which pass through a vesicular condition, and which succeeded with all species, with the exception of the Terice of the Echinococci, where an unfavorable accident may have prevailed, we sum up what we know of the development of these species, the following appears to be the case. According to Leuckart, at least in experiments with $T$. serrata, we find, twenty-four hours after administration, the six-hooked embryos in the blood of the large abdominal reins (especially the vena porta), and, on the fourth day, in the livers of rabbits to which they have been administered, small, white, clear vesicles, of 0.3 millim. in diameter, but rapidly increasing in size, which, on the sixtl, are already 1 millim. in diameter, and can only be isolated with difficulty. They consist of white masses of areolar tissue, deposited in strata, with bacillar and fusiform nuclei, and of the embryo, which is only 0.1 millim. in length, and 0.05 millim. in breadth. On these masses we distinctly see the above-described conversion into areolar tissue and serous cysts, and in them the formation of fatty aggregations (probably from decomposed cells), which subsequently become calcified. But these masses are by no means secreted only on the spot where we finally meet with the vesicular worm. The very distinct yellow streaks, or passages, formed of soft, yellow, exudation-mass, which, during the first fortnight after the administration of the Tanice, give the surface of the infested organs (for example, the brain and liver), an appearance as if microscopic field-mice or moles had been burrowing through them, prove clearly that the brood, at all events of many species, undertakes a further active migration in or upon the organs in question, which of course cannot be effected without irritation, inflammation, and functional disturbance, as has already been remarked. I pass over the particular symptoms thus produced. Every one will know in what they consist, by remembering that they coincide with those of an inflammatory irritation of the organs in question. Lastly, at the end of such streaks or passages, which become filled by injections from the principal veins, in consequence of the occurrence of rupture, according to Leuckart, the embryo makes its appearance in the form of a clear vesicle. In $T$. serrata the actual embryo, after the lapse of fourteen days, measures 1.5 millim.; in Conurus it is about the size of a grain of millet, at this period. The small vesicle (the worm), after it has begun to grow clear, acquires, in its interior, numerous large, clear, enucleate vesicles, whicl, according to 
Leuckart, are similar to sarcode drops. In the parencliyma we recognise a cortical layer, which gradually becomes thinner, and the cells of which are converted into muscular envelopes by fibre-formation; and a medullary layer, in which elastic vesicles or cells occur in great quantity. From the appearance of the medullary substance the growth of the little worm, which is capable of motion even before the muscular layer makes its appearance, advances with particular rapidity. Even in the first fortnight, and shortly afterwards, the form of the young cestoid worm varies according to the species. Some, such as the youngest Ccenuri, and Cystic. cellulose, tenuicollis, and fasciolaris, are spherical; others, such as Cystic. pisiformis, and probably also Cystic. longicollis and fistularis, are more oval. Many of those which are seated upon the surface of organs that project into closed, serous cavities, contiuue to wander for a time in the organ, until they finally fall into these cavities; the oval forms appear to have a greater desire for wandering than the round ones, although this circumstance varies in itself, according to the different species, as we also observe such a wandering in the round brood of Cœnurus. Up to the period above mentioned (about fourteen days after administration), the changes here described take place pretty universally, and in all places. But now, in all those individuals which have reached situations in which they do not find a favorable soil for their further development, there commences a retrograde metamorphosis to the state of caseous, granular, tubercular, or atheromatose masses, in which we may generally seek in vain for any remaius of the embryo, although this is certainly present. Many cases of miliary tubercular disease of particular organs may indeed consist in nothing else than the dead, fatty, and calcified young of worms. ${ }^{1}$ As regards the mode of disappearance of the above-mentioned passages, we

1 As regards Cysticercus pisiformis, Leuckart places the escape of the Cysticerci into the abdominal cavity in the third and fourth week; and in this case the worm and the enveloping mass are said to fall together into the cavity. But when this passage only takes place about the fifth or sixth week, the worm escapes into the cavity of the abdomen without its euveloping mass. All observations agree in showing that after the expiration of eight weeks the second encystation in the abdominal cavity las taken place; and then the Cysticerci seated in the pelvic cavity and in the rectum, are supposed to have escaped as Cysticerci from the liver into the abdominal cavity and passed further on; whilst I still lelieve that at least a part of them migrate there directly in the form of young six-hooked embryos. 
know nothing with certainty. Only this is ascertained, that during the first fourteen days after the administration the yellow streaks are extremely large and numerous in all those organs which constitute the favorite dwelling place of one of these cestoid worms in its secoud stage of development, but that in two or three months they have generally disappeared so completely (probably by absorption) that it is difficult to discover any traces of them.

In the third or fourth week, when the young brood of Cysticercus pisiformis measures about 2 millim., and that of Conurus is about the size of a large pin's liead or small lentil, we may see, according to Leuckart, beneath the structureless epidermis a layer of annular, transverse, and another of longitudinal, muscular fibres. The lougitudinal fibres are parallel and tortuous, and may subsequently be isolated in band-like streaks about 0.0019 millim. in breadth. Then follow fatty structures, and then the medullary substance. The latter consists of clear vesicles, combined with a tenacious albuminous substance, fat and molecules, to form a layer. At the point where the head is to be formed (therefore usually at the anterior end) a turbidity or condensation is now produced, by the aggregation of small nucleated cells, in great quantity, in the interstice between the muscular and medullary layers. This is the first foundation of the head of the tape-worm (Pl. I, fig. 8, $a-y$ ). Opposite to this turbidity or inflation a pit or impression (a sort of perforation) is observed externally, the inner wall of which is formed by the inverted epidermis, and which passes through nearly the whole depth of the globular foundation of the head. The latter appears like a peg firmly attached to the inner wall of the worm, and hanging down into the resicle, sometimes perpendicularly, and sometimes more obliquely (Cyst. cellulosce), to which a flask-shaped cavity, with a short neck, passes through the perforation. Goeze compared this position of the head to the light in a lantern. In the cell-mass of the tubercle of the head two layers are now found: 1, a peripheric layer, which grows into a fibrous, muscular pouch (receptacle of the central mass of the foundation of the head, the true receptaculum capitis, under which name, however, Von Siebold understands the caudal resicle); and 2 , a central layer, or the central mass of the head.

In the latter, and especially in its upper half, calcareous deposits make their appearance but sparingly at first. Two or 
four vessels rising in a tortuous form through the upper part of the lobe, and passing over on the external sac-like envelopes, are also observed; but notling is known of their ramifications.

The vesicle now constantly becomes larger and clearer, its contents becoming more fluid, and the medullary layer displaced as far as its peripheric layers, the epidermis and muscular layer grow thicker, whilst vessels and calcareous corpuscles ${ }^{1}$ make their appearance, especially in the circumference of the anterior part of the body, in the stratum between the muscular and epidermic layer, but not in the muscular layer, as stated by Wagener, in some cases before, in others after, the formation of the cephalic process. The vessels of this stratum, formerly regarded as a net of muscles by Pallas, and overlooked until the time of G. R. Wagener, are very strong, and surround the caudal vesicle with dendritically ramified stems (thin-walled tubes), uniting directly with the vessels of the head, which probably originate from them. In the vessels, which probably serve for the purpose of excretion, circulates a colourless, limpid fluid, which is set in motion by cilia. The latter are either whip-like hairs, or semicircular lobes, with a free margin, moving from one side to the other, which cannot be decided easily; according to Leuckart, they are situated only in the smaller vessels, although $I$ believe I have seen them also in the larger branches, in points of curvature, and especially where one vessel opens into another. These ciliary structures were discovered by Lebert, and afterwards particularly described by Virchow and Wagener. 'That these vessels unite into a pulsating tube, opening at the end of the caudal vesicle (Wagener), conld not be detected either by Leuckart or the author. Neither could Leuckart find any openings of the large vessels of the head towards the interior space of the caudal vesicle, but he sometimes found two openings on the neck, by which the longitudinal vessels are supposed to lead outwards.

' Even the calcareous corpuscles have their own proper fragment of history. Once they were regarded as eggs; subsequeutly their calcareous nature was discovered, and it was agreed that they consisted principally of carbonate with a very small proportion, perhaps, of phosphate of line. Some, such as Eschricht, regarded the corpuscles which dissolve with difficulty in acids as siliceous globules, but all believed them to bc a normal phenomenon, and the first indication of the formation of a skeleton in animals. IIuxley now suddenly declares them to be of a morlbid nature ("Anmals of Nat. Hist.,' xiv, 1854). There is equal reason, as Lenckart says, to call the calcification of the skeleton morbid. 
Of the intermediate stratum containing the vessels, it still remains to be remarked in general, that it is finely granular, tenacious, and of a cloudy, and, here and there, brownish appearance; sometimes blended into a continuous layer, sometimes into flakes, and that it bear's cleft fibres, which are swelled up, and contain fat-granules at the points of cleavage. The innermost stratum, the residue of the medullary layer, has its previously clear vesicles filled with fat, even with fat-drops. It is probalole that in this way is bronght abont a peculiar morbid process, which I have met with in a single instance amongst several hundred Cysticerci tenuicolles which I have examined. The ce udal vesicles were completely set with small white points, perfectly visible to the eye, which, under the microscope, presented nothing like calcareous corpuscles, but rather a fatty mass enclosed in a tolerably firm tissue, whilst at the neck of the vesicle a second small vesicle made its appearance, which contained fluid, and was not separable from the tissue of the neck. In this discovery I recognise the morbidly degenerated embryonic body of a Cysticercus tenuicollis, and, at the same time, a fresh support for my statements regarding the normal and healthy nature of the ordinary caudal vesicle of the Cysticerci.

From the moment when the formation of the cephalic process commences, the caudal vesicle ceases its activity in the true Cysticerci; its functions are then only passive, serving as a reservoir of nutriment, as a protective organ for the head, which requires repose for its further development, and as an organ which may at the same time also preserve sufficient room for the undisturbed development of the head.

The case is certainly different in the cystic worms with multiple proliferation. In these, as already remarked, besides the last-mentioned function, the embryonal vesicle constantly executes the proliferation at repeated intervals, and on the most various parts, both in the Conuri and Echinococci. Here, therefore, we can no longer speak of the remains of the embryonal vesicle as a true caudal vesicle. On the hollow cephalic process itself, various metamorphoses commence at different times in the different species, but at any rate not before the fourth week after administration. In the process which is, as it were, introverted in the caudal vesicle, and which, with its flask-shaped cavity represents, as already observed, the first foundation of the head of the tape-wolm, and, indeed, in the lower 
inflated end, and upon the bottom of the cavity, the foundations of the circlet of hooks are formed, and somewhat higher, on the broadest part of the cavity, the sucking discs. The formation of the hooks takes place, according to Wagener, in this way; a broad, annular fringe of small points or hairs is formed, with their bases seated upon the epidermoidal coat of the cavity. Only the lower ones are permanent, and become converted into an alternating double circlet of conical claws, like the horus of antelopes, of which the inner become the larger and the outer the smaller; the others fall off. As the point of insertion of the hooks forms a narrow annular ridge, a limitation and appendicular pouch is produced in the entire cavity of the cephalic process; this is the future rostellum. The points [of the hooks] are slightly curved outwards, and directed forwards. As soon as they have attained the size of the future uncini, their softness and alterability under pressure disappear, their walls become thickened by internal depositions in irregular strie, and at the base the new parts are then formed, especially the radical processes, the upper surface of which is a direct prolongation of the claw. The internal cavity of the claws or uncini is shut off by a peculiar formation, which is at first separated from the rest of the mass of the hook, has usually a horseshoe-like form, and represents the first foundation of the dental process. In the year 1852 I figured a circlet of hooks in the 'Prager Vierteljahrschrift,' which is certainly to be regarded as a malformation. If it be allowable to draw conclusions from these structures to the normal ones, we might feel tempted to suppose the occurrence in the formation of the shaft of a union of separate horny structures, but I believe, as a general rule, that in the formation of the shaft nothing but a production of the hinder wall of the claw takes place, and the attachment of peculiar structures to the ready-formed parts of the hooks only takes place on the spot where the dental process occurs. Moreover, no new formation of the hooks takes place, and they are evidently of equal development throughout.

The mode of attachment of the hooks in the skin is not so easily understood. Sacs are very common in the large-hooked Tonire; this is easily perceived in preparations in which the hooks have been removed by maceration, after they have been dried. But this sac-formation is very imperfect in the Cysticerci, in comparison with the Tania. 
As suon as the uncini? are formed, four licmisplierical sacs, blind appendicular cavities, make their appearance above them, and on the broadest part of the cephalic process: these are the four sucking discs (bothria). Internally, they are still at first connected with the central cavity of the cephalic process, and clothed with small deciduous hairs. By the conversion of the parenchyma surrounding them into radiate and annular muscular layers, they become completely shut off, aud muscles are also develcped round the fifth appendicular cavity, and close it up as a rostral cavity, on which an orifice is still to be found occasionally, for a short time, but rarely for a permanency, and which may even become a median sucker on the vertex.

The formation of the apparatus of hooks, \&c., is usually com. pleted towards the sixth reek. At the same time calcareous corpuscles collect, and the ressels become developed. WTe observe four lateral stems, which form a ring round the suckers and rostellum, and give off branches, occurring between the suckers, ascending and descending therefrom, and exhibiting some small variations in the number and arrangements of the ramifications situated towards the suckers. From this time it is casy to cause the protrusion of the head.

The life of the cestoid embryo might close with this stage of its development, as the head is so far developed as to be ready at any time for its erolution into a tape-worm. But the opportunity of doing this usually occurs only after a considerable time; and the cestoid worm employs his long interval to exhaust the rest of its formative faculty and porrer, in the formation, on the neck and the remaius of the embryonic body (caudal vesicle), of the so-called tape-worm body. This consists in a simple elongation of the tubular neck, and if, from the slight extensibility of the receptaculum capitis, there is no space for this, in a bending to a lateral position, and in a coiling up and conglomeration of the growing body, the histological structure of which cannot be ascertained on account of its richness in calcareous corpuscles; the length of the body produced is variable. If it becomes so large as to be unable to find room in the caudal vesicle (as in Cysticercus fasciolaris), the body, with the head, issues entirely from the caudal vesicle. But as through the whole period of cysticercal existence, the hooks are retracted into the head; this is the case also even in Cysticercus fasciolaris.

From the above metamorphosis, which is principally taken from 
Cysticercus pisiformis, but which may serve as a general scheme, there are certain variations according to the species. In Cysticercus cellulose the processes are exactly the same as those just described, but the cephalic process does not hang down perpendicularly, but obliquely, into the caudal vesicle; and in this the formation of the vessels and caudal vesicles are recognised from the first production of the foundation of the head. The latter also applies to Conurus, in which each individual head is formed in a separate inverted portion of the general embryonal vesicle, to which a sort of perforation leads from the outside. I have sometimes thought that I could pereeive, in this case, the same mode of formation of the head as is above indicated occurring here in the anterior thickened end of the little body enclosed in the inverted portion of the resicle,-consequently, an inversion of the cephalic process towards the interior of the structure contained in the inversion. Frequently, I might say in most cases, I could not detect any such inversion of the ecphalic structures in the above-mentioned internal body; but I observed, at the anterior end of the internal body, only a retraction of the rostellum with its hooks. The position of the hooks was as in the other vesicular worms, that is to say, the extremities of the shafts turned forwards and outwards, and the apices of the hooks inwards and backwards; and for the same reason the suckers were here also on a level with the circlet of cilia, and placed laterally from them, whilst in the other vesicular worms the suckers do not stand on one side of, but behind the rostellum, as long as the head is still inverted (Pl. I, fig. 9).

In Cysticercus fasciolaris the same formation occurs, at first, as in Cysticercus pisiformis, but subsequently the head and body are protruded from the caudal vesicle.

In all other species, even when there is no formation of a caudal vesicle, as in the platycercal and acercal forms, especially of cold-blooded animals, the formative process is fundamentally the same. For even in these the true tape-worm head is developed in the interior of the embryonal vesicle, at all events originally, in the form of a process, which is produced from the walls of the top cavity of the embryo, or from its hinder part. The form under which most of these formations have been hitherto observed, is not so much the primary as a secondary form, analogous to that which we have seen in Cysticercus fasciolaris. At the same time the head has already more and more attained the aspect of the 
mature tape-worm (especially in Tetrarlyynchi and other species of Cestodca), as it has gradually turned itself over from belinil, by which it rises more and more in the bottom of the vertical cavity, so that in opaque preparations it appears as if the head were formed by the elevation of a proper mass. Leuckart thinks that this apparent elevation may perhaps partly arise from the different form of the rostellum in true Cysticerci and the allied forms.

The heads of hookless Tenice may be developed from the eggs in the same way as the forms just mentioned, but, as a matter of course, with the omission of the look-formation. The most characteristic point in these cestoid scolices, wonld be the formation of the sucking apparatus.

Although certain Tetrarhynchi exhibit an isolation of the head, this may also be often produced originally in the abore manner, and the isolation be a secondary phenomenon. Leuckart compares the occurrence of these forms with the phenomena presented by Echinococci. It appears to me that these forms may be best understood by a comparison with Stein's cestoid worms from Tenelrio molitor (Sieb. and Köll. Zeitschr., iv, Taf. 20, fig. 12-14). Thus, regarding the vesicular candal appendage as proper to the Cestodea, as we have done, if we suppose the constriction placed behind the body to advance so far as to produce a complete separation, we have a scolex enclosed in one segment of the embryonic body; and by this division an isolated caudal appendage (caudal vesicle), and an isolated head with its envelope. It is also possible, in the last place, that there may be embryonal vesicles, which do not become larger than is necessary to form and enclose a single scolex in their interior; the walls of which, therefore, approach so closely to the scolex as almost to touch it, so that there is very little fluid between them. Of the existence of these latter forms, Van Beneden has furnished numerous proofs; the separation by constriction is supported by Zeder's observation on a cestoid worm of the pike.

Peculiar conditions are exlibited by the Echinococci, of which we may undoubtedly distinguish two great groups, to which I have given the names of Echinococcus altricipariens, and E. scolicipariens. In them, even more than in the Conuri, the passive function of the residue of the embryonal vesicle as caudal vesicle falls into desuetude, and its independent morphological destination as a mother-resicle becomes still more prominent. 
Even in its structure it differs essentially from the other ordinary cmbryonal vesicles. In the Echinococci, the epidermis of the embryonal vesicle adheres quite firmly to the enveloping cyst, and forms several concentric layers. The muscular layer which usually follows upon this is wanting, and instead of it and the true interstitial and medullary layer's, there follows a layer of a granular vesicular structure, with vessels and calcareous corpuscles. It is probable that the villous, obconical elevations or thickenings, which occur on the innermost vascular layer, become converted into new vesicles or broorl-capsules, which are, of course, destitute of the six small embryonal hooklets, and which produce the individual scolices, but which are seldom directly developed into scolices, united for some time with the mothervesicle by a stalk through which pass $2-4$ vascular stems, connected with the vascular system of the head. Even the individual scolices are probably in general prorluced in the interior of such capsules; and from the preceding statements it is not difficult on the whole to understand this process, as the scolex-formation commences in accordance with the type of the Comuri and Cysticerci by the production of cephalic processes in the interior of the separate brood-capsules. This formation of cephalic processes is not, however, effected in a place produced by the inversion of the mother-resicle, which may be reached from the outer wall by means of the above-mentioned perforation, but on the pedunculated vesicle, and indeed on the end of this vesicle which stands opposite to the peduncle. Thus, there only appears to be the following distinction between the two principal forms of Echinococci above-mentioned. In Echinococcus scolicipariens the broodcapsule remains adhering to the nother-vesicle by its peduncle and proliferates in this way; in Echinococcus altricipariens the brood-capsule, with its peduncle, separates from the mothervesicle, becomes thickened in its walls like the latter, and then proliferates independently. In the latter species both forms of production go on together in one mother-vesicle, and it also happens that brood-capsules separate not with, but from the peduncle, when their margins roll round, and the brood projects ontwardly in groups into the fluid of the mother-vesicle, the everted inner surface becoming the outer surface, or any separated brood which may occur free in the daughter-vesicles, is emptied out into the fluid of the mother-vesicles. A single, separated scolex can liardly ever become converted into a brood.capsule 
(daughter, or granddaughter resicle), as was supposed by Von Siebold and Delle Chiaje.

From these cousirlerations we cannot regard Echinococcus as a many-headed Cysticercus, like the Conuri, especially as we can nerer press out the Echinococcus-scolex from the true embrronal resicle by the application of pressure to the resicle from without, so that the scolex may afterwards bear about the remains of the embryonal resicle behind it as an appendage. It is only when we have cut up the mother-resicle, that a similar appearance is presented to us on examining it from the inside. We find the individual scolex on the brood-resicle of the scolices, bearing behind it the remains of the embrronal resicle on a peduncle.

The formation of the hoots, suckers, and ressels takes place here in the same way as in the other Cestoidea. The thick, opalescent, epidermic walls present particular difficulties in the detection of the vascular srstem in general, and especially that of the daughter-resicles.

As we have shown in the historical portion, the statements here made hare been established by the most multifarious experiments. I will not go orer this subject at length, and can only again remind the reader that the cheapest and quickest means of convincing himself of the truth of what has been said consists in the administration of Tenia serrata vera to rabbits. ${ }^{1}$

1 On account of the general interest possessed by progress of the expariments, I shall here refer particularly to some experiments in the administration of $T$. ccemurus to lambs, sheep, \&c. After I had informed the Saxon Ministry of the Interior of the abore-mentioned results of my first experiments (ride supra), with the request that they should allow these experiments, which come rather dear to the prirate medical man, to he repeated at the cost of the state, and on a larger scale, experiments were made, in the year 1\$5t, at the reterinary school at Dresden, under the direction of Professor Haubner, by that gentleman and myself. On the 6th Januars, 1854, I had at last obtained matnre T. crenurus, and administered them to two lambs in Drausendorf, which had been purchased at the expense of the gorernment. On the ith Jannary I carried $T$. ccenurus, protected from the coid, in mo clothes to Dresden, and with these four other lambs were fed in the veterinary school in the presence of the collected students. On the 19th January, fire of these six animals were affected with appearances of irritation and inflammation of the brain, and cerebral conrulsions. According to Professor Haubner, who was able to watch the animals in his establishment, the heads, the base of the horns, the eres, and the risible mucous membranes of the cephalic region were heated, and the latter reddened; the beatings of the pulse and heart were excited and increased (to $130-135$ strokes in a minute); the temperature of the body mas rarying and unequal, and the eracuations were diminished. Dullness, stupefaction, loss of appetite, and, to a certain extent, a neglect of rumination, were also observed, 


\section{In the progress of the metamorphosis of the six-hooked cestoid} brood into scolices, just treated of, we have also seen that a portion

with tremulous movements of the ears, twisting of the eyes, conrulsive writhings, and bendings of the head and neek to one side or the other, fallings to the ground, twitching of the limbs, gnashing of the teeth, foaming at the mouth, and, in short, all the signs of eerebral convulsions resembling epilepsy, in which, moreover, several of the auimals twisted the head principally towards one side or in a circle.

The first dissection, marle on the 22d January, 1854, again showed the small vesicles (i.e. my young Conuri) olsserved in my first experiments, as well as the chamels of exudation, at the end of which there was sometimes a vesicle, surrounded hy a more abundant exudation. Besides these, innumerable minute particles of the size of a grain of sand oecurred in the most various situations in the lamb under examination; for instance, in the osophagus, heart, diaphragm, peritoneum, \&c. In the subsequent dissections the same small vesicles were net with in the latter situations, but it was distinctly seen that instead of growing they had dininished perceptibly in size, in comparison with those just described, and were, therefore, further advanced in degeneration, so that the organisms situated in these parts may justly be regarded as strayed and arrested young Cestode worms. On the $17 \mathrm{~h}$ February, forty-two days after the alniuistration, the vesieles were more decply imbedded in the brain, as large as small peas, and exhibited the first turbidity, or the commencement of scolex-formation. In the other dissections similar results were obtained.

On the 5th May, 1854, Professor Ilaubner again administered mature Trenia conurus to eight sheep. On the eighth and tenth days after administration two lambs were examined in vain for the migrating brood. On the twelfth day, a sheep, which was previously ehlorotic and ill with vertigo, exhibited the well-known vesicles in the brain; a second died of vertigo on the twentieth, a third on the twenty-first, and a fourth on the twenty-fifth days. Two animals eseaped. Of the Tania canurus sent to me by Professor Haubner on the 5th of Nay, I forwarded some specimens in white of egg to M. Gurlt, Director of the Veterinary School in Berlin, and here also vertigo made its appearance with exactly the same appearances and results on the eleventh to the fonrteenth days after administration. Gurlt also found the strayed brood in the diaphraghm and other places. On the 24 th of May mature Tcenia coenurus were taken from a dog on the farm of M. Kind, of Kleiubautzen, who has taken a lively interest in the experi. mental elaboration of this question, and administered to two lambs and one fullgrown ewe, of which the latter was not afiected, one of the lambs was only slightly touched with vertigo, and presenterl no Canuri when dissected eight weeks afterwarls, whilst the otluer, which had apparently escaped, exhibited developed vesicles of Cœnurus at the same period. Encouraged by the success of my consigument to Gurlt, I forwarded from Kleinbautzen, on the 24th of May, mature Trenice conurus in white of egg to Van Beneden at Louvain, Leuckart at Giessen, Gurlt at Berlin, and Escluricht at Copenhagen. The worms arrived safe and sound at these places, on the 26th, 21 st, and 27 th May, and twelve, fourteen, and sixteen days after administration the disease showed itself at all these stations, and indeed with the greater rapidity and intensity the longer the road which the Tania had to pass, and therefore the later they were administered.

When, on the 11th June, 1854, I sent fiesh Tania comurus to Professor Röll, at the Veterinary School at Vienna, he allowed the proglottides to lie for several days in the rain, and beeome covered with mould, and only administered them when they began to 


\section{of the Tenice pass through a true cysticercal (bladder-worm) state, whilst the other part, without ever arriving at this state, furnishes}

grow mouldy. The rapidity and intensity of the result was extraordinarily increased, so that he absolutely regards putridity as a meaus of assisting the infection.

As the vertigo always makes its appearance in sheep at a definite time after the administration of Tenia cœnurus, and with some practice in the experiment, one may previously state pretty exactly in what stage of derelopment and of what size thie expected vesicular worms will be found, the experiments on the production of the cystic worms satisfy the requirements of the most rigid analysis; at least I will hind myself as regards Canurus, Cystic. cellulose, and Cystic. pisiformis, to determine pretty exactly how large and how far advanced in development these forms will he, aiter the administration of $T$. coenurus, $T$. solium, and $T$. serrata. As regards the experiments in the administration of $T$. crassicollis to mice, I bave never, like Leuckart, been able to rear Cysticercus fasciolaris [in this way], as the white mice of my colony acquired such an appetite for flesh, from the day on which I began to feed them with $T$. crassicollis, that they deroured each other, which was also observed to be the case by Leuckart.

With regard to the other species of çstic worms, all experimenters who are in a position to determine the species of Tania and cystic worms will regard my statements, confirmed by Haubner, Leuckart, Van Beneden, Eschricht, Röll, Müller, \&c., as correct, in opposition to those of Von Siebold and Nay, and admit with me-

1. That we can never rear all the known kinds of cystic worms infesting our domestic mammalia from one species of Tania.

2. That from the eggs of Tania serrata only Cysticercus pisiformis, from those of T. solium only C. cellulosa, from those of T. ex Cysticerco tenuicolli only C. tenuicollis, from those of $T$. crassicollis only $C$. fasciolaris, from those of $T$. Conurus only Conuri are produced, and from those of $T$. crassiceys (Rud.) of the fox, according to Leuckart, only C. longicollis; and

3. That each of these species can be developed only in a limited number of animals. Thus hitherto we have succeeded in rearing the Cyst. cellulose only in the pig after the administration of $T$. solium; the Cyst. tenuicollis, from $T$. ex cyst. tenuicolli, only in goats and sheep; the Conuri, from T. Conurus, only in sheep and cattle; and the C. pisiformis, from 7'. serrata, only in rabits; whilst the brood of all these Tcenia, when administered to other aninals than those mentioned with the particular species, always strayed, and soon died without becoming further developed in the unsuitable dwelling-place.

How important these experiments are in the determination of the species of Tænial and crstic worms, will be perceived at once by erery one. They complete the attempts to determine the species of Tænial and cystic worms according to their hooks, which, howerer, is not so difficult as Von Siebold supposes. I appeal to the words of Professor Rüll, in an article 'On the result of the administration of the mature segments of a species of Tape-worn (T. canurus) of the Dog,' \&c., 1. 11: "These three species (T. cœnurus, T. serrata vera, T. ex cystic. tenuicolli,) of which I hare received specimens from Dr. Küchenmeister, may be easily distinguished from one another, hoth from the form of their bodies in general, and also especially with reference to their circlet of hooks, when they have once been carefully examined; and Von Sielsold therefore appears to be in error when he states, in his very recent publication, "Ueber die Band- 
exactly the same structures (cestoid heads $=$ scolices). The latter I have divided, in opposition to the Cysticerci, into platycercal and acercal forms. Without flattering myself that I can conclusively settle the question, "whether we have any external means of predicating what Tæenia must and will pass through a true cysticercal, or a more or less cystercoidal state," I may be allowed, nevertheless, to call attention to the following points, and, at the same time, I take little notice of the fact that true Cysticerci only occur in warm-blooded animals, especially mammalia, and cysticercoid structures principally in cold-blooded animals.

1. The eggs of all Tomice which pass a true cysticercal stage in the bodies of mammalia, are distinguished, not only by their small size and the small size of the embryo and its six hooks, but also by their brown, hard shell, beset with asperities exterually, which, in a certain position of the microscope, give the egg-shell the appearance of a kind of concentric stratification, which, however, is only an optical appearance. The eggs of the Tcenice, with only a cysticercoid phase of development, have softer, colourless, transparent shells, are much larger, and contain a much larger embryo, furnished with larger hooks.

2. The Tenice with a cysticercal phase of development are inferior to the platycercal and acercal forms in regard to the length and cylindrical form of the rostellum.

3. The Tenice with a cysticercal stage all possess during this a highly-developed receptaculum capitis, which forms a part of the future neck, in which, as long as this stage lasts, the head is introverted, and which must not be confounded with Von Siebold's receptacuhm scolicis, the true caudal vesicle. The allied platycercal and acercal forms are destitute of the accumulation of water, and of the receptaculum.

If, now, a cestoid vesicle which has immigrated into a suitable host, and which originates from a Tcenia which passes through a vesicular state, being disturbed or entirely stopped in its proliferation by any cause, remains sterile, it becomes converted into an Acephalocyst. Suclı as were destined to become true Cysticerci then possess in their walls the structure of the cysticercal caudal vesicle; and those which should have become Echinococci exhibit in their walls the concentric structure of the Echinococcus-

und Blasen-würmer,' Leipzig, 185 1, "that he has obtained T. serrata by the administration of Cunurus cerebralis to dogs. But these three species also differ in respect of the results of administration." 
vesicle. $\mathrm{U}_{\mathrm{p}}$ to this time only Acephalocysts which belong to Echinococci, and one which probably belonged to Cysticercus tenuicollis, have occurred. They become destroyed at last in the body of their lost, in the same way as the corresponding proliferant forms.

If the six-hooked cestoid-brood gets into animals which are not suitable to it, or into snch organs in an animal otherwisc suitable, as are not adapted for the particular species of cestoid worm, it is destroyed in a very short time, usually even in the few first days after its immigration. The form which they acquire we lave already referred to, and indicated that a confusion of them with miliary tuberculose disease of the organ. is not only possible, but may frequently have occurred. If any one wishes to obtain a knowledge of truly strayed cestoid embryos, he has only to administer mature proglotticles to various animals, and he will then find that he meets with a greater number of strayed individuals in an animal the sooner it is dissected after an administration, and also the narrower the limits of the normal diffusion and thriving of a species in the body of an animal. Thus, in Cenurus, which is so extraordinarily limited in its dwelling-place (the brain, and perhaps the spinal marrow), we find the most frequent wanderings, but far more rarely in Cysticercus cellulose, destined to dwell in the cellular tissue, which is distributed through the whole body, and in Echinococcus which is also widely diffused in the body. But it is quite unjustifiable to call those cystic worms strayed which have arrived at full development, like other creatures of their kind, but which occur in places with regard to which we cannot easily understand how the cystic worm conld get from them into the intestine of the animal in which it becomes converted into a Tenia, of which we shall speak hereafter. I will not indicate, with Leuckart, that in this case the brood of a frog which lias got into a puddle which lias dried up before its evolution, is also to be called strayed, and will not devote any space to the above question. But I cannot suppress here, that I am firmly convinced that we do not yet know any species of Cestodea which becomes developed to the second stage in one species of animal, unless this animal-except where civilisation may have introduced here an artificial, insurmountable hindrance-can be devoured by the animals in whose intestine these vesicular worms are capable of becoming mature 
Tania. ${ }^{1}$ The law of nature nevertheless exists, although, fortunately for man, it may have fallen a sacrifice in his case to the advance of civilisation.

I I may mention here that the Cyst. cellulosa occurring in the human body, the Echinococci, and any Cyst. tennicolles which may be found in the same situation, are called strayed by Von Siebold, because they could never rench the intestine of other mammalia which they usually infest. It is true that in support of this assertion he raises no oljection with regard to these worms and the Trichina spiralis, except the following exclamation: "That these parasites should be originally intended to take up a temporary abode in the human body, that they should here lie waiting for an opportunity to migrate, which can onty present itself if the man harbouring the wellknown asexual parasites were to be devoured by a particular beast of prey, is an opinion which every reader of these pages will certainty reject as incompatible with the diguity of man, and in place of it readily admit that these parasites could only have strayed into the interior of the human body when some opportunity presented itseif." The untenability of a natural history hypothesis must have made great progress when mystical reasons must be seized upon, and an appeal made to novices on peculiar notions of humau dignity. With such delicate references to the dignity of man, how long will it be allowable to call man a mammal? Is not this too a profanation of this dignity? But what is the use of dwelling upon such things? If we pass to the examination of this subject without too high notions of the dignity of human nature, we may suppose with regard to the Echinococci that dogs and cats, for example, have the opportunity of devouring Echinococcus-vesicles of man which have been evacuated by expectoration, by voniting, or with the fæeces or urine. Morenver, in countries such as Iceland, in which these parasites are endemic, and the human inbabitants live in constant intimate contact with their dogs, we must also take into consideration that in the puncturing or removal of such vesicles loy the surgeon, they may easily be thrown to the ground or fall there unawares. If the dngs, which only wait until something to eat is thrown to them by their masters, should be in the vicinity at this time, they would derour these animal vesicles with their contents as a welcome booty, before the surgeon or the patient and his people had time to allow a doubt to rise in their minds whether this behaviour of the dogs towards the vesicles taken from thcir masters could be compatible with the notion of the dignity of human nature. Are there none of my colleagues who have already found their bright ideas of the dignity of human nature irjured because a mother who wished to show the doctor the caseous stool, or the caseous romited masses of her child, has found the vessel in which these masses were, or the dirty clothes, quite empty, and on the cat, cleaning herself in the vicinity, distinct indications of low well this animal has relished the evacuations of her child? In this case what is the use of all high notions of the dignity of human nature! With the progress of civilization the devouring of human bodies has certainly been diminished; such deep internient of human bodies has been introduced, that if hyenas occurred with us they could not so easily get at them; wolves and other carnirorous animals have been driven so far from the vicinity of man, that the latter can rarely become their prey; and lastly, in order to maintain the species, Nature has cven taken care that not merely one, but several species of animals occur as the hosts of these cestoid larva (e.g., man, with the pigs and apes, for Cyst. cellulose; these and the ruminants for Cyst. tennicollis and Echinococcus scolicipariens; man, and sometimes also the ruminants, for E. altricipariens). But all this is no contra- 
Just as in Leuckart's cxample of the brood of the frog, we should have to speak of straying only when snch cestoid scolices reached a suitable intestine at a time when they had not yet perfectly developed hooks and suckers. With these I could never rear mature Tenice. In this case those cystic worms which have arrived in their normal position would have to be denominated strayed, because the animal infested by them was destroyed by a predaceous animal before they had become so far developed that on being placed in favorable conditions they were capable of a higher development.

A deformity (or, as it might be called, a morphological degencration,) must also be referred to here, and again amongst the Tanice; I mean the scolices of tape-worms which instead of four, possess six suckers, and when they are armed bear a proportionately larger number of liooks than the greatest number possessed by other creatures of their species, and which also, when in the mature form, constitute triangular instead of flat colonies (strobile). Thus, according to epistolary communications, Rokitansky has seen a Cyst. cellulosce of the human subject which bore six suckers; and I have indicated that it would be of great importance for the proof of the conversion of cystic worms into Tenice, if we were to seck for such deformities in Coenuri, and administer them to $\operatorname{dog} s$, in which I have twice accidentally found triangular $T$. conurus after the administration of the scolices. From the triangular Trenice, if any, we should again endeavour to rear Comuri, and in this way we should at the same time obtain an enlarged kisowledge of the laws of hereditary characters in the animal kingdom. To speak in Von Siebold's sense of a degeneration of all cystic worms is certainly unjustifiable. The only degenerated forms are those above mentioned, those with morbid deposits in the walls of the vesicle (Cyst. tenuicollis), and sterile acephalocysts. Or some day we may make use of this expression for all cystic worms, if we can discover the individual worms in great quantities and con-

diction of our primary law that the animal infested by cystic worms is the regular, or perhaps also only the exceptional prey of that infested by the Tania, and even man, as a bearer of cystic worms, may infect other predaceous animals with Trenia. The dignity of human nature and the laws of civilisation nust consent to allow themselves to rank below the universal laws of Nature; and, when we regard the individual beings in their general relations to the Creation, only make their appearance in the second place. 
stantly repeated in other species of animals, in a form resembling that in which we are acquainted with the platycercal and acercal Cestodea of the cold-blooded animals; or, for example, if we meet with Cysticercus cellulose in some animal in a form similar to that of Stein's cestoid worm of Tenebrio molitor, or that of Von Siebold's worm of Arion. Until this is the case we cannot place the cysticercal Cestodea in opposition to the other only cysticercoid forms in the relation of normality and degeneration.

In conclusion, we have still to refer here to the circumstance that a great number of the cestoid embryos which become developed to the scolex state, die and are destroyed, either by a natural or a pathological death. Of a natural death of the cystic worms causer by the weakness of age, we conld only speak if we were acquainted with the extreme limits of the existence of these Cestodea, which is not the case at present. We only know that their life in the cystic state may probably extend to several years. They die a pathological death when primary or secondary inflammatory processes and altered conditions of secretion are set up in the enveloping eyst (in consequence of inflammatory actions in the organ inhabited by the worm). It may easily be that previous phenomena of the same kind, but of a lower degree, occurring during the development of the embryonal vesicle into a scolex may lead to the formation of aceplalocysts, and that the similar phenomena of a higher degree occurring subsequently, after the development of the scolex, may not merely arrest, but actually destroy, the life of the individual. In such cases we see the enveloping cysts thickened with layers of exudation, the vessels increased in number and size, and beset on their inner surface with small red excrescences (such as are also found elsewhere in serous cavities), amongst which calcareous masses and masses of cholesterine are sometimes deposited. Their fluid contents are no longer limpid and thin, lut bloody, dingy yellow (from decomposition of the colouring matter of the blood), and morc tenacious. The walls of the cystic worm also become turbid, yellow, dingy, and opaque. $U_{P}$ to this time the phenomena are the same in all vesicular worms, but subsequently differences occur in the details, according to the species to which these animals belong. Those which are known under the names of Coenurus and Cysticercus, from the moment when the nutritive fluid contained in them acquires the nature just described, allow 
this previously absorbed fluid to pass mechanically through their walls, and fall together, so that their sides come in contact over larger or smaller spaces, and gradnally in their whole extent. If such a cyst be opened, we meet first of all with free fluid of the nature described; and on one of the walls of the cyst, or most commonly at its base, with the collapsed and compressed cystic worm. The scolices (whether one or more) of these cystic worms are found to have extended their necks, heads, and jointed bodies, whether deprived of their hooks or not. At the same time, in accordance with the laws to which inorganic fluids are subjected, the fluid deposits a calcareous layer round the dead cystic worm on its onter and inner walls, and this may easily be broken off in large pieces. 'The cystic worm acts, in this case, like a rough body, or a crystal which is laid in a mother-liquor, and from which the crystallization or precipitation of the salt proceeds. Chemical decomposition gradually extends further and further in the contents of the cystic worm. The proteinaceous fluid is continually deprived of its aqueons constituents by absorption on the part of the walls of the cyst, and a sort of precipitate is formed of that well-known fatty, caseous, greasy mass, which, being rich in calcareous matter, at first forms a sort of lime-soap, but finally becomes converted into a complete calcareous deposit, exactly such as we observe in the so-called old apoplectic cysts in process of cure. During this process, any of the hooks which may have still remained adherent to the heads of the scolices, become completely detached, and at the same time imbedded in the calcareous mass. In all the cases above mentioned, with the exception of the last, the collapsed cystic norm may be very easily displayed and recognised with a little practice, even after it has been dead for years. This process goes on somewhat differently in the Echinococci. In these, the true primary vesicle, originating from the six-hooked embryo, never detaches itself from its enveloping cyst, so that no accumulation of fluid takes place between the resicle and the enveloping cyst. Although a few purulent points between the cyst and the worm appear to indicate that a similar process may occur here as to a greater extent in the Cysticerci, this, however, is never general. The contents of the Echinococcus vesicle, after its death, consist of the same mass that we have seen above to occur between the enveloping cyst and the outer wall of the caudal vesicle of the compressed cystic worm. Now 
can the inner wall of the Echinococcus-vesicle give rise to the same phenomena as are elsewhere exhibited by the serous inuer wall of the cysts? The latter certainly appears improbable, and we may, perhaps, come nearest to the truth if we suppose, either that after death the wall of the Echinococcus allows the passage of the purulent mass secreted by the serous wall of the cyst, or, which appears to me most probable, that the Echinococcus-vesicle is ruptured in particular places, that the pus passes through these into the cavity of the vesicle, that from its contents proteinaceons detritus, calcareous matter, and cholesterine are deposited, and that the scolices and hooks which liave been set free are enreloped in these masses. In the pig, at any rate, I lave found pus-globules between the cyst and the vesicle, in places where these had separated from each other after the death of the worm. Whoever knows how difficult it is to separate the worm and its cyst during life, and how rarely this is done without tearing, will not consider that I am going too far with my supposition of the secondary entrance of the pus into the inner cavity of the worm after its death through the cracks produced during its collapse. The daughter- and granddanghtervesicles appear to be capable of continuing their existence after the death of the mother-vesicle, and the latter are usually without pus, calcareous masses, and the like, when they are in good preservation and have no openings. The enveloping cyst presents the same phenomena as that of the Cysticerci, especially of Cyst. tenuicollis.

In referring to pathological death we have still to notice the artificial pricking of the embryonal vesicle which has become developed into a cystic worm. We are aware, from the experiments in the cure of Conurus by puncture, that the thin-walled forms, after their vesicles have been punctured, become completely collapsed and destroyed in consequence of the injury. In Echinococci, for example, in the kiduey, in which I have seen daughter- and granddaughter-vesicles pass off, and then again an entire eessation at various intervals, a cure appears to be capable of taking place. Möller has very recently seen the undisturbed growth of a punctured Echinococcus.

We now eome to the question of what further becomes of the resting scolex of the cysticercal, platycercal, and acercal Cestoid forms of the third stage of development? In answering this question we are led to the consideration of- 


\section{IV.-The Scolex passing into activity.}

In the year 1851, as has already been observed, I had come to the notion of testing the opinion formed by Von Siebold upon the identity of the hooks of $T$. crassicollis and Cyst. fasciolaris, which was previously known to the older writers, and of the exceptional conversion of this cystic worm into a particular tapeworm in the intestinal canal of a certain predaceous animal, by the intentional administrations of cystic worms to certain mammalia. By these investigations I arrived at the conviction that all the cystic worms which I could obtain passed into this metamorphosis, and that the cystic worms occurred in those animals which serve as the prey of the predaccous species which are capable of developing the cystic worm into a tape-worm in their intestine, or, in other words, that the animal infested by cystic worms is usually the source of food, or the prey of that infested by tapeworms. These laws liave been confirmed by the most various observers; for example, by Von Siebold, Lewald, Haubner, Gurlt, Röll, Eschricht, Van Beneden, Möller, and especially by Leuckart, and enlarged by the latter as regards Cyst. longicollis, so that this subject may be regarded as set at rest. It is now our task to describe the processes which occur more particularly.

The host of the cystic worm is devoured by a carnivorous predaceous animal, and by this means the cystic worm arrives, together with his previons host, in the stomach of the carnivorous animal. During the process of digestion, the enveloping cysts in which the cystic worms were enclosed, or, if the worms lived free in cavities, these latter, perhaps both (cysts and carities), are digested, or even opened previously by the teeth of the predaceous auimal, when the cystic worm escapes freely into the carity of the stomach. Here the worm extends itself, its caudal resicle collapses, from the escape of the fluid through some opening which has been made in it, and perhaps also, in extremely rare exceptional cases, from its escape through the uninjured walls, in accordance with the laws of exosmose. On the caudal vesicle and the middle of the body of the cystic worm, digestion begins to act perceptibly. The body at the same time elongates and extends itself, but the head, together with the short neck, is still inverted, as during the cysticercal period of existence. But 
now the head with the neck seeks to extend itself, and this takes place somewhat in the following way. The head, the hooks of which still exhibit the position of eysticercal existence, that is, with their apices directed backwards towards the suckers, and their shafts towards the apex of the head, draws itself as it were outwards through the neck, by turning itself inside out. As a matter of course the whole worm is at the same time as it were turued inside ont; and the margins of the hear and neck which were previously turned in, become the free onter sides of the worm. At this moment, if we wished to make a section through the anterior extremity of the worm, we liave to cut through not only two, but three layers of the parenchyma of the body, the caudal vesicle, a layer of the middle body, and the neck. During this turning the hooks have generally retained their position, or have begun to acquire that position of which I shall speak hereafter. From Leuckart's experiments, in which he placed naked, but otherwise uninjured cystic worms in a piece of the stomach of an animal at bloodlieat; it appears that at the first, and indeed within five or ten minutes after its introduction into this stomach, the worm extended its head, feeling about as it were for a short time, whilst it maintained a lively action with its suckers, and rapid peristaltic movements with its caudal vesicle; but immediately afterwards it contracted it again within the neck and middle of the body, which remain extended. In artificial digestion, this takes place until the caudal vesicle is dissolved, which is done in from eight to ten hours. In experiments by feeding, the worm is usually found in the small intestine five or six hours after its administration; its head again extends and it attaches itself to the wall of the intestine. The body and the collapsed, or more or less digested caudal vesicle, ${ }^{1}$ are now separated from the neck and head, and it is often seen within the first twenty-four hours that the adhering

1 When Leuckart enclosed a naked but uninjured Cysticercus in the small intestine of an animal, he certainly saw the caudal vesicle collapse, but it was never digested, for which a sojourn of one or two hours in the stomach was always necessary. If then a Cysticercus be very rapidly driven through the stomach to the intestine, and especially if it be still enclosed in its enveloping cyst, similar circumstances may occur. This was the case, at any rate, in those specimens described by me in the 'Prager Vierteljahrschrift,' which I found in the intestine of a dog that died two hours and a half after feeding, and which had a collapsed caulal vesicle, but had exterded and attached themselves, and still bore the enveloping cyst upon the collapsed caudal vesicle. 
scolex bears behind it the middlc-body, and the caudal vesicle on a fine filament, (that is a rudimentary transverse fold, or socalled segment). Nothing more than the scolex-head and neck of the third stage of development remain, and these alone are transferred into the new one. The length of the remaining parts varies, first with the different species, and then with the various individuals of the different species, according to the duration of their existence in the vesicular stage, and according to the length which their neck had attained during this stage.

On the abdominal extremity of the Cestoid worm, which is now, after casting off the body, greatly shortened, we now see shreds and flakes hanging, together with a funnel-shaped constriction. These are the rudiments of the receptaculum capitis, which was also extended during the changing of the Cysticercus which has become a Tonia, and formed the boundary between the head and body. A portion of this receptaculum is then always cast off with the borly and the caudal vesicle, and a portion wraps itself into the funnel-shaped constriction of the young Tania. The shreds remain for two days, and then at cicatrized notch is observed. It lcads, according to Leuckart, into a cylindrical cavity, passing through the whole body as far as the rostellum; its walls grow greatly, by which means the scolex is converted into a solid and not inflated body. At various times, sooner or later, according to the evolution and age of the cystic worm, (in Cyst. pisiformis, for example, in two, or at the utmost four days, but not as Lewald supposed in fourteen days), the formation of segmeuts commences, and with this, consequently, this stage of development is concluded.

I repeat here that Tanice cannot be reared from such scolices as do not exlibit perfectly developed hooks. They die immediately.

The first transformation of all cystic worms introduced into the intestine of a warm-blooded animal takes place in the same way, but the process stops before the commencement of segmentation in those cases in which the intestine of the animal in which the vesicnlar worm has arrived is unfavorable for it and its further development. All the subsequent growth in this case becomes an inarticulate, tail-like appendage, and such a Cestoid worm in an unsuitable intestine remains stationary half-way between the fourth and fifth stages of development. Moreorer, in this condition, it lasts only for a short time, and at the end of a fortnight there is usually no trace of it to be found. 
The transformation of the platycercal forms into mature Cestodea takes place exactly like that of the cysticercal forms; in the acercal forms no casting off of a portion of the former embryonal vesicle takes place, but the whole of it is retained, and the formation of segments commences immediately upon it.

However, it is as well (if it be desired to obtain various results from the administration), to remove the worms from their envelopes, and to make an incision into those which possess very large vesicles, as when uninjured they are very easily vomited. The teeth of the predaceous animal are sure to injure the larger vesicular worms, such as Echinococcus and Cysticercus tenuicollis.

In nature we only find the tape-worms in question in animals which live in freedom, and which can get freely at the animals infested with cystic worms. Animals kept constantly chained up, or in rooms, stables, \&c., and fed only with boiled, baked, or dry food, do not bear in their intestines even the tape-worms which occur in free animals of their species, any more than the vesicular worms which are found external to the intestine in the latter. The circle of animals in the intestine of which a particular species of vesicular worm thrives, is not usually large. When experiments in the administration of cystic worms are made, any diarrhœa which makes its appearance in the animals experimented on must be quickly stopped by opiates. Irritation of the intestines, and especially diarrhœa, destroy the results.

From the moment at which the extended cystic worm has attached itself in the intestine-and begun to derive its nourishment therefrom, when at the same time certain changes take place in its body and caudal vesicle, which, for example, is ruptured-commences the transition into the last stage, and a creature of this kind may certainly be called a young Tania. Thus we speak at once of a butterfly when the animal which was previously inclosed in the pupa case bursts its envelopes, and issues into a new medium, the open air. Freedom in an open, free space, change of medium, and the altered and more active vital phenomena of the animal, which it acquires in order to seek voluntarily for its own nourishment, constitute the change from a pupa to a butterfly, and the same things render a cystic worm a true young Tenia, whether it still bears behind it its candal vesicle for the moment, in the same way as the young chick its egg-shell, or has already cast off this and commenced its further 
development. Von Siebold has objecter to this nomenclature, and thinks that, " in this case all that is necessary is to press out the head of the vesicular worm, and the transition to Trenia-life is effected." I am no friend to sophisms and word-siftings, but I think that when a comparison is to be made, the cardinal points of the comparison must be retained, and whether I or Von Siebold have missed the analogy, I shall leave to others to decide. We have seen that the cystic worm keeps its head still retracted whilst in the stomach, or if it is protrucled it is soon retracted again, and the hooks are not turned out so as to adhere, but retracted, and their apices directed backwards and inwards, and their shafts forwards and outwards. As long as the worm keeps its hooks in this position, no one will call it a Trenia, even if it should have elongated its body and neck.

We have still the last question to consider-How does the scolex, after entering upon its activity, become converted into a tape-worm colony $=$ Strobila ? and for this purpose we must regard

\section{The Strobila = the so-called tape-worm colony.}

Immediately after the healing of the cicatrix on the neck, and on the former receptaculum capitis, there commences, between the posterior end of the head and this cicatrix, a budding forth of the body, produced without sexual propagation, and which becomes constricted into segments by transverse furrows or wrinkles. By the constant production of new masses on this place, that previously formed is continually pushed further back, so that this cicatrix is at last removed to a considerable distance (varying according to the species) from the head. During this time the individual divisions and segments increase and grow in the same ratio as their removal from the head; they at the same time acquire sexual organs, male and female, in each segment, and which are very rarely (if $O$. Schmidt's observation on the Tania dispar of the Frog ${ }^{1}$ should be confirmed, and the spermatozoids have not been overlooked), and probably never entirely wanting in the colony. Finally, when they have attained a sufficient size and maturity, they produce the embryos (Section II), and last of all cast themselves free in the form of the

1 'Ueber den Bandwurm der Frosche, Tania dispar, und die geschlectslose Fortpflanzung seiner Proglottiden,' Berlin, 1855. 
proglottides (Section I). With the first separation of segments, the segment which bore the above-mentioned cicatrix, and which is also usually characterised by its being aborted and more or less sterile, is lost. We might perhaps more correctly say that this cicatrixbearing segment is therefore the first fragment which separates from a mature tape-worm colony. On it, at least in the species which behave like Siebold's cestoid worm from Arion, we slould necessarily find the embryonal hooklets, if these were not too small. The want of this aborted cicatrized segment is a proof that the strobila has already given off fragments or segments.

If we were to give a definition of the strobila, it is a series of separate joints, individuals, which is produced from the active scolex in the space between the part of the latter which must be called the head par excellence and its citatrized extremity by a sexual reprodnction, which remains in direct union with the scolex which forms its point of support, and which, when examined from the anterior to the posterior part, presents asexual segments, half and fully-developed sexual segments and segments engaged in sexual retrogression, of which the last have become truly independent individuals.

We have still to refer to the anatomical structure and to the development both of the sexual organs and of the brood.

As regards the structure, we find, in the first place, no digestive apparatus in the whole colony, nor up to this time have nerves been detected in it. 'The most important points of structure in the tapeworm colony appear to be a dissemination of calcareous corpuscles and the formation of the vessels. Of the vascular system of the head we have already spoken under the development of the scolex, and at the same time seen that a union of the four lateral principal vessels takes place in the head; that even in the head smaller branches are given off from these main stems; that these vessels probably open ontwards at the spot where the receptaculum capitis (a portion of the so-called neck, as already remarked,) passes over into the caudal vesicle, without uniting into a pulsating tube, as in the Trematoda; that these vessels certainly differ in their arrangement from those of the Trematoda, which they may resemble in their function; and that the homologue of the pulsating tube in the Cestodea may be placed, not at the hinder

1 "A single ganglion has been discovered situated in the axis of the head, and sending off nerves to the suckers in some Trniadx."-Huxley. ED. 
part of the body, but probably in the ring uniting the four vessels, which runs round the rostellum of those Cestodea which posscss a rostellum, or in the simple transversc uniting branch, which occurs in the anterior part of the head of those Cestorlea which have no rostellum. In favour of this riew we have not only the absence of a strong communicating branch or ring of this lind in the anterior part of the body in the Trematoda, but also the well-known observation, that in the microscopic examination of uninjured Cestodea the cephalic vessels may be very easily recognised by the employment of only a moderate pressure; that this also succeeds very well when the colony is wrapped round like the renversé of a bandage, and cut off behind this part. The ressels of the head also and those of the anterior part of the body immediately become empty, and thereby less distinct when the worm is cut through its anterior part, but subsequently, and in the posterior segments, the fluid cannot be driven back from the tail towards the head by pressure, which would be possible if there were a pulsating tube at the hinder part.

There is certainly no doubt that the vascular formation in the head, especially as regards the anastomoses formed about the suckers and rostellum, differs according to the species. This can be better explained by figures than by words. In order to study the system of cephalic ressels, I recommend the reader to administer vesicular worms, and to kill the animal experimented on from forty-eight to sixty hours after administration. With a little pressure we then obtain with the microscope a very distinct view, especially when the young Trenie are examined in their proper medium, that is, in a little intestinal mucus. The four lateral longitudinal canals already mentioned are direct continuations of the four longitudinal canals already existing in the scolex (head). Besides these there is a system of very small, numerous capillaries, although they may not be met with in the way represented by Blanchard, after lis injections. According to Wagener, whose statements are confirmed by Meissner, a considerable number of small vessels, destitute of walls, issue from the larger ressels, which possess proper walls. In both kinds of ressels, especially in places where vessels communicate, ciliary formations are observed, which, howerer, are wanting, according to him, in the four vascular trunks; these I think I have seen, at least at the points where the smaller ressels open into the larger ones. 
In the upper part of each segment a vascular ring is formed, from which smaller vessels issue. The vessels themselves are structureless tubes. According to Wagener, a pulsating tube might be proper to them, but only during the period of their existence in the vesicular state; this, however, neither Leuckart nor I have seen, and, as always remarked, I rather look for its analogne in the communicating branches of the cephalic ressels. Nevertheless, this vascular system may be an excretory organ. In the Bothriocephali, and in Tanie without a rostellum, the vessels communicate without forming a ring.

The muscles consist of transverse and longitudinal fibres, which may be best recognised in the neck. Immediately under the skin lies the thick layer of longitudinal fibres. The suckers, peculiarly muscular parts, are with radiate fibres uniting in the middle of the sucker upon which lies a layer of circular fibres, and the rostellum. The latter exhibits a predominance of longitudinal fibres, which at the end of the rostellum often spread themselves in the interior of the body in the form of a tuft. The rostrum itself is filled internally with structureless mass or fluid. Whether small muscular fibres run to the little hooklets of the embryo is still a question in dispute.

Position of the hooks in the Tanic.-I have already spoken of the position of the hooks in the cystic worms, and also of their attachment to the skin, and at the same time remarkcd that no muscular fibres run to the apices of their shafts. The hooks rather ride upon the skin, and indeed in small impressions or pits, which in the large-hooked species, and especially in age, acquire the form of actual sacs, of which, as a matter of course, from the quite different position of the hooks during the vesicular period of existence, we find only slight indications at that time. The elevation and depression or spreading of the hooks are not even now effected by peculiar muscles, but by changes in the movement of the parts of the head, particularly of the rostellum, and especially by the pressure of the tenacious fluid contents of the rostellum to and from the roots of the shafts, and by the rostellum itself being at the same time pushed forward and retracted. The movements cammot properly be compared with simple lever-movements. We may come nearest to the truth if we compare them with the action of those metal hooks made use of by packers in moving bales. But the 
hooks differ even from these instruments, as in the middle where the handle passes into the hooks, they have a process which is certainly intended for unhooking, and which I formerly called the hypomochlion. This denomination, to which I will by no means adhere, is quite correct for the act of unhooking, if we suppose the hook to be an imaginary double-armed lcver, which it resembles at the moment of adhesion, and at the same time regard as the point of support, not the apex of the shaft but that of the spine (hypomochlion), upon which, in unhooking, the apex of the claw and the shaft as it were move up and down. If we omit this ideal view, the apex or root of the shaft can alone be regarded as the fulcrum of the hook acting as a one-armed lever, to which the force is applied, as it were, by the skin of the rostellum and head and the contents of the former. The spine which effects the loosening of the immersed hooks supports itself in this act against the wall of the intestine of the host, exactly as the packer, when he wishes to remove his hooks from the bale, presses against it with the knuckles of the hand grasping the handle. The knuckles of the liand, in this case, exactly take the place of the spine in the hooks of Tanice, and in a great number of hooks the free surface of the spine corresponds with the space which is formed between two knuckles of the hand. We have two elevations which press against the bale, or, in the hooks of the Trenice against the intestine, and between them a valley-like pit, into which the outer wall of the bale, and with the hooks of Tanice the wall of the intestine, presses; by which means, in the latter case, the spine obtains a firmer support. From this mechanism it is evident that the spine furnishes at all events a temporary and subsidiary fulcrum, and probably in the immersion of the hooks prevents their sinking too deep, and consequently their breaking away during removal, at the same time facilitating the latter. If we now consider the circular arrangement of the hooks, it follows therefrom either that the adbesion takes place at once in a circular surface, which is certainly admissible in the yielding walls of the intestine, or that a spiral advancing morement of the head of the worm is possible on and in the walls of the intestine, so that the worm must at the same time twist itself partly upon its longitudinal axis. It is difficult to ascertain with certainty whether both or only one of these two kinds of morements of the hooks occurs. 
In our Tanice the positions of the hooks are so extraordinarily various, that we scarcely know how to indicate them satisfactorily. This much is certain, before the hook of the cystic worm buries itself in the intestine, as the hook of the young Tania, it has first to elevate itself perpendicularly about a quarter of a circle from behind and below, anteriorly and upwards, and afterwards to turn itself round about a quarter of a circle in the horizontal plane. In order to retract its looks as a tape-worm, the animal must also elevate these hooks a fourth of a circle, at the same time turning itself round about a quarter and retracting itself, and on again immersing the retracted hooks, it must push these forwards and, allowing the looks to turn one fourth round upon themselves, describe a quarter of a circle in the horizontal plane. This at least applies to the hooks situated on the side of the circle. These movements will be best understood with a wax model.

The sexual organs consist-1. Of a symmetrical lateral yelk. stock (vitellogene), placed to the right and left; that is, a perpendicular canal, filled with yelk-masses, with dilatations and blind saes, which run outwards and inwarls. Between these, and quite posteriorly, lies-2. The germ-stock (germigene), which is usually double, rarely single, with its clear, cellular egg-germs; and above this-3. The uterus, with developed eggs of various forms, and furnished with a germinal vesicle. At the point in the posterior third of the segment where 2 and 3 meet, and where 5 also appears to come, 4. The posterior end of the vagina is to be found. It forms a long narrow passage, which leads, in a curved form, from the point of union just mentioned to the middle of the segment, and thence outwards horizontally beneath the sac of the penis. Between all these parts, and especially above the uterus, lie, 5. The testis (Hodenschlauche Schultze), which Van Beneden ealled "cellules transparentes," with seminal cells or long seminal filaments. Sometimes we can only detect upon it a pointed prolongation, sometimes small canals (vasa efferentia), collecting in, 6, a common seminal duct, which, runs in transverse and parallel convolutions, and, with the vagina, opens into 7 , the sac of the penis, which opens outwardly above the vaginal orifiee in 8, the genital pore, sometimes isolated from the female vaginal orifice, sometimes united with it in a scxual cloaca as in the Tanice with which we have to do.

This is briefly the general type according to which the sexual 
organs of the Cestodea are formed. It may be recognised particularly well in Bothriocephalus rectangularis of the barbel, when the parts are pressed together by means of a compressor between two glass plates.

The structure of the Tanice with which we are particularly occupied here is best recognised when some of their anterior segments, exhibiting the first foundations of sexual organs are pressed between two glass plates, and the whole is held up to the light for examination. Posteriorly and laterally, in the median line, lie the two wing-like clear germigenes; above them is the dense testicular tube, and between the two the first formation of the uterus, (a perpendicular clear canal, particularly dilated above). The vitellogenes lie in the form of opaque bands partly on the outside of the longitudinal canals. All these parts are very firmly imbedded in the parenchyma; the vagina and seminal ducts scarcely exhibit a double muscular wall. As already remarked, they possess a beaker-shaped sexual cloaca closely surrounded by muscles, in which the cirrhus and vagina open in common; this occurs in most Tenia, but not in all (for example, not in $T$. elliptica).

At the bottom of this space, which is furnished with tumid margins, we see above the distinct orifice for the male sexual apparatus, and below it the smaller vaginal aperture into which the male organ, which is protruded from the first-mentioned orifice, in the form of a small papilla or of a longer cylindrical filament (cirrhus s. lemniscus), enters during copulation. The male organ is pyriform, and exlibits internally transverse and longitudinal muscular fibres, and externally a structureless epidermis. The penis lies in a peculiar pouch, whicl may be called the cirrhus-pouch (sac of the penis). In its interior runs the vas deferens, the inner membrane of which turns outwards during the protrusion of the penis, and then gives the exterior of the penis an appearance as if it were beset with fine retroverted hooks.

In the vagina no internal, direct connection of the male and female sexual organs takes place, and this is also denied by Van Beneden in the Trematoda. At its entrance into the lower part of the uterus it becomes enlarged into a true seminal receptacle, and the combination of the structures necessiry for the formation of the ova undoubtedly takes place in the vicinity of this point at the lower part of the uterus.

The large germigenes lie right and left, close to the descending 
vaginal branch, and more towards the middle of the segment, in the form of lobate glands, with cæcal tubes and a tiausverse efferent duct; they do not, however, contain the ordinary contents of germigenes, but small, refractive, displaccable, homogeneous vesicles, destitute of both nucleus and membrane. They are, consequently, only places for the production of germinal vesicles. We find as many pairs of germigenes in one segment as there are vaginæ and porigenitales. The vitellogenes (cutaneous glands of Van Beneden), which are situated more peripherally, are smaller or larger, transverse, cæcal tubes, united by a central longitudinal stem, with fine, coherent, fitty granules and efferent ducts, which cannot be traced as far as the uterus.

The uterus is a simple, median canal, which is gradually developed from below upwards, where alome it exhibits dilatations, which become elongated and branched, and are developed at the expense of the other sexual organs. The testes, which are readily recognisable in the younger segments, are clear, roundish vesicles, reaching 0.15 millim. in cliameter, placed at the side of the uterus, especially in the upper part of the body, close to and beneath the germigenes. Vasa efferentia, which are probably present, although perhaps ouly temporarily, are never distinctly visible. When the seminal duct begins to fill, the testicular vesicles dehisce. The seminal duct, a repeatedly contorted canal, ruming transversely through the middle of the segment, has already been referred to. Care nust be taken to avoid regarding empty branches of the uterus as testes. The contents of these branches are small, clear, seminal cells, and afterwards simple, very long, capillary seminal filaments.

The maturity of the segments commences at various distances from the head in different species. We first of all see a transverse streak in the middle of the segment (vagina and penis); then the separation of this streak into two canals; then the commencement of the testes and germigenes; then that of the vitellogenes; afterwards that of the uterus; and lastly, the seminal filaments, after the transfer of which the development of the embryo begins.

As regards the development of the eggs and embryos, we shall follow Leuckart's statements. Before him nothing had been made known on this subject, except by Kölliker (Müller's 'Archiv,' 1843, p. 91), and also by Van Beneden, who speaks of a segmentation of the vitellus. Before the filling of the seminal 
receptacle (fertilization), there are in the uterus numerous clear, round corpuscles, like the germ-granules, but somewhat larger, and bearing on their outcr surface a small agregation of grains (vitellus). Round both a delicate substance is scen deposited. 'Thus the germinal grain (a sort of germinal vesicle) and germinal corpuscle form a common oval mass. An egg-menbrane, and a germinal vesicle furnished with a germinal spot, and surrounded by a vitellus, such as we usually find in the eggs of animals, are therefore deficient in the eggs of the Cestodea.

After the filling of the seminal receptacle, the germ-grain of the cestoid egg breaks up by contiuual division into a mass of small, round, clear vesicles or cells, which at first resemble the germ-grain, and subsequently exhibit a paler envelope with a nucleus. There is therefore no endogenous or new formation of cells round nuclei in the egg, but division or segmentation. The spheres of segmentation measure, after the first division 0.0095 millim.; after the second, which occurs rather towards the poles than in the middle of the egg, two larger and two smaller spheres are formed, and we also subsequently find unequal splieres, which at last become unmeasureable. Finally, the aggregation of cells, which was previously blackberry-like, becomes globular, and nearly homogeneous, and increases considerably. The granular, vitellus-like mass, placed close to the germinal grain or germinal vesicle, which lies beside the latter like a cone or little roof, does not take part in this division; the enveloping mass is more distinct. There is consequently a division analogous to the segmentation of the vitellus, which, however, does not occur in the entire primitive egg, but only in the germ-grain or germinal vesicle, and in which the small aggregation of gramules on the outer surface of the germ-grain is not included. It has certainly been generally admitted of late, that in the process of the segmentation of eggs, not only the vitellus, but also the germinal vesicle divides. Moreover, in the eggs of other animals also, the vitellus is sometimes deposited not around, but beside the germinal vesicle, for example, in Lizzia and Oceania. The principal distinction consists in the want of the vitelline membrane, and the envelope round the mature embryo is a new formation. The aggregation of cells formed by division, and the granular vitelline mass, now remain for a time unchanged in the common envelope; some cells then disappear, and numerous nuclers-like granules remain. 
The envelope then becomes firmer and more membranous; its contents draw together inwards, and become converted into a small, spherical corpuscle, which is surrounded by a separate membrane, and on the outer surface of which (4--) 6 small hooks are attached, which afterwards grow inwards to a greater depth. This is the embryo. At the same time, the external envelope is frequently covered with asperities or tubercles, as in our Trenice, and becomes converted into the egg-shell, which is truly not an egg-shell, but an embryonic structure (a sort of amnion). The small vitelline mass remains outside this so-called egg-shell in the form of a crumbly mass, envelopes itself in an albuminous enveloping membrane, or becomes a second, internal envelope, which, howerer, would be erroneously regarded as a proper egg-envelope.

Thus we have seen how the segments, with their embryonic structures, are developed, and, when they have become the hindmost in the colony, cast themselves loosc. Their destiny has been already described (sections I and II), and thus the subject las been concluded, but which we will again sum up briefly. The developmental history of the Cestoidea is best understood if we consider it from the following points of view :

I. The mature sexual animal, which is produced by asexual gemmation, separates from the colony as suon as it has attained its maturity, migrates actively from the intestinal canal of its host into free nature, and thence passively into the stomach of another usually herbivorous animal. It bears within it-

II. The grand-nurses or embryos produced by sexual, and perhaps by asexual reproduction, furnished with four or six hooks, which are destined to enter passively into the stomach of a herbivore, and thence to migrate through the body of the latter, either actively or by the intervention of the vessels, activepassive-actively. (The asexual propagation of the brood in the Cestodea is rendered improbable even by the fact that in the whole developmental series of these Cestodea, a sexually mature animal has never been met with).

III. The resting scolex (uurse) produced by asexual gemmation in and by the enlarged, six-hooked embryo, still concealed within this embryonal vesicle, or lying beside it enclosed in peculiar cysts, or in closed serous cavities. In its non-gemmiparous part the embryonal vesicle acquires, according to the species of cestoid 
worm, and according to the different hosts (cold or warm-blooded), sometimes the form of a globular vesicle, sometimes that of a flat, band-like strip, and sometimes is only just sufficient to corer the scolex, lying quite close upon it, when it really forms nothing but a receptaculum capitis. Thus we obtain three forms allied to each other in their degree of development;-the cysticercal forms (Vermes cystici, including Conuri and Echinococci); the platycercal (similar to Stein's cestoid worm of Tenebrio molitor, and Von Siebold's from Arion empiricorum); and the acercal (certain embryos of Tetrarhynchi). Every one of these is a normal form; even the cysticercal forms are neither morbidly degenerate, nor become dropsical, nor strayed. The formation of vesicles is settled by the species of worm, and by the animal infested (warm-blooded). 'The species of cystic worms have never yet been found in any animal without the resicnlar structure, and in an acercal or platycercal state the caudal vesicle does not occur in the very succulent forms living in cold-blooded animals, from which the cestoid worm can constantly and readily derive fluids. As was known by Goeze, the caudal vesicle is a reserroir of nourishment. The embryos of all the Cestodea which pass through a vesicular state are extraordinarily small, possess very small embryonal hooks, and are enclosed in brownish yellow envelopes, which are uneren exterually. All three forms are undeveloped immature forms, and must therefore be struck out of the system as genera, and further must be arranged with the Cestodea.

IV. The resting scolex transferred into the intestine of an animal becomes converted into the scolex passing into activity. The latter is distinguished from the resting scolex by the extension of the entire body by the altered position of the adherent apparatus (suckers and hooks), by the attachment in the intestinal canal, and in the cysticercal and platycercal forms by the casting off of the barren portion of the embryonal vesicle and the formation of a cicatrix on this spot. In the acercal forms nothing is cast off, nor is there a cicatrix-formation.

V. The strobila $=$ the tape-worm colony, budding immediately from the scolex which has become active, by asexual propagation (gemmation) is more or less distinctly jointed, and becomes sexually mature posteriorly. Its last segments, which are cast off and lead an independent existence, are called proglottides (I), and bear within them the embryos produced by sexual reproduction (II). ${ }^{1}$ 
Special Part.

The Cestode worms occur in man either only in the mature state, and then in the human intestine (Bothriocephalus latus; Tania mediocanellata; Tania nana; and if the Tania of the Hottentots, mentioned under 3 , is not a mere variety of Tania mediocanellata, probably this also); or only in the larva or scolex state (Cysticercus visceralis autorum seu tenuicollis, according to Eschricht; Echinococcus veterinorum seu scolicipariens and $E$. hominis seu altricipariens); or lastly, in all known stages of development (Tania solium and Cysticercus cellulosa).

\section{First Order-Bothriocephali $=$ Dibothria}

Cestoidea 2 osculis suctoriis aut 2 foveis marginalibus, oblongis aut longitudinalibusoppositisinstructa. Capite subtetragono, depresso, articulato plerumque, inermi. Pori genitales omnium articulorum in linea mediana animalis et in ejus superficie abdominali siti. Scolices extra tubum intestinalem in cystidibus peculiaribus ad vermium platycercorum modum, aut in tubo intestinali animalium minorum aquaticorum statu immaturo viventes; Strobila in tubo intestinali animalium aquaticorum rapacium, avium maritimarum et mamnalium viventes; Proglottides verce interdum absunt, interdum adsunt, sapissime in longa articulorum serie conjuncte dehiscentes. Embryones sex hamulis armati; ovulorum testa sapissime colorate.

Of this division, which is particularly abundantly represented in predaceous fishes, and more sparingly in piscivorous birds, especially the marine Raptores, examples occur in but few mammalia. Thus Creplin once saw two young, small Bothriocephali in the intestine of a cat in Greifswald; Natterer found them in Brazil in Felis malivora and Procyon lotor; Fischer in Phoca monachus; and Schilling in Phoca fretida. Of the terrestrial mammalia inlabiting inland situations, only man harbours Bothriocephati. 


\section{Bothriocephalus latus $=$ Diboifurium latum.}

Pl. II, figs. 1, 2, 3, 4, 5.

Caput oblongum, inerme, 2 bothriis-foveis marginalibus, formam rimce aut fissurce (fente) adoptantibus; collum subnullum; articuli numero circa 2000, maturi omnino latiores (ad 27 millim.), quam longi, socialiter decedentes; pori genitales in linea mediana siti, masculus major et superior, ex quo penis lavis et brevis prominet, femineus minor, posterior inferiorque. Scolex quiescens ignotus; scolex activus cum strobila in hominis tubum intestinalem incolens, lonyitudinem 7-8 ulnarum, secundum Dujardinum ad 20 "metres" (?) exhibet.

Embryones 6 uncinulis (?) armati, in ovulis 0.028-32 mill. lonyis et 0.002 mill. latis, ellipticis, flaro-fuscis, operculo dehiscentibus inclusi.

Synonyma.-Ténia à anneaux courts, ou à mammelons ombilicaux; T. large; T. à épine; $T$. lata, T. grisea, $T$. vulgaris, T. membranacea, tenella, T. dentata, T. humana inermis, 'T. de la première espèce (Plater and Andry). Halysis lata or membranucea, the broad tape-worm, Nelaken, Lindworm, Baandworm, Baendelorm, Brimile mask, the tape-worm, jointed worm; Kosso; Luig ditg; the short-jointed worm.

It would be unnecessary and superfluous for the practical man to clear up the confusion prevailing here. The names given are, to a great extent, common, popular names for tape-worms in general. A portion of the names referred to, however, applies most remarkably to the hookless $T$. mediocanellata. Since the time of Bremser, who first correctly determined this worm, it has borne the name of Bothriocephalus latus; but it is not advisable to retain the names of Swiss tape-worm and broad tape-worm as synonyms, as this nomenclature gives rise to a confusion of this parasite with $T$. mediocanellata.

The exact knowledge of this worm has scarcely been at all advanced since Eschricht's classical work, for which reason we have depended upon Eschricht, except in the consideration of the scolex of the Bothriocephali and their prophylaxis.

\section{A. Mature state.}

It is only this grade of development that occurs recognisably 
in the human body, and therefore especially interests the medical nistil.

Colour of the living worm bluish-white. Specimens preserved in spirits change greatly in colour. Thus I possess Bothriocephali which appear quite white on the sides of the ovarian organs, and others of a dingy brownish-yellow colour. Eschricht proved that the colour arises from the pigment which colours the egg-capsules being dissolved in alcoliol, and it is at the same time very possible that the browner or whiter colour may in part be owing to the degree of concentration of the alcohol employed in their preservation.

Active scolex, or head.-The five heads hitherto examined by me, of which I could only obtain one tolerably fresh, at the end of March, 1855, were obtusely conical. The two lateral pits (the analogues of the sucking discs of the Trenia) are fissuriform; they appear, like the sucking discs on the feet of flies and mites, on leeches, \&c., rather to effect the arlhesion in accordance with the well-known laws of partial or total vacure, than to have anything to do with the nourishment, which is probably introduced through the entire skin. An actual opening on the head of Bothriocephalus could not be detected any more than in other Cestoidea. As a matter of course, the head must acquire many various forms during life, and in spirit, specimens will retain the form which the worm possessed at the moment of its death; on which account I must call such figures as Clerc's, and their copies (as for instance, in 'Seegrer-Wundt,' pl. ii, figs. 5 and 6), mere playthings.

The neck is more distinct in young than in old individuals, in which transverse wrinkling, $i$. e., segmentation, commences immediately behind the head.

The strobila, or jointed body. - The name of ventral surface is given to the side on which the sexual apparatus opens; the opposite one is called the dorsal surface. Each segment has four margins-two slightly undulated, free lateral margins, and an anterior and posterior margin, by which the segment is articulated to its upper and lower neighbours in the colony. Although the breadth preponderates over the length (in the proportion of $3: 1)$, the form is nevertheless very variable, according to the predominating contraction of the longitudinal or transverse muscles. In the central line the segments are more or less thick (up to $\mathbf{l}^{\prime \prime \prime}$ ) and darker brown, according to their various degrees of maturity and the cliarging of the ovaries and uteri 
with ova; the lateral margins are flatter and whiter. In the latter, Eschricht describes seven layers-1. Skin. 2. Ventral granular layer, or, more properly, calcareous granular laycer. 3. Parenchymatous, transparent layer. 4. Ccntral graumlar layer, also consisting of nothing but calcareous corpuscles. 5. Repetition of layer $3 ; 6$, of layer 2 ; and $\tau$, of layer 1 , on the dorsal side.

When Eschricht speaks of only four layers in the central parts, this is no essential difference of structure, but he can only mean thereby that on these parts the calcareous granular layers (as above, layers 2, 4, and 6 ) are wanting; these arc incorrectly described by Eschricht as mutritive organs, under the denomination of smallest granules $\left(0.001-5^{\prime \prime \prime}\right.$ in diameter) and nuclear bodies $\left(0.0075-0.012^{\prime \prime \prime}\right.$ in length and $0.00 \tau-010^{\prime \prime \prime}$ in breadth). We may easily convince ourselves of the calcareous nature of these bodies by treating them with acetic acid, in which they dissolve with effervescence, whilst they remain unchanged in alkalies. Moreover, Eschricht has given up his previous opinion, but still appears to think that the calcareous corpuscles of the Cestoidea contain silica, althongh I cannot find the chemical reasons for this supposition in liis works. As a matter of detail it is to be obserred that the skin is divided into a cuticle and corium, that it is inverted at the generative openings, and sprinkled throughout sparingly with calcareous corpuscles, which are abundant in the neighbourhood of the pori genitales and on the hinder margins of the segments. These have been taken by many authors for cutaneous glands (folliculi compositi). A portion of the so-called cutaneous follicles may also have been loose terminations of certain parts of the sexual apparatus (vide supra). The parenchymatous layer exhibits contractile cellular tissue (organized sarcode), which consists of threads rumning at right angles, forming a wide network, and interrupted by the deposition of the calcareous corpuscles, and contains very weak transverse and stronger longitudinal muscular strix, which, howerer, are less dense than in the Tanice.

Vascular system. - Whoever has an opportunity of examining my fresh specimens, will certainly find, as in all Cestoidea, those lateral longitudinal cords, which, as is well known, contain a limpid fluid. What network this vascular system may form, we cannot tell at present. Unfortunately, we have no means of rendering these ressels again apparent in spirit specimens, or of 
making successful injections. Lschricht saw these vessels lying more towards the middle than towards the margins.

No nervous system has yet been detected. Visual oryans, and special organs of touch are wanting, as is also a respiratory system.

Genitalia.-Although the genitalia generally lie singly in each segment, they are sometimes seen double.

Female sexual oryans:-a. Vulva, or vagina: a small opening on the hinder margin of the porus genitalis, just over the penis.b. Uterus, five, six, or seven altemating horns on each side in the median line. The uppermost liorns are the thickest; then follows a pair of thinmer, but very long horus; the rest are thin and small. I call this the uterus, becanse mature ora are found in this region. In it we distinguish an cxternal cutaneons layer, the capsule of the egg-receptacle, and the inner membrane, $i$. e., a thin sac, twisted ronnd into itself.-c. A piyment capsule, = Eschricht's coil (knäuel), which secretes the brown colouring matter, and perhaps the shells of the ova; it is $5-6^{\prime \prime \prime}$ in length, enlarged like a sac in the middle, and opens into the uterus directly at its commencement. Inasmuch as this pigment-mass penetrates outwardly through the walls of the capsule, it may, perhaps, be able to gire a yellow colour to the agglomerations of calcareous corpuscles, which has led Eschricht to think that these yellow bodies are a peculiar glandular system.- d. The true ovaries, with vitellogenes, fic., are sacs studded on each side of the pigment capsule. They are better recognised in specimens preserved in alcohol than in fresh specimens, and appear to form a convolution of numerous varicose creca.

Male sexual oryans, - $a$. The opening of the penis is situated on the borders of the first and second quarters of the segment, on the elevation produced by the vesicle of the penis and the thick horns of the uterus, which is flatter in front and more swollen behind.-b. The penis, which easily projects from the anterior portion of $a$, is of equal thickness thronghout $\left(\frac{l^{\prime \prime \prime}}{8}\right)$, and usually protrudes $\frac{1^{\prime \prime \prime}}{2}$ beyond the margin of $a$; the waved margin of the skiu forms its praputium. The glandule praputii of Eschricht are calcareons corpuscles, which are liere collected in masses.c. Sac of the penis, a vesicle situated in a proper capsule, $\frac{1^{\prime \prime \prime}}{4}$ in length, $\frac{1 \text { "' }}{6}$ in breadth, between the uppermost thick horns of the uterus, and in which the penis is suspended to a strong, 
twisted stem, $\frac{1{ }^{\prime \prime \prime}}{4}$ in length. - d. The seminal ducts, placed on the dorsal side of the capsule of the uter'us in the interspace between the lateral horns, are $\frac{1^{\prime \prime \prime}}{5}-\frac{1}{25}{ }^{\prime \prime \prime}$ in thickness, but have no perceptible connection with the vesicle of the penis or the testes. $e$. The testes, according to Eschricht, are a layer of white granules $\left(0.030-0.080^{\prime \prime \prime}\right)$, placed in a corresponding network, and containing in their interior, fine, spiral filaments (spermatozoid capsules).

\section{B. Ova and Embryos.}

The ova, of which we have already spoken in the definition of the species, exhibit an external hard, brittle shell, which is only broken up by a very strong pressure into polygonal fragments with sharp edges, but frequently breaks in such a way that they represent operculated ora, exactly like those of the Trematoda. If MM. Seeger-Wundt only describe the former, they cannot have made an independent examination. With a little practice, especially with the employment of caustic potash, we may easily discover the degree of pressure necessary to cause the operculum to open. From the opercular opening a limpid vesicle then emerges, in which, however, I have not yet found the six hooklets, probably from want of skill.

Although Von Siebold allows these hooklets to possess a sinilarity with the hooks in the circlets of the Trenice, it is certainly going too far to expect to find in these resemblances or diffcrences such as are seen in the mature species. It is, however, a question whether at least a part of the eggs of the Bothriocephali are not produced with undeveloped embryos, so that the latter are only perfectly formed free in wature, as in the eggs of the Ascarides. The mechanism of the immigration of the embryos, if they are really furnished with six hooklets, will be found in the Introduction.

Resting scolex. - In order to trace this gradually in its course, it is undoubtedly most advisable to explain exactly the behaviour of these organisms when we meet with them in other parts of the animal kingdom. In the intestines of fishes, especially marine fishes, certain cestode worms live, which are furnished with a band-like, inarticulate appendage, but still exhibit no commencement of sexual development, and which, as was first ascertained by Creplin, and as we have already mentioned, become converted 
into mature Bothriocephali in the intestines of higher fishes, or of the marine birds of prey which live upon these fishes. Whether these creatures in the intestine of the fish have been developed there, or whether they only reached the intestine with one of the animals on which the fish feeds (as, for instance, a crab, a mollusc, or an insect), in which they had become converted into a scolex, after the animal had swallowed the eggs of the mature Bothriocephalus to which they belong, is still mndecided. There may, therefore, be two possible ways for the production of the mature Bothriocephali. Either the lower animal, which harbours the scolex in the same way that the host of the Cysticercus bears those creatures, is devoured by an animal (such as a large predaceous fish, bird, or mammal), in the intestine of which the scolex, being set free, immediately developes itself; or the first-mentioned animal is first of all swallowed by another, in the intestine of which it certainly passes through the same preliminary changes which occur when a Cysticercus gets into a suitable alimentary canal, but is unable to develope these to maturity. It is only when this second animal is devoured by another belonging to a higher species, that the scolex attains the conditions by which it can become developed into a mature Bothriocephalus. At present, certainly we cannot say whether in particular species of Bothriocephali only one or the other of the above-mentioned direct or indirect processes takes place, or whether both paths are followed by one and the same species, as if nature wished to secure to each individual the broadest possible base of probability for the preservation of its species. It is true that, in the latter case, we must suppose that the host of the mature Bothriocephalus can obtain the first animal which harbours the scolex outside its intestine, as well as the second, which contains it within the alimentary canal, and use them both as food. ${ }^{1}$ Here, unfor-

1 Von Siebold, as I have already mentioned, was the first to produce artificially in Tania a grade of development, which, in its nature corresponds with the scolices lyelonging to the Bothriocephali. Thus, if rabbits be fed with Cysticerci of the rabbit, or dogs and cats wilh Cysticerci which do not find a favorable soll for their perfect development in the intestines of those animals, but gradually become abortive therein, a form is obtained which bears, instead of an articulated Cestode body, a simple, inarticulated, band-like, flat, massive appendage, not furnished with a candal vesicle. Such animals attain a length of 10 to 20 millim., and are the perfect analogues of those scolex structures which are met with in the intestine of the sticklebacks and other 
tunately, we are completely in the region of conjectural zoology ; but I am firmly comvineed that my colleagues, who live in the districts infested by Bothriocephalus, and especially on the seacoasts, will not be long before they give us the explanation. The first thing to be done is to adninister the mature ora of Schistocephalus dimorphus (Creplin), from the intestinal canal of certain marine predaccous birds, to sticklebacks, or other small sea-fishes kept in a confined space, in order to see whether or not numerous immature Schistocephali are developed in the intestine of the fish itself. If not, we are certainly justified in supposing that the stickleback first derives the scolex from one of the auimals on which it feeds. If Schistocephati are produced, we must suppose that the actire migration of the young does not take place in these animals, but that there is only a passive transportation from one intestine to another, and that this is sufficient for development. In such cases the young must certainly be hookless, and sinilar in form to the mature animals, in which latter case it rould also be conceivalle that species of cestode worms may pass through their entire development in the same alimentary cimal.

If we apply what we have just discussed at length to the Bothriocephalus latus of man, we must admit that we have no data as to the production of this worm in the human subject; we do not know what migration the youngest brood makes, or when it becomes converted into a scolex. In the obscurity prevailing here, all attempts to furnish hints will certainly bc

fishes. These forms were employed by me to demonstrate the untenability of Dujardin's and Von Siebold's opinion, that the Cysticerci were formed sulseqquently from developed cestoid heads. But I also administered these Cestoidea obtained from the intestine of the rabbit to dogs, in order to see whether Tania serrata may be raised from them, or, in fact, to ascertain whether, after this second transference, these creatures continued their transformation in exactly the same way as the true Cysticerci of the rabbit. I fed a dog with fire of these young Tania, which I had bred in the intestine of a rabbit from Cysticerci of the same animal. In eight days the dog exhibited no Trenice serratce. Whether subsequent experiments will furnish results, I must leave for further information. It will be seen from this, that I endeavoured in this way, per analogiam, at once to solve the question whether those band-like scolices of the fishes had probably been first in another animal, and might have been produced from scolices which had already been exposed to a migration into an unsuitable intestine. I say expressly, only " might have been produced," and not "must have been produced," as I only offered a sulstitute for an experiment, but must leave the direct proof to experimenters living on the seacoast. 
excusable, and even the following one must be mildly criticised. What there is good and tenable in it will be seen in the future.

When Creplin fond Bothriocephali-which, as is well known, are extremely rare in all terrestrial mammalia-in the cat at Greifswald, the answer to the question, how the cat obtained them, is easily given. This cat certainly got them in the same way as the marine birds of prey, by devouring sea-fishes found upon the shore, or the intestines of fishes, which, especially in sea-port towns, are often left in large quantities by the fishermen, in places where they gut the fish in preparing them for salting or smoking, and which, even in the kitchens of private louses or hotels in those districts which abound in fish, are frequently thrown to the expectant cats. A similar process camot be proved with regard to the Bothriocephalus latus hominis; for from the intestinal canal of what fish could man derive the Bothiocephutus, as he eats nothing of this kind? Perliaps the geographical distribution may give us a little clue. I will not discuss the question, whether I have a right to think that the Bothriocephali followed the great expeditions of the migration of peoples from the east, and whether they were introduced by the Mongols and Tartars into Russia and Poland, and thence spread into East Prussia, Finland, Sweden, and Norway; and by the Arabs and Moors into Africa (Abyssinia and Algeria) and Spain, and thence into the South of France aud Switzerland; but also by the great, and, as it were, local migrations into large commercial towns and emporia (Hamburgh, Rome, Naples). But, nevertheless, the present geographical conditions of all these places allow them to be looked at in a common point of view. They all lie in low situations, on large marshy districts, on the shores of rivers and lakes, or of the sea, and especially in places exposed to inundation. Could the scolex live in a low aquatic or marsh animal, as, for instance, in suails of the smallest kind? and could men swallow the latter in any way whilst eating raw salad, raw cucumbers or melons, raw fruit which has lain upon the ground, or raw roots, such as turnips, onions, \&c., without either peeling, or, as is frequently done by country people, after peeling them with the teeth?

Carl Vogt has stated that we infect ourselves with Bothriocephalus by using sewage water, in which the ova from the proglottides of this worm which have passed off with the human freces exist, as a inanure for salad. Here the ova remain; we 
eat them with the salad, and thus introduce the germ of the Bothriocephalus into our bodies. We certainly, as we have already stated, andopt this mode of infection for the crstic worms which occur in the lumman boriy, as, for instance, for Cysticercus cellulose and tenuicollis, and perhaps for the Echinococci (to which, howerer, Vogt does not ascribe this course), but certain]! not for mature Cestoidea. For even with the Bothriocephali we must assume a migration of the embryos into other animals, and not a development of all the stages in the same intestinal canal. I willingly admit, howerer, that so long as the six embryonal hooklets are not found with ease and certainty in Bothriocephalus latus-and this I have not succeeded in doing, although I liave spent hours in the examination of both fresh and spirit specimenswe have no incontrovertible proof that the embryos of Bothriocephalus must perform an active migration through the tissues of their host. But even if there were no six hooklets attached to the young of this cestode worm, the above-indicated passire migration of the embryos into the intestine of another animal, and their conversion in this intestine into an asexual band-like scolex, seems to me at present much more probable than the development of all the grades in the same intestine, on account of the dissimilarity which exists between the embryos and their parents. For these reasons I must, for my own part, admit that Vogt's hypothesis is still equally untenable, with all the others which have been set up regarding the production of Bothriocephalus.

Physiology.-According to Eschricht, the vital manifestations of Bothriocephalus, and its reactions with chemical and mechanical irritants, are more sluggish than those of Tania solium. I have never, myself, seen a perfectly fresh Bothriocephalus. The adhesion is always effected by the two sucking pits, although Seeger-Wundt also states that this takes place by means of a small umbiliciform depression (Saugflache) of the apex of the head, which is certainly possible if a frontal sucker could actualiy be detected in this little pit. The small number and less perfect development of these sucking organs, as compared with those of the Tania, at once explains why Bothriocephalus latus is expelled with such remarkable ease.

Eschricht and others have already proved the power of imbibing fluids possessed by the bodies of the Bothiriocephali and all Cestoidea. Transudation takes place distinctly by contact with 
water, and at the same time small, pellucid, oleaginons drops (sareode) issue from the body. Whilst the Nematoda and Echinorhyucli swell up considerably, even to bursting, by imbibition, the stronger transudation in the Cestoidea compensates for this imbibition; and, on the whole, only a slight swelling is produced. This explains the circurs stance, that in violent watery diarrhœas the Nematoda, deprived of their power of adhesion, excessively swelled, pass away much more readily than the Cestoidea, whieh usually, at the utmost, are rendered sickly by the contact with water, and throw off more of their last segments, which are more exposed to swelling in comparison with the first joints of the colony, but long resist the most violent diarrhœas (not excluding even cholera). It is a general observation, that in the Bothriocephali whole series of segments pass off spontaneously, but never single segments, as in the Tanie. Reliable data as to the duration of the life of a single individual are wanting. The statements of authors as to Bothriocephali of from fifty to sixty feet long are incorrect. Where the coil of worms expelled is carefully examined we shall find several specimens, even in smaller ones of from ten to twenty feet in length. At least, this was the case with a coil of worms of twenty feet long, given to me as a single worm, but from which I could unfold a worm of fifteen and another of five fect. Madame Heller and others have not very rarely seen several specimens of Bothriocephali together.

Prognosis. - The removal of Bothriocephalus latus is effected more easily than in any other human Cestoidea.

Therapeutics.-For the present, as is evident for the reasons just given, there is no means of prevention (prophylaxis). But we may recommend in our neighbourhoods, that all passed or expelled fragments of this worm should be burnt or preserved in spirits, so as to destroy their embryos.

Direct Therapeutics.--See the methods of tratment for Trenice. In this case, the ordinary treatment with Filix mas is sufficient, and certainly that with extract of pomegranate root.

Literature.-Besides the bibliography on Cestoidea to be given at the close of the book, consult especially the work of Eschricht, and that of Van Beneden, "Sur le développement des vers Cestoides." 


\section{Secoud Order-Trenice.}

Caput subglobosum aut tetrayonum; acetabulis-osculis suctoriis 4, rarissime 6 , muscularibus, orbicularibus, symmetrice oppositis, valde contractilibus; rostello imperforato, retractili, in scolicilus quiesccutibus inverso, in activis s. Tceniis maturis propulso, hamulorum simplici, duplici, aut multiplici corona armato; corpore plerumque albo, plano, depresso, bilaterale aut triquetro, articulato (strobila); articulis maturis androgynis, aut non sexualibus (?), sponte et alio post alium deliscentilns, Trematode cuidan similibus (Proglottides); systemate vasculoso perclaro; poris genitalibus lateralibus, plerumque alternantibus, masculo najore et anteriore, femineo minore et posteriore; genitalibus perfectis. Scolices quiescentes et immaturi formam cysti-, platy-ant a-cercan ineuntes. Scolices activi cum strobila longitudine et latitudine valde variantes. Embryones 6 hamunculis armati, parvuli, pervivaces; ovula in illis qui formam cysticercam ineunt, minima, pileatu, flavescentia, in ceteris majora, leviora et clariora.

I. Tania which occur in man in the mature state.

1. Tenia solium, and its scolex-nurse=Cysticercus cellulose.

Tab. III, figs. 1-10, and Tab. IV, hooks iii.

T'senia matura $=$ Scolex activus cum strobila : longit. $4-5$ metres $=6-8$ ulnarum, latit. ad 13 millim. Caput $=$ scolex sensu strictiore, breve, antrorsum planum, 0.56-0.75-1.0 mill. lat., acetabulis validis, prominentibus $0 \cdot 192-231^{\prime \prime \prime}=0 \cdot 1.34-0.521$ mill. long., et $0.182-224^{\prime \prime \prime}=0.410-0.505$ mill. lat. ; rostello parvulo 0.4 mill. ad latera nigrescente; hamulorum 22, 24, 28, 30, plerumque 26 , duplice ordine, longit. $0 \cdot 167$ quoud majores, $0 \cdot 11$ mill., quoad minores hamulos (secund. Leuckart), 0.18 et 0.12 secund. meas mensuras, unque th stylo hamulorum ex longit. fere similibus, fornâ hamulorum onnino vastá; loculis hamulorum perclaris, nigrescentibus; collo perparvo, fere nullo; corpore antrorsum maxime attenuato, deorsum ad 10-14 mill. lato, articulato, poris genitalibus alternantibus, interdum irregulariter; utero ramis 6 10-13, irregulariter alternantibus, denuo ramificatis instructo; 
corporibus calcareis in capite rarioribus $\left(0 \cdot 004^{\prime \prime \prime}=0.009\right.$ mill. lony. et lat.), in corpore crebrioribus et majoribus $\left(0.005^{\prime \prime \prime}=0.012\right.$ mill.) Proglottides ad 16 mill. longee et ad 6 late, ad inferiorem partem crassiores, margine magis toroso et angulis mayis prominentibus, quam ad superiorem partem, ut in aliis Treniis, ovulis $0.016^{\prime \prime}=$ 0.036 mill. long., 0.016" $-19^{\prime \prime \prime}=0.036$ mill. lat.; testấ ovulormn crassiore (0.0063 mill.). Embryonibus 6 hamulis ornatis, 0.0280.032 mill. long. et lat., miyratione indigentibus.

Habitat.- Solitarie ant sodaliter (ad 40 usque) in tubo intestinali hominis, inque teris diversissimis; vix in Cane domestico.

Scolex quiescens $=$ Cysticercus cellulosa, vesicâ candali hand magnâ (ubi phurimum 15 mill. in diametro) transverse ellipticâ; corpore inverso, transverse rugato, 8-10 mill. longo. In tubum intestinalem translatas intra 3 menses maturescit. Habitate in teia cellulosâ tolius corporis et nonnullis corporis cavitatibus clausis (oculis cerebro, sc.) imprimis in homine, Sue scrofi domestica, rarius ferâ, Simiâ, Cervo, Capreolo, Cane domestico (Arachnoid. et muscul.); valde dubiosus in peritoneo Canis domestici et Muris Ratti. Per injuriam a nomullis Cœnurus cerebralis hominis nominatus.

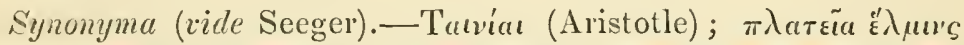
(Hippocrates); Lumbricus latus (Plinỵ); Treniø solium (Linné, and most authors); T. cucurlitina (Pallas, Bloch, Goeze, Batsch, Schrank); T. vulgaris (Werner); T. dentata (Gmelin, Nicolai); T. osculis maryinalibus solitariis (Linné, Bradley); T. armata humana (Brera); T. lata (?) (Reinlein); T. fenestrata (Delle Chiaje); Halysis solium (Zeder); Pentastoma coarctata (Virey); T. sitymatibus lateralibus (Bonnet); T. secunda (Plater); Vermis cucurbitinus (Plater); T. solitaria (Leske); T. articulos demittens (Dionis); Kürbiswurm ; langgliedriger, Kürbisförmiger (Goeze, Batsch, Jördens); gezähnetter (Batsch); bewaffneter Bandwurm (Brera); Kettenwurm (Bremser); 'T. à longs anneaux (Bonnet, Cuvier); T. sans épines (Andry); T. de la seconde espèce (Andrý); Le solitaire, Ver solitaire, 'T. bandelette, armé, à épines; Catena de cucurbitini (Vallisnieri); Vermi cucurbitini (Cocchi); Chabb al Kar' (pumplin-graiu) of the Arabs. ${ }^{1}$

' Ibu 'Adürt gives the following narrative in the 'Al-Bagan al migrib,' ed. Dozy i, p. 295: "Then God tried him with a disagreeable disorder, which is called Chab) al-Kar' (pumpkin-grain), and which consists in a worm (fixing itself) at the issue of his anus, which gnawed the intestine and the neighbouring parts. Then large rams' tails 
The folluwing names are given to it in eommon with Bothriocephalus latus and Trenia melliocanellata: le Ver Plat; Tapeworm ; Jointerl worm; Bändelorm ; Brinicke-mask; Lingditg (Tumale, in Africa); Kosso (Abysinia).

The worm presents fire known steps of development, which we have not exactly separated in the special description, but will mention here: 1, the sexual animal = moylottis ; 2, the grandnurse $=$ six-hooked embryo; 3 , the resting scolex $=$ Cysticercus cellulose in the parenchyma, areolar tissue, and cavities of the body; 4, the active scolex = nurse, that is, the Cysticercus celhulose, which will become a Tania solium in the intestine; and 5, the strobila, the series of segments of Trenia salium produced by gemmation from $\mathrm{w}=$ Trenia solium.

\section{A. Tenia matura.}

That the name of Trenia solium has been ineorrectly applied to this worm, which so rery frequently occurs in society, we have long been convinced. I have very frequently seen expelled $2-3$ from one person ; my colleague, Dr. Pfaff, 7 ; Madame Heller, 30 ; and Dr. Kleefeld, of Göllitz, once counted 40 worms expelled from one patient; and I have found 10 in a criminal (vide infra, where the reasons for the companionship of these worms will be found).

The Strobila-Head: Although this varies somewhat in size, it is rarely larger than the head of a common piu. It bears a tolerably abundant, dingy, blackish-brown pigment, which is deposited in pirticular abundance around the base of the short rostellum, and in the saes round the stalks of the hooks; after this, it is in the greatest quantity on and around the sucking discs, decreases in density and intensity of eolour posteriorly, and terminates in an undulated, pretty clear line between the head and neck. I saw this pigment in great abundanee, and very black, in two Treniœ expelled by M. Rose, in Genadedal, at the Cape of Good Hope, and which lie sent to me. It pene-

were brought, in order that he might insert them into him, so that the worm (or worms) might gnaw these instead of him, and he might thus olstain a little rest. When these were again drawn out, they were all gnawerl to pieces by the worm, and new ones were then applied to the anus. The worms, however, did not cease to gnaw until his genitals fell off, and he in consequence died." The case undoubtedly refers to a cancer of the, rectum in a patient, who at the same time suffered from tape-rorm, and is interesting even on account of this complication. 
trates gradually into the interior of the whole $22,24,26$, or 28 hook-sacs of our Tenia, between these and the hooks, and mav perlaps, when collected in very great abundance, elevate the looks and finally push them out altogether. I cannot state whether this, as is usually said, is a mere indication of age, or whether it may not also take place in consequence of a hyper. genesis of the pigment itself, without being connected with age. Moreover, we must not forget that a great number of the cases in which the falling out of the hooks by age is mentioned, are to be attributed to the fresh heads having remained too long in water or in the evacuations, or to decompositions when the dissections have been made after a considerable interval. Placing them in too-concentrated spirit, in time canses the hooks to leave their sacs. Virchow states that the pigment is molecnlar, granular; sometimes, on the front of the head, crystalline, and like melanine; and that it is sometimes also imbedded in vesicles. I have also sometimes thought that I have found such crystals, both in mature Tanice and in Cysticercus cellulosce, even that of the pig.

The hook-sacs, which, as well as the looks, are placed in a double circular series, may be best compared, as to form, with the beaker-glasses of the chemists. Even when the hooks have fallen out, they are very distinctly visible, from their black coloration by the pigment. Their length corresponds pretty exactly with that of the stems of the hooks in both series. 'Their breadth for the first series is, in the miclde, $0.021-28^{\prime \prime \prime}=$ $0.047-0.063$ millim.; for the second series, $0.017-21^{\prime \prime \prime}=$ $0.039-0.047$ millim. For the base of the first series, 0.010 $0.017^{\prime \prime \prime}=0.023-0.039$ millim.; and for that of the second, $0.010^{\prime \prime}=0.023$ millim.

The upper orifices, through which the stems of the hooks issue, measure, in the first series, about $0.010-0.017^{\prime \prime \prime}=0.023-$ 0.029 millim. in length; and $0.007-0 \cdot 010^{\prime \prime \prime}=0.019-0.023$ millim. in brearlth. 'lhose of the second series do not appear to differ greatly from this, but are more difficult to measure, fiom their greater softness.

In number and position the hooks correspond with the sacs just mentioned. As in all Tanice, the points of all the hooks fall in the same circle; their spines, which appear to act in the manner of hypomochlia, also fall nearly in a common circle, or, at the utmost, in two circles lying rery close together' the roots 
of all the stcms lie in two circles at a considerable distance from each other. The form will be best seen from the figures. (Pl. IV.) The most essential critcrion of this species lies in the stem, especially in the root of the stem of the hooks of the second series, which presents on its posterior surface a small hunate notch, and also in the tuberculiform curvature on the same side of the stems of the first series. The size of the hooks will be found in the table of hooks.

From the centre of the liook a small hood-or cap-like rostellum, round the base of which the sac stands, often projects. It is perfectly clear, destitute of pigment at its apex, and has no calcarcous corpuscles.

The sucking discs (ventousen) are nearly circular, frequently somewhat oval, and surrounded by a circular collateral branch of the longitudinal canals, by which a sort of large vascular net is formed. By maceration the sucking dises may be procured, isolated in the form of rounal balls or discs, in which no perforattion is perceptible. By the iuversion of these discs in the form of a cup, or in the manner of the finger of a grlore, towards the middle line of the animal, they are converted into effective suckers.

Close behind the sucking discs, and near the head, the vessets collect into four main branches, which are united quite at the front of the head by a common trausverse branch, as thick as, or thicker than themsclves. Oscar Schmidt has very recently expressed the opinion that anastomoses are effected between the ressels of the two sides, in the fully developed segments (proglottides), by means of transverse branches.

In the vessels of various Cestoidea, Virchow, Wagener, and others have seen with the microscope a sort of ciliary epithelium projecting in to the vesscls, and moving in the fluid. It appears then, as I have convinced myself, as if we saw a short luminous flash pass across the field of vision. To recognise this, it is best to work alternately with direct and transmitted light. In many Trenire, but especially in T. solium, I have thought, when employing the highest magnifying powers, that $I$ saw, in the interior of the oscillating contents of the vessels, very small, dark, molecular corpuscles, the nature of which I do not venture to explain. Might not these be pigment molecules, which are deposited from the vessels in the head? 
The calcareous corpuscles ${ }^{1}$ reach about to the middle of the sncking discs; they are few on the head, nsually very small, and appear as if composed of two or three concentric layers. To obtain a clear view of them the focus must be altered in various ways. As a general rule, it may be admitted that the head of cestode worms in the second stage contains more corpuscles, and these of larger size, than that of the mature Tenia. In examining, on the head of a Tenia, a space as large as the field of my Plössl's microscope (eye-piece 1 ; object-glasses $1+2+3$ ), I counted 60,70 , to 110 calcareous corpuscles in this space.

The sleuder neck, of about $6^{\prime \prime \prime}$ in length, exhibit no traces of transverse striation or segmentation. The calcareous corpuscles are somewhat more abundant, and also in general larger than iu the liead.

Behind the neck commences the true, jointerl borly of the Trenia, in which I counted 8.25 segments in one case, and in which the specimen was ten feet two inches in length. The proportionate size of the segments, which gradually increase posteriorly, will be best seen from the following statements: First, a space of $4^{\prime \prime \prime}$ contained 50 transverse divisions, and afterwards the same surface showed $32,27,22,14,11,10,9,8,7,6$, $5,2 \frac{1}{3}, 2,1 \frac{2}{3}, 1, \frac{4}{5}, \frac{5}{7}, \frac{2}{3}, \frac{1}{2}$ segments. In length the segments increased gradually from $\frac{1^{\prime \prime \prime}}{12}$ to $\tau^{\prime \prime \prime}$. In this species, as in all Cestoidea, contact with water causes the emission of Dujardin's sarcode in oleaginous drops.

Sexual organs.-From the 280th segment onwards, there is seen, in the median line of the Cestoidea, a simple browuishyellow canal, with short, lateral ofishoots, towards which two transverse, slightly coloured lines (seminal cord and vaginil) run from the sides. At the $317 \mathrm{tl}_{1}$ segment commence the first iudications of the alternating pori genitales, in the form of prominences; at the 350th the pores themselves become distinct. Between the 280th and 400th segments, an accumulation of small, yellowish, loose aggregations of corpuscles lying in the pareuchyma is seen gradually becoming more distinct; from the 420 th segment ouwards, the upper end of the median canal (uterus) becomes

1 Von Siebold certainly lays too much stress upon these in the detcrmination of species, which is mueh the same as if we were to impute to carbonate of lime the property of aequiring as many forms of amorphous, merystallinc deposition, as there are species of animals and their respective Tonice. 
enlarged and clubbed, and the first commencement of the socalled ova collect in the lateral offshoots, which at first appear to stand more elusely in the upper than in the lower half of the segment. From the 500th segment, the lateral shoots exhibit a teridency to give off smaller shoots or excrescences towards the sides, but these always appear to be larger and more numerous in the upper half of the segment, and never reach directly to the main stem. From the 600th segment is seen one-shelled, clear ova, which move readily in the off'shoots of the uterus after the preparation has been treated with acetic acid. From the 625th we find two-shelled ova, which coustantly become thicker and darker coloured, until in the $650-700$ th segments they nearly resemble the mature ova, although still mixed with an abundance of inmature ova, and then exhibit the little embryo with its six hooklets.

The structure of the generative organs is as follows: Male organs.-The penis is siclile-shaped, light rellow, smooth, and perforated, so that the onter slin of the penis is seen to turn inwards at its apex; it is abont $0.122^{\prime \prime \prime}=0.276$ millim. in lengih, $0.035^{\prime \prime \prime}=0.0 \% 1$ millim. in biealth behind and $0.017^{\prime \prime \prime}=0.039$ millim. in front. When retracted, it is received by a peculiar bell-shaped organ (a sort of prepuce), which is $0.175^{\prime \prime \prime}=0.395$ millim. in length, and from the hinder end of which springs : strong, hlackish-brown seminal cord, which takes a tortuous course, turning at a right angle towards the uterus, and rumning nearly to this, in which it forms convolutions of $0.014^{\prime \prime \prime}=0.031 \mathrm{millim}$. in breadth. I lave not yet been able to obtain a testis and spermatozoa, such as Wundt states he has seen and figured.

Female organs. - The varina lies on the side of the sac of the penis, which is turned towards the hinder end of the worm, and opens into this near the penis with a funnel-shaped aperture, $0.028^{\prime \prime \prime}=0.063$ millim. in breadth. At first it runs parallel to the seminal cord, but quits it about the middle of its course, and then bends in sharp curves towards the main stem of the uterus, into which it opens with a small swelling. The vagina appears to be an inward prolongation of the chitinous epiclermis. Its lumen measures $0.007^{\prime \prime \prime}=0.015$ millim., and its diameter is therefore only about half that of the individual ora. This diameter can hardly be so much increased by the abbreviation of the sheath, as to render it equal to that of the ora, so that we might suppose that the eggs could pass out through this ragina from an 
'I ub 1


Higs

"rig
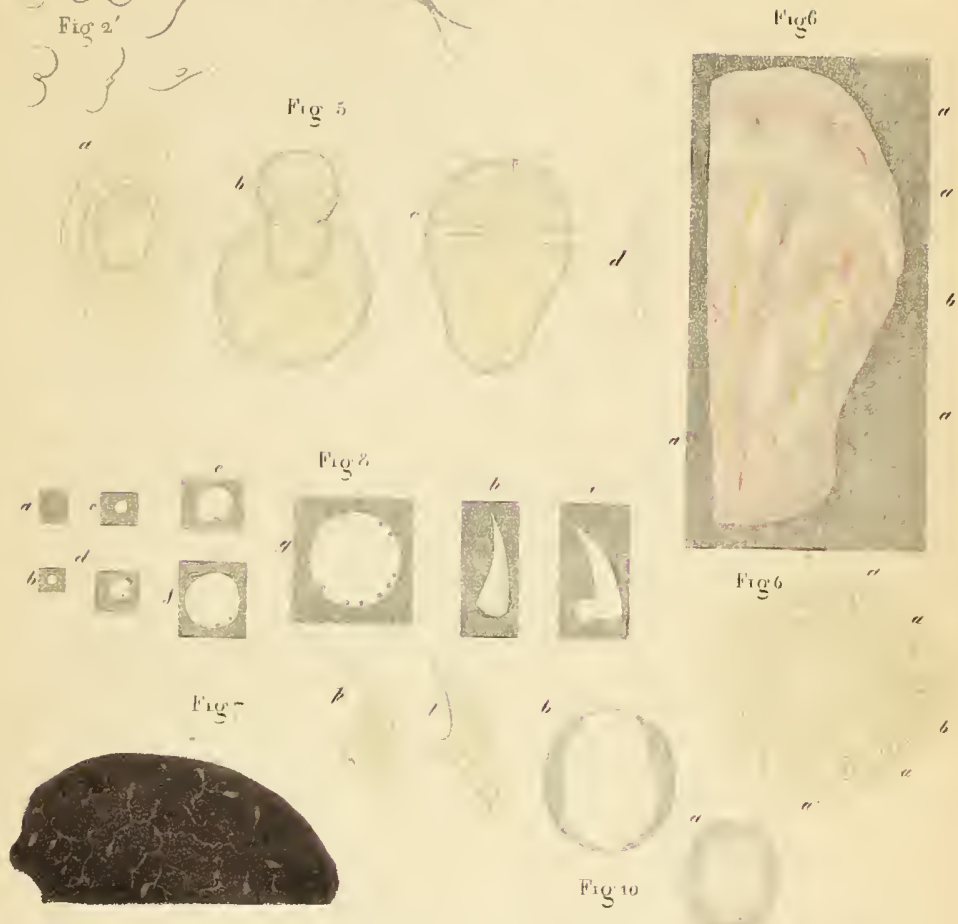

Fig

Figa
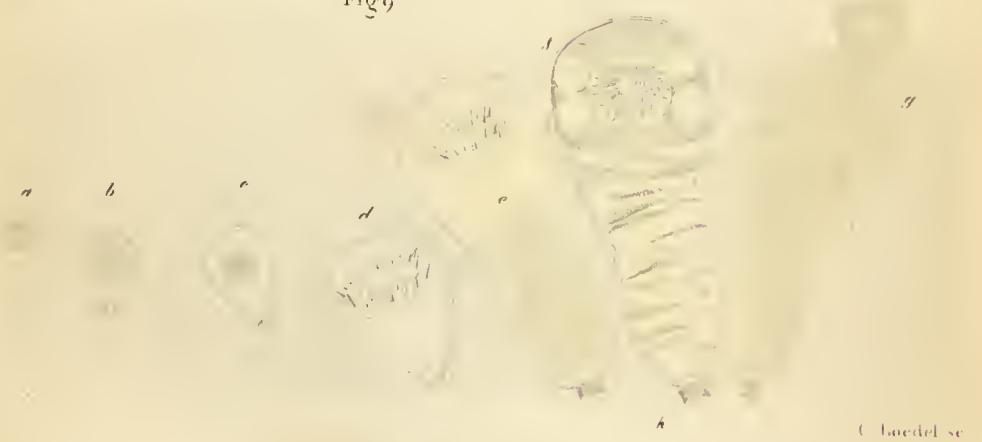

uninjured proglottis. At its junction with the uterus, also, the vagina forms a small funnel-shaped swelling.

The uterus forms a tortuous median stem, into which open numerous dendritic lateral branches placed opposite to each other, and alternating irregularly. Their number is usually uneven, $9,11,13,15$, rarely as many as 20.

As ovaries, including the organs for the formation of the germ, vitellus, and egg-shells, we may perhaps indicate some small cæca, which are only perceptible in semi-mature segments, and which appear to have an ontlet towards the median stem.

Upon the formation of the embryos in the egg, I have no direct observations, and I must refer to what Van Beneden has stated with regard to other Cestoidea.

The structure of the individual joints, when cut throvigh, is as follows, passing from the exterior to the middle.

1. Epidermis without calcareous corpuscles, consisting of a chitinous mass.

2. Longitudinal muscular fibres, with an abundance of calcareous corpuscles.

3. Transverse muscular fibres, with a few calcareous corpuscles.

4. Uterus and its branches, with ova.

I am acquainted with no secretory organs in the skin, although Van Beneden thinks there is a secretion of a "mucus destiné à labrifier la surface du corps." In examining the skin, care must be taken to avoid being deceived by the sarcode, which issues on the contact of water.

в. Scolex of Treniu solium = Cysticercus cellulose, its seat, the mode of its transference, and production, and its nature.

This scolex is the Cysticercus cellulose of author's. This is evident from the similarity of its head with that of Trenia solium, and the consideration of the general as well as the particular circumstances under which $T$. solium occurs, and from the possibility, by cxperiments in feeding, of converting Cysticercus cellulose into Trenia solium, and the eggs of the latter into Cyst. cellulose (vide infra).

Ordinary halitation of $C$. cellulose.-The ordinary habitation of this vesicular worm is, as is well known, the flesh of the pig, and we find that Trenia solium is almost entirely unknown where the use of this flesh is avoided, as, for example, amongst those 
Jews and Mohammedans, who live strictly according to their religious precepts, and who are not deprived of the opportunity of procuring their meat from "clean" butchers' shops in which pork is never sold, and also amongst the $\Lambda$ by'ssinian Carthusians referred to by Reinlein, ${ }^{1}$ who keep a strict fast and only feed on fish, or where, in consequence of the breeding of pigs being given up, these animals are almost entirely absent, as Eschricht tell us is the case in Iceland, where, in consequence, Tania solium is very rare. But, on the other hand, we find this Tenia rery abundant wherever the breeding of pigs flourishes, as in Poland, Hungary, England, Pomerania, and Thuringia, ${ }^{2}$ and especially amongst those engaged in trades which bring them in contact with raw pork and therefore with raw Cysticerci (as butchers, cooks, eatinghouse keepers, \&c), or in people who obtain portions of ready cooked or smoked sansages and hams from the butchers' shops. The most direct mode in which the transference may be effected is, as experience has shown, the habit of eating raw pork (Kleefeld's patient; Professor Merbach's observations; Thuringia, especially Nordhausen, Russia, Abyssinia). Hence also, perhaps, arises the more frequent occurrence of Tania solium in temperate zones, and especially in Central Europe.

The importance of the subject may excuse the prolixity of the following remarks: The reason why we find Tania solium so plentifully in butchers and their families is, that the butchers contamiuate their own hands in sausage-making and also the blades of their knives in cutting $u p$ and selling meat. When they now wipe their mouths with the hands thus contaminated, or place the knife bedaubed with Cysticerci in their mouths, or lastly trausfer these Cysticerci from the knife to the bread or sausages which they cut up for themselves, their families, or servants, the insignificant and scarcely perceptible Cysticerci are introdnced into the mouth and swallowed. Cooks and even housewives who cook and who have much to do with raw pork, infect themselves, partly by means of their hands or utensils, and partly by tasting the mixed masses of meat prepared from raw pork and other uncooked meats for the making of puldings before

1 Reinlein, 'Bemerkungen über des Ursprungs des breiten Bandwurms,' Wien, 1812 ; and Rüppel, 'Reisen in Abrssinien.'

2 We unfortunately have no reports as to the occurrence of $T$. solium on the Sandwich Islands and similar places, where the breeding of pigs has prospered since the time of Cook. 
they are put into the frying pan, or in the preparation of homemade sausages before drying.

But we also see the possibility of the Cysticerci being introduced into private honses with the articles of animal food procured from the butchers' shops to be eaten without preparation, such as raw hams, and blood and liver sausages, especially when these articles of food are purchased by retail in small portions, when the Cysticerci have been transferred to them by the knife used in cutting them up. ${ }^{1}$ Thus, for example, my wife found Cyslicerci in the water used in washing sansages, which must have been adhering to the hands of the butcher when filling the sansages, and thus have been transferred to the external surface of the gut. 'Lastly, the direct proof of these assertions has been furnished by myself, in making the following experiments upon a murderer condemned to death. 72, 60, 36, 24, and 12 hours before

1 Several mistakes have lately been male with regard to the manner in which T. solium is communicated, and these bave been referred to me. Thus, according to Thompson ('Uber die Krankheiten und Krankheitsverhalmisse auf Island,' Schleswig, 1855, p. 72), I have stated that "Tenia solium is very general in certain (listricts where the common people eat raw bacon upon bread." As the Cystic. cellulosa never occurs in the fat, but only in the flesh, I have spoken of the use of raw meat. Moreover, further observations are constantly being made known, that the use of raw meat generally disposes to Tenice. In seven anæmic children brought up upon raw flesh, Scharlan, of Stettin, found tape-worms, and these were said to have had no raw pork. But whether these children had not oncc had raw pork, or whether raw beef does not also frequently contain the germ of the common tape-worm, is a matter for further investigation. To returi to Thompson, I do not blame him greatly for his statement, as I consider it as an error of a verbal nature. But we have not to do with a verbal error, but with ignorance of what I have said, and the presumption of criticising a work without taking the trouble of realing the original, as in the note of Dr. Bchrend, the editor of Ilenke's 'Zeitschrift für Staatsarzneikunde,' which is appended to page $7 \mathbf{l}$ of Riecke's article, in which the latter calls attention to the importance of my investigations to police-officcrs. "But the Jews, probably becanse Moses was alrearly acquainted with Kïichenmeistcr's metamorphosis of the tape-worms, in conseqnence of his prohibition, did not eat pork at all, for the Asiatic Jews still live strictly according to their religious laws and precepts. If this link in the chain is wanting, the explanation falls to the ground." If M. Behrend had read the original, he would have seen that I regard the occurrence of Cystic. cellulose, both in the roe and in other rnminants, as esprecially possible in the east. The link in the chain thercfore is not wanting. M. Bebrend continues-" Shonld not the kind anxiliarics of 1813-1815 rather be taken into account by IIerr Küchenmeister?" These auxiliaries have nothing at all to do with the matter, except that perhaps during their sojourn in Germany, a greater number of segments of $T$. solium may have passed off from human subjects on German soil, morc pigs may have become measly, and from these again more men may have been infected. 
execution 12, 18, 15, 12, and 18 specimens of Cysticercus cellulose were administered to the criminal partly in rice or vermicelli soup cooled to a blood heat, and partly in blood-puddings from which the fat was removed and replaced by Cysticerci. The Cysticerci had already lain serenty-two hours in a cellar before I discovered them by ehance, as I have stated further in 'Wittelshöfer's neuer medic. Wochenschrift,' No. 1, 185̄, and before I could administer them. The last administered had consequently lain about 130 hours out of the living organism. I hardly believe that those Cysticerci which had lain more than 80 hours were still eapable of derelopment, any more than I can beliere this to be the case with the Cysticerci contained in smoked sausages and hams. ${ }^{1}$

1 Here we hare also a couple of similar assertions, which Von Siebold has put forth to the world without taking the tronble of submitting thein to an experimental proof. Just as, without experiment, he asserts that the sheep infect themselves with C'enuri by devouring the dried eggs of tape-worms ('Uber die Band- und Blasenwürmer, p. 107), "that these eggs possess a great tenacity of life, and can long resist injurious external influences (cold, heat, dryness, \&c.) ;" he also maintains (p. 111) that "boiled or roasted measly pork can never give origin to a Tania solium in the intestinal canal of man, as by the degree of heat necessary in the cooking of such meat, the Cysticerci in it will be completely destroyed; but the case is different with smoked sausayes, for which many bulchers use measly meat. How easily, with the present artificial and rapid method of smoking, may a sausaye stuffed with measly meat be consumed so soon and so fresh, that one or another of the scolices of the conceated Cysticerci may retain its ritality, and awaken from its apparent death, in the intestine of man, when the development of the tape-worm would not fail." The following kind of dried meats are smoked : 1. Varions sorts of bloodsausages.-As these are boiled before smoking, they cannot come under consideration. Here also belongs the smoked-tongue sausage, so called par excellence. 2. The Cervelas sausage.-This is prepared with the strongest spices-pepner, ginger, salt and saltpetre, and is also, like hams, often pickled before snoking. 3. Smoked sausage.-The last two kinds are certainly often made without pickling or boiling. 4. Hams.-If Von Siebold thinks that the artificial smoking with wood-vinegar is still employed in those districts from which we are principally supplied with smoked meats, he is very much mistakell. I have made exact inquiries on purpose, from butchers who are just returning from their journies, and who have themselves established large warehouses for smoked meats. According to their statements, the quick smoking is quite given up; and, in my opinion, it would be difficult to give the Westphalian hams their delicious flavour if they were to be smoked with wood-vinegar, instead of smoking them with juniper slicks, as is usually done in Westphalia. It is a remarkable thing to assert, that an animal which, during life, bears its nourishment about within a resicle (caudal vesicle), can continue its existence when deprived of this reservoir in a half smoked state, as in a half smoky torpidity (Rausch-Winterschlafe). Such an assertion would certainly only be put forward from that side which regards the caudal resicle as a morbid organ. Had Von Siebold experimented with such half-mummied Cysticerci, there might have been some reason, as the result of observations made, for putting forward assertions so improbable 
On dissection, forty-eight hours after execution, I found ten young Tania, of which indeed six were deprived of their hooks, but four distinctly showed the hooks of $T$. solium. The little Tania were $4-8$ millim. in length, had exserted their hooks and proboscis and attached themselves therewith to the intestine, and possessed a small band-like appendage, some $2-5$ millin. long, which was notched or inverted at the extremity, as it is seen in those individuals which are found, for example, in the intestine of a dog three days after the administration of the Cysticerci of the rabbit.

Subsequent experiments of the same kind will certainly give us the means of tracing the progress of this Tenia as it increases in age, according to the various times of administration of Cysticercus cellulose. In the meanwhile the preceding experiment is a sufficient proof of this conversion of the cystic worms into Tcenia in the interior of the human intestine, and also of the mode of infection.

I take this opportunity to mention that I have never yet been able to find Trenia solium from Cyst. cellulose in the intestine of the dog. Von Siebold only bred immature and generally stunted specimens. Many of the Trenia solium which authors supposed they have found in the intestine of the dog, must have been T. ex Cyst. tenuicolli. As in small torns without a common slaughter-house, the Cyst. cellulose is usually concealed by the butchers, I have had a difficulty in obtaining Cysticerci cellulose, three, four, or more days old and always cut open, and thus I have convinced myself, by various experiments, that the scolex of a Tenia only retains its power of development in its dead host as long as no putridity occurs, which happens within three or four days in summer. The six-hooked young resist longer.

\section{Other habitations of Cysticercus cellulosae, and other modes of infection with 'Trenia solinm, caused thereby.}

With the exception of the doubtful Cysticercus cellulosce of the peritoneum of dogs and rats, the Cysticercus occurs and contradictory to nature. It appears, however, from my experiments with the criminal, that the intestine presented no traces of those Cysticerci which had lain more than five days in the air with the caudal vesiclc uninjured. 
with certainty in the muscles of the dog, and in those of the roc, and it is also met with, thongh more rarely, in hears, rats, apes, and men. Dog-killers, therefore, may infect themselves with $T$. solium by means of measly dog's flcsh, and other men by eating the measly flesh of the animals mentioned; amongst which, especially with the oriental romadic people, cattle stand in the first rank; as from the close, mutual intercourse between the man and his herds, the latter miglit casily contaminate themselves with the ecrgs of Tania solium. For this reason we sce that the immunity of the Jews and Mohammedans is by no means absolute, and, on the contrary, that the occurrence of $T$. solium, even amongst them, is not impossible.

Theoretical proof of the identity of $\mathrm{T}$. solimm and Cysticercus cellulosæ.-The latter, like all cystic worms, forms a vesicle of the size of a pea or very small bean, with a little, white head in its interior, from which the true scolex may be crolred by pressure. This scolex bears a head with four, and sometimes six sucking dises, (the latter especially in the human brain), round which the vascular sistem runs, and afterwards collects into two longitudinal canals on each side. The short rostellum bears from twenty-two to twenty-eight lrooks placed in a double crown. Besides these, the head exhibits a sparing brownishyellow, or blackish-brown pigment, ${ }^{1}$ and under favorable circumstances, by pressure, fire sacs round the stems of the hooks. The neck is very short, poor in calcareous corpuscles, opaque, and colourless; the body, which follows, is wrinkled, richly set with calcareous corpuscles, and the head is inverted into it as long as the caudal resicle is alive and uninjured; after the death of the rorm the head becomes everted. The caudal vesicle consists of contractile tissue, which forms circular, parallel rings when contracted. It is homogeneous, destitute of ressels, and calcareous corpuscles, and consists of an organic substance, which belongs to the class of the so-called mixed protein substances,

1 Leuckart thinks, because he found the black pigment in Cyst. cellulose and Cyst. tenuicollis of the pig, but never in Cyst. cellulose of the human subject, that the piginent is not produced by the worm itself, but by the animal infested. That Cyst. cellulose hominis bears pigment, is proved by the observations of Virchow, Günsburg, Möller, and others. It will then probalyly come to what I formerly stated in opposition to Virchow, when he derived the pigment-crystals solely from the hæmatosine of man. I supposed, that this property of forming pigment-crystals and molecules belonged not only to liuman blood, but also at least to that of the pig. 
and is nearly allied to chitine, but dissolves, when boiled in caustic alkalies, rather more easily than the latter. The addition of iodine produces no reaction of cellulose, although this is not a rare constituent of the envelopes of the lower animals, as, for instance, of the Tunicata. The vesicle contains a fluid containing albumen, fat, and calcareous matter, upon the production and nature of which we have already spoken. I will also dwell no further upon the object of this vesicle, which is only the enlarged six-lrooked embryonal vesicle, and which at any rate fulfils the double office of a reservoir of nourishment, and a proliferous organ, as I have already spoken at leugth upon it in my book on the Cestoidea, and also in the general portion of this Manual. Our scolex never lives in the true fatty tissue, but only in the muscles, in the cellular tissue, the brain and its cavities, within and between the membranes of the eye, and in the orbits. In the serous cavities of the body, such as the brain and the orbits, it lives free; in the other parts of the body it is enclosed in cysts which originate from the host, and the walls of which present the microscopic composition of those parts of the body in the neighbourhood of which the cestode worm has its habitation.

The above-mentioned characteristic marks, which are presented by the everted head and the short neck, agree exactly with those of Tania solium, aud we should only have to repeat what we have said as to the head of $T$. solium, or in the general part upon the greater abundance of calcareous corpuscles in the eystic worms, and the gradual disappearance of these structures during Tæuial life. Only this one circumstance may be mentioned, that du'ing the scolex period the hook-sacs keep in the background, and only become more distinct, and, at the same time, more resistent, at; the period when the black pigment is deposited in a larger quantity on the head, and especially round and in the sacs. A figure of the most essential parts, such as is given in Pl. III, and a comparative measurement of the sucking dises and hooks, which will follow at the close of the section "Cestoidea," will render the matter more intelligible thin the most exact description. But to complete the proof of the identity of Cysticercus cellulose, we must not only succed, as above recorded, in converting Cyst. cellulose into Tania solium, but reversing the matter, we must also be able to breed Cysticercus cellulose by 
the administration of the egrgs of Trenia solium. And in this also we have succeeded.

Experimental proof of the conversion of the six-hooked embryos enclosed in the eygs of Tienia solium into Cysticercus cellulosæ.

After I had made experiments on the production of Cysticercus, in the year 1851, by the administration of the eggs of Trenia solium to rabbits and dogs, and expressed the opinion that the pig infects itself with Cysticercus cellulosa when it meets with the eggs and proglottides of Trenia solium upon the pastures, and after I had published in Günsburg's 'Zeitchr. für Klin. Mediz.' for 1853, my observations on the production of staggers in sheep, by administering to them the young of $T$. comums, Van Beneden at the close of the year 1853, set about administering $T$. solium to two pigs. He actually succeeded, in this way, in rendering one pig measly, and upon this he has reported to the Acadenies of Sciences in Paris and Brussels.

Amongst the experiments already mentioned as instituted in common by Professor Haubner and myself, by order of the Saxon ministry of the Interior, was also the experiment upon the production of Cystic. celluluse. Five pigs and one sheep were fed, by Professor Haubner, with segments of Tania solium, partly furnished by Professor Richter, of Dresden, and partly by me.

1. On the 30th of March and 5th of April a pig received a number of mature segments of Tenia solium which had been expelled the day before by medicines. The experiment gave no result, as appeared from dissection on the 15th of May.

2 . On the same days a second pig was fed with the same Tenia, and also on the 20th May with fragments of Trenia solium which had passed off spontaneously. It was killed on the 13th September, but in this case also there was no result.

3 . On the 7 th, 2-th, and 26 th of Jume, and the $2 d$ of July, three sucking-pigs were fed with segments of tape-worms, partly given off spontaneously and partly artificially expelled, and on the 13th July they were again fed with artificially expelled segments. One of these pigs was killed on the 26th of July, and exhibited young Cysticerci corresponding with the days of administration, of which the largest individuals formed vesicles 
of the size of a hemp-seed, with a central turbidity, $i$. e. the commencement of the head. The second pig was killed on the 9th August, when thousands of Cysticerci were found in all parts of the body; the largest individuals were as large as peas, and exhibited a distinct head, whilst the smallest were only of the size of a hemp-seed. The third pig, which was killed on the 23d of August, was uniformly set throughont all parts of the body with Cysticerci of various degrees of growth and development. The largest were almost perfectly developed; others resembled those last described. I undertook the examination of a weighed piece of the flesh, and found 133 Cysticerci cellulosa in $4 \frac{1}{2}$ drachms of it. If we calculate from this quantity the number of Cysticerci which would have existed in 1 stone or $\frac{1}{5}$ th cwt. of the pork, we obtain the great number of 88,000 individuals in this weight. A fourth pig, of the same litter, to which no Trenice had been administered, exlibited no traces of Cysticerci on dissection.

A fragment of a Tenia solium which had passed off spontaneously, was given, almost by mistake, to a sheep, but it did not sticceed in making the animal measly; nor have Professor Haubner and I been more successful in rendering dogs measly by the administration of Tenia solium, as was previously done in the year 1851 .

It is of no consequence to us at present why the first two pigs, as well as the dogs and the sheep mentioned, were not rendered measly. We do not yet know the circumstances exactly, which facilitate or hinder the production of cystic worms in general, still less in one particular case; nevertheless it is evident that the causes of this might lie either in the animal experimented on, (in its age, its feeding, or its personal immunity from cystic worms), or in the tape-worm administered, (whether its young were perfectly developed and healthy, or more or less weakened, or perhaps even killed, by the medicines). Especial interest attaches to the third series of experiments, which refers to these examined pigs of one litter, to which the same Tanice were administered and which all became measly. It is to this last circumstance in particular that Professor Haubner thinks, and I agree with him, that we must lay the most weight. 'Tlic occurrence of Cysticerci in all the animals fed with the same material is the main point, and is of the greatest value and interest to us. 
We think that we have a certain right to judge that the production of measles from the eggs of Trenia solium is now placed berond a doubt by the experiments of Tan Beneden and ourselves.

Leuckart, who lias also repeated and confirmed this experiment recognised in the mode in which Cysticercus cellulose is developed from the embryo of $T$. solium, exactly the same type as that above described as the type of the formation of the socalled Cysticerci in general. It is, however, wortly of note, in regard to Cyst. cellulose, that this worm acquires the vesicular form, and also becomes covered with a vascular net, rather early, at a time when no trace of the future head can be observed (fig. 1). The first foundation of the head commences in Cyst. cellulose, not before, but probably soon after the seventh week, at which time the embryo is about $2.5 \mathrm{millim}$. in diameter. The first trace of the head appears in the form of a lens-like thickening 0.07 millim., which shows itself as a white, turbid spot on the clear and transparent wall of the vesicular worm, and consists of

Fig. 1.

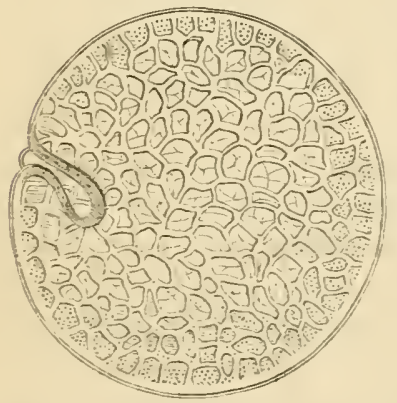
roundish and fusiform cells with a small (0.0017 millim.) oval nucleus and some calcareous corpuscles in their ricinity The head at the same time does not hang perpendicularly but in a diagonal direction from the wall of the resicle into the cavity; it is very slender, with thin walls, and in Cysticerci of $3.5 \mathrm{millim}$. is about $0.4 \mathrm{millim}$. broad and 1 millim. long.

In Leuckart's experiments all parts of the organism with the exception of the chambers of the eye were affected with Cysticerci, and amongst others the cavities of the skull, lungs, subcutaneous arcolar tissue, orbits, conjunctiva, optic muscles, \&c. With regard to Cyst. cellulose in the brain they were the smallest $\left(2 \frac{1}{2}-5\right.$ millim. in longitudinal diameters, in other places as mucls as 8 millim.), and liy in great numbers $(40-50)$ like the young Ccenuri free upon the surface of the brain and between the convolutions in the substance of the brain, in the rentricles, and between the lamella of the dura mater, forming projections from the surface of the brain and 
impressions in the lining of the skull. Affections of the brain rluring the immigration of the brood, and the growth of the Cysticerci, were not observed, or were perhaps overlooked; according to the keeper's statements the animals were remarkably stupid. Ir'. regular forms caused by excrescences and constrictions, belong only to the cyst and not to the worm. According to Lenckart, Cyst. cellulose could not be reared in sheep and rabbits from eggs of T. solium.

An experiment made by Dr. Ton Ammon and Professor Inambuer, in which incisions were made in the conjunctiva of the eye of one of the pigs, and after eggs of Tenia solium had been introduced into them, the eye was kept closed for some time with strips of sticking plaster, unfortunately led to no result. In my opinion, however, the embryos should liave been set free by crushing the eggs between two glass plates, and the free and hooked young introduced into the eye; but this experiment was not tried, as the funds granted to the agricultural section were exhausted, and the most interesting questions for the agriculturalist were settled. In this way we now survey the whole cycle of the development of Tenia solium and Cysticercus cellulose, and we at the same time see, by accurate microscopic examination, that the development of these Cysticerci, takes place in exactly the same manner as we have described in the general part of this work, for which reason we shall forbear from dwelling further upon it here. Unfortunately hitherto the six embryoual hooklets have entirely escaped us, and we do not know whether they are taken up by the surrounding exudation which is furnished by the host, and becomes converted into cellular tissue, and thus imbedded in the walls of the newly formed enveloping cyst, or whether they remain attached to the animal itself and to its caudal resicle. Nor do we know how this is with the Cysticerci, which occur in closed cavities (in the eye and brain), whether in these cases the hooklets fill to the bottom of the cavities which replace the eysts, or whether they remain adherent to the so-caller candal vesicle. Nay; we do not even know whether six-hooked embryos occur freely in water, and whether, which is very probable, they do not then easily lose their hooklets and become unfit for migration. Only this is certain, that the acts of immi. gration are accompanied by irritation and inflanmation of the orgaus selected for passage, and that we do not possess any active remedy for the destruction of the embryos at the moment of immigration. 'That the greatest cleanliness be observed in the 
preparation of fruits, herbs, and roots which are to be eaten raw, and that everyone who harbours a Tania solium should get it cxpclled as soon as possible, are the only preventive means that we know of. Should some experiments which I am now instituting lead to any result, I will give them to the readers of this work in an appendix. As we are writing a text-beok of the diagnosis and treatment of the parasites of the luman body, the occurrence of Cysticercus cellulose in man concerns us particularly, and although the Cysticercus cellulose belongs to the section of immature Cestoidea, in order to avoid separating what is intimately connected by too great a space, we shall add here what we have to say-

Upon the occurrence of the Scolex of Tænia solium = Cysticercus cellulosæ, in the human body.

The Cysticercus cellulose has hitherto been found in the most various parts of the most various muscles, especially in the muscles of the heart, in the cellular tissue, in the brain, and in the eye of man.

In all these regions of the body it acquires various forms and sizes, according to the space which is afforded for its derelopment; and in the ventricles of the brain and the eye especially its caudal vesicle attains even the size of a walnut, and the most remarkable forms. Ton Siebold, speaking of the production of these remarkable forms in the vesicle of the Cysticerci, says (p. 64) "the excess of nourishment will give rise to exuberant growths and degeneration of the body of the embryo;" and he then treats (p. 68, and in figs. 27, 28) very diffusely of this very simple process, which may be summed up in the following few rords so that every one nay understand it. It is not only the excess of nourishment that, in the first place, determines the size and form of the Cysticerci, but rather the softness, rielding nature, and looseness of the tissnes in which the Cysticercus occurs. Wherever a vacant space or a yielding spot occurs, the cystic worm, in its endeavours to increase in size, penetrates, and this may give it and its cyst a hernia-like appearance. With these forms, however, we have little or nothing to do; the nature of the worm remains the same.

According to the various positions occupied by the worm, the 
symptoms which it produces also vary. It is quite harmless in the subcutaneous cellular tissue, where it was observed by Uhde (who, in describing his results, has made some frightful reflections upon the generatio equivora), by A. von Graefe, in a patient also suffering from Cysticercus in the eye, by Romberg, and by Stich, who has long treated the patients in question in his hospital. In the muscles, perhaps with the sole exception of the muscles of the heart, it also causes little inconvenience or injury. When situated in the muscles of the heart, and especially in the papillary muscles, it may lead to softening of the muscles, and during the period of its retrogression, shrivelling, or calcification, to abbreviation of the papillar muscles, to defects in the valves, and to the formation of diverticula and aneurisms, with their consequences. Whether a rupture of the cyst, occurring during the period of retrogression, when this has proceeded to the greasy, fatty degeneration by setting free the greasy masses into the blood, may give rise to the formation of thrombus in the ressels, and to the consequences of this, so beautifully indicated by Virchow, we have no observations to show. 'There is no diagnosis for it in the deeper inuscles of the living man, not even when seated in the muscles of the heart.

Its influence when situated in the eye is of more importance. Since Sömmering discovered this parasite in the human eye, it lıas been found by Mackenzie, Baum, Esthlin, Höring, Sichel, A. von Graefe, and others. Since the discovery of the ocular speculum by Helmholtz, A. ron Gracfe has done the most service to this branch of oplithalmology; aud what follows is the description given by him, partly in the first volume of his 'Archiv' (p. 453, \&c.), and partly in friendly communications to me by letter.

When, as in the cases of Baum, Esthlin, Höring, and Sichel, the parasite is between the conjunctiva and the sclerotica, it is not very dangerous, sometimes exciting no injurious action at all upon the power of sight, and may easily be removed by operation. But even in this position it may become dangerous to the eye, inasmuch as it causes the absorption of the subjacent structures of the bulb, and, consequently, injures the whole structure of the eye and indircetly the visual power. The phenomena are as follows, according to the different positions inhabited by the worm-

a. When it is situated in the anterior chamber of the eye, in which it was first seen in the living subject by Sömmering and 
Schott, the symptoms were the frequent recurrence of ophthalmias, subconjunctival injection, coating of the hinder wall of the comeat, as if with a finc cxudative rapour, clsronic, but particularly local iritis, which was exacerluated periodically by the constant accompaniment of rather violent, symptomatic ciliary neurosis, and which made its appearance at the very commencement of the affection. By this the visual porrer is of course dimmed, at least at times. The diagnosis can only he furnished by the recognition of the worm, which assumes the most various forms. Sometimes the resicle lies quiet at the bottom, and sometimes it rises up and thus covers the pupil entirely, sometimes only partially when the worm has not yet become large and has perfect freedom of motion. A portion of the vesicle may, also, even pass through the pupil towards the posterior chamber of the eye, and thus close up the pupil. The Cestode worm may even appear to be amalgamated with the eye, but this is only an illusion, as this mion would be formed not by the worm but by its enreloping cyst, the tendency to the formation of which we find indicated, according to Graefe, in the exudative cloudiness on the linder wall of the cornea and on the iris, as well as in the adhesion of a circumscribed spot in the vesicle to the lower margin of the pupil by meaus of yellowish exudation, and in the cylinder described further on. In Graefe's case, a romul, milky, somewhat transparent vesicle, of the size of a pea, made its appearance in the anterior chamber of the eye; on its lower part sat a perfectly opaque, white knol, on which sereral lateral swellings (sucking discs) were detected even with the naked eye, but better with the lens. The morements of this body were of a peculiar constrictive character, procceding from the fundus of the resicle, and diffusing themselves in an undulatory manner over the lateral portions; they increased during rapid morements of the eye with simultaneous protrusion and retraction of the head, but were not augmented by increased irritation from light, as Graefe ascertained by the worm remaining quict when very strong rays of light were allowed to pass throngh the pupil, greatly dilated by atropine. Even when the axis of vision was perfectly fixed, the animal constantly moved. As to the growth of the vesicle, one of the patients stated, that she first observed it five months previously, and that it attained its full size in fourteen days. Graefe has attached a note of interrogation to this latter statement, but, as I believe, unjustly; for, in the first place, it follows from Graefe's statement that the woman had 
already sufiered for ten months fiom remittent ophthalmia of the right side, that at least five months must have elapsed since the immigration of the six-hooked embryo before the woman observed this vesicle; in that case five months are sufficient for perfect development, which was certainly completed when the woman first noticed the vesicle; and, lastly, it is certain that if the space be not too much limited the resicle thus far developed increases extremely rapidly in size, as Leuckart and I can affirm by reference to the rapid growth of Cystic. tenuicollis.

b. In the posterior chamber of the eye.-The consequences are always the same as in $a$. I had myself had the opportunity of seeing a case which was regarded as Cysticercus protruaing forwards through the pupil; but I conld not ascertain this positively either by the examination of the uninjured eyc or by that of the portion of the pseudo-formation removed by operation and sent to me. Unfortunately, nothing could be discovered of hooks or sucking dises, but on a large spot of the part removed the microscope certainly showed granular structures, which disappeareck with acetic acid, but was not altered by caustic potash, and which were analogous to the calcareous corpuscles of the Cestodea. I must leave it undecided whether this had anything to do with a Cysticercus. An undoubted case of the occurrence of Cysticercus cellulosce in this position is reported by Von Graefe ('Deutsche Klinik,'No. 45, 1856 ; 'Sitzungs-bericht der Ges. für wiss. Med.,' August 11th, 1856). 'The Cysticercus lay upon the linder wall of the eye, and was so distinctly perceived by the patient himself that he was able to draw the shadow which the animal produced upon his retina. In this case the rapid development of the animal at first was remarkable.

c. In the vitreous humour.-The detection of Cysticercus in the deeper parts of the eye in the living human subject has only been possible since the introduction of the ocular speculum of Helmholtz into surgical practice. It is necessary, however, to be careful in these inquiries, and to know how to avoid illusions. Dr. A, von Graefe was the first to recognise this parasite in the vitreous humour of the living human subject, and he has most kindly communicated what follows, at my request. " $\mathrm{A}$ membranous cylinder of about one millim, with transparent membranous walls, is observed in the retina, near the dingy, brownish optic nerve; it is directed forwards, so that it runs through the vitreous body nearly in the direction of the axis of vision. In 
this cylinder the Cysticercus lies. The posterior end of this cylinder reaches to the retina, but the fundus of the vesicle of the Cysticercus separates distinctly a little before it. Anteriorly the longish vesicle diminishes in calibre, and runs, somewhat constrieted in the middle, into the neck region in front. The head itself is situated about in the centre of the eye, and appears as a whitish swelling, the true relations of which are concealed by the enveloping eylinder, and from which various streaky, pseudomembramous rays run forwards and towards the lens." Still in front of the body just described, and on the hinder wall of the lens, lies a second body similar to a Cysticercus, as to which Von Graefe was not perfectly clear at the time, but which rnight possibly be a dead Cysticercus. Even in the first case, movements could not be distinctly perceived, a circumstance which must be explained by the position of the structure exnetly in the axis of vision, and by the fact that the sac referred to is itself in a constant state of rocking motion, and consequently it is very difficult to get a clear view of the independent morements of the worm. Nevertheless, Grate believed he recognised the undulatory contraction of the hinder portion (caudal vesicle) of the worm.

During the continuance of the malady just mentioned, the patient, who was aflieted with strabismus, and on that account sought Griefe's advice, conld still distinguish fingers at a distance of several feet, but during fixation, the axis of vision was diverted considerably inwards from the object. The patient could not deeypher the largest print even with magnifying glasses. The . other eye was sound. Trenia solium was present; but there was no Cysticerci in other parts of the body.

In No. 45 of the 'Dentsche Klinik' for 1856 (Sitzungsbericht der Ges. für wiss. Med.' July 21st and August 11th, 1856) Von Graefe reported upon a moveable Cysticercus cellulose in the vitreous humour, which already began to exhibit turbidity in consequence of the irritation to which the animal gave rise in it. Von Graefe established a coloboma in the sclerotic coat, and afterwards extraeted the Cysticercus with great difficulty by incision of the sclerotica. In this operation the caudal vesicle was torn off, and the liead and neek, which were seized by a serre-tête, could only be got out after several attempts. Of the cyst only a portion was removed. The suekers of the Cysticercus contiuued to move for twenty minutes, under the microscope. The visual power of the patient inproved; he could read large print, count 
fingers, go out, \&c.; but at the time when Von Graefe made lis report, all dread of chronic chorioiditis was not got rid of.

d. In the retina.-In one case the patient observed, three weeks before his visiting Graefe's hospital, a cloud in front of the left eye in the middle of the field of vision, and diffusing itself thence towards the sides, so that the patient only had a perfect sensation of light from the sides, whilst in the middle of the axis of vision only large and strongly illuminated objects glimmered as if through a thick cloud. In eourse of time, however, the sensibility to light was entirely extinguished in this eye. The lens and vitreous humour were clear, but in the middle of the retina a shining greenish body was seen, which was bordered by couvex circular margins and lay a little outwards from the centre of the retina on the outside of the optic nerve. The rest of the retina was healthy. Examined in the reversed image, the body appeared as a perfect, roundish, greenish vesicle, four times larger in diameter than the entrance of the optic nerve. It was firmly attached to the retina, and projected with its anterior' wall into the vitreous body, in whichwas perceived a white, button-like, projecting appendage, distinctly marked by its greater opacity and its colour, which shifted its place, although no separate parts could be perceived upon the knob, and over which a pair of vessels ran forwards. On this account Graefe supposed that the worm liad a fine enveloping membrane. When the axis of vision was completely fixed, the walls of the vesicle exhibited flattenings or cuplike impressions in several places simultaneously, together with movements which diffused themselves in an undulatory manner. In three weeks the vesicle had increased abont one third in diameter and reached to the optic nerve. The head had passed from the centre to beneatl the upper margin, and appeared to have grown like a small vesicle out of the previous one, that is to say, the enveloping cyst had probably burst, and a small vesicle protruded which sat upon the former. On the head distinct swellings and a neck-region, sometimes extended and sornetimes retracted, were now seen. Ten weeks after the first observation, the vesicle was not remarkably enlarged, but less greenish and more transparent. The above-mentioned vessels appeared to be obliterated cords. The small appendage was nearly as large as the original vesicle and covered the optic nerve entirely. The rest of the retiua had lost its colomr, and was covered with irregular, blended, pale spots, of which Graefe did not know 
whether they lay in or behind the retina. In five months the first vesicle was completcly collapsed, and instead of it a folded, trausparent, membrane, without determinate outlines, was to be seen waving up and down, and the second vesicle also was less distinctly detected with indeterminate outlines. The animal, however, was still alive, and its head lay towards the nose. Cystic worms appeared on no other part of the body, nor did the patient suffer from tape-worm.

In a second case, in which no Cysticerci appeared on cther parts of the body, but in which segments of Tanice were passed, glimmerings, cloudy vision, and complete dimmess of sight appear to have established themselves gradually in the right eye, in which inflammation had from time to time been set up, accompanied by violent attacks of headache on the right side, until at last only a slight appearance of light remained. By means of the speculum, a round, resicular body, with the before-mentioned undulatory movements, was seen above the place of entrance of the optic nerve. Its fine, bluish-green colour was deadened by a slight veil (enveloping membrane). As if inverted in the vesicle, a white head was secn, which alternately extended and retracted a neck. In this case also the above-mentioned greenish spots were seen upon the retina. In course of time the shining colour gradually disappeared; but there was no change in the form and size of the entozoon. In nine months instead of the vesicle, only a colourless membrane, or a system of such membranes, which covered the greater part of the hinder surface of the eye, was seen floating in the vitreous humour. The sensibility to light, had entirely disappeared. Although, as already remarked, there was no external appearance of Cysticerci, Graefe thinks that the previous weakness of onc arm, the riolent hearlaches, the glimmering, and the subjective appearance of light in the other eye, must be referred to a simultaneous existence of Cysticerci in the brain.

In a third case, Graefe saw the vesicle shining immovably to the right in the outer part of the back of the eye, through a septum of translucent membranes, which penetrated the hinder part of the vitreous body; he saw the movements of the resicle and the neck distinctly, but the sucking discs indistinctly. This eye was quite blind; the other was healthy. There was no trace of a tape-worm, or of Cysticerci, in other parts of the body.

In the latter cases, at the first glance, the greenish colour, 
which Graefe does not explain any further, must strike one. 'The explanation appears to me to be simple. The Cysticerci themselves are translucent and bluisl. As, in employing the ocular speculum, we examine the eye by lamp-light, the bluish tint thus in the first place acquircs a greenish appearanee. But then, in this case, the colour of the vitreous humour and its changes, in consequence of the inflammation of the retina, and the complementary colour of the exudation and of the lamp-light, must also be taken into consideration.

In a fourth case Graefe saw the Cysticercus lying on the retina, projecting very far into the vitreous humour, and enclosed in a system of folded, floating, but tolerably transparent membranes. This also was observed by the patient, probably by chance, in the first period of pregnaney. The consequence was a complete amaurosis, exeept a feeble glimmering of light beneatl and on the outside. The other sound eye participated consensually with subjective appearauces of light and a diminution of the power of vision without perceptible material clanges. T. solium not mentioned. I cannot omit to call attention to the fact, that in the eye of the pig, also, Cysticercus cellulosce prefers the vitreous humonr and the retina for its habitation. Thus Von Nordmann in one case found six Cysticerci in the vitreous humour, and, on the posterior wall of the same eye, beneath a menbramous coat, six other Cysticerci close together.

e. Under the retina. - In this situation Von Graefe ("Deutsche Klinik,' No. 45, 1856; 'Sitzungsber.,' August 11th) has seen a Cysticercus, the removal of which, with the aid of the speenlum, he thinks might be possible.

$f$. In the brain.--Here we should require to be very prolix, if we were to describe the particular symptoms aceording to the position oceupied by the cystic worm. The general observations on the formation of tubercles in the brain are of use here, and we refer to the pretty well established facts upon this subject, whieh will be found laid down in every text-book of pathological anatomy and pathology, upon pseudoplastic deposits in the brain. In the general section upon the migration of the Coenuri into the brain, we have represented pretty exactly the consequences of the migration of Cysticerci into the brain, and only the vertiginous movements need to be excepted from amongst the symptoms in the human subject. Where these symptoms occur, a rapid 
growth and quick increase of the disorder is remarked, which, in the course of a few months or years, may come to a stand-still or end perhaps in convalescence. The diagnosis of the parasites is generally impossible during life, and we can only speak of a probable diagnosis in those cases in which, simultaneously with cerebral symptoms, Cysticerci occur in other and superficial parts of the body, and the presence of Tania solium, at the same time or at an earlier period of life of the patient, can be ascertained.

The general prognosis of this cystic worm varies according to its position. Favorable when the worm is situated in the general envelopes of the body, or in any of its superficial parts, it becomes more doubtful in proportion to the depth at which the cestode is seated in an important organ, the number of Cysticerci present, and the size of the indiridual cysts. The prognosis is, therefore, favorable in the anterior chamber of the eye, but becomes unfavorable in the retina and in the brain. With the lapse of time the Cysticercus is certainly destroyed, becomes calcified aud shrivelled, which of itself may produce an alleviation of the symptoms caused by it.

Treatment of Cysticercus cellulose.-There is no prophylaxis for the prevention of the production of this parasite, the embryos being too small to be seen and recognised, unless we place in this category the destruction of the proglottides of Tenia solium by fire, desiccation, or spirits. If the brood have once got into the stomach, we do not yet possess any means of destroying their porrer of derelopment alid killing the brood in the stomach. All my attempts at feeding rabbits or sheep with powder of Filix mas, pomegranate-root pills, turpentine pills, oil of rosemary pills, and an old secret remedy of the shepherds, before, simultaneously with, or some time after the administration of eggs of $T$. serrata or T. Ccenurus, in order to prevent the exclusion of the brood, gave no results. Eren pills of insect-powder (Pyrethrum roseum) did not entirely protect them, although the number of Cysticerci found appeared to be less than is usually the case after administrations. The indications of treatment are essentially easy with regard to this cystic worm.

1. If it can be reached by the knife, it may be removed.

2. If this be impossible, the means of killing the worm, in imitation of nature, must be practised.

3. And further, we must endeavour to expel Tcenia solium as 
quickly as possible from those who suffer from this worm, so as to cut off this possible constant source of the production of Cysticerci in one individual.

The Cysticerci in the subcutaneous cellular tissue and in the anterior and posterior chambers of the eye which are within reach of the knife, or the conching needle may be removed by cutting, or broken up by the couching needles; but this last process is less advisable, as the chitirous structure of the vesicle does not disappear by absorption. When the Cysticerci are in the vitreous humour, we must, according to Von Graefe, endeavour to remove them by incision of the sclerotica.

With the Cysticerci living on the retina and in the brain, our endeavours must, ex theoria, be directed to causing their death as soon as possible, after which, as observation shows, fatty degeneration, calcification, and shrivelling take place in the worm, which may be accompanied by an alleviation of the symptoms in consequence of a partial diminution of pressure, just as we see this takes place after apoplexy. Unfortunately, however, we have no means of effecting this object, and even in the eye, into which, according to Donders and Graefe, certain remedies applied externally can penetrate by absorption, experiments by dropping in filicate of potash and preparations of santoin were of no use, according to Graefe. We must, therefore, wait quietly until the parasite is destroyed by the favorable action of the organism, or by time. How long a cystic worm may live in an organism, how many years it may wait, without suffering injury itself or becoming destroyed, or be converted into a Tenia when it gets into a suitable intestine, are points unknown to us. If we knew these things it would be possible to predict at what time the death of the worm might take place, or a remission of the disorder be expected. In short, there is no active treatment for the latter purpose, although, according to Von Graefe, with those which are seated beneath the retina, it might perhaps be possible to undertake the operation by the employment of the speculum.

\section{Tenia mediocanellata (mihi). Pl. III, figs, 11-13.}

Up to the time of Bremser a second species of Trenia made its appearance from time to time in the system; it was probably known to Pallas, Brera, and Andry. Since Bremser's time, 
howcrer, people began to think that the broad tape-worm of previous authors was only Bothrocephalus latus, and that there was no second large species of Tonia inhabiting the human body. Opinions, such as that of Schmidtmüller, who, I am sorry to say, gave me no information in answer to my inquiries on this subject, and that of Nicolai, who mentions this Trenia in the following words," "capite inermi aculeato sessili, articulis dilatatis brevioribus, marginis utriusque medio latiore, alternis osculato, majoribus transverse striatis, emarginatis," met with just as little attention as the hints which occur in rarions reports of travels with regard to this Tania. Thus Tutschek (in the 'Ausland,' No. 2, for' 1853) mentions the occurrence of a broad tape-worm (Tcenia lat $a=$ ndakun $)$ in Tumale, in Africa. Four years ago I found this worm in Zittau, and saw it myself in five patients amongst others; I also saw it in a woman from Bremen and a man from Lubeck. Twice I had the opportunity of seeing fragments of it, through Professor Richter, of Dresden, and three times through Dr. Zenker. I saw many examples at Madame Heller's, in Hamburgh, and afterwards received two perfect specimens from her. Gurlt, of Berlin, received a specimen through his son from Langenbeck's Hospita], and Professor Leuckart saw another in Giessen. In short, as to the existence of this species, which Tan Beneden, Eschricht, and J. Müller have recognised from my preparations, there can no longer be any doubt amongst those who institute exact comparisons and examinatious. If any doubt should still prerail in the determination of the species, it is as to whether a third large species of Tania, besides $T$. solium and $T$. mediocanellata does not inhabit the human intestine. So much for historical introduction. If the head of this Tania did not resist attempts at expulsion with such extraordinary obstinacy it would long since have been recognised.

Tænia matura.-Species longissima (ad 12-14 ulnas longa) latissima, crassissima. Capite inermi, permagno, ad 2 millim. lat., valde nigrescente, acetabulis 4 permagnis (ad $0.36 \sigma^{\prime \prime \prime}=0.829$ millim. long. et $0 \cdot 259^{\prime \prime \prime}=0.711$ millim. usque lat.)

Systemate rasculoso: in capite simpliciore, quam in T. solium; corpor. calcar, ad 0.012 millim. in capite, ar 0.018 millim. inarticulis magnis, mayisque numerosis, quam in $\mathrm{T}$. solium.

1 Neuer Zeitschrift fur Natur und Heilkunde, Von Ammon, Choulant und Ficinus, i, p. 464 . 
Rostellum nullum. Collum perbreve, sed distinctins, quam in T. solium. Articuli posteriores latissimi, ad 17 millim. lat. et ad 9-14 millim. long. crassi, poris genitalibus irregulariler alter. nantibus. Proglottides permagnce et pervivaces, scepissime sponte et sine facibus humanis ex ano demisse, rgrotumque valde perturbantes; in maxima sua extensione. $25-30$ millim. long. et ad 7 millim. lat.

Uterus permultos ramos (ex utroque latere usque ad 30), in margine libero claveformes, non amplius dendritice, ad summum bifurcatim divisos, inter se parallelos.

Ovula magis ovalia, laviora et clariora, quam in Trenia solium, ad 0.036 millim. longa et 0.02S-33 lata; testât crassá, uti in 'T. solium. Embryones 0.028_-32 mill. longi, 0.023-26 lati.

Scolex quiescens ignotus. Fortasse in Sue aut Bove, fortasse in animal. inferior. ordinum.

The epidermis of this animal is thick and very distinct, of soft structure, consisting of delicate lines crossing each other, and without calcareous corpuscles. The epidermis is followed by a layer of longitudinal muscles, which run through the whole body of the animal, and form bundles of $0.245^{\prime \prime \prime}=0.545$ millim. These, as well as the next layer of transverse muscles, contain the calcareous corpuseles imbedded in them. The fasciculi into which the layers can be split are about $0.070^{\prime \prime \prime}=0.158$ millim. iil diameter ; they pass nearly to the upper and lower margins of the segments, but always disappear at a short distance from these rnargins.

The size of the sucking discs, which are quite black, gives the head of this Tania a considerable bulk, and it is easy to understand how the older authors spoke of four large black eyes in this animal. I have seen, in all, seven heads of this Tenia; two of these are in Paris, and were given with my prize essay; one is in the possession of Van Beneden; I possess two myself; I lave seen one with M. Gurlt, and the other was left with the patient. From their size, they were all of different ages; the segments were of different sizes, but the heads of all were in the same state, and only that expelled in Travemünde was paler, because more sparingly furnished with pigment.

The very simple vascular net-work consists of a transverse branch, running through the free space between the four sucking dises; from this a branch runs to and around the sucking dises, until the four well-known longitudinal vessels are developed from them 
in the neck. I did not detect any anastomoses between the individual branches of the sucking dises. The longitudinal branches constantly become thicker as the segments increase m size, aurl, when cut through, show a distinct hmen, each two lying close together. I could not detect the anastomosing tranverse branch on the posterior margin of each segment, which should always occur in the Trenice. On the other hand, at these points I found small enlargements of the vessels, distinguished by a kind of valvular apparatus, which appeared to open before the fluid streaming from the head, but closed itself against that ruming back towards the head. When an air-bubble acciclentally occurs in these swellings, the action of this vascular cone may often be easily recognised by a little pressure, especially in spirit-specimens softened again in caustic potash. When the segments are held against the light, these dilatations are particularly well shown, projecting half into the upper, and half into the lower segment. Hence we can ouly hope to makc successful injections by operating from the head backwards.

The segments, which have a great tendency to increase in breadth, are at first 1 millim. in length, and about 3 in breadth. Afterwards, also, the breadth predominates over the length for a long time, for the segments are 10, 14, 15, 17 millim. broad, by 9-14 millim. long. But this proportion does not remain constant, and segments of $1-1 \frac{1}{2}$ in. in length, and only $3-4$ lines in breadth are met with. By this means the first half of the segments acquire the appearance of segments of Bothriocephalus, with lateral genital pores. The clange of form is explained by the circumstance that only the longitudinal muscles reach from the upper to the lower margin of the segments, whilst the transverse muscles cease at a greater or less distance from the margins. That the last segments, or proglottides, have a tendeucy to pass away without freces, is beyond a doubt, but this also takes place with $T$. solium, although more rarely. The segments pass when the patient is standing quietly, and, falling into the trowsers, he suddenly has a moist and cool feeling about the legs, and when he seeks to free himself from this unpleasant sensation, he finds a single proglottis attached to or creeping about his leg. When this Trenia is expelled, it breaks off with remarkable ease close to the neck, and then the first segments form series of joints, which hang one after the other like the pearls of a necklace upon a thread. These are the segments erroneously regarded by Seeger- 
Wundt (Taf. ii, figs. 19 and 20) as degenerated, lypertropic segments of $T$. solium, arranged one after the other in the mamer of a rosary. After the lapse of about ten weeks from the time when one of these Tenice has been expelled up to the neck, a fresh passage of proglottides always takes place. From figs. 13 and 14. of Bremser's first plate also, but especially from the half untwisted, fig. 14, it is clear Bremser, unknown to himself, had a Trenia mediocanellata before lim.

Although the passage of proglottides without freces occurs sometimes, even with Trenia solium, it is not the case to such an extent, or so constautly, as in Tania mediocanellata; from which we must conclude that its reproduction and growth is extraordinarily rapid, and that the animal must even be more injurious to its host than $T$. solium, as indeed is prored by experience. The passage of the segments without faeces is a constant annoy. ance to the patient. The proglottides adhering to the uaked body in the trowsers, or under the petticonts, being disagreeable, from their clammy coldness, disturb the patients greatly; and women especially are afraid lest the proglottides shonld fall unperceived upon the ground when ther are walking or standing. How really terrible the passage of these proglottides may be, appears from the statements of one of my patients, who wrote to me at the end of June as follows: "On the 6th of April I observed the first passage of proglottides, and since then they pass nearly every day, sometimes more, and sometimes fewer. On the 24th of May, from the morning to evening, 21 passed spontaneously; on the 17th of June, seven within fifteen minutes, and later on the same day two at once." If I reckon 20 proglottides daily, from the 6th of May to the 26th of June, this gives in all 10 pieces, and if we calculate the proglottides only at 1 inch long, which is very little, we get 83 feet 4 inches. If we reckon only 15 proglottides daily from the 6th April to the $26 t_{1}$ of June, when an expulsion takes place, this would give $80 \times 15=1200$ proglottides, or 1200 inches $=100$ fect of tapeworm passed in the course of $2 \frac{2}{3}$ months, and we must calculate that in the course of one day $1 \frac{1}{4}$ foot of tape-worm had been passed and regenerated. This is certainly an enormous quantity, when only a single specimen was present, which, however, was proved to be the case by the last successful expulsion.

The troublesome tickling on the sphincter muscle from within, when the segments forced their passage, and the clamminess on 
the legs, upon which, in the patient here referred to, they immediately deposited their egrgs, which appeared like white, damp, sand, plagned the patient most.

Besides those which passed spontaneously, 5-15 proglottides passed daily with the frees from this patient. As these also immediately laid their eggrs, the freces looked as if sprinkled with white sand. With such quantities, it is perfectly justifiable to assume the number 20 as the daily average passed.

Genitalia.-The pori genitales are extremely large and swollen, so that it is very difficult to discover the penis. In this, however, we may succeed sometines by carefully removing the swollen part, and then trying to press out the penis. It is thicker and shorter than that of $T$. solium, and passes posteriorly iuto a very thick seminal cord, which may be disentangled from the segment for a long way, and does not lie in such close convolutions as that of $T$. solium. The sac of the penis resembles that of the other Tenice, but is of very large size, namely $0.019^{\prime \prime}=$ 0.1 millim. in breadtlı at the widest, and $0.028^{\prime \prime \prime}=0.063$ millim. at the narrowest part, and $0 \cdot 175^{\prime \prime \prime}=0.395$ millim. in length. The separate convolutions of the seminal cord are $0.010-0.017^{\prime \prime \prime}$ $=0.023-0.039$ millim. in thickness. The penis itself is $0 \cdot 140^{\prime \prime \prime}$ $=0.316$ millim. in length; at its apex, about $0.014^{\prime \prime \prime}=0.031$ millim. in breadth, and at its base about $0.028^{\prime \prime \prime}=0.063$ millim.

Female generative organs. - The vagina, which is enlarged $\left(0 \cdot 031^{\prime \prime \prime}=0 \cdot 071\right.$ millim. $)$ at its cxternal orifice, and diminisles in its further course to $0.017^{\prime \prime \prime}=0.039$ millim. is strongly pigmented, and opens in the lower third of the segment into the uterus, with a dilatation of $0.033^{\prime \prime \prime}=0.079$ millim.; it rums at first along the lower side of the seminal cord, and parallel to it, until it suddenly bends downwards. The lumen of the sheath in its middle measures $0.037^{\prime \prime \prime}=0.015$ millim.

The uterus is a thick-walled, straight, merlian canal. In spirit preparations, especially, with thick specimens, the canal, when observed in its whole extent, forms a kind of pearl necklace-like string, or a continuous tube, round which the sides of the worm enfold themselves. This tube, which appears to be continuous, and which I regard as a canal, induced me to call the species $T$. mediocanellata.

The numerous lateral branches of the uterus spring opposite to one another, and run parallel and perfectly undivided nearly into the margins of the segments, when they either terminate in a 
cacum, or, at the ntmost, become bifurcate, but never, as in T. solium divide dendritically.

The ova, $0.016^{\prime \prime \prime}=0.036$ millim. in length, and $0.012-0.014^{\prime \prime \prime}$ $=0.028-0.033$ millim. in breadth, are on the average rather sinaller, of a lighter brown colour, smoother, more oval, and less globular than in $T$. solium. The egg-capsules exhibit only two consecutive layers, and are more easily broken than those of T. solium.

The scolex in unknown. In Dresden it cannot be rare, as the Tenia occurs there not uncommonly. Unfortunately our material extends no further, and pigs lave not been fed with the eggs of this Tenia. It is not improbable that the cystic worm belonging to this species may occasionally occur amongst the specimens pronounced to be Cysticercus cellulose. A very intelligent patient, from whom I at last expelled a Tenia by mcans of my extract of pomegranate root, writes me that he had observed his Tenia from the time when, during a long absence of his wife, he had dined from home at an eating-house, and frequently ate raw beef-steaks and green salad and radishes. The scolex was either seated in the beef, or in mollusca, which might have been in the salad or on the radishes.

The embryos resemble in size and structure those of $T$. solium. Their migrations are unknown.

Habitat.-Its residence is not so limited as one might perhaps suppose, for it appears to occur in Europe and Africa. As some persons have found fault with my previous geographical diagrammatic statements, I pass orer them here, and refer to my work on the Cestoidea.

Variety-Tenia from the Cape of Good Hope.

Pl. III, figs. $14-16$.

Nihil notum, nisi Strobila pars posterior. Articuli per totum corpus, cristâ longitudinali mrediti, crassi, et longi. Pori gomitalcs marginales, alternantes. Uterus et ovula simillima illis Tæuiæ mediocanellatx. Verisimillimum est, strobilam mihi notam proliferatam esse a Tronix mediocancllatæ scolice quodam 6 osculis ornato.

By the kindness of Dr. Rose, surgeon, at the Cape of Good 
Hope, I have receired a considerable number of segments of this worm, unfortunately destitute of neck and head. It was expelled by pomegranate-bark, and appears, like Tcenia mediocanellata, to be difficult of expulsion.

What we know of it at present is as follows: Its total length must be at least $6-10$ yards. Its segments are very thick, white, and fat; in the mature state more than 1 inch in length, 3-5"' in breadth, and extremely massive. They are distinguished by lıving a longitudinal ridge running along the whole of the mature and immature segments. The genital pores are irregularly alternate; the penis so much concealed behind the thick, inflated margins of the genital pore that it is hardly discoverable. The uterus is formed by a thick median stem, into which 40-60 lateral branches open; these resemble those of T. mediocanellata, or perhaps still more those of Tcenia ex Cystic. temuicolli, especially when we consider the arrangement of the branches like the teeth of a rake at the upper and lower margius of the segments. The ova are oval, rather roundish, uneven, and $0.013-0.015^{\prime \prime \prime}=0.030-0.034$ millim. in breadth by 0.017 $-0.019^{\prime \prime \prime}=0.038-0.040$ millim. in length. They allow the sixhooked embryo, which is $0.010^{\prime \prime \prime}=0.021$ millim. in diameter, to shine through them distinctly. I never saw such remarkably developed embryonal hooklets in any other human Tanice; the central ones resemble stilettoes. The inner hooklets were 0.0031 $-0.0038^{\prime \prime \prime}=0.0069-0.0071 \mathrm{millim}$; the outer ones $0.002 \mathrm{I}^{\prime \prime \prime}=$ 0.0046 millin. in length. The calcareous corpuscles were as large and numerous as in T. mediocanellata. This Tenia is particularly rich in cholesterine, for very large and numerous flakes of the substance made their appearance in the deposit which $\mathrm{I}$ obtained from the sediment at the bottom of the bottle in which this tape-worm came from the Cape.

The migrations of the six-hooked embryos and of the scolices are unknown to me. Rose writes that it is impossible that the latter should live in the flesh of pigs, as the worm was obtained from a Hottentot, and the Hottentots, like the Jew and Mohammedan, eat no pork; a thick Tania occurs in Abyssinia, amongst the Mohammedan inhabitants. It is known at the Cape of Good Hope that the Hottentots brought this tape-worm with them from the Caffer wars, in which they enjoyed themselves amongst the cattle of the Caffers. The scolex, therefore, appears to live in the cattle, and perhaps, also, in the sheep of the Caffers, and it 
may be a question whether the scolex might have been Cysticercus tenuicallis.

Very recently the Tanice with continnous ridges passing through all the segments of the colony have attracted my attention in a remarkable degree, because I have twice found Tenia Ccenurus with six sucking dises and a three-cornered body, one angle of which resembled the longitudinal ridge of our Tania. Hence the question rises whether the Tania, No. 3 , is not a variety, with six sucking dises, of a species already known either in man or some other mammal (T. mediocanellata, T. ex Cysticerco temuicolli).

\section{Tania nana (Bilharz, Von Siebold).}

Corpus filiforme, depressum; caput antice oltusum, collum versus sensim attenuatum, acetabulis subylobosis, rostello pyriformi uncinulorum bifidorum corona armatum. Articuli transversi; cirri unilaterales, ovula globosa, testa lavi simplici (?) instructa $\frac{1}{100} "$ "' magna. Longitudo totalis 6-10"'. Patria Ayyptus, in hominis intestino tenui semel reperta numero permagno.

The small filiform Trenice have broad and perfectly developed segments, and a large quadrangular head, at the angles of which the round, sucking discs are placed upon globular elevations; the head is flat in front and gradually diminishes in breadth and passes into the long sleuder neck, which is followed by segments which constantly become broader, mutil at last, at the hinder end of the body, they acquire three or four times the width of the head. These Trenice only occupy a linited space in the ilium.

The ova are globular, with a thiek, yellowish capsule, which is probably double, for Bilharz speaks of a capsule and perhaps a kind of thin vitelline membrane, as the contents of the ova contract under the influence of alcohol. The six looklets of the embryo Trenice are distinctly seen in the fresh ova. Although Von Siebold himself received specimens, he has contented himself with a very superficial figure of this Tenia, and has not even thought it worth while to give the number, measurement, or a good figure of its hooks, so that the fig. 18 in Pl. V of the 4th volume of his 'Zeitschrift' might just as well have been omitted by him as by us in this place; the hooks are probably very small. From the number of the Tanice found, and their 
erident small size, I have been induced to express the opinion that this worm might be a Tania Echinococcus. It is to be hoped that we shall soon see whether this Tania be anything like $T$. Echinococcus altricipariens.

\section{Phanonexology axd Diagnosis}

\section{Of all the mature Cestoidea occurring in the human intestine, both Bothriocephali and Trenire.}

Of the symptoms produced by Tania nana we know nothing, but in general the larger Cestoidea inhabiting the lruman intestine agree in the following particulars.

The stronger an individual is in hinself, the less the irritability of his nervous system, the fresher his colour, the more regular his appetite and nourishment, the better his foorl, and the less he is inclined to diarrhœa; in one word, the less tendency lie has to chlorotic phænomena the less does he complain of his symptoms when he suffers from tape-worm. It has been universally attempted to attach the greatest importance to the accompanying chlorotic symptoms, which are only increased in pejora by the great consumption of food on the part of the tapeworm, or to suppose that, by the great appetite of the tapeworm for proteinic substances, calcareoris salts and fat, chlorosis itself may be produced. According to the degree of this chlorosis, the more will the patient complain. Seeger gives the following statement with regard to the frequency of particular symptoms from a statistical table of 100 patients with tape-worms. Sixty-eiglit times there were cerebro-spinal affections and partial or general convulsions (for example, epilepsy, hysteria, melancholy, hypochondria, abdominal spasms, dyspnœe, and convulsive coughing) which may even rise to maniacal attacks and mental weakness; forty-nine times nausea even with romiting and fainting; forty-two times various pains in the abdomen; thirtythree times disordered digestion and irregular eracuations; thirtyone times irregular appetite and voracity; nineteen times periodical, habitual headache, usually on one side; serenteen times sudden colic; sixteen times undulatory movements in the abdomen up to the cliest; fifteen times dizziness or delusions in the senses 
and defects in the speech; and eleven times shifting pains in various parts of the body. All these symptoms, however, are deceptive, if we should ascribe them to the presence of the tape-worm. Very often, when they are present, they do not disappear even when the worm has been expelled, a proof that the latter is not their first canse. Meyer Ahrens, and before him Bruce and Rüppell, mention that, according to the belief of the Abyssinians, the tape-worms only thrive in a healthy intestine, so that they regard it as a sign of illness when they harbour no worm. It is clear that this faith has some foundation; but it is equally clear that exceptions occur. All that has been said, therefore, furnishes no absolute data for the diagnosis, not even though the mode of life of the patient, his residence in certain districts particularly notorious for Cestoidea, his trade or certain of lis labits might lave furnished favorable moments for the acquisition of tape-worms. Under all circumstances there is but one certain diagnostic phenomenon, that is to say, the emission of segments, or series of segments, of cestode worms. This issuing of the segments may take place in several ways, by the amis or the mouth, or through abuormal openings in the walls of the intestine and abdomen. The way per anum is takcu by the worm either simultaneously with the fieces, especially when these are diarrhœal, or without this accompaniment. This is the commonest way. The second, per os, is an extremely rare way, but it may occur in violent vomiting, especially with intussusception. It may, perhaps, be explained by the circumstance, that the segments cast off prefer to proceed towards the side to which the posterior part of their body is directed. 'This may perhaps be concluded from those dissections of animals in which we find the head nearest to the anus and the hinder extremity of the body nearest to the mouth, and perhaps also freely cast off segments on the way towards the stomach. I saw the latter, for instance, in a Tom-eat, from the mouth of which proglottides crept a few hours after death, and in which the head of the worm was situated towards the anus and the hinder extremity towards the stomach, whilst free segments were moving abont between the stomach and the hinder end of the worm. The last course, through abnormal openings in the walls of the intestine and the abdomen, has often been doubted by authors, and was described by the ancients as the passage of the tape-worm through the navel, \&c. When the bearer of a tape-worm has a wound in the 
abdomen, which communicates both with the intestine and the onter world, as for instance when an intestinal fistula exists in him, the passage of individual segments, or serics of segments, through the fistula is rendered possible. Whilst I am writing, there is in Dresden a patient, belonging to a good fanily, from whom proglottides passed through an intestinal fistula in the neighbourhood of the navel. The surgeon who liad the dressing of the wound soon found repeatedly elongated thin organisms, which moved about in the matter on the bandages. He brought some of them to Professor Richter, who recognised these extraordinary productions as proglottides.

Nay, there is even another way by which it is possible that the segments may pass outwards, which, rare as it may be, was certainly known to the ancients, namely, the passage of the segments through the urinary bladder. This course also woukl be intelligible in cxceptional cases, as, for instance, if an individual suffering from tape-worm had recto-vesical fistula.

The passage of the mature segments of tape-worm is not physiologically connected with any certain time, and if, notwithstanding, they pass more frequently at certain times than at others, neither the moon and its phases, nor any other periodical times, have any influence upon it, but it always depends upon periodical external or internal causes. Thus, for instance, in the case of Trenia solium, it cannot be a matter of indifference that pork is eaten especially at certain times (from Oetober to March). And as the Cysticerci are thus more frequently swallowed by men at this period, and must have become developed three or four months afterwards into Tanice, which are giving off their segments, the months from January to July must also be the favorite months for the passage of the fragments of tape-worms. On the other hand, however, these months are by $n 0$ means the only ones in which pork is eaten, and therefore segments of tape-worms may also make their first appearance from an individual in other months. To this we must add the circumstance that when once a tapeworm has become mature, it constantly forms segments which are destined to pass out, and this may continue through the whole year. For how many years this may be possible cannot be stated, as we do not know how long any tape-worm is capable of existing in the same human intestine. That this may possibly be for a considerable number of consecutive years, is a supposition necessitated by the practical experience that we constantly 
see fresh series of segments produced from a remaining scolex or head of the same tape-worm. It is also unknown to us how often this total regeneration up to the head can be repeated by one specimen of a worm. If we bear in mind this regeneration of the worm from the remaining head, and consider further that in 3-4 months after the expulsion of the previous colony, a new one, which gives off its segments, has grown up, we have before us an additional reason for the occurrence of a fresh emission of segments at certain periods of the year. As it may also be proved that after eating certain fruits, such especially as strawberries, cranberries, bilberries, grapes, and black currants, raw and green fruits, especially plums, melons, cucumbers and other salads, and after "sauerkraut," a giving off of larger or smaller pieces of tape-worms takes place, often extending to whole colonies up to the neck, we have a further reason why at the time these fruits are eaten, and especially at the period of the ripening of strawberries, bilberries, grapes, and black currants, which expel whole colonies, the segments of Trenice pass off with particular readiness; and also why a more abundant passage of the segments seems to take place annually at certain times. Even in the use of herrings, pickled herrings, herring salads, and strong beer, there is a variation according to the time of the year, and generally at times a total cessation in the consumption of particular articles of food. From this point of view exact statistics may hereafter perhaps be prepared, but this must be carefully framed with as wide a margin as possible. To drag in the seasons of the year otherwise than as they regulate certain conditions of nourishment is unjustifiable, and those who speak of the influences of the moon's phases upon the tape-worms in any way should be regarded as nothing less than mocnstruck.

If we have thus seen that the diagnosis of the presence of tape-worms is only possible when we see their segments pass off, we may, by the close examination of the mature segments, and

- Von Siebold asserts of Tania serrata and other Tania of the dog, that the single individual Tania only live a very short time in the intestine after the first period of their maturity, and then perish by age. This, à priori, contraliets the observations upon the Cestoidea of the human intestine, and also my own observations upon the Trenice of the dog. For I have kept dogs chained up without any fresh administration of Cysticerci, and seen them give off proglottides for 5-6 months together, when, upon dissection, the Tanice have been found in good condition. I have not continued the experiment longer. 
especially of their uteri and collections of ova, at once distinguish the four large species from the human intestine, and predicate what species of cestode worm are to be expelled.

The mature segment of a Bothriocephalus latus is charactcrised by the collection of its dark-brown ova in the middle of the segment, and by the separate opening of the vagina and penis in the middle of its ventral surface; the ova are oval, and, when pressed, open with an operculum.

The mature segment of Tenia solium has a uterus with a tortuous median stem, from which the lateral branches, which rarely exceed 9-15 in number, are given off in an irregularly alternating manner; the branches are dendritic, but often only on one side; the porus genitalis is simple and lateral, and the ova are roundish, and rough externally.

The mature segment of Tenia mediocanellata has a straight median stem, from which numerous (30-50) regularly opposite lateral branches are given off; these are undivided, or at the utmost bifurcated, and run horizontally through the segment, and usually parallel to each other. The porus genitalis is lateral and simple, and the ova are rough externally, and rather more oval.

The mature segment of the Tania No. 3-the Tania of the Hottentots-has a median stem and branches, very similar to $T$. mediocanellata, but the lateral branches at the upper and lower margins run more obliquely from above downwards, or vice versd. The branches which approach most closely to the upper and lower margins acquire a form which nearly resembles that of the teeth of a rake; the porus genitalis is lateral, and the ova resemble those of $T$. mediocancllata, but the embryo is armed with more distinct hooklets than in the other Tania of the human subject. The most distinctive character, however, is formed by the ridge which rums through the whole body of the Tenia. The rest is best explained by the figures on Pl. I and II.

The general prognosis is favorable, with the exception of T. solium. Thus, as long as it is not proved that the embryos of this last Tania cannot make their escape in the intestine and become converted into Cystic. cellulose in the tissues of the same man, its presence in the intestine is always a subject of fear and apprehension. For this reason these animals, when they do not trouble their host, may be left to themselves, with the exception of $T$. solium, against which I always operate, on precautionary grounds, whenever I meet with it. Bothriocephalus latus is the 
most easily expelled, and next to this $T$. solium; $T$. mediocanellata is difficult, and so, apparently, is the Trenia of the Hottentots. It is only those who expel the last two species with certainty, or totally in many cases, that can claim to be able really to expel tape-worms. For $T$. nana, which escapes diagnosis, we have also no prognosis and no therapeutics.

Treatment.-If the multitude of remedies recommended for any disorder is an evidence of their want of power against it, we must say that the therapeutics of the tape-worm is extremely defective. And, in fact, it leaves much to be desired, at least as regards the pleasantriess of the remedies, and the disugreeable secondary effects which sometimes accompany the best remedies and destroy their action.

I pass over the particular remedies which Seeger reproduces in detail (pp. 89-198), such as cold water ; or the popular remedies, such as a quantity of water in which green flax has been steeped for ten days, taken early every day, mare's milk, sea water or solution of common salt; and also sal ammoniac, flowers of sulphur, the Oleum nucum Juglandium, the Amara of the Schools, the Semina Sabadilla, the Cicuta, hydrocyanic acid (two drops every half-hour), bitter almonds (6-8 daily), opium, the Semina Santonici or Cince, the Rad. Valeriance officinalis, camphor, assafoetida, petroleum (20-30 drops on three consecutive days, with a purgative on the fourth day), or the Tinctura Assafcetidce, $5 \mathrm{vj}$, and petroleum, together (forty drops four times a day, increased after two days to a tea-spoonful every three hours-a tedious method), the uncertain Ol. anim. rectif. sive Dippelii (5-6 drops daily in broth), the Ol. anthelm. Chaberti (also recommended by Bremser; dose 5-10 drops, rising to sixty drops, which requires great caution), the bark of Geoffroya Surinamensis and G.inermis, the bark of the root of the black mulberry tree, Morus nigra (a popular remedy much in vogue in Asia Minor), the root of Pteris aquilina and the drastic purgatives, such as tartar emetic, calomel, castor oil, croton oil, jalap, gamboge, and elaterium : and I also pass over the numerous new remedies which have been recently mentioned by Dr. Walpers in the 'Pharmac. Centralblatt' for 1851, p. 618, as Abyssinian remedies for tape-worms, namely, the Radix Oykert = Sasari, from Silene makrosolen (lose ziiiss); the Radix Habbe Tphokko=Habba Dchoggo= Madjamedjo = Mitschamitscho, that is, the bulbs of Oxalis anthelmintica (dose 3xv); the Radix Adaudasch from Euphorbia, depauperata (dose 
$57 \mathrm{gr}$.$) ; the Herba Haudukduk, a Euphorbiaccous plant (very$ juicy, dose $18 \mathrm{gr}$.) ; the Cortex Tambusch, from Rottlera Schimperi; the Herba Buffafala, from Bryonia scrobiculata; the Folia Aule = Woira, from Olea chrysophylla; the Herba Zelim = Habbe Zelim, from Jasminum floribundum (never given alone, but always with Kousso); the Radix Ternacha or Jernacka, from Verbascum Ternacha or phlomoides (dose 70 gr., often mixed with Kousso); the Herba Maddere, from Buddleia polystachya; the Herba et Flores Belbilda or Bilbilta, from Celosia trigyna (zss).

I have tested a great many of the remedies here mentioned by placing living tape-worms in a mixture of the particular remedies with white of egg, and determining the time in which the Trenia died by the assistance of the rotation apparatus, the two poles of which I introduced into the mixture.

In castor oil the Tenice lived about $7-8$ hours and about an equal time in a salad made with unwashed herrings, potatoes, large pieces of onion and garlic, vinegar, and a large quantity of oil; in Cuprum oxyilatum nigrum (Rademacher) they lived for days. After the administration of castor oil for four days, the Tenia of a $\operatorname{dog}$ were also quite lively. Stizolobium Mucuna, or Dolichos pruriens (cow-itch) administered internally to dogs with honey, produced violent diarrhœes, accompanied by punctiform. spots of extravasation in the intestine, by which means fiagments of Tanice, but few entire ones, passed off. The decoction of the pods of this remedy only produced diarrhœa; and the Tania lived uninjured for twenty-two hours in a mixture of the hairs of these pods with white of egg. Tin behaves in exactly the same manner. Electricity has no destructive action upon Tenic.

It is otherwise, however, with Kousso, in the infusion of which, mixed with milk, the Tanie died within half an hour of their introduction, and with oil of turpentine, in a mixture of which, with white of egg, they died in $1-1 \frac{1}{4}$ hour. In a decoction of the Brayera $=$ Kousso, mixed with white of egg, the Tenice died in $1 \frac{1}{2}-3$ hours; in a decoction of Rad. Punice granatorum, mixed with white of egg, in 3 hours, and with the same decoction mixed with milk in $3-3 \frac{1}{2}$ hours. In a mixture of Extract. filicis maris ather., with white of egg, the Tania died in $3 \frac{1}{2}-4$ hours. The so-called filicine (filicic acid of Lutz), mixed with white of egg, also has an energetic action upon the Tania, which die therein in the course of a few hours, and exhibit œdematous swellings in various parts. 
After these remarks I will give the particular methoris of expulsion which have been put forward, arranged according to the remedies, and for this purpose I make use of that portion of the work of Seeger-Wundt which refers to this subject, and of the historical treatise by Dr. Meyer, of Coswig (pp. 101136) who, under the title of 'Die Wurmkrankheiten, eine 1830 in Berlin gekrönte Preisschrift,' has just published a book, which, being written without the least knowledge of modern helminthology, contains nothing useful, except the enumeration of methods, which, however, are thrown together in as disorderly a manner as by Seeger. I shall also add something from my own cxperience with other remedies.

1. Spigelia anthelminthica.-In Martinique, according to Noverre, they do not make an infusion, which has but little action, but a syrup from specimeus of this plant, which they collect at the period of its weakest vegetation. The dose is three table-spoonfuls for grown persons and one tea-spoonful for children of three year's old, administered on three consecutive days; and on the fourth a gentle aperient of manna, calcined magnesia, or castor oil, to remove the dead worm. A little cold water and lemon juice are added to each spoonful of the syrup at the moment of arlministration. For two hours after taking it nothing shonld be eaten; but children are allowed a little bread or cake. A peculiar secondary effect of the remedy is that it produces an instantaneous amaurosis and bloated appearance when it is taken either in the sunlight or in artificial light, for which reason it should be administered at bedtime and the light immediately removerl. In cerebral affections alone this remedy is not to be given. This method is one that could not easily be brought into use in Europe.

2. Sabadilla.-Schmucker gets the yellow, elongated capsule, with the blackish sabadilla seeds and the partitions in which this pointed seed lies, recluced to a fine powder. After the patient has been relaxed on the previous day with rhubarb and Glauber's salts, half a drachm of the sabadilla powder is given to him in the morning, with the same quantity of fennel sugar, and he afterwards drinks 1-2 cups of chamomile or clder-flower tea. Vomiting may easily be produced by this, and, according to Schmucker, if there be worms in the stomaclı they are thrown up. On the secoud day the same dose of sabadilla. If no more of the worm makes its appearance, the paticnt takes half the 
quantity of sabadilla on the third and fourth days in the morning and evening. On the fifth morning, whilst fasting, an apcrient is administcred, and the living or dead worm is purged away. Then follows, according to Schnucker, a long treatment for the worm-mucus, which may last for twenty days, and which consists in giving the patient three pills, each consisting of five grains of sabadilla powder, made into a mass with honey, and every fifth day an aperient. Children from 2-4 years old receive only two grains of sabadilla powder. Morcover, Schmucker has seen garden-worms and living Ascarides quickly die witl convulsive morements when lie sprinkled them with sabadilla powder. (This method should not be entirely forgotten for the Ascarides.)

3. Sulphuric acid. - Weigel dissolves _ss-j of Glauber's salts in $2 \mathrm{lb}$. of well-water, and gives a cupful of it every night; and twice a day 30 drops Elix. Vitriol. Mynsicht., or 10 drops Elix. Acidi Halleri, in half a cup of sugar and water. This is to be continued even for months. (It is certainly now quite obsolete.)

4. Drastic purgatives and mercurials.-a. Drastics with Oleum Chaberti, or Bremser's method.-Of an electuary made with Pulv. Sem. Cinæ, Jss ; Rad. Valer., $3^{i j}$; Rad. Jalapp., Oiss-ij; Tart. Vitriol., ziss-ij; Oxym. Squill., q. s. ut f. elect.; a tea-spoonful is taken 2-3 times daily. Two tea-spoonfuls of Oleum Chaberti are then given every morning and evening in a mouthful of water; water is taken after it, and a clove or a little cinnamon may also be chewed, but no substances which produce eructation, such as candied orange-peel. When sickness is produced by taking this fasting, the remedy is administered $1-1 \frac{1}{2}$ hour after breakfast; when giddiness follows it the dose is diminished; and when there is burning at stool or scalding urine, milk of almonds or oil emulsion is given. Thus the patient in ten or twelve days consumes $\mathrm{J}^{\mathrm{j} j}$-iiss, after which he takes a gentle aperient, for example: R Pulv. Rad. Jalapp., Эj; Pulv. Fol. Sennæ, `ss ; Pulv. Tart. Vitriol., 3j. M. f. pulv., div, in 3 part. æq. D. S. 1 powder every honr. The oil is then again taken, and the patient is allowed to use $5 \mathrm{iv}-\mathrm{v}$, or even vj-vij, in all. I do not think that at the present day any one will bring this method into use. The worm is never expelled in toto, but rots away; it is no wonder that any one who expels tape-worms in this fashion should never, any more than Bremser, learn to distinguisl the Tenice of the human intestine. I adrise that Oleum Chaberti should be given up at once. 
6. Drastics, amongst others calomel, or Schmidt's method.A methorl which, probably only on account of its violence, is still famous, and is employed in cases in which all others have failed.

Preparation. - To ascertain positively the presence of the tapeworm, the patient is directed to eat no meat at dinner ; at uight he receives a herring-salad without potatoes, but with large quantities of onions and sngar, and after it drinks much sugar and water. The next morning he takes the following powder witl syrup: Re Rad. Jalapp., gr. xv ; Sem. Santon., Oss; Gi Gutti, Calom., aa gr. vj; Elæos. Tanaceti, $3^{\mathrm{i}}$; and afterwards drinks black coffee, with a great deal of syrup, or very rich meat broth. Upon this fragments, and sometimes eren the whole, of the worm pass away; when, on the suspicion that another worm may still be there, the expellent pills are immediately given.

R Assafœtidæ, Extract. Gramin., aa $5^{\mathrm{ij}}$; Gi Gutti, Pulv. Rad. Rhei, Pulv. Jalapp., aa 3ij; Pulv. Ipecac., Pulv. Hb. Digit. Purp., Antim. Sulfur. Anrat., aa Эss; Calomel, Эij; Ol. Tanaceti, Ol. Anisi, aa gtt. xv. M. f. pill. gr. ij, consp. Pulv. Lycop. S. Six to be taken every hour. Between the first and second doses the patient takes a table-spoonful of castor oil, and afterwards weak black coffee, with plenty of syrup, between the doses. In the afternoon the worm passes off. If this takes place slowly, a little more castor oil is given in the meantime, and by way of precaution the six pills are administered three times on the following day. (For my own part, I think that this method ought not to be again employed immediately, when one whole worm has been passed. My own observations liave shown me that when several worms inhabit the same intestine, one of them, in passing out, always tears away so much of the others, that the medical man, who certainly must make a careful examination, may see whether there be only one or several tape-worms.)

If this total expulsion of the worm does not take place after the lierring-salad, but there is only an expulsion of single segments, the patient on the following day takes the following mixture, from the morning until seven o'clock in the evening: $\mathbf{R}$ Pulv. Rad. Valer., 3vj; Fol. Sennæ, ziij; fiat Infus. Colat., 年j,


3ij. At noon a thin gruel, with herring, and about eight o'clock in the evening a herring-salad, with raw ham, \&c. Sugarwater to drink.

I consider this method as too exhaustive, aud explain the neces- 
sary subsequent treatment of at least two months, the cause of which is, "that nearly always for 4-6 weeks after the cure more or less worm-mucus passes off," in this way, that the worm-mucus is nothing but a chronic diarrhœa (catarrh. intestinal. artificialis aut traumaticus) cansed by the strong purgatives. Gottel also saw two relapses, and Schmidt himsclf speaks of nests of small worms-a proof that even this metlod is not infallible.

c. Hufeland's method is too tedious, uncertain, and cxliaustive, to render it necessary to mention it.

d. Ritscher's method.-The patient drinks several cups of water-gruel, and then, if a grown person, takes Đss of Dover's powder, and, two hours afterwards, a table-spoonful of castor oil, which is repeated hourly until operation. This is all repeated, if necessary, the next day.

e. Ettmüller's method.-At seven o'clock in the evening the patient takes Calom., gr. xij; Lapid. Cancror., $Э \mathbf{j}$; and, about nine o'clock, Ol. Amygd. Dulc., 亏iss; which usually operate twice during the night. At seven and nine o'clock the next morning the patient takes a powder of $12 \mathrm{gr}$. Gi Gutti and $4 \mathrm{gr}$. Rad. Valer. and Sem. Cinæ, when the worm is entirely expelled.

$f$. Lagine's method.-In the evening the patient takes a clyster of decoction of figs, and the next and two following mornings, whilst fasting, a glass of white wine, with $-\mathbf{R}$ Rad. Valer. syl. rec. pulv., 3j; Putam. Ovor. calcin. et preparata, gr. $\mathrm{xx}$; when the patient should lie in bed, lightly covered, and perspire. For three hours he neither eats nor drinks; then he gets some soup, and observes a strict diet. On the fourth day the following aperient is given: $\mathrm{B}$ Merc. Dulc.,gr. $\mathrm{x}$; Panaceæ Mercur., gtt. iv ; Diagryd. Sulphurat., gr. xij ; Syrup. Flor. Persicorum, q. s. ut fiat bolus, D. S., to be taken in the morning, fasting. Two hours afterwards the patient receives a glass of the following tisane: $\mathbf{R}_{k}$ Fol. Senn. mund., $\bar{J}^{\mathrm{ss}}$, infunde in Aq. ferv. libr., ij, adde Sal. Tartar. fixi, gr. viij, digere per noctem et col. ad usum. An hour after the first glass of the draught, some meat-broth is given. According as the bowels are opened, the draught is continued or not. In the evening another clyster as above described. When pain in the stomach is present, the treatment is commenced with an emetic. The treatment is repeated once or several times in the same course, from the powder to the aperient.

g. Lieutaud's method.-R Diagryd., Cremor. Tartar., aa Đss; 
Antim. Diaphor., grr. xij; Pulv. Rad. Filic. Mar., Pulv. Rad. Mori Fruetu Nigro, aa Oss. M. D. S. at once. And R Pulv. Salbin., Semin. Rutæ, aa gr. viij; Mercur. Dulc., gr. iv ; Ol. Essent. Tanaceti, gtt. vj. M. fiat cum syrup. persicorum bolus, D. S., to be taken at onee, and a glass of an infusion of peachkernels in wine to be drunk after it.

$h$. Desault's method is almost ludierous. He rubbed mercurial ointments into the abdomen, and between the rubbings in administered strong doses of calomel. By this means it is certain the worm will very rarely be expelled, but we may make pretty sure of producing salivation.

$i$. The method of Clossius.-As soon as the presence of the Tcenia has been ascertained by means of turpentine, the patient is kept for four weeks upon a diet entirely consisting of pungent, salted and smoked food, and cheese. With this the patient must drink more wine than usual. For a few days before the administration of the purgative, the patient takes, every evening, a grain of opium or Laud. Liquid. Lyd. Frequently only a single administration of the purgative is necessary. R Mercurii dulcis, Lapidum Cancrorum præparatorum, aa gr. xij. M. f. pulvis, S. No. 1.-Be Ol. Anygd. dulc., 弓ss. S. No. 2.R Gi Gutti, gr. xxxvj; Rad. Angel., gr. viij; Pulv. Card. bened., Pulv. Epilept., aa Эј. М. etc., divide in partes æequal. No. 3.-About four or five o'clock the patient takes No. 1 in a little water, takes only lialf a supper at night, and No. 2 at bedtime. The next morning, if possible whilst still in bed, he takes one of the three powders in a little tea, or in a wafer. In two or three hours, vomiting and liquid evacuations usually oceur, and this is to be assisted with tea or thin broths. If the worm has not passed in two hours, the second powder is administered, and, after again waiting for two hours and a half, the third, after which the worm is always expelled. The worm either passes in a living state on the same day, or on the following day dead. The remedy is rarely unaccompanied by diarrhoca and vomiting, so that the worm itself passes out with a natural stool. For the reasons already given in the geueral section, I can never approve of this method with $T$. solium, as the long preliminary treatment may easily give rise to a dissemination of the embryos in the intestine, and to Cysticercus cellulose in various parts of the body. Trenia solium, above all, requires quick methods. 
Methods with some newer and rarer remedies.

a. Schebdi $=$ Phytolacca dodecandra or abyssinica, Zatzé. Professor Martius, of Erlangen, lad the kindness to send me some of this medicine. I gave ten pieces of this fruit to a clild, although, according to prescription, ninc of them should be sufficient for an adult. Only a few fragments of the worm are expelled, the rest of the tape-worm remained, and has again shown itself, according to the statements of the parents. This remedy probably acts only by the sharp angles of its coat, and the small spines or hairs on its outer surface.

b. Fructus Saoria, according to Martius Soarice, Sauarjae, the fruit of Mœsa picta, Hochstetter (vide 'Med. Neuigkeiten,' 185 k, No. 13, p. 101). Walpers describes the medicine as follows: "The fruits are berry-like, measuring $l_{\frac{1}{4}}$ " in diameter above the middle, with the tips of the calyx persistent, and containing about twelve reddish-brown, nearly tetraliedral seeds." The powder of the seeds is taken in pea-soup. According to the experience of Walpers and myself, the medicine acts harmlessly.

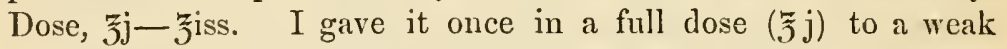
woman-cook, who, according to the statement of the medical man attending her, was suffering from $T$. solium. He had been mistakeı, and it proved that the patient had suffered from Ascaris lumbricoides, and the remedy, a present from Professor Martius, had been administered to no purpose. The consequence of its administration was slight diarrhœa. A boy of ten years old received $\xi^{\text {ss }}$ of the remedy in pea-soup. About three yards of worm passed off the next morning, still alive. Several attempts to expel segments were made five months after the administration of the medicine, without producing any result. No portion of tape-worm was expelled. Nevertheless, at Christmas, after he had eaten carp cooked with gingerbread sauce, the boy was immediately attacked with vomiting and stomach-ache just as at the time when he harboured his tape-worm. He could not be persuaded, therefore, for the time that he did not still suffer from tape-worm. Nevertheless, it is quite possible that the worm was really dead and had passed off gradually unobserved. Dr. Zürn gave the remedy once with and once without result.

Dr. Strohl, of Strasburgh, in an article in the 'Gazette Medicale de Paris,' for 1854 (Des principaux Tænifuges actuellement employés, et de deux nouveaux médicaments de ce 
genre importés d'Abyssinie, le Saoria et le Zatzé), and in the 'Deutsche Klinik,' No. 48, for 1856, has reported upon some experiments marle with the Siroria. Notwithstanding the facility with which the remedy is taken, it appears not to be advisable, as its action is too uncertain. I may give a summary of Strohl's results as follows:

1. In two cases in which the remedy was administered where Tenice were really present, the worm was never expelled up to the head, but always in fragments, which frequently reached nearly to the head.

2. These fragments were usually expelled alive; they were only dead in one case.

3. It was lioped that the remerly would have such a poisonous action that the worm would be destroyed by it, which the Abyssinians indeed suppose to be the case with this remedy, but not so much as with Kousso; this, however, is by no means proved, as all further check is wanting.

4. Violent actions only occurred three times, and these are attributed to the sickly state of the persons experimented on in other respects.

5. The remedy was easily taken; its taste is less repulsive thin that of other remedies; nausea, vomiting, and a little pain in the abdomen are usually the only consequences.

6. After taking the remedy the urine is always of a violet colour, like a dilute solution of a persalt of iron to which a few drops of a solution of tannic acid have been added.

7. Strohl prescribed the remedy in the following way: The night before the cure only broth ; the next morning $5 j$ of freshly powdered Saoria in one or two pints (for adults) of an aromatic infusion, sweetened as much as possible, and taken in two doses. In 2-3 hours the bowels are usually acted upon; should this not be the case, Oleum Ricini. On the day of the cure a light diet is to be observed. If the operation on the bowels be but slight, purgatives are given on the folluwing day to remove the remains of the worm, and the remedy is repeated in a few days if there be reason to suppose that the head remains. (This was always the case.)

8. For Ascarides and Oxyurides this remedy appears to be deserving of recommendation.

There are, however, two essential errors into which Strohl has fallen, and which I must correct. 1. His assertion that even by 
other methods the worm is usually expelied in fragments, and without the head, is untrue. This does not apply to my methods, and I require that, with a good remedy for tape-worm, the entire worm with its head should be expelled. 2. Strohl could not account for the origin of a tape-worm in a child of two years old. After long inquiry, he found that there were numerous cats in the house, with which the child often played! He continues, "Should we not suppose in this case that the child had swallowed the rorm of a cat, which had then become developed in lier body? In our district, however, it is the butchers that furnish the greatest number of tape-worms." I think it is unnecessary to reply to such zoological opinions, as they are expressed without any knowledge of the natural history of the individual species of Trenice. Their contradiction will be found in the preceding pages.

c. Mucenna $=$ Cortex Musennæ, Abusennæ, Besennæ, from Besenna anthelminthica, a leguminous plant. It forms cylindrical pieces of bark, 5-10"1 in length, with a smooth, green epidermis. The bark of old stems is useless. The ordinary dose is $5 \mathrm{rj}$, as Pruner states in his 'Diseases of the East.' The remedy is administered stirred with honey into a stiff paste. I have given this agent, also received by the kinduess of Professor Martius, without any result. Single fragments of worm were indeed given off, but the rorm remained, and it was only in the following rear that I freed the patient from his two Tanice by means of pomegranate bark. Perhaps the medicine had lost its power by loug keeping.

\section{Methods with Tin.}

a. Richard de Hautesiarl's method.-R Gi Gutti, gr. $\mathrm{x}$; Sem. Coloc., gr. iij; cum Amyg. amar. Triturentur et cum Syrup. Absinth. f. boli ij. To be repeated erery eight days.


Ol. Ror. Mar., 3ij, cum Elixir. purg. f. pillul., gr. x, pond. S. Two pills morning and evening, and six ounces of a decoction of fern root to be taken after them.

R Stanni. puriss., Mercur. vivi, aa $\bar{\jmath} \mathrm{j}$; Stanno liquefacto, adde Argent. Viv., postquam mixtum refrixerit, in pulverem cum Conch. Præp., 3j, redigatur.

R Ejusdem Pulveris, Conservæ Abysinth., aa ร̃ij, fiaut c. Syrup. Abysinth., q. s. S. D. Two drachms twice a day.

By far too energetic a prescription. 
b. Matthieu's method.-Preliminary treatment: For some days the patient is to keep a sparing, light diet, such as a herring diet, and then for two or three days to take the follow-

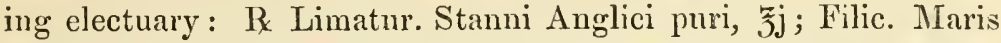
pulverisat., $3^{v j}$; Semin. Cinæ Pulveris, ${ }^{\mathrm{ss}}$; Pulv. Rad. Jalapp., Saì Polychrest., aa $3 j$; Mellis comm., q. s. ut fiat elect.; a full teaspoonful every two hours. As soon as the worm makes itself felt [which may very often be the tin filings making themselves felt], a tea.spoonful of the following electuary is given every two hours: $\mathrm{R}_{\boldsymbol{x}}$ Pulv. Rad. Jalapp., Sal Polychr., aa Эij; Pulv. Scammon., Эj; Pulv. Gi Gutti, Эss; Mellis commun., q. s. nt fiat elect.; or a little castor oil, or a castor-oil clyster, until the worm passes off.

c. Mayer's method.- $-\mathrm{j}$ tin is made into an electuary with honey, and the dose is gradually increased to $5^{\text {ss }}$ of tin.

d. Autenrieth's method.-A powder composed of Эj Stam. Rasp., or more properly of the less irritating granulated tin and Filix Mas, is administered six times a day for three days, followed by a purgative, of which the best is a decoction of gamboge with the addition of castor oil.

$e$. Alston's method.--On the Thursday before a change of the moon (!) an aperient is given; on the following Friday, in the morning, fasting, a syrup with $3 \mathrm{j}$ of tin; on Saturday and Sundar, 5 ss of tin; and on Monday an aperient. I think this method must be quite obsolete. Even Bremser found it insufficient. Even in three months segments of Tanice were being given off again.

f. Dupuis's method.--For those who will not give up the irritating tin filings, this appears to be the best mode of administering tin. Without any preliminary treatment, the patient takes, at six and half-past six in the morning, each time a powder of Stann. Rasp. Angl., Oss; Tannini Puri, Gi Gutti, aa gr. v, and Elæosacchar. Cajeput, gr. iiss; and after each dose dinks two cups of black coffee. In two lours the worm passes off', usually with colicky pains; on the occurrence of which, strong black coffec is immediately given. For the subsequent treatment a tincture of iron.

g. The process is still better when, as Becker recommends, the chemically precipitated tin is used. According to Becker, it is certain in its action, does not irritate the intestine mechanically, and is to be recommended in doubtful cases; it is, however, 
diffieult to be obtained in the shops. However, once for all, I protest against the administration of tin filings, and I believe that no one can have much pleasure in giving this remedy, who has seen the eechymotie irritation of the intestine after its administration to living animals, and heard them whining, ol seen them twisting about during life.

Recently I have twice made use of tin, prepared by precipitation from chloride of tin, in an extremely finely divided powder, by making it into an electuary with honey, a little Extr. Punie. Granat., Extr. Filic. Mar. Ather., and Gi Gutti, or jalap. Even young and wcakly children support this remedy very well. On one occasion the entire worm passed, dead, on the second day. In the other case, in an adult, several yards passed after the administration of this remedy, but the remainder of the worm was only expelled by my ordinary mixture. The remedy is uncertain, and only to be recommended for children and individuals who are much reduced.

\section{Methods with Oil of Turpentine.}

The dose of this remedy is $z^{\mathrm{ij}}$ at once, in the morning, fasting, and if no stool results, another $5 \mathrm{j}$-ij afterwards (Fenwick and Copeland); or, 艿 Ol. Terebinthina made into an electuary with honey, in two doses, at night before going to bed (Thompson); or, $5 \mathrm{j}$ - iiss (Schmidtmann); or, with an addition of Ol. Filicis Maris (Mayor). Or the patient for three days is only allowed to eat water gruel, with small portions of white bread, three times a day; and on the next day, whilst fasting, takes the following mixture: R Ol. Terebinth.,


worm is not expelled on this dily, the dose is repeated on the following day (Merck). Some also give $3 \mathrm{ij}$-iiss, one half in the morning and the other at night. This is one of the most effective agents against tape-worms, as Lange, of Konigsberg, has repeatedly found recently in his own experience. In turpentiue mixerl with white of egg, tape-worms which I had laid in the mixture died within one hour and three quarters. As has already been remarked, the touchstone of a remedy for tape-worms is not whether it expels Bothriocephalus latus or Tania solium, but whether it is also capable of effecting this with $T$. mediocanellata. That oil of turpentine is efficacious in the latter case, I ean prove at any time; for the finest specimen of Trenia mediocanellata that I ever saw, was expelled by it. In general, also, it acts pretty rapidly. 
Lastly, it also has the advantage, that it expels the worm entire and in one piece, which I regard as a requisite of a good vermifuge for tape-worms; partly for reasons of medical polity, and partly upon purely scientific zoological grounds. For reasons of medical polity $\mathrm{I}$ advise this, because the patient requires, and justly, to see the result; and the same must be the case with the medical man, in order to form his opinion as to the value of his method. Many worm-expellers may perhaps save themselves, by always having the head of a tape-worm in store, which they may slip quickly into the fluid in which they wash the worm itself, or into which the washed worm is brought to him-a manœuvre which medical polity would approve as readily as the manouvre of that famous surgeon, who advised his pupils, in a case of lithotomy, always to have another stone conveniently at hand, which they might pretend to take ont of the wound, when there had really been no stone in existence. I regard such manœurres as dishonorable, and always admit it quite openly when I can find no head. I advise it upon pure zoological grounds, for it is only thus that we can easily obtain materials for a certain determination of species.

But notwithstanding these properties, the present remedy has its weak points, dependent on its secondary effeets. The principal thing is not to give too small doses, which readily produce sickness, inclination to romit, ulceration of the mouth, griping pains, and suppression of urine; nor too large ones, as these, especially when they do not produce bilious stools, readily cause tenesmus, and bloody stools and urine; and as the remedy, when taken fasting, readily causes sickness even in large doses. According to some writers, its action varies with the season of the year and the climate. Thus, Thom. Sehmidt (see 'Clarus's Arzneimittellehre,' p. 703) says that it should never be given alone as a purgative in large doses in winter and in moist cold weather, because under such circumstances it has only a heating and not a purgative action. In conjunction with other purgatives, especially castor oil, it assists their action in doses up to half an ounce.

Lastly, according to Copeland, when turpentine is administered after a purgative, or the oil itself does not act as an aperient, tenesmus and bloody urine occur most readily, so that the remedy must then be stopped, and we must endcavour to act upon the bowels with castor oil. Taking everything into account, I regard it as the best metliod to administer this medicine at bedtime, as 
Thompson recommends, and in a dose of $3 \mathrm{j}$; but triturated with $3 \mathrm{j}$ of castor oil, or $1-2$ d̉rops of croton oil, $2-3$ yolks of eggs, and $5 j$ of honey; and to give it in $2-3$ portions in the course of $1-1 \frac{1}{2}$ hour. For children, half the quantity. Thus given, it is ecrtainly one of the most energetic remedies for tapeworm, and justly merits fame in those cases in which pomegranate root has produced no result.

Clossius employs turpentine only as a test for the presence of a tape-worm.

\section{Method with Kousso.}

Kousso $=$ Flores Kousso $=$ Kosso $=H a b i$, i.e., the dried and powdered flowers of Brayera anthelminthica. This remedy, which is making a great noise at present, is adulterated in many ways. J. Clarus found Kousso obtained from Jobst to be adulterated with sawdust. I have alrearly indicated that the sawdust might be probably the dust of a medicine for tapeworms, and, indeed, of the coarser stalks and twigs of the Brayera. It is still more probable, however, that these woody fibres or chips might come from the root of Verbascum Ternacha, which, as well as the leaves of Jasminum floribundam (Herba Zelim), is, as is well known, often added to Kousso, and is even administered alone, in doses of $\% 0$ grains, as a remedy against Tania. In other respects, it acts as a pretty strong narcotic on lower animals, as, for example, when thrown into water it stupifies fishes. For these reasons I should in this ease say, not so much that the agent is adulterated, as that it is often administered in combination with other Abyssinian remedies for tapeworm. According to my experiments, even the thick T. crassicollis of the cat died very soon in white of egg mixed with a decoction of Kousso flowers. The Tania were dead within an hour. The dose of the powder of Kousso is zrj to $3 \mathrm{j}$. For my own part, I have always been more or less unlucky with this remedy, which, in the ordinary mode of administration, shares all the defects of the other remedies for tapeworms, and easily produces sickuess and violent pains in the intestines. In my own experience, I have generally seen the worm expelled in innumerable fragments after the use of this remedy or its preparations. I have only seen larger or smaller portions of the worm, or, at the utmost, the worm up to the neck expelled by it; but have never found the head. In one case I certainly detected frag. ments of tapeworm in the evacuations for three months. Once 
I saw the worm passed up to the neck in the morning, but the head was expelled ouly after the patient had, of his own accord, at once taken a second dose of Kousso, and thus brought upon himself no slight pains in the bowels.

Very recently, Professor Martius, of Erlangen, and Professor Vou Raimann, of Vienna, have done particularly good service with regard to the mode of employing Kousso. Aceording to Martius, the powder of Kousso always killed the worm, but in no case did the head pass away. He therefore endeavoured to isolate the active constituents of the resin. A red resin obtained from Kousso had no action. It was otherwise with a soft resin of the Kousso, of which $9 \mathrm{ij}$ were obtained from $3 \mathrm{vj}$ of Konsso, but in which there was certainly still some red resin and a waxy substance. This soft resin, or, more correctly, resinous mixture, was dissolved in alcohol at $36^{\circ} \mathrm{R} .\left(=\mathrm{J} 13^{\circ} \mathrm{F}.\right)$, and filtered; the alcoholic solntion was dropped upon sugar. As soon as the alcohol was eraporated, the solution was again poured upon the sugar, the whole was well dried, and reduced with sugar to the finest powder, sugar being added until with $\ni$ ij of soft resin the whole quantity weighed 5 ss. This very finely divided resin was mixed with $\overline{5} \mathrm{j}$ of honey, and the whole administered in a period of twelve to sixteen hours, commencing at four o'clock in the afternoon. The next morning an aperient was given (castor oil or a sait). In this way, with this resin most kindly sent to me by Martius, I treated three patients in September, 185 4 ; one of them being a very weakly boy of 14 years old. In all three cases the worm was expelled up to the neek, but in such a fragmentary condition that it was impossible to find the head. This will be the more easy to believe when I mention that the smallest of the expelled fragments towards the neck were scarcely two to three lines in length. One of the patients again passed segments of tape-rorms at the end of December.

Perhaps the more farorable result depends upon some small practical precaution, of which I am not yet aware; but although I must admit the efficacy of the remedy, and the more willingly from the ease with which Martius's resin is taken and endured-. as I hare never seen any bad secondary effects, - at the same time, the extremely fragmentary state in which the worm passes prevents me from giving the remedy a preference over turpentine and pomegranate root. Quite recently, Professor Raimamn, of Vienna, has employed the following method: $5 \mathrm{vj}$ of Kousso are 
macerated for trenty-four lours in cold water, and then boiled for half an hour. This infuso-decoction is then taken whilst fasting in two portions, without straining, and, therefore, with the flowers in it ; and two hours afterwards, $\overline{3}_{j}$ to $\overline{3}^{\mathrm{ij}}$ of castor oil. From the report in Hebra's 'Zeitschrift' for 1854, it appears that the remedy was rery well borne, and acted with certainty.

\section{Method with species of Aspidium.}

A. With Aspidium Filix mas (MIale Fern).-This remedy, which will always maintain its renown against the Bothriocephali, appears hardly to maintain its reputation with regard to Tania. Buchheim, of Dorpat, emplors a soft resin obtained from this drug, with good results, against Bothriocephati. Filicine (filicic acid of Lutz) has as yct found but little acceptance in practice. The most efficacions preparation appears to be the etherial extract of Filix mas, and it would not, perhaps, be unadrisable to administer the powder of Filix mas, mixed with the etherial extract, so as to increase the surface of contact of the medicine as much as possible. For my own part, I prefer adding the extract to pomegranate root. As regards the most farorable season for collecting the root, author's are not ret agreed.

a. Wawruch's method.-Preliminary treatment: 3-1 days of low diet, consisting of strong beef tea, with white bread, three times a day, with the emplorment, at the same time, of the following resolvent: $\mathrm{R}$ Rad. Taraxaci et Cichorei, aa $\tilde{5} \mathrm{j}$, fiat decoct. per $\frac{1}{2}$ hor.; Colaturæ, $\frac{5}{5}$; adde Ammon. Chlor. præp., Эj ; Syrup. Cichorei cum Rheo, 亏̃ss. M. D. S. Two table-spoonfuls creery two hours. With this daily laxative clrsters of milk, linseed, Hb. Alth., Flor. Terbasc., and Flor. Papar., are ordered, and, on the erening before the expulsion, a very rich gruel ( $\frac{1}{2}$ pound of water and $2-1$ ounces of butter and wheat bread).

Expulsion.- - In the morning, fasting, the patient takes a thick gruel ; and about fire, six, and seren o'clock, a clyster of linseed and milk; about cight o'clock, two table-spoonfuls of castor oil ; at half-past eight, Pulv. Rad. Filic. Mar., Эij-Oir ; at nine o'clock, tro table-spoonfuls of castor oil ; at half-past nine, the Fern powder again; at ten o'clock, two table-spoonfuls of castor oil; and at half-past ten, the third powder. After each dose, the patient washes his mouth out with tea made from Flor. Tilire and Summit. Millefolii, and, in the interrals, he chers Flavid. Cortic. Aurantior., of which a dose of $\tilde{5}^{\mathrm{ss}}$ is prescribed. At one o'clock, the patient 
takes a powder of Gi Gutti and Calomel, an gr. v-vj, with Đss Sacch. alb., and puts softening poultices upon the abdomen. If the worm be not expelled, castor oil is again given in half an hour; in a second half hour, gamboge powder; then castor oil again; and possibly, if no traces of inflammation make their appearance in the abdomen, the powder of gamboge and calomel is given again at half-past four. At the same time a clyster is administered every liour.

The subsequent treatment lias for its object the removal of the inflammatory state of the intestines, by mild diet, leeches, \&c. The treatment is said always to fail at the time of full moon (Wolfring).

b. Weisshan's method is a modification of that of Wawruch. His preliminary treatment lasted at first only one or two days, but afterwards three days. On the second, third, or fourth day, follows a herring diet; and on the following day the expulsion in the manner of Tawruch, except that Weisshaar gives the castor oil in meat broth, and, instead of orange peel, candied calamus. Instead of the large quautities of fern powder he only gives $\mathrm{xv}-\mathrm{xx}$ gr. pro dosi, witl $15-20 \mathrm{gtt}$. Ol. Filic. Mar., and eren the latter alone to irritable subjects. Recently Weisshar gires


two table-spoonfuls of castor oil; in an hour, the first powder of gamboge and calomel; in half an hour, oil again; in another half hour, the second powder of gamboge and calomel, and so forth. According to the account given by Weisshaar to Seeger, he easily expels $T$. solium by this means; $T$. mediocanellata (mihi), according to him, requires strong doses of oil of turpentine. Weisshaar's subsequent treatment J omit altogether, inasmuch as it presupposes the reproduction of the worm in the intestine, and no longer agrees with our present knowledge.

$c$. The so-called Wurtemberg method, purchased by the State from Bechler and Rapp, consists of the following treatment. Expulsion; One ounce of fern root is boiled for an lour with three pints of water, in a corered pot; one drachm of eut, fresh Cort. Mezerei, is added to the hot decoction, which is strained in ten or twelve minutes through a cloth, and then mixed with two or three drachms of finely powdered fern root. The patient takes this at once in the morning, fasting; or in three portions, at intervals of an hour. In three or four hours sickness and disorder of the stomach cease, and then calomel, freshly pre- 


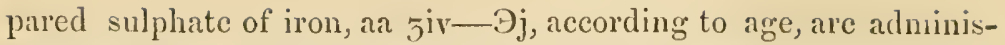
tered, and repeated in case of romiting. 'The worm is generally expelled in the erening; when this is not the case, a rich gruel is giren on the same ercning, and on the following morning, fasting, rhubarb and Rad. Jalapp., aa gr. $x-x v-$ Oij. .

d. Alibert's method.-On the first day, R Rad. Filic. Mar., jiv, coq. c. Aq. Font., 1b.iij, usque ad remanentiam, lb. ij ; Colalturie adde Syrup. Helminthochort., $\tilde{J}^{\mathrm{ij}}$. M. D. S., to be drunk in cupfuls during the day. After three hours of repose, Alibert administers Calomel and Cornu Cervi Ust., aa gr. iij, made into a bolus with Conserr. Rosar., q.s. ; in the crening $5 \mathrm{j}$ of cil of sweet slmonds, and, on the second day, the following purgative: R Scammonii, gr. xriij; Rad. Fil. Mar., Jँj; Gi Gutti, Calonel, al gr. xij, to be taken in three portions, in sugar and water.

$e$. Bicking's method.-This method commences with a sort of cold-water cure; with drinking and clysters of cold water, and a strong diet, such as we meet with in hỵdropathic establishments, in which also a cold bath every evening, with a douche upon the stomach and liver, and in summer a shower bath is employed. When the tape-worm is very troublesome, the Neptume's girdle of these establishments; and lastly, animal magnetism must not be forgotten. With this diet a saturated decoction of $5^{\text {ss }}$ of fern root is drunk cold after every meal, when the worm will be expelled in from three, six, eight, to fourteen days. If this treatment be prescribed for ncrous patients, as Seeger has done, without the cold water appendix, there is nothing to be said against it. Seeger's modification of it appears to me still deserving of trial and recommendation with very irritable, sensitive, and weak individuals.

$f$. N'uffer's method, which has also been adopted by Odier, with a slight alteration.- The evening before the treatment the patient takes a thin gruel (two ounces of butter to a pound and a half of water); a quarter of an hour afterwards, a glass of wine, and, if necessary, a clyster. The next morning, fasting, ziij Pulv. Filic. Mar. in $5^{\mathrm{iv}}-\mathrm{rj}$ Aq. Tilix. In case of romiting, the remedy is repeated; and if a little sickuess be felt, black coffee is administered. 'T'wo hours afterwards, the following aperient pill is given: R Calom., Scamm., aa gr. $\mathrm{x}-\mathrm{xv}$; Gi Gutti, gr. v, vij-viiiss; Confect. Hyacinth., q.s. M.D. With weak patients, and children, to be given in two doses. If the bolus should be thrown up, or should it not have operated in four hours, or if 
the worm liangs out of the anus, 3 rj- 3 j of Epsom salts, dissolved in warm water, are given. If the worm be not expelled by this, the gruel and powder are repeated at night, but the next moming Epsom salts are given insteal of the bolus. Instead of the latter, Odier gives a table-spoouful of castor oil with meat broth, every half hour. This is extoller as a very certain method against Bothriocephati.

y. The method of Blossfeld and liapp, which is very much extolled.-On the previous evening, a thick paste of bread and milk. In the morning, 5j Pulv. Radic. Filic. Maris is given every hour, in an ounce and a half of nutmeg tea (Muskut-Lünel). After six or eight doses the worm is expelled. Rapp advises the root to be always procured fresh, and administers $5^{\mathrm{vj}}-\bar{z} \mathrm{j}$ of it in one dose.

7. Dubois' method.-After a preliminary treatment of eight or nine days, consisting in a scanty diet, to which garlic roasted under the ashes is added, he prescribes rubbing of the abdomen several times a day with a liniment made of camphor, balsams, and nut oil, and also with crushed bulbs of garlic; also a ptisane of Helminthochordon and Filix mas, and a nightly clyster of marshmallow water. After this has passed off, a clyster of milk; and early in the morning, $\overline{5}$ as Filix Mas in broth, and, every half hour, a portion of the following mixture: R Res. Jalapp., Scammonii, Gi Gutti, aa Oss; Syrup. Rhamni cathart., q. s. ut f. Boli, grv. vj.

$i$. Wolftheim's method.-On the day before the cure the pationt has a scanty diet and herring salad; on the rext

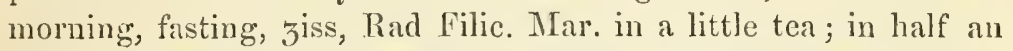
hour the same dose; in another half hour, one table-spoonful Ol.


Then, after the last dose of cod-liver oil, thrce or four ounces of Epsom salts are drunk until the worm is expelled, which generally takes place in ten or twelve liours. In case of thirst, black, sweet coffee is given, and in case of vomiting, this is stopped. According to Böckling this method answers equally well without the cod-liver oil.

$k$. Beck's method.-Abont four or five o'clock in the afternoon the patient takes a powder. R Mercur. Dulcis, Эj; Cornu Cervi ust., Cinnabar. Antimon., aa gr. $x$, in a talsle-spoonful of

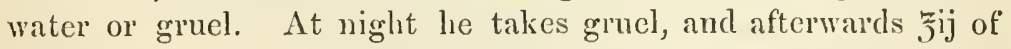
oil of almonds. The next morning, fasting, he takes a powder of the following composition in a tablc-spoonful of syrup: R Rad. Filic. Mar., zj ; Rad. Jalapı., Gi Gutti, Hb. Cardui Bened., Ebur. 
ust., aa $3^{\mathrm{ss}}$. M. fiat pulvis, diride in partes requales 3 . For drink, tea, made from peacli kernels. In two hours, romiting usually occurs two or three times, and the paticut drinks weak broth or tea. The evacuations are carefully examined. If the head of the worm be still wanting, the second, and, finally, the third powder is given. If this does not answer, a clyster of decoetion of bitter herbs with Sal anglicum is administered, and if the worm should not be expelled even then, the following porder is giren within three hours: R Pulv. Rad. Jalapp., Hb. Gratiol., aa Эj. MI. f. p. doses 3 . According to some authors, as, for instance, Meyer, the combination of Filix with purgatives does not answer at all.

l. Mayor's method.-Mayor, of Geneva, who regards the root of Filix mas as specific against Bothriocephalus, but tin and pomegranate root against Tenia solium, states that the powder of the fern root should appear quite green, as otherwise it is inefficacious. He gives $5^{i i j-i v}$ in a mixture of balm tea, and $\overline{5} j$ of gum syrup. This draught is to be taken at night, and the next morning $\overline{5}$ iss of castor oil.

Mayor gives the Oleum Filicis Maris in the form of pills, $30-50 \mathrm{gtt}$. in twenty-four pills, of which twelve are taken at night and twelre in the morning, and an hour afterwards 亏iss of castor oil. He gives the fluid cil pure or mixed with castor oil, in doses of $3^{\mathrm{ss}-\mathrm{j}}$, but usually gires the caster oil afterwards.

$m$. Herrenschandt's method.-According to Herrenschandt himself, when the stomach of the patient is in good condition he gets, in the morning, fasting, and at niglit, after a light supper, for two consecutive days, a drachm of Pulv. Rad. Filic. Maris or Femin., in water or in wafer. The roots should be collected in the autumn and dried in the shade. On the third morning, fasting, the following powder is given: $\mathrm{B}$ Gi Gutti, gr. xij; Sal. Abysinth. Neutr., gr. xxx; Sapon. Starkei, gr. ij. In two or three hours this is followed by slight romiting and feeal evacuations once or twice, during which the patient drinks lukewarm water or tea. Three hours afterwards he takes $\tilde{5} \mathrm{j}$ of castor oil in meat broth, and again in an lour; and if, after this, the worm is not expelled within two hours, he takes another ounce. If this does not succeed, a clyster of water, milk, and $\tilde{5}^{i i j}$ of castor oil is administered.

n. O. Bang's method.-For three days the patient takes 
only one basin of meat broth, with white bread. At night he has a clyster of warm milk. On the fourth day he takes also eight cups of black coffee with plenty of sugar, and $2-3$ large herrings in the form of salad with plenty of vinegar, pepper; oil, and onions. On the fifth day he takes, alternately, every two hours, one third of a herring, and a heaped-up tea-spoonful of Pulv. Rad. Filic. Mar., and with this $2-3$ cups of coffee. At night a milk clyster and a dessert-spoonful of American castor oil. On the sixth morning, fasting, two tea-spoonfuls of Filix powder; an hour afterwards two table-spoonfuls of castor oil, and the same quantity every two hours until the worm is expelled. During this he drinks tea, and, lastly, for the subsequent treatment, iron is used.

The fern powder alone is given by (a.) Ullersperger.-Without any previons treatment he gives 3 iij-iv of the roots freshly peeled, treated with alcohol the day before, and lets the patient lie in bed. When no romiting takes place within two hours, an aperient of $6 \mathrm{gr}$. Calomel and $9 \mathrm{j}$ Sapo Jalapp. in pills is given. This is a very celebrated, rapid method.

b. Mayer.-On the day when fragments pass off spontaneously the patient takes a herring salad at night. At six o'clock the next morning ziij of Filix powder, with $\tilde{5}^{\mathrm{vj}} \mathrm{Aq}$. Flor. Tilia, is given in tea-spoonfuls withont stopping, and immediately after this a table-spoonful of castor oil, and then a cup of thin broth. The oil is then continued every half hour until $\frac{5}{5} \mathrm{j}$ are consumed. For any sensation of fulness and nausea hot black coffee is given. About twelve o'clock the greater part of the worm is expelled, and the head passes at one or two o'clock. For subsequent treatment an Amarum.

$c$. Karsten.-A mild aperient and scanty diet the day before. Early in the morning $3^{i i j}$ of fern root in tea-spoonfuls. In case of sickness, thin broth is given. Between eleven and one o'clock the worm is expelled without any further treatment.

Besides the methods just described, other medical men have also employed the Extractum Filicis. 'lhus, Peschier gives the following prescription: R Extr. Filic. Mar. Astl., Эj-zss; Pulv. Rad. Filic. Mar., q. s. ut fiant pill. 20. D. S. in two portions, half an hour before bedtime, after fasting from five o'clock in the evening; next morning an aperient. 'Tott, Schocnemann, and Von Haselberg also gave the remedy before bedtime with good results, in the same way as Peschier. Nicolai also has given $Э \mathbf{j}$ 
Filic. Mar. Asth. twice at bedtime, and the next morning an aperient. Kieser and Miller gave the extract for several days together to the total amount of 5 iij, with good results.

After several days of sparing diet, Mösing gave fifteen of Peschier's pills to the fasting patient at nine o'clock, and again at half-past nine; his prescription is as follows: R Extr. Filic. Mar. Eth., 5iss; Pulv. Rad. Filic. Mar., q. s. ut fiant pill. xxx. Soon after the administration of the last dose he gave $\tilde{5}^{\text {iij }}$ Infus. Semn. compos. at once.

Funk gave the extract, night and morning, with syrup and a little gum, and then gare castor oil every hour until it operated.

Noss gives an aperient on the preceding clay, and then gives the extract to the fasting patient with syrup; $9 \mathrm{ss}-5 \mathrm{ss}$ of the extract twice, with an interval of an hour. He then gives castor oil every hour.

Friedrich, on the day when segments have passed spontaneously, lets the patient eat a herring salad at night, and afterwards drink a glass of wine with a biscuit. He then gires $3^{\text {ss }}$ of the extract at bedtime. The next morning, from six o'clock, he gives every hour tiro tablc-spoonfuls of castor oil, or a tablespoonful of a mixture of $3 \mathrm{gr}$. Ol. Crotonis and $5 i j$ Syrup. commun. If the patient has a tendency to romit, croton oil must be aroided. In the intervals between the purgatives the patient may drink a cup of broth or chamomile tea. If the worm be not expelled by nine or ten o'clock, he abstains from all attempts at expulsion by aperients.

Albers makes the patient observe a strict diet for $1-3$ days, and on the day before the cure relaxes him with Glauber's salts.

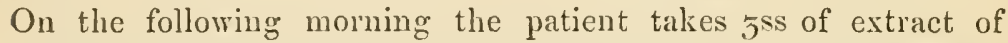
fern whilst fasting, and the same quantity an hour afterwards; 1-2 hours afterwards he takes castor oil.

Rayer gives 72 drops of Peschier's thin extract of fern, made into pills with the powder of the root, of which eight are to be taken at night and eight in the morning. Two hours afterwards, castor oil.

Magendie prepared a tincture from the buds of the fern, and had pills made from it, each containing a drop of the tincture. From eight to thirty pills were sufficient for expulsion.

B. With Aspidium athamanticum (Kunze) = Panna.-In his 'Prodromus Floræe Capensis,' p. 306, published in 1850, 
Dr. Pappe mentions the Ucomocomo-bark as an anthelmintic used by the Zulu Cafires at Port Natal, which was particularly employed for Tcenice. He refers to it as Aspidium athamanticum of Kunze. It is probably identical with the Pama. As France and England have had their Konsso-mania, Germany must also go through its Panna-mania. For this remedy, which, according to Dr. Berg ('Deutsche Klinik,' No. 46, 1856), is certainly an Aspidium, perhaps A. athamanticum (Kunze), but probably not a distinct species-A. Panna, as Dr. Lucanus of Quedlinburg, thinks-we are indebted to a brother of Dr. Behrens, of Quedlinburg, who is living in Southeru Africa. It has given rise to a lively dispute, since Dr. Behrens called attention to this wonderful remedy in No. 53 of the 'Berlin Nationalzeitung,' for the 11th of March, 1853. The 'Magdeburger Zeitung' for the year' 1856 again sang the praises of this remedy, the origin of which was kept to a certain extent in obscurity, and the 'Deutsche Klinik' for the 26th of July, 1856 (No. 30), reported that ont of 90 cases, Dr. Behrens had expelled the. worms with the head in 83 ; that in two cases the worm was not found; twice nothing was again seen of it; and that the remedy produced no result in three cases, because it was thrown up. At the same time the remedy was sold at a price of three dollars, for a dose of 5 iss at the utmost, which ought certainly to have given a very fair profit.

In the three cases in which $I$ administered it, or saw it given, it did not fulfil the expectations which one would form of so expensive a remedy. One patient took the remedy early on the 19th of February, 1856, and as no passage of the worm had taken place at moon, he took a second dose, besides Panna clysters. The Tania mediocancllata, from which this patient suffered, ayain threw off proglottides on the 22d of Novenber, 1856. The worm was then expelled hy my extract of pomegranate root. A second patient suffered with two Tania mediocanellate. A drachm of the remedy and a Panna clyster brought to light two Trania, completely broken up, in twelve hours; on these, notwithstanding careful examination, no head was to be found.

A third patient, who suffered from $T$. solium, which is so easily expelled by cxtract of pomegranate root, certainly lost fragmentary series of segments, but without the head, which would probably grow afterwards.

But if any one wishes to employ this medicine, which scarcely possesses any advantage over Aspidium Filix mas, unless it be its 
expensireness, which also shares all the disadvantages of Kousso, especially that of expelling the worm in fragments, and which, lastly, from its extraordinary slowuess of action, from the necessity of a tedious preliminary treatment, produces sickness, vomiting, sc., as well as other remedies-if any one will nevertheless employ it, then, according to Dr. Behrens, the following rules are to be observed :

1. Preliminary treatment.-For three or four dajs before the cure, nothing but easily digestible food is to be taken; all sorts of flour gruel and cakes arc to be avoided, as well as potatoes, and all spirituous liquors; because in dogs to which the latter were administered, the Panna produced no result (!). For habitual costireness, Carlsbad salts or lavements are to be administered.

2. Day of cure.-In the morning, fasting, every quarter of an hour, 20-30 grains of Pama powder in as little water as possible, or in light beer, until $5 j-5$ iss have been consumed, according to the age and condition of the individual. If the bowels are not moved, castor oil is given some time after the last dose. Too early an administration of castor oil tears the worm away, according to Behrens, in consequence of the too early occurrence of peristaltic movements; if it be administered tou late it is also injurious; it should be given when the worm has arrived in the colon, which is easily to be ascertained, as the patients (by hoaxing the surgeon,) may indicate how the worm passes down. It is best given two hours after the last dose. When the bowels are violently moved, and too much of the medicine has been given, the worm passes in fragments (which it certainly does even with doses of ouly $3 \mathrm{j}$.) When the worm hangs out, Panua clysters are administered (which are also of no use, K.)

Disagreeable circumstances soon disappear-they are, vomiting, especially in men, which, however, may be suppressed by the will, and is not injurious when it does not occur for an hour after the taking of the remedy; and congestion of the head for about an hour and a half. Pregnancy is no counter-indication, any more than lactation and menstruation. Hysteric patients may take $2-3$ grains daily for a considerable time, which stops the passage of the segments for some weeks (but certainly will not kill the worm.)

Of course the remedy which furmishes such extraordinary 
curative results is also a remarkable tonic, acting for a long time after the cure (!).

\section{Methods with pomegranate bark.}

Dioscorides (в.с. 50), and after him Celsus and Pliny, mention the Radix Punice Granat. as a vermifuge. In the Middle Ages the bark was neglected as a vermifnge, although Michael Hero (1553) and Ad. Lonicerus (1609) make mention of it. In the East Indies, however, its fame in this respect has remained the same from time immemorial, and from thence it was brouglit into Europe by the English physician, Buchanan, and has since always maintained its celebrity. Amongst the Germans, Bremser refers to Buchanan's method; Flemming, in 1810, published the first observations. On the introduction of the remedy, Breton in England, Gomez in Portugal, and Mérat, the translator of Gomez, in France, did good service. Seeger, who deserves credit for the statisties of this medicine, states that of 419 cases treated with it up to 1852,371 are reported as complete cures, 24 as doubtful, and 24 as unsuccessful. I could considerably increase the number of successful cases, partly by my own observations, and partly by those made by others according to my method, but Seeger's statements are quite sufficient here.

The pomegranate tree (Punica granatum) grows in the East and West Indies, in the South of Europe, especially in Spain, and in our greenhonses. It grows to a height of 16-20 feet, and has beautiful red flowers. The bark of the roots is collected in the spring, before flowering, and dried in the shade. It forms tubular or rolled pieces, $2-6^{\prime \prime \prime} \operatorname{long}$, $\frac{1}{2}-1^{\prime \prime \prime}$ broad, and $\frac{1}{4}-1^{\prime \prime \prime}$ thick, with externally uneven, wrinkled tubercles, and a grayishyellow spotted epilermis, a yellowish parenclyma, and a fibrous greyish-brownish-yellow inner layer, which is here and there dingy green, and to which pale-yellow alburnum often adheres. The rest will be found in every Materia Medica. Attempts have been made for a long time to find the active principle of this bark in some particular alkaloid. But all experiments liave been in vain. Latour de Trie's granatine was only mannite. Tannic acid; and, amongst others, gallic acid, giving a green colour with iron, are the principal constituents: and with these are resins and a body resembling piperine (Landerer), the existence of which, however, is not yet determined with certainty.

In my opinion, besides the adulteration of the commercial 
bark with that of Buxus sempervirens, Berlieris vulgaris, and Capparis spinosa, and its impurity from an abundance of alburnum, the only things that concern the practical man arc the following:

1. 'The fresh bark-of which, however', more is used ( 3 iij $=z^{\mathrm{ij}}$ of dried bark) -acts more gently than the dried bark (Breton).

2. The bark of the root is more active than that of the trunk; $5^{\mathrm{iv}}$ of the latter $=\overline{5}^{\mathrm{iij}}$ of the root. The bark of the branches has no action (Schmidtmüller).

3. After maceration for at least 12-21 hours, the bark is well boiled, and, according to Cenedella, it is better made in earthen than in metallic vessels; it is filtered whilst hot, as on cooling active substances appear to be thrown down again. The decoction was formerly most gencrally used, but I prefer the extract. The best metlod of preparing this is as follows : R Cort. leviter contusi Rad. Punic. Granat., 亏iv; maceretur per horas xxiv, cum Aq. Distill., lb.j, posthxe coque in leni calore per

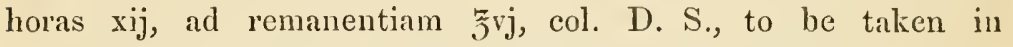
$3-4$ doses at intervals of from half an hour to one hour.

4. According to both Schmidtmüller and Gomez the East Indian bark-and which, according to Dr. Wiggers, is thicker-is to be preferred to the European.

5. Schmidtmiiller always gave the fresh bark, or advised the use of the extract prepared in the East Indies from the fresh bark by Waitz. According to German medical men also, the fresh bark, even that cultivated in Germany in gardens and greenhouses, is more efficacious than the dried bark, and WVaitz's extract is very active. The dose of the latter is $5 \mathrm{j}-5 \mathrm{j}$.

6. The fresh extract which is sent to us from the Last Indies acts in the same way as an extract prepared from the dried bark in the steam-apparatus. I prescribe as much of it as is obtained from siv-vj of the dried bark.

7. The most efficacious form under all circumstances is the solution of the extract in a certain quantity of water. The method of administering the bark in powder (gr. xij- $Э j$ for children, 9 ij for adults, every half hour or hour, until six powders are used) is certainly the least advisable of all. The extract itself, made into an electuary with honey, or administered in pills, is to be recommended when there is great tendency to vomit, but on the whole its aqueous solution is the best.

8. An alcoholic extract is also recommended by Deslandes, and recently by Martius, and an etherial extract has been pre- 
pared by Waitz in Java. Of the latter 3 iij-iv are administered in $\overline{5}^{\mathrm{V}}$ of fennel water with Syrup. Cortic. Aurant., $5 \mathrm{j}$, in three doses, at intervals of half an hour. The alcoholic extract, very carefully prepared in the "Johannisapotheke," in this place, I liave seen only once given.

9. Although, for the preparation of the active substance of the bark, which must consist especially in a resin, boiling water is to a certain extent sufficient, the addition of caustic potash or soda, or of a little white wine, to the water employed in the maceration, and afterwards in the decoction of the bark, greatly increases the efficacy of the extract.

10. Old bark which has remained long in the warehouse is to be rejected as inefficacious, and not to be employed in the preparation of the extract.

Seeger narrates that Breton and Gomez poured a decoction of pomegranate bark over living tape-worms, when they curled thomselves up, became contracted, hard, and twisted, appcared to experience pain, and died within fire minutes in convulsions. Whoever takes the trouble of repeating this experiment, will sec how artistic, but at the same time low untrue, this description is. In the experiments made by me, as already described, with pomegranate bark, I obtained satisfactory proofs of the energy of this excellent remedy.

Of the particular methods of administering the decoction I may mention the following as the best known:

a. With fresh bark-Buchanan's method.- Z Jiij of fresh Cortex Radicis Punic. Granat. are boiled with three pints of water until two pints remain, and drunk in cupfuls at short intervals until the worm is expelled. By this violent vomiting, colic and purging are produced.

Breton's method.- - 5 ij of the fresh back are boiled down


lb. $j$, and the decoction drunk by cupfuls.

Mérat's method.-At night ₹̈ij of fresh bark are infused in lb. iss of water, and left to macerate through the night, and boiled into lb. $\mathrm{j}$ in the morning. It is then filtered and well pressed. This decoction is to be taken by the patient in threc equal parts in two hours. The treatment is only discontinued in case of too great heat or cold. If romiting occur after the first dose, we are not to be deterred from giving the following doses; but if the patient romit thesc, we must desist from the treat- 
ment. The worm may even be expelled from pregnant women without injury, in the fifth and sixth months.

Schmidtmüller's method.--After one day's fasting and the administration at night of $\overline{5}^{\mathrm{ij}}$ of castor oil, $\bar{J}^{\mathrm{iij}}$ of fresh bark, after macerating for twelve hours in $\overline{5}$ xij of water, are concentrated to $5 \mathrm{vj}$ by a gentle heat, and this fluid is taken in three doses within an hour.

In all these methods evacuation takes place without purgatives, as the fresh bark usually acts as an aperient itself; and in this lies the great advantage of the fresh bark, and a principal cause of the great uncertainty of most of the previous methods, in which the dried bark was employed. To produce the aperient action with certainty, the dried bark needs the addition of purgatives. According to my experience, the neutral salts and the true drastics, such as jalap, are greatly to be preferred to the oils. But they all have something to be desired; but I regard it as the most natural plan to imitate the purgative action of the fresh bark by the addition of some other agent which acts as a purgative. To refer to particular methods here would be superfluous, as they all agree. At the utmost they vary in the dose of the bark and the preliminary treatment with castor oil.

As regards myself, I prefer the Extract. Radic. Punic. Granat., prepared according to the prescription above given, to all other remedies for tape-worm with which $I$ am acquainted. As the cases scattered through medical literature and my own experience hare shown me, the Kousso loses much of its value, because the worms are expelled so much broken up in the region of the neck, whilst in almost every case of expulsion effected by the pomegranate bark we find it stated, "The worm was passed in one piece with the head," or "The entire worm passed unbroken, and in a single coil ;" reason enough for our taking trouble to make the administration of this remedy more agreeable, and by which we can render its results still more certain.

b. Combined methods with pomegranate bark and Filix mas.One of the first who combined the etherial extract of fern roots $(Э \mathrm{ij})$ with the decoction of commercial pomegranate bark, was Von Klein, of Stuttgart.

I myself combine the aqueous extract of pomegranate bark, prepared as above, with Extract. Filic. Mar. Ather., in the following manner: R Extracti Radic. Punic. Granat. aquosi, 


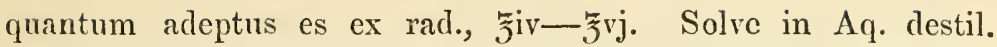
fervidle, ${ }^{\mathrm{yj}}$-viij. Adde Extract. Filic. Mar. Ather., Эj--3ss; Extract. Tanaceti vulgar., $3 \mathrm{ij}$; Gi Gutti, gr. iv, vj, ad. x. M. D. S. To be shaken. A cupful to be taken in the morning (six or seren o'clock) fasting. A similar dose in three quarters of an hour. The third is kept in reserve. If the worm should not be expelled in an hour and a half after the second dose, the last portion is also to be taken. I formerly gave Natr. Sulf.; now I administer immerliately Gi Gutti, gr. iv - vj, with good results, If vomiting occur, a table-spoonful of the medicine is given every ten minutes.

To alleviate the tendency to vomit, the patient should gargle after every dose with fresh milk, but without swallowing any of it. Between the doses also lue may talic as much Elwosacchar. Citri as will lie on the point of a knife as often as he likes. If no cvacuation have taken place three hours after the first dose, and the worm lrave not been expelled, an aperient is administered. With Tenia solium castor oil is usually sufficient, 1-2 table-spoonfuls every half hour or hour; or, R Gi Gutti, gir. vj-viij; Pulv. Rad. Jalapp., gr. $x-x v$; to be repeated again in case of need in two hours. With T. mediocanellata I have found the best results with a stronger aperient: $\mathrm{R}$ Calomelan., gr. iv-vj; Pulv. Jalapp., grr. $x-x v$. M. D. S. at once.

Subsequent treatment.-None, except tonics in cascs of great weakness.

Preliminary treatment.-At the season of fresh strawherries* and grapes I give half a pint of the fresh fruits crcly morning, fasting, for $6-8$ days, and on the evening before the expulsion a herring salad, with plenty of vinegar, onions, raw and boiled ham, and plenty of oil, and to very costive persons $3 \mathrm{j}$ of castor oil; after which the patient may drink a large glass of light Rhenish wine, or a glass of bitter beer (Bavarian, Waldschlosschenbier, \&c.) If these fresh fruits cannot be had, the salad alone must suffice.

In very obstinate cases of Tenia mediocanellata, I let the

1 I take this opportunity to mention the methodical strawberry treatment, which I have adopted in various cases, without having a tape-worm to treat. I have cmployed strawberries taken fasting for three or four weeks together in eases in which whey and mineral waters could not be borne, but in which regular mineral-water treatment slould have been preseriber from the presence of abdominal stoppages, chronic cramps of the stomach, and similar disorders. 
patient take so much of the ordinary Electuar. Lenit. of the English Pharmacopocia, with the addition of Extract. 'Tanacet. vulgar., $3^{\mathrm{ij}}$, to the ounce of electuary, as is necessary to produce a couple of soft motions daily; lie then takes the mixture, and not beforc. Fasting the night before the cure is bad. The medicine does not agree well with a perfectly empty stomach.

Another method is as follows: Re Rad. Punic. Granat., 亏vj;

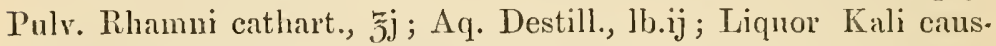
tici concentrati, gtt. x. Macera per horas 12-14, coque leni calore in balnco vaporat. per horas 24 , ad remanentiam extracti MI. D.S. as above. As a matter of course, no Natr. Sulfuricum is to be added in this case, and the woody parts are to be removed by washing and pressing some time hefore the conclusion of the evaporation, the washing water employed being evaporated with the rest. As this extract may be kept as well as the preceding one, all that is necessary, when it is kept in store, is to discolonr a portion colresponding with the dose of ponegranate root prescribed, in $\overline{3} \mathrm{vj}$-viij of hot water, and before administration to add to it $Э \mathrm{j}-\zeta^{\mathrm{ss}}$ Extract. Filic. Mar. Ether. The keeping of the extract cannot injure the action of the medicine even in case of fermentation, as, according to Latour de Trie and Ferrus, the remedy when undergoing fermentation is still nore certain in its action.

I have no experience of the Extract. Rad. Punic. Granat. spirituosum. I arlministered it once combined with Kousso, and Extr. Filic. Mar. Ether., made into an electuary with honey, in a very obstinate case of Tenia mediocanellata; the only result was that I expelled two of these Tanice up to the neck, although I gave after it an infusion prepared from 5 vj of macerated Kousso (Raimann). I must, however, observe, that the employment of the aqueous extract, prepared according to the above prescription in a honey electuary, appears to be less advisable than its solution in water.

To sum up everything in a few words, I may give the following general counsel :

1. For the expulsion of the Bothriocephati, simple methods with Filix mas, and especially with its etherial extract, are sufficient.

2. For the expulsion of Tania solium, the methods just recommended of administering the ayueons extract of pomegranate bark with the addition of Extract. Filic. Mar. Ether., are the 
most advisable. It has appeared to me lately that the addition of Gi. Gutti, gr. iv-riij, to this mixture, was better than that of Natr. Sulf.

3. 'This method is often sufficient even with $T$. mediocanellata, especially when the above-mentioned calomel powder is given afterwards as an aperient.

4. In obstinate cases with one or more $T$. mediocanellata, the method recommended by Thompson, and not essentially modified by me, which will be found at the close of the scction of "Metliods with Turpentine," is better than any other, except, perhaps, the method employed by Becker with tin precipitated by galvanism, the latter in such a manner that Dupuis's plan, mentioned under $b$ of the methods with tin, be modified by giving, instead of Stann. Rasp. Angl., Oss, the same quantity of Stannum galvanice precipitatum.

5. Kousso has never answered with me so well, that I could prefer it, when given alone, to the other remedies. It is, lowever, probably capable of giving good assistance.

6. The other methods, but particularly Schmidt's, as also the long fasting cures, deserve to be struck out of the resources of the medical art.

7. If the worms depend from the anus, a cup of strong black coffee with plenty of sugar is given immediately, and, if necessary, also an aperient of calomel and jalap.

II. Immature Trenie inhabiting the human body exterior to the intestine; Cystici and Acephalocystides of the older authors.

\section{Cysticercus cellulose.}

See the article Tenia solium, where this is treated of at length.
2. Cysticercus tenuicollis (Eschricht) = Cysticercus visceralis, autorum. Pl. II, figs. 6- 10 .

[Trnia matura: Corporc crasso 4 ad 6 seu 6 ad 1200 millim. long., Tæniæ solium corpori simillimo. Capite globoso-sphcerico, 
parvulo; osculis sutoriis et rostello perparris (0.34 millim.) collo tenuiore, quam in 'T. scrrata et Cœnuro; hamulis duplice ordine positis (32, 38, 40 ad 4.2), ex Leuckartii mensuris 0.178 et 0.114 mill., ex meis $0.175-215$ et $0.117-126$ longis, proceris, ninus aduncis, spinâ (Dorn, Tap, dental process) in hamulis majoribus perlonght, tenui et rectâ, in hamulis minoribus etiam longiorc et bipartita et stylo, qui unguis maynitudine superatur, instructis. Strobila ex articulis composita, quorum postremi longit. habent 10-15 mill. et latitudinem 4-5 mill.; pori genitales irregulariter alternantes; uterus trunco mediano perlrevi, ramis lateralibus majoribus perpaucis $(9-11)$ et perbrevibus, unde ramificationes in turmis posite emittuntur. Ovula 0.039 mill. long. et lat.; testâ crassiore $(0.0057$ mill.) et embryonilus 0.02 long. et lat. Proglottides perlonge et procerc.

Habitat in Cane domestico et Cane Lupo (T'enia maryinata, autoruns).]

Scolex quiescens $=$ Cysticercus teunicollis. Vesicâ candali tenui permagna $\left(1,2,4,6^{\prime \prime}\right.$ et ultra), corpore $14-30$ mill. et ultra lonyo, 5-10 mill. lato, cylindrico; collo 8-15 mill. longo, capite uti in Tania filis 2 gelatinosis, pone collo ex receptaculo capitis aut scolicis in vesica cavitatem emissis. Metamorphosis in Taniam 10-12 hebdomates post pastum peracta.

Habitat: Rarius in hominis abdomine (mesenterio et hepate), sapius in Ruminantium, Equi, Suis Scrofe, Sciuri, Simice, Sc., cavitate abdominali.

The mature Trenia from which this eystic worm is derived lives in the intestines of dogs, especially sheep-dogs and butchers' dogs, and also, no loubt, in those of the wolf: According to Leuckart, it is identical with Rudolphi's Tania marginata of the wolf. In size it most resembles $T$. solium, from which, however, it is distinguished by the form, number, and size of the hooks, by the degree of dilatation of the uterus, the great development of the lateral longitudinal vessels, and by the structure of the neck. Although the hook-sacs and pigment are more distinct in $T$. solium, traces of them may, nevertheless, be discorered in this species. This worm grows to a length of about $2-3$ yards; its mature segments are essentially distinguished from those of all other large-hooked Tamice of the dog by their size, equalling or even frequently exceeding those of $T$. solium in this respect. I shall err little from the truth, in expressing the opinion that the Tanice described as T. solium 
in the intestines of the dog by the older authors, generally belonged to this species. For the detcrmination of the species the table of sizes given at the end of this section, and the figures of the hooks on PI. II, figs. 7-9, are sufficient.

The rather slender and less strongly curved hooks are remarkible by the extraordinary length of the spine (Dorn, Tap, Zahnfortsatz) in both series, and at the same time stand nearly at a right angle, with the apex rather directed a little downwards. The spine of the second series is, in its greatest length (see table of looks, p. 242, second series, $d, a$ ), nearly equal to the stem, which, especiaily in the hooks of the secoud series, is very small, short, wcak, and slender. In both hooks, the stems are ouly about 0.02 mill. longer than the claws or sickles.

In tolerably firm specimens the neck is drawn together in spirits, so that it appears to form a strong cmre or noose. With this appearance it is difficult to see the justice of the application of the name "temicollis" to this Trenia, which has been adopted for it by Dr. Möller and the committee of examination in Copenhagen, even withont taking into consideration the fact that the name "Trenia tenuicollis" has already becn employed for a Trenic of the martens and polecats, the Cysticercus belonging to which I have found in the liver of the field-mouse. The marginal genital orifices are irregularly alternate. The uterus is formed by a short, thick, dilated median branch, from which a very few principal branches are given off towards the sides. Of the latter I have counted as many as eleven. They divide into numerous short diverticula, which are at first undivided, and only fork near the margins of the segment, towards which they are generally directed perpendicularly. In consequence of this arrangement, the uterus acquires the appearance of a garden-rake, at the upper and lower margins of the segment. The different short diverticula, msually stand perpendicularly upon the last principal transverse branch, and at its lowcr extremity even the stem of the uterus divides in the form of tceth. I regard this form as very characteristic, and venture from this to distinguish the segments of this Tania from those of $T$. solium, T. Ccenurus, and T. serrata veru. It follows as a matter of course, from what has been said, that the isolated segments, when thrown off (the proglottides), considerably exceed the segments of the other large-liooked Trenice of the dog in size, and in this respect equal those of a Trenia solium which 
lias not had a too abundant supply of nourishment. In the human subject it has not yet been found, and, indeed, there ean very rarely be an opportunity for a man to aequire this Tonia, as its scolex from its size attracts the attention of the butclicr, so that it is eut out, thrown away, and swallowed by the expectant dogs. An experiment made with Cystic. tenuicollis on the murderer referred to under $T$. solium gave no certain result, and it must remain for futurity to determine whether this Tenia thrives in the human intestine or not. Dr. Möller, also, who swallowed several Cysticerci tenuicollis, did not acquire any Tcenice ex Cyst. tenuicolli. I have often bred it in the intestine of the dog; it becomes mature in 10-14 weeks. It is as well, in the artificial administration of the cystic worm to dogs, to cut the caudal vesicle, as uninjured vesicles are easily romited by dogs. Moreover, this cutting is the most in accordance with nature, as, when the butcher throws such a Cysticercus to a dog, the latter chews and injures it before swallowing it, which is not the ease when we push the cystic worm down the throat of the dog.

The six-hooked embryos live cnclosed in eggs of 0.039 millim. $=0.0176^{\prime \prime \prime}$ in lengtl and the same in breadth.

The eapsules of these eggs have a much lighter colour than those of the other large-hooked Tania of the dog, and they are smoother on their outer surface. The embryos themselves present the well-known six embryonal hooklets pretty distinctly; these are of the following size : 0.003 millim. $=0.001^{\prime \prime}$ in length, the embryo being 0.022 millim. $=0.004^{\prime \prime \prime}$.

That these eggs must be at some time or other in the human intestine, and that the embryos must be found for a time free in the human body, is a matter of course; but our means are not sufficient to discover the migrating embryos with our present instruments.

The scolex state of this Tania forms the Cysticercus tenuicollis, which, having been frequently seen in man by the earlier authors, was mentioned by them as Cystic. visceral. hominis ; but having become more rare in modern times, or at least amongst us and the civilised nations of Europe, has therefore been entirely struck out by modern authors, or placed amongst

I In domestic animals the Cysticercus tenuicollis was known (vid. sup.) to Hartmann and Tyson: Peyer, in 1689, also described it, but only as a hydatid, and it was known to Bartholin (1653), Steno, and Harder. 
the donbtful Helmintha, as by Diesing and Virchow. Rudolphi certininly does not venture to deny its occurrence, but says of it, "res valde ambigua, mihique in cadaverum humanorum aliquot millibus nunquam visa." It is to Eschricht that we are indchted for having proved that this worm really occurs in the human subject. Eschricht, moreover, thinks that many cystic worms of this species have occurred encysted in the liver of the human subject, and I add to this that they may also probably still remain in muscums of pathological anatomy in unopened cysts, having been regarded hitherto, as for instance by Diesing, as Echinococci, or perhaps even as Acephalocysts. Although I have formerly seen in the livers of domestic animals many cysts which simultaneonsly harboured Echinococci and Cysticerci tenuicollis, it happened only very recently - when I was about giving to a dog a number of cysts cut ont of a pig's liver, which had all the same appearance, and nearly the same firmess of the walls of the enveloping cyst, were miformly imbedded in the tissue of the liver, and one of which, when opened and examined with the microscope, was proved to be Echinococcus veterinorum-that I nearly allowed myself to be deccived by appearances. And althongh the pig contained six cysts with Cystic. tenticollis in the mesentery, I had, nevertheless, from the similarity of their exterual appearance, regarded the cysts cmployed in feeding my dog only as Echinococci, and I was, therefore, not a little astonished when a healthy Cysticercus temicollis escaped from one of them. In fact, when the enveloping eyst is unopened there is sometimes hardly any cxternal difference to be found between Echinococcus and Cystic. tenuicollis, especially when the latter has its habitation in the liver; and I call the attention of pathological anatomists to this circumstance. We have already seen that a case of Cysticercus tenuicollis must have been referred to by Bonetus and Platerus ('Observ.,' lib. iii, p. 635). In the historical portion of his interesting report, Eschricht shows that the case observed by Kölpin, on the mesentery of a man, and reported by Bloch, is the first certain ease of Cystic. temic. hominis. Kölpin himself compared his discovery with the eystic worm figured by Pallas ('Microse. Zool.,' xii), which is a true Cystic. tenuicollis.

'Treutler's ease of Cystic. visceralis, which is copied by Jördens, is also deserving of a closer examination, for in this also, accord. ing to Eschricht, a badly reproduced rudiment of Cyst. tenuicollis must be referred to. 
Zeder's case also appears to have been one of true Cyst. tenuicollis, so that all the cases do not deserve the negative criticisin of authors, down to Virehow. Eschricht, who has done such good service in reference to the Cestodea, mentions, as cases of true Cystic. lenuicollis, two cases which occurred at a very recent period, and which are both to be met with in Schleissner's 'Nosography of Iceland.' I am sorry that I must here coutradict the respected Danish naturalist, and acknowledge that I can only regard the case observed by Schleissner limself as a true Cystic. temicollis, whilst Thorstensolun refer's to an Echinococcus hominis autorum, or more correctly Echinococcus altricipariens (mihi), from the liver. Thorstensolm's case, according to Sehleissner, is as follows: "A boy of four years old had suffered for several months fiom a swelling of the right side of the abrlomen, with subsequent dropsy, and at the same time also from the passige of Lumbrici and Ascarides through the anus. On the right sicke there was a fluctuating swelling as large as a child's head, which, when opened, gave issue to a quantity of fetid, thin matter, with a number of hydatils as large as pigeons' eggs." 'That this case refers to an Echinococcus will be admitted by every one who has ever seen one with daughter- and granddaughtervesicles of every grade of development in which the cyst-walls of the daughter-vesicles possess the thickness and elasticity, and, in consequence, the property, caused by inbibition, of moving in lukewarm water in an undulating mamer. This is also shown by the fact that the cyst of a Cysticercus, even if it should attain the bulk of a child's head, never contains more than one scolex, in, or rather on, the vesicle which it encloses. Whatever number of Cysticerci may exist in the abdomen, there is always the same number of separite enveloping cysts, even when, as $I$ saw in one case in a pig, which had not been artificially infected, their number on the mesentery alone amounted to eighty. Even liere I did not see the absorption of the walls of two approximated cysts, so far advanced, that one cyst might have enclosed two Cysticerci. If therefore we pierce such a cyst, masses of uninjured hydatids cannot flow out, as in Thorstensohn's case, but this refers to another kind of worm, which can only be an Echinocnccus. Thus an uninjured resicle never issues from the picreed or cut cyst of a Cysticercus, but only an injured one. Eschricht has probably allowed himself to be led to the supposition that a Cystic. tenuicollis is treated of by Thorstensolm, by 
his having onee found two free, ron-eneysted Cyst. tenuicolles in the abdominal cavity of an ape. Esehricht, probably supposing that in the production of ascites, these resicles, if free, might eseape from the abdominal cavity, has forgotten, in the interpretation of Thorstensolni's case, that this referred to the puncturing of the sacenlated swelling (Echinococcus-cyst of the liver), which, moreover, was in articulo mortis and becoming purulent, and that the puneture in question did not give issue to resicles living freely in the abdominal carity, but to the contents of the swelling of the right side, after which operation the secondary ascites eaused by the swelling also gradually disappeared.

But althongh we must cancel this case, Esehrieht still retains the undiminished merit of having first proved by deseription and very well executed figures, that Cysticercus tenuicollis really oceurs in the human abdomen, and that in the ease deseribed by Sehleissner himself, this Cysticercus is referred to.

The symptoms agree in all essential points with those of Echinococcus, and we may, therefore, pass over them hcre.

As regards the strueture of this cystie worm, its frequently enormous eaudal vesicle, which in animals may attain the size of a child's head, is rendered remarkable by the eoneentrie wrinkles or rings, visible externally, which pass round the worm, and which are crossed by very fine longitudinal striae, so that, when the worm is laid flat upon a plate, and the eye placed horizontally towards the surface of the worm, the whole lias a very finely chequered appearance. Fven in dead Cystic. tenuicolles, inerusted with ealcareons matter, these eouecntrie rings may be reeognised, and the ealeareous deposit often forms a true, I might say, plaster east of the form and strueture of this eystie worm.

It is also to be observed that the wall itself, when the transverse section of the dead Cysticercus is examined, presents a structure eonsisting of concentric strata, analogous to that whieh we shall deseribe in the Echinococci. Here, however, it is so extremely fine and deliente, that we have some trouble in finding it, and can only sueceed by examining the transverse sections upon a dark ground, after we have had some practice in discovering it in the Echinococci. Compare also the article on Acephalocysts, with regard to which I believe I have proved that they partly belong to this speeies.

Prognosis. - A small number of these worms, or one of them, if 
not of very large size, cannot generally be very dangerous, but their general prognosis agrees with that of the non-animal hydatids in the human body, and is to be judged according to the organ of the abdomen attacked. The position of the C'ysticerci in the mesentery is undoubtedly more favorable than in the liver. I should not, howerer, suppose that these parasites, if they occurred in larger numbers, would be as indifferent and harmless in man, as is often the case when we find them in our domestic animals; because from the upright position of man, they much more readily produce inconvenience from pressure in lim than in the lower animals, in which swellings of this kind are coustantly being drawn towards the anterjor wall of the abdomen by their own weight, and prevented from pressing upon the vital organs and upon the large blood-ressels which lie more backward. For this reason, I think, we must not push the analogy between cystic rorms occurring in man and animals too far ; and we may expect that injurious consequences, such as dropsy and other phenomena, may occur much more readily in man than in animals, a circumstance which, as far as I know, has been hitherto but little taken into consideration in comparative pathology.

Therapentics.-The indications are of two kinds-1. Prophylaxis. 2. Direct therapentics. Recent observations have convinced me that even in animals it is not a matter of indiffercnce when a large number of them are present in one animal.

1. The prophylaxis is easy in theory, as it can only consist in the counsel not to infect ourselves with the eggs of Tcenia e Cysticerco tenuicolli; but difficult in practice, as we cannot easily state the mode in which we can best protect ourselves from this infection. That Cysticerci tenuicolles are produced by swallowing the eggs of the abore-mentioned Trenia, is as fully proved by experiment as the production of Cysticercus cellulose from the eggrs of $T$. solium. I first administered the eggs of this Tenia to three old sheep, without their exhibiting any Cysticerci. One of these sheep became rertiginons, but, as appeared on dissection, not in consequence of the migration and development of the embryos of Cestodea in the brain, but in consequence of an Oestrus Ovis in the frontal sinus. I then fed two lambs, and found in one of them an irritation of the brain and spots of cxudation in various places, but no trace of a cystic worm, although the dissection was performed four weeks after the 
administration of the eggss. If the embryos had migrated here, they had been aborted and destroyed immediately after irritation of the brain took place. The second lamb had only a single developed Cystic. tenuicollis.

At the same time the observation was made, that in the fold in which these lambs were left withont isolation, several lambs became sickly, and contained Cysticerci in the mesentery, although these resicles had not previously been observed in this fold.

Professor Luschka informs me that after administering the ergos of one Trenia to a young he-goat he found a Cystic. tenuicollis, and Professors Leuckart and Röll have also affirmed that in many experiments upon sheep and goats, which they fed with eggs of Trenia ex Cysticerco lenuicolli sent them by me, Cysticerci tenuicolles had been bred. The most convincing experiments must be the two following, institnted by me (vide 'Ueber die Trenia ex Cysticerco tenuicolli, \&c., Moleschott's 'Untersuchungen,' Bd.i, p. 352) : On the 9th of April, 1855, two sucking lambs of 28-30 and 20-22 days old, which had never been on the meadow, received mature segments of the Tenia cx Cysticerco tenuicolli. In April and May they sickened, and lost their appetite and vivacity. The stronger and older sheep soon recovered; the younger and weaker one became violently affected with peritonitis, but yet recovered so far in June as to be able to stand up, move about, and scek its mother in order to suck. At the end of May an umbilical abscess opened in the animal, and from this period its recovery advanced rapidly. On the 1st-8th Junc, a shepherd's preservative against the staggers was administered to the lambs, and afterwards, on the 9th and 10th of June, they received Trenia Conurus. On the 23d of June the stronger sheep showed indications of vertigo, and on the 25 th the weaker one. When the animals were dissected, on the 26th of June, the ordinary appearances after the adninistration of Trenia Cconurus were met with, and also inmense numbers of Cysticercus tenuicollis, corresponding with the time (seventy-nine days) after the administration of the Trenia ex Cyst. tenuicolli. The phenomena were exhibited in the greatest intensity in the younger lamb, which presented more Cysticerci than the older one, especially on the convex surfice of the liver, on the sicle wall of the ductus choledochus, on the mesentery, and on the spot where the base of the uterus, the arch of the vagina, the rectmm, and the bladder lay; and also in the pleura, the pericardium, and the 
diaphragm. The latter and the convex surface of the liver were firmly united, and in other places, between the liver, the stomach, and the intestines, there was union by fibres and false membrancs. At the same time the entire convex surface of the liver was corered with a thick rind of exudation. After the separation of the diaphragm from the lirer, 4-5 parallel superficial streaks were observed, which rescmbled swollen hepatic ducts with Distoma, and contained the cystic worms. The walls of the ductus choledochus were swollen, rigid, and dirty yellow, as were also the walls of particular cysts in the liver (remaius of inflammation), whilst the cysts in the mesentery and intestines, on the pericardium, and in the lungs, were without traces of inflammation. On the stomach remains of inflammation showed themselves as morbid growths, and the bladder was thickened, rendered turbid, and discoloured. That the mode of production of this scolex is hereby proved, is perfcctly evident. In shecp the Cysticercus usually occurs single. The pig offers a far more congenial soil for the development of the brood, in which, as before remarked, I found as many as eighty living Cysticerci, without reckoning the dead ones. I have hitherto not had pigs at command for this purpose. It need not trouble us for the present that the experiment is not always crowned with success; it is sufficicnt that it has repeatedly succeeded in different places, especially in my last case, and that we may admit that, under particular, farorable circumstances, such a cystic worm is developed from the eqgos of this Tenia even in man. Above all things, however, we may suppose that, as this Tania dwells especially in the intestines of the dog, its eggs must occur most plentifully in those places where sheep-dogs and butchers' dogs are most numerous. Thus, as I found this Tania accidentally in dissecting a sheep-dog on the property of M. Kind, of Kleinbautzen, and not long since repeatedly in butcher's' dogs in Zittan. From this we may presume that it is also abundant in other places where there is an extensive breeding of sheep. Now, as in Iceland the sheep-dogs and the breeding of sheep (vide infra) play an important part, a frequent opportunity will be offered in that land for the escape of the eggs of the Trania into the external world, and for their getting into drinking-water, and with this, or with raw articles of food grown in moist places, into the lumman stomach. For the prophylaxis, therefore, it is in the first degree necessary, that the dogs, as soon as they are seen to 
pass large, slender, white proglottides, ${ }^{1}$ should be freed from their Tania in closed spaces, and the expelled tape- 10 orm rendered harmless by fire or spirits; then that the shepherds and butchers should be counselled and instructed to give their dogs no bladders out of the mesentery, liver, and abdomen generally, and that, where this disorder is endemic, particular care should be taken in the use of drinking-water in free nature, and of those articles of food which are consumed raw, and which, standing upon a moist soil, had an opportmity of coming in contact with the floating eggs of this Trenia. Local usages and customs in the mode of life must furnish further data. See also the propliylaxis of the Echinococci. The destruction of the brood of the cestoid worms, when introduced into the stomach and just immigrating, by the administration of anthelmintics, has never succeeded with me. The object which I had in view in these experiments is perfectly clear. Had I succeeded in discovering a remedy which would prevent the further development of the brood, then, in countries where these parasites are endemic, this remedy would have to be administered daily to the inhabitants. The same thing would also be done with the domestic aninals. It would be interesting in this respect if agriculturists could tell us whether those farms are permanently free from Ccenuri, \&c., in which species of Pyrethrum occurred on the meadows. It is also to be taken into consideration, as already indicated, that these vesicular worms, as well as the Echinococci, have become rare in the same proportion that the diet of the inhabitants has become

' As it lies beyond the purpose of this text-hook to give the specific distinctions more exactly, I must confine myself to the description of the nature of the proglottides just given. The white proglottides passing with the excrements of dogs can only belong to T. Conurus, T. serrata, T. ex Cyst. lenuicolli, and $T$. solium; the latter of which, however, I doubt. The form of the proglottides is sufficient for their distinction. Those of $T$. Conurus are very narrow and slender; those of 'T. serrata broad and somewhat shorter; and those of $T$. ex $C$. tenuicolli are nearly of the size of the segments of T. solium. If the proghottides be pressed betwcen two glass plates, we see the further distinctions above mentioned between T. solium and T.ex Cyst.tenuicolli. T. Cœnurus has a very slender uterus, with unramified and not very long lateral hranches, of which about twenty may be counted on each side; $T$. serrata vera has a nterus with broader lateral branches, which are ramified, and form diverticula on all sides, and also very commonly emit a large transverse branch to the porus genitalis. Besides the reasons for the distinction of the species given here and formerly, it may also perhaps be pointed cut that, as 1 have slown in Moleschott's 'Untersuchungen,' Band i, p. 270, et seq., the hooks are produced in all the species upon very different models. For more details as to this difference, I nust refer to the work quoted. 
more regular and nore careful in the choice and preparation of food, and perhaps even still more that these cystic worms decrease in a district in the same degree as the number of free rlogs becomes less, which they may, in consequence of dog-taxes, \&c.

2. Direct therapeutics. - If the embros be once introduced and developed, our art possesses no remedy, except the puncture and complete removal of the cystic worm itself, for, as we shall see in the Echinococci, it is by no means impossible that injured cystic worms may again recover themselves. Vesicles, at which we cannot get with the trocar, remain inaccessible to treatment. Whatever number of eysts there may be, the same number of punctures must be made in the different places where they are situated, if a cure be desired. Next to puncture witl the trocar, the galvanic acupuncture might be worth a trial.

There is no doubt that the Cysticercus tenucollis sometimes decays spontaneously, and that in this case an alleviation of any symptoms may take place by the sinultaneous diminution of the swelling caused by absorption. In the pig, at the bottom of those cysts which contained dead Cysticerci, I lave repeatedly found the latter more or less covered with a calcareous crust, with their walls collapsed, their caudal vesicle empty and contracted, the rest of the cyst filled with a chalky, fatty mass, containing cholesterine, the walls of the enveloping cyst shrivelled, and, when the cyst is situated in the liver, its walls thickened. There is no doubt that the therapeutist must constantly endeavour to discover how Nature conducts this process, which brings about the death of the Cysticerci. Inflammations of the enveloping cysts usually appear to cause the death of the worm, and the question arises, whether, besides puncture, we can by any other means induce inflammation of the enveloping cyst, and by this the death of the worm. At present, we are acquainted with $n$ such therapeutical agent. See also Gracfe's observations on Cysticercus cellulosa.

Literature._- Bonetus Sepulchr.,' l. c. Kölpin and Block, in 'Biblioth. nova,' pp. 393 and 394. Treutlin, 'Observ. pathol. anat., pp. 14-16, tab. iii, figs. 1-4. Jörden's 'Helminthol., p. 56, tab. v, figs. 8-11. Gmelin, 'Syst. Nat.' p. 3059, No. 5. 'Zeder Naturgesch.,' p. 458, No.11. Wepfer in 'Biblioth.,' No. 390. Leuckart, 'Die Blasenbandwürmel' und ilure Entwicklung,' Giessen, 1856, p. 4, et seq. (Historieal). Principal work, - 'Undersögelder over den i Island endemiske Hydatide. 
sygdan,' by Eschricht, separately printed from the 'Bibliothek for' Laeger', January, 1851, and Schleissner's 'Nosographie Islands.'

\section{Echinococt.}

The Echinococci have long furnished a point of dispute for helminthologists. Some only admit a single species of Echinococcus; others two; and others that there is a still greater number of spccies,- such as Lenckart, who regards an Echinococcus of the camel and that of the peacock as distinct from the other species. The Echinococci are usmally divided (and amongst. others even by Von Siebold) into Echinococcus hominis and $E$. veterinorum. This is incorrect, for Haubner and Creplin have ascertained the occurrence of Echinococcus hominis in cattle, and, on the other hand, Von Ammon has found $E$. veterinorum in the human eye; and from Eschricht's description of the Echinococeal disense in Iceland, it appears also, that in that island, both species oecur in the human subject. That the latter two species are really distinet, further proofs will be furnished in the following remarks. We shall pass over here the differences by which the Echinococci are distinguished from the Cysticerci and Conuri, and only mention in passing that the Echinococcuscyst proliferates almost throughout its whole extent, and that we eannot speak of it as a caudal vesicle; that the Echinococcuscyst is firmly attached to the enveloping cyst; that the walls are composed of lamella; that no muscular layer follows upou this stratified membrane, as in the Cysticerci, but that it is immediately followed by a layer of a granulo-vesicular strueture, with a vascular system and calcareous corpuscles. All these points will be referred to in detail herenfter. But the differences iu the developmental history of the two speeies will be more exactly detailed. From the internal vascular layer of the Echinococcus-resicle, spring small buds, which, forming conical or villus-like elevations, sometimes measuring 0.4 mill., become converted directly into Tania-heads, in the formation of which there is not usually an immediate conversion of the processes into heads; but first of all a transformation of the processes into small brood-capsules, $0 \cdot 7-2$ mill. in diameter, and it is only in these that the scolices are produced or budded forth. The process, which at first adheres by a tolerably broad base, becomes in this way cleared, its contents more fluid, 
and a small globular vesicle, allhering to the inner wall of the Echinococcus, is formed, presenting an external structureless epidermis and an inner grmular layer. In the grmular layer of these processes which have been dilated into vesieles, we observe vessels, which are connected with those of the Echinococcus-vesicle, and, subsequently, when the small vesicles have attained a certain size, again lead to the formation of processes in themselves. Thus, from these new $(4-10)$ processes the scolices of the Teniu are produced, with a general increase in the size of the capsule. This occurs essentially in accordance with the same type as in the Cysticerci, with the sole difference that, as Leuckart has pointed out, the cephalic processes become hollow from the inner end, which is turned towards the eystic worm, and not from the wall of the resicle. The inmediate neighbourhood of this cavity is also contracted with the rest of the parenchyma of the cephalic process, without ever forming a caudal vesicle, which would be cast off during the transition into the strobila. The wall of the vesicle, in which the head is inverted, afterwards forms the hinder part of the young Trenic. If anything is lost in this transformation, it can only be the rudiments of the stem which occurs in all individual scolices of Echinococcus, and contains $2-4$ vessels, originating from the vascular system of the brood-capsule. When the Echinococcus-heads are developed in the interior of the process which has become converted into a vesicle, which always takes place uniformly, the broodcapsule bursts, and its walls, and with them the inner layer with the individual licads, turn inside out. Lastly, the groups of Echinococci, which often swim about freely in the Echinococcussac, detach themselves, and the individual scolices fall separately into this sac, where they die, whilst new generations are produced. Moreover, the histological structure both of the mother-vesicle and of the daughter-vesicles (vide infra) shows that the formation of the heads never takes place on the outer wall (Huxley), but on the inner one. Up to this period the process of formation is the same in both species of Echinococcus; but now a new mode of generation makes its appearance. This consists in the production of the so-called daughter-vesicles, which are vesicles swimming about freely in the fluid of the Echinococcus, and which exactly resemble the mother-vesicle in their structure and in their proliferant activity. Their morle of production is 
not quite clear. The observation of Lebert, who sometimes found a rudimentary peduncle upon them, is in favour of their laving been primarily pedunculated processes similar to those to which we have just referred, with only the single difference that they do not remain attached and burst in that condition. A third mode of generation, which only occurs in Echinococcus altricipariens, has been observed by Virchow and Luschka in the human body. It ocrurs, however, only in those specimens of this Echinococcus which intrude themselves into vacuities in the tissues and the interior of vessels (blood-vessels and lymphatics) in the form of cylindrical tubes. Within these narrow cylindrical tubes various resicular appendages, furnished with filiform peduncles, are formed, which then probably become sefrarated by constriction and form closed resicles. These appendages, or vesicles separated by constriction, can then proliferate again, or, which appears to be the nost usual occurrence, they remain bar'en, and become Acephalocysts. The colonies are mixed, actually proliferating in the mother-vesicle, and in certain daughter-resicles, but usually sterile in the parts separated by constriction; although I do not believe it to be impossib]e for the latter to proliferate. In them, therefore, we have, - simple scolex-formation, ordinary formation of daughter-vesicles, and regeneration of so-called daughter-vesicles by the constriction of particular buds or by a sort of fission. The latter, however, is only a slower and more distinct process, occurring in the cylindrical diverticula of an Echinococcus-colony, of that mode of formation by which the daughter-vesicles are produced, and, accordiug to Lebert, frequently pedunculated. The most important distinctive indication of this mode of generation lies in the products which sometimes thus originate. Such vesicles, when completely constricted, may again become independent colonies (Echinococcus- or Acephalocyst-sacs), which are totally unconnected. It wonld, therefore, be erroneous to suppose that when several Echinococcus-colonies occur isolated in an organ, the same number of the six-hooked embryos of the Trenia of the Echinococcus must have arrived at development. Even Virchow las indicated, that all such colonies in one organ may originate from a single embryo. In the appendix to the second part of the German edition of my Text-book, I called attention to this production by constriction or fission, which has recently been pointed out by Luschka. The importance which the mode of generation and life here mentioned possesses for pa- 
thological anatomists, on account of its having becn confounded with alveolar colloid, will justify us in treating of this subject more in detail hereafter.

Although it will have been seen that two distinct models may be distinguished in the mode of production of the Echinococci, it is, nevertheless, difficult to find a suitable nomenclature for the two species thus formed. The denominations-

\section{a. Echinococcus scolicipariens, and \\ b. Echinococcus altricipariens,}

may, perhaps, appear the most proper, and I shall employ them in the following pages. ${ }^{1}$

a. Echinococces scolicipariens = Echixococces veterinorum of the carlier authors.

Sỵnon.: Tenia visceralis socialis gramulosa (Göze); T.granulosa (Gmelin) ; Vesicaria gramulosa (Schrank); Hydatigena granulosa (Batsch); Hydatis erratica (Blumenbach); Polycephalus hominis (Göze); Polyc. granulosus (Zeder); Polyc. humamus (Zeder) ; Polyc. Echinococcus (Zeder); Echinococcus veterinorum (Rudolphi et plurimi autores); Echinoc. Givaffee (Gervais); Echin. Simice (Rudolphi aliique); Echin. granulosus (Rudolphi); Echinoc. Infusorizm (Leuckart); Echinoc. polymorphus (Diesing).

[Trenia matura: Tania minima, ad 3 mill. longo, corpore 3-aut 4-articulato; capite subgloboso, 0.3 mill. lato; rostello parvulo, rotundato, 0.125 mill. longo; osculis suctoriis magnis (0.13 mill.); animalis in duplice ordine positis 28-36, quorum majores ex Leuckartii mensura 0.045 , minores 0.038 , ex meis mensuris 0.031 et 0.028 habent; cullo longiusculo; articulis 3-4, quorum ultimus toto corpore longior (2 mill. long., 0.6 mill. lat.) est. Utero medianâ loculis et stolonibus nec ramis propriis instructâ; ovulis ovalibus, 0.031 long. et 0.030 lat., testâ 0.0019 mill. crassâ, cavitate internâ 0.027 lat. et 0.030 long.

Habitat: In Canis domestici, imprimis in Canis lanii fortasse etiam in Canis Lupi tubo intestinali.]

Scolex quiescens=Echinococcus vetcrinorum seu scolicipariens : Vesica minus pellucida, membranacea, in pariete ad $1-2$ mill. crassa, ex pluribus $0.005-0.01$ mill. crassis lamellis concentricis

1 See, on this subject, a paper by Professor Huxley "On the Anatomy and Development of Echinococcus veterinorum" in 'Proceedings of Zoological Society of London,' December 11th, 1852.-ED. 
composita, parvulas gemmas (brood-capsules) stylosas gignens, in quibus scolices singnli proliferantur, magnitudinem 30 mill. et ultra exhibens. Scolices sociales gemmis diruptio libere in vesicam emissi, parvuli, capite Trenice modo dicta. Metamorphosis in Treniam post $7-8$ hebdomades peracta.

IIabitat: Interdum in homine, plerumqne in aliis animalibus plerumpue domesticis ex ordine Ruminantium et Herbivoracium. ${ }^{1}$

Trenia matria.-This Trenia has not hitherto been found in the human subject, but it was known to Rudolphi, and was found by him accidentally in the intestine of a pug-dog (a breed which is now extinct according to Vogt). Rudolphi regarded them as lieads of Tenia cateniformis (cucumerina) produced by spontaneous generation. (See 'Entoz. hist. nat.,' i, p. 411.) Röll afterwards found it in Vienna in two dogs; and Von Siebold and I, without knowing anything of each other, simultaneously ascertained that Röll's Trenia was not $T$. serrata juvenilis, but a peculiar species of Tenia, derived from Echinoc. veterinorum. Haubner and I also found this Tenia in great quantities in dissecting a sheep-dog in Kleinbautzen, and I fomnd it myself again in a butcher's dog. As far as I am aware, no one has yet bred this Tenia hy the intentional administration of its Echinococci, except Ton Siebold in 185:, and myself shortly afterwards, as my plates sent to the Academy of Sciences in Paris will prove. Since that period I could obtain no Echinococci for administration, until, at the end of the month of December, 185 4 , I obtained two vesicles, which were given by me to two dogs, and one by Haubner, in Dresden, to a third. Since then I have frequently given them. This Tenia always occur's in society, prefers taking up its position in the upper parts of the small intestine, is hardly $3-4^{\prime \prime \prime}$ in length, and becomes mature even in the third segment; it requires for its perfect development a period of about eight or nine weeks, according to Von Siebold only seven;

1 Many who are not exactly acquainted with the subject may be puzzled locause in the figures of this and the following species different parts of one and the same worm occur in one figure very mequally magnified. I must adnit that I did not know low to do otherwise without adding to the number of the plates, which are in themselves very expensive. I shall be thankful for any hint in connection with this, and beg those who may only become acquainted with the subject from this book, to bear in mind that for the purpose of diagrammatic representation an error in regard to proportional size has, perhaps, been made. 
in which time, however, I have always found it immature. For the size of the hooks vide infia.

Eyys and six-hooked embryos. - There can be no doubt that these little creatures must occur at some period in the intestines of man, getting there with drinking-water, or with raw articles of diet, which have been derived from a damp soil, and which we have already mentioned sereral times, such as salad, strawberries, roots, turnips, and fallen fruits, especially such as have been collected after a wet day and eaten raw with the peel on. ${ }^{1}$ Like the embryos of the other T'ania, however, they escape the human eye on theil entrance into the human body. Their migration itself is certainly performed like that of the other cmbryos of the Tanice, by their perforating the intestine and getting into the abdominal cavity, where they prefer attaching themselres to the liver or the kicheys, or to the organs lying in the thoracic cavity. A portion of them, howerer, may migrate along the ductus choledochus to the outer surface of the liver. In the spot which they select they take up their position in the same way as the other Cestodea, and the euvelopes formed round them have the same properties as with the latter, but are, nevertheless, distinguished by the thickness of their walls.

Scolex. - I have never had an opportunity of seeing this scolex with certainty in the human subject, althongh I have repentedly seen it in pigs and sheep. It has certainly been seen by Gescheidt in the eye, and by Eschricht. I shall therefore treat of this worm here in accordance with Eschricht's interesting comnunications, with additions which I shall take the liberty of making from $m y$ own observations on this creature when found in animals. There can be no doubt that Eschricht has seen it, and I here quote from his memoir already cited, all that refers to a consumptive Danish miller's man (l. c., pp. 15-16) who suffered from Echinococcus. Schleissner's two Icelandic cases belong to $b$.

The scolex forms a vesicle which can hardly exceed the size of a large apple. According to Eschricht, it measures $2 \frac{1}{2}-3$ inches, and forms a firm attachment to the organ in which it dwells. The anatomical elements are the same as those of all enveloping

1 The common people, as is well known, say that tape-worms are acquired by eating apples, and especially the so-called bloom on ripe apples. I have already shown the impossibility of this supposition, but I must admit that an infection with cystic worms of all kinds by eating raw windfalls with the skin on is certainly possible. 
cysts, only they are more conccaled and more abundantly permeated by proteinous unorganized substances, by which the walls themselves become thickened, and the mode of secretion of the fluid by which the worm is to be nourished becomes more difficult to understand. The thickuess of the walls is not the same in all parts, but in one of Eschricht's cases it was about $\frac{1^{\prime \prime \prime}}{6}$ on the free side looking towards the peritoneum, but nearly $4 . \prime \prime$ in the interior of the liver. In this envelope, distinctly separate layers or strata could be detected and partly separated; the innermost being $\frac{1}{6}-1$ millim. in thiekness. The immermost stratum is also smooth, like the surface of a serons cavity. It is to be observed also that the enveloping cyst is seldom regularly romd, but has various excrescences in the part which lies in the parenchyma of the organ in which the vesicle is imbedded, which there correspond with similn excrescences in the cystic worm living in it. I repeat, what I have already stated once, namely, that such excrescenees are not essential; that we do not know how they are caused, whether by the inhabitant, or by the impulse of organization in the enreloping cyst, which appears to me to be the most probahle; and, lastly, that these exerescences only oecur in those individuals of all the cystic woms which live imbedder in the parenchyma or the cellular tissue of parenchymatous organs, but never in those which live in free, simple carities of the body - a distinction to which attention has not hitherto been directed, and which, nevertheless, satisfactorily and distinctly explains everything.

A second vesicular body fits exactly to the inmer surface of the innermost layer-this is the true cystic worm, the so-called mother vesicle of the Echinococci, that is, the six-looked embryo, which, continually increasing, has attained an extraordinary size. It is a matter of difficulty in general, at least my attempts for several years have never been successful, to get the cystic worm uninjured out of its cyst, although I have sometimes been able to loosen a greater or less portion of the resiele from the inner wall, to which, however, it adheres rather firmly. To manage this, I advise that the uropened cyst should be left for some days in spirits, and then that a short ent should be made with blunt-pointed scissors in a thick part of the cyst, and ncarly passing through its walls. The margins of the somewhat gaping cuts in the cysts are then seized with two pairs of forceps, with which the walls of the cut are gradually drawn asunder, when the 
inner vesicle gradually separates from its enveloping cyst. If such a cyst be cut throngh, the gelatinous, very elastic wall of the cystic worm separates from the cyst at these cut places, and rolls itself up, when witl a forceps it may easily be separated in its whole extent from the inner wall of the cyst, in which case the worn furnishes a true representation of any inequalities in the outer cyst.

As regards the structure of the walls of the true Echinococcus vesicle, it is characterised by the following circumstances, which must be accurately estimated, on account of Acephalocysts :

1. The walls are extraordinarily elastic, and tremble, like jelly, when touched, even after they are empty, which we do not see in the walls of a Cysticercus.

2. The walls of such a resicle never collapse entirely, as is the case in the Cysticerci, nor do they lie, like these, after death, flat at the bottom of the eurclope-cyst, but even when dead they still adhere to particular spots in the envelope-cyst, in which case an adhesion takes place between the latter and the worm as if by plastic exudation.

3. The cut margins of such cysts roll themselves up, which gives them a gaping appearance.

4. The trausverse section of the walls of such a cystic worm distinctly shows a structure consisting of more or less numerous consecutive circular strata, varying according to age, which we find merely indicated in dead Cystic. tenuicolles, and in so low a degree that it requires considerable practice to detect even very slight indications of such lines.

With regard to the structure of this Cestode, Eschricht says that the walls consist of two similar membranes, which are only loosely connected, and of which the outer one is of a cartilaginous nature, and the other, which is thin and smooth, has the texture of a mucous membrane, is large enough to bear an epithelium (which Von Siebold, as I think rightly, denies), and beset with

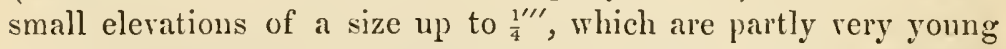
scolices in the act of development, partly further developed

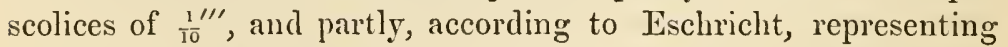
the points on which such scolices formerly sat. In the fluid contained in these vesicles there are also free scolices, part of which are still furnished with the remains of the stalk, and which, on the application of pressure, form flat discs with the outline of an apple cut down the middle; from the hinder third of this, 
towards the stalk, a circlet of $30-31$ looks, in a double series, shines through, and from its anterior extremity the four sucking discs appear in the same way (as Weull has correctly perceived and figured, and as Eschricht supposed, but, as he says, did not actually see), and in these discs the well-known roundish calcareous corpuscles, measuring $0.01-0.02$ millim., are imbedded (vide infia). If the Echinococci be left uncovered to roll about upon the field of vision, we see that, as Eschricht states, they are not really round vesicles, but flat discs (or depressed sacs), on one surface of which, towards the anterior portion, there is a blunt elevation. These scolices of Echinococcus are the analogues of those structures "hich Tan Beneden has figured on pl. viii of his work already quoted, and in other places; so that in speaking of the individual scolices we can hardly call them cystic worms.

The calcareous corpuscles have but slightly marked sides and angles, and rather a round, cellular appearance. Eschricht, who thought he saw a nucleus in them, has probably been deceived, either by the deposition of the calcareous matter in concentric layers; as is sometimes the case, or hy the glimmering of a small corpuscle through a larger one behind which it lay. $\mathrm{He}$ thinks also, that although the calcareous corpuscles occur in various parts of the skin, they have, neverthelcss, a certain regularity in their distribution. Thus they form a distinct circle close to the outline of the body, another round the hooks, and a series along the middle line, whilst a lighter space occurs between the poles and the circlet of hooks, that is to say, about the position of the sucking discs, the neighbourhood of which is generally free from a deposition of calcareous corpuscles. I can confirm these latter statements from particular cases of Echinococci in animals, but here I rarely saw it in this manner. The number of calcareous corpuscles-which Eschricht, howerer, regards as cclls containing silica-is often small, and often much larger, as for instance, more than a luundred in one individual. The younger an individual is the smaller and less distinct are the corpuscles, and the fewer of them are there in the animal; the older it is, the more abundant are the corpuscles. The size of the hooks, according to Eschricht, is 0.02-0.022 millim., or about $0.01^{\prime \prime \prime}$, a statement which, as we shall show further on, is not quite correct, as the hooks of the first and second series vary amongst themselves. 
Symptomatology. - Single cysts of this Echinococcus will scarcely produce any symptoms during life, as the growth of this species appears, on the whole, to be rather limited. I hare never yet seen a cyst of this specics, in an animal, which had attained the bulk of a large apple, or of a goose-cog. The vesicles are generally of the size of a walnut or a duck's egg, and they project but little, or scarcely at all, above the level of the liver. For this very reason their diagnosis in man presents the greatest difficulties. The disturbance in the functions of the liver will in general be small, and ouly become more considerable when a great number of such vesicles inhabit the liver, their injurious influence becoming more striking by their increased numbers. The right hypochondrium and the cardia are son,etimes painful on pressure, and rather more duhness is exhibited over the liver as far as an inch and a lialf and more below the false ribs and over the cardia, with irregular evacuations and symptoms of jaundice.

Pathological anatomy.-The liver is swollen, particularly behind, pale, of a uniforn, grayish-brown colour. On its surface it presents larger or smaller spots of a whitish-yellow colour, and of a more or less regular form, generally but slightly raised in this species above the surface of the liver, although there may be exceptions to this in the case of very much enlarged vesicles. On the whole, therefore, the resistance to the pressure of the finger and the feeling of fluctuation are but small, and I also believe that the sensation of the so-called liydatid-buzzing is never to be felt here. This species, as will luave been seen already frorn this description, has its seat too deep in the parenclyma of the liver to project above the level of its surface.

By closer attention hereafter, we shall certainly often meet with this species of Echinococcus in the human subject, and convince ourselves that many of the cases described in literature up to this time referred to this species. But what would be the use of attempting to criticise the old materials in this manual? It is sufficient for us to liave called attention to the occurrence of this species in the human body, and to bring forward from the literature of the subject the two interesting cases, namely, the case observed by Von Ammon-Gescheidt, of the occurrence of Echinococcus hominis between the choroid coat and the retina, which refer's to this species, and Möller's ease.

a. Von Ammon's case.-The eyclids and the parts surrounding 
the bulb were in the normal state, the right eyeball was strongly convex, slightly hardened, tense, and staring; the sclerotic coat and the cornea were normal, the iris brown, coated in isolated spots with yellow exudations of lymph, the pupil distorted, the upper segment of the leus somewhat turbid, and deeper down presented a dingy yellow and widely diffused turbidity. The left eyeball, which resembled the right one in form and hardness, had a pale-blue iris, with small superficial vessels. The obseured lens was pressed downwards, the place where the lens ought to have been was filled with a yellowish-brown mass, and only the upper segment of the lens was perceptible. Dissection: When the eye was divided into two segments by a transverse incision, it was found that a fine white membrane pressed into the incision, between the cut choroid and selerotic coats. The choroid itself was brownish, destitute of pigment, and rich in varicose vessels; the retina appeared to be shriyelled up with the vitreous body into a white, reddish-brown mass, was quite cord-like at the entrance of the optic nerve, increased in breadth and circumference anteriorly, became folded, and was intimately amalgamated with the corona ciliaris and processus ciliaris. In the space between the retina and the choroid sat the white vesicle, of which it has already been stated that it pushed itself out through the ineision. When the external, white, firm, and slightly transparent envelope of this vesiele, which sprang from the middle of the lower surface of the retina and spread itself in a circle round the retina, with its two sac-like extremities meeting above, was carefully opened, a little scrous fluid issued, and at the same time a delicate bluish-white membrane appeared enelosed within the first-mentioned envelope. When this was tom open, a serous fluid also issued from it, which contained a quantity of small, round, oval or olive-like vermiform corpuscles, and the latter were, as perceived, attuched to the inner surface of the delicate membrane. On some of them four small suckers were distinctly seen, but no circlet of hooks was deteeted. They formed a perfectly homogeneous mass without perceptible internal structure, and were regarded as an Echinococcus.

From the description just given it follows distinctly that this was an Echinococcus of the first species, or scolicipariens, and that I am certainly in the right if I a not refer it to our second species.

It is, however, to be regretted that not a single one of these 
small attached bodies was examined, from a desire to save the very rare, nay unique preparation. Although Von Ammon lias hitherto looked in vain for the hooks, they would certainly have been found at that time; and eren now, a great number of those in this position must certainly have the circlet of hooks still inverted.

ß. Möller's cuse.-In Norember, 1853, a soldier came into the hospital with an extraordinary swelling of the abdomen; he was very anemic and cachectic, had taken part in the war in Schleswig-Holstein in 1848, and had the ague in 1850. On examining the abdomen it was found to be filled and extended to such a degree by sacculated swellings that the circumference of the belly above the navel was twice as much as the whole length of the body. Distinct undulating morcments were felt in the tumour on laying the hand upon the abdomen. The disease had commenect shortly after his dismissal from the army, at the conclusion of the war in Schleswig-Holstein. There were two cicatrized wounds in the right hypochondrium, caused by the punctures which harl been made by surgeons out of the hospital. The patient died, completely exlansted, on the Ist of December. A post-morten examination showed imnumerable Echinococcusvesicles in the abdomen, in the spleen, liver, and psoas muscle, from the size of a man's head down to that of a small microscopic resicle. Unfortunately no administration of these Echinococci was made. (Möller, 'Bibliothek for Lagger,' 1856, p. 58.)

I must, however, in reference to the first interesting case, call attention to one observation which differs directly from all previous observations, namely, the issuing of a quantity of serous fluid (which is certainly described as small) on the incision of the outer membrane, whilst the true mother-vesicle of the Echinococcus was still uninjured. This can only be explained by the fact as we shall see in dead Acephalocysts, the resicles produced by Echinococcus can also separate from the enveloping cyst in particular parts, although never completely or in all parts. In Von Ammon's case the worm had probably separated in one place whilst lying in the eye, a little fluid had collected in this spot between the Echinococcus and its cyst, and it happened that this was exactly the place cut into in the dissection. As a general rule, the connection between the enveloping cyst and the Echinococcus appears to become more intimate with time, but to be less firm in the earlier periods. 
In general the contents of the fresh and vigorous living vesicle are the ordinary, limpid, proteinaceous fluid, which in the Echinococci contains also succinic acid; ${ }^{1}$ and after death the same phenomena occur in it as in that of the Cysticerci, namely, turbidity, pus-formation as it is usually called, fatty degeneration, and calcifieation, which, however, as follows from the results described, go on, not between the enveloping cyst and the Echinococcus, but within the Echinococcus itself. As regards the statement that a formation of pus takes place in the interior of the Echinococcus-vesicles, I will not directly deny the possibility of such an occurrence; but I do not exactly see how the process of pus-formation can go on with the encapsuled fluid, enclosed by an Echinococcus. The ovarian cysts can certainly not be brought in here as analogous cases, in which these processes take place, as in these we have to do with the tissues of the human body, but here with a fluid separated from the human borly by a worm. If we examine the purulent mass in the cysts of Cysticerci, we certainly find a quantity of large granulated corpuscles, resembling pus-corpuscles, and sinaller molecular granules. And this is no wonder, as the worm not firmly connected with its enveloping membrane, and this has the power and opportunity to act on a great part, like the in. flamed inner wall of a pus-forming ovarian cyst. I lave no experience of Echinococci in the human subject, but we find authors speaking of purulent Echinococci in every text-book.

1 The detection of succinic acid, which, as is well known, is produced, amongst other wars, by the action of nitric acid upon fat or fatty acids, and is also formed in the spontaneous decomposition of certain organic substances in the presence of unch water, is best effected, according to Ileintz ('Lehrbuch der Zoochemie,' p. 239), in the following way: The fluid of the Echinococcus is evaporated; the syrupous extract is mixed with a little muriatic acid, and repeatedly agitated with water and ether, free from alcohol, until the ether can take up nothing more. On the evaporation of the etherial solutions impure succinic acid remains. This is purified by dissolving it in water, evaporating the filtered solution, washing the residue with cold alcohol, and repeaterl recrystallization from the alcoholic solution. Siscinic acid may also be detected in other animal substances in this way unless hippuric or benzoic acid be present at the same time, in which case some precautions would have to be employed, which will be found in Ileintz, l. c., p. 232.

When we consider how casily a great many organic lime and potash salts, which are readily converted into carbonates, become transformed into succinates, we are, perliaps, justified in thinking that a part of those calcareous corpuscles of the Cestorlea, and especially of the Echinococci, which do not effervesce when dissolved in acids, may contain succinic acid iustead of carbonic acid. 
The preceding will be sufficient to incite the pathological anatomists to a fresh and morc exact investigation of this circumstance, so as to let us know whether the dead vesicle of an Echinococcus can take on the functions of a true serous mem. brane of the human body and replace it functionally in every particular. In dead Echinococci of the liver of the pig I saw the following processes: turbidity of the contents, bloodiness, absorption of the fluid through the walls of the cyst, flaccidity of the walls of the cyst, and conversion of the contents by long absorption into a tough, syrupous, dingy coloured fluid, but there were $n$ o pus-corpuscles.

If the mother-vesicle of Echinococcus be extracted from its enveloping cyst, we find, between the inner wall of the cyst and the outer wall of the vesicle, plastic exudation, which is thicker in some places than in others. This probably serves both for the enlargement and thickening of the walls of the enveloping cyst, which is strengthened from within outwards, and for the agglutination of the cyst and worm.

Each individual scolex when alive in its mother-vesicle usually has its head retracted, and only protrudes it after death, when it generally loses its hooks. The scolices, still attached by their stalks to the inner wall of the Echinococcus, may also be brouglit to protrude their heads when the mother-vesicle is cut open and left for 12-24 hours lying in its fluid. Whilst at first we only find scolices with inverted heads on scraping them off, we now meet with numerous scolices with their heads protruded, and of these the majority still bear the whole or a part of their hooks. The four sucking dises of the scolices are also distinctly seen.

The experiment of raising Echinococci from the eggrs of its mature Tania, was made once upon one of the animals already frequently mentioned as having been purchased for this purpose at the expense of the Saxon government. Professor Haubner fed a pig with the T. Echinococcus found in Kleinbantzen, and found, on dissecting it several months afterwards, immense numbers of small vesicles, resembling young cystic worms, in the most various organs and parts of the body. Unfortunately none of these vesicles had attained to further development, but we are certainly justified in concluding, per analogiam, that these vesicles were really young Echinococci, which, however, from some uriknown reasons, had remained stationary in their development, or had been brought to destruction in consequence of a peculiar indi- 
vidual immunity of the animal experimented on, or pcrliaps of too riolent a reaction shortly after the immigration of the embryo. (See Appendix.)

Therapeutics. - The indications are those which have already been frequently mentioned.

1. Prophylaxis.-We have seen that the mature Tania belonging to this species occurs in the intestine of the dog, or perhaps, more correctly, in those of the species of the genus Canis. We can easily understand how dogs, especially shepherds' and butchers' dogs, and perhaps also wolves and foxes, where the latter, as in Iceland, feed upon sheep, may get at this Tenia. In districts where the breeding of sheep, cattle, and swine flourishes, the above-mentioned species of dogs, and especially the shepherds' and butcher's' dogs, have plenty of opportunities of devouring vesicles of this species of Echinococcus, and it is consequently not difficult to make conjectures as to the entrance of the eggs and six-hooked embryos into the human body, which can only be the same as those which we have propounded regarding the production of Cysticercus tenuicollis, and which must have acquired a very high degree of probability from the experimeuts of Professor Haubner and myself.

The first prophylactic injunction must consequently be directed against the scolex occurring in the above-mentioned animals, - the Echinococcus scolicipariens of the domestic animals. According to our observations and experiments, butchers and shepherds who slanghter for themselves, or horse-slaughterers, should not be allowed to throw the cystic worms, or what is more intelligible to such people, bladders, ${ }^{1}$ which occur in the livers and other organs of the above-mentioned domestic animals, to dogs as food. We must endeavour to show the people what injustice they do in this manner, as unintentionally, and without knowing anything about it, they may become the cause (certainly remote) of one of their fellow-men becoming infected with an Echinococcus-vesicle, because by this administration they produce the Tenia Echinococcus constantly in fresh quantities, and thus favour the passage of the cggs and embryos of this Tenia into

1 It will be the best plan with people of this kind to frame the ordinance in the ahove universal fashion. The man of seience will eertainly understand the difference, and here it requires the special linitation. But what does it signify if a vesicle is thus indicated as suspicious to the laity, which, in reality, may be regarded as innocent? 
the external world, by which the human subject may be infected in the way indicated. Butcliers, slanghterers, and sheplierds should be instructed to destroy the bladders wherever they mect with them, either by buruing them, or, if they choose, putting them into spirits; and this destruction might be ordered under threat of punishment.

In districts where these Echinococcus-vesicles are plentiful in the domestic animals, and where we may therefore suppose that, notwithstanding the counsel just given-as the mode of proceeding of the butchers and slaughterers with such vesicles, laving become a regular custom, will be rooted out with difficultythe Trenice still oceur in the free dogs of these localities, so that these eggs will also constantly be escaping, the people should be careful about drinking unboiled water, and using raw roots, salads, and fallen fruit. I know very well that it wonld be utopian to expect that the opinions here expressed will be quickly diffused among the people; but this nust not restrain me from expressing them, and urging on governments to have proper instructions disseminated amongst the people, in the popular schools, by societies of which the object is the publication of popular works of instruction. From the microscopic size of the developed Tenia we can direct no treatment against it; in fact, we cannot tell what dog suffers from it, and even if we had expelled it, we could hardly find it in the dung.

2. A direct treatment of the Echinococcus is only possible when we can get at the vesicle.

Literature.-Gescheidt, in Von Ammon's 'Zeitschrift für Opthalmol.,' iii, pp. 437 and 446. Eschricht, in 'Undersögelser over den i Island endemiske Hydatidesygdom.' Von Siebold upon Tania Echinococcus, in Siebold and Kölliker's 'Zeitsehr. für Wissenschaftl. Zool.,' 1853, iv, p. 409, et seq. Röll, in 'Verhandl. der Phys. med. Gesellsch.,' in Würzburg, iii, 1852, p. 55. Küchenmeister, 'Ueber Cestoden im Allgemeimen und die des Menschen im Besondern.' To this species belong PI. III, fig. $17 a-d$, and Pl. IV, figs. 1-9, of this text-book. 


\section{b. Echinococcus altidcipariens = Echlnococcus Hominis antorum.}

(Pl. III, figs. $18 a-g, 19$, and Pl. IV, fig. $10 a-e$.

Synomyma.-In the confusion which prevails, it is no wonder that this species has been everywhere mixed up with the preceding one; compare, therefore, the preceding species.

Tania matura: Hucusque iynota.

Scolex $=$ Echinococcus altricipariens : sen E. hominis (antor.) Vesica animata Echinococco scoliciparienti similis, sed omnino eo multo major (ad $\frac{1}{2}$ ped. in diametr.) Scolices singuli quiescentes majore hanulonm minorum numero ( 46,52 et ultra) armati parantur a, aut ex modo E. scoliciparientis; $\beta$, aut in gemmis aut capsulis a vesice matris superficie interna solutis, in quibus iterum scolices et vesice secundarice scolices gignendi si preditce gignuntur (mother-, daughter-, and granddanghter-vesicles); $\gamma$, aut fortasse in vesicis, que divisione quadam aut sectione ex vesica matre in vasibus animalis hospitis repente et serpente formantur. Vesica mater nihil alind est nisi vesicula embryonalis 6 hamulis armata et valde amplificala; vesicula filia et neptis hamulis 6 destitute, quia ex vesicula embryonali rectâ viâ non exortce sunt.

Habitat: Non solum in homine, sed etiam, antoribus Haubnero et Creplino, in mammalibus majoribus domesticis, et quidem in diversissimis et hominis et illorum animalium corporis regionibus.

Ovula: Hucusque ignola.

Tenia matura.-I should not wander far from the truth if I were to assert that this Trenia may probably occur in the human intestines, and indeed in the intestines of those individuals who suffer, or have suffered from the species of Echinococcus belonging to it in some part of their bodies, and in whom such a colony of Echinococcus has opened towards the intestine. Perhaps, as I have already said, the Tenia nane of Bilharz and Von Siebold had such an origin, and was a Tenia Echinococcus altricipariens. This Tenia may also be enabled to develop itself in the intestines of domestic carnivorous animals, especially dogs and cats, as well as in man; and I shall presently, in considering the circumstances of Iceland, cndearour to show how these animals may acquire 
this Tania from Echinococcus-vesicles dwelling in the liuman subject, and not merely from those which occur in animals. A first experiment, made in the year 1853, to breed Tienice from Echinococcus-vesicles passed from the living human subject, was unsuccessful, and I have unfortunately only the same report to give of a second experiment made with vesicles passed from the same individual. Dr. Zenker also was unsuccessful in a similar administration. Pathological anatomists and hospital surgeons may do what they can further, and should not omit to administer such Echinococcus altricipariens to dogs.

That the eggs and embryos must occur at some time or other in the human body is a matter of course, but from their small size they are overlooked, in the same way as those of the other Tania, of which we have already treater.

The Scolex = Echinococcus altricipariens, occurs not only in man, but also, as Haubner and Creplin have proved, in the larger domestic mammalia, especially the Herbivora. ${ }^{1}$ The histories of patients scattered in literature all belong to this form, inasmuch as they refer partly to enclosed daughter-vesicles of Echinococcus found on dissection in Echinococcus-sacs, partly to the spontaneous passage of such daughter-vesicles through the urinary passages, through the rectum, through the stomach in vomiting, or through the lungs, and partly to a similar passage through the punctures or incisions made for surgical purposes. From these, however, we see how widely this species is diffused over the surface of the earth, and we may also see from the accounts of cases and dissections given by Schleissner, in his ' Nosography of Iceland,' that this form not only occurs in Iceland, but that it must be the predominant species there, and the one which makes its appearance epidemically; and Eschricht's observations made on an Icelander also refer to this species. Dr. Thorstensohn's case at Reikjavik, in Iceland, mentioned by Schleissner, refers to this species no less than the majority of Schleissner's cases, of which, however, one certainly belongs to Cysticercus tenuicollis, as Eschricht has shown.

To what a degree of endemic diffusion this species has arrived, especially in Iceland, appears from the fact, that during his residence in that island, Schleissner saw fifty-scven human patients suffering from Echinococcus. In Iceland this disorder

' See also Ifuxley, in 'Proc. Zool. Soc.,' on Echinoc. veterin. in liver of Zebra. (Loc. Cit.-Ev.) 
occurs more frequently and extensively inland than on the coasts, so that, for example, in Sandfell-sogn, Dr. Schleissner found $2-3$ members of each family suffering from it. On the whole one eighth of all the cases of illness occurring there are referable to this plague, and Thorstensohn thinks that every seventh living human being in Iceland suffers from Echinococci, which even according to Schleissner is no exaggeration. Moreover, the female sex is much more liable than the male to be attacked by this disorder, and the abundance of the Echinococci increases with age, men being most frequently attacker by Echinococcus between their thirtieth and fortieth, and women between their fortieth and fiftieth years.

A very interesting case is that communicated by Thorstensohn to Schleissner, and given by the latter in his work. I shall reproduce it here, almost as a model of a history of a case of Echinococcus altricipariens. ${ }^{1}$

"Case from Dr. Thorstensohn, of Reikjavik.-A boy, of four years old, had suffered for several months with a swelling of the right side, and afterwards became dropsical. He had frequently evacuated worms, both thread-worms and ascarides, and also others of a less common form. On his visit, Thorstensohn found a considerable anasarca, so that the whole body weighed sixty pounds. In the right side there was a fluctuating swelling of the size of a child's head. This was opened, when there issued from it a quantity of thin fetid matter, as well as a great number of hydatids of the size of a pigeon's egg. These were roundish, with a tail towards one side. (This was certainly the remains of the stem on which the vesicle had been sitting.) When they were put into lukewarm water they exhibited a distinct movement, especially as they contracted and expanded themselves, nearly as the Stincus marinus moves in the sea. After a purgative of calomel and rhubarb, a number of thread-worms and ascarides were removed, together with some gray worms rather more than an inch long, and thicker than the common ascarides (probably, Anchylostomum duodenale, Küch.), besides some hydatids. The wound was kept open,

1 I am indebted for this to the kind intervention of Professor Eschricht, of Copenhagen, who had the goodness to write, on purpose, to Dr. Thomson, who is just engaged in the translation of Schleissner's work, 'Island fra et laegevi deuska beligt Sỵspunkt,' and who, in return, was so good as to translate it and send it to Professor Eschricht for my use. 
the issue gradually diminished, and in a fortnight the boy had recovered. The same paticnt liad also a fluctuating boil on the lower lip. When this was opened with the lancet, a thin, watery matter flowed out, and besides this a living worm of the colour, form, and size of the common maggot. Thorstensohn explains this by supposing that the egg of a fly had got into a crack in the lip, and that the latter had then closed up before the egg was hatched."

An interesting account of a casc, which may serve as a model for Echinococci in the lungs, is given by Vigla, in the 'Archives générales,' for September, 1855.

It is true that the celebrated blow ("Stoss"), in this case from an ox, still plays its part, but in other respects it is rery well described. The symptoms were, pain in the breast in the neighbourhood of the right mamma, especially during motion, diffieulty of breathing, absence of cough and expectoration, emaciation, anrmia, and impossibility of lying on the left side-the patient could only lie on the right side or on the back; the voice weak and altered, as in compression of the trachea, or nervi recurrentes; the right side of the chest much arched, and the intercostal spaces and cutaneous veius dilated. The left side of the chest was only more developed behind in consequence of the coexistence of scoliosis.

Centim.

Circumference of the right half of the chest at the level of the 7 th dorsal vertebra 43



Percussion over the whole anterior portion of the right side of the chest, with the exception of the uppermost intercostal space, and down on the right side to the narel, throughout a length of 28 centimetres, was dull. The dulness also passed backwards to the angle of the right shoulder-blade, and eren a little beyond this towards the left. The lobes of the liver, which were pushed obliquely upwards, had displaced the heart, and pressed it up into the left axilla, where the sounds of the heart were audible. The respiratory murmur was absent throughout. In front, fluctuation was felt in the right intercostal spaces. 
The characteristics of this spccies of Echinococcus, as distinguished from the preceding, are as follows:

1. The enveloping cyst, and the mode of annexation of the inner wall of this cyst to the primary vesicle of the Echinococcus derived from the six-hooked cmbryo, are similar in this and the foregoing species, but the cyst formed by $E$.altricip. is much larger than that of $E$. scolicipariens, and for this reason projects far above the level of the organ in which the colony sits.

2. From its much greater size results a proportionately increased interference with the functions of the organ attacked, and eventually of the whole organism.

3. With regard to the animal itself this distinction occurs, that we not only find single scolices or a single resicle in such a colony, but that we have here to do with the constant production of fiesh vesicles with young (daughter- and granddaughtervesicles), sometimes with, and sometimes without, the production of separate scolices adhering directly to the walls of the vesicle. That the hydatids occurring in Iceland exclusively exhibit this structure appears from the case furnished by Thorstensen to Schleissner, as well as from the following remarks which are quoted from Schleissner. "The hydatid-sacs are formed not only in the human liver, but in very many parts of the abdomen, and are often of enormous size. Hundreds of hydatids are frequently evacuated through the external opening of the sac, or with the stool, and in vomiting. They do not, however, occur only in the interior of the body, but also very frequently in the skin, where they appear like large saccular swellings. The course of the disorder is very chronic." In this description I have purposely avoided the words " production of similar vesicles in themselves," as the vesicles produced do not, like the original mother-vesicle, bear six embryonal hooklets, which these secondary and tertiary vesicles certainly never possess at any period of their existence, as they never have occasion for them. Moreover, it is unnecessary for me to state particularly that the six hooklets may be sought for in vain even on the mother-vesicle, as although they are certainly present, they must, from their extreme minuteness, escape the eye on such a large vesicle, or in its enveloping cyst. The smallest of the granddaughtervesicles are but just visible; they are about half the size of a pin's head, and enclose four, five, or morc scolices, which adherc peripherically, by a small stalk, to the inner wall of the common 
cyst, but converge with their free ends towards the centre of the cavity of the small vesicle. (See Pl. III, fig. 18.) In very large daughter-vesicles individual scolices also swim about. freely.

4. The individual scolices produced or mursed by the mother-, daughter-, or granddaughter-vesicles, are in general more slerder than those of the preceding species; they have the head, with its double circlet of hooks, more frequently protruded during life, at least within the larger daughter-vesicles, exhibit distinctly marked sucking-dises, and bear a much greater number (46--52 -54) of looks, which, on the whole, appear much more slender thau in the preceding species. From this we see that Livois' statements regarding the number of hooks, \&c., are perfectly correct.

5. The dwelling-place of this species is by no means limited, indeed we may say that there is scarcely a part of the body in which it may not be found; thus it occurs in the liver, the lungs, the kidneys, the sheath of the testicles, the spleen, the ovaries, the breasts, the throat, in the subcutaneous cellular tissue, in the bones, \&c.

6. With the augmentation of the secondary and tertiary cysts in the mother-cyst, the latter, and with it the swelling increases in size; the more rapidly this takes place, the more does the swelling increase, which facilitates the recognition of the disorder and its natural cure, inasmuch as the mother-cyst is burst in this way, and in most cases probably becomes destroyed. We must not, however, always depend upon this last issue, for the burst colony appears to heal again in a remarkable manner, and then to be in a condition to recommence its production of fresh daughter-vesicles. At least the remarkable case of a patient observed by Jüttler and myself is in favour of this last opinion. In this case, daughter- and granddaughter-vesicles passed off through the urinary passages for a twelvemonth, but after a very strong evacuation they at last ceased. After this had lasted a year, the patient again suddenly observed an abundant passage of daughter- and granddaughter-vesicles in the latter part of January in this year. It is certainly possible that a second colony may have existed close to the first, and that this was now full-grown and burst, but we may still adopt the supposition of a healing of the first colony.

7. In general the prognosis of this disorder appears to me to 
be more unfavorable than that of the preceding species, although its diagnosis is easier on account of the more rapid growth and greater bulk of the swelling, the occurrence of the hydatid-buzzing and the more distinct sensation of fluctuation.

The structure of the walls of the mother-resicle is the same in both species, and is characterised by the numerous parallel concentric layers in the substance of the walls, which appear more distinctly marked in the daughter-vesicles, and make their appearance with remarkable clearness after treatment with caustic potash with the addition of a drop of common red ink.

Very recently ("Verhandl. der phys. med. Gesellsclı. zu Würzburg,' 1855, pp. 84-95) Virchow has proved that the so-called alreolar colloid of recent authors, such as Buhl (Rubener's illustrirte medicinische Zeitung, 2 Jahrg.) and Zeller' ('Inaugural-abluandl. unter Luschka's Vorsitz,' Tubingen, 1851), is nothing but a number of emptied Echinococers-yesicles. This pathological product must, therefore, by no means be confounded with cancer, as indeed Zeller proved; but this disorder must necessarily, I think, be regarded as the consequence (Virchow) of Echinococci; and it must not be supposed, as Zeller, (who las given very good figures of the Echinococci) found, he would have it, that we have to do here only with an accirlental concurrence of Echinococci. I refer the cases here treated of to Echinococcus altricipariens s. hominis, and shall describe them first after Zeller and then after Virchow.

In Zcller's case the liver was studded throughont with hollow spaces of various form and size, which were covered with a perfectly transparent, glassy, colourless, or slightly yellowish, gelatinous film. Larger cavities of this kind occurred, with others of the size of a pea or a grain of millet, of which the smaller ones werc situated towards the periphery. But between the small alveoli there were sinewy, granular, dull-white strix and partitions, which were irregularly divided, but became more thickly deposited towards the outside. The alveoli were roundish, elongated, irregularly sinuated, communicating by larger or smaller openings with the neighbouring cavities, and werc coated on the smooth inner surface, which was free from epithelium, with a crumbly mass, which was sometimes softish and orange yellow, forming a round or angular finely granular matter, soluble in acetic acid and potash, entirely filling the cavities of the smaller vesicles which contained oil-drops, gall-pigment, crystals of hæmatoidine, phosphate of am- 
monia and magnesia, and a small quantity of cholesterine and crystals like dumb-bells, which mighit be easily taken out of the cavitics. Between the gelatimous matter and the inner surface of the alveoli there werc, sometimes, calcareous deposits, which often completely surrounded the former. The gelatinous mass itself, to which the inmer wall of the alveolus exactly fitted, was of a roundish elongated form, folded, and beset with ridge-like processes internally, or with indentations externally. The socalled colloid-vesicles, which were of various sizes (0.012-1 mill.), consisted, especially the smaller ones, of colourless, transparent, structureless, soft, elastic, extensible masses $(0.004$ or 0.01 to 0.016 or 0.020 ), with tolerably thick walls, furnished with a fine concentric striation. In these, in Zeller's case, there were young Echinococci in the interior of the alveoli, placed in one series, or, more correctly, in the interior of the colloid-vesicles which were situated in these alveoli, which were placed more towards the periphery of the liver. The colloid-mass formed the clothing of all the alveoli, and formed a perfectly clear, thin, soft layer, which was easily torn into shreds. 'The Echinococcus-vesicle (daughter-vesicle) lay free in the cavity enclosed by this colloidmass, that is to say, notwithstanding Zeller's process, by the mother-resicle of the Echinococcus. This Echinococcus-vesicle was collapsed, yellowish, folded, might easily be taken out whole, and when cut open cxhibited the little Echinococci sitting upon its inner surface, like fine white sand. The walls of the daughterresicles were of a brownish colour, and sprinkled with corpuscles of $0.008-0.04$ millim. in diameter. These corpuscles were oval, globular, pyriform, kidncy-shaped, or flattened laterally, sometimes with an indistinct, sometimes with a regular and distinct stratification into $2-3$ or more layers, which were generally 0.0013 millim. in thickness, rarely radially striated, colourless, yellow, or even of a fine green colour. They became clear in the mineral acids, and in acetic and tartaric acids, sometimes with an abundant evolution of carbonic acid (carbonate of lime), sometimes without evolution of gas for a long time; the latter also sometimes commenced very suddenly after the long action of the acids, but was very rarely entirely wanting. When treated with sulphuric acid, crystals of sulphate of lime shot ont in tufts of needles, in single, well-formed crystals, lying on one another in four-sided tables, or in swallow-tail-like twin crystals, so that we must suppose that the corpuscles consisted of 
phosphate of lime, and an intimately intermixed organic sub. stance.

The scolices produced in such a daughter-vesicle had the usual form. The calcareous corpuscles measured 0.008-0.016 millim., were very dissimilar in form and colour, and exactly resembled the structures just described in the walls of the mother-vesicles. On the addition of sulphuric acid, crystals of sulphate of lime were formed, but there was decidedly no evolution of carbonic acid. No fibrous structure could be detected in the larger vesicles. Sometimes individual vesicles were soldered together, their walls were in conjunction and could not be separated by pressure; others communicated by an opening, which was generally narrow, producing all sorts of remarkable forms (elongated series of vesicles; a disorderly heaping together, with a communication of many or all of the vesicles with each other; a large vesicle with apparent or real excrescences, or a combination of small vesicles with a large one, from without; perhaps, a constriction of the large vesicle in particular cases.) The walls of this Echinococcusvesicle (that is, the so-called colloid-mass) were insoluble in cold and boiling water, in alcohol, ether, and acetic and phosphoric acils; they acquired a yellow colour with nitric acid, and dissolved in hot acid with a straw-yellow colour, which was quickly rendered orange yellow by ammonia or potash; they dissolved in muriatic acid with a gentle heat, forming a dark brown fluid with a tinge of violet; with concentrated sulphuric acid they formed a dark brownish-red fluid, and dissolved readily in potash to a clear, colourless fluid, which remained unchanged after the addition of acid; with Millon's test (pernitrate of mercury, with protoxide and nitrous acid), they acquired, like white of egg, an intense red colour, even in the cold. In an alkaline solution, neutralized by acetic acid, tamnin produced a slight precipitate, acetate of lead no precipitatc. The latter produced a turbidity in the solution in nitric acid, which was again soluble in an excess of acid; ferrocyanide of potassium gave no precipitate. Tilanus and Schraut assert the identity of the colloid-mass with mucus (Schleimstoff). At all events these bodies are very similar.

Virchow admits that he las scarcely anything to add to the description given by Buhl and Zeller, especially the latter. On the surface of the liver, thick, necklace-like, white cords were seen running, like roots, for a certain distance. On making a section through a callous wall of 8-10 millim. in thickness, a 
cavity of the size of a fist was discovered, the contents of which wore a granular, fatty, purulent matter, and mixed with shreds. The inner surface was tubercular, as though cleft, with secondary cavities at the bottom, which were separated from the large cavity by tumours. 'This cavity exhibited a yellow, coherent coating on the lower and hinder portions, and also globular, vesicular, projecting bodies, as large as hemp. seed, in a greenish-white mass. Its walls consisted of sinewy ligamentous tissue, and internally of an aggregation, becoming gradually thicker, of small gelatinous vesicles lying in very small cavities (alveoli). Where the wall was thinner, flat pits were met with instead of these small alveoli. All the alveoli contained small gelatinous masses, generally of a yellow colour (the collapsed Echinococcus-vesicles). In Virchow's case the true tumour-mass, which was nearly as large as a cliild's head, extruded through a very large space of the parenchyma of the liver, and exhibited everywhere an alveolar tissue, although the alveoli were mere points. The abore-mentioned necklacelike alveolar cords of the surface were in connection with the portions of this tumour which lay towards the periphery, and round the tumour there were large numbers up to the size of a walnut, isolated in the parenchyma of the liver. From the larger tumour similar masses extended continuously towards the porta hepatis, thence to the capsula Glissonii, and with it for 6 centim. into the immediate vicinity of the intestine, in the form of a hard, tubercular, sausage-like cord, about 2.5 centim. in thickness. In short, throughout the whole extent of this tumour, necklace-like canalicular lines were seen running close to the gall-ducts and branches of the portal rein, compressing them and inflating them in a corresponding degree in other places, so as nearly to cause rupture and perforation of the walls. The individual ampulle of these necklaces were of various sizes, up to 1 centim. in length, and $3-4$ millim. in breadth; they had simuated walls, and contained gelatinous, membranous, folded or vesicular formations, in a slimy, grecnish paste.

All the canals of the liver, the gall-ducts, portal vein and hepatic veins and arteries were compressed and irregular here and there, in consequence of the intrusion of the knots of the tumour. The duchis choledochus and hepaticus were displaced and laterally compressed, leading to a stoppage of the bile: 
the ductus cysticus was still partly pcrmeable, and the gallbladder was very full, and projecting beyond the margin of the liver; posteriorly the gall-ducts were dilated into sacs, with thin, bilious or clear contents, with calcareous, bilious concretions, whilst the liver was strongly jaundieed, or even of a deep greenish-yellow colour. The parenchyma was normal, although very poor in cells in some places.

On the mieroscopic examination of the tumour in question, sections of it showed thick fibrous stroma with numerous fusiform and reticular cells, partly under fatty degeneration and partly with a large quantity of yellow and brown pigment. Between the bundles of fibres normal parenchyma was sometimes found inserted. In the midst of the connective tissue lay the gelatinous masses, in round, longish, dilated, and contracted cavities $(0.03-$ 16 or $0.3-0 \cdot 4$ millim.), which became considerably enlarged ( 6 millim. in length, $2-3$ millim. in breadth) towards the middle of the liver, especially in the porta and externally to it. The gelatinous mass in the smaller cavitics regularly consisted of walls of several strata, furnished with parallel strix and finely granular contents; it was rarely spherical, generally folded internally, furnished with indentations externally, and, according to the size, $0.025-0.05$ or $0.06-0.08$ millim. in thickness. In proportion as the vesieles increased in size, they approached more closely to ench other, and the larger gelatinous masses, which dilated in water into distencled membranes, and gave exit to small withered vesicles (daughter-vesicles) up to the size of a hemp-seed, could be drawn out. All the membranes exhibited the above-described structureless, equally striated texture, with here and there externally an amorphous coating of fragments and small lumps, and internally a turbid gramular lining, which I have above described as caused by the scolices of Echinococcus. The larger membranes exhibited the well-known process of vitrification of the Echinococcus . membranes, stellate or granular moniliform seattered bodies, of a fatty lustre, resembling the similar cells of the mueous membrane, the processes of which, inereased to broad, canalicular, connecting threads, formed a larger body and resembled lymiphatic vessels in course of development. In the interior of the body a fine folded membrane was recognised, forming a longish or roundish sne furnished with the above-mentioned shining deposits; this gradually became spherical, and after the thickening of the previous stellate body formed a capsule analogous to the young 
Echinococci, which, however, only exlibited two parallel layers (an outer one of 0.04 and an inner one of 0.025 millim. in thickness). Yellow, granular, and diffused pigment, and benutiful small crystals of hæmatoidine, were also deposited. The sacs thus closed frequently remained long in connection with the processes.

From the surface of the membrane also, small, yellowish, knobbed appendages were given off, containing a cavity in the knobbed extremity.

Around and between the membranes lay in groups concentrically stratified bodies, consisting of calcareous salts with organic basal substance, measuring from $0.025-0.03$ millim., held together by granular connective tissue. The fluid of the carities in the interior of the alveoli contained acicular, caraway-like, and probably fatty crystals, and besides these the scolices of Echinococcus made their appearance both on the inner wall and free in the contents of the alreoli, generally with the circlet of hooks retracted, some larger (0.23-0.33 millim. in length and 0.12 millim. in breadth behind) with the head protruded but mostly destitute of the circlet of hooks, and others hookless and so small $(0.12$ millim. long and 0.07 millim. broad) that Virchow thinks they had not attained to the formation of hooks. Their calcareous granules measured up to 0.006 millim. The hooks, unfortunately, were not measured.

After this description, Virchow sums up his views as to this structure as follows:

" 1 . These tumours have nothing to do either with cancer or with alveolar colluid. The distinctions from the latter consist in the composition of the tumour out of isolated animals becoming developed close together, in the passage of the tumour into central ulceration by retrogressive metamorphosis of the auimals and the stroma, and in the regular progress of the animals from the surface of the liver towards the intestine and porta, on which the largest and fullest vesicles were placed, whilst only small and collapsed vesicles occur on the surface.

"2. The Echinococci of the liver do not take up their abode in the gall-ducts (Schröder van der Kolk), but the gelatinous masses follow the portal system and form aggregations, more or less connected, as though situated in a system of canals, close to the biliary and blood-ressels. They are placed therefore in the lymphatic vessels. Perhaps the great resistance of the walls 
of the lymphatics is the eause of their rapid diffusion in certain directions, and of their slight development in comparison with Echinococci in other situations.

" 3 . As only transparent membranes occurred in the greater part of the tumour, the animals had probably long been dead, and their vesicles collapsed, after their eontents had been absorbed. However, this membrane alone is sufficient for the diagnosis, according to Virchow.

"4. Virchow wonders that he found no hooks of Echinococci in the larger superficial vesicles, as it is well known that these are not absorbed. This can only be explained by the fact that these vesicles had been converted into the true sterile acephaloeysts, so that sterile Echinococcus-vesicles must also occur in man, produced from immature, hookless animals.

" 5. Apparently the process here referred to cannot be explained by an extensive immigration of the embryos of Echinococcus, but only by the production of the young in the liver itself. Perhaps we shall find data for the explanation of the production of Echinococcus-buds, in the neculiar, stellate, anastomosing, and probably cellular nets, from which a larger system of canals is formed, in which coarsely granular bodies were developed into large vesicles, surrounded by a thick eapsule.

" 6 . In the process liere deseribed we meet not only with several vesicles lying in the same cavity, but with an actual nesting of one vesicle within the other."

In Virchow's 'Archiv für pathol. Anatomie,' \&c. (x, pp. 206209, 1856), Luschka communieates another case of this multilocular, ulecrating Echinococcus-tumour. The liver, which was swollen up to nearly twice its natural size, only contained parenehyma in the right lobe, and this was very dry and permeated by an abundance of thinly fluid bile of a strong yellow colour; the hepatic lobes were at the same time sharply separated, not by vessels, but by ligamentous partitions. The left hepatic lobe, which was converted into a sac of the size of a man's head, contained a yellowish-green, floceulent, pus-like fluid; its inner surface had the appearance of a dingy-green felt, and exhibited larger and smaller tubereles and innumerable roundish openings. The wall, 0.5 to 2 centim. in thickness, consisted of the greatly thickened peritoneal coat, and a pale-yellow, cartilage-like solid mass growing exuberantly against the cavity and the parenchyma of the right lobe; in this there were innumerable smaller and 
larger roundish vacuities or alveoli (scetions of a system of canals opening by many mouths into the sac). In the porta hepatis, and in the quadrangular and Spigelian lobes, there were knots of the size of a bean to that of a wahnut, and along the ligamentum suspensorium hepatis there were knotty cords corresponding with the branches of the lymphatic ressels, of the same composition and appearance as the wall of the snc. The system of canals containing the gelatinous mass diffused itself, starting from the porta hepatis, not only into the lymphatic ressels, but also especially into the ramifications of the left branch of the portal veiu. The passage of the mass from the larger into the smaller vessels could be traced; but it could not be stated with certainty where its primary seat had been, whether in the ramifications of the portal vein, or in the lymphatic ressels, or in both together, or in the interstitial tissue of the capsula Elissonii-as perforations had evidently taken place, which, to a certain extent, interfered with a definite conclusion. The gelatinous mass consisted principally of readily pliable lamellæ, of various thicknesses and a glassy transparency, and with a more or less distinctly stratified arrangement; in the cavities referred to it contained larger and smaller, spherical or much branched, uninjured, hollow structures, with exactly the same kind of lamellar walls (Echinococci furnished with diverticula). The contents of these hollow structures con-. sisted of a fatty granular mass, sometimes with colouring matter of the bile and crystals of hrematoidine, and only in extremely rare cases with very small embryoes of Echinococci filled with granules, and, as it were, in progress of decomposition, with an inverted, imperfect circlet of hooks.

Some resicles of about the size of a liemp-seed, existing singly or several together in the ramifications of the left branch of the portal vein, were especially remarkable. These vesicles, with the walls 0.08 mill. in thickness, had the well-known concentrically stratified, glassy structure of Echinococcus-vesicles. From the inner layer of substance small elevations arose on many places; these were prolonged into delicately outlined peduncles, scarcely 0.004 nill. in thickncss. The peduncles formed diverticula of various forms, the smallest of which were only 0.04 mill. in length, and clavate, and formed a cavity with finely granular contents and a delicate structureless wall. Othcr excrescences were larger, lobed ( $2-4$ lobes) or simple, and at the same time rariously constricted, often to such a degree that the individual segments of 
the excrescence were only connected as if by the finest threads. Particular segments of the larger excrescences, however, alicady exhibited the lamellar structure of Echinococcus with the granular contents. Together with these bud-like excrescences there were also, in the above-mentioned vesicles, isolated, smaller vesicles already scparated by constriction; these were spherical, biscuitshaped, and otherwise variously formed, being especially furnished with pelunculiform appendages. No hooks, suckers, \&c., were ever found in these formations.

I have myself been for years acquainted with the process here described with reference to Eclinococcus scolicipariens, although only in domestic animals. It would also have long since been known to surgeons, and the whole confusion as to the question of alveolar colloid now set aside by Virchow could never have been produced, if more attention had been paid to the comparative pathology of the domestic animals. I regarded the affair as so simple that $I$ only referred to it in a few words in a previons part of this work.

Had I anticipated the necessity of giving a more exact account of the processes which take place when the cystic worms, by entering into every possible neighbouring vacuity in the tissues, form runners and appendages, and these organisms with their appendages become destroyed, or become separated by constriction, I would have done so. However, I see how necessary Virchow's corrections were, and for this reason I may be permitted to refer to the subject here. It will be easily seen where I differ from Virchow, and I may be allowed to call the attention of pathological anatomists to the livers of pigs, sheep, and cattle in connection with the study of this process (although without nesting and the formation of daughter-vesicles), and to advise them, in connection with the course of development or the sterility of such colonics, to makc experiments on the administration of the cggs of all sorts of Tenia, which pass through the intermediate state of cystic worms.

With regard to the first point I must agree unconditionally with Virchow.

With regard to the second point, however, we must not proceed so exclusively as Virchow has done. As it was in the blood of the portal vein that Leuckart found the cmbryos of Tenia serrata, as Luschka met with the larger diverticula in this vein, and these extended from tho larger branches into 
the smaller ramifications of the portal rein we may certainly conceive it possible that althongh the majority (vide supra, in the general section) might migrate actively out of the ressels, yet an embryo might exceptionally become further dereloper within the interior of the vessel. It is certainly possible, at the same time, that in rare cases only, a subsequent penetration of the ready-formed Echinococcus-colony into the interior of the vessels and an advance of them might take place. For wherever an embryo is capable of closing the passage of the vessel, wherever it can resist the force of the current of blood pressing against it in such a way as to be enabled to continue its individual being and life, it will become further dercloped, although its external appearance during growth must certainly be modified by the local anatomical circumstances. What is describer by Buhl, Zeller and others, as alreolar cancer and alreolar colloid, is certainly, as Virchow states, as well as his own case, an Echinococcus of the lymphatic system of the liver. Probably all cases of Echinococci of the liver, of similar anatomical structure, both in man and animals, are also Echinococci of the lymphatic system. It is of no consequence to the increasing vesicle, which, as is well known, penetrates into all vacuities in the tissues, so long as it only can find room.

Thus, then, it forms a larger resicle in the lymphatic ressels, probably as a sort of centre or colony from which runners penetrate towards all the lateral branches of the lymphatic system; these go off exactly like the fingers from the palm of a glove, and send off radiating rumners in every direction where a lateral branch of the lymphatic system enters. Thus a rery great part, nay, perhaps the greatest part, of the lymphatic system of a liver may be penetrated by such runners from one centre, and, strictly speaking, become obsolete. The penetrating branches of the colony, howerer, will be constantly dilating the lymphatic vessels into which they have penetrated, as they meet with no very great resistance from the soft parenchyma of the liver, and at the same time also thicken their own walls, which, however, also puts an end to the dilatation of the walls of the ressels themselves. Thus, at all events theoretically an Echinococcusembryo may permeate the whole liver, or at least a very great part of it, if it has penetrated into the lymphatic system.

But, nerertheless, the walls of the vessels will present obstacles 
to the development, at least in this case it will never attain to the size of the mother-vesicles of Echinococcus which we meet with in other places. The fluid will therefore be reduced to a minimum, and the development of the young will be more sparing. Moreover, Echinococci usually only proliferate on certain places; others remain quite barren. It appears to me that the former takes place usually more towards the bottom of the tumour than at its upper part. Then in each particular case the same mode of development certainly occurs, which is proper to the species of Echinococcus. In the domestic animals wc usually find in the gelatinous masses the simple formation of scolices (Echinoc. scolicipariens). In the cases of Zeller and Virchow we see the complicated scolex-formation, namely, the simultaneous production of scolices and nurses (Echinoc. altricipariens). But within these lymphatic ressels a peculiar process of constriction appears to go on sooner or later. Individual runners may be separated by constriction from the main vesicle by the contraction of the lymphatics in particular places, and then continue to grow on their own account. They are frequently still attached to the parent-vesicle by a scarcely perceptible thread (vide Zeller); perhaps even this thread is cut off by constriction, and we have isolated, or apparently isolated, separate vesicles, which perhaps may still betray a connection with the main resicle on close examination. But if this constriction has taken place, and the separated resicle continues its proper life, it will probably retain the degree of proliferation belonging to it during its life in connection with the main vesicle. If the space of the mother-eyst cut off were proliferant, it will continue to proliferate, and if not it will probably not do so. Thus we may explain why the resicles placed towards the periphery are without scolices, daughter-resicles, and hooks, as the upper part of the main cyst, from which they are separated by constriction, is rarely proliferant. In this way also we may easily explain the occurrence of sterile cysts in other parts of such livers. A single six-hooked embryo, therefore, may be the cause of many isolated Echinococci of the liver, or acephalocysts. 'This gires us the best key for the explanation of Vircliow's second, third, fourth, and fifth points. I agree with Virchow, therefore, also when he speaks of a multiplication of Echinococci from a single vesicle in such cases, but only if he understands a constriction of this kind in that case. In $n$ other way can we 
speak of the origination of the origiual vesicles from a single germ, and all otlier isolated vesicles must ccrtainly be accounted for by an equal number of separate germs. Whether all the Echinococcus-vesicles of the liver referred to were produced from a single germ, is therefore questionable-embryos may, probably, have immigrated directly into many places. With regard to the colour of the folded Echinococcus-vesicles (gelatinous masses of the alveolar colloid) we have still to mention that many of the membranes of the resicles presented so white, fresh, and delicate an appearance, that it might be supposed that they and their germs were still alive. If I am not mistaken, I have once bred Trenia Echinococcus scolicipariens from a folded, gelatinous mass, beset with scolices, taken from the liver of a pig. However, Virchow's assumptions, as far as they refer to the production of acephalocysts, agrce exactly with mine.

Symptomatology. - The general and partial functional derangements, the objective phenomena, and the subjective seusations vary according as the position of the Echinococcus is more superficial or the reverse, according to the organ which it has selected for its dwelling-place, according to the size which it has attained, the pressure which it exerts, and the vicinity of large nervous or vascular trunks. The phenomena produced by it agree exactly with those caused by other equally large tumours in similar situations, upon which every text-book of special pathology and therapeutics, or surgery, will fumish information. In order to avoid too great prolixity, I pass over the symptomatology, and shall only mention that when the organ inhabited is one containing air, auscultation and percussion furnish important information, which we shall refer to in the diagnosis.

Diagnosis.-The most certain evidence of the presence of a colony of Echinococcus in the body of a patient is the passaye of the gclatinous vesicles ahready described from open cavities of the body, which occurs after the bursting of such a colony, or the similar passage of such vesicles from the punctures or incisions made into tumours. At the same time, however, the little scolices of the Echinococcus must be found in the vesicles; part of these retain their hooks, whilst others want them, and when their sucking-discs are indistinct they resemble (at least I know no better comparison) very small dolls inclosed in cradles, or have the form of little swaddled children. 
When the vesicles passed have an opening, the little scolices slip out only too easily, and if we do not find the structures just described, we do not know whether we have not before us a sterile colony or acephalocyst. I will answer for it, and every one who has experience will confirm this, that even where the hooks are wanting, the little Echinococci are easily recognisable by the above form. In this way we may recognise the Echino. cocci of the kidneys when the vesicles pass out with the urine (J. Müller, Frerichs, myself, and others); when they pass through the mouth, by coughing, from the thoracic viscera, especially the lungs, although the colony may at first have its station in the pleura ${ }^{3}$ and the colonies of the liver and spleen when the vesicles are seen to pass from the mouth luring vomiting, or from the anus. But even here it is always possible that we may be in crror as to the position of the colony, and we only acquire a certainty as to the cxistence of Echinococci in the body. Thus no doubt Echinococci of the ovaria may perforate towards the amus, and also through the vagina or the bladder, nay, even Echinococci of the liver may pass through the bladder when they are of enormous size. In the examination of such cases we must carefully consider whether we can discover the original seat of the swelling which was formed by the colony, thence trace its growth further by the diminution of the swelling existing before the bursting, and obtain a further foundation for our opinion by the comparison of the former and actual conditions. Every thinking practitioner will be able to form the differential diagnosis for himself easily with the assistance of auscultation, and especially of percussion, and combination of auscultation and pereussion. We shall only indicate this in a superficial manner. Thus, after the perforation of a cyst has taken place in the direction of the intestine, it may easily liappen that, where shortly before there was a circumscribed swelling which gave dull tones on percussion, a very distinct air-tone may be suddenly observed in consequence of the entrance of the gases of the intestines, just as we often see these phenomena occur in ovarian tumour,

1 A very credible teacher of surgery mentioned a case to me in which a gelatinous vesicle was thrown up by a patient whilst conghing, and fell into the spittoon, when a eat came and ate up this gelatinous body. This conld only have heen the daughtervesicle of an Echinococcus or an acephalocyst. Ilowever, the story of the cat is no longer to be regarded as a fable or an absolute impossibility, since our experiments in fecling have shown how greculy dogs and cats are after cystic worns. 
when perforation takes place into the intestines. If we employ auscultation and percussion simultaueously on this spot, we may also probably succeed, if the perforation be narrow, in hearing the air escape through this opening into the intestine with a whistling or lissing sound. Similar results may also be produced by a perforation of the Echinococcus-colony in the direction of the bladder, in consequence of the entrance of the atmospheric air into the sac of the Echinococcus through the urethra. In case of the perforation of an Echinococcus-colony of the liver into the lungs, or of the lungs themselves into one of their bronchi, the clear drum-like percussion-tone which takes the place of the previous dull tone, will guide us in the establishment of our diagnosis, and we shall be further assisted by combined auscultation and percussion by the signs just described; and lastly, by simple auscultation, the whistling entrance of the air into the Echinococcus-sac, and the amphoric noise of respiration diffused through the sac, or, when there is free fluid in the sac, even associated more or less with a formation of bladders (either large or small).

When such a perforation has not taken place of itself, but we have before us a tumour of considerable size (recognisable by percussion or palpation), and especially when there is a sensation of fluctuation, when aueurismal symptoms are wanting, and the general health is good and less injured than would be expected from the size of the tumour in cancer, the diagnosis is best formed by an explorative puncture, and the microscopic examination of the evacuated fluid for Echinococcus-scolices, or for the albuminous gelatinous shreds of the Echinococci, as was done, for example, by Robin in Vigla's case. Dr. Pockels, of Holzminden, has also informed me of two cases in which Echinococcus-resicles were expectorated. One patient recorered, the other died.

These are the only cases in which we can with certainty establish the diagmosis of Echinococci during life. All other cases in which unopened swellings are characterised positively as Echinococci during life, are to be classed more or less in the series of diagnostic tricks, which may succeed with the most practised hand nine times, and fail him on the tenth. The diagnosis can never be brought beyond one of probability, and the surgeon must be contented to make his diagnosis for a sacculated swelling filled with fluid or cystic swelliny, and merely endeavour to distinguish the swelling from solid, parenchymatous tumours, as to 
which every one can obtain information for himself in the ordinary manuals of surgery and speeial pathology and therapeutics. The most useful objective symptoms are, the existence of a sacculated swelling, which is elastic to the tonch and of a peculiar eonsistency and form, in places where swellings do not usually occur, but where, when these do make their appearance, they are generally Echinococci. The lighest degree of probability, we may almost say certainty, that an unopened swelling belongs to a colony of Echinococcus, is attained by the diagnosis, when a swelling occurs in places such as the liver, spleen, kidneys, heart, lungs, breast, throat, or testicles, where Echinococci usually take up their abode, in an individual from whom at the same time Echinococci are otherwise bronght to light, either artificially or naturally. We may then with tolerable certainty regard any existing tumours, which also possess the properties of sacculated cysts, as colonies of Echinococcus. One of the most important symptoms for the diagnosis is furnished, although only in particular cases, by percussion. Piorry, as is well known, was the first to call attention to a sensation which is felt by the finger employed in percussion or the hand when pressing, the swelling-a surt of trembling (fiémissement) which resembles the sensation produced by the clang of a repeater, or a springsofa, in the finger that taps it, and which, for the sense of touch, nearly resembles the oscillations detected by the eye when coagulated jelly is set in motion by any cause. This symptom has sometimes been pereeived, sometimes not, but it appears certain to me that it can undoubtedly be observed in particular cases, the nature of which, however, is unknown. An attempt has been made to explain this trembling by the fact, that the individual Echinococcus-cysts which swarm about in the mothervesicle are brought into collision within the latter by the shaking, and this canses the trembling experienced by the finger. In consequence of the confusion which prevails amongst practical surgeons with regard to hydatids and Echinococci, I must dwell upon this symptom longer than will perhaps appear justifiable, and I will endeavour here to give an explanation of the hydatid-trembling. In my opinion-

1. This hydatid-trembling can only occur when several gelatinons, tremulous cysts, which are inclosed within a larger vesicle, also capable of gelatinous trembling, are in auy way set in motion. 
2. The sensation which is thus produced by touch, not only reminds one of the oscillations perceived by the eye when coagulated jelly is set in motion, but by the percussion of coagulated gelatine inelosed in glass, the same kind of sensations, recognisable by the touch, are actually perceptible. We may easily convince ourselves of this by filling a small glass bottle (of about $5 \mathrm{ss}-5 \mathrm{j}$ ) with gelatine dissolved in hot water, such as is employed for microscopic preparations, leaving it to set, and then tapping upon the outside of the bottle, laid horizontally. By this means we shall easily perceive that this trembling is not only recognisable by the eye, but also by the tonch, and further that, according as the bottle is or is not closed with a cork, and according as more or less air is left in the bottle above the gelatine, different degrees of trembling are experienced.

3. For the perception of such a sensation it is by no means necessary that the individual cysts should come into collision (as has hitherto been supposed); but this trembling may certainly be produced by the circumstance that the walls of one or several cysts tremble in themselves by percussion, and communicate this motion to the nearest cysts, which are still in a quiescent state, without touching them directly, and thus the addition of the trembling of the whole of the cysts at last becomes perceptible in our hand. Of this faculty of the animal walls of the Echinococci every one may easily convince himself, when he is in possession of daughter-vesicles of Echinococcus. If such vesicles be laid upon a glass plate, they will continue to vibrate for a long time after the application of a moderate force to the glass plate, even when they have been long kept in alcohol.

4. From this it follows also, that the cysts of Echinococcus scolicipariens will exhibit no hydatid-trembling, but, at the utmost, a simple fluctuation, because they contain no daughter-vesicles capable of trembling.

5. We also see at once that the hydatid-trembling can only occur in colonies of $E$. altricipariens, and even here only under certain favorable circumstances. First, a certain number of daughter-vesicles, which must not be too small, so that the quaking may communicate to several neighbouring vesicles, and a greater action may be produced by addition. Second, a certain consistence of the fluid surrounding the individual vesicles, with regard to which, as appears from the laws of the trans- 
mission of undulations of concussion, the fluid must be the better arlapted for the production of this phenomenon when it has a certain degree of viscidity, but not so high as to impede the tremulous motion of the walls of the vesicles themselves; and, lastly, a particular position of the claughter-vesicles at the moment of trembling. With regard to the latter, we should certainly take into consideration the circumstance whether one or more of the daughter-vesicles are attached to the mother-resicle, which is shaken by percussion, or swim freely in the fluid; and perhaps eren the circumstance whether or no such daughter-resicles are attached to the spot agitated by the percussion.

6. For this very reason we have also indicated that the phenomenon of the hydatid-trembling will neither occur in all cases of E. altricipariens, nor uniformly at all times in the same case; that it may sometimes occur and sometimes be absent in. one and the same case, but that, where it occurs, it is one of the most important symptoms, and often alone raises the diagnosis to one of probability.

7. For the less experienced even this symptom will not be absolutely infallible, as it requires practice to distinguish it from the sensation of fluctuation or trembling occurring in gelatinous pneumonia or in tumours.

8. Acephalocysts being only barren Echinococci, as we shall show in the following Appendix, what we have said of the two species of Echinocorcus applies equally to them; but in other respects an acephalocyst is not of particular importance to us.

In reference to all otler symptoms, such as the objective symptoms of compression of the organs caused by the size of the swelling, swelling of the extremities by pressure, \&c., and the subjective symptoms produced by the swelling, the reader may consult the text-boolis of special pathology, therapentics, and surgery.

As to the etiology of this disorder, no one now-a-days will believe in its production by al blow or fall upon the organ where the Echinococcus is sitnated, or in any conjectures of that kind. $\Lambda$ s the only cause, remains the swallowing by the patient, at some period of his life, of one or more eggs or six-looked embryos of the Trenia Echinococcus altricipariens. Neither is it allowable to refer to telluric influences; but, nevertheless, we must remember that the mode of life of men in particular locali- 
ties may be generally favorable to the introduction of the eggs of the Tania in question into the stomach, and that, on the other hand, it is a general observation that certain Cestodea frequently have a very limited habitat.

The duration of the life of the Echinococci does not appear to be very short. According to Eschricht, one patient must have borne his colony eighteen years.

The prognosis of the Echinococci varies according to the situation of the swelling, the accessibility of the organ attacked for operation, and according to the primary or secondary injury to important organs and the whole system; but the prognosis is more favorable than is generally supposed. The tumours, when they are accessible, are amongst the number of curable tumours; they may cure themselves by bursting, and when they are once got rid of, relapses in the same colony are rare and exceptional cases, and cvery new Echinococcus produced usually owes its existence to a new immigration of embryos. But for this very reason the continuance of the mode of life in endemically affected places furnishes a more nufavorable prognosis. The natural cure by the bursting of the colony and the passage of daughter-vesicles may be accompanied by symptoms dangerous to life, or, if it takes place in the direction of the larger bronchi, by difficulty of breathing, or may even lead to actual suffocation.

The therapeutics in this case are prophylactic and direct. The prophylactic agree with those of the other cystic worms, but, as the Tania belonging to it, and its host, are still unknown, we can only give indications, which I shall detail in a separate Appendix of "Reflections on the endemic occurrence of the Echinococci in Iceland."

The direct therapeutics lie entirely in the province of surgery. The reader may consult surgical manuals for the treatment of innoxious, sacculated swellings, according to their various positions. We must attempt to get rid of the accessible ones either by the galvanic acupuncture, by incision or puncture, employing the necessary surgical precautious; in other respects all internal treatment and every cure with ointments or salves are to be avoided, let them bear what name they will. What is the use of the treatment with iodide of potassium, or the rubbing in of mercurial ointments? In the most favorable cases the worm may perhaps be destroyed and die. But what is gained by this, when 
the violently irritated enveloping cyst must be only too ready to continue secreting fluid, by which, therefore, the increase in volume of the swelling is not prevented. Such medicaments, like the employment of pressure, could only promise some results in the carliest periods; subsequently, and when the development of the cyst has proceeded far, we probably produce the formation of pus, a process which is never indifferent to the general organism, or, at the best, causes a partial reduction of the swelling: and a remission of certain symptoms, but never a cure.

That an active surgical process is possible even in Echinococci of the lungs is shown by Vigla's case. As the paticnt supported the explorative puncture well, the half of the following fluid (iodine, iodide of potassium, aa $3^{\text {iiiss; }}$ alcohol, $5 \mathrm{v}$; distilled


the wound was then closed. In an hour an iodic intoxication was producel, and lasted for several hours, when it disappeared; the heart approached the median line; more resonance was present under the collar-bones and in the left part of the chest, with increased respiratory murmur, and in the course of several days and weeks cellular respiration was set up. T'he movements of the diaphragm appeared to go on equally well on both sides, and the intercostal spaces exhibited mobility even on the right side, although more strongly on the left. The heart beat in the fourth and fifth intercostal spaces, a little outwards from the nipple. In about a year nothing remained but a prominence of the bony framework on the right side, and the patient had been constantly at his business, but throughont the right side cellular respiration was audible.

\section{Appendix.-Acephalocysts.}

These structures, which were introduced into science as long ago as 1804 by Laennec, are independent animal organisms, notwithstanding all the demonstrations made in opposition to this view, especially by Siebold. I even allowed myself to be led away for some time by Von Siebold's great authority, to assert the same opinion; but I am now converted from this view, in consequence of my administrations of the eggs of Tenice, and retract what I said as to the non-independent animal nature of these structures in a note in Vierordt's 'Archives.'

Now howerer, we may be 
brief in treating of these creatures; and it is sufficient to remark, that acephalocysts are six-hooked cestode embryos, the growth of which has moceeded without hinderance, but which nevertheless have remained barren, or, more correctly, which have never attained to proliferation and the production of scolices. If such acephalocysts occur in places where normally developed Echinococci usually take up their abode, we cannot call them strayed cestoid embryos, but only embryo Cestoidea which have been disturbed in their normal development and remained barren.

For my part I regard as the chruacteristic marks of acephalocysts - 1. The presence of a resicle adhering to the imner walls of a larger cyst, from which it is capal,le of being detacher, or from which it is already detached in particular spots, but never all over, and collapsed in wrinkles, and which presents very sparing calcification in its white, scarcely discoloured walls themselves. 2. The transverse section exhibits walls consisting of very distinctly developed, parallel, concentric layers. 3. The walls have a peculiar, gelatinous, elastic trembling. 4. The contents consist of a watery fluid, or of a substance whish has a purulent consistence, and contains the microscopic elements of cill. cifying encysted proteine masses in the act of resorption. Lastly, the vesicle sometimes conceals, in its interior, secondary cysts with gelatinous wals, in which, however, we seek in vain for scolices of Cestodea or their remains, especially their hooks. The acephalocysts which are referred to here belong to the following three species of Tenice:

1. Acephalocysts derived from Tenia Echinococcus scolicipariens. -Many of those acephalocysts which bear no danghtervesicles in their interior must be referred to this species.

2. Acephalocysts derived from Tenia Eckin. altricipariens. -These are acephalocysts with a formation of daughter-vesicles. With regard to these, lowever, I would observe that many examples may probably have slipped in as aceplatocysts, which in reality were true Echinococci, in which, from the want of good instruments, or of practice in investigation, or from other causes, the scolices could not be detected. The symptoms, progress, proguosis, etiology, and treatment are the same as with the Echinococci. The only remarkable thing, perhaps, is the circumstance that the enveloping cysts of acephalocysts with clear, watery contents, and of a small size, are thicker and more cartilaginous than those of the true proliferant 
Echinococci, in which a similar structure of the cyst usually occurs only in large colonies, or in those which contain the remains of dead scolices and purulent grumous masses.

3. Acephalocysts derived from Tania ex Cysticerco tenuicolli. -What Eschricht regarded as possible has since proved to be the case; in one administration of eggs of T. ex Cyst. tenuicolli to a lamb (vide Cysticercus tenuicollis), I found a sterile Cysticercus tenuicollis in the midst of hundreds of other, equal-sized and fully developed Cysticerci of this species. This sterile individual bore perfectly distinct indications of life. I do not know whether other specimens of Cysticercus or Camuri have been met with in a living but barren state, but there can be no doubt that this is possible.

I have seen dead, barren Cysticerci and Conuri of this kind. These, however, are distinguished from the dead acephalocysts derived from Echinococci in that the intimate contact of the cyst and the worm has ceased, and the latter lies collapsed at the bottom of the former; its walls are of a dingy yellow colom; the fluid las escaped from its interior between it and the enveloping crst, but sometimes a firm calcareous mass, sometimes a more fatty mass, is deposited upon it in a dense, detachable stratum. If there be a whitish turbid spot, or in the Conuri several of these, in one or several parts of the vesicle, forming the indications of the incipient processes of scolex-formation, which was interrupted immediately at its commencement by unknown causes, probably produced by death, we cannot call these structures acephalocysts, because a proliferation had just commenced. All structures which are really to be called acephalocysts, and which are living, sterile specimens of Cysticerci and Conuri, are distinguished from those derived from Echinococci in that the walls of the latter consist of very distinct concentric layers, tremble like jelly, and are extraordinarily elastic, whilst, as I have convinced myself in one living acephalocyst from Cystic. tenuicollis, the walls of the analogous structures derived from Cysticerci are considerably thinner, by no means exhibit the elastic consistence of jelly, and cousist of such fine and delicate concentric layers, that indications of them can only be detected by great care and practice. Lastly, the latter exhibit, although but sparingly, a deposition of calcareous corpuscles, in particular spots within their walls, in greater abundance than the Echinococci. 


\section{Crsticercus vesica hominis (Creplin).}

In Müller's 'Arehiv' 184.0, p, 149, Creplin reports that, in the 'Sanitätsberichte des Königl. Medic-colligiums von Pommen’ (1835, 2 semest., p. 52), Dr. Weitenkampf, of Barth, mentions the case of a young woman, twenty-two years of age, in whom, after taking cold, loss of roice, pains in the bronchi and in the larynx, \&c., oceurred, and from whom hydatids, from the size of a pea to that of a hazel-nut, were evacuated with strangury in eonsiderable quantities erery five or six days, for sereral months. As Creplin supposed these to be hydatids, he made inquiry of Weitenkampf, and reeeived for answer, "that each of the vesicles, of which he had examined a hundred specimens, only contained a single worm (Tania hydatigena), the head of which was furnished with tolerably large oscula, and a eoronet composed of many hooks. The fluid of the vesicles was clear lympl, and no small eorpuscles were swimming about in it." Creplin now thinks that these were Cysticerci. Dr. Weitenkampf, to whom I have applied for further information, sending him some of the resieles from $\mathrm{my}$ patient referred to before, has, I am sorry to say, given me no answer, notwithstanding my repeated request. I eannot, however, help saying here, without cireumlocution, that I regard the struetures here described as Echinococcus altricipariens from the human kidney. 


\section{APPENDIX.}

REFLECTIONS ON THE PRODUCTION OF THE HYDATID DISEASE ENDEMIC IN ICELAND, IN AS FAR AS IT IS CAUSEU BY ECHINOCOCCI.

When we find that the Echinococci, and especially Echinoc. altricipariens, are an endemic disease in Iceland, and from the travels of Von Troil, and the "Voyage en Islande, fait par ordre de S. M. Danoise, traduit par Gauthier de Lapeyronie," that a sort of vertigo (Hoved Sotten) occurs there endemically in sheep ${ }^{1}$ and eattle, which is curable by the trocar, on the employment of which a watery fluid is evacuated from the brain, it is very evident that Coenuri are not of rare occurrence in Iceland, and that they are a great plague to breeders of cattle, and we must conclude that Iceland is a land which presents a more favorable soil for the development of the cystic worms in general than many other countries. From analogy we may assume that one reason of this lies in the fact, that the places where these cystic worms are particularly plentiful, that is to say, the districts in the interior, must be humid, as it is well known that Conuri rarely thrive in dry districts. The numerous hot wells in those districts of the interior of Iceland favour the production of this humidity of the soil, in part directly, by the water flowing from them, and in part from the vapours which rise from them into the air in considerable quantity. In this, therefore, we liave a confirmation of the general observation as to the production

1 The Icelandic sheep have pointed ears and a short tail; sometimes they have two, three, or four horns, which are sometimes straight, sometimes bent forwards, and sometimes backwards, and sometines no horns. One animal gives four pounds of wool, which falls off in the spring without shearing. 
of cystic worms, and it is certainly obvious that in such districts double care is necessary. But moisture alone cannot he the cause of the cystic worms-for this we require the eggs of particular Tanice with their six-hooked embryos. As regards Echinococcus scolicipariens, the inference founded on analogy is easy. We know that with such an extraordinary development of the breeding of cattle and sheep, for which dogs are required, it cannot be difficult for the dogs to infect themselves with those Tanice belonging to the cystic worms of the sheep, which are slaughtered in great numbers in Iceland-such as Tcenia Conurus, T. Echinococcus veterinorum of authors, and T. e Cysticerco tenuicolli. Man, also, may easily acquire an Echinococcus scolicipariens, from the eggs which have escaped externally, as we have already seen, and as we shall soon see more distinctly; and the more numerous the dogs are, the more will such Tcenice be present, and their eggs escape into the outer world. The more frequently also will the opportunity be given for these eggs to find their way into the human subject, if no hinderance of any peculiar kind exists. But it requires a further explanation, and a deeper investigation of the local conditions, to discover how Echinococcus altricipariens is produced in the human subject, and how it can propagate itself.

Where, we may ask, in the first place, does the mature Trenia belonging to this species take up its abode? Its dwelling-places, in my opinion, can only be two, namely, the intestiue of man himself and that of the dog; in the latter of which situations, indeed, most of the cystic worms which occur in the larger domestic mammalia, can develope themselves into Tania. As a matter of course, a man suffering from Echinococci may infect himself with $T$. Echinococcus, by the bursting of his Echinococcuscolony in the direction of the intestine, where the scolices contained in the daughter-vesicles are poured out, and become Tanice. But, after what we have alrealy said upon Tania solium, it is equally evident that just as a person who harbours a $T$. solinem may infect himself with Cysticercus ccllulosa, the bearer of Tania Echinococcus will also be in a condition to infect himself with Echinococci. In such cases we should easily explain the increase of the Echinococcus-tumours with age in certain individuals, and their constant new formation. Besides, the views here laid down agree with our further observations in Iceland, where, according to the few known exact histories of patients, 
such cases are certainly not wanting in which the Echinococcuscolonies open towards the intestine. The process might also take place by the eggs of those Tanice which have become mature in the human intestine, escaping externally, and being swallowed by other men, after the eggs had been driveu about.

It is now a problem for the surgeous of Iceland, in the dissection of those individuals who luad suffered from Echinococcus, and espccially those from whom Echinococcus-vesicles had passed off externally, to see whether a Tcenia occurs in the intestinal canal of the Icelanders, agreeing in the form of its head and in its sucking dises with the second species of Echinococcus. Moreover, it is desirable that the surgeon who is treating a patient from whom Echinococcus-vesicles pass off, either per anum or by vomiting, should submit him to treatment with the remcdies for tape-worms, so as to destroy the young cmbryos hefore they attain maturity.

But this cannot be the only source of infection of the Icelanders with Echinococci, there must still be a further migration of the embryos externally as well as another place in which the scolices of the Echinococcus-colony may become mature Tenice. It is at present unknown to us whether the sheep, cattle, and larger graminivorons domestic animals in general, in Iccland, suffer generally from Echinococci, and then from what species; and it would be worth while for Icelandic surgeons to tell us what species of Echinococcus occur in the lastmentioned domestic animals, or to send the vesicles which occur in the liver, the peritoneum or other abdominal viscera, the lungs, the kirheys, \&c., of different sheep, cattle, and horses, to the continent of Europe, for examination with good microscopes. Many cases of dropsy in sheep may belong here. If it were possible for a sheep-dog here and there to infect himself in this way with one or other of the two species of Trenice Echinococcus, this would still only be a rare case, at least as regards the second species.

There still, however, remains another way in which the dogs may obtain the scolices of Echinoc. altricipariens directly from man, withont any occasion (to remore Von Sicbold's fears) for giving so much offence to the diguity of man as to suppose that in order to obtain this worm the dogs in Iccland are compelled 
to devour their masters. Even here the proof lies more at hand than we should perhaps have supposed. It is a well-known fact, as already observed, that colonies of Echinococcus evacuate their daughter- and granddaughter-vesicles with the foces, by romiting and coughing, and with the urine, or that these vesicles are set free by the incision or opening of such Echinococcus-cysts by the trocar or knife of the surgeon. Hitherto, no doubt, these vesicles have been too inconsiderately dealt with, - they have been allowed to lie just where they fell, as, for instance, with the freces, ${ }^{1}$ or the vesicles removed by the trocar have been thrown upon the open dung-heaps. As a matter of course dogs can easily get at all these places, and, especially in the half-wild state in which these animals live in Iceland, they will greedily fall upon and devour these vesicles upon the dung-lieaps, or those evacuated in the immediate neighbourhood of the patient by coughing, vomiting, or with the urine, and thus easily infect themselves with immense numbers of Tania Echinococcus altricipariens, if these resicles, as is frequently the case, are passed uninjured. In order to give a further support to this hypothesis of the passage of the vesicles into the intestine of the log, we must certainly first of all consider the question whether so many free dogs do really occur in Iceland, that they may easily get at these evacuated vesicles. All travellers agree as to the number of dogs possessed by the Icclanders, and I borrow the following remarks partly from the works already referred to and partly from the travels of Olavius.

The Icelanders in all districts keep the following three kinds of dogs in considerable numbers.

1. The sheep- or cattle-dogs (Faar houndar), of which there are two sub-varieties. The smaller of these two races has long hair, short and weak legs, a pointerl snout, and a curly tail; the other has curly and coarse hair. The Icelanders employ them in seeking for lost animals; as the sheep, as well as cows and horses, in Iccland, usually seek their food for themselves, often without herdsmen, the whole year round, and thus, of course, may readily stray upon the pastures and in the moun-

1 I find no account, in the descriptions of travels, of the Icelanders making use of closed privies; everywhere nothing but open dung-heaps are spoken of. Besides, the Icelander may also deposit his dung in the open air, just when the necessity comes upon him, and indeed it cannot be otherwise with fishermen and shepherds. 
tains. The shepherds, however, who have the care of larger flocks, employ these dogs to drive down those sheep which have clambered upon projecting rocks where the shepherds cannot follow them, and thus prevent them from straying. A sign from the shepherd with his finger towards a projecting rock is sufficient to tell the dog what he has to do, and to drive the sheep quietly back to the flock without danger.

2. Hunting dogs (Dyr houndar). This variety has smooth hair and long legs, and greatly resembles the common Danish dog. In a land where the flocks of sheep are the principal riches of the people, they must also have the means of freeing themselves from the numerous enemies of these flocks. In Iceland these enemies are especially the large species of foxes (white and brown); the eagles, which prey upon the lambs; and the raven, which is fond of picking out the eyes of the sheep, and attacks the sheep which have just lambed and are prevented, by the pains of labour, from defeuding themselves as well as the new-born lambs. The hunting dog is employed in chasing the foxes, helping in following the fox, and in digging him out; he may frighten away the raveus, and probably call the attention of the shepherds to the place where an eagle approaches the flock.

3. A kind of house-dog (Dssery houndar), which appears to be like the preceding, but has a tail of only two or three inches in length; he serves for watching the housc and goods.

Thus we see the Icelanders are everywhere accompanied and surrounded by free dogs, and what we have just said will have sufficieutly indicated that these animals, continually going about in the vicinity of man, have the opportunity of acquiring the Trenia Echinoc. aliricipariens from the Echinococcus-vesicles evacuated from man.

From this it appears that the duty of the Icelandic medical man is,-

1. To examine the Icelandic dogs for the occurrence of this Tania, or, if serviceable microscopes are wanting there, to send the intestines of sheep-dogs which have lived in the neighbourhood of a family from which such vesicles are or have been given off, to Copenhagen, for examination, and I would also thankfully receive consignments of this kind. ${ }^{\text {" }}$

1 No further precantion is necessary execpl to tie up the intestine cut off at the 
2. 'To give instructions that the vesicles in question, wherever' they may be evacuated, either artificially or naturally, should be burnt, but never to allow them to be thrown upon duug-heaps, or places where they can be got at by the dogs.

As soon as the dogs have developed the Tonia Echinoc. altricipariens to maturity in their interior, they escape externally with the dung, and get into the water, and also on the pastures and vegetables, as we have already often seen. In Iceland, also, the following circumstances may concur. Not only the humidity of the soil in the districts in which the Echinococci are endemic, of which we have already spoken, but the warm temperature, remaining the same summer and winter, of much of the runuing water ${ }^{1}$ which is used for drinking, caused by the entrance of the numerous hot wells into the water, may, perhaps, not be entirely without influence, as the lukewarm temperature appears to agree particularly well with all the lower animals, and therefore, probably, also with the cestode embryos in question. For the rest, the mode of life of the Icelanders affords the following peculiarities which may, possibly, be regarded as the principal causes of the communication of the infection of the egrgs of Trenia.

Possibility of infection by drink.-In Iceland there are six kinds of drinkable natural waters made use of.

1. Glacier-water, - a water which reaches the valleys in a milky state, and is only drunk in case of need.

2. Rain-, and 3, brook-water, which do not come from glaciers, and are very fresh and wholesome.

4. Spring-water, which is still more frequently used, and is considered as very wholesome, but generally has a styptic action upon the intestinal evacuations.

5. A very cold water proceeding from springs which never freeze, and-

6. Cooled thermal waters, when these have not too mawkish a taste.

It is evident that the waters mentioned under 2, 3, and 4, and perhaps 5, may be especially the agents in the transport of the eggs of the Trenice into the human intestines. The

pylorus and at the passage of the small intestine into the colon, and send it, in spirits, to its address. The stomach and rectum are unnecessary for this investigation.

' I may refer, for example, to the River Reykedal, which, in spite of its warmtl, is overstocked with cxtremely fat trout and salmou. 
drinking-water most proper for the prevention of this transportation would certainly be the cooled thermal water mentioned muder 6 , or other water boiled and cooled in imitation of this process.

Artificial beverages. - The commonest beverage is acid whey (Blanda), which is mixed with the ordinary drinking-water. As a matter of course the same may apply to this, that we have said of the natural drinking-waters just referred to. I cannot omit to remark, also, what a necessary dietetic, or popularly medicinal beverage the acid wheys are in Iceland, as they are proper to neutralize the too energetic action of the styptic waters to a certain extent, in the same way as their substitute,-

Sorrel water. - In the summer the leaves of Rumex acetosa are laid in the water and left there mitil all the juice is extracted. This beverage is employed for some time during the summer, but not freely until the winter. What we have said of the dilute wheys applies also to this. All depends upon the water added to it. Water with one twelfth of old whey (Syre), forming a sort of intoxicating beverage, is also drunk. I do not know its amount of alcohol, and have, therefore, no means of judging whether the embryo Tanice are capable of living in this beverage.

Raw food.-The Icelander, belonging to a race of people amongst whom the sciences still flourished in the sixteenth century, and who had already their own printing establishments in 1522, never eat raw flesh; cven edible mussels and oysters are used by him only as baits in his fisheries, but not for eating, except in scasons of the greatest scarcity.

Vegetables are rare upon this island, although the Governmeut has taken the greatest trouble to introduce at least the oleraceous vegetables. Our green salad is only cultivated in the kitchengardens of certain personages, and a few of the higher people. This, therefore, can hardly come into consideration. Instead of this, however, we may lay a suspicion of transferring the eggs of tape-worms into the human subject upon-

1. The lierb of Rumex acetosa, the common sorrel, the raw leaves of which the Icelanders are fond of cating.

2. Bilberries, the fruits of which they employ in the preparation of bilberry jelly, with cold milk, and the herb of which they use in various ways, without eating it, as they collect it for the purpose of dyeing.

3. Strawberries. 
4. Angelica, the freshly collected stems of which are caten raw, without any preparation, or at the utmost washed a little before use, whilst the roots are not used in many places, and left for the foxes, which, in consequence of the want of sweet grapes, cool their desire for dainties upon the sweet roots of the angelica.

At present we carnot discover any other causes of the transference without appearing to go too far. The Icelander is not partial to green vegetables, and even leaves the water-cress, so much esteemed in other places, untouched.

By the method of distributing the dung upon the pastures, the eggs of Tanice may very easily get to the above-mentioned raw articles of diet, and the dogs, which run about and deposit their dung upon the rocks, may also be the cause of the transportation of the eggs of Tanice by the agency of rain to strawberries and bilberries.

The principal prophylaxis is the destruction of the Echinococcus-vesicles wherever they come to light, and the prophylactic treatment of those patients from whom Echinococcus-vesicles pass off through the intestines, must be by means of our most efficacious remedies for Tenice administered in small doses and through a long period, in order to kill or expel the Trenice. With regard to the destruction of immigrating embryos, see the experiments in the Appendix at the end of the book.

\section{SUPPLEMENT TO THE CESTOIDEA.}

After the first lialf of the section Cestoidea was already printed, the following notes reached me; they appear to me to be sufficiently interesting to find a place here. Dr. Ficinus, of Stolberg, supported by abundant observations, regards habitual cephaliea in the crown of the head, with simultaneous alopecia on the crown, as dependent upon tape-worm. He found this symptom almost always accompanied with tape-worm, although only in women. This would be a confirmation of Sibert's supposition that in disorders of the small intestine (the seat of the Tania), the cephalæa extends to the rertex. ('Centralzeitung,' xxiv, No. 39.) This symptom has not occurred to me.

Dr. Pockels, of Holzminden, on the Weser, has informed me by letter that in his native place tape-worms occurred in extraordinary abundance in the human subject, and that an acquaint- 
ance of his, who was born of German parents, and had never travelled far, had scarcely left his dwelling-place, which was free from traffic, when he suffered at once from Tenia and Bothriocephalus latus. He administered Kousso with Filix mas, anch relaxed the bowels carefully, some hours previously, with castor oil.

I have stated above that I liad found it impossible to protect animals from infection with eystic worns, by giving them pills of Filix mas and extract of pomegranate root, when the eggs of tape-worms were administered to them at the same time. The foresters about Holzminden state that they have never found the wild swine of that locality infected with Cysticerci, but it was remarked to Dr. Pockels that they were particularly foud of ferms. 


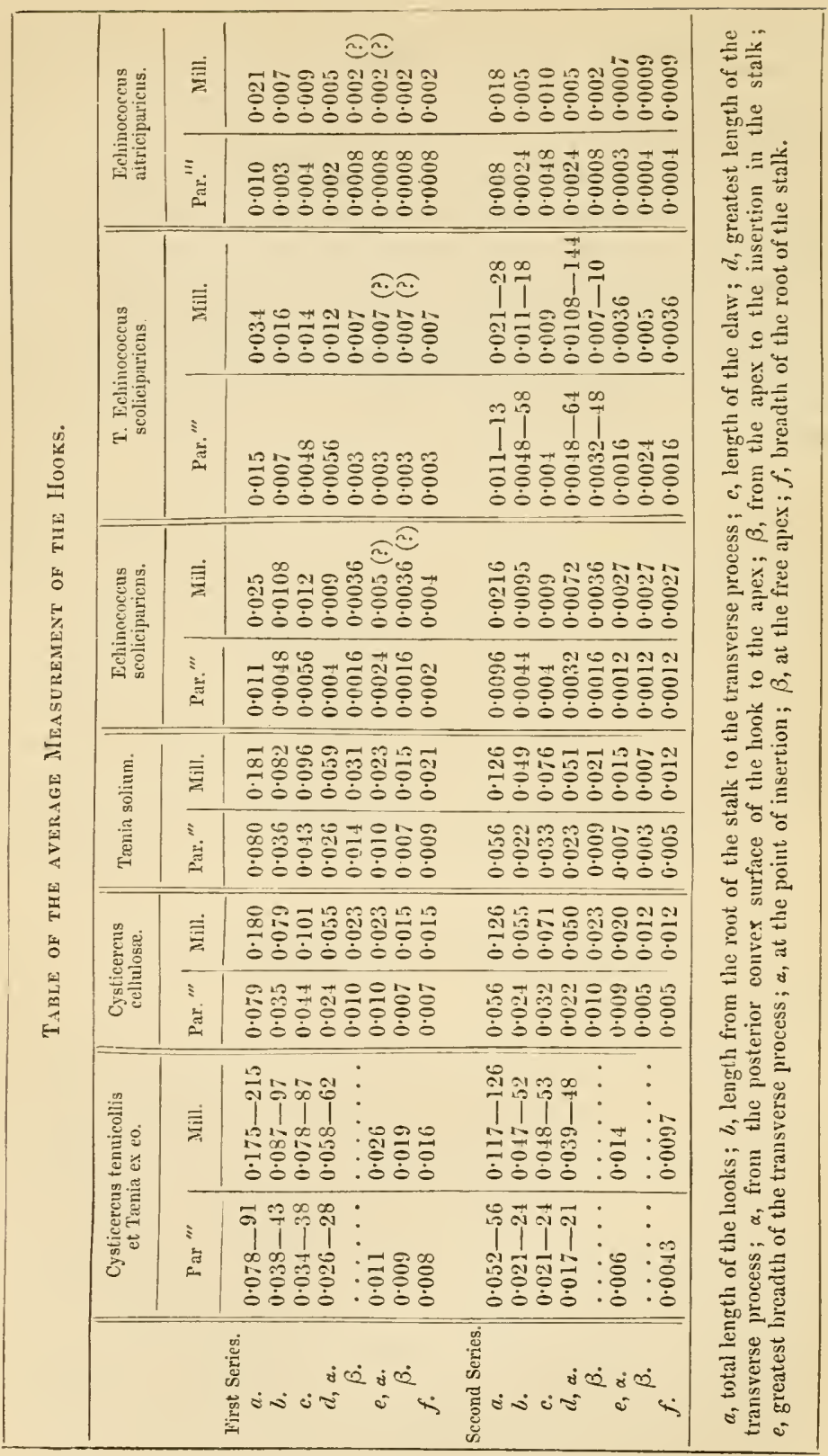


Average size of the hook-sacs of Tania solium :

First series-In the middle, $0.025^{\prime \prime \prime}=0.055 \mathrm{mill}$; ; at the base, $0.018^{\prime \prime \prime}=0.045$ mill.; at the opening, $0.015^{\prime \prime \prime}=0.05$ mill.

Second series-In the middle, $0.02^{\prime \prime \prime}=0.045$ mill.; at the base, $0.010^{\prime \prime \prime}=0.023$ mill.; at the opening, $0.010^{\prime \prime \prime}=0.023$ mill.

Size of the sucking discs in- -

a. Tania solium, $0 \cdot 22^{\prime \prime \prime}=0.498$ mill. in length, $0 \cdot 2^{\prime \prime \prime}=$ 0.45 mill. in breadth.

b. T. mediocanellata, $0.367^{\prime \prime \prime}=0.829$ mill. in length, $0.3^{\prime \prime \prime}=0.678$ mill. in breadth.

The sucking discs of the Echinococci are searcely $0.008^{\prime \prime \prime}=$ 0.02 mill. in diameter.

Eggs of $T$. solium, $0.016^{\prime \prime \prime}=0.036$ mill. in length, $0.017^{\prime \prime \prime}=$ 0.039 mill. in breadth.

Eggs of $T$. mediocanellata, $0.016^{\prime \prime \prime}=0.036$ mill. in length, $0.013^{\prime \prime \prime}=0.032$ mill. in breadth.

Eggs of Trenia from the Cape of Good Hope, just as in T. mediocanellata, scarcely larger.

Eggs of T. Echinoc. scolicip., $0.0145 \mathrm{P}^{\prime \prime \prime}=0.0148 \mathrm{~W}^{\prime \prime \prime}=$ 0.0328 mill. in diameter. 


\section{Second Sub-class.}

Trematoda $=$ Myelmintha $($ Diesing $)=$ Egelwürmur = Platyelmia isoluta $=$ Isolated Flat-worms (Küchenmeister).

Animalia solitaria, plerumque hermaphroditica, rarissime sexu distincto et poris plerumque suctoriis, medianis aut lateralibus instructa. Canalis cibarius furcatim divisus aut ramosus, rarissime simplex. Evolutio fit plerumque metamorphosi et sapissime generatione alternante, rarissime sine illis. (Leuckart, in Van der Hoeven.)

Although Leuckart does not place the Monostoma as a distinct order beside the Distoma, but as a subdivision of the latter, I still allow them to stand here as a distinct family, as this is the general practice, and no important error can result from the retention of this division. Any one who does not agree with this has only to place the section upon Monostoma after that which treats of the Distoma.

\section{Familia I. Monostoma = Tribus II. Monocotylea;}

XVIII. Monostomum (Diesing).

Synon. - Cucullanus; Festucaria; Fasciola; Amphistoma; Distoma et Monostoma.

"Corpus depressum vel teretiusculum; caput continuum vel collo discretum. Os terminale el anticum, ut plurimum acetabuliforme, integrum, crenulatum, inerme $v$. armatum. Apertura genitalium perclara, duplex; mascula infra os, interdum, acetabuliformis, pene protractili; feminea pone masculum, minima, ut plurimum inconspicua. Porus excretorius supra caude apicem anteri margine caudali. Animalia mammalium, avium, amphibiorum et piscium corpora, i. e., preter tractum intestinalem organa varia inhabitantia, libere aut folliculis inclusa." (Diesing.) Metamorphosis et generatio alternuns inter evolutionem, uti in Distomis. The ventral 
sucker is therefore deficient, and Diesing gives a warning, "Cave, ne Bothriocephalidearum articulum solitarium pro 'Monostomum' habeas, aut porum genitalem, interdum callosum, cum acetabulo confundas."

\section{1.? Monostomem lentis (Von Nordmann).}

In the month of May, Professor Jüngken extracted a lens which was not quite obscured and was still soft in its substance (incipient cataract), in the upper strata of which there were eight Monostoma. They were $\frac{1}{10}^{\prime \prime \prime}$ in length and moved, although but slowly, when they had lain in warm water.

This is all that we know of this trematode worm, and all my endeavours to get sight of a specimen have been fruitless. Professor Jüngken writes me that he handed over the animals to Vou Nordmann, and that he unfortumately does not know what has become of the preparation. All my further inquiries also as to what has become of Nordmamn's preparations have hitherto been unavailing. I can therefore only give a general opinion upon the case, and at least, as it appears to me, it is very possible that Von Ammon's Distoma and the Monostoma lentis of Nordmann are identical, that is if a trematode worm is really in question here. If, on the one hand, Diesing warns us against taking the porus genitulis of separate segments of Bothriocephuli, which is sometimes callous, for a sucking cup, and thus making Monostoma ont of structures which are nothing of the kind, the following words of Dujardin also show that even distinguisher observers (amongst whom Vou Nordmamn is nudoubtedly to be placed) have deceived themselves, and declared things to be Monostoma, which were rather Distoma. Thus Dujardin, speaking of the Monostomum ocreatum of the mole in his 'Hist. nat. des IIelminthes,' p. 344, where he describes this as identical with Distoma lorum, says, "de mon côté, en cherchant ce Monostome à Rennes, $j$ 'ai trouvé non un Monostome, muis un vrai Distome filiforme, que j'ai reconnu être le même helminthe, en comparant trois exemplaires envoyés de Vienne au Muséum de Paris."

It is only from the want of opportunity of examining for myself that I have still allotted Nordmam's entozoon a separate place here. Diesing also appears to think that the Monostomum discovered by Nordmann is identical with Von Ammon's 
Distomum. But how he could have referred to the place where Von Ammon speaks of Distoma ophthalmobium under Monostomum, and alleged under Monostomum lentis that the Distoma treated of by Von Ammon might perhaps be a Monostomum, must be difficult of comprehension by any one who compares Von Ammon's plates. It would have been more correct liad Diesing cited the passage in Nordmann under Distoma ophthalmobium, and written amongst the literature of this animal, "Monostoma, Von Nordmann (?)." It is also a question, as I have observed above, whether in the case of this Monostomum we have to do with a trematode worm at all, and not rather with a young Cysticercus cellulosce. As long as 1848 or 1849 I found in the cyst of a large Cysticercus of the rabbit, a small worm with a single structure resembling a mouth at the anterior extremity of its body. Even then I regarded this organism as a young Cysticercus, although Von Siebold assured me that from its form the worm could only be regarded as trematode. Since that time I have examined hundreds of spontaneously bred young Cysticerci, and observed that before the hooks and sucking dises grow in them, and before the well-known collection of nutritive fluid takes place in their interior in larger quantity, they form organisms, which bear an inversion at the anterior part of the body, possessing a deceptive resemblance to a mouth, so that we might well think that we had a Monostomum before us. Whoever has repeated the experiments of breeding Cysticerci will admit that $I$ am right with regard to the possibility of this illusion.

Literature.-Von Nordmann, 'Mikrograph. Beiträge,' Heft ii, Vorrede, p. ix.

Familia II. Distomea = Tribus II. Monocotylea ; XIX. Distomum (Diesing).

Corpus depressum, vel tertiusculum, armatum vel inerme. Caput continuum, vel collo discretum. Os terminale, vel anticum, ut plurimum acetabuliforme. Acetabulum unicum ventrale sessile, vel pedicellatum medianum, ab extremitate postica plus minusve remotum. Aperturce genitales approximate, sapissime ad exitum conjuncte (cloaca instructe), supra vel infra acetabulum sita. Animalia plerumque hermaphroditica, rarissime sexu distincto. 
Ovula embryones parentibus rarissime similes, plerumque dissimiles aut fimbriatos, uut fimbriis destitutos continentia, quare evolutio fit metamorphosi et generatione alternante.

Statu immaturo aut libere in natura vayantia, aut in organorum parenchymate, imprimis in animalibus inferioribus inclusa. Statu maturo entoparasita animalium preprimis vertebratorum, ant libere in variis organis et cavitatibus apertis et clausis viventia, aut in folliculis inclusa (Duj. and Dies.)

\section{Distoma hepaticum = Distomum hepaticum.}

Plate V, figs. $1-10$.

Corpus planum, armatum, saltem in juventuti; atate magis profectâ adluc in collo. Individua juniora $4^{\prime \prime \prime}=9$ mill. longa, $\mathrm{I}_{\frac{2}{2}}^{1 \prime \prime \prime}=3.3$ mill. lata; adulta 8-14"' $=18-31$ mill. longa ; $3 \frac{1}{2}-6^{\prime \prime \prime}=8-13 \frac{1}{2}$ mill. Iata.

Collum subconicum, breve. Os haud nodulosum, terminale, triangulare, $1 \cdot 4$ mill. latum.

Acetabulum 1.5 mill. latum, ore majus superum ad colli basin, aperturâ triangulari, 3-4 mill. pone os situm.

Orificia genitalia fere contigua, media in parte inter os et acetabulum sita. Penis cylindricus, 3 mill. longus, 0.5 mill. latus, falciformis, prominess, uncinulis parvulis armatus. Testicul imaxima ex parte media in corporis posterioris parte siti, ex trunco mediano et ramificationibus, ad finem cœcis, compositi.

Organa vitellina ad latera animalis sita, inter se horizontali quodam et transverso ramo conjuncta et statim in uterum simplicem, magnitudine crescentem, multifarie volutum transeuntia.

Ovula flava, mitra quadam parvula aut obteculo dehiscentia, $0.056-0.063^{\prime \prime \prime}$ (V. et Par.) $=0.126-0.144$ mill. longa, et $0.035-0.038^{\prime \prime \prime}=0.079-0.086$ mill. lata.

Embryones, Cercariarum utriculi aut Redice, nec mimus Cercaria liberæ, si omnino hee forma prebetur, ignota. Migrationum modus nondum cognitus. Distomum juvenile immaturum semel subcute humana inventum.

1a. Distomum hepaticum maturum in hominis hepate.

Skin and parenchyma.-Our knowledge of the skin of the 
Trematoda in general, is very imperfect. Von Siebold takes no particular notice of it in his 'Manual of Comparative Anatony,' (pp, 114, 115), so that we cau only cite here the general remarks: "The strong membrinous cutis allows a delicate, homogenous epidermis, and a tolcrably firm corinm, to be distinguished." Upon Distomum hepaticum, Von Siehold does not once treat more at length in the notes appended to the text. From the difficulty of eximining this thick bodied species of Trematoda, I hope that I shall be fairly criticised, both here and in the description of the other parts of the animal, and I only venture to give what I found in an examination of this worm continued for months, whilst at the same time I may remark that I have been principally assisted in my investigations upon the internal structure of the Distoma by comparison with the work of Dr. Aubert, of Breslau, upon Aspidogaster conclicola. It will be of the most serviceperhaps, if, for the purpose of comparison with our Trematoda, I prefix a short description of the trematode skin from Aubert.

"That the outermost skin of the Trematoda is very thin and transparent and apparently homogeneous, is best seen where it forms folds, where it is torn and has turned over, where it has folded itself strongly in consequence of contraction and death, which also occurs most distinctly in torn fragments, or where the skin is raised up from the parenchyma after long immersion in water, and during, or after, the death of the animal by a subcutaneous accumulation of water. The want of action of reagents upon it is in favour of its chitinous nature. It covers the whole body, and also enters into the œesophagus and genitalia, appearing to cover the lattcr both within and without." The greater part of what is here said also applies to Dist. hepaticum.

Although, by laying these Distoma in water for days I never could detect any formation of vesicles or elevation of the epi.. dermis in a vesicular form, I nevertheless succeeded very well occasionally in detaching separate strips of the epidermis with the forceps. The structure of this skin was very finely granulated and quite homogencous, as was seen in places where the skin was folded. Jmmediately after this layer follows an extremely fiuely striated layer, in which the longitudinal fibres appear to exceed the transverse ones. No pores or vacuities in the skin could be detected anywhere. The hairy or spinous coat had nearly fallen off from the skin of the mature Distoma, or was only still to be detected on the portion between the mouth and the sucking 
cup. In young Distoma which are still immature, I have always found it, and generally diffused orer the sides of the whole body. With regard to the parenchyma of the Distoma, Aubert says, "The parenchyma, which is rendered more finely granulated, darker, and more brittle by acids, and very slowly dissolved by alkalies, and which probably consists of two substances - a granular mass (perhaps analogous to the stearine tablets of the Infusoria), and a transparent, homogeneous mass (sarcode) containing these granules - is tough, and slowly extensible and contractile in all directions, so that from the want of direction in its structure it exhibits contractility in all directions."

The consistence of the parenchyma of D. hepaticum also very closely resembles that above described. A variation prevails here only in regard to the muscular fibres, which is of the more importance, as by this means a circumstance may be explained which has given origin to several different interpretations.

If a fragment of the parenchyma of a Distoma be moistened with a little dilute sulpliuric acid, and the latter be allowed to act only until the edges of the preparation have become white and opaque, and the preparation be then washed quickly with a little water, the following clearly distinguishable muscular layers are perceived:

1. A layer of longitudinal fibres, lunning straight and not very strong.

2. A layer of very thick and long transverse fibres, but little twisted.

3. A layer of short, often fusiform, thick transverse fibres, often very strongly bent into an $\mathrm{S}$-form, and-

4. A layer of short, thick fibres, uniting into an obtuse cone, placed at more or less regular intervals, and inserted between the previous laycrs rather in an oblique or perpendicular direction. This layer is particularly remarkable for the change which it undergoes in water. Thus, if we examine individuals kept in water, these obtusely conical bundles of fibres have disappeared, and we find in place of them small quadrangular structures, very obtuse towards the apex, on which an extremely fine striation is now to be observed. The same structures are also detected after the treatment of such individuals, preserved in water, with dilute sulphuric acid; but a similar appearance is never observed in animals which have been taken directly out of the gall-ducts, and examined without any preliminary treatment with water. 
These structures resemble the squares (Felder) in the foot or in the sucking cup of Aspidogaster conchicola, figured by Aubert. I cannot help thinking that the structures seen by me are the same which have led Keber and others to speak of pores in otlicr Trematoda. I regard the squares or spaces in question as vacuoles, which become inflated and filled with water by contact with that fluid, but are not so easily perceived when the animals are treated without water. They appear and disappear, therefore, according as the interior of this obtuse muscular cone is full or empty of fluid, according as its inner walls are in contact or kept asunder.

Nervous system and organs of the senses are wanting.

Alimentary apparatus. - This apparatus is composed of a mouth placed at the anterior point of the body, that is the so.called anterior sucker. This is followed by a sort of constriction (cesophagus), and this by a goblet-shaped pharynx, the larger opening of which is directed forwards, but backwards when broken. The pharynx consists of two layers of contractile substance. According to Aubert, in Aspidoyaster the inner larer is longitudinally and the outer transversely striated, without its being a true transversely striated muscular substance. The case is exactly the same in $D$. hepaticum. It is only to be observed, that the anterior margin of the pharynx appears as if notched. For this reason it may be thought to be composed of several pieces; I always believed that I could count three such segments. The pharynx is followed by a very short, simple, somewhat narrowed portion of intestine, which runs to the level of the sac of the penis, where it divides into two large stems, which, making a small excursion, run round on the sides of the sac and ventral sucker, and again approach each other behind the rentral sucker, without, howerer, uniting by anastomoses, and finally run parallel and near to each other to the hinder margin of the Distomum, where they terminate in crca. This intestine is distinguished from that of many other Distoma, in that a quantity of variously dendritic branches are given off laterally from the two main stems, the finest ramifications of which run to the lateral margins of the animal, where they terminate in crea without anastomosing. All these branches of the intestinal canal contain bile in our Distomum, and by this means, when they are full, their course may be very clearly traced. In large Distoma I have counted 14-15 lateral branches on each side, given off from the 
two main stems above mentioned. Besides these, on the space between the mouth and the base of the ventral sucker, there are on each side five very short, slightly branched stems, which run forwards and laterally. This structure of the intestine is an essential point to furnish us with data in any inquiry after the young of this Distoma dispersed amongst the lower animals. We may expect, à priori, that amongst the cercariform creatures, those alone can belong to $D$. hepaticum which exhibit a similar arrangement of the intestinal canal. By continued pressure from behind forwards, the entire contents of the intestine may be expelled. The intestine is soon freed spontaneously by long keeping of the animal in water or bile. Sometimes, also, we find the larger Distoma, when wedged into the narrow ducts of the liver, deprived of their biliary contents. As regards the position of the intestine, I think that we shall come nearest to the truth if we place it about the middle of the parenchyma, and neither nearer to the dorsal nor to the ventral surface.

Excretory organ.-Under this denomination we combine, what particular author's have treated separately under the names of respiratory and circulatory systems and excretory organ, or aquiferous system and excretory organ. But in the first place there is no respiratory system, either in the Trematoda in general, or in our Distomum in particular. Neither can we speak, either of distinct circulatory and excretory organs, or of a separate aquiferous system and excretory organ. Both are only parts of one and the same system. It is to Van Beneden that we owe the first discovery that the aquiferous system passes into the excretory organ, and where this takes place. Aubert has recently confirmed Van Beneden's observations as regards Distoma tereticolli, and lias positively seen one of the granules of the aquiferous system, of which we shall speak presently, slip into the excretory organ and return again from this into the aquiferous system. This transition is also certain in Nordmanu's Diplostoma, and in the Diplost. rachicum of Henle, so that Aubert thinks that we are perfectly justified in applying these observations, per analogiam, also to the other Trematoda, and regarding the whole of the organs here treated of as one and the same; namely, as an excretory organ. ${ }^{1}$ For the investigation of the structure of this

' In Von Siebold and Köliker's 'Zeitsclırift,' vi, pl. xiv, fig. $3 h$, the passage of the so-called water-vascular system into the excretory organ is very beautifully represented 
organ in our Distomum young individuals, sexually immature, are the best adapted, and especially those whose intestine contains little or hardly any bile. In these we clearly see light, contorted canaliculi, branched towards the margins, collecting in the middle into a straight sac, which is dilated in the form of a bell near its extremity. In adult individuals the system in question becomes more distinct when the intestine is emptied, and the Distomum lias been kept for some time in bile or water. It forms an immense number of small branches, which penetrate into the furthest portions of the body, sometimes collect into larger stems, and pass into a tolerably strong terminal stem, which runs in the median line of the hinder portion of the animal, and becomes dilated and bell-shaped at the extremity of the body, where it opens occasionally, and gives issue to molecular contents, mixcd with larger, lighter bodies. I could not discover any splincter muscle at this part of the end of the body. As regards the contents of this whole system, they are characterised by their limpid colour, and by small, diaphanous globules, such as we find in all Trematoda. By direct light these bodies shine out of the vessels with a chalky white colour. According to Von Siebold and most authors, these bodies, which possess a tolerably firm consistence, are regarded as calcareous corpuscles, analogous to the well-known calcareous corpuscles of the Cestodea. I have not succeeded in effecting the destruction of these bodies in Dist. hepaticum with acetic acid so rapidly as in the Cestodea, nor have I observed a similar evolution of bubbles of carbonic acid. It is therefore by no means clear to me whether these globules are to be regarded as carbonate of lime, or whether they may not perhaps be earthy salts of another weak acid, which dissolve slowly, and without evolution of gas, under the action of acetic acid. Many of these corpuscles may, perhaps, also belong to the masses which we denominate sarcode. For my part, therefore, I believe that the true nature of these structures has not yet been ascertained, however many of our first authorities upon this subject may regard the affair as settled.

by Aubert. It is only to be regretted that in the explanation of the figure on p. $374 \mathrm{k}$, we read "Origin (Ursprung) of the water-vascular systern from the excretory organ." The word origin (Ursprung) is adapted only to produce confusion as to the nature of the organ. It would be much better, and more suited to the description given, if we read instead-" Point of transition (Uebergangsstelle) of the water-vascular system into the part of the system which has hitherto been called the excretory organ." 
Whether ciliated lappets occur in this excretory organ in our Distomum, I cannot say, as the Dist. hepaticum is too massive and thick in the borly. It is well known that they are deficient in one species and prescnt in another, and they appear as a general rule to possess no great functional value.

Organs of reproduction.--1. The female sexual organs lie more towards the ventral surface of the animal, and consist of a germ-stock with its efferent duct, two vitelligenes, a short ovirluct, a sac-like uterus, and a vagina.

a. For a long time I could not quite make ont the germ-stock in our Distomum. I regard as this organ a round body which lies behind the cordate point of union of the two vitelligenes in the median line of the body, and a little way behind the last convolutions of the uterine sac. This is the same structure that others have taken for a testicle. In spite of all the trouble that I have taken to unriddle the nature of this round body, I have only succeeded in coming to an approximate understanding of it. I souglit in vain in this body for spermatozoids, which would have rendered it a vesica seminalis interna. But as often as I isolated it and examined it in this state, I could only detect in it, with the highest magnifying powers, a great number of very clear, oval, empty, capsular structures; for which reason I have been tempted to regard this organ as the germ-stock, but without venturing to give this interpretation as the only correct one. This structure at any rate opens into a common canal with the efferent duct of the vitelligenes, in which true egg-structures immediately make their appearance, and which at the same time contains immense numbers of spermatozoids, which are agglomerated together in masses in the midst of and around the individual eggs which are still transparent. From here onwards, the union of the germiual vesicles and yelk-globules, as well as the formation of the egg-shell, certainly goes forward.

$b$. The vitelligenes (yelk-sacs) form two organs placed at the sides, consisting of blind sacs, forming repeatedly branched, beautifully dendritic or racemose figures, which reach anteriorly into the level of the cirrhus, and posteriorly into the caudal extremity, where they are only separated by the excretory organ, and thus prevented from passing into each other in this close point of contact. They collect on each side into a common and tolerably strong stem, running parallel to the lateral margins of the animal, from which, at about the point where the anterior third 
of the animal passes over into the central one, a straight branch runs horizontally towards the median line of the animal, and unites with the branch of the opposite side. Rarely (about once in fifty examples), instead of one main stem coming from the side, we meet with two which unite at an acute angle, but always before the middle line, to form a single branch, which then runs horizontally towards the branch of the other side, and behaves just as we have above described. The point of union of these two stems is the only anastomosis which the two vitelligenes form throughout. By this union a cordate dilatation is produced at this spot, from which a very narrow canal issues anteriorly in fine, scarcely visible convolutions. Soon afterwards this canal becomes somewhat wider, and we meet with separate pale eggs, surrounded by true egg-shells, which are probably produced by the conjunction of the structures of the vitelligene, and those furnished by the organ mentioned under $a$, after the ducts of the two organs have united. The contents of these yelk-sacs are yelk-corpuscles, yelk-globules or vitelline cells, which during their passage through the efferent duct above described acquire all sorts of forms, fitting themselves to the passages through which they must pass. Each of these vitelline agglomerations consists of single yelk-globules, measuring about 0.0018 mill. $=0.008^{\prime \prime \prime}$ Par. or Vienna. In the cordate dilatation the agglomerations have about the following size: 0.028 mill. $=0.012^{\prime \prime \prime}$ in length, and 0.014 mill. $=0.006^{\prime \prime \prime}$ in breadth, and they consist of from $30-50$ individual yelkglobules. When quite fresh the yelk-sacs appear white or pale yellow, but when the animals are allowed to lie for a good wlile in bile, they acquire a darker-yellow colour. They lie in the midst of the parenchyma of the body, but nearer to the ventral than the dorsal surface.

c. The oviduct, which follows these, is very short, forms some very wide spiral turns, and passes without any perceptible boundary into the uterus; indeed it might, perhaps, be denominated a uterus even from its commencement.

d. The true uterus is turned more towards the ventral surface of the animal. At first, the dimensions of the convoluted simple uterus are small, the eggs lie in a single layer, and still possess white, or rather colourless shells, through which shine their contents, similar to those of an egg in process of segmentation; subsequently, the convolutions gradually become wider, and the 
layers of eggs closer in the interior of the canal, whilst the colour of the egg-shells themselves constantly becomes darker and yellower, and their contents less uneven and granular. I have never yet succeeded, however, either in $D$. hepaticum or in the Bothriocephali, in recognising the exact form of an embryo, or been able to free it by pressure or breaking the eggs. The difference in the colour of the eggs, in different convolutions of the uterns, causes the colour of the uterus itself to be different also. The last convolutions situated posteriorly are white and clear, the anterior ones dark yellowish.

e. The vagina is a tortuous and rather narrow canal, just wide enough to allow of the passage of an egg moving in the direction of its longitudinal axis. It runs at the margin of the ventral sucker, and beneath and behind it to the place where the penis protrudes from the skin, where it is enlarged in the form of a funnel. Here it has a common opening with the penis. It is hardly possible, or very difficult, to exhibit this part in the living $D$. hepaticum; but the arrangement of the parts here described may be very easily seen by pouring boiling water over a living Distomum and scalding it, and then crushing the animal completely, but slowly, between two glass plates.

2. Male sexual organs. - a. Testicles.-The two testicles (anterior and posterior) differ entirely in our Distomum from those of most other Distoma, and as the only object has been to find the ordinary conditions again, a grcat number of mistakes have been published, but the true state of matters has long been overlooked. The testicles of Distoma are neither oval nor round, but they are amongst the multifariously lobed and notched testicles, and from their nature they must come nearest to the testicles of Amphistomum subtriquetrum giganteum and Distomum hians, which in consequence of a number of very deep incisions, form a tuft of blind canals. Thus, in the middle of the whole hinder two thirds of the animal, we see a complication of repeatedly en. twined, cecal, intestinal convolutions, reaching immediately to the inner borders of the lateral yclk-sacs, and ceasing pretty exactly at the above-mentioned part of the latter. Hence it happens, that these structures may be taken almost uninjured ont of the body, when we cut away, witl a fine knife, the lateral margins of the animal as far as the yelk-sacs extend inwards. In front, from the ventral sucker, this organ extends in a pair of small, lateral shoots, which, to choose a readily accessible figure for 
comparison, present the greatest resemblance to the terminations of Burnett's fungus (Pl. V, fig. 2, of the Vegetable Parasites, vol, ii), or those of the Hanoverian Leptomitus (Pl. I, fig. 8, vol. ii), to the level of the hindmost four or five convolutions of the tubular uterus. They appear to replace the vesica seminalis interna or anterior, which is deficient here, and which in form usually resembles the other segments of the testes. The lobate form of the latter is to a certain extent to be recognised in our Distoma, even in the form described.

In their position, therefore, these structures agree with a great number of the testicles of Distoma, that is to say, they lie in the abdomen behind the ventral sucker, but they occupy an enormous space in the abdomen, in fact the entire space which is left free by the yelk-sacs. The further anatomical structure of these organs is as follows: The above-mentioned convolutions collect into two principal stems, which in general are scarcely thicker than the lateral convolutions. One of these stems lies more in the posterior, the other more in the anterior half of the body. The former ceases therefore in the posterior half of the body, but the latter a little way behind the point of union of the yelk-sacs. This is effected without any particularly marked boundary, without the formation of a clubbed end, or anything of that sort. Quite in front, two more stems are given off right and left, which run on the sides of the animal nearly to the middle of the uterus, are extended and spread out at their extremities, aud thus resemble the form of the abovementioned regetable parasites. This termination is very well shown by Mehlis in his plate viii, especially on the side which lies to the left of the spectator. The separate stems of the two testicles can hardly be isolated, as each testicle sends out its branches towards the side of the other. We must regard as the anterior ends of the testicles, the points from which a thin filament or efferent duct, ductus spermaticus, springs and runs forwards. These filaments are very thin, of the same colour as the mass of the testicles, and run round the sides of the structure which we called the germ-stock in the female genitalia, at first in a parallel direction, but unite subsequently at an acute angle; they run directly through their whole course, make no lateral digressions, and pass forwards at the dorsal surface of the animal, concealing themselves behind the convolutions of the uterus, and sometimes making their appearance when the animal is 
pressed in the spaces of the parenchyma left free by these convolutions. As soon as they have arrived at the level of the veutral sucker, behind which they lie, and by which they are concealed when the animal is examined from the ventral surface, they converge still more, until at last they unite a little way from the base of the sac of the penis, or vesica seminalis exterior, forming a short, thick stem, opening into the last-mentioned organ, and filling it with spermatozoids, which may be easily effected merely by the help of the muscular contraction of the abdomen. I have repeatedly been able to trace the course of the two seminal filaments, from the point where they originate from the testicles to the vesica seminalis exterior. One of these filaments is longer, and extends into the hinder half of the Distomum; the other usuatly originates a little way behind the point of union of the yelk-sacs of the two sides, that is to say, at the point of transition of the anterior third of the whole Distomum into the middle third. From this doubling of the filaments, follows the above-mentioned doubling of the testicles, as we suppose that a testicle has only one efferent duct. Taking into consideration the points to which these funiculi spermatici may be traced, we spoke above of a posterior testicle $i$. e., the one with the longer funic. spermat.), and an anterior one (i.e., that with the shorter funic. spermat.) The point of origin of eacl of these two filaments sometimes forms a sagittate point, namely, when the last two or three lateral convolutions of the penis, which are situated posteriorly or lateral, unite at a very acute angle.

The question still remains, whether, besides the above-mentioned outlets of the testicle, there may not be another communication with the egg-preparing organs, so that, as in other Trematoda, self-impregnation might be possible without self-copulation, and without an immersio penis. In Mehlis's figure viii we see the foremost branch of the left side of the testicle opening into a vesicular organ, which lies between the two funiculi spermatici, and behind the point of union of the two yelk-sacs. I have also seen this repeatedly, and it was not going too far to regard this vesicular structure as a vesica seminalis interior, destined for selfimpregnation without copulation. But, as already observed, I can only regard this vesicle as the germ-stock; but I must consider the anterior branch of the testicle just mentioned as the substitute of the ves, sem. interna.

If others succeed in detecting 
spermatozoids in the vesicle $a$, I shall regard it as a ves. sem. interna, although I confess that even from the colour of this structure, I can hardly suppose that it is a vesica seminalis interior. $\Lambda$ s regards the colour, all the seminiferous organs, and therefore even the above-mentioned dilatations of the testicles, are brownishred, and, in fact, lighter or darker according to the calibre and number of the free filaments.

It still remains to furnish the microscopic proof that the convolutions already described by Mehlis as testicles are really those organs. If we make a fine transverse ineision in the middle of the animal and far behind the point of union of the vitelligenes, we shall also have removed therewith some of the upper convolutions, and may easily isolate them. But at the cut surfaces of these convolutions innumerable seminal filaments flow ont, and I have attentively observed this singular spectacle for a long time. Thus we observe simple, hyaline cells; then stellate ones, consisting of five cells ; then some in which caudated cells, as it were, protrude from these cells, and also free bundles of fine long seminal filaments and individual isolated filaments.

For the last investigations I of course made use of fresh, living Distoma, and, as the medium in which I examined them, sugar and water. For the investigation of the anatomical arrangement of the separate portions of the genital system, I employed the process, above described under the section "vagina," of scalding the animals with boiling water-a process which merits being more brought into use in the examination of various lower animals.

b. The sac of the penis (cirrhus-pouch) itself, and the whole of the reproduetive organs conneeted with it, lie immediately on the anterior surface of the ventral sucker, and open towards the ventral surface. Here we clearly distinguish the oval, or, more correetly, retort-shaped end, formed by the true penis-sac, a swollen white mass when examined with the naked eye, dingy blackish-r'ed under the microscope, and containing immense numbers of spermatozoa, which, when they can be examined in a more isolated condition, exhibit a lively swarming. Anteriorly this penissac passes into a distinctly recognisable, contorted, ductus ejaculatorius, with a double outline, in which I once observed distinct peristaltic movements for several minutes after taking the whole apparatus out of the body of the living animal. Thus, sometimes one wall contracted at the bending of the canal, and 
the opposite wall expanded, or vice versâ. Sometimes this movement proceeded from belind forwards, sometimes from before backwards. Anteriorly the ductus ejaculatorius opens into a membranous, sickle-shaped, very thick penis, perforated through the middle, beset, especially towards the apex, with concentric, close layers of very distinct points or spines, which generally fall off easily. The spinous external skin of the penis is an inversion of the general cutaneous covering, of which a fue layer also enters into the inuer opening of the penis. When the back of an ordinarily fine scalpel is placed perpendicularly upon the auterior margin of the ventral sucker, and pressure is applied with a second scalpel directed obliquely from before backwards, from the buccal sucker towards the first scalpel, it is always easy to cause the protrusion of the penis. If it be then eut away at the ventral surface of the animal with a pair of scissors, we shall easily detect the coating of spines, which, however, appears to be very easily lost. In this way every one may readily convince himself of the existence of the spines. This coating of spines appears to me to furnish an argument in farour of the statement of some authors, as, for instance, Dujardin, that the epidermis of Dist. hepaticum is beset throughout with spines. As this spinous coat of the skin certainly always occurs normally, and pretty evenly diffused in the earliest portion of the life of our Distomum, but in course of time is lost by the movements of the animal, without leaving any traces, this may also probably be the case with the penis; and it is only the rare use of this organ, and its inverted position, that preserves it from having its spines rubbed off. Thus the spines of the penis remain, as it were, the last traces of the previous very general spinous coating of the epidermis. As regards the act of protrusion of the penis itself, it is most probable that this takes place voluntarily in the Distoma in the following manner. The parenchyma of the animal in the vicinity of the penis, or, as Mehlis thinks, the membrane enveloping the anterior sexual apparatus (i.e., the penis-sac), contracts circularly, and thus presses from the sides upon the root of the penis, whilst at the same time the skin is undoubtedly in a certain state of cxpansion, but not of contraction. This appears from the simple consideration that the root of the penis is pretty thick, and measures at least $\frac{1^{\prime \prime \prime}}{2}$ in diameter. The opening from which the penis protrudes through the skin is not usually perceptible, or, at the utmost, forms a cleft.like inversion, 
but, as may be seen from the diameter of the penis, it is capable of considerable dilatation. According to Aubert, there are two muscular layers in the penis of other large Trematodu"Longitudinal, elastic, circular, and, perhaps, transverse fibres, although we cannot speak of a true transverse striation of the muscles, as the substance, when crushed, loses its striation and breaks up into irregular fragments." It is the same in this case also.

I will also mention here a simple method by which the portion of the sexual organs of which I have last spoken may be best isolated. From the firm consistence of these parts, we may easily succeed, with a fine needle, in laying them bare and isolating them entirely. It was in a penis-sac, with its appendages, removed in this way from the living animal, that I saw the before-mentioned peristaltic movement of the ductus ejaculatorius most beautifully. The relative positions of the external opening of the retracted penis and the vagina, are as follows, as correctly described by Mehlis: Near the anterior margin of the ventral sucker we observe a small oblong, or obtusely triangular, pit or cleft. If this be drawn asunder, two openings make their appearance, of which that situated posteriorly, and towards the left, is the vaginal orifice, and the other that of the penis.

If we glance once more at the sexual conditions of our Distomum, we find, with the compound microscope, in the interior of the hindermost convolutions of the uterus, reddish-brown aggregations or masses of spermatozoa, which exhibit the most lively swarming on their free margins, and may be isolated as moderate agglomerations. To the naked eye these spots appear white; they project posteriorly beyond the level of the other convolutions of the uterus, and in attempting to isolate these white spots, we are sure, with some practice, to find immense numbers of aggregated spermatozon. As some of these formations appear to lie in the uninterrupted canal of the uterine convolutions, we may perhaps assume that they have reached this spot in consequence of a self-impregnation accompanied by copulation; but, on the other hand, as the testicle undoubtedly also opens here directly towards the true dilatations of the uterus, ${ }^{1}$ they may be the consequence of a self-impregnation without copulation. The Distoma are therefore hermaphrodites, with the fol-

1 Recently I succeeded in pressing spermatozoa out of the testicles through the funiculus spermaticus into the sac of the penis, under the microscope. 
lowing sexual actions: self-impregnation with and without copulation, and impreguation and copulation with a second individual.

\section{Action of this parasite upon man, its phenomenology and pathological anatomy.}

Melilis mentions as observers of this parasite in the human subject-

1. Malpighi, who found it both in man and animals.

2. Chabert, who expelled them in great numbers with his empyreumatic oil from a girl of 12 years old.

3. Bauhin, who, however, aecording to Bremser, had no true Distoma before him.

4. Biddloo, who was well acquainted with the alterations which these parasites prodnce in the livers of animals, and met with them also in the human liver.

5. Wepfer, who often found the gall-ducts of the liver filled with " hirudinibus."

6. Pallas, who found Distoma fixed in the gall-ducts of the liver in a female subject in the Anatomical Theatre at Berlin.

7. Brera, who met with them in the liver of a man suffering from scurvy and dropsy.

8. Melilis himself. He narrates the following history of a widow, of 31 years old, living in Clausthal. From her appearance Mehlis had loug suspeeted that her liver was disordered, when one day, in the year 1821, she brought him nine specimens of $D$. hepaticum, which, as frequently before, she had thrown up on the same day, still living and moving, together with a large quantity of bloody coagulum, with repeated fainting fits. Gentle purgatives, to remove any worms that might be in the intestine, brought no more to light, and the patient felt well. Fourteen days afterwards, when collecting sticks in the woods, she was suddenly seized with tenesmus, and numerous worms were passed agglomerated into a lump with mucus, but without freces. In the next year there occurred frequent yellowness of the face, slight dyspncea, which compelled her to sit still, short cough, uneasiness, inflation of the abdomen, tension and pain in the hypochondria, great weakness of the limbs, and with various convulsive appearances and fainting fits, vomiting of thin mucus and blood, with consequent alleviation. The general health, appetite, and digestion 
were unimpaired; but potatoes and hard fare disordered her stomach. In June, 1823, the tightness of the chest, the shortness of breath, the short dry cough, and the weakness of the joints increased. Suddenly there occurred all sorts of opisthotonic phenomena with aphonia lasting for several days, very frequent violent cough, difficult respiration, great pain in the hypochondria and the chest, and extreme pain of the distended abdomen. After several remissions and exacerbations repeated vomitings then took place, when, besides the food taken, some corrupted bile, a membranous substance, and a great quantity of coagulated blood, many worms were again evacuated, still in a living state, according to the reports in the vicinity. Of these a portion were thrown away. Mehlis now had everything that was passed collected in a spittoon. The patient vomited three times more, and passed several uninjured $D$. hepaticum, as well as a great number of fragments of Distoma and fifty specimens of $D$. lanceolatum. Distoma never presented themselves in the stools. From this time the patient slowly recovered; but still suffered frequently from similar disorder's in the following year, so that Mehlis believed the old guests still held their post.

The whole history of the case looks like a mystification by a hysterical patient. For, notwithstanding his requests, Mehlis was never present when the worms were vonited, and the only passage of worms through the amus took place in the wood, when no one was present. It appears to me to be rery suspicious that the patient complained that, althongh she was in general in good health, potatoes and heavy diet did not agree with her, which appears as though she had speculated on obtaining better fare, from the compassion of her neighbours, and medical men who took such particular interest in worms. Under these circumstances, it is to be regretted that from the lamented early death of Melilis he could not subsequently dissect the paticnt, who is perhaps still living, and must now be sixty-five years old. The principal reason of my doubts lies in the period at which the case occurred. It was then the fashion to vomit lizards, frogs, eels, and fishes, which were supposed to have been borne in the body. Mehlis's patient might have made use of Distoma obtained from the butcher, and thus have deceived her doctor and relations.

9. Very recently, according to Dujardin, Duval has found this worm in the vena porte of the human subject at Rennes. The 
size given only agrees with a young $D$. hepaticum, but still better with a D. lanceolatum. But whatever it may be, this Distomum could only have reached the venc porte, after it had been injured by cutting, from a gall-duct which must also have been injured. The mode of life of our Distomum could not allow of its dwelling in the blood, and Duval might have found a correction of his error at page 7 of Mehlis.

Since this I find no further proof of the occurrence of this worm in the human liver, and even in Rokitansky's rich experience, which is also made use of by Wedl, there is no other example. ${ }^{1}$

I have omitted Bucloolz's case, as, from the figures given by Bremser, it belongs to $D$. lanceolatum. Bucholz found his Distoma in the body of a prisoner who died of putrid fever. During a visit of the Grand Duke of Weimar, Bremser asked for a pair of these Distoma, which were preserved in the Museum at Jena, and from the figures given by him they are specimens of D. lanceolatum. To ascertain whether, besides these Distoma, D. hepaticum was also present in the liver of this prisoner, I applied to Professor Oscar Schmidt with the request that he would go through Bucholz's Distoma again, and inform me whether the bottle in question contained only $D$. lanceolatum, or whether D. hepaticum was also present. My letter did not reach Schmidt, who was alrearly gone to his new destiuation. Any results which may be obtained by fresh inquiries in Jena will be found in the Appendix.

Whoever is acquainted with the devastations which this Distomum is capable of producing in the livers of our herbivorous domestic animals, will rejoice, with Bremser and Wedl, that these animals occur so rarely in the luman subject. However, it is certainly necessary for the complete understanding of the malady produced by Distoma, that we sloould give close attention to the changes which these parasites cause in the livers of our domestic animals when inhabited by them, as incleed has ahready been done by Mehlis and Bremser. In the conrse of the last winter I have been able to obtain a very abundant harvest of Distoma, as these parasites have been extremely plentiful during the last moist years, and especially in the antumu and winter of

1 Rokitansky's last edition was not in my possession when I wrote this. Any correetions that may be neeessary will le found at the end of the book. [See Appendix B for further information on this subject.-Tinss.] 
185 $1-55$, and have caused great devastations in many flocks of sheep.

The gall-ducts are frequently unaltered by these worms; but are generally considerably dilated, and then often resemble cords of the thickness of the finger. At the same time their walls are remarkably thickened, callous, cartilaginons; the inner walls of the vessels are dingy, rough, meven, and beset with bony, calcareous concretions (phosphate of lime and magnesia), often coloured by bile, which adhere firmly to the walls and eren close up the smaller branches. These phenomena extend to the smaller gall-ducts, and these are seen of the thickness of a goosequill, and often filled with a yellowish, dingy, slimy matter, resembling pus in its external appearance. The secretion of bile in the ressels thus destroyed constantly suffers more and more, nay, it may even cease entirely, or we only find as much bile in the larger ducts as may have been poured into them from the smaller lateral branches uninhabited by Distoma. The bile itself, which is found in the gall-bladder, is altered in its colour ; instead of greenish yellow it has become dingy grayish yellow, and it has an unusual consistence, as it is mixed with a very considerable quantity of mucus. However, it is usually found in tolerably large quantity in the gall-bladder. This last circumstance certainly appears at the first glance to be very contradictory to what has just been said, and also to the fact that the enormous size of the gall-ducts, and the hardness of their walls, has causcd death, by mechanical pressure, on a great part of the tissue of the liver and rendered it useless; but it is easily explained by the circumstance that when the Distoma are presentin great numbers, they close up the ductus choledochus almost hermetically, so that the bile behind them and in the gall-bladder is kept back. To sum up the symptoms here described in a few words, we must regard as the first consequences of Distoma in the liver, dilatation and catarrh of the gall-ducts, and destruction by pressure and disappearance of large portions of the parenchyma of the liver in the vicinity of the eularged gall-ducts.

Further consequences of these morbid circumstances are, although perhaps rarely and only temporarily, icteric phenomena, which, however, quickly disappear after the removal of the stoppage in the efferent biliary duct. Whether actual symptoms of incarceration, such as we find with tightly wedged gallstones, may occur in consequence of the passage of the worms 
through the ductus choledochus and during the time of the residence of the Distoma in this canal, at least at the commencement and when the first Distoma are about to pass outwards, and then only temporarily and with a rapid change, we have no exact reports or observations on the sheep, and certainly none as to the human subject.

Towards the periphery and in the finest gall-ducts the eggs of the Distoma often collect in quantities; they appear half dried, form a greasy but granular mass, and are capable of effecting a total obliteration of the gall-clucts attacked. In particular places we find a biliary deposit upon or surrounding the isolated eggs ; this is the first attempt of nature to make use of these eggs as the nucleus of future biliary concretions. The same masses of eggs occur in the greasy masses of the gall-bladder, and here generally floating about freely, so that, without exaggeration, we may speak of the occurrence of millions of eggs in such livers. There is also no doubt that gastric symptoms of various kinds will occur in a secondary series, and that the general nourishment must suffer. How far permanent or temporary obstruction is produced by the temporary retention and diminished secretion of bile, I cannot say. It is certainly more essential that digestion ceases from the disturber secretion and flow of bile, whence results a high degree of that chlorotic state, which, according to the statements of experienced farmers, shepherds, and veterinary surgeons, at once characterises the animals suffering from Distoma, by a turbidity, great want of lustre, and a rather greasy appearance of the eyes, so that the above observers can detect the existence of the Distoma from the eyes. This seems, however, a very deceptive symptom.

Diagnosis. - The local circumstances, the endemic occurrence of Distoma in a district, the great humidity of preceling years, and the moist soil of the meadows may perhaps, with the abovementioned circumstances, furnish the sheep-breeder and the veteriuarian with data for the diagnosis of the presence of Distoma; but for the surgeon these last-mentioned circumstances are certainly quite valueless, and the first-mentioned ones, as they associate themselves with other liver-complaints, are of such doulstful significance, that it is quite impossible to found upon them even a diagnosis of probability. There is only one possibility of establishing the diagnosis of Distoma in the living 
human subject; that is, the passage of Distoma with the faces or matters vomited. How this is possible every one will perceire who has seen, in the warm liver just taken out of the freshly killed animal, the ductus choledochus stuffed full of these animals, or who has found flukes in the intestines, on killing or dissecting the animals in the spring, about the time of their first going to the meadows, the occurrence of which is well known to all observant sheep-breeders and veterinarians, and was also proved to me by Professor Haubner. Nay, credible sheep-breeders have assured me that they have often found these worms in the spring upon the droppings of the sheep. The passage of the Distoma upwards or downwards is therefore the only pathognomonic indication of their presence in an animal or individual.

As regards the prognosis the Distoma-malady, although not dangerous, is generally unfavorable, because at present our knowledge of remedies which pass to the liver and act upon the gallducts is very scanty; our knowledge of true anthelmintic remedies is still more so; we know nothing at all of remedies which can reach the gall-ducts, or of any certain means of prophylaxis. We must consequently leave everything to exterual circumstances, and involuntarily throw ourselves upon the goodness of Providence.

Therapeutics.-In this case, as with the preceding worms, the therapeutics are divisible into prophylaxis and direct treatment.

If we commence for once with the latter point, the general laws of therapeutics will show that, after the detection of the malady, calomel must be recommended, and perhaps still more those mineral waters which appear to act upon the gall-ducts and on the formation of gall-stones, such as Carkbad, Marienbad, Kissingen, and similar springs. Together with these remedies we might have the greatest expectation from Durand's medicine for gall-stones, the well-known mixture of oil of turpentine with sulphuric ether, on account of the turpentine, that chief remedy for worms. Experiments with santonine were made without result in a sheep-fold, the proprietor of which is an extremely intelligent agriculturist. By the administration of gypsum it was thought that the disorder was cured, at least the sheep became less chlorotic, more vigorous, fresher in appearance, and better in appetite. For my part I regard the action of the gypsum only as symptomatic. The worms were probably but little touched by it, and the beneficial effect of the process probably lay in the improve- 
ment of the secondary, chlorotic symptoms by the salt of lime. Another experiment was made in the same sheep-fold by lining the troughs with lamp-black. The result was unsatisfactory.

Lastly, upon my recommendation, the principal remedy of Durand's mixture, turpentine, was administered to several sheep, and followed by a purgative. The result of the remedy, which has long been in ligh esteem amongst sheep-breeders, upon the sheep set apart for the experiment, was still unsatisfactory, probably because the quantity of castor oil administered as an aperient was too small. We have not given up the further prosecution of the affair, and if anything useful should be discovered by us, we shall not omit to report upon it subsequently.

Bremser put the greatest reliance in C'habert's oil, a remedy which has passed gradually out of use in the present day, on account of its dangerous qualities.

The most important thing to obtain would be a rational prophylaxis, founded upon the developmental history and mode of life of these Distoma. As we are here acquainted only with general outlines, and our knowledge of the details with regard to the different species is still deficient, we will first of all give a brief summary of the general subject according to Steenstrup, De Filippi, G. Wagener, \&c.

From the egrs of the Distoma, which usually escape externally, there issues either an infusorial ciliated embryo, which swims about for a time and becomes converted by a change of skin into a nurse (yrand-nurse, Steenstrup), or, according to G. Wagener's investigations, the nurse (grand-nurse) itself. These nurses (grand-nurses, Steenstrup) are often completely organized animals (Redia, De Filippi), possessing a mouth, an intestine resembling a cacal tube, and a single or double opening for the exclusion of the young, or they are simple, oval, or elongated sacs without any traces of internal organization and without motion (the Cercaria-sacs of the older writers). In the interior of these Redice or Cercaria-sacs, but not by extemal gemmation, the young Trematoda are now produced from the germ-granules existing there; these are rarely destitute of a tail (for example, Distomum holostomum, Von Sicbold), usually possess a tail-like caudal appendage, sometimes cleft, which enables them to swim about in the water, but which they lose on immigration. The Trematoda, which are furnished with a tail (Cercaria), must first pass through a multifarious metamorphosis; penetratiug from 
without through the skin into other animals (especially aquatic mollusca and insects, and perhaps also other higher animals which occasionally visit standing water), so as to get from thence into higher animals, where the Trematoda finally become mature. The account to be given hereafter of Distomum hepaticum in the sole of a man's foot, makes it appear very probable that even D. hepaticum is one of those species which pass through a Cercariaform and bore through the slin of other creatures with loss of the tail. However, I do not hesitate to call the specimen of $D$. hepaticum here referred to an individual which had got into an unsuitable place. The second tailless form of the joung Trematoda above mentioned appears to get at once, and whilst enclosed in the nurse, into the intestine of ligher animals without any active migration. Althougl, up to the year 1855 there was no certain evidence of the mode of transformation of these young Trematoda, yet, after the great discovery of Steenstrup, it was not difficult to conjecture that sheep, rabbits, men, \&c., might infect themselves with $D$. hepaticum by their devouring small mollusca inhabited by the brood of the Distomum in question, which were living upon the grass of the meadows, or by swallowing small aquatic mollusca, or free broods of Distomum, when drinking from stagnant, marshy waters. As a matter of course, the pos. sibility of this mode of infection was stated openly by public teachers of the veteriuary art and of zoology, and also by myself in lectures to the agricultural societies of my native country, although I received epistolary correction for this idea from one of the first German helminthologists. But the priority could not have been ascribed to any one but Steenstrup himself; and neither Leuckart, Haubner, nor myself, nor others will claim any priority in this respect. According to Gerlach, the eggs of D. hepaticum were administered to lambs without result, and from this, it appeared clearly that a further development of the eggs of Distoma passing out with the dung of the sheep, exterior to the body of the sheep, is necessary.

An essential proof of the truth of these views regarding the production of $D$. hepaticum has been furnished by De la Valette St. George. In his Inaugural Dissertation, which is adorned with two admirably executed plates and is entitled 'Symbolæ ad 'T'rematodum evolutionis historiam' (Berlin, 1855), De la Valette enlarges upon the developmental history of the Trematoda. In the embryos of a Distomum from the intestine of Sterna Cantiana, 
which are furnished with cilia, but at the same time also with a mouth and the commencement of a ventral sucker, we may, just as in the similar embryos of Aspidoyasta conchicola described by Aubert, find an example of the form above described, which, like the tailless young Distoma enclosed in the nurse, pass directly and without any active migration into the mature form, when they are introduced into other animals. We must not, however, allow ourselves to be misled into regarding embryos formed in this way as being always young Distoma which become converted directly into the mature form; they may also be nothing but the earliest stages of the Redice, ard this circumstance must be well borne in mind. That $D$. hepaticum bears a brood of this kind certainly does not appear to me impossible, according to the observations hitherto made, but it is very improbable, and, in accordance with the results given above, I regard it as most probable that the young brood of $D$. hepaticum possess a tail.

When De la Valette set abont administering the tailed, freeliving forms, that is to say the Cercarie, the result of a metamorphosis of these forms into mature Distoma did not occur. He then directed his attention to the forms originating from the Cercarice just referred to, which are enclosed in cysts, and although still asexual, are already in other respects somewhat further developed. Such enclosed young Trematoda are found partly in the bodies of mollusea and aquatic insects, and perhaps alsoif we may draw conclusions, per analogiam, from the Monostoma to the brood of Distoma-partly free in the water. At least, De la Valette saw, under his own eyes, young Monostoma free in the water surround themselves with a cyst, certainly by the solidification of a fluid secreted by the Distomum.

The further development of such enclosed Cercurice, when they have reached the stomach of an animal, takes place in the following way: The Cercaria, which has become converted into a young Distomum, escapes from the cyst with either the head or the tail foremost. The nucleated cells of the Cercaria have already disappeared; in the armed species the hooks are seen distinctly, and in all we see particular systems, such as the system of exeretory vessels and the ciliary vessels with thin liyaline globules. The contractile sac of the excretory system is elongated; the foundations of the testes and germ-stock make their appearance. When administered in this state, the young Distoma are quickly provided with germ-stock, testes, and ovaries; 
the excretory organ, which is filled with globules, emits regular transverse branches over the sucking disc.

In order to determine the mutual relations of the Cercarice, enclosed and tailless Cercaria (young trematode larva), and mature Trematoda, we have as data, as in the Cestoidea, in the armed species the spinous ring and the anterior part of the head, in the unarmed the simple boring spine in the same spot and the dilatation of the intestine. According to De la Valette's experiments, it is certain that the Cercaria echinifera is converted, very rapidly in the intestine of warm-blooded animals, and slowly in cold-blooded species, into D. echiniferc (Val.); that Cerc. flava of the Ephemera becomes transformed into Monostomum flavum of the finches and sparrows; but that $C$. echinata is converted into D. echinata Anatis Boschadis (Zeder.)

From these experiments we also see, when we run through the animals experimented upou by De la Valette, which are partly cold-blooded, and partly warm-blooded animals (e. g. Coluber natrix, Rana temporaria, Fringilla domestica and F. montana, Columba domestica, and Lepus cuniculus), that the diffusion of the Trematoda in the animal kingdom is by 110 means confined within such narrow limits as that of the Cestoideu.

If we apply what has thus been established by experiment, per analogiam to Distomum hepaticum, the following may appear to be most probable with regard to the mode in which the Distoma reach the liver of man, and domestic animals of the classes Herbivora and Omnivora. Although it is still urknown to us how the embryo becomes metamorphosed, and into what Cercariasacs or Redia it is converted, and where these Cercaria-sacs or Redice live; although we do not know whether the brood of $D$. hepaticum is tailed or tailless, and where it encysts itself, whether free in the water in the manner of Monostomm, in aquatic mollusca or insects, or in higher animals which occasionally visit stagnant waters-yet there is much probability that the herbivorous or omnivorous domestic mammalia infect themselves with free encysted young Distoma either by devouring snails which adhere to the grass of the meadows, especially in moist pastures, or by drinking from impure, stagnant waters (marsh or pond water). Exactly the same thing would then take place in man, by means of snails adhering to salad, fallen fruits, radishes, turnips, and other roots. Nay, such small snails might even be introduced with dry fodder iuto the stomachs of our domestic animals during 
the winter, loy their eating the small species passing their winter sleep in their closed shells or the shell-less slugs adhering to roots protected from frost in warm cavities or cellars. Whether the production of $D$. hepaticum in the human liver may take place by drinking impure water, must remain quite undecided. The finding of a young Distomum in the sole of a woman's foot appears to be in favour of an immigration, and a mode of existence similar to the Cercarice.

For the benefit of those who may wish to trace the mode of production of $D$. hepaticum more closely by experiment, I may remark that De la Valette found no trematode brood in Limnaus auricularis, Planorbis carinatus, Cyclas cornea, Succinea amplibia, Helix pomatia, Limax agrestis, Anodonta anatina, Mytilus polymorphus, and in the bivalve mollusca about Heligoland; but inet with them in Paludina vivipara, P. impura, Limnceus stagnalis, and Planorbis corneus.

1 b. Distomum hepaticum, juvenile, immaturum sub cute humana.

In No. 45 of the 'Mittheilungen der Naturforschenden Gesellschaft in Zurich,' 1850, Bd. ii, pp. 89 et seq., Giesker and Frey report that the former was consulted, on the 20th December, 1848, about the wife of an overseer in a silk-factory near Zurich. Since the middle of August, a surgeon lad been treating this woman for an inflammation in the middle of the sole of the right foot. A somewhat elevated swelling, usually about $1-1 \frac{l^{\prime \prime}}{2}$ in diameter, had made its appearance, sometimes towards the onter, sometimes towards the inner edge of the foot, and this, without ever breaking, usually disappeared again in six to eight days. Nevertheless, the middle of the sole always continued somewhat swollen and painful, so that the woman could only tread upon the point of the foot, and was hindered in her occupations. All attempts to cause the separation or breaking of the tumour were vain. In December, 1848, the sole of the foot presented a pale-red swelling, which extended from the inner side of the calcaneus obliquely outwards to the metatarsal bone of the little toe, but which could not be in connection with the bones, the periostenm, or the muscles of the sole of the foot, as the toes were perfectly moveable. It was situated rather in the areolar tissue, beneath the fascia plantaris, was not painful to the tonch, yielded longitudiually, and appeared to belong to a deep-seated hollow passage. 
There was no fluctuation. A little above the margin of the foot, directly under the malleolus internus, there was also a circular, slightly elevated swelling, of an inch in diameter, exhibiting a pseudo-erysipelatous redness. Upon this there was a small blackish-red spot, somewhat larger than is seen on the inflamed stings of bees and other insects. No opening conld be detected in the epidermis. No splinters of wood, nails, or fragments of glass liad entered the foot. From the outside of the ankle the swelling had gradually extended over the lower part of the leg and the sole of the foot.

Dr. Giesker considered that the disorder originated from a foreign body, which would be separated by the occasional inflammation of the edge of the foot. He therefore opened the swelling by an incision in the inner edge of the foot, and then observed that the black spot in the centre of the swelling led to a small canal, which was in connection with a larger one in the sole of the foot. This, which corresponded with the position of the second swelling, was also opened. It ran under the fascia plantaris, between this and the flexor's of the toes, terminated in a creal extremity at the ball of the little toe, and contained no pus, or other foreign body, but only coagulated blood, and separated, discoloured areolar tissue. After the bleeding was stopped, lint was introdnced into the wound, and the bandage was left without being renewed for eight days. On the removal of the bandages for the first time, and the application of strong pressure from below, a worm-like animal, which moved in water, issued with the pus. The house-surgeon regarded this as an illusion, and took hold of a second similar body, and unfortunately crushed it between his fingers, supposing it to be areolar tissue. On the 1Ith of February the cure was completed.

The animal could not have been introduced into the diseased spot by the lint of the bandage. Everything indicates that the animal had been in the borly long before the opening of the swelling, and that it had produced the passage and the varying inflammation. The animal was recognised as a young D. hepaticum, of six lines in length, by Frey, and also by Von Siebold. It is most probable that it had penetrated directly in the form of a Cercaria into the sole of the foot. The woman may have given opportunity for this by wasling linen in the more stagnant parts of the Lake of Zurich, or by bathing her feet or her whole person in the lake. 


\section{Distoma lanceolatum (Melılis).}

Pl. V, figs. 11, 12 .

Corpus levi, lanceolatum, planum aliquid pellucidum, aut ovulis flavofuscum, 4.5-12 millim. seu $2-6^{\prime \prime \prime}$ longum, 2 ad $2 \cdot 2$ millim. aut $1-2^{\prime \prime}$ latum in anteriore parte tenuius, acetabulo finitum, in posteriore aliquid obtusum. Collum continuum, conicum, planum, longius, quam in D. hepatico. Os fere terminale, globosum, 0.48 mill. latum, acetabulum orbiculare, 0.48 mill. latrom, $1 \cdot I$ mill. pone os situm, ore majus. Gsophagus 0.48 mill. longus, bulbus œesophagi $0 \cdot 10$ mill. latus; intesinum bifurcatum, rectum, simplex, non amplius ramificatum, 0.04 mill. latum.

Genitalia inter os et acetabuhm ventrale sese aperientia, inter intestini bifurcationem sita.

Vesica seminalis exterior = cirrhus claviformis ; funiculus spermaticus flexuosus; penis longus, cylindricus, plerumque rectus; testiculi 2 majores et tertius minor vesicam seminalem internam exhibens; unus pone alterum et pone acetabuhm ventrale siti, vix lobati. Organa vitellina multo minora, quam in D. hepatico, albida, lateralia, ramificata, $1-1 \frac{1}{2}$ mill. longa, in ovarium et nterum intrantia, longiora quam in Dist. hepatico et tenuiora, sed colore obscuriore predita, multifarie voluta. Ovulo multo minora, quam in Dist. hepatico, 0.041 mill. $=0.018^{\prime \prime \prime} P a r .=0.0185^{\prime \prime \prime}$ Vienna longa et 0.0246 mill. $=0.0108^{\prime \prime \prime}$ Par. $=0.011^{\prime \prime \prime}$ Vienna lata, sed in slatu maturo multo obscuriora quam in D. hepatico et nigro-rubra.

Systema excretorium: Tasa lateralia, ad collum usque mominentia, ibique recurrentia et intumescentiâ minore, ad animalis apicem sitâ, finita.

This parasite was seen in the human subject by Bucholz (vide supra), and apparently by Chabert and Mehlis (vide supra, under $D$. hepaticum), unless, as already remarked, Mellis's case was a mystification of the surgeon.

After the above we have but little of a general nature to add. The animals are narrow and clongated, and are particularly distinguished by the long neck, by the want of any spinous coat, and by the female sexual organs especially occupying the abdomen, and the testicles the anterior part of the body. This last circumstance alone should have been sufficient to separate this species from $D$. hepaticum, and to prevent their being 
regarded as young individuals of that species. I shall speak a word as to the necessity for the separation of the two animals. Whoever compares the annexed figures, and also takes the trouble to examine young $D$. hepaticum of abont the same size as $D$. lancerslatum, will be convinced that Schaeffer, Rudolphi in his earlier works, and Melnlis were right in establishing two distiuct species, and that Gocze, Bloch, Zeder, Bremser, and Rudolphi at a later period, were quite in the wrong in regarding $D$. lanceolatum as a young $D$. hepaticum.

As to the structure of the separate parts of the Distoma, there is still the following to be said. The buccal sucker is mucl larger in proportion than that of $D$. hepaticum. Áccording to Walter (Sicbold and Kölliker's 'Zeitschr.,' viii), the long, tortuous efferent ducts of peculiar glands, which are sometimes isolated, sometimes united, permeate the buccal sucker on its outer wall, and open in this may in its innermost wall. These efferent ducts, which carry the finely granular contents of the glands towards the buccal sucker, with distinctly visible lively movements, serve as the efferent canals of the glands which act as salivary organs. The pharynx, which in D. hepaticum forms a sort of cup in very good proportion to the size of the buccal sucker, is very small and globular in D. lanceolatum. The round pharynx is followed by a short common csophagus, and at the level of the apex of the sac of the penis there commences a bifurcation of this intestinal canal, which runs simply and without auy ramifications on each side at the sides of the uterus, nearly to the hinder extremity of the latter, where it terminates in a creal and somewhat clavate enc. Its contents are a dark, finely granular, molecular mass. As untriment, this parasite makes use of the bile from the finer gall-ducts, but also, perliaps, the blood which circulates in the walls of those vessels, as I have seen most of the gall-ducts inhabited by this Distomum filled with thinly fluid contents of a blood-red colour.

The testicles lie one behind the other, and in the anterior part of the animal, immediately behind the rentral sucker. They are lobed by lateral indentations; the anterior one is smaller than the posterior, and each has a funiculus spermaticus which opens anteriorly into the penis-sac. Immediately behind the larger posterior testicle, and about at the level of the point of union of the yelk-sacs, lies a rery small retort-shaped body, bent backwards, with an efferent duct opening posteriorly, which appears 
to lead nearly up to an organ which may represent the germ-stock of the Trematoda.

The female genitalia consist of a pair of very small dendritic yelk-sacs, placed at the sides of the animal, in the middle of its length, and mited by a straight branch running transversely across the animal. Immediately behind this point of junction lies an organ with clear, white, globular structures, which may be the germ-stock. It is probable that the spermatozoa coming from the internal seminal vesicle, the vitelline bodies, and germcells here meet together, for behind this spot we soon meet with the true eggs in conrse of formation. These structures occur in the convolutions of a very long oviduct, which is repeatedly twisted into loops, and which passes directly into the uterus. The further these convolutions pass backwards, the yellower they become, until at last they are quite of a dark yellow colour when they arrive in the neighbourhood of the candal extremity of the animal. From this point the loops turn back again, and continue forming loops in the same way as before, often covering the loops of the first series, either entirely or partially. When this convoluted tube has returned about half its way forwards, the eggs acquire a dak-brown colour, and these brown convolutions are seen to pass np to the level of the anterior extremities of the two yelk-sacs, and at last end in a very long vagina, which is at first convoluted, but afterwards rms straight, and opens, with the penis, on the anterior margin of the ventral sucker. In the full condition it is very easy to detect this last circumstance.

The system of excretory vessels consists of a pair of longitudinal canals, which rum quite at the sides of the animal, reaching in front nearly to the pharynx, where they bend round, and become thicker posteriorly to their extremities. At the apex of the abdomen these two stems open into a common dilated portion, and allow their contents to escape through a cleft opening in the middle of the abdomen of the Distoma. This canal is often seen produced externally in the form of a bell, and only then opening.

The pathological anatomy is much less charactcristic than in the case of $D$. hepaticum. There are properly no perceptible great injuries to the liver. The diagnosis is only possible when the worms pass of; the prognosis is better than with $D$. hepaticum; the etiology is unknown; and the therapeutics are the same as with $D$. hepaticum. 
3. Distomum heterophyes (Von Siebold). Found by Bilhar'z.

$$
\text { Pl. TV, figs. 11, } 12 .
$$

Descriptio: Dist. heter., hermaphroditum.

Corpus ovato-oblongum, depressum, subtus planum, supra leviter convexum. Acetabulum oris subapicale, infundibuliforme, parvum. Acetabulum ventrale paululum ante medium situm, magnum (acetabulum oris decies et ultra superans), globosum. Pharynx muscularis, globosa; canalis cibarius ante acetabulum ventrale in 2 partes crecas divisus. Cirrhus post acetabulum rentrale situs, et oblique cum sinistra ejus parte coalitus, globosus, acetabuliformis, circulo incompleto setarum 72 minutissimarum, ramulis 5 secundis instructarum coronatus, testiculis organoque germinifero globosis. Lonyitudine $\frac{1}{2}-3^{\prime \prime \prime \prime}$; latit. $\frac{1}{4}^{\prime \prime \prime}$.

Patria: Agyptus; in hominis intestino tenui bis repertum, numero permagno.

On the 26th of April, 1851, and once subsequently, Bilharz found a great number of small red points in the intestine of a boy. 'Ihese were small Distoma, with mature, reddisl-brown eggs shining through them. The Distomum is oval, obtuse behind, more acute in front. The buccal sucker is small and funnelshaped, and opens rather towards the lower surfice than anteriorly. Behind it commences the sliort, narrow, membranous œsophagus, which is followed by an oblong muscular pharynx, and then by a narrow cibarian canal, which divides as usual, in front of the ventral sucker, into two lateral intestinal tubes, terminating in creal extremities in the hinder part of the body. The muscular ventral sucker lies before the middle of the belly, and is twelve times as large as the buccal sucker. Behind this lies the penis-sac, which is itself not unlike a sucking disc upon superficial examination, and exhibits on its surface a circle of seventy-two small, peculiarly formed horuy filaments (analogous to the fish-basket-like liorny ribs of the penis-sac of Polystomum and Octobothrium, Von Sieb.), which present towards the sides five small branches of equal length, placed one behind the other, and set on at an acute angle. At the spot where the penissac is coalescent with the ventral sucker, the horny filaments are wanting. In the hinder end of the body lie the two roundish 
testicles; between these and the penis-sac the small, round germ-stock, and behind this a blind sac (vesicula seminatis interior) in which a lively spermatozoid-swarming could be detected. In the midst of these organs lie the oviducts in many convolutions, and externally, quite at the sides of the body, the branched yelk-sacs. The excretory organ also opens here in the middle of the abdomen, and evacuates the well-known characteristic corpuscles. The skin is beset with small spines directed backwards, which are particularly numerous and distinct in front.

Bilharz collected some hundreds of this Distomum in one case, and still left a great number in the body. Its influence upon the animal economy is unknown.

Therapeutics. - Where the existence of these animals is ascertained, from specimens passing off with the frecs, I consider it would be advisable to expel them with the ordinary anthelmintics (see the treatment of Tanice and of Ascaris lumbricoides). Castor oil with oil of turpentine, and calomel alone or with jalap, arc particularly to be recommended.

The following two Distoma live in closed cavities or organs.

\section{Distomum homatobium (Bilharz).}

Plate VI, figs. $1-13$.

Descriptio vermis secundum Bilharz.

Distomum hrematobium, sexu distincto.

Maris corpus molle, allidum, filiforme, parte anteriore totius longitudinis octava vel nona ("trunco") depressa, lanceolata, subtus plana vel concava, supra leviter convexa, superficie lavi, reliqua corporis parte ("cauda") terete, margine corporis ab acetabulo ventrali retro utrinque versus faciem ventralem conflexo, eoque modo canalem "gyncecophorum" efficiente, apice postico, attenuato superficie externa tuberculi spiligeris conferta, superficie canalis interiore linea mediana lavi et partibus lateralibus aculeis minutissimis scabra. Acetabulum oris apicale subinferum, triungulare. Acetabulum ventrale sub finem "trunci" insertum, orbiculare eadem magnitudine cum acetabulo oris. Superficies utriusque acetabuli granulis crebris minutissinis scabra. Canalis cibarius sine pharynge musculari ante acetabulum ventrale in 2 partes divisus, in 
posteriore "caude" parte denuo unitus, cacus. Porus genitalis inter acetabulum ventrale et canalis "gynacophori" originem situs.

Femine forma dissimilis, tenerrima, yracillima; corpus taniceforme, lave, hyalinum, antice sensim valde attenuatum, cauda canali nullo apice angustatu. Acetabula et canalis cibarius, ut in mare. Porus yenitalis cum margine posteriore acctabuli ventralis coalitus.

Longit. 3-4 lin.; mas feminam latitudine multo superans.

Patria: Egyptus in hominis vena portarum ejusque ramificationibus et in vesice urinaria parietibus. In venis meseraicis reperiuntur mares feminam in canali gynacophoro gerentes, in renis intestinalibus et hepaticis, in vena lienali semper vidui.

On the 1st of MIay, 1851, and still further subsequently, Bilharz wrote to Von Siebold, stating that he had found in the blood of the portal vein a new, white, elongated entozoon, resembling a nematoid worm when examined with the naked eye, which was a Distomum with a flat body and a cylindrical tail ten times as long as the body. This tail was no loosely attached, deciduous portion of the body, as in the Cercarice, but a continuation of the substance of the body of the worm itself, which was flat and rolled round towards the ventral surface, at the sides forming a semi-canal, and somewhat sinuated at the apex, and into which the bifurcated creal intestine, which contained blood-corpuscles throughout its whole extent, passed very distinctly. In the veins of the uninjured mesentery, when lield up to the light, specimeus of the worm were soon found, which harboured a gray filament, moving to and fro, in the furrow of their tails. This filament resembled the animal first described in form, only much more delicate and fine; its posterior cxtremity, however, was not rolled into a canal, but band-like and complete, inclosed by the above-mentioned furrow of the otlier animal like a sword in its sheath, but in such a manner that it could easily be drawn out of this furrow. The first animal was now clearly recognised as the male, and the second as the female.

Besides the structure already described, the male presents the following peculiarities: It has a smooth, soft skin on the anterior part of the borly, and its tail is sprinkled with numerous small tubercles beset with short hairs. Each of the two sucking discs is beset with inumerable, extremely small, apparently flat granules, as is also the inner coat of the canalis gymccophorus; 
these, however, appear to be little projections which gire these spots the appearance of a shagreened surface. The middle line of the canal is free from these granules.

The nale sexual organs lie between the body and tail, behind the ventral sucker. Here, where the two lateral margins double downwards to form the canal, $5-6$ roundish or oval organs are perceptible, of which the $4-5$ posterior are testicles, and closely filled with delicate cells, whilst the foremost has trausparent contents; its walls also exhibit double outlines, and pass in front and beneath into an efferent duct, which opens freely exterually, with prominent lips.

Bilharz detected no swarming of spermatozoa.

With regard to the penis we know nothing, and it is also unknown to us whether those asperities and granules occur only, or in particular abundance, in those males which are embracing their females, or whether they are only found in places where we meet with sexually united animals.

Description of the female.-The intestine, which is forked before the ventral sucker, unites again posteriorly in the female to form a large grayish-brown tubular sac, which winds about down the middle line of the abdomen, and terminates in a crecil extremity a little way from the end of the tail. This simple portion of the intestine is surrounded on both sides up to its furcate division by ramifications of the yelk-sacs, which at that point unite into a single efferent duct. Here also lies the germigenous organ witl its delicate cells, which occur in the other Trematoda, and from this a long, thin-walled oviduct, of nearly equal dianeter throughont, runs forward between the two branches of the intestine; it contains perfect eggs furnished with germinal vesicles and shells, and opeus at the hinder margin of the ventral sucker.

Eygs.-These are oval, strongly pointed towards one end, which is always directed backwards in the uterus and oviduct, and they occur in great quantities, and in every possible degree of development. They have generally a delicate, thin membrane, to which, as already observed, a pointed process is attached, and they contain in their interior a transparent mass without distinct outlines, but furnished with variously grouped small granules. These eggs were found, as we shall shortly see, in the action of the parasite upon the limman subject, deposited in great masses, and quite in heaps, on various parts of the inner surface of the intes- 
tines and bladder ; part of them were opaque, and filled with yelkmass; in part the embryo shone through the yelk-mass, which was for the most part absorbed; and part of them contained, together witl a few yelk-corpuscles, mature embryos contracted into a globular form, or extended and elongated, moving in every direction, or even in the act of bursting the egg-shell. In the latter case they extended themselves in length, and with a strong jerk ruptured the egg-shell towards the side, which always took place with a longitudiual slit under the inspection of Bilharz, although he also met with egg-shells which were slit transrersely and obliquely. The vitelline membrane was torn at the same time, and the little animal escaping, according to Bilharz, with its hinder end first, began to work slowly with its ciliary coat, and endeavoured to free itself from the egg by lively movements in all directions, which often occupied a considerable time. The little animal, after its escape, had a longish cylindrical form, thicker in front and obliquely conical behind; at the anterior end was a proboscidiform projection, with a sucker-like impression, and over the whole body a ciliary coat, by the aid of which it moved, revolving in the water, and alternately extending and contracting itself. Through mucus, egg-masses, \&c., it crept in the manner of a worm. In the anterior end of the body two pyriform corpuscles were seen lying close together, from each of which a thin stalk ran to the proboscis; in the hinder part were numerous, small, globular bodies. No reception of nourishment took place. After remaining for about an hour in water, the animal acquired superficial vesicular (mulberry-shaped) projections, lost its power of motion, and became dissolved.

The next step in development was seen by Bilharz in 1851, but not further comprehended or indicated. The best description and figure is due to Griesinger, whose memoirs I make use of here, and on which I shall also depend in the pathological portion.

The further development of the above-mentioned, infusorial embryos, is as follows:

Griesinger and Bilharz often found, in the midst of the calcified eggs which had allowed their embryos to escape (= eggshells), deposited in various parts of the liver and of the mucous membranes, peculiar, husk-likc, doubly compressed, or round, bi-convex, sharp-edged, lougish, brownish-yellow bodies, furnished with a toothed excrescence, which were of the same size as the 
eggs. These were also found by Bilharz, but only once, in the interior of the oviduct of the female, the further course of which contained ordinary eggs. The excrescence was conical, and placed on one side, near to the more obtuse extremity, and was situated on the above-described sharp margin. In these structures, in which Bilharz only found a few small bodies accumulated towards the process, Griesinger discovered living creatures on the 29th of March, 1852. Thesc moved by contractions and extensions, until the thin shell, which Bilharz says was clothed on the inside with a (vitelline) membrane, suddenly tore, and the animal slowly crept out. For many hours it underwent several changes of form by elongation of the neck, but was then lost in the intestinal mucus. The figure given by Griesinger exhibits distinct cilia, the presence of which, according to Billarz, at first was doubtful, until, in the summer of 1852 , he also recognised the same cilia distinctly. According to the latter, these embryos were in nowise distinguishable from the true embryos already mentioned. Griesinger also saw similar animals living free in the intestine. On the addition of a large quantity of water their movements ceased; and, to speak zoologically, they gradually acquired a different form, with escape of sarcode globules or drops. Once Bilharz observed positively, that a body of this kind, furnisherl with a process, reached the interior of a vessel.

Bilharz now thinks, according to his last communications, that these capsules which occur in the liver, in the mucous membrane of the bladder, and in the ureters, remain after the evacuation of their embryos, becoming partly enveloped by calcareous deposits, and partly filled with calcareous matter, in the same way as the empty egg-shells themselves, and give rise to the process shortly to be describer. According to Bilharz, however, when situated upon the mucous membrane of the intestine they are much more completely got rid of.

In explanation of these structures, to which Griesinger paid particular attention, Bilharz expressed limself pretty decidedly in the appendix to his first communications, to the effect that they are not true eygs, although he once found one of these capsules furnished with a spine quite in the anterior part of the oviduct of a female, but probably a lighter grade of development, such as a sort of pupa-case of the animal already cscaped from the egg. Subsequently he thought that these capsules pro- 
vided with a spine formed the envelopes of the embryos in the act of migrating out of the human body, and that this structure in the oviduct had only passed through its metamorphosis at an abnormally early period. Finally, Bilharz expresses the opinion that these capsules cannot be destined to protect the embryos in their outward migration, as they, (but never true eggs, were fomd in many places in the tissue of the mucous membrane, and that they remain fixed in the tissue and become calcified, just like the empty shells of the true eggs. If we combine all this, we see at once that Bilharz is not in a position to explain the signification and importance of these structures. We shall not be any more successful. The only thing which might, perhaps, yive us data for an explanation, is a comparative glance at the class Infusoria. That the embryos of the Tiematoda, and especially those of our Distomum, resemble Infusoria is well known. That the Infusoria are not only subject to a change of skin (Ehrenberg), but also to a simple ency'sting process, is known to us from the works of Stein and Cienkowsky, only to mention one or two; and we even know from Guanzati that such an encysting process is necessary in certain kinds of Infusoria, if they are to retain the faculty of returning to life after drying upon being moistened with water, or of supporting a high degree of cold. These circumstances are, at all erents, adapted to make us think, that as no change of skin is in question, no pupa-case can be spoken of, but that these spinous capsules are the cases of the embryos of Distomum formed by themselves, within which, like the six-hooped cestode embryos in the cysts formed by their host, they pass to a higher grade of development, and at the same time increase in size, as we see from Gricsinger's figures. Unfortunately, however, we have now got to the end of our knowledge of the history of the development of our Distomum, and the question remains whether the mature Distoma are at last formed by the intervention of an outward migration, with or without an intermediate step analogous to the Cercarice, notwithstanding the continuance of Griesinger's last stage in the body.

Action of D. hamatobium upon man, according to Griesinger. -This parasite is extraordinarily abuidant in Egypt, for in 363 dissections its occurrence is noted 117 times by Griesinger, and he even thinks that the lower stages may have been overlooked. 
Alterations of the bladder by the presence of this worm.-The lowest degree of the disorder in the mucous membrane of the bladder is presented by the more or less eircumscribed spots, upon which is observed strong hyperæmia, much bloody extravasation, swclling and inflation of the mucous membrane, or tenacious mucous, grayish-yellow masses of exudation in which the eggs are imbedded. There are generally only small spots varying in size from a lentil to that of a shilling, especially on the hinder wall of the bladder. It is rare that the whole inner wall of the bladder is injected and ecchymosed. The urine is mucous, but pale and clear, and Bilharz fomd eggs in the urine passed. In subsequent stages grayish-yellow, yellowish, diseoloured elevations, mixed with many pigment spots, are found, covered witl a very smooth, tenacious mucous membrane, as if it had been kept in spirits. These elcrations frequently form a soft coat, sometimes a line in thickness, mixed with bloody extravasations, and peeling off in small fragments at the surface, which is so firmly attached to the nncous nembrane, that, in detaching the former, the uppermost layer of the latteris separated with it. Sometimes the calcureous incrustations of the eggshells, the cleposition of the salts of the urine, and the aggregations of eggs give the whole a sandy texture. Very rarely this coat covers true ulcers with loss of substance. Frequently nothing is to be seen but dingy red, gray, or black, somewhat elevated pigment spots, together with fresh injection and apoplexy of the healthy mucous membrane.

All this is the consequence of the Distoma getting into the smaller vessels, and laying their eggs, which at last escape from the ruptured ressels in these situations. My friend Reinhard, of Bautzen (to whom I had transmitted a portion of the bladder of the negro boy referred to by Griesinger and Billarz, and which Professor Griesinger kindly handed over to me), saw, hanging out of a vessel accidentally opened by me, one of these Distoma, which bore lis female within lim, but in other respects allowed nothing more to be detected.

At other times we find, on the mucous membrane of the bladder, single or aggregated excrescences or vegetations, varying from the size of a pea to that of a bean, and of a yellowish colour, or ecchymosed with blood. They are $1-3^{\prime \prime \prime}$ in heiglit, verrueose, fungous, cleft into separate points above, like cock's-comb or raspberry-like condyloma, and narrowed or pedunculate at the base. They are 
generally found in the soft, ycllowish-gray, tender, crumbly, marrow-like, firm, pulpy, infiltrated, submucous tissues, permeatcd by coagulated blood or pigment, above which there is a normal, but thickened, mucous membrane, only deficient on particular spots, when the submucous tissue theu peels off in small pieces; or they are placed between the mucous and cellular membranes in the form of a grayish-yellow layer of exudation, like fresh, typhous, Peyerian flakes. At the base of isolated, very furm and solid excrescences, the section shows a cellular stalk, and a sort of radiating framework, which is only a continuation of the normal submucous tissue. Between these different forms there are all sorts of transitions. The muscular membrane of the bladder is, at the utmost, slightly hypertrophied; and on one occasion only did the serous membranes and the nearest portions of the parietal lamina of the lining membrane of the abdomen exhibit the same darkly pigmented cock's-comb excrescences.

In the smooth-edged spaces of these excrescences, sitting in the submucous tissue, formed by the diverticula of its vessels, and only constituting productions of the vessels, Bilharz first found the Distoma, and in the mucus and exudation over these spots their eggs. We may from this conclude that the Distoma congregate there to lay the eggs which are to be passed out.

Action of the Distoma in the ureters.-Not only the mucous membrane of the bladder, but also that of the ureters, or the latter alone, and in rare exceptional cases even that of the pelvis of the kidney, is attacked by the same process. In the ureters we then see irregular, insulated, grayish-yellow, slightly elevated plates, with a soft, tender, firmly adherent coat, of dark urinary gravel, sandy to the tonch. This gravel is nothing but a mixture, in molecular masses, of imbedded eggs of Distoma, either empty or containing embryos, with blood, exudationcorpuscles, and crystals of uric acid. Individual embryos also occur free, but Griesinger only found these in a dead state. In consequence of the thickening of the submucous layer, strictures of the ureters, with partial or total dilatations above them, take place, as well as retention of urine and its consequences, especially when hypertrophy of the muscular coat occurs at the same time. The kidneys are generally somewhat swollen and filled with blood, and the mucous membrane of the pelvis of the kidney injected. By long duration of the affection the kidneys are subject to fatty degeneration. Pyelitis, and fan-like dilata- 
tion of the pelvis and calyx, with complete atrophy of the substance of the kidney, also occur. The aggregations of eggs of the Distoma are not unfrequently the nuclei of deposits of gravel and stones, consisting principally of crystals of uric acid, in the kidncys, ureters, and bladder, and thus give rise to the wellknown consequences of stone and gravel. This is the lithiasis of the Egyptians, already described by Prosper Alpinus in his 'Medicina Egyptiorum.'

That these uropoëtic disturbances have an injurious action on the whole organism in time is a matter of course. They lead to general illness, and finally death, which, after the complete destruction of the constitntion, usually results from pueumonia (perhaps that kind of mechanical pneumonia indicated by Virchow, in which the coagulum and similar insoluble bodies borne along by the circulation, stop up the capillaries of the lungs), diarrhoe, or other disorders. Inasmuch as these animals live upon the blood, they might probably cause chlorosis, but no case appears to Griesinger to show that the Distoma alone could be the cause of this.

Action upon the intestinal mucous membrane.-In the large intestine changes not unfrequently take place exactly similar to those described in the bladder. We find apoplexy, deposits in and upon the submucous and supra-mucous tissues, verrucose and lobate fungons excrescences, and also the aggregations of the eggs of the Distoma in the vessels of the mucous membrane, where the eggs are often fixed in rows in the tissues of the mucous and submucous membranes, in and beneath the croupous exudations upon the intestinal ulcers, and, lastly, after the rupture of the vessels, upon the free surface of the mucous membrane. For a moment the thought might occur to us that this Distoma bears the same relation to the endemic, acute, and chronic dysenteries of the large intestine in Egypt, as the Acarus to the itch (Bilharz); but Griesinger, and afterwards with lim Bilharz, convinced themselves that this is certainly a coincidence, but a purely accidental one, standing in no relation of cause and eflect, as in very many dysenteries the Distoma are entirely wanting.

Action upon the liver. - The entire trunk of the portal vein is sometimes found filled with mature animals, with eggs in the substance of the liver, and it is not impossible that the Distoma 
situated in these places may give rise to a tough, dry, anxmatous consistence of the liver, or perhaps cren to abscesses.

Symptomatology with reference to diaynosis. - The direct indications of the disorder are to be sought in the uropoëtic system, especially in the urine itself. Canseless hamaturias are suspicious, especially in consumptive individuals. Perhaps the essential hæmaturia of tropical countries, such as the West Indies and British India, are due to this cause. The diagnosis can only be made perfectly certain during life when eggs are found in the bloody urine, and in other evacuations, as was done by Bilharz. Data are also furnished for the diagnosis by the not uncommon pyelitis, or other disorclers of the bladder, by the acute exacerbations of certain disorders of the bladder and kidneys, as well as by an indefinite illness, with occasional disturbances in the urinary secretion, and, in severe cases, perhaps even enlargement of the kidneys. Frequently the Distoma may of themselves produce a severe, acute disorder, or catarrh of the pelvis of the kidney, accompanied by a uniform, blackish-red hyperæmia of the renal substance, without any other change. 'i'he most usual disturbances, howerer, belong to the province of chronic disturbances in the urinary system, such as urremia, \&c. But wc may also suppose a putrescent infection of the mass of the blood in consequence of the death of Distoma in the blood of the portal vein, or a transference of the eggs and embryos into the most remote vessels, amongst which we may even mentiou the left ventricle.

The seasons of the year appear to be not without influcnce upon the frequency of the worm; it is more abundant fiom June to August, and more rare in September, October, and January, which is, probably, connected with the quality of the food, \&c., at different scasons.

Therapeutics. - According to Griesinger, the medical man has to bear in mind and answer the two following questions:

1. How do the Entozor penetrate into the body? and what articles of diet facilitate this? Griesinger thinks that in this respect three descriptions of food are particularly suspicious: $a$, the unfiltered water of the Nile; $b$, the bread, grain, and dates; and $c$, probably to the greatest extent, the fishes which are used in a half-putrid state $=$ Physich.

2. To administer anthelmintics against this disorder. These must be of a nature to cure the complaints mentioned, and 
especially the chlorosis. Griesinger therefore prescribes calomel or turpentine as a remedy, the latter especially, because it was absorbed without alteration from the intestine, and found again in the urine passed from the form of drops. The use of onions, garlic, \&c., would, perhaps, also be efficacious.

Possibly nothing but great hygienic regulations, which are still a pium desiderium, will lead to a rational prophylaxis in these cases.

The discoveries here detailed remind us that without helminthological knowledge the study of the diseases of tropical and warm climates, cannot he successfully entered upon. We may still look for many new discoveries in this department.

\section{Distomum ophthalmobium (Diesing).}

Pl. IV, figs. $13,14,15$.

Corpus ovato-lanceolatum depressum, variabile. Collum breve subcylindricum. Os terninale orbiculare. Acetabulum ore $\frac{1}{3}$ majus, subcentrale apertura circulari. Longitud. $\frac{1}{4}-\frac{1}{2} "$; latitud. $\frac{1^{\prime \prime \prime}}{6}$. (Diesing.)

"In the eye of a child five months old, born with cataracta lenticularis cum partiali capsule suffusione, which died from the well-known atrophy of infants under Von Ammon's treatment, Gescheidt found four specimens of Distoma between the lens and its capsule. Even with the naked eye these animals were recognisable as small turbid spots on the anterior wall of the lens. The little animals, $\frac{1}{4}-\frac{1}{2} \frac{1 \prime \prime}{2}$ in length, were enveloped by an opaque, veil-like, white mass, and presented themselves in various positions. One specimen, which lay free and motionless, was rather elongated, with the sucking disc turned towards the lower surface of the wall of the capsule. Two others had the caudal portion contracted, and a vial-like form, and still exhibited slight indications of vitality on dissection thirty-six hours afterwards. Thus a cruciform figure was formed, with ohtuse, rounded angles, where the head and tail were clongated, whilst the body was contracted and increased in its brearth. The fourth specimen lay extended on its side; it was white, lancelate, and motionless. The anterior sucking disc was about one third smaller than the central one, semicircular, with scarcely perceptible ridge- 
like margins and radiating fibres; the cosoplagus was short and narrow, and soon passed into the nearly uniform intestine, which was bifurcated a little above the central sucking disc, and ran down on each side of this towards the caudal extremity, where, being covered by the ovaries, it could be traced no further. The oraries were indistinct, and their cotyledons appeared to be arranged irregularly transiersely."

Such is the account given by Gescheidt in his memoir (Ton Ammon's 'Zeitschrift,' iii, No. 4). Ton Ammon, who has in vain endeavoured to find the preparations referred to in the Pathological Collection of the Academy of Dresden, in order to send them to me, has represented these Distoma in his fine work upon the congenital defects of the human eye, from which the figures are copied. ${ }^{1}$

\section{в. Nematelma =Nematoidea =Tumead-worms or Round- WORMS.}

\section{General Part.}

The worms here to be treated of were referred to by Rudolphi as Order I, "Nematoidea ; corpore elongato, tereti, elastico ;" but by Diesing, in his 'Systema,' as Sub-class I, Achrethelmintha; Section II, Ach. elastica; Order VI, Nematoidea, and described in the following terms: "Corpus elasticum, cavum, subcylindricum; tractus cibarius simplex; caput in proboscidem hand protractile. Endoparasita, tandem rarius extus libere vagantia."

We make use of the name Nenateluia here, in order to maintain a greater uniformity for the two divisions.

Corpus teres, elasticum, sape attcnuatum, filiforme, ore centrali vel subcentrali; canalis cibarius aut distinctus, aut obsoletus, anoque destitutus. Metamorphosis in paucissimis. Migrationes active aut passive in permultis.

In the human subject we meet with the mature Nematode worms, partly in open cavities of the body furnished with mucous membranes (intestinal canal, lungs, kidneys, \&c.) ; partly in the subcutaneous cellular tissue, with an artificial external communication; and lastly, during their youth and in an immature state, encysted in very various muscles, especially primitive muscular fasciculi. The study of the individual rorms belonging to this 
class has not yet advanced so far tliat we can undertake an exact division of them into genera, as Dujardin and other helminthologists suppose. There is no doubt that both Dujardin's attempted division into seven sections, although this recommends itself strongly by its simplicity, and the extraordinarily elaborate division of Diesing, in course of time, and the more they are worked out according to Von Siebold's views, will certainly undergo more and more alteration. Above all, Diesing's treatment of the nematode worms leaves much to be desired, whether with regard to the indication and estimation of anatomical facts (see, for example, the section Trichine, in which the primordial lines of the genitalia are certainly to be found), or to the classification of the round-worms, and the establishment of the separate species (compare the divisions, Gordius, the 118 species of which are to be reduced to 3 , according to Von Siebold, or Mermis, the 17 species of which are to be reduced to 2 , according to the same authority; or the section Nematoideum hominis No. 2, which is a Pentastomum). For these reasons I shall not adhere to a strict classification. I shall select the names most generally employed, and shall not observe any fixed order in the enumeration of the particular species, but rather review them in accordance with their dwelling-place in the human body.

The distinct presence of a digestive apparatus, divisible into mouth, œsophagus, stomach, intestine, and anus, the separation of the sexes into two individuals, the certain detection of a nervous system in some of them, and the apparently jointed structure of the round worms, brings them near to the Articulata. In the human subject we must take into consideration: I, the Trichocephali and Trichine; II, the Oxyuri; III, the Strongyli and Ancylostoma; IV, the Filarice; and V, the Ascarides.

It is not very long since it was thought that the Nematoidea were the most accurately known of Entozoa, but now-a-days we must admit that we have more positive knowledge of the listory of the development of the cestode worms, and even with regard to the Trematoda possess a conjectural zoology, which lias as much if not more claim to probability than is the case with the developmental history of most of the round worms.

The nematode worms, or at least a great part of them, appear only to be able to reach maturity when they undertake various immigrations and cmigrations duriug their youth; one species of round-worm occurring in the human body, however, as we shall 
soon see, must be to a eertain extcnit capable of a migration also in the mature state.

The migration in the young state eonsists in the eseape outwards of the eggs of these worms with the human frees, witl which they get into dungpits, cesspools, and sewers, as Richter and Von Siebold have already stated. Here they are surrounded with water, and liave to bear the most various temperatures, but are transferred with manure and by the rain to the fields, meadows, and drinking-water. The tolerably hard shells of the eggs protect the germs contained in them with the yelk from all external injurious influences, and permit the latter, as appeared from the investigations of Newport and Bisehoff, and has now been aseertained by Verloren and Richter, to become further developed, and allow of the completion of the process of segmentation out of the uterus of the worm, or they envelope the embryo which is ready formed in the uterus of its mother on its going forth into the external world. The latter, however, appears to be of rarer oecurrence in man, and we may, perhaps, admit that the nematode worms occurring in the human subject rarely produce and harbour the young in their uteri, which already resemble their parents in external form, although they are only of a microscopic size. This probably ouly oecurs in the Filarice; the other speeies are mostly oviparous. I will here treat at once of the process of the formation and development of the eggs and seminal corpuscles in the nematode worms.

With regard to the formation of the eggs of the nematode worms in the ovigerous tubes, particular credit is due to Bagge, Kölliker, and, above all, to Meissner ; with regard to the formation of the seminal corpuseles, to Nelson and Meissner; for the observation of the entranee of the latter into the vitellus, whether through an actual micropyle of the vitelline membrane, or in consequenee of a meehanical pressure into the egg whilst still destitute of a vitelline membrane, and the changes of the vitellus which afterwards take place (which had been aseertained by Barry in the manmalian ovum, and by Newport in that of the amplibia), to Nelson, who has been violently attacked in various ways, but with exactly the same injustice as Keber; and, after him, especially to Meissuer, and Thompson of Glasgow, and also to Bisehoff and Leuekart; and with regard to experimental investigations on the eggs of nematode worms in water and other fluids, to Verloren, and, independently of him, to H. E. Richter. 
Even before the last-mentioned authors, some of the English writers and Bischoff had ascertained that the segmentation of the eggs of worms takes place and advances in various, even strong, chemical fluids.

The literature of this subject is as follows: "Report to the Royal Society of London on Nelson's Memoir upon Ascaris mystax, made by Thompson, in May 1851 ;' Bischoff, 'Wiederlegung des von $\mathrm{D}$. Keber bei den Naiclen und D. Nelson bei den Ascariden behaupteten Eindringens der Spermatozoiden in das Ei, Giessen 185 4 ;' and 'Bestätigung des von Dr. Newport bei den Batrachiern und von Dr. Barry beim Kaninchen behaupteteu Eindringens der Spermatozoiden in das Ei, Giessen, 25th May, 185t,' with additions by Leuckart; Meissner, in Siebold and Kölliker's 'Zeitschrift,' Band vi, p. 208; and Bischoff, in the same journal, vi, 377 ; and, lastly, Thompson 'On the Seminal Corpuscles, the Eggs, and the Fecundation of Ascaris mystax,' in Siebold and Kölliker's 'Zeitschrift,' viii, p. 425, in a letter to Kölliker.

To furnish the development of the creatures to be treated of here in as connected a manner as possible, we shall, following the observers just mentioned, give a preliminary summary of some things which properly belong to a subsequent place and indeed to the special examination of the sexual organs.

The first foundations of the ovigerous tube of the nematode worms are formed, according to Kölliker, by the occurrence at the extreme apex of the future tube of a series of cells, the contiguous walls of which become dissolved, so that their communicating cavities gradually run together to form the ovigerous tube, which increases by new formation of cells at its apex. The production of the lowest parts of the ovary is unknown, according to Kölliker. I do not know whether the large globular cells which I found throughout the middle of the body on both sides of the intestine in a young immature Ascaris lumbricoides of $1_{\frac{1}{2}}$ inches in length, are those which, gradually approaching each other, become amalgamated to form the generative sac, this would not be improbable from their position.

In the fully developed female organ (ovigerous tube), which forms a long, simple, partially double or multiple tube, twisting about the whole intestinal canal, we may distinguish, according to Meissner, the following six parts :

1. The Germ-stock (Eierkeimstock), is the exceedingly small 
extreme portion of the ovary, formed ouly of a tunica propria without an epithelial coat. It is analogous to the germ-partition (Keimpach) of the insects, generally smooth on the outside, sometimes constricted at its anterior open end by a sort of delicate sphincter (for example, in the Mermites, which are nearly allied to the Nematoida), and dilated in the middle. In this, again, are found the fomale germ-cells, cells circumscribed by the most delicate lines, exactly analogous to the male germ-cells, and with a vesicular nucleus and nucleolar corpuscles (see these structures further on). The nucleus divides into daughter-nuclei (nucleolar vesicles), and these again into 8,10 , or more nuclei (new nucleolat vesicles), which, becoming affixed to the walls, each push out the walls of the germ-cell individually. These projections constantly become more independent, and grow into daughter-cells, which represent the young ora with their nuclei, daughter-nuclei, and germinal vesicles in which the germinal spot is afterwards devcloped, but always remain in open communication with the mother-cell until the maturity of the contents, the yelk; they then become pyriform and provided with a stem, which, forming an open canal, connects the lateral cells with the mother-cell. As soon as they begin to fill with yelk, they are called eggracemes (Eiertrauben).

According to this view of Meissner, therefore, the germinal vesicles are formed several together, in separate mother-cells by endogenous increase. At the same time the mother-cells become converted, by a sort of bud-formation, into a group of smaller cells, each of which possesses a germinal vesicle and a separate membrane (a rudimentary egg). These young are also united by a peduncle to the remains of the original mother-cell; but the remains of the mother-vesicle, always lying in the centre of the ovigerous canal, as in the Gordiacei and also in the Ascarides, form a central axis, which is often very distinct (but sometimes indistinct), and arouud which the ova themselves are arranged like radii.

Neither Bischoff, nor Nelson, nor Thompson, can coincide with this view, and Thompson especially objects, certainly not unjustly, that Meissner has been too quick in extending his observations on the Gordiacei to the other nematode worms. The abovementioned observers never found a union of the eggs in groups, for example in Ascaris mystax. The germinal vesicles were always free in a granular fluid, which gradually collected round 
each of them, without the individual formations ever being united in any way by a solid axis. They do not yet possess a vitelline membrane, as this only makes its appearance after fecundation. The above-mentioned authors, therefore, certainly admit the possibility that the first germinal vesicles miglit perhaps increase in a mother-cell in the interior of the blind extrenity of the ovarian tube, but assert that the individual germinal vesicles, whether isolated or grouped several together, do not become enclosed in a vitelline membrane till a very late periorl, and that the latter is by no means a residue of the mother-cell, aud the cause of the procluction of the bunches of eggrs of which Meissner speaks.

2. The Vitelliyene (Dotterstock).- - It is rather long, and when, as in the Ascarides for example, its walls are tolerably thick, it is smooth externally; but when, as in Mermis, it has yielding walls, it is alternately pushed out in a racemose form and constricted. In the first kind, which we find in the Ascarides, the groups or racemes of ora which are arranged in the form of flat, circular, stellate discs, furnished with as many rays or sectors as the mother-cell has daughter-cells, are pressed against one another like layers, in such a manner that they exhibit the disposition of a galvanic battery, or of the pieces in a roll of money. In Ascaris lumbricoides, the mother-egg, with the daughter-eggs, has the appearance of a wind-mill, looked at from the front; regarded separately, each daughter-egg forms an isosceles triangle, like the sail of a wind-mill, and communicates at its apex with the mothercell or mother-egg. In the so-called vitelligene, or yelk-producing organ, on the inner surface of which, according to Nelson and all subsequent observers, there are ridges of a finely granular appearance, running longitudinally in a slightly spiral direction, the vitelline mass is addled to the eggs. According to Nelson, Thompson, and Bischoff, the vitelline mass is deposited from without upon the free gerninal vesicle. The small, dark, vitelline granules, which constitute the most striking part of the vitellus, appear first of all as a deposit on the outer surface of the gcrminal vesicle, and even subsequently, the vitellus, wherever it may be produced (whether from the peculiar projections of the vitelligene, or from the fluid surrounding the germinal vesicle), is nothing but an accumulation from without, which is by no means held together by a peculiar membrane, but only by a gelatinous, clear, connecting substance, as is the case also, accord- 
ing to Leuckart, in a certain number of other animals. The clear, non-granular boundary line of the yelks of young eggs may easily be taken for a membrane, whilst the true vitelline membrane is only produced subsequently according to Thompson, probably by the condensation of the limiting zone. Neither Nelson, Bischoff, nor Thompson, believe in the existence of a micropyle on the spot where the eggs, according to Meissner, have separated from their stem.

Meissner, incleed, describes this process otherwise, and considers the vitelline substance to be deposited within the ready formed vitelline membrane. He describes this as follows:- In the vitelligene the central mother-cell first becomes filled with a granular mass (vitelliue grannles). When the mother-cell is quite full, the vitelline granules pass through the open peduncles or through the apices of the above-mentioned triangles, into the interior of these triangular bodies (daughter-cells, daughter-eggs), the delicate walls of which become the vitelline membrane. The mother-cells or mother-eggs, as the centres of the stellate discs, fall, at the same time, into a commou axis, which, however, is no true axis, but an axial line (rhachis), which really only occurs in the Strongyli. The daughter-eggs are arranged in a radiate form round and upon this axis. The eggs are seated, like currants, singly upon a longer or shorter stalk, which passes directly into the vitelline membrane of the mother-cell. Towards the germstock the rhachis and eggs gradually become smaller and more delicate: but towards the albuminigenous tube thicker, larger, and more mature. In the albnminigenous tube this arrangement of the eggs, and with it the rhachis, ceases. The young eggs may consequently be regarded as diverticula of the rhachis itself, on the walls of which the individual, ready-formed germ-cells, therefore, probably attach themselves, and become gradually surrounded by it. If the rhachis could be traced into the germstock, we should have to regard it as the germigene itself; but as it only occurs within the vitelligene, and a distinct germigene exists in the Strongyli, we must now give up the idea that this actually existing rhachis is the germigene, however plausible this supposition might be. Individual ova, on separating, pass in a triangular form into the albuminogene.

3. The albuminogenc (Eiveissschlauch).- - It begins with a considerable dilatation where the vitelligene is narrowed by a splineter formed by a small layer of annular muscular fibres, and 
is usually tolerably long and without epithelium; it corresponds with Nelson's oviduct. At the point of transition from two into three, the lateral daughter-eggs separate from their germ-cells. In the Nematoidea, at least in the Ascarides, it presents the peculiarity that very large nucleated cells, with granular tenacious contents, are placed upon the inner surface of its proper tunic; each of these forms a tubercular, very decidedly villous, tongueshaped ridge, projectiug far into the interior of the tube. These villi, bursting, scatter their contents, which are then employed for the formation of the egg-envelopes, as we shall see further on, amongst the processes which go on after fecundation. In the nearly allied Mermis, this tube consists of alteruating Haustris (like the large intestine of a rabbit), and of small chambers, along the whole length of the tube, which are caused by circular folds projecting into its interior. The latter constantly become more and more rare towards the Tuba, cease at length, and become changed for a net of polygonal cells. Instead of the epithelium, we observe here in the walls, scattered, very large, clear, delicate, longish cells, with one or two small dark nuclei, never reaching beyond a neighbouring chamber; besides pale, large, tenacious, and adherent globules, (probably, albumenglobules). 'The eggs found in this tube are still for the most part triangular, but round in some species (Mermis), and at first furnished with an opening in the vitelline mombrane, (that is, the still uncicatrized remains of the stem), to which Keber has given the very suitable name of the micropyle. However, the mutual cohesion of the whole contents of the albuminigene in the Ascarides, is a serious hindrance to the tracing of the process here described, for which the Mermis albicans is especially adapted.

4. The Tuba.-It is short, narrow, the thinnest part of all, but may be greatly thickened by the deposition of muscular fibres (longitudinal and annular fibrous layer), destitute of epithelium, and in Mermis furnished with folds, which probably contribute to its dilatation. As in the albuminigene, each egg enters here separately. In conscquence of the pressure of its wall against the long sides of the eggs, and the pressure upon their poles, wc usually find in it a more quadratic form of egg, which often acquires the round form quite suddenly under the cye of the observer on entering into the fundus ulcri. In the portion of this division nearest to the albuminigene, as also some- 
times in the lowest portion of the latter, the eggs, already fertilized and in progress of development, are pressed extremely closely, one behind the other, the germinal vesicles make their appearance in the mildle, and as they all lie in the middle, they aequire the appearance of a string of figs, or still better, that of segments of Bothriocephali. At the point of transition of the narrow tuba we see a peculiar sphineter.

5. The Uterus. - It exhibits externally a pretty strong muscular layer (mostly ammular fibres), and internally a coating of regular, liexagonal epithelial cells, with small dark aggregations of granules (certainly oil-dlops) in the middle, often detaching themselves in greater quantity behind the eggs, and, as horny structures, probably contributing to the formation of the chitine membrane of the chorion. It wideus pretty rapidly at its commeneement, that is to say, where the tuba passes into it. Anteriorly the uterus narrows rather quickly, and when it is double or multiple, the branches unite at an acute angle quite in front, towards the vagina. The function of the uterus, in which the eggs acquire their round form, is certainly in part the enveloping of the eggs with the chorion, and in part to allow them to pass through that well-known remarkable process of segmentation, which we shall mention particularly at the conelusion.

As regards the coating of the eggs with the chorion, this takes place in the following manner. A solidifying mass, secreted from the side walls of the uterus, is deposited in concentric and constantly increasing layers round the vitelline membrane, which often adheres to them in little folds as the innermost layer. By this means the egg-shell constautly becomes thicker and more resistent. This outer egg-membrane or chorion is usually smooth, rarely tubercular, thick, less transparent, and always round and without appendages, as in the human Nematoida. In particular species, however, the chorion only remains for a short time in its simple form, and acquires a sort of process of very various form, sometimes at the anterior end, sometimes at the posterior one, and sometimes at both. Of the human Nematoida, only two deserve especial mention on account of this chorion. The eggs of the Trichocephali, like those of the Trichosoma, are distinguished by a short direrticulum, as it is called, which is certainly produeed by the deposition of the secretion producing the chorion ouly upon the sides, and not upon the ends, probably in consequence of a strueture still indiscovered, and of peculiar move- 
ments of the egg in the uterus. I have also seen a peculiar condition in those eggs of Oxyuris vermicularis, which pass last out of the uterus in artificially produced oviposition (which never succeeded with me except when the Oxyurides were put quickly upon an object-glass, covered with a small glass, without turning them at all upon their axes, and only then covered with saliva). At one end, probably the hinder one, they bear a light liood or cap, which, as it afterwards disappears, is probably nothing but the expression of the fact, that in them the deposition of the chorion is not yet complete. In the uterus, during the deposition of the eggs, we see the most beautiful peristaltic movements, of alternate undulatory constriction and dilatation.

6. The Vagina.-It is covered with an epithelium of the form of that of the uterus, which, however, is usually smaller, and appears sometimes more or less, and sometimes not at all, swollen and thickened at its external orifice. At its outer extremity it is dilated into a campanulate form, and has a transverse cleft in the middle. It appears to be closed by a pair of lobes or valves, which rest together in the middle. When a number of egrgs has collected in this bell, they force the lobes asunder, the cleft opens, and the eggs are laid by jerks, in Oxyuris always several together.

The principal question now is: Where are the eggs fecundated, and what subsequently takes place in them? With regard to this process we are still very much in the dark; and the following four views come into opposition with each other.

1. Nelson first asserted that the peculiar seminal corpuscles press themselves into any part of the surface of the vitellus, or become presser into it by the contraction of the oviduct, but that they do not penetrate of themselves into the vitellus, and that the chorion is only formed subsequently around this vitelline mass. According to Meissuer, fecundated eggs are always characterised by an irregular, as it were ruptured, surface, and this appearance is not to be regarded as accidental, or produced by mechanical action.

2. Biscirof denics that there is any penctration of the seminal corpuscles, and thinks that the struetures described as semiual corpuscles werc epithelium, which had acciclentally attached themselves to the vitellus, or had penetrated into it. Wedl also represents them as epithelium. Nelson has recontly stated that lie is very well acquainted with the large nucleated 
cells lining the oviduct, which represent the epithelia, and have nothing to do with seminal corpuscles. Consequently we must not regard the seminal corpuscles as epithelium, as the same changes are never exhibited by such epithelial cells, as are described in the seminal corpuscles, and vice versâ. This assertion of Bisschoff only had a passing success, and must be regarded as controverted.

3. Meissner, who describes the seminal corpuscles as penetrating into the vitellus through a particular opening (micropyle), states, that the fecundation takes place, at least in the Ascurides, in the albuminigene, in which the eggs arrive naked, without chorion, and with an open microprle. The production of the micropyle would be easily explicable according to the above statements of Meissner. The egg remains open at the point where it was attached to the mother-cell by means of the stalk, where it exhibits a canal-like process, and allows the vitellus to escape on the application of a gentle pressure. The eggs which stood in the form of a circular disc around a germ-cell in the germ-stock beliave in the same way. There are also eggs produced singly from the germstock, which are connected with the walls of this canal. The orifice of the stem, after separation, takes the place of the micropyle. Through this the seminal corpuscles enter the egg. Its lumen is usually turned towards the tuba from which the seminal corpuscles advance. The seminal corpuscles may also reach the micropyle by the pressure of the egg-tubes, which exhibit peristaltic movements, and by the agency of friction between the eggs.

4. 'Thompsov found in all females of Ascaris mystax, and at all times when males were simultaneously present in the intestine of the cat, seminal corpuscles mixed with eggs in the female efferent organs, and in the upper parts of the oviduct (albuminigene), appearances similar to those which Nelson describes and figures as the penetration of the seminal corpuscles. On the passage of the eggs from the so-called germ-stock into the true oviduct they changed their consistence, became soft and extremely yielding to pressure, and in passing through the narrow parts of the oviduct they altered in their forn. At the same time the eggs acquired the uneven appearance described by Nelson, and single or numerous seminal corpuscles adhered to their surface; such seminal corpuscles were far more rare on the smooth parts of the eggs. They sat upon the vitellus, sometimes 
with the side, sometimes with the closed, and sometimes with the open flocculent end, and were partially imbedded in the egg, but never entirely, as stated by Meissner and Nelson. According to Thompson, the seminal corpuscles probably assist in the softening of the vitellus, but we do not know whether the irregular, and, as it were torn, appearance of the surface of the vitellus depends upon the action (adhesion) of the seminal corpuscles, or whether the latter attach themselves by preference to sections of the vitellus which are naturally uneven. Thompson does not, like Nelson, regard the ragged surface of the egg, and the adhesion of the seminal corpuscles at that point, as unconditionally necessary for fertilization, but as partly accidental to a certain extent, and caused by the softuess of the surface of the vitellus. The fact advanced by Nelson is established with certainty, that the seminal copuscles come in contact with the eggs of Ascaris, at a time when they possess no true vitelline membrane, and when they have become so soft and delicate, by the reception of a peculiar fluid, that they can take up seminal corpuscles into themselves and unite with them.

If we sum up what has been said in a few words, it is certainly established that there is a (more or less complete or only partial) penetration of the seminal filaments into the vitellus, but the disputed point round which everything turns is the question whether the egg, at this time, is still destitute of a distinct vitelline membrane, as the English authors and Bischoff assert, or whether a peculiar membrane with a micropyle exists, as Meissner supposes.

Now, before taking into consideration the final purpose of the seminal corpuscles, we must go a step backward, in order to glance over the whole history of the development of the seminal corpuscles. Thompson observed this process to take place in Ascaris mystax in the following way:

The blind extremity of the tubular testis consists of a delicate membrane, in which isolated, clongated gramular nuclei are imbedded. In the interior of this part of the testis we see $4-5$ convolutions of a peculiar tube, apparently situated in the interior, which, lowever, according to Thompson, is a consequence of the action of water. In the blind extremity of the testis, and in the neighbouring parts, there are delicate, moleated cells of : $\frac{1}{2500}$ " and $\frac{1}{1200}$ "in diameter, and besides these numerous smaller and more simple corpuscles and nucleoli. The smaller cells have 
a single central spot or nucleus, but the larger ones contain several internal cclls or nuclei of varions sizcs, and are probably the mother-cells of the smaller cells, which are undoubtedly the germs of the seminal cells. Meissner also states that limpid cells, with a vesicular nucleus and nucleolar body, arc produced as male germ-cells in the blind extremity of the testicular tube.

As the smaller cells mentioned by Thompson advance into the next darker portion of the testicular canal, each individual cell surrounds itself with the solt granular mass contained in the canal, and increases about three times in size. In this way are produced oval structures, slightly pointed at the two ends, which are at first without an enveloping membrane, but are subsequently provided with one. They become clear on pressure, or by the application of acetic acid, and then exhibit the nucleus or mucleolar body distinctly. Thompson regards the granular mass in the testicular tube as an analogue of the vitclline mass, and thinks that the granular mass, which is probably a product of sccretion of the tube, is deposited from without upon the cells, and not produced in their interior. Meissner describes these cells as filling themiselves with a grauular mass, analogous to the vitelline gianules, and therefore from the interior. At the same time the vucleus disappears, and the cells become polygonal by pressure.

The scminal cells thus formed now advance into the lower constricted portion of the section of the testis, which is filled with a granular mass, when they are, according to Thompson, ${ }_{100}^{1}-\frac{1}{500} "$ in diameter, round, and surrounded by a distinct external membrane. According to Meissner the granules now draw back on all sides from the cell-wall, and cease to be homogeneous. According to Thompson they experience two different changes, divide into several segments, usually four (Bischoff and Thompson), but according to Mieissner, erroneously, into eight, and then, in each of these segments, short, linear, radiating structures are formed, the granules, according to Meissner, arranging themselves regularly, in a radiate form, around a clear, enucleate centre. The centre also divides into small nuclei, which unite witl the above-mentioned segments, and thus are produced cells with daughter-nuclei, which howerer do not advance far in segmentation. The daughter-nuclei form the foundation for the production of the development-cells of the seminal corpuscles; these nuclei, advancing at regular distances apart to the peripliery of 
the cell-wall of the germ-cell, and becoming affixed to the wall, by which they drive out the cell-wall before them, and give the germ-cell a biscuit-like tetrahedric form. 'The diverticula of the cell-wall gradually becoming constricted around these daughternuclei, the latter become independent development-cells of the seminal corpuscles (brood-cells of the seminal corpuscles, according to Reichert), like the mother-cell. Immediately after the constriction a small, strongly refractive nucleolar corpuscle appear's in the middle of the nuclens. The whole development-cell now represents a large, clear vesicle, with a lenticular nucleus affixed to the wall, consisting of granules elegartly arranged in a radiate form, which have a small nucleolar corpuscle in the centre. Meissner observed this process in several Ascarides, and thinks that in the end he entirely agrees with Reichert's observations on Strongylus. The ouly difference between them is that Reichert allows a cell-gemmation to precede the first gremmation of male germ-cells. Reichert did not see the division of the germ-cells, but speals of endogenous cell-formation of the development-cells of the seminal corpuscles, around the contents of the mother-cell, which, according to Meissuer, may occur not only in species of Mermis, but also in true nematode worms. According to Meissner, the seminal elements, during their stay in the testis, nsually remain in the last-mentioned stage of development (in the form of vesicles or globules of $\frac{1}{120}$ " in diameter', and in this state they reach the female vagina. From this globular form results the mode of action of the penis of the Nematoida in copulation, which will hereafter be described. Moreover, according to Meissner, the seminal corpuscles are found in this state in the vagina, in the uterus, and in the albuminigene, but rarely in the tuba, from which they are quickly evacuated.

'Thompson describes the formation of the seminal corpuscles from the individual segments of the seminal cells in the following way : In the vas deferens we find an immense number of nucleated, granular cells, of various forms, but equal size $\left(\frac{1}{1200}-\frac{1}{1000}{ }^{\prime \prime}\right)$, with their contents for the most part uniformly granular, and rarely exhibiting a radiate arrangement. These cells are the freed segments of the scminal cells. Their onter part is indistinct, very finely granular, and only allows an envelope to be detected on the application of water. The more strongly refractive inner part or nucleus, which makes its appearance distinctly on the 
application of water or acetic acid, occupies two thirds of the entire cell, and possesses a small, dark, nucleolus. These structures are exactly like those which are met with in the vagina of fecundated females; but the corpuscles found in the vagina are somewhat clearer in their outer part, and have a distinct hemispherical nucleus or body in their interior. Both with and without the use of reagents we find that the similar structures taken out of the vas deferens, and out of the lowest parts of the vagina and uterus of newly impregnated females, exhibit exactly the same conditions of form and structure. Their size, their general appearance, their molecular external layer, and the peculiarly curved form of the nucleus or inner portion, with a granular mass around the nucleolus on the open side, agree so much, that we cannot avoid admitting that the structures in question, occurring in the female generative organs, have been transferred there from the male organs, and are therefore seminal elements, which only arrive at their higher development in the female organs. We may say, therefore, that the male nematode worms deposit their semen in an immature or half-mature state.

The changes undergone by these structures in the female organs are, according to Meissner, the following: The nucleus attached to the wall of the development-cell becomes clearer, and loses its radiate structure. At the periphery of the nucleus is formed a sharp, refractive line, or a dark seam, the substance of a portion of the nucleus, and indeed that adhering to the cell-wall, becomes condensed, whilst the portion lying towards the interior of the lumen of the cell, remains unaltered and finely granular. Whether in certain other Nematoida, as in Mermis, the entire nucleus is condensed, so as to become converted into a bacillar corpuscle, is still unknown. In the Ascarides, the lastnamed structure acquires the appearance of a flat, watch.glass or saucer-like corpuscle, which gradually encloses the portion still remaining granular, and endeavours to push its extremities together from the periphery, but without ever entirely closing. At the same time it thickens somewhat, so that we see double outlines, and it has acquired the form of a bell-shaped beaker, open at one end, and somewhat turned outwards at the edge, with finely granular contents. The process either closes with this, and the seminal corpuscle becomes free, or the beaker extends still more and becomes thinner, like a small test-glass; the closed end usually thickens in a clavate form, and then bends 
semicircularly in accordance with the dimensions of the cell-wall, because it has no room when extended.

According to Thompson, the onter part of the seminal cell, which in the male forms a nearly homogeneous, finely molecular, layer, becomes clearer and thinner on the side where the seminal corpuscle afterwards lies, but at the opposite side, that is, the one situated nearer to the open end of the future seminal corpuscle, the molecular contents accumulate in greater quantity. On the application of water, or even of saliva, the finely granulated outer layer becomes converted by imbibition into a large, clear, vesicular mass, like sarcode. The granular envelope, which gives occasion for the formation of this clear mass, is a perfectly natural formation, and is, in fact, the residue of the original radiate, but afterwards granular substance, which occurs in the segments of the original seminal cells.

The nucleus, that is to say the inner, strongly refractive part of the seminal cell, becoming gradually converted into a flaskshaped or bell-shaped structure, forms the seminal corpuscle. According to the side from which this seminal corpuscle, which is bounded by a dark, double outline, is examined, its appearance varies. When seen from above or below it is nearly circular; from the side and in profile (the usual position) it appears in its earlier stages semicircular, as if open on one side and furnished with a finely granular, sarcode-like mass, which swells up in water, extends into the interior, and contains a distinct point or nucleolus. In water, and also, although rarely, even without the application of any fluid, this sarcode-like mass issues in the form of a vesicle or drop from the open side of the seminal corpuscle. A seminal corpuscle unaltered by imbibition occupies somewhat more than the half of its development-cell, and is, therefore, cap-shaped, or semicircular. Perfectly developed seminal corpuscles, which occur in the upper parts of the ovary, have lost all traces of envelopes and rescmble an elongated tube closed at one end, and furnished at the other with a somewliat enlarged mouth; they have become flask-like or glove-like. They still possess the dark, double outline, but it is somewhat thinner, and the finely granular mass with the molecules also exists at the open end of the semiual corpuscle. Intermediate steps between the two forms are met with. The ordinary form of the seminal corpuscles occurring in the female generative organs is that of a cupola or bell. They are certainly the product of the 
male organs, but not, as Bischoff, Wedl, and others asserted, epithelial structures of the female organs. The less-developed forms occurring in the female genitalia, are also seen in the vas deferens; the development of the seminal corpuscles within the female organs increases from bclow (vagina) upwards (uterus and albuminigene), and here the sequence of the stages of development may be very well studied. The seminal corpuscles always move frecly in the latter places, and, according to Thompson, never adhere to the inner surface of the female genitalia. The seminal corpuscles of the nematode worms have no filaments, and are motionless. In the nematode worms and all motionless seminal corpuscles of other animals, the filament is replaced by the open space, at which the granular substance has collected, together with the nucleolus.

When the seminal corpuscles have become mature, their development-cells, according to Meissner, often acquire various forms ; hence the pyriform or wedge-shaped seminal corpuscles of Bagge, Reichert, and Von Sicbold. By the bursting of the elementary ccll, the corpuscle which was previously lying bent in the cell suddenly acquires an extended position, and the cell-membrane is broken through at the point where it is succeeded by the finely granular substance at the open flocculent, thicker end of the seminal corpuscle. With this flocculent end the seminal corpuscle slips forth, but the whole does not follow. ${ }^{l}$ The cell-membrane remains sitting like a cap upon the bell-shaped, closed portion of the seminal corpuscle. The thickness of the flocculent end of the seminal corpuscle now stands constantly in a corresponding relation to the opening of the vitelline membrane (Keber's micropyle), fixes itself to this and penetrates into it, during which the cap-like, revolute, cell-membrane becomes a preliminary adhesion of the seminal corpuscle to the egg, although the flocculent end of the scminal corpuscles is sufficient for the actual adhesive attachment to objects (as is proved, for in-

1 Amongst the seminal cells in the male generative organs, and, although rarely, in the lowest parts of the female organs, we find, together with the true seminal corpuscles, smaller oval corpuscles of $\frac{1}{2500}$ " in diameter, without distinct nuclei or nucleoli; they are pretty strongly refractive, have a smooth surface, and-except in the absence of the nucleolns-are tolerahly similar to the nuclei of the other original seminal cells. Bischoff, certainly erroneously, takes them for the true developed seminal corpuscles; Thomson, on the contrary, regards them as abortive corpuscles, which is more proJable. 
stance, by the seminal corpuscles sometimes attaching themselves with this end to the inner surface of the albuminigene), and therefore to the vitelline membrane and its micropyle, whilst the opposite smooth end of the seminal corpuscle can never effect any such adhesion. Such an egg, with its seminal corpuscle adhering to the micropyle, looks like a pear with a stalk, the latter being represented by the seminal corpuscle. At first, indeed, before the seminal corpuscle has fixed itself, only contact may take place. As soon as the flocculent end of the seminal corpuscle is firmly fixed in the micropyle, whilst the upper extremity still projects freely, movements may be detected in the egg which are communicated to it by the seminal corpuscle, whilst the further penetration of the seminal corpuscle into the interior of the egg, consists in a flowing in. Auxiliary momeuta in the advance of the seminal corpuscles towards the micropyle, are to be found in the direction of the micropyle within the albuminigene towards the tuba; the peristaltic motion of the tube, which may be seen very well, as I have already stated, in all parts of the egg-tube in Oxyuris vermicularis, and the action of the external muscular layer upon the albuminigene, and the movement thereby produced, so that the eggs gradually become rounded in the albuminigene. The entrance of the seminal corpuscle into the egg may take place pretty rapidly, for in the lower part of the albuminigene we usually find eggs with seminal corpuseles in the periphery of the yelk, between it and the vitelline membrane. The number of seminal corpuscles which enter varies; as many as ten of them have been observed in one egg. As soon as the seminal corpuscles have performed their function, they enter upon a retrograde development, namely, a gradual conversion into fat. This is the case, however, not only with those which are lucky enough to get into the eggs, but also with the great number of unemployed ones, which are thus again excluded from the female organs, and lastly, also with those which have missed their object by being prematurely developed, and remain in the testis or vesicula seminalis. The fatty metamorphosis shows itself in this manner: the outline of the bell-shaped portion of the seminal corpusele begins to grow sharper and darker, acquires a peculiar fatty lustre, lias greater refractive power, and a rounder form, whilst the lower extremity gradually contracts to form a simple, clavate, thickened end, having its nucleolar corpuscle in the middle, or the seminal 
corpuscle rescmbles a little bell, from which the clapper peeps out below. On the seminal corpuscles which have not reached an egg, the cell-membrane which partially covers the corpuscle is still well preserver, whilst the fatty metamorphosis goes forward in the other parts. In the seminal corpuscle penetrating into the egg, the cell-membrane does not appear to penetrate with it, but to remain upon the egg as an empty membrane. What becomes of the nucleolar corpuscle is unknown. The finely granular, flocculent mass, at the lower extremity of the seminal corpuscle, does not pass through the fatty metamorphosis, in which, however, the most important, and essentially fertilizing part of the seminal corpuscle participates. In this process the seminal corpuscles sometimes form elongated and narrow, and sometimes short, thick, and bacillar, strongly refractive corpuscles, both in the egg and the albuminigene, and at last become rounded off into oil-drops soluble in ether.

In animals in which the micropyle is rery small and narrow, the seminal corpuscles have a filiform shape in a state of maturity; this they sometimes acquire even within the testis, in which case the penis, like that of the Trematoda, forms a closed, hollow canal, but sometimes only after reaching the female sexual organs, when the penis is imperforate. Circumstances similar to the latter occur in the Mermides, which are nearly allied to the Nematodia. Here the seminal corpuscles have the appearance of a thin bent rod, which remains fast with one end in the derelopment-cell, and forms a sort of thick head upon the rod. If it loses this head, or if the latter remains seated outside the micropyle, the true seninal corpuscle can certainly reach the yelk through the micropyle. Whether similar processes take place in the human Nematodia is a question. The first kind of seminal corpuscle and the larger micropyle, are the usual forms amongst them, if not the ouly arrangements that occur.

When the egg is fecundated in the albuminigene by the entrance of the seminal corpuscle, and has gradually acquired a more distinctly ovoid form, it surrounds itself with the contents of the villi of the albuminigene, which solidify upon the vitelline membrane in constantly increasing layers. These tough, albuminous contents, which are set free by the bursting of the villi, do not mix immediately with water, and at first form clear reddish drops; afterwards they dissolve in water, and frequently 
also, as in Mermis, cake together in lumps. At first we only sec the external outline of the rounded egg, sharper and darker, and sometimes we may still detect the micropyle, which is frequently furnished with a vesicle, the remains of the membrane of the development-cell; the micropyle becomes closed by the thickening of the envelopes, and we observe that a pcculiar alteration commences in the interior of the yelk. The germinal vesicle has by this time disappeared; at the periphery of the vitellus there are structures resembling fat-drops. According to Meissner, these are the seminal corpuscles which have become converted into fatdrops, which, however, according to Thompson, is by no means proved, although he is not in a position to state what finally becomes of the seminal corpuscles. Thompson-who is very well acquainted with these clear, round or oval, strongly refracted globules, which are apparently surrounded by a peculiar membrane, but who could never detect their production from the conversion of seminal corpuscles-regards them as an indication of a change in the intimate constitution of the vitellus, which is in itself connected with fecundation. These (fat) globules afterwards fuse directly with the vitellus, which again changes its chemical nature, and loses its emulsion-like condition. From the vitelline granules which are particularly accumulated in the middle of the egg, very clear, reddish, shining drops issue, and attach themselves at its periphery like a wreath, and regularly, close to the vitelline membrane; processes which take place pretty rapidly. This gives the egg a spotted appearance, and Nelson calls it the spotted state of the vitellus. The vitelline granules dissolve, and the contents of the yelk are a pale yellowish mass, with a few larger and smaller granules, different from the previous vitelline granules. During the same period the whole mass constantly becomes more and more condensed; the periphery is coated with homogeneous contents; the yelk draws back from the vitelline membrane, diminishes in volume almost one half, and swims as a transparent mass in the interior. In this interval the egg has passed down into the uterus, and become enveloped by a chorion. At the same time small folds frequently appear in the vitelline membrane, which assumes the contour of the egg-envelopes. After this, a small clear space forms in the middle of the yelk, surrounded by gramules more densely pressed together at its edges, and with the appearance of this space (the first enbryonal cell, according to Kölliker,) commences 
the remarkable action of the segmentation of the yelk. This small space (first cmbryonal cell) passes through the process which has been represented by Bagge. It is only when the small, clear, central space lias divided itself into two parts, that the actual segmentation begins, the vitelline grains accumulating around the two small cells thus produced. But when once the clear centre in the egg is divided into two, then the first furrow is formed at the periphery of the yelk. Now the process goes on in the way deseribed by Bagge, Von Siebold, Kölliker, \&c. By this first furrow, two globules, similar both in size and colour, have been formed. In the middle of one of these globules, a small cell is now again produced in the first place, before any further division takes place, the globule itself becomes more densely crowded with granules, and darker and more opaque towards the margin. A new line of segmentation is produced in it, sometimes in the longitudinal axis, sometimes in a divergent direction, and by this means a new globule of segmentation. But before a further segmentation takes place in the globules formed, one or several of these clear central spaces are always first produced, and then only new lines of segmentation shoot up, and new globules are produced, which in their number exactly correspond with the number of the globules of segmentation just formed. To continue the first description, we observe that a new line of division immediately goes off obliquely from the second line towards the periphery, and consequently four globules of segmentation are produced. From this point onwards the strict order of the formation of new globules of segmentation in a progressively increasing series of numbers ceases; the globules of segmentation, which are pretty equal in size amongst themselves, become rounded off towards the periphery. At the same time, the globules constantly become smaller, more similar and numerous, by the progress of division, until in this way they have acquired the appearance of a mulberry. Upon this the globules arrange themselves into a beautiful and very regular oval, and almost all round this we perceive a light border between the globules of segmentation and the vitelline membrane. The oval then bends in the middle; the two poles (cephalic and caudal extremities) endeavour to approach each other, and the creature acquires the rough form of a worm without any internal structure. 'The two poles then pass by close to one another, and the cylindrical form of the embryo constantly becomes more dis- 
tinct, the formation of the future heal being always preceded by that of the candal extremity. With the extension in length, the thick club-like creature becomes constantly more slender, the globules smaller, the skin as if covered with graunles, the interior filled with similar globules, and, finally, a perfectly worm-like, moving creature, the perfectly formed embryo, is produced from it, which at last perforates the egg-shells (vitelline membrane and chorion), and then swims freely about upon the field of vision. In many species of worms, but not in all, the vitelline membrame is extended by the growth of the embryo, and with it the enveloping stratum of albumen and the chorion. How long a period clapses between the fecundation and this moment camnot be stated, but in many species the process is only concluded after a long time (in Ascaris lumbricoides about twelve months). 'The structure of the young worm, which resembles its parents, is usually very simple. We only observe a granular mass (remains of vitelline globules). The empty cosophagus, the interior of which is indicated by two lateral lines, with the appended empty stomach, the cavity of which is often triangular, and the first commencement of the intestine behind the stomach, can be distinctly recognised. The space from this to the eaudal extremity is filled with fine grains, and forms the foundation for the intestine. An anus is not yet visible; even the mouth appears still to be deficient at this period. In the round-worms furnished with weapons on the head, these organs are of course formed simultaneously, and are realy before the embryos quit the egg-shells and start on their migrations.

We might still mention here the question of the embryologists, whether the globules of segmentation just referred to, with the enclosed nucleated embryonal-cells, are to be regarded as compound cells, analogous to the ganglionic globules, or to the unfecundated egg, and to be explained in the manner of cellformation? Kölliker and others have shown that this is not the case, because the cell-formation always precedes the former as the causative momentum, although the enveloping of the embryonal cell with the yelk presents a very important momentum of development. According to Kölliker, therefore, we are compelled to suppose that the remarkable phenomenon which we call segmentation, is the expression of an attraction which is excrted by the embryonal cells upon the surrounding yelk-mass.

'The metamorphoses just described take place partly eren in 
the body of the mother (for example, in the Filarice), and partly outside the uterus of the female worm. The latter, again, may occur within the body of one and the same host, which may, probably, very seldom or perhaps never be the case; or, as usually happens, outside the body of the previous host in the open waters. That the latter is a very general occurrence we know from the investigations of Verloren and Richter.

In the early part of the month of August, 1853, Verloren put a fragment of a mature female Ascuris marginata of the dog into water, so as to preserve the eggs in the water by the prevention of evaporation. Of these he examined specimens from time to time under the microscope. The segmentation of the vitelli and the development of the young immediately commenced. In abont fourteen days the process was completed, and perfectly developed young worms made their appearance; these mored briskly within the egg-shells, but did not break through them, as Verloren expected, from similar successful experiments by Schubart. With the decrease of temperature towards autumn and winter, the mobility of the embryos within the eggshells also diminished, until at last it entirely ceased in the winter, but recommenced in the following spring, and again became very distinct in the summer months. During the whole course of the experiment a spontaneous exclusion of the embryos from the eggs never took place. In these eggs, therefore, the following remarkable peculiarities may be observed. The eggs of other animals may, inceed, lie for a long time before the young make their appearance; as, for example, in many insects, but this always takes place within a year; the eggs of many animals may also be delayed for a long time in their development, but then the development of the young cannot have commenced at all. But if this be once the case, and the young be developed, it must either be excluded soon, or it dies in a few days; whilst, in the present instance, the ready formed embryo lives more than a year in the egg-shell, like other worms in an encysted state, which live enclosed in their cyst. Both are, probably, enabled to live for a certain time unclanged in the egg-shells or cysts, both, as is well known, agreeing in bcing

1 Aanteelingen van het verhandelde in de vergarlering der Seotie voor Natur-en Geneskunde van het Provinciaal Utrechtseh Gcnootscliap van Kunstcn en Wetenschappen,--Gehonden den 9 Septembre, 1851. 
asexual, and therefore their species difficult to determine; this condition is only changed by other favorable circumstances, and the animals thereby carried on towards their development. Lastly, it is certain that the embryos of the nematode worms may pass the winter in a sort of torpid state in the open waters.

When Verloren set free the embryos artificially by crushing the eggs, they soon died, partly stifled by the fungoid structures growing about them, and partly from their becoming the seat of fungoid growths. ${ }^{1}$ Independently of Verloren's investigations, and at a period when the experiments of that savant could not have been known in Germany, II. E. Richter, of Dresden, had also put the eggrs of an Ascaris lumbricoides into water (on the 15th November, 1854). The eggs, which were all without living embryos, and which had not even exhibited globules of segmentation, were not examined by Richter for some time after their being placed in water; but ou the 15 th October, 1855, (consequently after the lapse of eleven months,) he found living embryos in all the eggs, of which he sent a considerable number to Haubner, Leuckart, and myself. These were employed in experiments, which unfortunately furnished no result.

When I examined dry eggs of the same worm, which Richter had sent to me, I had only the opportunity of confirming Richter's statement, that on the 15th November, 1854, the eggs had hardly commenced any development.

All this shows that a portion of the eggs of the nematode worms issues, in the first instance, passively from the borly of their previous host into the external world, and first of all passes the stage of its development, up to the formation of embryos, in the open water. The details with regard to the different species will be found in the following pages. Now according as the ready formed embryo is, or is not, furnished with a boring apparatus, will the mode of its migration vary. The unarmed species are,

1 I here pass over Verloren's other experiments. The attempt to rear freed embryos in meat or in bread and water always failed. Moreover, I see no reason why any growth should have been expected in this case. At the utmost, if they still exerter an active faculty, they might encyst themselves, when they would not lave hecome more highly developed, but would have been asexual in the manner of the Trichinc. $\Lambda$ tinal explanation of this subject can only be olstained by the administration of such eggs to various higher and lower animals. 
probably, contented with a passive migration from intestine to intestine, and it is, perhaps, sufficient for this purpose that the egg of a worm should pass out into the water, undergo segmentation, and form the embryo there, and that the cmbryo should be swallowed with drink, and become directly further and more highly developed in the intestine of its new host, which must usually belong to the same species as the previous host; but in the armed species, on the other hand, a mixed, passiveactive-passive, migration will take place. We may, perhaps, draw conclusions, per analogiam, as to the migration of the armed brood of nematode worms, from what has been said by Von Siebold with regard to the brood of Mermis albicans, and by Meissner, with regard to Gordius, and the destiny of the brood of these animals.

In the case of the so-called Filaria of insects, Von Siebold convinced himself these round-worms are no true Filaria, but that they belong to the peculiar genera of round-worms, which are usually called Gordius and Mermis. In their fully mature state they wander from their previous dwelling-place, and perforate the walls of the body of their host in any soft place, in the same way as the larva of the horse bot-fly, which finally quits the stomach and intestine of the horse, or in the manner of the larva of the gadflies, which, at a certain time, bore their way out of the cutaneous excrescences of cattle. A peculiar instinct impels them, in the perfectly developer but still asexual state, to such an emigration, in consequence of which they leave their previous dwelling-place for a new phase of existence, which brings them to their sexual developments, and we find them in the open water or in moist spots in the ground, in digging up beds, or making drains in the fields, or in drinking-water. Von Siebold then succeeded further in ascertaining how the immature but almost completely developed rorms taken out of the caterpillars of the small ermine moth (Tponomeuta evonymella), immediately burrowed with their heads into the moist earth of the flowerpot upon which they were laid, and in the course of the winter became sexually mature in this flowerpot, which was kept moist, developing eggs in their interior, which were afterwards deposited in the earth, to the number of many hundreds. In the first days of spring the embryos were completely developed in the interior of these eggs, and embryos, which had left their eggshells, were then soon found. When Von Siebold had noticed 
this, he took a number of very small caterpillars of the small ermine moth which had just been enticed out by the spring sun, and threw thirteen specimens of these caterpillars, which, as he had ascertained by the microscope, contained as yet no young thread-worms upon a watch-glass containing moist earth from the above-mentioned flowerpot, in which, as he had convinced himself, lively young of the matured thread-worm (Mermis albicans) occurred. In 18 hours 5 of these caterpillars contained embryos of Mermis. In a second experiment, made in the same way with 33 caterpillars, there were, in 24 hours, 14 individuals with embryos of Mermis; each of these caterpillars contained 1, and 2 of them even 3 embryos. In experiments made in the same way with the caterpillars of Pontia Cratcegi, Liparis chrysorrhea, and Gastropacha neustria, the same result also occurred. On the day after the experiment, embryos of Mermis were found in 10 out of 12 such caterpillars; 5 of them contained 2, and 1 even 3 embryos. (Vid. Von Siebold über die Band- und Blassenwürmer, nebst einer Einleitung über die Entstehung der Eingeweidewürmer, pp. 9-12.') Still more interesting are the results which Meissner has obtained with regard to the migrations of the Gordii, and from their importance in relation to the theory of the production of Trichnice, I shall refer to them further on. From what has just been said, and from what we shall mention hereafter, about the Trichince, we may certainly come to the conclusion, that " many Entozoa, and certainly those which remain parasitic in their last, i.e. sexually mature stage, do not migrate into the animal appointed for their habitation, in order to become further developed in it, until they have elsewhere attained a certain development and bulk." (Vid. Von Siebold, 1. c., p. 13.)

Amongst the round-worms of the human subject, the brood of Filaria medinensis may, perhaps, behave most like the Nematoida just referred to. It is true that in the other human Helmintha we have not yet seen an exclusion of the brood from the eggshells when laid in water: it is true that such an exclusion would be necessary if the brood of Filaria should enter the body, as is gencrally supposed, by adhering to the fect of those men or animals that wade in marshy or stagnant water; but we know, at least from Malgaigne and Robin, that the brood lives

I Translated into English, and published with this volunc.-[TısNs.] 
for several days in water, and that it may be dried up and again brought to life by water. Aeeordingly there would eertainly be a possibility of infection by direct immigration from without; but it is just as possible that the brood may only be set free after a passive immigration into the stomach of a liuman individual, and then bore onwards into the blood-vessels, and reach its future habitation through these.

With regard to the developmental history of the other species, we are still equally in the dark. The little that we know positively at present may be summed up as follows.

1. The Oxyurides (thread-worms) are apparently capable of an active migration, even when mature aud sexually developed; they prefer performing these migrations at night. Any one who inquires in his practice will hear his patients complain that little worms creep out of them by the anus, causing a violent itehing. Thus a shoemaker eame to me for advice, as the Oxyurides disturbed him at night. As soon as he went to bed and got warm, the Oxyurides began to mareh out of his anus, with violeut itehing, and wander about in the aual folds, and even, in his opinion, attempted to free themselves by biting. Once, when lie did not know what to do with himself, he wakened his wife and begged her to see whether she could not diseover what it was that troubled lim so much. By means of a light the woman found the little white worms, and picked them off, and sinee then, whenever he was again troubled, she always did him the same service. Moreover, that Oxyurides creep from the anus into the vagina, in little girls, is a fact known to the oldest surgeons. It may also be taken for granted that the worms found were females, and indeed pregnant females, as the males are far too small to be detected, although we may also suppose that the males may sometimes emigrate. However, the emigration of a single pregnant female is suffieient to explain the infection of whole families with Oxyurides. From what has just been said, the following hypothesis may be dedueed as to the aetive migration of mature females of Oxyuris from the intestine of one human being to that of another. The sleeping of a married couple, one of whom is affected with Oxyurides, in the same bed, which is especially the case amongst the poor who only possess one bed, the slceping of these parents with their chilaren, or of several ehildren together, one of which is troubled with Oxyurides, is 
sufficient to infect whole families with these worms. For if only a single female which emigrated at night, has wandered into the intestine of one of the bedfellows who lias litherto been free from Oxyurides, the perpetual infection is established in consequenee of the abundant reprodnetion of this parasite. In this process we have an analogue to the immigration of certain Cercaric, which, swimming freely in the water, creep directly into the reetum of the frog. What becomes of the young Oxyurides which pass out with the faces I know rot. After keeping the eggs for six months in water I could discover neither mature embryos, nor a distinct segmentation. I usually saw in the interior of the egg, at a considerable distance apart, two rather large hyaline globules, and round about finely granular detritus, and I do not know whether in this case there was a decomposition of the vitellus in accordance with the laws of putrefaction, or with those of development. The former appears to me most probable, and then perhaps the development of the embryos would only be able to take place in the animal borly with the aid of animal warmth.

2. The mode in which we beeome infeeted with Trichocephali may be the same as that by which, as we have already shown, the infection with Trenia solium is effected. That pigs contain Trichince exaetly like those of man, is evident from the observations of Leidy, in Philarlelphia, deseribed further on ; he has therefore given the name of Trichina affinis to the encysted round-worm discovered by him. We shall hereafter attempt to prove the probability of a relationship between Trichina spiralis and Trichocephalus dispar. It is therefore suffieient that we should eat raw "triehinous" pork, to bring Trichocephali upon us, and all that is necessary is to refer to the mode of infection with Tenia solium by the use of swine's flesh already indieated. Unfortunately the experiment of administration to dogs has not suceeded (vide infra), and it is also to be regretted that at present we possess no statisties as to the occurrenee and diffusion of the Trichocephali with reference to the trades and occupations of their human hosts. After preserving the eggs of Trichocephalus for six months in water, no cmbryos appeared, but ouly numerous, clear, but pretty regularly arranged globules, in the place of the vitellus, which eertainly presented the same appcarance as the processes in inc segmentation of the vitellus. 
3. The mode in which the liuman subject is infected with Trichina spiralis, from the preceding indications, must be analogous to what we have already stated with regard to the infection of man with Cysticercus cellulose. Here, also, we may suppose the following things to be possible. The most probable supposition is, that the female of the worm appertaining hereto (Trichocephalus) scatters her young in the intestine of her human host; and these, after escaping from the egg-shells, bore through the walls of the intestine, and further on through the borly, especially towards the primitive fasciculi of the muscles, where they encyst themselves, like the Cysticerci, being incapable of becoming developed immediately to mature worms (Trichocephalus) withiu the human intestine. In this case it would certainly be necessary that the embryo, which is to become a Trichina, should either possess a boring apparatus, or be capable of bringing its oral organs to a point in such a manner as to adapt it for boring. However, it is still an undecided question whether, with the brood of nematode worms, as with that of the Ccstoidea, it is necessary for further development, that the eggs, with their brood, must first have passed the stomach of a host.

Man might consequently swallow the brood of the species of worm belonging to Trichina (Trichocephalus) with drink; or, if the mature animal dwells in the human intestine, it might be carried back to the stomach by tendency to vomit, escape here, bore through the alimentary canal, and establish itself in the muscles of the body. From the great number of Trichina which occur, their introduction with drink is perhaps the least probable.

Whether the brood swims frecly in the water, and bores its way into the human body from without, is a question which may certainly be proposed, but which can hardly be answered in the affirmative.

In this way it would almost appear as if the immigration of at least some of the round worms inhabiting the human intestines takes place in the same manner as that of Trenia solium by the use of flesh which is impregnated with the immature germs of the roundworms in question, whilst the immigration of those which occur in the muscles is sometimes direct and active from the outside (Filaria medinensis), probably connected with the season of the year, and sometimes passing from the exterior (Trichina spiralis), 
or a self-infection, analogous to the infection of the sufferers from tapeworm with Cysticerci (Trichina spiralis).

4. In the examination of the question how we become infected with the different species of Strongylus, I find myself totally without data. I mentioned at the time, in Virchow and Reinliardt's 'Archiv.', that I had found in nodules of the lungs of the slieep the young of a nematode worm, which was probably that of a Strongylus, although I have not hitherto known how to apply this fact to the advancement of the question of the production of the species of Strongylus in the human body, especially those which occur in the kidneys or in the lungs.

5. With regard to the production of Ascaris lumbricoides also, we are destitute of any certain knowledge. "In Europe," says Bilharz, l. c., "as far as I remember, they ascribe the Ascarides and Oxyuri to bad flour and bread; and in Egypt the common people, who feed principally on regetables, and indeed for the most part on raw leaves and roots, are especially troubled with round-worms," whilst, for instance, in Egypt, the use of raw meat is correctly enough set down as being the cause of the production of tapeworm. How far this supposition is correct, or how far the infection in this case also is produced by the consumption of animal substances, is a question which still needs a close examination. Thus we might suppose, that small swails, caterpillars, larræ of insects, or small beetles and mature insects, may adhere to the leaves and roots which are eaten raw, and which creatures may harbour the progeny of round-worms, most probably in the encysted state. They thus get accidentally into the human intestinal canal with the raw leaves and roots, and there acquire a higher development. These worms would consequently reach man as a herbivorous animal, but only in the above-described, indirect, accidental way. In the retiology of the Ascarides, we must not forget, that the localitics in which they most generally occur, are usually moist low grounds. Thus the valleys of the Nile, in Egypt, as also the provinces Smaland, Halland, and Schonen, in Sweden, are favorite districts of the Ascarides, and are peculiarly moist coast districts. They are also found in Germany, in the neighbourhood of Zittau, which is exposed to the overflowings of the Neisse and Maudan, and in the vicinity of Glauchan (according to communications from Dr. Pause), which is subject to be overflowed by the Mulde. We have now, however, said all that can call for our attention here at present, and I only mention as a matter of curiosity that 
the youngest Ascaris lumbricoides which I have seen, is a specimen which I expelled from myself in July, 1853, in treatment for tapeworm, which is neverthcless nearly two inches long; of this I shall speak further on. Opinions, such as those expressed not long since by A. Benuchair and $P$. Vignier in the 'Gazette de Paris,' 1853, Nos. 29 and 30, are ccrtainly antiquated in Germany, and may be passed over in silence. The times are past in which the generatio equivoca made its appearance, with a peculiar predisposition to worms; although this view may hide itself behind an extremely plausible account of the remaining of the acids in the blood, the formation of neutral salts, dealkalization of the blood with production of weakness, and acid intestinal mucus, or behind fine-sounding theories of the actions of remedies. What is there positive in words like the following? "In the predisposition to worms, the thick mucus of the intestine comes under our consideration in the first place, as, being acid itself, it cannot purify the blood from acids. From a portion of the mucus the worms are produced by generatio aquivoca, with the assistance of asthenia and adynamia. The worms produced, as the analysis shows, are still more acid than the mucus, from which they are produced. Emetics, drastic purgatives, mercury, antimony, and arsenic, certainly kill the worms, but weaken the constitution, and thus actually rouse the generatio aquivoca into activity, and thus cause the formation of worms, \&c." This sample will suffice to show how little tenable there is in these last French attempts at the explanation of the mode of production of the Ascarides.

Unfortunately here we are not even assisted by Richter's experiments. By his means, indeed, we know that the eggs of Ascarides become further developed, free in the water, and that the embryo is formed here; but hitherto all administrations of these eggs to dogs, pigs, and other mammalia, have been unsuccessful. It is true that no human individual has been experimented on, and yet the direct transfer of the eggs with the embryos may be sufficient for the perfect derelopment of Ascaris lumbricoides in man. On the other hand, however, it is also possible that there is a previous migration through animals used as human food.

What more we have to say upon the round-worms in general, may be summed up in few words. The rest follows with the consideration of the species. The general cutaneous covering is 
a chitinous substance; the muscles are principally formed of longitudiual fibres, whilst transverse fibres are never wanting; the parenchyma appears to be rich in vacuoles, whence results the great inflation of these worms in water; on the sides there are sometimes a few longitudinal lines, upon the signification of which we shall speak under Oxyuris vermicularis; a nervous system certainly occurs in them, although it had hitherto been overlooked, and has recently been detected with certainty only in certain Oxyurides, and I believe I have found parts of it also in Trichocephalus; the alimentary canal is divided into a muscular cesophagus and stomach, a thin-walled intestine partly furnished with epithelium, and an anus; the sexual organs are divided between two different individuals; the orifice of the vagina lies rather anteriorly, and that of the male sexual organs more towards the posterior end. Peculiar clasping organs are found in the species of Strongylus. A ventral sucker, which occurs in certain Oxyurides, appears not to be possessed by $O$. vermicularis. The penis is sometimes simple, sometimes double, and sometimes lobed. It is not perforated, as in the Cestodea and Distoma, and if it had been perforated, it would have required a much greater lumen, and consequently a much greater calibre, on account of the nature of the spermatozon. For whilst, in the Distoma, for instance, the spermatozoa are always seen moving in the form of simple threads, in the Nematoida they are observed to be of a more or less globular form. To transfer these globular structures into the vagina, all that is required is a hollowed furrow, in which the seminal globule, if I may express myself so, rolls forward, just as the ball is rolled back in a skittle-alley, from the person who attends to the setting up of the skittles, to the players. In this it is of no consequence whether the ball runs on a furrow which is formed out of one piece, like the channel on the gable of a house, or between two longitudinal laths directed obliquely towards one another, but do not completely touch at their point of greatest convergence, as may be seen, for example, if we allow a billiard-ball to roll forward upon two cues, or in a furrow composed of several laths, placed together in such a way that they actually form an angular, but yet a nearly semicircular space, in which the ball rolls forwards. The first of these threc kinds of furrows occurs in the worms with a simple penis (Oxyuris, Trichocephalus); the second in those with a double, non-lobate penis (Ascaris and Filaria); and the third in the Strongyli and 
their allies. With regard, to the latter, however, I do not know whether each of the two lobate penes forms a furrow, or whether the two together only form a single furrow. From this it will be seen that in general I adopt Creplin's opinion, according to which the penis of the Nematoida acts in the same way as the ovipositor of many female insects. At the same time the penes appear of themselves to effect the dilatation of the vagina of the female, at least in soft-walled worms; the simple ones, which are conically pointed in front, but widened above and behind, must act in the same way as simple uterine specula; the double ones like Ricord's speculum, and the lobate ones like those furnished with several arms, such as that of Segalas. Sometimes, however, this action is effected by peculiar organs entering with the penis into the vagina, which we must certainly distinguish from sucking surfaces and structures like sucking lobes, and which we shall meet with and describe amongst the Tricocephali ${ }^{1}$ and also in the males of Oxyuris and Strongylus.

After this general introduction, I turn at once to the consideration of the particular species.

I. Trichocephalus. Synon.-Trichuris (Roederer); Ascaris (Linné); Mastigodes (Zeder).

The name of Trichocephalus proposed by Goeze in 1782 has since met with general acceptance, and Zeder's attempt in the year 1803 to substitute that of Mastigodes for it, must be regarded as a complete failure.

In Diesing's system, the Trichocephali are placed in the Subclassis I, Achethelmintha; Sectio II, Achath. elastica; Ordo VI, Nematoidea; Subordo II, Proctucha (ano instructa) ; 'Tribus III, Gamonematoidea (tractus cibarius proprius simplex liber; organa genitalia segregata); Sectio II, Acrophalli (penis in extremitate caudali e Jursa protractilis); Familia I, Trichotrachelidea (collum longissimum capillare; penis in vagina tubulosa); XLIII Trichocephalus. Dujardin treats of the Trichocephali in the first class, -Nematoidea, of which they form the sixth genus. The exact systematic description to be given, with the assistance of Diesing's and Dujardin's works, is as follows :

Corpus longissimum, ex 2 partibus formatum, quarum anterior, tenuior filiformis posterior crassa, organa sexualia continens.

I The corresponding auxiliary organ in Trichocephalus dispar is precisely like a thrcearmed uterine speculum. 
Mas : tenuior quam femina; penis simplex; organon copulatorium auxiliare spinosum, ex 3 branchiis compositum.

Femina: mare major et crassior; vagina musculosa in abdomine sese aperiens; uterus simplex; ovarium simplex. Animalia ovipara, vix aut rarissime vivipara.

Ovula oblonga, subfusca, in utroque extremitate collo quodam parvulo prominente ornata (en une sorte de goulot court, Dujardin).

1. Trichocephalus dispar, with its progeny known as Trichina spiralis (Owen and Luschka).

As we shall endeavour to show in what follows that the Trichocephali and Trichince are related together, we have first of all to indicate the various places in the system to which these two Entozoa are usually referred. Diesing in his 'System' treats of Trichocephalus dispar in the place just referred to,-XLIII, Trichocephalus, Species 1; and Dujardin, as Species 1 in his sixth genus. Trichina, however, is placed by Diesing in the Subordo II, Proctucha; Tribus II, Agamonematoidea (tractus cibarius proprizs simplex liber. Oryana genitalia nulla); IV, Trichina, Owen (corpus capillare teretiusculum), as No. 1, Trichina spiralis, whilst the meritorious Dujardin places it, and certainly with perfect justice, in his first appendix to the nematode worms (Nématö̈les vrais, qui ne peuvent être elassés surement dans les précéllentes sections des Nématöides), as a genus unprovided with a number. Although the conviction has been constantly gaining ground that the encysted, ascxual nematode worms are only the young of known species of Entozoa in course of migration (a circumstance entirely ignored by Diesing in his classification, which is founded rather on the external form than on the embryology and development), very few attempts have been made to arrange these asexual round-worms with their mature parents, or, to speak more correctly, to discover the mature parents of these nematode worms, and thus to free the classification of these Entozoa from unnecessary names, and entirely get rid of superfluous genera. The course to be adopted in this case is the same as that which we have already followed with the Cestodea, and which we have indicated as necessary to be followed with the Trematoda. In the attempt to 
get Trichina spiralis into its place, we have consequently three things to do.

Can we undertake such an arrangement-1, by a strict examination of the anatomical ${ }^{3}$ peculiarities in the structure of the worms to be compared; 2 , supported upon the administration of the living, encysted round-worms in question to different animals; and 3, supported upon a similar admiuistration of the mature eggs of eertain round-worms. In the present attempt at arranging the Trichine with the Trichocephali, I lave laid this triple course clearly before me, and followed the first and second of the paths indicated, but have been obliged to omit the third from want of material. As we shall see further on, the administration of Trichina spiralis to dogs led to no result, and I have at present to undertake this arrangement of the Trichina spiralis of Luschka and Owen with Trichocephalus dispar only upon the similarity of the anatomical structure. This being done, I must also at once bring together the synonyma of the two forms.

Synonyms of Trichocephalus dispar (Goeze).-D Trichuris (Roederer and Wagler, 1761, 1762; Wrisberg, 1767; Bloch, 1782; Lamarck, 1816, who calls the worm Trichure in the French, and Trichocephalus in the Latin text); Ascaris (Linné); Mastigodes (Zeder, 1803).

Synonym of Trichina.-Cysticerci species (Hilton); Filaria (of most authors).

Systematic description of Trichocephalus dispar.-Cutis transverse striata, marginales rugas ad anum versus magnitudine adductas exhibens. Caput 0.02 mill. latum, retractile, obtuso-acuminatum, interdum per parvâ papillá instructum. Fractus intestinalis constituitur ex osophago ab initio recto, angustissimo, paullo post toruloso, sensim per totum collum intumescente; ventriculus pyriformis, ad latera sua glandulas 2 perparvas aut appendices alosas aut nervorum ganglia gerens. Animalia facibus humanis pro nutrimento utentia. Mas: omnino colore clarior, fusco-albior; circiter 37 mill. longus (caput et collum 22; truncus aut abdomen 15); in trunco 0.5 mill.-1.0 mill. latus; formam spiralem amans. Testis et funiculus spermaticus simplex, ad intestini tenuis formam volutus; una cum tubo intestinali ante anum in cloacam communem apertus. Penis simplex; 3.35 mill. longus; 0.042 mill. ad $\epsilon x$ tremitatem infundibuliformem, 0.027 mill. ad apicem versus latus ; 
vayina levi cylindrica instructus. Extremitas caudalis organo copulatorio auxiliario, spinis armato, subcylindrico ormata, cujus longitudlo 0.151 mill. $=0.198^{\prime \prime \prime} P(t) .=0.203^{\prime \prime \prime} V$., latitudo in parte libera 0.090 mill. $=0.039^{\prime \prime \prime} P a r .=0.010^{\prime \prime \prime} V$., in parte opposita fere 0.049 mill. $=0.0216^{\prime \prime \prime} P .=0.022^{\prime \prime \prime} V$. est. Cloaca communis musculose in maribus longitudo circiter 4 mill. $=2^{\prime \prime \prime} P$.; latitudo 0.261 mill. $=0.116^{\prime \prime \prime} P .=0.119^{\prime \prime \prime} V_{.}$; latitudo foraminis cloace ipsius $=$ (the lumen of the canal formed by the cloaca) 0.130 mill. $=0.058^{\prime \prime \prime} P .=0.059^{\prime \prime \prime} V$. Spermatozoidlia globuliformia ad 50 mill. longa.

Femina: in trunco rectior, minus curvata, mare aliquid latior, minusque elasticu et flexibilis, abovulorum in utero et ovariis copiam, eaque de causa colore magis fusca; extremitate caudali obtuso acuminata.

Ovula fusca cum generis speciminibus; 0.054 mill. $=0.022^{\prime \prime \prime}$ $P$. et $V$. longa; media in parte 0.025 mill. $=0.0112^{\prime \prime \prime} P$. et $V$., in apicibus 0.01 mill. $=0.0018^{\prime \prime \prime} P$. et $V$. lata. Embryonum migrationes adhuc ignota. Verisimillimum est, Trichinas, quas dicerunt spirales, Trichocephali disparis embryones esse.

Description of Trichina spiralis : corpus plerumque in spiras 2 retortum, ad anum versuts crassius et obrotundatum, ad caput attenu. atum; tubus intestinalis, uti apud Trichoc. disparem, ab initio multifarie retortus, ventriculus pyriformis cum lateralibus 2 appendicis alosis (lobulis aut glandulis aut nervis), intestinum rectum post coarctationem quandam iterum incrassatum, rectâque viâ ad anum in extremitate posteriore eâque crassiore apertam profectum. Funiculus quidarn secandus in utraque extremitate cacus et semilunaris genitalium primordia format (?)

Longit. vesicularum $0.2-0.5-0 \cdot 7^{\prime \prime \prime}=0.4-1.0-1.5$ mill.; latiludo fere mediam partem exhibet.

Lonyitudo vermiculi ex cystide liberati et evoluti secundum, Luschka $\frac{1}{3}-\frac{1}{2}$ "' ; secundum meas mensuras $1 \cdot 115$ mill. $=0.50^{\prime \prime \prime}$ $P .=0.518^{\prime \prime \prime} V . ;$ latitudo in capitis apice 0.008 mill. $=0.0036^{\prime \prime \prime}$ $P .=0.0037^{\prime \prime \prime} V . ;$ latitulo extremitatis posterioris seu ani 0.024 mill. $=0.0108^{\prime \prime \prime} P .=0.111^{\prime \prime \prime} V$.

The Trichocephalus dispar was first discovered by Morgagni in the cacum and vermiform appendage of typhous patients, and is mentioned in his 'Epistolie Anatomica.' Subsequently, in the year 1761, it was found by a student of Göttingen, who regarded it as a young Ascaris lumbricoides, or a very largo Oxyuris vermicularis, although Roedercr aud Wagler immediately recognised 
it as a distinct worm, which they found abundantly in the epidemic "Morlus mucosus" observed by them, admitting it to be produced by generatio rquivoca during this disease, of which they regarded it as a pathognomonic indication. For a long time, indeed, it was supposed that this worm only existed in the intestinc of typhous patients, but it has now been found that it has no particular relation to any disorder of the human intestine. The physiological zoologist is compelled to conceive the affair in the following way. The dwelling place of our worm is the lowest region of the small intestine, near about the ileo-cacal valve, and the large intestine with its appendages; in short, that region of the intestine in which the chyme is just becoming of a rather thicker consistence. From the dingy colour of the worm, which is principally caused by its feeding upon human excrement, it probably escapes the eye of the observer in gencral, and is only detected with ease when the intestines are free from the thick, dark-coloured contents (the true refuse of the food).' This will be the case especially in disorders associated with diarrhœa of long duration, or with recent, violent, very watery diarrhœa. Thus probably it happened, that the worm was at first found only in typhus and typhoid disorders, whilst it was overlooked in the dysenteries accompanied by stagnation of the freces in the large intestine. But if we were to soften the contents of the large intestine in water, and pass the frecs thus softened through a fine sieve, as some people do in seeking for the heads of tape-worms after attempted cxpulsion, we should meet with the worm much more frequently. By a process of this kind we should also certainly convince ourselves that authors who say that these worms usually inhabit the human intestine only iu small numbers, or even singly, are very much in the wrong, and that the numbers found by dissection are usually so small only because the diarrhœa has already remored most of the worms, and only the stragglers, certainly the most vigorous marauders of the troop, are still to be found. Moreover, cases are known in which the Trichocephali were found in considerable number. Thus, even Rudolphi says, "Trichocephalus dispar in 7ominis caco et colo vulyatissimus, in tenuibus rarior," and further, in the third observation, "in omnibus fere cadaveribus humanis a me examinatis offendi Trichocephalos, semel ultra 1000 specimina in femince intestinis crassis vidi." Bellingham also once found 119 specimens in the cæcum alone of an individual in Dublin. 
This worm has been found in Europe and Africa in children and adults, and probably occurs also in other parts of the world.

Anatomy and physiology of the worm.--Of the form of the body we shall speak presently; we commence with the skin. In both males and females it consists of transverse rings (Werll) passing into each other, which are formed of the well-known chitinous substance, colourless, and, to a eertain extent, elastic. On the free margins these arc somewhat pointed, or appear rather rounded when seen from the surface, by which the worm acquires sometimes a morc undulated, sometimes a more serrated appearance. Moreover, fine, small elevations, sometimes round (like warts), sometimes acute (like spines), run round the animal upon the epidermis, which Wedl has indicated in his figure $191 \mathrm{~h}$, and which I also think I have seen in some specimens, especially on the anterior part of the borly, but which I have omitted to figure, both on account of their indistinctness, and because they would easily have destroyed the clearness and intelligibility of the figure. As far as I could make out, these little warts and spines are only retained in patches upon the worm, and very readily fall off from spaces of considerable extent. However, any one can easily form an idea of them for himself, if he imagines the whole body covered with the same coat of hooklets, which we find upon the copulatory organ of the male. Here they remain longest, and perhaps are more persistent in this part because this organ is retractile, and therefore much less exposed to external friction, \&c., than the general epidermis of the animal. IIere, thercfore, we have an analogue of what we have seen in the Trematoda, when speaking of the penis of Distoma hepaticum.

In treating of the skin we have still to speak of the longitudinal streak which runs down on each side of the worm, and which is particularly distinct upon the anterior part of the body, but is also present upon the abdomen, and which has had very various significations given to it by different author's. Dujardin refers to it in these words: "Tégument strié transversalement, avec une bande longitudinale hérissée de petites papilles." The little papillac are an attribute of the entire skin, as we have seen; but certainly, by their falling off in groups, may also occur in band-like streaks. Wedl speaks of a band-like streak, and inquires whether it is not a structureless layer. In my opinion this streak is nothing but an optical plıcuomenon, caused 
by the cessation, at this spot, of the parenchymatous contents of the animal (intestine and muscles), and the rapid approximation of the two empty layers of the epidermis of the animal. As the worm is round, and a small space still remains between the completc fusion and the closest possible approximation of the lamellæ of the skin, and the shadows of these two lines do not fall exactly in one level, the whole presents the appearance of a band. If, as appears to be the case, Wedl intended something of this kind by the expression "structureless layer," I perfectly agree with him in his opinion.

Body.-As the Trichosoma consist of a thin filiform, and thick, catgut-like portion, so also do the Trichocephali, only that in the former the anterior, and in the latter the posterior, part of the borly is the thickest. Only the mature females are distinguished by their external form from the males. Thus, the male coils up both the anterior part of the body and the abdomen in spiral turns, in the same way as the other nematode worms. Hence we always meet with the male more or less in the form of a spiral or of a repeatedly twisted cord. It would be difficult to judge from this how the worm could have been characterised by the name of whip-worm (Peitschenwurm), if we were not obliged to admit that this name is very suitable to the females, and these, being larger, were probably first discovered. Thus the abdomen of the latter may be very well compared to the straight, thick, stiff, short, stick or stem of a whip, to which the slender body is attached like the lash of the whip (as in a dog-whip or sledge-whip). The anterior thinner part presents no further differences in the males and females. The head is pointed towards its anterior extremity, but always terminates somewhat flattened. Even when the worm is treated with white of egg, and in fluids whose contact with the worm does not usually cause the emission of sarcode globules, we often perceire, at the extreme tip of the head, the protrusion of a small, hyaline, onion-like structure, which passes off in an obtusely conical form anteriorly, and which I rarely saw wanting. This appears to me to show that we have to do in this case with a peculiar structure, capable of eversion and inversion, belonging to the worm, and not with a drop of sarcode. This apex of the head of the worm is perforated by a mouth, which is followed by a long, straight, rather cleft-like apparatus. After running about $0.8 \mathrm{mill} .=0.4^{\prime \prime \prime}$ in the male, the digestive apparatus becomes enlarged, and forms very narrow dilatations and constric- 
tions on the sides. This latter at least takes place, undoubtedly, in the portion of the intestinal canal which is situated more towards the end of the so-called neck; previously, and in the anterior part of the neck, a similar arrangement seems rather to be apparent; and the similar appearance seems to be produced by the narrow intestinal canal forming very narrow turus from one side to the other. The further the intestinal canal proceeds backwards, the broader and thicker does it become, until at the point where the anterior part of the body passes into the abdomen it is again narrowed to a slender thread. At the sides of the whole of this region of the intestine there is a tolerably evident layer of muscles or contractile parenchyma, which penetrates into all the vacuities of the convolutions of the alimentary canal, and forms a mass of small triangles, with their apices turned towards the intestine, and the apices of which appear, as it were, to hold the alimentary apparatus stretched towards the sides. At the base of the hindmost dilatation of the alimentary apparatus in the anterior part of the hody, and at the place where this passes into the above-mentioned thin thread which leads to the pyriform stomach, there are two wing-like appendages directed forwards, which in general are of a much lighter yellowish colour than the alimentary canal itself, and which appear, in Trichina spiralis, to turn back again. I regarded these as glands, or small creca, or appendages of the alimentary canal, but have become doubtful of the correctness of this interpretation, since I have been acquainted with Walter's investigation of the nerrous system of Oxyuris. They may, perhaps, be portions of the œoshageal ring which occurs in the Nematoida. Unfortunately, I have had no opportunity of examining fresh Trichocephali with this view, so that I must leave the signification of these wings an open question. The inner wall of this entire apparatus appears to be clothed with a round, granular, sparing epithelium, which, however, Wedl regards as verruciform elevations, and therefore as a kind of gland or villi, looking towards the lumen of the alimentary canal. This part is followed by the pyriform stomach. At this point, also, the thin anterior body ceases, and with the point where the stomach is found we arrive at the point of transition of the anterior part of the body (collum) into the abdomen (truncus, abdomen), which there presents essential differences in the two sexes, which are well worth close attention. Upon the pyriform dilatation of the stomach follows, first of all, 
in both sexes, a narrow, short tube; whicl, however, very soon acquires a greater diameter, so that the intestine in these places is about 0.2 mill. in brearltli. Ili the male, the intestine then runs down in a tolerably straight, or, at the utmost, simply contorted course, and with its diameter remaining nearly the same, on the inner side of the worm; that is to say, on the side towards which the caudal extremity of the male bends round. About the point where the penultimate third of the abdomen passes over into the list third, this intestine again narrows itself into a very thin tube, which runs obliquely across the worm as far as a little beyond the middle, and near to the onter sirle, where it opens and projects a considerable piece into a large, strongly muscular, tubular sac, near a second canal, which is also very narrow, and runs more directly dowwwards. The two narrow canals are closed at their points of opening into the large muscular sac, with loop-like or valvular contrivances, by which the retrogression of the contents of the large sac into the canals opening into it, is certainly prevented. This muscular sac forms an apparatus which serves the male sex as a common cloaca and seminal efferent luct, of which we shall speak again under the sexual organs. In the male, consequently, the intestinal canal ceases some distance before the caudal extremity, and the excrements pass out through the cloaca just mentioned. In the female the intestine runs in simple contortions, directly, and in a straight line, into the anus, and is of the same calibre througliout as far as the anus itself, which usually presents the appearance of a cleft, produced by the assistance of muscles or contractile tissue occurring in that place.

The sexual apparatus of the male consists of a simple penis, a funiculus spermaticus or testicle which opens into the abovementioned tubular sac, and an appendix copulatorius. I was unable to find the commencement of the organ which forms the semen, as it conceals itself behind the penis and the common sac just referred to; and I could not follow it any further than to the point indicated on Pl. VII, fig. 1 , between $i, k$, and $e$, which, however, we may perhaps consider as the blind extremity of the testicle. From this point the organ for the preparation of the semen rises upwards, gradually becoming wider behind, and beneath, and close to the intestinal canal, in undulatory curves, up to the short, canallike, contracted part of the intestine, which lies between the anterior extremity of the stomach and the creal, yellow appendages 
of the last intestinal convolution of the narrow anterior part of the body. Here the seminiferous organ bends round in a loop, passes over the intestine towards the other sile of the worm, and then runs downwaris for a considerable space, with its margins mululated, and at its broadest places is about twice as thick as the intestine, or abont 0.4 mill. Afterwards, at the same turn in which the intestine of the male was described as becoming narrower, this seminiferous organ contracts into a very short, narrow, straight tube, which opens into the dilated, muscular cloaca, with tolerably thick uniform walls, close to the portion of the intestiue already referred to, and is also closed with a valve at this point. This diseharging canal of the testis, or funiculus spermaticus, appears to be the same part which Wedl figures as the crecum-like commencement of the testis. As the walls are thicker here, and therefore the interior of the canal, when empty, must be distinguished more clearly, and by its paler colour, it is easily explained how Wedl was deluded into supposing that these pale lines were the efferent ducts of the cxcal testicle, whilst they are nothing but the simple lumen of the anterior extremity of the long testis, which opens by an efferent duct, overlooked by Wedl, into the tubular sac serving as a common efferent canal for the excrement and semen. The seminal elements themselves are quite correctly described by Wedl, and consist of a granular mass provided with light, round bodies (the ringed spermatozoa, or, more correctly, the seminal globules of the nematode worms); they may be very distinctly traced into the sac just described as serving in common for the cloaca and sexual apparatús. About at the same level where this repeatedly mentioned, thick-walled cloacal tube commences with a knoblued dilatation, or a little more anteriorly, originate, on the inmer side of the wall, two band-like, clastic stripes or bands, which in a short time unite into a sort of light case or tube, which receives the penis in its interior (the retractile sheath of the penis). The penis itself is simple, enlarged in the form of a funnel at its root, becoming constantly more and more pointed towards its free extremity, where it terminates in a bluntly rounded point, like the end of a hollow sound, and it is hollowed out throughout its course in the same way. The sheath of the penis just deseribed opens into the lowest third of the cloaca, so often referred to, by penetrating through that wall of the cloaea which is turned towards the side of the worm designated as the inner side, 
and the walls of the sheath appear to coalcsce with the wall of the eloaca just mentioned. The elastic sheath of the penis, formed, as already remarked, of elastic bands, by its contractility cnables the penis to project or retreat into the cloaca. It appears to me to be most probable that during coition the infundibuliform root of the penis itself is pushed forward to the point at which the above-mentioned elastic envelope of the penis opens into the eloaca, and at this point takes up the seminal filaments or globules, which are then conducted forward to the vagina in the furrow of the penis. The kind of mechanism by which the transfer of the scminal globules to the female vagina is effected has already been referred to.

In the act of copulation, the male is assisted not only by the possibility of bending his caudal extremity into a semicircular form, and thus embracing the female, but also by the existence at the very extremity of the cloaca, of a cylindrical protrusible and retractile appendage, which is certainly intended to enter the vagina. This appendage (bur'sa, gaine renflée ou vésiculeuse of authors) forms a tube, the basal substance of which is the general skin of the body. On its surface it possesses small warts or spines, which have already been mentioned under the general integument, which liave their points directed upwards and outwards, and certainly assist in the fixation of the male in the vagina of the female during copulation, and remain longest upon this part of the body without falling off, because this tube itself being retractile within the abdomen of the male, and on the whole but rarely used, is less exposed to mechanical injury or friction from without. This appendage, moreover, has several excisions at its extremity, by which the whole acquires an appearance as though it were composed of several branches, which separate in a gaping manner at their free end. I can compare this appearance with nothing better than with that of the anterior extremity of an expanded uterine speculum with several arms. The number of branches formed by these tubes, is not so easily ascertained; there are certainly three, if not four, which I have several times thought I counted. By this structure also the act of copulation itself is essentially assisted and facilitated. Thus, in the first place, the free ends of the tube must lie together in the form of a cone, and open the somewhat thick-walled rigid vagina. As soon as the tube enters the vagina, the branches probably separate; and, as it were, throw themselves outwards, 
like the tips of the branches of a Ricord's nterine speculum, by which the vagina is liept expanded and the entrance of the penis is reudered possible; this, from its small diameter, certainly requiring a means of support dluring its stay in the vagina. This tube can never act as a sucking apparatus for adhesion.

With this we quit the description of the male, and beg the reader to compare Pl. VII, figs. 1 and $1^{\prime}$. The serrated denticulation of the lateral walls is omitted; compare the female, fig. 2 .

In the female the intestine, after it has become widened again suddenly behind that contraction which follows upon the portion of the intestine which is furnished with ceca, runs in the form of a strong tubular sac, entirely or partially covered by the oviferous orgaus, and remaining tolerably straight, and of nearly the same diameter, directly to the extremity of the abdomen, when it becomes narrowed into the form of a cleft, by a muscular closing apparatus a little way from the caudal extremity ; but at its point of issue forms a tolerably broad anus, appearing as a circular orifice, which projects in a verrucose, nearly square excrescence in the centre of the extremity of the abdomen.

The disentanglement of the finest terminations of the female sexual apparatus is a matter of great difficulty, but the following may be detected witl ease.

Between the little creca above-mentioned and the anterior end of the pyriform stomach, in the same place where the seminiferous organ of the male bends over from the inner side outwards, a twisted, tolerably thick tube runs directly over the intestine, transversely towards one side (the onter side) of the worm, where it opens with an orifice of about 0.08 mill. $=0.036^{\prime \prime}$ Par. $=0.037^{\prime \prime \prime} \mathrm{V}$. in diameter in the lumen. The vagina possesses no appendage projecting outwards, as is the case, for example, in the vagina of many Trichosoma. This is the opening of the vagina. Its commencement quickly makes some narrow convolutions of equal calibre posteriorly, and then becomes dilated into a pretty large, simple, uteriue, tubular sac, which runs straight backwards immediately upon and over the intestine, and which after it has passed through about six-sevenths of the length of the entire abdomen of the worm, turns back upon itself and runs forward, then again backward, and still nearer to the anus, without, however, quite reaching it, rums back, coiled and complicated in convolutions, which gradually become 
thinner, passing in the most various dircetions, sometimes formard, sometimes backward, up to the level of the raginal opening, and thence again runs backward, and also passes once more to the other side orer the contracted part of the intestine already referred to. At this spot the tube has already become very thin and filiform, but its finer extremity can be traced no further. The convolutions last described form the orary, and as far as they could be traced, they only present the same phenomena as those of the other nematode worms, of which we sliall speak further under the Strongyli. I shall only add a few worrls upon the eggs themselves. The eggs of both kinds of worms have an external, brownish, tolerably thick shell, distinctly bordered by two outlines, of a longish oral form, or more correctly of the form of a small longish cask, or of a large fish-basket. This shell, lowever, does not reach to the poles of the oval, but ceases a little from the commencement of these, and from the poles of the egg protrudes a small, light, wart-like body of a roundish shape, which forms, as it were, a sort of cap on the poles. Dujardin says of these eggs :- "Les œufs d'une forme oblongue sont revêtus d'une coque résistante, qui se prolonge aux deux extrémités en une sorte de goulot court, ì travers lequel la membrane interne plus diaphane paraît faire saillie." Mayer has described this little cap under the name of a "short diverticulum," and this certainly depends upon the formation of the eggs in the fleshy oviduct. They contain sometimes only relk in course of segmentation, sometimes ready formed, joung embryos. The fate of these eggs, with the brood, is undoubtedly to pass outwards, then either to be swallowed probably by various species of animals, which man employs as food, in the bodies of which the brood then migrates onward, and fixing itself in their muscular layers becomes encysted there, or perhaps also to wander directly from without into the bodies of their hosts, which, however, appears very improbable to me. That eren this question will be cleared up in time by experiment, I am firmly convinced, and $\mathrm{I}$ only regret that, from want of material, it has hitherto been impossible for me to administer the mature eggs of Trichocephali. Perhaps my request expressed in letters to the Imperial Medical Society of Vienna, and to two of the most celebrated German pathological and physiological anatomists, to undertake experiments of this kind, may hare a result. In the institution of experiments of this kind, I had 
originally the dog in my eye, but perlaps wrongly, as this animal appears to be better adapted to further the development of certain further advanced, encysted, but still immature entozoa in his intestine, than to produce the encysted forms from the embryos which have migrated through the walls of his intestiual canal. I advise any one who may have the means for this experiment at command, to make it upon sheep, rabbits, or, above all, upon pigs. For without at all believing that all the hitherto discovered, encysted, immature nematode worms belong to one and the same species, I think that Diesing's Trichina affinis, which Leidy found in Philadelphia in the extensors of the thighs of a pig, and which can scarcely be said to be larger, may be irlentical with our T. spiralis. For this reason, therefore, I advise the administration of the cggs of Trichocephalus dispar to the pig, which is moreover the victim of a Trichocephalus within its intestine, which we know as $T$. affinis, and which is regarded by many as identical with $T$. dispar.

This last announcement of the occurrence of Trichina affinis in the flesh of the pig, however, gives us a hint as to how man may possibly infect himself with Trichocephalus dispar. This wonld take place in the same way as we have described under Trenia solium; that is to say, by the consumption of pork which is beset with Trichince. Upon the unsuccessful expcriments in the administration of the true Trichina spiralis to dogs, the reader may consult the following remarks.

Trichina spiralis, Owen and Luschka, as the brood of Trichocephalus dispar engaged in migration. (Pl. VII, figs, 5-8.)

This asexual worm, first deseribed by Owen in 1835, was first seen, according to Diesing, by Tiedemann in the year 1822, at least he first found the cysts of the worm. Subsequently, the worm was seeu by Hilton and Wormald in 1833, by Paget and Knox, and also by Kobelt and Bischoff in 1841, and in Denmark by Mönster and Svitzer in 1813. In Germany it has been seen and described repeatedly. But, nevertheless, the descriptions of the worm have been very imperfect, mintil that given by Luschka and Herbst in 1851. Luschka's anatomical 
description, with the exception of a few small errors, leaves little to be added, for which reason we shall here examine the worm, its mode of life, and its other peculiarities, in accordance with Lusclika's communications in the third volume of Siebold and Kölliker's 'Zeitschrift fül Wissenschaftliche Zoologie,' pp. 69-79, at the same time making use of the facts demoustrated by Meissner with regard to the migration of the joung of the Gordii in the seventh rolume of the same journal, and also weaving in our somewhat differcnt views as to the structure, mode of immigration and derivation of Tricline. The seat of the worm is, as is weil known, the muscles of roluntary motion, and it is sometimes so diffused in these, that cren the smallest muscles, such as those of the tympanum, the interna! muscles of the laryux, of the eye, and of the tongue, the muscular fibres of the alimentary canal down to its middle, the diaphragm, the constrictor cunni, the sphincter ani intermus, \&c., are not spared. In the heart and the sphincter ani externus, however, no traces of this worm have yet becn found. The muscles inhabited by Trichina are, as it were, found thronghout, both on the surface and in their depths, with small, dingy-white granules, resembling grains of sand. The arrangement of the capsules of the worms within the muscular tissue is irregular; sometimes they lie in groups, sometimes singly, sometimes arranged in a line one belind the other, but do not nsually touch each other with their ends, as both Luschka and I can prove, although this contact, described by Owen, may easily take place in other cases. In the places where the capsules of Trichina are seated, fatty tissue is constantly inserted, and indeed, generally at their anterior and posterior extremities; this, which is collected together in large globules or cells, is placed about the Trichine which occur singly, in such a manner that the layer of fat is thickest in the neighbourhood of the ends of the capsule, but thence gradually diminishes in a conical form towards the surrounding spot of muscle which has remained free from Trichina, so that we see distinctly that the fat is only deposited to fill up the space which must necessarily be produced after the Trichina has penetrated between a couple of muscular fibres, and pressed these apart. A discoloration of the muscle inclining towards a pale red, or a greater degree of softness, can hardly be a consequence of the worm itself. In Luschka's 
case, for instance, even the muscle of the heart, which was free from Trichinc, was tender and exhibited fatty degeneration, and in other muscles also entire moniliform longitudinal series of fatty vesicles were deposited. Such phenomena are to be ascribed to accompanying discases, as in Lusehka's case to dyscrasia alcoholica, and at present we do not know at all whether any particular texture of the muscles preeminently disposes them for the flourishing of Trichina. The development itself may be as follows: When a human being swallows in any way the eggs or the youngest brood developed into ready-formed embryos which occur in the eggs, or perhaps also when any female Trichocephali residing in the small intestine of a man scatter their eggs with the ready-formed embryos in them, which may not be of very rare occurrence, within the human small intestine, and also probably as far as the stomach, and when in either case the egg-shells are burst and the embryos set free in the intestinal canal, the desire of migration proper to them awakens in them, and they set out, like the embryos of many other Nematoida, in the shortest and easiest way towards the part of the tissues which they particularly prefer as their dwelling place. Whilst the brood of the Gordiacea, which are deposited in the water, free themselves from their egg-shells, according to Meissner, by boring through it with their twelve hooklets, and then pierce directly through the articulating membrane of the tarsi of the larve of Ephemera during the night into the feet of the latter, and then advance between the primitive fasciculi of the muscles through the foot into the body; in the case of those young round worms, whose brood is neither deposited in the water nor escapes there, but which reach the intestinal canal in the interior of their cgy-shells, the bursting of the latter may take place with the assistance of the digestive process, and then the migration may go on through the thin walls of the intestinal canal, and they further advance in the body, by pushing forward between the displaced muscular fibres. That in this case, as in that of the Cestodea, the intestinal canal may furnish a point of immigration from the exterior, is best shown by the fact that the muscles of the tongue, pharynx, and cosophagus, as well as the Sphincter ani internus, are visited by the Trichince. In some cases also the blood may be the bcarer of the migrating brood. Meissuer not unfrequently found the young within the blood-vascular system, and, for example, often attached to the inner walls of the 
heart, and once even to a valve of the dorsal ressel, so that the little animal was shaken to and fro with the ralve, and in the same way Leuckart, according to communications by letter, has also found the brood of the cestorle worms so abundantly in blood-vessels that he thinks the blood is the most usual course of migration, and furnishes the readiest explanation of the widely diffused occurrence of analogous grades of development of other parasites in the same body. For my own part, I believe that both courses of migration are followed simultaneously, but I do not venture to give an opinion as to the greater frequency of one or the other. With regard to the possibility of a self-infection in the case of those who harbour Trichocephalus dispar, the rearler may compare what has been said respecting self-infection with Cysticercus cellulosa. But however this may be, after the immigration, which may certainly often occur in this manner that a second, third, \&c., embryo follows the line of march struck out by its predecessor and remains stationary behind it (linear arrangement) or in its neighbourhood (arrangement in groups), the further process is certainly the following, with which we have alrearly become acquainted amongst the Cesiodea, and which Meissner has distinctly traced in the larva of Ephemera. When the embryos of the Gordiacea reach a spot which they recoguise as suitable, they resign themselves to repose, lie still, contract their head and proboscis, bend the abdomen again sharply round, so that the caudal extremity comes to lie close to the anterior extremity, without presenting any new organ, or throwing off any other, and then surround themselves closely with a clear thin wall, sharply limited externally and produced by secretion from the Gordius itself, whilst the muscular fasciculus surrounding it loses its structure, and a granular, fragmentary mass lies around it, frequently also indicating the way by which the Gordius came; or in other parts of the body, the host forms a cyst closely adherent to his tissues, consisting of concentric layers of a fibrous or lamellar substance with imberlded cell-nuclei. The processes in the encystation of the Trictince may take place in this last-mentioned manner. 'The brood, when it has arrived at the desired place, comes to at state of repose, approximates the head and caudal extremity in spiral turus, without however contracting a part of the head, and is then perhaps surrounded even on the part of the worm with a peculiar layer, but certainly enveloped, on the part of the lost, 
with a capsule and cyst in which the worm increases in size to a certain extent, and besides the intestinal canal, developes the primitive foundations of an organ which we shall hereafter find to belong to the generative apparatus. In this case also no organ of the worm is cast off in the metamorphosis, as is the case, for example, in the Cercaria. The structure of the cnveloping membranes of the young Trichine which occur in the muscles of the human subject has not yet been observed, but from what Meissner says on this subject and what we know of the Cestoidea, we may certainly draw some definite conclusions. The immigration itself will hardly take place without inflammation of the tissues passed through, to which the human organism answers by exudation, which also furnishes the material for the capsule enveloping the Trichina, of which, making use of Luschka, we give the following description :

The cyst, which varies greatly in dimensions (on an average 0.32 mill. in length and 0.038 mill. in transverse diameter), is sometimes oval, sometines circular, sometimes cxhibiting elongated extremities on both sides, sometimes only at one cnd. In Luschka's case the latter formations were extremely rare, and the oval forms were the most common; by other authors, those with a process on one side are said to be the more ordinary forms, and these were also the most abundant in the case observed by Zenker, and presented to me to make use of, and indeed so abundant, that Zenker in sending me the fresh muscle with Trichince, called my attention at once to this variation from Lusehka's observation. Besides the forms with a process on one side, I also had the opportumity of detecting processes on both sides. Luschka very rarely found tubular or gourd-like cysts.

According to the time which has elapsed sinco the immigration, the cysts are sometimes transparent and sometimes opaque, and then white by reflected and dark by transmitted light, rich in sharply defined, larger and smaller elementary granules, which are placed more or less close together, always less close towards the periphery (lcaving lighter spots and a lighter periphery of 0.024 mill. in breadth), and which give the capsule a tolerably rigid texture, so that it grates when eut. 'These structures, which imitate the form of the elementary granules, are probably nothing but carbonate of lime, or lime salts combined with an organic substance. That this deposition of lime salts in the walls of the eysts increases with the time which has elapsed 
between the immigration and the moment of dissection, must be self evident; however, it is also to be observed, that the deposition of the lime salts depends also upon the age of the host. 'Thus, for cxample, in Zenker's case, which was also investigated by me, the cysts were firm, but in general very transparent, the patient was of middle age; in Luschka's case all were calcified, the patient being about eighty years old. But if once the calcareous deposition referred to las taken place towards the walls of the cysts, no transparency can be produced cither by solution of potash or acetic acid, nor any change by boiling with ether, or keeping in that fluid. The addition of concentrated muriatic acid, however, appears to reestablish the solubility of the carbonate of lime by the destruction of the organic compounds, as, after the application of this, abundant air-bladders are, erolver, and even the darkest cysts become clear and transparent, and allow the worm to be perceived in their interior.

According to Luschka the cyst of Trichina exhibits two layers, different both in their composition and signification. "The outer layer, which especially determines the form of the cyst, where peculiar processes exist, forms these as solid prolongations, into which the inner envelope is rarely continued and only in cases of great dilatation. The tissne consists of irregularly arranged, very fine fibres, which, crossing each other repeatedly, form a narrow-meshed net, and behave towards caustic potash and acetic acid like ligamentous tissue, except that the fibres do not entirely disappear, but offer a partial resistance." The last circumstance was referred by Luschka, in 185̃ l, to the age of the particular fibres; but according to his more recent, admirable inrestigations, we see in this reaction a proof that in this case we have to do with the same fundamental formative material, which we also meet with in the cysts of the Cestoidea, that is to say, "protoplastic fibres of the cellular tissue," to which Luschka, before he was aware of their mode of production and nature, had given the name of serous fibres, and to which I also, following Luschka, gave the same name, in my book upon "the Cestoidea in general and those of man in particular." A true lamellar structure cannot be recognised in this layer, although it can be broken up into separate band-like structures. In older cysts it is difficult, in young ones easy, to bring the inner layer into view, after tearing the outer one. The outer envelope is at the same time the bearer of a very distinct 
vascular net, which may be particularly well traced by direct light, and which probably effects the conveyance of nutriment less by direct transudation, than by similar processes to those with which we have become acquainted amongst the encysted brood of the Trenice.

The inner, nearly homogeneous, or but sparingly fibrous or granular layer, which is always roundish, resists the action of caustic potash, acetic acid, and muriatic acid; it is very rich in calcareous corpuscles, and belongs rather to the Trichina itself, but is probably rather agglutinated, than truly coalescent with the outer envelope, as may be seen from perpendicular sections which show a distinct separation of the lwo layers, and from their partial separation in consequence of treatment with muriatic acid. That this enveloping layer is derived from the animal itself, I am, for my own part, as firmly convinced as Luschka, and I only regret that $I$ could not detect the same in those capsules of Trichine which enclose two or more worms in common, that Meissner has done for analogous cysts of Gordii with twins. Thus, according to the latter, each young Gordius is enclosed in a cyst formed by the worm itself, within the cyst formed by the liost. In Meissner's fig. 36, Pl. VII, we distinctly recognise the outlines of these separate envelopes formed by the worm, especially at the spots between the two worms where these cysts cover each other. Perhaps it is owing to my clumsiness that I could not find these separate cysts, and others will perhaps succecd in furnishing this proof; or they may not exist at all or at any time in this Trichina, or, lastly, they may be absorbed again in the places between the worms, in most, and especially in the older cases, which is by no means improbable.

Gairdner found Triclina in all the transversely striated muscles ('Montlily Journ. of Med. Science,' May, 1853, p. 473). Sanders and Kirk state that there are around the worm-1, an external fibrous envelope; 2, a tolerably thick layer of a white, transparent, homogeneous substance; and 3, an internal round capsule. These observers frequently saw a small cyst lying upon a large one, and in two cases a small round vesicle at the narrow end of the cyst.

The contents of the cysts cousist of one or more animals, and a small quantity of fluid, which keeps the inncr envelope extended. The fluid is sometimes clear', as in Kobelt's and Zenker's cases, because the Trichine in these were comparatively young; some- 
times, in cysts with worms which had not long been dead and destroyed, it showed traces of organic retrogression aud decomposition. Luschka observed in them either the well-known molecular granulations or larger corpuscles, measuring on an arerage 0.008 mill., partly round, partly elliptical, perfectly translucent, and homogeneous, or but rarely delicately granulated, sometimes isolated, sometimes deposited in groups, united by fine molecular corpuscles (fat), not converted into polygonal forms by mutual pressure, quickly soluble in caustic potash, but unalterable by acetic acid, and with a distinct nucleolus measuring $0.00013 \mathrm{mill}$. In cysts with worms which had long been dead, or in those which contained no worms, these corpuscles were entirely wanting. The wormless cysts are rare, according to Luschka. Amongst several hundreds, scarcely ten occur; and I do not at all remember having found any such. According to Luschka, they contain a clear, thickish fluid, with small formative elements, or only a few elementary granules, but they exhibited two distinct layers, whence he assumes that the Trichina must lave perished hy arrest of development in its earliest period, and therefore soon after the formation of the inner membrane, but that the cyst itself cannot become empty by the death of a fully-developed worm within it, because the remains of the dead worm might be plainly discovered in other cysts. I cannot entirely agree with this opinion of that frequently mentioned and highly esteemed savant, because I do not find it stated by lim that the wormless cysts were at the same time the smallest, scarcely recognisable or measurable cysts. For, if we suppose in general, that the inner layer of the cyst is a product of the worm, and that its formation is commenced at ence by the worm in its earliest period, and almost simultaneously with the moment of encystation, which is also my opinion, and which we have seen to be the case, according to Meissner, amongst the Gordii, we must also further admit that the new formation of the inner layer ceases with the death of the worm, and that therefore, if the worm lave died in its earliest youth, as Luschka thinks, the inner layer must also have stood still in its growth. This last circumstance must, then, necessarily lead to the result that the cysts either remained quite small, or that, if the outer layer increased in size, and the inner could no longer increase with it, the latter would adhere in pieces to the inner wall of the larger cyst. Of neither of these occurrences do we find any mention by Luschka, and we caunot consequently suppose 
that any cyst of this kind may have been subsequently broken in some way, either of itself or by mechanical causes, so that the ready-formed worm may have wandered into the vicinity of a capsule, and there again inclosed itself and become encysted by the organism. It appears to me as though we must suppose, that these wormless cysts have previously inclosed a further developed Trichina, and that a complete solution of the worm must have taken place. The chemical possibility cannot be denied, à priori, and I only regret that the matcrial for investigation was not within my reach, and, from my scientifically isolated position, never can become so. The histological nature of the cyst, no less than the analogy with the Cestoidea, indicate that in the cysts of Trichina we have to do with structures which are analogous to the serous cavities. We may therefore, on the one hand, assume that the fluid surrounding the Trichina is furnished by the serous enveloping cyst as the destined nutritive material for the Trichina, and, on the other hand, that this serous product is subject to the same changes and transformations as other serous products. As we here see a fatty calcareous metamorphosis prevail, we meet in others, for example, with a metamorphosis of the serous contents into thickish, honeyyellow (Meliceris-like), or sizy masses. Now, as we know by experience, that in the fatty calcareous metamorphosis the outlines of the worm are preserved, and its rudiments remain in the position occupied by it during life, it becomes a question whether the sizy or Meliceris-like transformation of the serous contents (to which transformation the circumstance that the fluid of wormless cysts of Trichina appeared to be thickened, seems to point), may not perhaps be capable of dissolving the chitinous skin of the Trichina. Had an ovarian or other cyst with size or melicerislike contents, been at my disposal, I should lave taken the chitinous skin of some freshly killed nematode worm, and left the two in contact for a time, at the temperature of the human body, to sce whether the skin of the nematode did or did not dissolve in the fluid. As I did not possess this, I must leave the experiment to others. As regards the worm itself, we find, as has already been observed, en passant, sometimes two or three, but generally only one specimen of the worm in a cyst. What Luschka and others say of the tenacity of life in the Trichine I can only confirm. Although I could not obscrve that the Trichina could even support a freezing temperature, still I dis- 
tinctly saw the worm alive in putrefying muscle. Luschka never remarked movements of the worm as long as it is incloserl in its cyst; and I only succeeded in sceing the free Trichince move, which they did very briskly. There is a very simple means of setting the worm free easily, which I do not find referred to by others, and which I will therefore describe here. All that is necessary is to remove one or both poles of the capsule of the Trichina by a perpendicular incision with a fine scalpel, and the expulsion of the worm may then easily be effected by pressure. The fear of injuring the worm by this incision is unfounded, because the worm always occupies the middle of the capsule, which, at the same time, prescnts the greatest diameter, and is still in the coiled-up state whilst within the capsule.

The skin of the body is glassy and transparent, but composed of a great number of rings, the limits of which, as already statecl by Luschka, are marked by fine circular lines, which give the worm a transversely striated aspect, and on the concare margins of its curvatures a very fincly serrated appearance. Besides the transverse strix, we also find a few longitudinal strix in the skin. Moreover the articulated or ringed appearance just described, is ohserved still more distinctly in incrusted and even in dead individuals, on which acconnt this appearance is no product of the preservation of the worms in spirit, as Henle formerly stated.

From the further statements of Luschka, and the figures given by him, which, with the exception of the deficient anus, are perfectly true to nature, and which are, consequently, copied by me, only corrected by the insertion of the anal orifice, it lias become easy to trace the anatomy of the animal, and both by tearing the worms with needles, and by the application of pressure, I have perfectly produced that interesting and instructire form which Luschka has figured to render the alimentary apparatus intelligible. The head is represented, not, as the observers before Luschlia supposed, by the thicker extremity of the body, but on the contrary by the thinner one. I lave observed, also, as Luschka states, that the animal performs, as it were, morements of examination with the thinner extremity of the body, and that a protrusible and retractile pedunculated papillie sometimes projects from this thin end, which also remains after deatl. From this pointed head there runs, in the first place, in the median line of the animal, a line, which 
according to its movements, is longer or shorter, sometimes straight, sometimes undulated, thicker or thimner, and marked by two dark lateral outhines; this is the narrow commencement of the alimentary canal. This is followed by a caual which constantly increases in width posteriorly, with a simultaneous gradual enlargement of the Trichina; this occupies the anterior two thirds of the worm, and sometimes reaches nearly to the lateral margins of the worm, but is sometimes further removed from them, so that a vacant space occurs between the lateral margins of the worm and the margins of the nearly spiral intestinal tube, which at first forms undulatory curves nearly touching each other, and in their further course form a series of constrictive saclike dilatations, which are probably capable of enlargement and contraction. Besides this, transverse strix run across the worm, which give it the appearance of consisting of ring-like joints pushed one into the other. 'The contents of the intestine consist of fincr and coarser elementary granules, often with the outlines of the roundish or elliptical bodies contained in the cyst. At the passage of the second into the last and thickest third of the body, the intestine, which has hitherto presented a moniliform appearance, forms a pyriform or infundibulate figure with smooth outer walls, which presents a very short narrow neck, followed by an intestine which is again enlarged to a certain degree, and runs, without dilatations, in a slightly undulatory course, through the end of the abdomen nearly to its extreme obtuse apex. The contents of this portion of the in. testine are paler than those of the upper tube; larger elementary corpuscles with dark outlines are perceived, and in the living

1 The clear round points, which, according to Luschka, lie under every transverse line, but the import of which he could not discover in any way, do not in reality exist, but are optical appearances, which probably depend upon the eircumstance that the contents of the intestinal canal, which are tolerably elear in themselves, are thinnest in the middle of the intestine behind the constrictions, as this very point in each constricterl portion of the intestine forms the highest and foremost point, but the contents undoubtedly pass more backwards and towards the dilatations. If the intestine of a Trichina were as full as it could hold, the light would be ilefieient, as also if the contents were dark-colourcr througholit, as is the case, for example, in subsequent stages of existence with the Trichocephali which live upon the dark-coloured paste of the intestines. These points may also perhaps be owing to the convolntions of the intestine, which at first are very elose together, lcaving, nevertheless, small vacuitics where the convolutions do not quite touch each other. The parenchyma shining through these vacancies forms the liglst points. 
animal the contents of the intestine are secn moving towards the apex of the abdomen. The relations become more distinct when the worm is torn to pieces, and I have had the opportunity of confirming Luschka's statements with regard to the ordinary nature of the intestinal canal. At the base of the pyriform or infundibuliform body which is formed by the anterior part of the canal at its passage into the hinder third, we always observe a pair of lateral pedunculated vesicles, which, according to my observations, hang more loosely behind, or depend from the sides perpendicularly upon the intestine. I regard them either as a kind of cæecum, or as glands.

The lindermost part of the intestinal canal always exlibits, according to Luschka, an epithelium-like layer, without any perceptible second layer serving as a foundation. The rest of the intestine presents a homogeneous membrane with scattered elementary granules.

Lastly, Luschka refers to an occurrence with regard to the intestine, which Bischoff and Farre also appear to have observed, but which I could not succeed in sceing. Once, namcly, after artificial preparation, the intestine appeared as though its wider portion consisted of two lateral halves, between which a thin canal led iuto the funnel-shaped structure, and passed at once into the thinner end. Bischoff, in connection with this, speaks of a longitudinal vessel; for my part I regard this discovery as the result of preparation, and do not think that it represents an ovigerous organ which passes into the anterior part of the worm, as Luschlia appears inclined to think. I will pass immediately to the organ which represents the first foundations of the genitalia, and speak hereafter more particularly upon the presence or absence of an anus. Besides the intestinal canal, running directly from the mouth to the extremity of the abdomen, and furnished with a pyriform or infundibuliform stomach, of which we have just spoken, a second tube, which is always distinct, may be detected in the hinder third of the body. In the description of its course and the indication of its desti. nation I differ to a certain extent from Luschka. The latter states that the tuhe commences with a cæcal portion at the place where the intestiue acquires the infundibulate form, and proceeds, without any bending, nearly to the end of the tail. Here the rounded cxtremity of this tube is seen, without any perceptible opening, although this must exist, according to Luschka. 
To prove the existence of this orifice Luschla appeals to the fact that he once succeeded by pressure in evacuating contents out of both tubes, which first poured into the cavity of the lower part of the body, and, by further pushing forward of the object, passed out by the opening of three valves at the blunt extremity, without any indication of a rupture being perceptible. At the same time, according to Luschka, there is almost always near the upper end of this tube, a body of a roundish or polygonal form, composed of 18-20 dark elementary granules, which has been regarded by all observers as belonging to the generative system. Its contents are scattered formative elements, most frequently perfectly clear, roundish bodies, which differ greatly from the conterts of the intestinal canal of the Trichince and from the structures swimming in the fluid of the cyst. Luschka regards this second tube as the male generative organ, and the dark body referred to as the testis, but, as the place of formation of the eggs, the wider tube in the anterior half of the body, which perhaps stands in such close union with the nutritive canal, that a separation, such as was seen by Luschka in the single case already mentioned, is rarely possible.

There is certainly no doubt that Luschka has fallen into an error in this case. Even the simple observation that this thicker tube was always scen even by Luschka, and that the appendage indicated by him as the testis was always visible, must suffice to render Luschka's view doubtful. For either all the Trichince were destined to become males, as the tube was absent in none of them, or the males occurred in an enormous majority as compared with the females, of which we can hardly have a further example amongst the Nematoda, or lastly, according to Luschka's supposition of the simultaneous existence of an ovigerous organ, these Nematoda must all be hermaphrodites.

In my opinion, this tube, which is certainly closed before and behind, is the first foundation of the yenitalia, and indecd of both the male and female internal sexual apparatus. In all cases, we observe at the level of the tubular portion of the above-described infundibulate organ (stomach) the caeal tube already referred to by Luschka; but I could also sce it on the other side of the worm, bending over or under the commencement of the stomach. At the hinder extremity it always ceased a certain distance from the anus. In both scxes the first foundations of the generative organs are similar; in both we find the 
anterior and posterior ends of the canal ending cæcally during the stage of Trichinal existence; in both, the sexual orifices must be subsequently produced by an external dehiscence of the tissuc. The future funiculus spermaticus and testis grow at the anterior crecal extremity distinctly orer to the other side of the intestine, and here always terminate cacally; the other, ready-formed branch of this apparatus dehisces towards the walls of the intestine, a little way from the extremity of the abdomen, so that, from this point, the male seminiferous organs and the intestinal canal form a cloaca with a common orifice.

The foundations of the female genitalia are similar. Here, also, the anterior crecal tube passes over to the other side, and reaches the neighbourhood of the chitinous lateral wall. At this point the canal must dehisce simultaneously with the integnment also at the level of the anterior part of the stomach, or but a little way behind it. The other end of the cxcal tube, which is near the extremity of the abdomen, also bends orer to the other side, and runs forward, whilst between these parts all sorts of convolutions grow out, and lastly the ovary, the uterus, and the vagina are formed from them. At no period of Trichinal existence does this tube open outwards, but the Trichina exhibits only a single orifice at the extremity of the abdomen, namely, that of the anus. The complete, aistinct fusion of the organs in question could certaiuly only happen at that period of the life of the animal when it had arrived in a place (in an intestine) adapted for its further development, and in which, consequently, the formation of the genitalia is completed. As I cannot think, even from the teleological grounds above stated, that the Trichine are only male individuals, we must assume that the tube referred to may subsequently become dereloped and converted in the way described by me into the internal sexual orgaus of both sexes, and afterwards form any sexual organs which may still be wanting, and that, therefore, it is almost impossible to determine, during the Trichinal existence, to which of the two sexes the mature animal would belong. Therefore, I agree with those authors who regard this tube as the primitive foundation of the sexual organs in gencral.

The abdominal extremity of the worm, that is to say, its thicker portion, is perforated in its middle by the anus, into which the above-described intestine directly passes. Luschka says "that, at the extremity of the abdomen, we find three dark 
lines of 0.016 mill. in length on an average, which have usually been described as a little cleft, but have also been regarded as a mouth. From the cylindrical form of the worm, we certainly only see one cleft, but if the worm be allowed to move, or another position be given to it during examination, by shifting it about, we are convinced of the existence of three clefts. These three clefts, however, are the expression of the presence of three valves, which the animal can open and close at pleasure. If these valves bend back, a portion of the tube protrudes, and produces an appearance as if the worm were torn, until the valves close and the ordinary form returns." Finally, Luschka concludes with the following leading sentence, which is eveu rendered particularly prominent by the mode of printing: "It is quite indubitable that in Trichina all the tubes in the cavity of the body lave free extremities, and that their contents are ovly separated outwardly by the opening of these valves."

I have not been able to come to this conclusion. Tlic pressure employed by Luschka, which was often very strong, certainly led him here to mistake the true state of the case. There is no doubt that the intestine passes directly, through a sort of simple cleft, into the anus. The authors who speak of this cleft are perfectly in the right. But at the extreme end of this cleft there is an apparatus, which might certainly be called valvular. At all events, in the mature state, these valves may probably still be indicated in the females, and form that button-shaped process at the extremity of their abdomen in which the anus opens, and which I have represented in Plate VII. From these valves in the male, however, might probably be developed the spinous copulatory appendage, which still plainly bcars at its extreme free cnd the traces of a previous lobate organ, as it appears to be composerl of several leaves. Although I thought I usually observed four segments in the copulatory appendage, I may have been under a mistake. At least I could not make out clearly whether this organ consisted of three or four leaves, although I adopted four as the more probable number.

Luschka supposes the intestine to hang freely in the interior of the membranous cylinder formed by the worm, and sometimes to lie close to the inner wall of this cylinder and sometimes at a distance from it, which then essentially alters the appearance of the object, and also confirms this view by the circumstance that it is casy to strip off the skin partially or wholly when tearing or 
erushing the worm. 'This latter fact can certainly not be denied, but nevertheless I do not believe in a frec suspension of the internal parts within the membranous cylinder which is formed by the external envelope of the worm. On the contrary, I believe that there is always an cxtremely delicate, elastic, structureless parenchyma between the walls of the intestinc and the envelope of the body, which yiclds and allows itself to be displaced, dislocated, or compressed on the lightest pressure, and only becomes converted into a more highly organized and morc resistent parencliyma, which may be recogniser as composed of muscular fibres, during the subsequent development of the animal. One proof of the existence of a tissue of this kind is afforded by the two dark, but very fine lines, rccognisable in every position of the animal, running from the head to the caudal extremity; even according to Luschka, these indicate the existence of contractile fibres, which have to do with the abbreviation and elongation of the animal, and, as has already been stated under the Trichocephali, they are the optical expression for the boundary lines to which the parenchyma extends within the membranous cyliuder.

Further destination of the Trichina.

There is no doubt that a great number of the Trichine, if not all those specimens which occur in the muscles of man, become abortive and die. The latter then lie in their cysts in the midst of the cyst-fluid, which is in course of sebacification, desiccation, and calcification, rolled in spiral convolutions, in the same way as the Trichince met with in a living state. These spiral structures are broken up into a number of fragments, which partly lie loosely together, partly still have some connection, aud, as Luschka further states, are marked in their separation by dark transverse lines. This arrangement, as also the ringed appearance of the fragments, which resemble minute portions of glass, weighs with me as a further proof of an indication of the segmentation of the body of Trichina, which, in breaking up, separates in the direction of the rings and in particular places of this kind. Acids and alkalies have no action upon these remains, the intestines of which at all events have undergone fatty degeneration and passed over into the mass surrounding the worm, together with which they then pass through further changes which go on in it. 
But how these encysted nematode worms, with our present state of civilisation, can reach, before the period of their deathwhich, however, only occurs very late, perhaps in 30-40 years, or after a still longer period in particular cases-places in which they are in a position to pass through their further and higher development, is beyond my power to divine. Even the administration of these Trichina to dogs gave no result, either in the experiments made by me or those made elsewhere; in about six weeks I found nothing of Entozoa which resembled the Trichince. In my experiments I certainly made two great mistakes. In the first place $I$ fed the dog with muscle in a state of incipient putrefaction; instead of which it would have been more judicious to have scraped off the individual capsules of the Trichine, and perhaps, in order to facilitate the escape of the worm, to have cut them at one end. As usual in dogs confined in a room, a brisk diarrhœa took place in this case after the administration. I fell into a second error by not examining the cxecum and large intestine of the dog with sufficient care. To avoid this error, I advise future experimenters to soften the excrement of the large intestine of the animal employed in the experiment in lukewarm water, and pass it through a fine cloth or hair sieve, by which means they will more easily find the worms, and none of them will be lost.

The experiments of Zenker and Lenckart terminated as unsuccessfully as my own. The latter had the kindness to inform me with regard to his experiments that he sought in vain in the intestine of rabbits, cats, and dogs for Ascarides which might have been produced from the Trichine administered. In the intestinal mucus of mice, however, he found young Trichince two days after administration, and Trichince might perhaps be cliscovered in the intestinal mucus of other animals. All further expectations, however, unfortunately remained anfulfilled, as the thrce other mice experimented on had acquired an appetite for flesh by the administration, bitten each other on the third day, and were thus destroyed on the fourth. This latter fact is not isolated, for my colony of white mice also killed each other by gnawing, which manœurre commeneed from the time when I had fed them with fat pices of Trenia crassicollis. In experiments of this kind we must, therefore, keep the mice separate. However, none of us found Trichince in the muscles of the 
animals experimented on, as might have been expected from IIerbst's experiments.

It now remains for me again to sum up the reasons which determine me to regard the Trichina of Owen and Luschka, and, I repeat, only this species, for the young brood of Trichocephatus dispur, and both these nematode worms, hitherto placed separately, as belonging to onc species.

1. As regards the skin, both Trichocephalus dispar and Trichina spiralis have a peculiar ringed and jointed structure, which presents itself more distinctly than in many other Nematoda.

2. In both a longitudinal stria runs down the sides, indicating the limit to which the contractile parenchyma of the worm, in which its internal organs are imbedder, reaches. Above these strix we only meet with the layers of the skin free from all parenchyma. These strix are certainly at the same time the points of attachment of the parenchyma to the inner wall of the integument of the Trichina.

3. The alimentary canal is organized in exactly the same way in both. Thus in the first place the mouth and anus are situated exactly in the centre of the two extremities of the body, the anterior and posterior. Even this simple circumstance excluded the whole of the Ascarides, Oxyurides, and Strongyli, and a great number of Filaria, from any relationship with the Trichina spiralis of Owen and Luschka. Of the Nematoda occurring in the human subject, the Trichosoma and Trichocephali, from their form, still remained for comparison. The Trichosoma are distinguished by the extraordinary thinness of their bodies and the scarcely perceptible increase of the circumference of the animal at the abdomen, whilst the Trichocephali and Trichine have a distinctly acuminate, thin anterior end, and a thicker, blunt posterior extremity. It was this circumstance that first led me to suspect the identity of the two latter worms, and we shall see that the further comparison only lends new support to this identity. In Trichocephalus dispar and in the Trichina spiralis of Owen and Luschka, there is at the thin anterior extremity of the body a small, globular, button-shaped structure, capable of being protruded from and retracted within the mouth, which is wanting in other Nematoda. Immediately after this mouth follows a spiral-like portion of intestine (commencement of 
the ocsophagus), which becomes dilatcd after a short course and forms a portion of intestine, which, increasing constantly in thickness posteriorly, considerably exceeds the thicker abdomen in length, and at first by various close convolutions, but afterwards by constrictions and dilatations, resembles the appearance of a necklace, in which the beads become larger posteriorly.

At the spot where the thinner portion of the body of our worm passes into the thicker and posterior portion, this moniliform intestine ceases in both worms, and passes into a pyriform or infundibuliform muscular portion, which may be called the stomach. At the point of trausition of the anterior part of the intestine into the stomach there are a pair of small pedunculate, alary appendages or glandules, which appear to be little caca, and which hang down rather flatly during the Trichinal existence, whilst in Trichocephalus they rise forwards and upwards, close to the mouthpiece of the funnel. In Trichina they are filled with colourless contents, in Trichocephalus certainly with coloured masses, which however are distinguished from the rest of the intestine by a much lighter colour. These wing-like, cæcal appendages, furnish one of the principal supports of the systematic diagnosis of the two worms. Hence the intestine immediately behind the tube of the funnel passes over again into a dilatation, and then runs backwards in a tolerably straight or scarcely undulated line, towards the extremity of the abdomen, in the centre of which it opens more or less directly.

4. Lastly, the second tube which occurs in the abdomen together with the intestinal canal, speaks above all in favour of the identity of the two worms. Its auterior blind extremity reaches, in Trichina, up to the level of the stomacl, and looks towards the other side, to which it actually erosses, and may subsequently become the vagina by dehiscence, whilst the posterior blind end grows out from the spot to which it reached during the Trichina-life, forming all sorts of ovarian convolutions, by which female Trichocephali are produced. But when male Trichocephali are to be formed from Trichince, the anterior extremity of this tube certainly runs over the intestine at the same place, but not to the margin, but it passes backwards on the other side of the intestine, and at the same time conceals itself beneath the intestine. The posterior blind extremity of the eanal dehisces here into the intestine, a ecrtain distance from the 
anus, and both these pass outwards together, whilst the structures regarded by Luschka as valves may unite to form the tube, beset with spines, which serves as the copulatory organ.

In this way the probable developmental history of the worm presents sufficient data for the placing together the two worms, although hitherto experimental evidence cannot be furnished either for the production of Trichince from eggrs of Trichocephalus clispar, or for the conversion of Trichince into Trichocephalus dispar.

For these reasons, however, I regard the Trichine as the brood of Trichocephali engaged in migration, by swallowing which we infect ourselves with the Trichocephalus dispar of both sexes. At the same time, however, I may also observe, that if experiment should in any way prove that the Trichine are only converted into male Trichocephali, I would immediately accept this view,

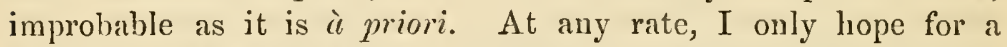
decision of this question by expcriment, although, determined by zoological reasons, I already regard the relationship of the Trichince and Trichocephali as certain. But the migrations of the Trichince are also of great importance for the theory of the nematode-like animals described by authors as Hamatozoa, which luave always hitherto appeared to be asexual worms. As far as they have been referred to in the human subject, we might perhaps think that, if worms at all, they must have been in most cases the youngest, migrating brood of Trichocephalus, before it had yet fastened itsclf, and become encysted and converted into Trichina. That the brood of the Nematoda, like tlat of the Cestodea, may get into the blood during its migration has already been stated.

By the opinion just announced, as to the production of the Trichine, I have come into opposition with that of Herbst expressed in the 'Nachrichten von der G. A. Universitat, \&c., zu Göttingen,' No. 19 for 1851, and No. 12 for 1852, and which has recently found much acceptance.

Herbst distinguishes the following species of Trichinc:

1. The Trichince of the hawk, the owls, the crows, and the woodpecker, regarded by him, notwithstanding their different sizes, as identical, and which are derived from Filaria attenuata, just as the species occurring in other birds will be derived from such Filarie as are peculiar to these birds.

2. Those occurring in man, which, at the same time, are very 
similar to those of the cat. At the same time, Herbst leaves it undecided, with regard to the former, whether it is derived from an indigenous species of Filaria or from the Filaria medinensis. The latter appears to him to be inadmissible, on account of its comparatively frequent appearance in England; an opinion in which Herbst will have but little support amougst zoologists and surgeons.

3. The Trichince of the mole and frog, which, according to him, are identical, and with regard to which Herbst himself states that, whilst the Trichina of the frog might be derived from Filaria neglecta and rubella, no one has yet found a Filaria in the mole.

It appears to me that it would have been better, recollectiug Reinhardt's observation upon the spleen of the mole, to consider the Trichince of the mole as the descendants of a species of nematode worm, which, according to the form of the egg, must be ascribed to the Trichosoma as Von Sicbold thought, or to the Trichocephali. This only furnishes a fresh support to my opinion expressed above, that it is certainly incorrect to regard the Trichine exclusively as the young brood of the Filarice, whilst they may equally be descended from other Nematoda. Besides the form, a circumstance which determined me, with regard to the collocation of the Trichince and Trichocephali, is the fact that hitherto no Trichosoma which might come in question here, besides and together with the Trichocephali, have been found in the human body; this, certainly, ought to be further inquired into.

It remains to mention that Herbst adopts a triple mode of life for the Trichince. 1, in the encysted state; 2, quite free, which are regarded by Herbst as living free and having escaped from eggs borne by the blood; and 3, half-free, in sacs of the peritoneum, and much larger than the first and second forms.

Experiments in the administration of Trichince gave Herbst the following results:

Three dogs, to which the flesh of a trichinous dog was given as food, all became trichinous.

In pigeons fed with trichinous mole's flesh, Herbst found many free Trichina, eighteen days after the feeding, in the muscles of the neck, wings, and thighs. A young daw exhibited free Trichince in all the voluntary muscles, eleven days after feeding with the same flesh. After feeding several weasels with frogs and moles which had not been examined for Trichince, their muscles also exhibited Trichina. 
IIerbst also introduced capsules of Trichine under the skin of dogs and cats. The Trichince in them were aborted in a few weeks.

According to him, Trichine living free cannot encyst themselves.

I did not like to leave unmentioned these views, which are in opposition to my own, but are also only provisional, although I do not believe that anything essential can now be gained from the above statements with regard to the Trichina of the luman subject, in so far as the form described by Owen and Luschka is concerned.

More recent experiments made by Leuckart, by administering encysted Trichince to mice, led to no further information. The Trichince certainly escaped in the alimentary canal of the mice, but that was all. My experiments in administering Trichince to frogs and rabbits produced no results. In the frogs the capsules acquired a green colour, which gave very pretty preparations.

Prognosis.-Good. Even the immigration of the brood of Trichina appears to take place without any general reaction, as it is also borne without injury for many years.

Therapeutics.-Unknown. Perhaps as regards Trichocephalus we must observe great precautions in the use of raw meats.

\section{Trichocephalus affinis (?)}

Although this worm, which is stated to have been found at Fort Pitt in a sphacelose tonsil, is rather a beard or awn of some graminaceous plant according to Diesing and Von Siebold, and we have referred it amongst the doubtful worms by the appended note of interrogation, we will still reproduce the determination of the actual species according to Diesing and Dujardin, for the purpose of an independent examination of the subject.

Caput latitudinis 0.019-0.022 mill., duabus lateralibus, vesiculosis et alatis intumescentiis instructum; cutis transverse striata, cum ligamento longo, papilluri, papillis majoribus et per endosmosin intumescentibus ornato; collum longissimum, capillare; truncus (corpus, Diesing) crassiusculus, in maribus spiraliter involutus, in feminis subrectus vel parum curvatus.

Mas : 80 mill. seu $25^{\prime \prime \prime} V$. longus; collum 53 mill. vel ad $17^{\prime \prime \prime}$ 
longum, 0.19 mill. vel $\frac{1^{\prime \prime \prime}}{8}$ ad basin latum; truncus 27 mill. vel $7-8^{\prime \prime \prime}$ longus, $0 \cdot 78$ mill. vel ${ }_{4}^{\frac{3}{4}}$ latus; extremitate caudali obtusa; penis vagina cylindrica, tubulosa, 1.55 mill. longa, 0.07 mill. lata, spinis parvulis aut lamellis triangularibus, retroversis, 0.005 mill. longis armata, antice dilatata; penis simplex, 6.75 mill. longus; 0.025 mill. ad 0.038 mill. latus, cum lamella pellucida instructus.

Femina: 60-70 mill. $v$. 24:" longa; collum $42-49$ mill. v. $18^{\prime \prime \prime}$ et $\frac{1{ }^{\prime \prime \prime}}{8}$ latum; truncus $18-21$ mill. v. $6^{\prime \prime \prime} ; 0.94$ mill. aut $v . \frac{3}{4}^{\prime \prime \prime}$ lata ; subrecta vel parum curvata; cauda obtusa; ovula navicularia, 0.061 mill. longa; in ovulorum extremitatibus duo nodule pellucidi magnitudinis 0.008 mill., unde longitudo totalis 0.077 mill.

Its usual locality is almost exclusively the cæcum of the ruminants. The characteristic mark of the species is the considerable length of the penis and its sheath.

\section{Oxyuris.}

As we have already seen to be the case with the name of whip-worm (Peitschenwurm) for the Trichocephalus, so is it here with the Greek name first introduced by Rudolphi. The denomination Oxyuris = Sharp-tail (from óंus and ovoà) only applies to the female, but by no means to the male.

The worm is placed by Dujardin as the 16th genus of the first elass of the Helmintha; that is to say, the Nematoda. Diesing has separated it from lis Oxyurides, and placed it with the Ascarides. Thus, whilst he treats of the Oxyurides, in the Order VI, Nematoidea; Suborder II, Proctucha; Tribe III, Gamonematoidea; Section I, Hypophalli (penis infra extremitatem caudalem), as Genus XVIII (corpus capillare, extremitate caurlali maris subrecta, alata vel exalata; pene in vagina bipartita. Os orbiculare), he has placed the Oxyuris vernicularis in the same tribe and section as Genus XX, Ascaris; A, Gymnoascaridre (corpus inerme); Division I, Apterocephala (caput non alatum); Subdivision I, Oxycerca, (a) macrurce, (a) caput epidermide inflata, 1, Ascaris vermicularis. The introduction of a vox hybrida like Oxycerce is enough of itself to make this above all measure artificial classification, appear but little acceptabic. With Dujardin and most other authors, we treat the Oxyurides as a 
peculiar genus of the Nematoda separated from Ascaris, and give the following description especially from Dujardin.

Corpus cylindricum aut fere fusiforme, sublongnu, in feminis retrorsum subulatum; caput inerne; os rotundum (in statu contractionis) aut triangulare (in statu actionis), trilabiatum; cesophagus musculosus, cylindricus aut claviformis ct canali triquetro perforatus; ventriculus globosus cavitate triangulari; intestimu in feminis ante apicem caude acute, in maribus in contro caudce apertum.

Mares: fere microscopici; plenumque spirales in fine posteriore obtusi; ponis simplex, uncinutus.

Femince: cauda acuta; vagina semper in parte vermis anteriore sita; uterus bilocularis cum ovariis 2. Ovula lavia, oblonga, non symmetrica, multo longiora, quam latiora omnino magna: 0.064. mill. ad $0 \cdot 136$ longa.

\section{Oxyuris vermicularis (Bremser, Deslongchamps, Dujardin,} Tou Siebold).

Synon.: Ascaris vermicularis (Limné; Goeze; Rudolphi; Schmalz; Creplin; Diesing); Fusaria vermicularis (Zeder) = Kinder-, Mastdarm-, Madenwurm = Arschmade = Aarsmade $=$ Darmschabe $=$ Smaa Spolorme = Börncorm = Barnmask = Bots (Thread-worms).

Bremser first separated this worm from the Ascarides, and certainly with perfect justice, notwithstanding the great authorities opposed to him. I place the worm as an Oxyuris, partly for the reasons already given by Dujardin, because œsophagus and pharynx are triangular, and the mouth is sometimes round, sometimes triaugular, according to the degree of its contraction; because the lateral, wing-shaped appendages at the mouth are simply a uniform inflation of the head, aud no true membranous wings; and because there are only three lips to the mouth; and partly on account of the nature of the male, which Dujardin himself never appear's to have seen. The males are very much smaller than the females, as is usually the case with the males of the true Ascarides. Then the caudal extremity of the male Ascarides usually forms a small face resembling the leaf of Sagittaria sagittifolia, whilst the candal extremity of Oxyuris vermicularis presents a round surface, which is capable of taking the form of a sucking surface. But, in the last place, the simple 
penis is completely and essentially distinguished by its small size and its form, from the penis of the Ascarides, which is usually double.

Having thus justified ourselves with regard to the name and position of the worm in the system, we may pass to the closer examination of the worm.

Corpus album; cutis transverse striata, in margine utroque cum duplice ordine dentium acutiorum et obtusiorum secundum. Dujardini mensuras 0.018-0.023 mill., secundum meas in feminis $0.024-0.030$ mill. $=0.0108-0.014^{\prime \prime \prime} P_{.}=0.011-0.015^{\prime \prime \prime} V$. , in maribus autem 0.008 mill. $=0.0036^{\prime \prime \prime} P .=0.0037^{\prime \prime \prime} V$., inter se distantium; caput 2 appendicibus lateralibus, vesiculosis epidermidis duplicaturâ; os rotundum, antice margine trilabiatum et angustum, asoplurgus carnosus, musculis longitudinalibus ct transversis, canali triquetro; ventriculus strictura; cesophago sejunctus, globosus, cum cavitate interna triquetra, et valvularum apparatu; epithelio polyedrico cum nodulo pellucido sparsim instructus.

Mas : $2 \cdot 05$ mill. $=0.90^{\prime \prime} P .=0.95^{\prime \prime \prime} \mathrm{V}$. adl 2.5 mill. ad $3 \cdot 37$ mill. longus (si caudam semper curvatam tanquam lineâ rectâ extensam mensus es) ; in capite una cum appendicibus 0.091 mill. $=0.011^{\prime \prime \prime} P$. $=0.012^{\prime \prime \prime} V$., sine appendicibus 0.024 mill: $=0.0108^{\prime \prime} P .=0.01 \mathrm{I}^{\prime \prime \prime}$ $V$., medio in corpore 0.123 mill. $=0.054^{\prime \prime \prime} P .=0.055^{\prime \prime \prime} V$., in cauda 0.023 mill. $=0.0144^{\prime \prime \prime} P_{0}=0.0148^{\prime \prime \prime} V$. latus. Ossophagus a 0.024 mill. $=0.0108^{\prime \prime \prime} P .=0.011^{\prime \prime \prime} V$. ad 0.041 mill. $=0.0108^{\prime \prime \prime} P_{0}=0.011 \mathrm{~V}$. ad $0.041 \mathrm{mill} .=0.018^{\prime \prime \prime} P_{.}=0.0185^{\prime \prime \prime}$ $V$. latitudinis intumidus est circiter 0.311 mill. $=0.137^{\prime \prime \prime} P$. $=0 \cdot 141^{\prime \prime \prime} V$. longus. Esophagum sequitur brevis tubi intestinalis strictu 0.008 mill. $=0.0036^{\prime \prime \prime} P_{0}=0.0037^{\prime \prime \prime} \mathrm{V}$. longa et 0.016 mill. $=0.0072^{\prime \prime \prime} P .=0.0074^{\prime \prime \prime} V$. lata. Postea sequitu" ventriculus : 0.115 mill. $=0.050^{\prime \prime \prime} P .=0.052^{\prime \prime \prime} V$. longus et 0.065 mill. $=0.0288^{\prime \prime \prime} P .=0.0296^{\prime \prime \prime} V$. latus cum valvularum apparatu cognito; iubus intestinalis paulo post ventriculum latitudinis 0.057 mill. $=0.025^{\prime \prime \prime} P .=0.020^{\prime \prime \prime} \mathrm{V}$. est, ad anum vero 0.008 mill. $=0.0036^{\prime \prime \prime} P .=0.0037^{\prime \prime \prime} V . \quad$ Penis simplex 0.057 mill. $=0.025^{\prime \prime \prime} \quad P .=0.026^{\prime \prime \prime} \quad V$. longus, ad basin 0.008 mill. $=0.0036^{\prime \prime \prime} P .=0.0037^{\prime \prime \prime} V$., in apice vero semper ad hamuli instar recurvato, latitudinis (adultinum 0.003 mill. $=0.001^{\prime \prime \prime} P$. et $V$ ). Funiculus spcrmaticus et testis simplex; spermatozoidia epithelionum imaginem simulantia. Caude apex in foveam suctoriam mutabilis.

Femina: $7 \cdot 81$ ex aliis al 10 mill. $=3 \cdot 18$, ex aliis $44.337^{\prime \prime \prime} P .=$ 
$3 \cdot 57$, ex aliis ad $4.56^{\prime \prime \prime} V$. longa; in capitis apice cum appendicibus 0.196 mill.$=0.087^{\prime \prime \prime} P .=0.089^{\prime \prime} V$.; sine appendicilus 0.065 mill. $=0.029^{\prime \prime} P .=0.0298^{\prime \prime} \mathrm{V}$. ; in medio corpore 0.49 ad 0.59 mill. $=$ $0.21-0.26^{\prime \prime \prime} P .=0.22-0.27^{\prime \prime \prime} V$. ; extremitas caudalis acutissima. Longitudo caudee (i. e., partis, inter anum et apicem) 1.798 mill. $=0.797^{\prime \prime \prime} P .=0.819^{\prime \prime \prime} V_{.}$; latitudo caude ad anum ipsam 0.26 mill. $=0.116^{\prime \prime \prime} P .=0 \cdot 119^{\prime \prime \prime} V$, inde diminuta. Esophagus 0.65 mill. $=0.29^{\prime \prime} P .=0.298^{\prime \prime \prime} V$. longus, in capitis apice 0.065 mill. $=$ $0.029^{\prime \prime \prime} P .=0.0298^{\prime \prime \prime} V$., in parte posteriore 0.098 mill. $=0.043^{\prime \prime \prime}$ $P .=0.044^{\prime \prime \prime} V$. latus. Strictura tubi intestinalis pone rsophayum uti in maribus perbrevis et 0.028 mill. seu $0.128^{\prime \prime \prime} P$. et V. lata. Ventriculus 0.172 mill. $=0.0768^{\prime \prime \prime} P$. et $V$, et longus et latus, interdum latitudine aliquid minor. Vagina ex Dujardini mensuris $1 \cdot 8$ mill. ex meis ad $1 \cdot 64$ mill. $=0 \cdot 7^{\prime \prime \prime}$ pone caput sita ; in vivis 1.06 -1.2 mill. $=0.46-0.54^{\prime \prime \prime}$ longa et 0.11 mill. $=0.049^{\prime \prime \prime}$ lata ; cum foramine latitudinis 0.13 mill. $=0.06^{\prime \prime \prime}$, longitudinis 0.15 mill. $=$ $0 \cdot 07^{\prime \prime \prime}$; uterus duplex, cujus ramus posterior $2 \cdot 0$ mill. $=0 \cdot 9^{\prime \prime \prime}$, cujus anterior 1.35 mill. $=0 \cdot 6^{\prime \prime \prime}$ longus ; ramosum ovulis impletorum latitudo ad 0.4 mill. $=0.18^{\prime \prime \prime}$ et ultra ovulis expulsis, 0.2 mill. $=0.09^{\prime \prime}$; ovarium duplex, in transitu uteri in anum 0.03 mill. $=0.015^{\prime \prime \prime}$ latum.

Ovula fere oblonga, non symmetrica; ex Dujardini mensuris 0.055 mill. lata et 0.064 mill. longa, ex meis media in parte ovulorum 0.029 mill. $=0.012^{\prime \prime} \quad P .=0.015^{\prime \prime \prime} V ., \quad$ in apicibus circiter 0.012 mill.$=0.005^{\prime \prime \prime} P .=0.006^{\prime \prime \prime} V$. lata et 0.05 mill. $=$ $0.022^{\prime \prime \prime} P$. et $V$. longa. Embryones viventes in ovulis nondum vidi.

In regard to size, three forms are met with.

1. The mature females, which are remarkable from their size, thickness, and whiteness, as well as by the fine, acute, capillary tail, with an obtuse, broad head.

2. The young immature females, which as regards colour are to be distinguished by nothing from the pale gray males, or at the utmost by their somewhat larger size, but which are easily recognised by their acute tails, and exhibit the female sexual organs in various grades of development, according to their age.

3. The mature males, which are rendered remarkable by their pale silver-gray colour and their obtuse anterior and posterior extremities, as also by the penis.

I pass over the form of the immature males, as they hare not 
yet been discovered, but ean scarcely exceed the size of a visible point. They will be recognised by their obtuse anterior and posterior extremities.

From Wedl's description it appears that he saw the first and second forms. All the three forms oecur abundantly together in one and the same intestine.

The skin, head, cesophagus, and intestine are similar in both sexes, of course with the exception of the comparative size.

The nervous system of the Oxyurides is, according to Walter extraordinarily developed, but has litherto been entirely overlooked. According to him, the nervous system of Oxyuris ornata is as well developed as in Mermis, cxcept that a separate intestinal nervous system is wanting. We have in the Oxyurides a central (eerebral and caudal ganglia) and a peripheric nervous septum. The brain = the eephalie ganglionie mass, in $O$. ornata is an aggregation of large ganglia destitute of a membrane, on the sides and in the middle of the mosophagus, and an aggregation of smaller ganglionic masses lying transversely under the brain. The latter sends out filaments on each side to the cesophagus, and upwards and downwards to the lateral ganglionic masses; the former to the muscles and fatcanals (Fettschlauchen) to the mouth and the four ridges of corium, in which they distribute themselves in fine ramifications (organs of sense), and downwards on each sirle a broad cord transversely inwards on the back of the œsophagus, where the two branches unite, and together with the ganglia form the œsophageal ring. From this ring, ramifications pass to the lowest parts of the lateral ganglia, transverse branches to the museles and fat-canals, and a

Fig. 2.

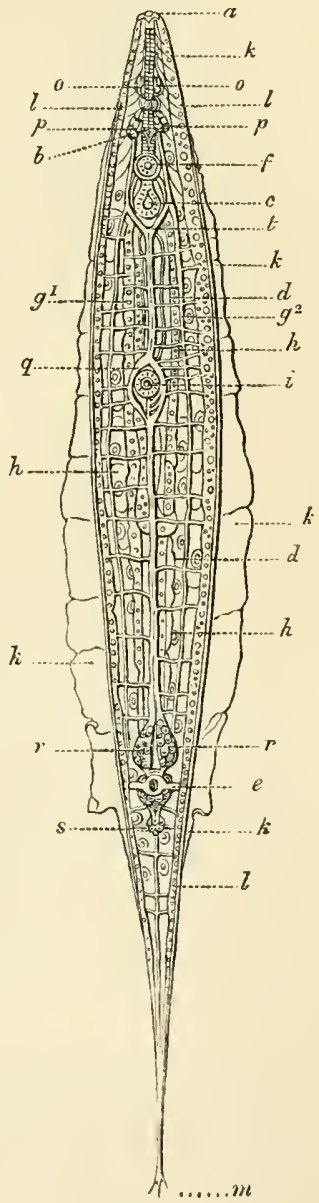

Fig. 2. Young female of Oxyuris omata, in which the generative organs are unde. reloped, viewed from the veutral surface; magnified 176 times. a. Oral aperture with 
Fig. 3.

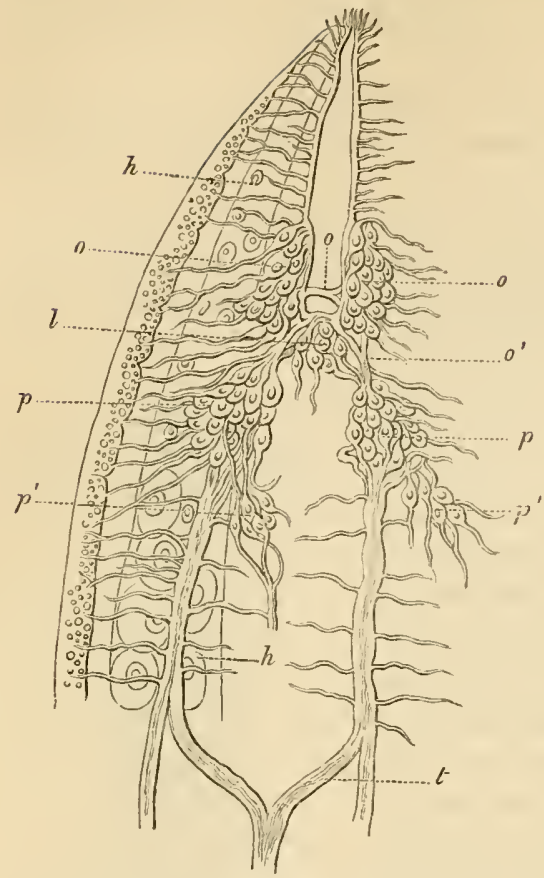

Fig. 4.



broad branch to the stomach, which divides into a central branch and a smaller lateral one. The broad branch runs round the

the surrounding three-cornered enlargements (organs of taste). b. Esophagus. $c$. Stomach. $d$. Intestine. $e$. Anal aperture with its circular sphincter and oblique muscles and sucking-disc. $g^{\mathrm{l}}$ and $g^{2}$. Two tubes proceeding from the same and running down by the side of the alimentary canal. $h$. Sarcode-tubes containing cellular drops, reddish vesicles (nuclei), and in these transparent corpuscles. $i$. Female generative opening with the cleft uterus proceeding from it. $k$. Epidernis of the anal and oral aperture covering the corium. $l$. Lateral fat-canals. $m$. The three-pointed tail. Nervous system; o. Upper lateral csophageal ganglion. $p$. Lower ditto; both are united in the middle by a transverse ganglion. $q$. Encircling of the ventral cord around the female generative aperture. $r$. Lenticular aual ganglion. $s$. Last ganglion of the tail. $t$. Union of the oesoplageal gauglia with the inner fibres of the common ventral cord.

Fig. 3. Cerebral ganglia (brain). o. The upper lateral œsophageal ganglion. $a^{\prime}$. Ganglion lying on the ventral surface under the œsophagus. $p$. The lower lateral œsophageal ganglion. $y^{\prime}$. Ganglion supplying the sucking-disc. $t$. Union of the two lateral branches of the ventral cord. $h$. Sarcode-tube. $l$ Lateral fat-canals.

Fig. 4. Caudal ganglia. $r$. Lateral pyriform ganglion. $r$. Transverse band nniting the two ganglia upon the dorsal surfacc. $r^{\prime \prime}$. Globular enlargement of the lateral ganglia. $r^{\prime \prime \prime}$. Reniform transverse ganglion. $s$. Last caudal ganglion. $x$. Single 
stomach, unites with that of the other side to form the largest peripheric stem in the ventral line between the intestine and fatcanals; in the female this divides at the vaginal orifice, runs round the latter, and then re-unites. Consequently, three peripheric stems issue from the brain, the last-mentioned central one and two lateral ones, which soon become unrecognisable. They send off branches (which rarely anastomose), at right angles to the muscles, fat-tubes and genitalia, especially the vagina. The œsoplragus, stomach, and intestine, receive branches from them and the neighbouring ganglia. The whole of the nervous trunks consist of longitudinal fibres placed at a greater or less distance apart; the transverse branches are produced by the union of a small branchlet coming from above and below, and disappear on entering the organ, in the form of small, homogeneous triangles, without further division. Neurilemma and cellular bodies are wanting on the ramifications of the nerves. Whether a dorsal nervous cord exists is still a question. The ventral nervous cord, by dividing at the dilatation of the intestine, before the commencement of the rectum into two large, but very short trunks, becomes converted into a large, pyriform, ganglionic mass, covering the intestine, or even exceeding it-the principal caudal ganglion; a transverse branch passing transversely therefrom over the rectum, gives origin to the formation of a moderate anal ring. Besides these nervous masses, two small globular ganglia lie laterally near the anal orifice, and a large, reniform ganglion transversely at the lower end of the anus, from which issue downwards two strongly converging branches, formed by the union of several filaments. Hcre also, lies the last fusiform ganglionic mass, which, at the commencement of the tail sends numerous fine, lateral filaments to neighbouring organs (muscles, fatcanals, male genitalia), and tapers to a fine point, which, after giving off numerous lateral branchlets disappears in the corium. It was seen and described by some autliors, as Goeze and Dujardin, as a ligament, but has always been misunderstood, or overlooked.

Methor of investiyation. - The cerebral ganglia are difficult to find, as everything depends upon the arrangement of the mirror, management of the light, \&c. For this purpose the older males 
are best fitted; they are to be cut through in the region of the stomach. The animals should be examined as fresh as possible, without water, rather with the application of turpentine. The caudal ganglia are hest found in young females, after the animal has been cut through above the caudal ganglia, and the uterus with its eggs has been removed. The sarcode globules in the penis and its muscles in the male, readily obscure the investigation in that sex. The peripheric nerves, especially their transverse branches, are more easily detected, especially in animals which have been cut through and deprived of their contents.

As regards the form of the ganglionic cells, unipolar cells with large nucleoli are seen, especially in the pyriform ganglion, in the ganglion placed about the lower margin of the rectum, and the middle of the cerebral ganglion; bipolar cells, which are longer and narrower, are seen on the margin of the cerebral ganglion, and in the fusiform ganglion, which is entirely composed of them. Apolar cells are wanting, as are also multipolar cells, of which, however, a few may, perhaps, occur in males, on each side of the pyriform caudal ganglion. The bipolar cells consist of a delicate membrane with finely granular contents and a nucleolus, sometimes double, with a delicate outline, usually situated in the middle.

The primitive nervous filaments are produced from the processes of the ganglionic cells (which are particularly visible on the marginal ganglion of the brain, and in the fusiform caudal ganglion); by the union of several primitive filaments of this kind, narrower or broader branches are produced (these are particularly visible on the upper and lower cerebral gangliouic masses).

I have unfortunately not succeeded hitherto in detecting the nervous cords in Oxyuris vermicularis.

The following is an abstract of the characters as they are given in Walter's beautiful investigations upon Oxyuris ornata (Siebold and Kölliker's 'Zeitschr.,' viii, pp. 163-201, tab. v. - vi).

The skin of the Oxyurides consists, according to Walter, of an external layer of epidermis, and beneath this, a delicate but densely fibrous corium.

The epidermis, in young individuals, forms a delicate boundary line, which does not separate in water, but is not, as in Mermis, composed of hexagonal cells but simply by exudation. At the 
oral extremity and on the tail, the epidermis and corium are firmly united, and both turn inwards at the natural openings.

During the motion of the animal broad folds are formed in the corium, which at the same time compel the epidermis to fold, as may be best detected when old, mature animals are cut through before the anus and behind the pharynx, and the contents of this part of the body are pressed out under the microscope. On the corium we see four seams running through the whole length of the animal (one on each side, and one along the dorsal and ventral surfaces) and between them a fibrous layer. In Oxyuris ornata, the latter sometimes consists of two layers, one transverse and the other spiral, but in general we only see parallel fibres, crossing each other at acute angles.

In Oxyuris vermicularis, the skin of which is colourless, the transverse striæ which are especially distinct during the contractions, are at the above-mentioned distance apart, and the skin projects on the lateral margins in a serrated form. These serrations form a double series on each side, the outer of which is more rounded and blunt, the inner more acute and sharper, especially in the males.

The parenchyma of the body does not extend into the tail, and in the anterior extremity in the neighbourhood of the mouth the lateral surfaces are free from parenchyma, so that when the worm is pressed flat, we see in that part two transversely ribbed, wing-like appendages, which are obtusely rounded off in front, but taper away gradually behind, and become amalgamated with the epidermis of the middle part of the body. They are indicated by authors as two lateral, wing-like appendages, composed of broad, band-like, hyaline lobes. The transverse ribs in these appendages, correspond either with the spots, when an intimate contact of the two inner surfaces of the epidermis forming the appendages takes place (either a constant contact, or only a temporary one in consequence of the transverse wrinkling occurring during movement), or with transverse nervous branchlets, which I could not ascertain clearly.

The muscular system of Oxyuris, according to Walter, is very highly developed. Thus, in Oxyuris ornata, close beneath the corium, we find several (4) longitudinal muscles regulating the general movement, and then smaller muscular groups in the interior of the body on various organs, and extremely seldom (only in the male sexual apparatus) muscular fibres ruming 
transwersely. Four tubiform longitudinal muscles originating from the ridges of corium, at the mouth are peculiarly interesting. They pass down to the tail, forming two ventral and two dorsal muscles, which diminishing anteriorly and posteriorly and becoming amalgamated with the corium, leave free baud-like stripes between them. The muscular canals consist of a longitudinally striated, or, more correctly, longitudinally folded sarcolemma, which separates in water and by coagulation, of an inner, tenacious, fluid substance with peculiar (round, biscuit-shaped) corpuscles (of a fatty lustre, moreable by pressure, and becoming converted into transverse plates by coagulation), and of a somewhat dark, homogencous basal substance (ligamentous substance, muscular fibrine) which forms a solid cylinder in the interior of the muscle.

In the earliest period the four longitudinal muscular canals were four sarcode canals, which become converted into muscular canals from the apices towards the middle. At a later period, the sarcode is entirely deficient in the muscles, and disappears generally from the moment when the nerves show themselves. As long as they are still sarcode canals large cells are seen in them on contact with water; these possess a nucleus which is reddish by transmitted light, and one or two round or biscuitshaped nucleoli, which finally, by long contact with water become pale and decrease until there is nothing of them but a shiny corpuscle in a delicate membrane. Withont the application of water, large acellular, albuminous drops are found in them; these flow out when the animal is cut through, and acquire all sorts of amrboid forms, which, however, always revert to the round or oval form and exhibit the clear contents with a reddish nuclear vesicle.

We must again revert to the four free, band-like stripes which exist between the muscles, and of which there are tro on the sides, one on the ventral surface, and one on the back. In the young state they form canals filled to orerflowing with fat. With the advancing derelopment of the animal, the fat gradually disappears; and in fully developed individuals, only single drops are seen from time to time, and the canals are generally empty and folded, and have become wriukled, empty whitish cords. They run from the head to the caudal extremity, and become united like the muscles with the corium. The branch rumning along the ventral surface bends round the various orifices occurring on this surface. There is certainly no doubt that these four fat-canals assist in the development of the animal, 
perhaps especially in the formation of its generative organs. Walter was unable to detect any efferent duct to these four canals. As far as I can glance over the whole arrangement, it must be the principal object of further investigations to ascertain whether a union of each pair of these canals in the apex of the tail to form a common canal does not take place. Thus Walter observed from the apex of the tail to the sucking disc placed in the upper part of the body, in the middle of the ventral surface, two canals, which are extraordinarily delicate towards the apex of the tail, running in innumerable convolutions around the intestine and laterally from it, becoming stronger towards the orifice of the sucker, having exactly the same contents as the fat-canals, and also, like these, losing themselves in the corium of the apex of the tail. Consequently, no information can be given at present as to whether these six canals are actually produced as six, or whether there are only four canals with two efferent ducts. We only know that these canals all bear the same contents during the youth of the animal, and that they also retrogress simultaneously, so that they probably have one other same function. Whether these organs are produced in the same way in the young state of Oxyuris vermicularis as in $O$. ornata, whether a perforated ventral sucker exists here, ${ }^{1}$ and becomes retrograded at a subsequent period of existence into a cleft which is easily overlooked; and whether these are not conditions which occur in all nematode worms, are points on which we are still in the dark. It appears to be very probable, however, that such circumstances occur in very many, if not all, nematode worms. Thus Bagge found a fine transverse cleft in the median line of the belly in Ascuris acuminatus; other's have found a similar organ in Strongylus hypostomus and a ventral sucker in Ascaris brevicaudatus. Dujardin and Von Siebold met with two canals opening in the median line of the belly in Ascaris dactyluris and paucipara, and it is probable that these authors had old worms before them, in which these organs had already become retrograde.

' Walter is of opinion that sueh a rentral sucker is, perhaps, necessary to the nematode worms during the early part of their existence, in order that they may adhere by sucking with it to the walls of their habitation during the period of their metamorphosis, and thus pass through this stage in greater quietmess. The sucker wonld then resemble other caducous organs occurring cluring the larval condition of animals; but sueh individuals would then le, as it were, larva of nematode worms. 
In Oxyuris vermicularis I lave not yet found this orifice; but it is very probable that $I$ have overlooked it. With regard to the four lateral cords see also Ascuris lumbricoides.

The alimentary apparatus consists of the following parts:

The mouth, reaching to the apex of the head, which is rendered very broad here by the wing-like appendages, is on the whole narrow and very muscular. In the Oxyuris ornata it terminates anteriorly with four ridges (Wülsten) of corium, in which a nervous dilatation, broad in front, pointed behind (a sort of tactile organ), is observed. Wedl mentioned three, or perhaps four, retractile papillæ in Oxyuris vermicularis; these are nothing but Walter's ridges of corium. The conditions which prevail in $O$. vermicularis are not very easily reviewed; but in this case also it is most probable that we have to do with four ridges of corium, although it may usually appear that there are only three such ridges. At any rate the ridges are unequal, and whilst two of them each measure about $0.025-0.028$ mill., the other two ridges, which cover each other, measure together about the same, which is certainly possible only if the ridges of corium (lips, papillæ) differ in size amongst themselves. The notches between the individual ridges measure about 0.0015 mill. in the male, and twice as much in the female. I asserted formerly that the number of ridges (papillæ) must be three, and upon this supported my assumption of the triangular form of the œsophagus, but I have since seen, from Walter's investigations, that this triangular form of the œesophagus has nothing to do with the ridges of corium, as the osophagus does not reach to the mouth, and the pharynx is round, and not composed of three pieces.

Between the mouth, the breadth of which is about 0.039 mill., and the œsophagus, there is a muscular pharynx (rich in annular muscles), which increases in thickness posteriorly ; at the hinder extremity of this there is a constriction, which corresponds with a small intumescence in front. The skin of the pharynx in the Oxyurides, according to Walther, is firm externally, structureless, and without folds internally. Between the pharynx and the cylindrical œsophagus there is a sort of diaphragm, a chitinous or cartilaginous lamella. Towards the stomach a new constriction occurs, which separates the œesophagus from the stomach. The cavity of the œsophagus itself is prismatic and triangular, as far as the stomach. The angles of this prism are formed by three firm cartilaginous seams, which occur in the interior of the 
cavity of the cosophagus. Externally there are three strong muscles, which determine the prismatic form; and inwards from these angles the skin is seen to be furnished with broad folds, covered in the earliest periods with distinct, delicate epithelium, which afterwards becomes firmer. All this is surrounded by a firm, structureless envelope, a continuation of the epidermis, which afterwards becomes the peritoneum.

After the cosophagus and behind the constriction follows the strongly muscular stomach, with a peculiar dental apparatus, according to Walter. The cavity of the stomach is also prismatic at first, but dilates immediately after a second constriction. The folds are wanting liere, but instead of them three converging cones are seen which are firm, acute, and chitinous, originating in the walls of the cavity, and are furnished with points projecting freely into the cavity. Superficially they are covered with small diverging folds, and in consequence have an undulated appearance. According to Walter, an epithelium is only observed in the Oxyurides in their earliest youth. On the outer surface of the walls of the stomach there are radiating muscular fasciculi issuing from a second membrane which exists between the stomach and peritoneum. On these circular muscles, between the above-mentioned membrane and the peritoneum, there follows a new strong muscular layer. Immediately behind the stomaci there is another constriction, with which the intestine commences; the course of the latter is somewhat different in the two sexes. After the constriction, which is followed by the corresponding dilatation, the intestine makes a turn forward, and afterwards runs, always maintaining a nearly equal diameter, in a pretty straight line, and only making a few convolutions, in the female more in the middle of the worm, but then passes to the inner side and opens into the somewliat narrowed anus, about 1.798 mill. $=0.797^{\prime \prime \prime} \mathrm{P} .=0.819^{\prime \prime \prime} \mathrm{V}$. from the apex of the tail on the inside of the worm, and indeed in its lateral margin. In the male the circumstances first mentioned also take place, only here the iutestine always runs on the outer side of the worm into the caudal extremity, where it opens on the outer side of the penis, by a cleft-like orifice, or perhaps by a common orifice for the penis and anus. Wedl has erroneously regarded the scminal cliord as the intestine.

The anatomical structure of the intestinal canal is as follows: The peritoneum of the stomach is continued into the peritoneum 
of the intestine, and the inner nembrane of the stomach into the epithelial membrane of the iutestine. The epithelium consists of a simple layer of large, delicatc-ralled, hexagonal cells, flattened against each other, with a pale nucleus and a distinct nucleolus. They resemble parement epithelinm, such as Luschka has figured in the intestine of Trichina spiralis. What Wedl figures as epithelium are seminal corpuscles. Between the epithelium and the peritoneum, we find, as a continuation of the muscles of the stomacl, fine longitudinal muscles, and an intermediate layer of cells. The latter, merely on account of its cells, is, according to Walter, an analogue of the liver (bile-producing organ), for which, however, it secms to me, he has forgotten to furnish the proof.

The rectum, according to Walter, does not present these three layers, and is destitute of the longitudinal muscles, but possesses annular muscles to close, and a strong transverse muscle to open the anal cleft.

The tail of the male has an obtuse extremity, apparently capable of conversion into a sucker, but this must not be confounded with the above-mentioned rentral sucker.

\section{Sexual relations of the Oxyurides.}

The males were discovered by Sömmering in the evacuations from an oil-clyster, with which the celebrated father had expelled the Oxyurides from his son, and sent to Bremser, who also found them subsequently, although but sparingly. Wedl also only met with them in small numbers, and Tou Siebold, curiously, nerer saw them, which also appears to have been Dujardin's case. And yet Dr. Zeuker has shown that they may be discorered with great ease. ${ }^{1}$ He has allowed me to state, that according to his experience, males occur abundantly wherever we meet with the females in great numbers. All that is necessary is, to scrape off the mucus from the walls of the large intestine with a scalpel, and place the mucous mass upon the object-glass. The collection of males is particularly successful when the excrement is evacuated from the intestine by diarrhœes. In this way Dr. Zenker collected about a drachm of diarrhœal mucus from the large intestine of a lying-in wornan, who died in Dresden from puerperal ferer, and

[' I have found no difficulty in discovering males. They are generally much ferrer in number.-Trass.] 
sent the bottle filled with it to me, with the observation that I should find a sufficient number of males therein, together with mature and semi-mature females. In this fluid, both M. Reinlardt, of Batuen, to whom I sent some of it, and mỵself, have obtained an abundant harvest (at least from forty to fifty) as regards the males, so that the old notion, diffused by many a text-book, as to the rarity of the male Oxyurides, is to be regarded as completely set aside by Zenker's means. Even with the naked eye, but still better with the lens, we may, according to Zenker, and as $I$ can confirm, detect the males in the form of small, translucent filaments or curls, when the diarrhoal freces and mucus, spread upon a glass plate, are held up against the light. They vary greatly in size. The addition of water is not advisable, as they then easily burst, and suffer a prolapsus of the intestines.

In the male generative apparatus we perceive,-

1. A simple seminigenous organ, in which jarticular parts can hardly be distinguished from one another, and which forms a canal of almost continuously equal calibre. The blind extremity of this organ, which would correspond with the testis, commences at the imner side of the worm, about in the posterior or middle third, and rises here in the space between the skin and the intestinal canal upwards to the level of the bulb of the œsophagus, bends round it, passes over towards the other side of the worm, and runs down a little on the other side of the stomach, on the outer side of the worm, between the skin and the intestine, towards the hinder extremity. Here it opens on the inner side of the tail, immediately beside, perhaps even together with, the auns. At its lowest extremity we find-

2. The so-called penis, which is simple, and in which the bands described in the Trichocephali passing to the sheath, as well as the sheath itself, are wanting. 'The penis has a fumel-shaped or' button-like swelled root, and then presents a tulular part, rmung pretty straight, and at its hinder extremity a small, hook-shaped, obtuse point, the concavity of which always looks towards the side which is turned away from the intestine, and therefore towards that indicated at the inmer side of the worm. Moreover, the penis, which is imperforate, and only hollowed out into a chamel, acts like the penis of the other Nemaloida, as a sort of ovipositor. In the interior of the scminiferous organ, and escaping through the posterior genital orifice by the agency of the penis, are scen- 
3. The seminal cells. These are large, round bodies, which present an extraordinary resemblance to the epithelium of higher animals, and have even been taken for epithelium by Wedl. At the same time they appear granulated. To the male sexual organs belongs, lastly-

4. A sort of sucking-pit at the extremity of the abdomen, which must serve as an auxiliary apparatus for the attachment of the male, and as an assistance to the voluntary twisting of lis abdomen. In the textbooks we find nothing about this apparatus, and yet it actually exists, although perhaps it assumes many forms, in different positions of the worm. At the obtuse caudal extremity of the male we see not unfiequently the whole of the free margins projecting as light ontlines, and from these margins anteriorly and towards the tissue of the worm, a small, cap or hood-shaped, hollow structure takes its rise, presenting the complete form of a sucking disc engaged in action. Whether this arrangement is produced by valvular seams or processes of the integument, or, as it appear's to me, by simple contraction of the obtuse caudal extremity of the male, cannot be stated with certainty. It is certain that it is possible for the obtuse tail to acquire a sucker-like form, and that this assists the adhesion of the male in coitu. At the same time I may remind the reader of the valvular apparatus in the stomach. This apparatus effects the complete prevention of the regurgitation of air and nutritive material forwards, and thus renders the intestine a completely closed tube. This circumstance must of course assist the action of the caudal extremity as a sucker.

The females, whose comparative size varies according to the state of maturity, are, under all circumstances, larger than the males. In the mature state they catch the naked eye, both by their size and their white chalky colour, which is caused by our seeing the pale, closely packed eggs shining out of the abundantly filled uterus. The vaginal orifice lies on the same side as the anal opening, and about as far behind the mouth as the anus is distant from the caudal extremity, as is shown by the measurements already given. It is situated before the middle of the female, longish oval, and recognisable externally by no remarkable fleshy protuberance. The tolerably long, slightly twisted vagina is followed by the uterus, which, as well as the ovary and Tuba Fallopii, is double in the Oxyurides. On the simple vagina follows the uterus, one branch of which, the 
longest, runs straight backwards, often a short distance beyond the anus, whilst its anterior and shorter branch runs, also straight, as far as the region in front of the bulb of the cesophagus, always supposing that the uteri are full. The branch which rums backwards, and at the same time gradually diminishes, cover's the entire intestine, and lies upon it, so that only the spot where the anus is situated remains free; if it be empty, the dark intestine shines through it distinctly. In the neighbourhood of the anus the uterus bends round towards the other side and runs forwards in the form of a considerably diminished finally linear chord, filled with granular yelk-masses, terminating in narrow convolutions behind the vagina. The branch which passes forward runs not so much upon, as close to, and on the inside of, the intestine, stomach, and œsophagus, pressing these organs more towards the outer wall of the worm. It also bends round at last quite anteriorly towards the other side, passes consequently to the outer side of the intestinal canal, and then runs backwards beneath it to just in front of the vagina as an ovary, terminating here in five convolutions, like the other brauch. It is difficult to see this in mature individuals, and I could not succeed in it, until at last I hit upon the idea of taking these worms out of my own fæces, with which one or two Oxyurides pass off daily. These I laid immediately upon a glass, covered it with a glass cover, and added some of my saliva. In about three hours the animals had deposited all their eggs, with peristaltic movements of the uterus, which expelled the eggs, 5--12 at a time, by jerks, at intervals of about 5-10 seconds. At the same time the margins of the uterus became crumpled, and the uterus appeared quite empty and without cpithelium. These movements of the uterus lasted for some hours after the last eggs were laid. Professor Vor Wittig, of Königsberg, who happened to be visiting me, was able to observe this oviposition with me. Pressure sometimes causes the vagina to open again when it has closed. The eggs, the form and size of which we have already described, are present in immense numbers, and are formed in the same way as the ova of other Nematoida, and contain the most various steps of development, from the segmentation of the yelk up to the filiform coiled up embryo within the egg-shell. The eggs which pass last out of the vagina have a small light point at one pole, probably the remains of their attachment and of their place of 
formation. During deposition they cane from the vagina, sometimes singly and in the direction of their length, sometimes several together, and even in the direction of their transicrse diameter.

General physiological remarks.-The locality of these worms is the lower part of the intestinal canal, especially the rectum, but they also pass further into it, and even into the small intestine, at least into its lower regions. Certainly such statements as those of TVulf, Brera, and Bianchi, who profess to have found them in a sac between the membranes of the stomach, in the œsophagus of a woman who had died from lingering nervous fever, and in one of the ventricles of the brain, are, as Bremser has already said, observations which no one will believe who has not seen them with his own eyes. Their further wandering within the intestinal canal itself, when the worms are otherwise found living free in it, will surprise no one, as the worms notoriously even wander out of the anus and into the vagina of females, in which, however, they must find a nourishment rather different from the intestinal mucus. Whether they can wander into the urethra of boys or men I do not know. It is a superstition to ascribe them alone or principally to childhood. I was myself consulted by a very old Saxon general on account of these tormentors; a second subject, the most troubled of any of my patients, was between forty and fifty years of age; and I myself still suffer from them in my thirty-sixth year, and only two years ago expelled from myself a young Ascaris lumbricoides. In short, thread-worms are limited to no age, and to no particular part of the world. They have the privilege orer other Helmintha, of being the tormentors of every age and every people.

The mode of their migration into the human intestine has already been referred to.

Action, diagnosis, and prognosis.--According to the number of individual worms present, and their position, their actions are various. A few worms scarcely produce any symptoms; numerous worms, especially when they are situated in the lowest part of the rectum, make themselves observable by an extremely troublesome itching in the anus and its external neighbourhood. C'ertain foods, especially carrots, onions, fruits, \&c., render the worms particularly restless, and they are then troublesome during the whole day with the itching referred to. In many cases this 
itching is laid to the account of the Molimina hamorrhoidalia, whilst it is a purely mechanical phenomenon. If the worms be not disquieted by any particular canse, the annoyances cease during the day but come on all the more violently when the patient goes to bed. For this renson I am inclined to regard the Oxyurides as nocturnal animals. Then they wander ont of the anus, keep off sleep, and make it restless, especially in irritable children; although adults, and even old people, are also tronbled in their sleep by this cause. The consequences of the constant itching are not only a general disturbance of the nutrition by the prevention of sleep, but it leads, after the age of puberty, to increased sexual irritation, onanism, \&c., in both sexes. The latter phenomena occur especially when we have to do with the female sex, and the worms wander into the ragina, which takes place not very unfrequently, and gire rise to mechanical irritation of the ragina, lencorrhoen, pruritus, \&c.

'The diagnosis can only be cstablished with certainty when worms are obserred in the eracuated frces. The quickest way of getting a clear diagnosis is by a clyster and the examination of the freces.

The prognosis is unfarorable, as although the disorder may certainly be relieved, it is only got rid of with difficulty, even with age.

Treatment.--I may be excused from enumerating liere all the remedies which lave been recommended for these worms. Internal remedies are in general but little to be recommended. Whoever has had to do with the expulsion of Trenice will, however, have had the opportunity of sceing that when the anthelmintics administered have been carried rapidly through the bowels by the addition of purgatives, they frequently remore a great number of Oxyurides. This applies especially to those which are administered in the form of powder, or in that of a difficultly soluble extract; for example, my extract of pomegranate-root, the powder of Kousso, Pamna, Filix mas, \&c. Thus Dr. Pockels, of Holzminden, gives Filix powder and Jalap in some sweet juice. With me, the long-continued use of a tea made from Flores Verbasci proved to be of good service. The flowers are left in the infusion, and used with it. The fine hairs of the flowcrs appear to irritate and disturb the worms meclanically. Violent diarrlocis, as well as violent purgatives, ouly diminish the numbers of the worms, but never entirely destroy them. 
Clysters, with various matters added to them, are the most adrisable remedies.

Sömmering expelled the worms from his son by a clyster of olive oil; others praise garlic-, wormwood-, or valerian-clysters, or clysters with an addition of Oleum Claberti, or Oleum animale Dippelii. Dujardin saw an abundant discharge after an addition of aloes. For my own part I believe that simple cold water clysters effect just as much as those just mentioned, but those of salt-water with oil still more. Very recently I' hare administered clysters of Natron santonicum (4-8 grains to a clyster for adults, for children one half), with the addition of two clrops of oil of anise, with good results. In the less obstinate cases these clysters are sufficient even when only the ordinary short mouthpiece of the clyster-syringe is introduced into the anus. Quict sleep is obtained by ordering the patient a clyster daily before going to bed. Cure can only be attained by long-contiuued nightly lavements, and in obstinate cases by making use of an elastic mouth-tube or catheter which has lately been recommended, especially by Griesinger, and which is introduced as far as above the flexura sigmoidea. In this way the stream of the enema reaches to the Oxymides above the flexura sigmoidea, which is a principal point. Unfortunately a great number of those specimens of the worm which conceal themselves belind the folds of the rectum escapes the action of the elyster. To those who are seut to the baths on account of Molimina lecemorhoidalia, to use alkaline aperient waters, and who observe Oxyurides in their fieces, and are also annoyed by them, especially at night, I would earnestly recommend the use of these waters in the form of lavements. It is also salutary, in order to remove the specimens which hare wandered into the small intestine, to administer Natron santon. internally for a couple of days, and afterwards strong purgatives, in order to remove or destroy the worms, which easily swell up and burst in water.

This is not an unsuitable place in which to refer to the time when anthelmintics should be administered. Popular belief places the most suitable time when the moon wanes; the same thing was taught by the old physicians, and even at the present day, surgeons who have much to do with worm patients say that at the time of the rane of the moon the greatest number of patients come to them to complain about their annoyance. As 
I suffer myself from Oxyuris vermicularis, it came into my mind to attain certainty upon this point by the daily examination of the faeces for Oxyurides, for some time. The results of these investigations, which were not made without some self-sacrifice, and which I continued from the 27th August, 1855, to the 25th July, 1856, were published by me in the 'Wochenblatt der Zeitschrift, der K. K. Gesellschaft der Aerzte zu Wien.' In the 329 days of observation, 93 Oxyurides passed spontaneously on 49 days during the wane of the moon; and during the increase of the moon, in all, 57 worms on 36 days. In the time from the full of the moon to its last quarter, there were 19 wormdays, with 41 worms; in that from the last quarter to new moon, 27 worm days, with 46 worms; in that from the new moon to the first quarter, 15 worm days, and 23 worms; and in that from the first quarter to the full moon, 22 worm days, with 38 worms, so that the weck from the last quarter to new moon, and after this, the week from the first quarter to full moon, would be the best adapted for the expulsion of worms. It would, however, of course, not be right to confine ourselves to these periods, when time presses. These periods are only to be used as a means of supporting our attempts at cure; good anthelminthies expel the worms at any time. The particular days of the phases of the moon have no essential influence upon the spontaneous passage of the worms, any more than days on which an eclipse of the sun or moon occurs. Of the particular days, it would appear that the most favorable for expulsion would be September, with 16; December, with 11; and November and February, with 9 days on which worms passed spontaneonsly; next to these, January and June, with 8, and July and October, with 7 such days; the least farorable are April, with 5, Mareh, with 4, and May, with 2 days.

\section{Strongyli and their allies.}

\section{A. Stronyyli veri.}

Corpore subcylindrici, utrinque attenuato; capite nudo, rarius alato, 2 appendicilnes lateralibus armato; ore terminali, nudo vel sex papillis instructo, vel orbiculari; cesophago triangulari, musculoso; cute temui. Mas: appendice multilobata aut radiata; penis simplex, vel duplex, multilobatus, ad digitorum instar. 
Femina: caudâ obtusâ, rectâ; ano in parte caudali; vaginâ antrorsum sitá; utero simplici ant bitoculari; orulis ma!gnis (0.06-0.12 mill.) Animalia ovi-aut vivipara.

Dujardin treats of the Stronguli veri as the fourteenth genus of his Nematoïles. Diesing lias treated of the two species here referred to in different places, and placed the Strongylus yiyas in his Genus LIV, Enstrongylus, of which he gives the following description: "Corpore subcylindrico, utrinque sensim attenuato, capite corpore continuo, ore terminali, orbiculari, papilloso; bursa maris terminali, integra, pene filiformi longo, hand raginato; vaginâ aut antrorsum aut reirorsum sitâ; systemati yangliorum distinctissimo. Animalia ovi-ant viripara, extra tubum intestinalem habitantia."

\section{Strongylus gigas. Tab. VIII, figs. $a, b$.}

Synon.: Enstrongylus gigas (Diesing); Lumbrici in renibus (Blasins); ant renalis (Redi); Lumbricus sanguineus in rene canis (Hartmaun); les rers sortis des reins et de l'uréthre (Moublet); Ascaris visceralis aut renalis (Gmelin); Asc. canis et Mustele martes (Schrank); Dioctophyme (Collet-Neygret); Fusaria visceralis aut renalis (Zeder).

Corpore mubro, cylindrico, longissimo, utrinque attenuato, striis aut annulis transversis interruptis et 8 fasciis fibrarum lonyitudinalium instructo; capite obtuso, truncato; ore orbiculari 6 papillis aut nodulis planiusculis, appropinquantibns; resophago 15-22 mill. circiter longo, tenui et anynstiore, qnam canalis intestinalis.

Mas : corpore antrorsum magis attemato, 110 ad 140 mill. = 10" -1' longo, 4-6 mill. lato; caudâ obtusấ cum bursấ membranaceâ patelliformi, circa 3 mill. latâ, truncatâ; pene tenuissimo simplici.

Femina: corpore utrinque attenuato, 2 decim. ad 1 metr. = 5"-3' longo, 5-12 mill. lato; caudế magis rectâ, obtuso-rotundatê; ano triangulari, oblongo, sub extremitate caudali sito; vaginâ antrorsum sitâ; utero simplici; ovulis fere glabulosis.

Bremser has already shown that this worm, which occurs, although rarely, in the abdominal cavity, the omentum, but especially in the kidness and winary bladder, more rarely in the lungs and liver, and only when strayed in the intestinal canal of martens, dogs, wolves, seals, otters, oxen, and horses, is still more 
rare in man, and that a great number of those acconnts which speak of worms passing off through the urinary passages are delusions, and consequently belong to the section of Pseudoparasites (Psendolielmintha). A portion of the older histories of cases may also, perlaps, refer to Ascarides or Oxyurides, which passerl outwards in consequence. of the production of intestino-vesicular or vesicnlo-vaginal fistulæ, or to membranous aud polypous blood-concretions, which from their round form were regarded as Strongyli, and which had probably olstained this form from the nreters, and when they were smaller from the tubuli uriniferi.

Since the knowledge of the fibrinous casts in the urine of patients suffering from Bright's disease in the kidneys, one source of the errors into which our forefathers fell, in stating that they had seen worms pass off with the urine, is certainly abolished. Bremser has already proved, that the rorm of Tulpius was only a coagulated fragment of blood; and also doubted the cases of Paullin and Barly; and with regard to Decerf's case, maintained at the same time with Dumeril, that about fifty worms, of $6-8$ inches long and of the thickness of the stem of a feather, as well as the thimmer worms, $18^{\prime \prime \prime}$ in length, which were evacuated from a man suffering with bloody urine in two months and a half, were only coagulated fibrine, whilst he certainly does not regard it as quite improbable that the body first passed, $14^{\prime \prime} 8^{\prime \prime}$ in length, and of the thickness of a quill, which was covered with blood, and was said to have been thrown away, was really a Strongylus. The cases of Lawrence and Barnett also belong, according to the common investigations of Bremser and Rndolphi, to the fibrinous coagula. What Bremser here still found doubtful, and regarded as Entozoa, of which he says that it is not improbable that in the smaller specimens, which were only passed once, out of the 800 - 1000 structures evacuated within a year, we have really young Strongyli, as may be seen from his figures, tab. iv, figs. 6-10. These, in my opinion, resemble at the utmost rolledup Trichocephali, but might have been equally well fibrinous coagula, as the woman suffered from pain in the loins and bladder witl retention of urine, and therefore probably from Bright's discase. How long such coagula retain their elasticity out of the urinc and in lnkewarm water, varies according to size, and other conditions. Dr. Wagner writes me, that he not long since saw such eylinder's keep very well for eight days, 
at the ordinary temperature of a room. It is therefore by no means improbable that congula of the size figured by Bremser might certainly keep, and retain their elasticity for forty-eight hours in warm water, so that I regard this case also as one of Bright's disease, associated with an abundant effusion of fibrine. Bremser regards the following cases as undoubtedly true.

1. That of the Archduke Ernest of Austria, wloo died in 1595, as gorernor of the Netherlands, and in whose kidneys Hugo Grotius found a stone and a still living worm, which had gnawed the neighbouring parts, i. e., had eaten into them.

2. The case of Ruysch, who was already acquainted with this worm in dogs.

3. The case of Blasius, who once found two of the "red worms, which often occur in dogs," of the length of an ell, in the lidners of an old man.

4. The case of Albrecht, who saw a soldier, after seven days' retention of urine, pass a worm of three fingers long and of the thickness of a quill through the urethra, with immediate relief.

5. The case of Raisin, in which a worm of three inches long passed from a man of fifty years old, after two years of renal colic with bloody urine, when a cure took place (a case which does not appear to me to belong to Strongylus gigas, on account of the small size of the worm, as even males of two years old are usually larger).

6. The similar case of Duchateau.

7. The case of Rhodius, who saw a round living worm of a span long passed with the urine, without any previous or subsequent urinary disorder, from a man prostrated by a violent fever, on the firth day of illness (a case which also appears suspicious to me, as an Ascuris lumbricoides may have been in question here, which had roluntarily wandered ont of the anus, and might have fallen accidentally together with the urine into the nightstool or chamberpot, whilst these were being used for making water).

8-12. The cases of Chapotain, Monceau, Holler, Remner, and Scheuk, in which worms were evacuated with the urine.

13 perhaps. The case of Hähne, in which a specimen occurred in the thoracic cavity. And-

14. One of the most certain cases, that of MLublet. A boy who had been freed from a calculus in the bladder, in his third year, by Moublet, was attacked in his tenth year by a violently painful swelling in the region of the loins, with scanty secretion 
of urine. Much pus flowed from the opened tumour, and the wound healed up. The disorder was renewed repeatedly for three years, and the operation was repeated. At last a worm, five inches long and of the thickness of a quill, came out of the wound, and finally a second worm, four inches long, but then complete retention of urine occurred, until two similar worms passed shortly after each other, and a perfect cure was the result.

Diesing enumerates only the cases of Blasius, Ruyseh, and Moublet, and adds to them a case of Bobe Morean ('Journ. de Méd.,' xlvii, Mai), and one of Stratton in the year 1843, which, however, he has furnished with a ?.

These are about all the cases in which true Nematoida come in question at all, and which might be regarded with some probability as Strongyliss gigas.' But nevertheless some of the eases here referred to may not so mnch have concerned this species of worm as the Ascaris lumbricoides. If therefore there is no doubt that Strongylus gigas is to be reckoned amongst the Entozoa found in man, we must undoubtedly be astonished that the worm has remained almost entirely unobserver since the time when the pathological anatomy of man raised itself to the rank of a science, so that even Diesing refers to no certain case of recent oceurrence. A case recently observed by Dr. Schenten, and repeatedly referred to in the 'Deutscher Klinik,' for 1855 (for example in No. 39), which was at first described with much certainty as Strongylus of the kidney, consisted, according to Gurlt's investigations, only of a blood-coagulum from the tubuli of the kidney. In animals also it appears to have become and to be becoming more and more rare, and it is not difficult to suppose that in a short time we may have to do only with a historical and extiust species of worm.

For this reason it cannot be expected that $I$ shall be able to make any essential addition to what the few authors who lave dissected this worm have observed. What I ascertaince fiom a specimen kindly furnished to me for examination by M. Gurlt, and already dissected by him, and from another female specimen, the investigation of which was not permitted me, but the dissection of which could not have been of any use to science, relates merely to details of size.

[' There is a fine specimen of this worm, taken from a humau kidney, in the Museum of the Royal College of Surgeons of England.-Trass.] 
When fresh, according to the statements of all authors, the worm has a red colour, which, I believc, only differs a little from that of very fresh, unwatered Ascarides, by its deeper red tint; in spirit this colour bleaches, and the worm becomes of a leaden greyish-blue. Four longitudinal stripes may be counted upon it.

The total length of the female, in the minjured spirit preprration at my disposal, was 19 Saxon inches; the vaginal orifice was fully 2 inches from the thinner extremity, which I have taken for the mouth. Dujardin says that the vagina opens about 1-2 inches from the caudil extremity, according to the size of the individual. To me the vaginal opening appeared to lic perhaps 2 inches from the moutl, at least to judge from the dissected specimen. In the dissected specimen the empty uterus measured $5 \frac{3}{4}$ inches in length, and was $\frac{1^{\prime \prime}}{4}$ broad; but the vagina was 1 inch in length. The ovaries disentangled as much as possible, and measured by the inch rule, with an approximative calculation of their terminal convolutions, gave a length of 83 inches. These ovigenous organs ran backward to the thicker ond (anus) to within $2 \frac{1}{2}$ inches from this. The osophagus was rather thin, muscular, widening posteriorly in a clarate form, and almost $1 \frac{1}{2}$ inclies in length. Diesing ascribes a distinct nervous system to this worm, saying, "in hac saltem specie systema gangliorum manifestissinum; and Blanchard also, as well as Von Siebold and Otto, speak of such a system. Blanchard, namely, has indicated two chords running down along the animal, and cerebral ganglion-like swellings in their course, as nervous branches, whilst the other two last-named authors only regard as a nervous end that visible longitudinal line which is to be seen along the middle of the ventral surface, which commences with a swelling in the head, and also terminates in the head, and during its progress gives off filaments right and left withont exhibiting ganglionic dilatations, and the finer structure of which differs essentially from that of the transverse muscular fasciculi. The ganglionic enlargements of Blanchard are nothing but puckerings in the course of these chords, which certainly occur usually in spirit specimens, hut are only found in fresh and living Strongyli, where the worms are met with in a contracted state. Only when we shall know something certain with regard to the analogous longitudinal chords occurring in Ascaris humbricoides, will the explanation of these be possible.

Symptoms, diagnosis, progress, prognosis, and therapentics.Without prejudice to any author, we may assert that we know 
nothing either of one or the other. If several worms, or one large female be present, the kicheys will be enlarged and an enlargement will be detected lyy palpation, percussion, and perhaps by inspection; but the eause of this swelling, of any How of blood from the urinary passages, or of any existing retention of urine, would only be recognisable when worms have actually passed from the bladrler. Therapenties can only interfere after the passage has taken place, and then only to alleviate irritation, by mucilaginous or oily remedies, which pass into the urinary passages, such as emulsions and mucilaginous decoctions, and tea.

2. Strongylus longevaginatus (Diesing) $=$ Filaria hominis bronchialis (Rudolphi), seu Hamularia subcompressa (Treutter and Rudolphi). Pl. VIII, fig. $2 a$ and $b$.

In the year 1790 , Treutter, on opening the emaciated body of a man of 28 years old, weakened by onanism, venereal excesses, and mereurial treatment, with a hereditary predisposition to dropsy and consumption, found in the unnaturally enlarged bronchial glands small worms measuring more or less than an inch, which were elongated, roundish, somewhat compressed laterally, blackish-brown, sometimes spotted with white, somewhat diminished towards the anterior extremity, semi-transparent towards the posterior extremity, and incurved at both ends after death. Aceording to him there were two moveable, projecting hooklets on the head. The indistinet eaudal extremity was obtuse. Of this Treutter made a peculiar genus, with the following description: "Corpus lineare, teretiusculum, caput obtusum, infra 2 hamlis prominentibus instructum." But Bremser with perfect justice disputed the independence of this genus, proved that the worms in question must be distinguished from the Filarice which occurred, for example, in the thoracic cavity of the shrikes, and reckoned amongst those worms which Rudolphi, Olfers, and Leuckart, as well as Natterer had found in the lungs of the species of Mustela. He also supported this opinion by the circumstance, that, according to Treutter, these worms were attached by the proboscis with such extraordinary firmness to the mucous membrane, that they could only be removel from it with extreme carc, and scarcely without tearing them to pieces, as is the case in the Entozon of the Mustelc. 
Bremser also indicates the two hooklets, as the pair of prominent penes, and consequently what Trentter calls the anterior part of the body, as the abdominal extremity, and the specimens found as males. Diesing has adopted this latter idlea, and has also placed the worm, found in 1815 , by the army-surgeon Jortsits, in Klausenberg, in Licbcnbürgen, in the substance of the lungs of a hoy of six ycars old, living partly free in the lung and partly adherent to the substance of the lung, along with 'Ireutter's Hamularia subcompressa. Tre accede to this opinion the more willingly, as the occurrence of Treutter's worm in the bronchial glands, which was doubted by Rudolphi, can furnish 110 reasons for separating these two Entozoa, as it is proved that Strongyli not only dwell willingly in open cavities (bronchi, intestines), but also in neighbouring glands (glandule meseraica et bronchiales). The young worms also, found by me in the lung of a shecp, which lived in tuberculous nodules and glandular swellings of the lungs, appear, according to Von Siebold, to have been the brood of Strongyli. Diesing has treated of this worm in the Genus LI, Strongylus; Sub-division ** os limbo papilloso. †Caput haud alatum, 2, bursa maris biloba, as Species 2., Stron. gylus longivarinatus, and described it as follows:

Caput truncato-conicum haud alatum : oris limbo papillis (labiis milii) $4-6$.

Corpus subcquale rectum albofuscum, maris antrorsum, femince, utrinque parm attematum; extremitate caudali maris inflexa; bursa subcampanulata bilobata, lobo singulo 3-radiato; vagina penis bicruri, cruribus longissimis linearibus, dimidice fere corporis longitudinis, aurantiacis, transverse tenuissime striatis; femince apice mucronata, apertura genitali supra cauda apicem.-Viviparus. Long. maris 6- $\mathbf{\gamma}^{\prime \prime \prime}$, crassit $\frac{1^{\prime \prime \prime}}{4}$; femine longit ad $\mathrm{I}^{\prime \prime \prime}$, crassit, $\frac{1 / \prime \prime}{3}$.

I regret that $I$ am unable to furmish any better figures of this worm. Rokitansky's stock contained only fragments of it. The bottle belonging to it had been plundered by an unknown hand. Diesing gave a denial to my request for a couple of specimens, or a figure, although I offered him preparations in exchange, "because his new species and genera would be illustrated by figures in the Memoirs of the Imperial Academy."

With regard to the consequences of worms in the lungs of animals, see 'Annales de Méd. Vét.,' 1855, p. 653, and 
Hering's 'Report,' 1855, xvii, p. 14\%, as also Gurlt's 'Mag. Supp.,' 1855. A worm-cough was observed in the form of a chronic blonchitis, for which Assafœtida, J̃j, with Ol. Chaberti,


In some young geese which were dull, and troubled witl agitation of the head, opening of the beak, and efforts to romit, with a croaking voice, and froth on the beak, Przibijlko found red coils of worms in the air-passages and their branches.

\section{B. Ancylostomum.}

Synon. : Anchylostoma (Dubini); Ancylostoma (Creplin).

According to Ton Siebold, the description of Dicsing, who refers to this worm as his Genus LII, is to be altered in the following manner, with the aid of Dubini's description.

Vermes subcinerei, vivipari, corpus cylindricum ; caput aliquid attenuatum; pharynx infundibuliformis, colore subfusco, parietibus resistentibus. Os acetabuliforme, subcorneum; apertura oris amplu circularis subdorsalis; dentes in fundo oris intra aperture marginem abdominalem 4 uncinati (os in altitudine infundibuli 4 uncinis intus recurvatis munitum et in fundo cum eminentiis conicis, in tabularm explicatione " punguli tegumentarii" nominatis, in uncinos versis, utrique generi communibus, Dubini) ; cesophagus carnosus, qui ad clave instar inter descendendum largitur; cutis transverse striata, unde 2 eminentice conica prominent, una alteri opposita, inter sextam anteriorem partem longitudinis vermiculi iotalis et inter reliquas posteriores vermiculi partes, quœ quinquies sextam longitudinis totalis partem exhibent; anus lateralis et aliquid ab extremitate caudali remota. Extremitas caudalis maris bursam terminalem integram, subtus ex cisam multivadiatam ex appendiculatam; penem duplicen longissimum exhibens; femina obtusa, aperturam genitalen retrorsum sitam prebens.

This worm, found by Dubini, in Milan, in the year 1838, in the human duodenum and upper part of the jejunum, and subsequently also by Pruner, Bilharz, and Griesinger, in the countries watered by the Nile, but which, according to Von Sicbold, has never yet been found in Europe, on this side of the Alps, but may, perhaps, as it appears to me, occur also in 
Icelaud, was established by Dubini, as a separate genus, Anchylostomm, and exlibited by Von Siebold to the meeting of naturalists at Gotha in 1852 as Stromgylus quadridentatus, but this name has recently been retracted by him, as Dujardin hiact already employed the name of Sclerostomum quadridentatum for the Strongylus tetracanthus (Mehis).

With resard to Dubini's proceeding in establishing a new genus, Ancylostomum, Von Siebold mentions that, from the horny nature of the capsule of the mouth, this worm might certainly have been arranged in the genus Sclerostomm, but that, nevertheiess, the genus Ancylostomum, established by Dubini, may very well be allowed to remain, as the parts of the mouth of this worm are distinguished from all other Strongyli by the asymmetrical arrangement of the dental apparatus.

Of the genus Ancylostomum, we are at present only acquinisted with the single species-

\section{Ancylostomum duodenale. PI. VI в, fig. 16-29.}

The synonyma of which have just been spoken of.

The description of $A$. duodenale ruus as follows, according to Diesing's description as improved by Von Siebold.

Caput apice rotundatum; oris limbi papilis conicis incequalibus, duabus minorilus, uncinis papillis impositis apicibus convergentibus. Corpus subrectum v. parum curvatum, anteriore parte transparens, ventriculo globoso nigrescento, posteriore flarido-fuscum, maris antrorsum attemuatım, extrenitate caudali inflexá; bursâ cyathiformi bilobâ 11-radiata, cujus radii ita sunt positi, ut triplicem eorum ordinem conspicere possis, in utroque enim latere ordinem quatuor, media in parte trium radiorum (radiis lateralibus utriusque 5 simplicilus: Diesing); radio dorsali apice furcato; femince extremitate posticá acute conicâ. Longit; rnar. 3-4." ; fem. $4-5^{\prime \prime \prime}$; crassit. ad $\frac{1}{8}{ }^{\prime \prime \prime}$.

As soon as the attention of Bilharz liad been called by Ton Siebold's letters to this worm, which had already been found in Egypt by Pruner, he found it in nearly every corpse, sometimes in small numbers, sometimes in hundreds of specimens, less in the duodenum than in the jejunum, between the transverse folds of the mucous membrane. One male is found to three females. At the oral end we observe a large, obliquely truncated, horny capsule, 
furmished with four strong teeth on the projecting portion of the upper nargin. The oral orifiee is turned towards the dorsal surface; that is, towards the surface opposite to the sexual and anal orifices. The animal attaches itself with its mouth so firmly to the mucous membrane, that the mouth is easily torn away when it is detached by force. Its nourishment is blood, as the intestine filled with this fluid proves. In the region of the middle of the osophagus, the secretory organ first found in the Strongyli by Von Siebold opens outwards, and forms behind the orifice an ampulla, produced by the union of two sacs, which pass backwards in a somewhat tortuous form, and a little way behind the commencement of the intestine become converted into fusiform (glandular) bodies. The contents of this organ are thickly fluid and finely granular, with a clear and apparently rather solid nuclens, of a perfectly homogencous appearunce in the middle of the two glandular bodies. The double penis is very long and slender. In a pair once found in coitu, the male was firmly adherent to the vagina of the female, by his caudal valie.

Pruner, as well as Diesing, has misunderstood the parts of the month in Ancylostomum. The former says, it fixes its four-fold sucking proboscis, with forty hooks, upon the mucous membrane. Von Siebold says upon this, that, as the spacious oral cavity of this worm is bent round with its wide aperture towards the back, the lower margin of the oral aperture is more strongly produced than the upper, as we perceive in a lateral view of the worm. Now within this lower margin, but not upon the upper one, and consequently at the bottom of the oral cavity, stand the four teeth bent round backwards, springing close together from four elevations of the horny walls of the oral cavity, but not arranged in the manner of a cross, as Diesing has it, and as is the case in Strongylus tetracanthus.

The two conical projections are cutancous papilla, which project from a small cavity in the skin in the middle of the clavate esophagus. They are processes of the tramsparent general integument, in the middle of which there is a small acute process of the substance situated under the skin. According to Von Siebold, they are perhaps tactile organs, employed by the worm when adhering by suction to the human mucons membrane.

Even Dubini spoke of corpora fusiformia, and also figured them. They make their appearance in both scies, and arc analogous to 
the secretory organs discovered by von Siebold in Strongylus auriculatus, and other Nematoda.

Pathological anatomy, symptoms, and therapeutics.-This worm is by no means of so little consequence to the individuals attacked by it, as one might perhaps think, and this depends particularly upon the number of the worms. We give the following, after Griesinger, who is the best clinical observer of this disorder.

The worm attaches itself firmly by biting into the mucous membrane and submucous tissue; the spot on which a worm sat is indicated by an ecchymosis of the size of a lentil, in the middlle of which a white spot of the size of a pin's head appears, which is pierced by a hole of the thickness of a needle penetrating into the submucous ligamentous tissue. From these wounds the blood often enters freely into the intestine, and then we find such a piece of intestine entirely filled with bloor which has flowed out of the punctured places. Frequently, however, the mucous membrane of the iutestine is beset with flat, livid, brownish red elevations of the size of a lentil. This is the case when the blood collects in a small cavity between the muscular cont and the mucous membrane. In this case, a specimen of the worm, having penetrated the walls of the intestine, often lies within this cavity itself, covered with blood, with which it has also completely filled itself.

One consequence of this disorder is anæmia; and Griesinger concludes that the chlorosis, so gerierally diffused in Egypt, which he had previously described as the "Egyptian chlorosis," and which in a greater or less degree attacks at least one fourth of the population, is produced by this worm.

Lower degree of the disorder.-Paleness of the gencral integument and mucous membranes, a gurgling noise in the jugular veins, tendency to palpitation of the heart, habitually quickened pulse, slight bodily lassitude without emaciation, often with a fat and heavy appearance, and occasional slight disturbances of digestion (Gastro-enteritis, or more correctly C'atarrhus intestinalis) occur. If this condition remains uncured for a long time, it passes through many intermediate steps to the higher degree of the disorder, which closes as chlorotic marasmus. Emaciation often commences rather late, œdematous swellings are formed on the lower extremities, on the eye-lids, \&c.; the skin, which 
was previously strongly pigmented, becomes dingy pale yellow, yellowish or greenish white, paler and grayer even in negroes, and at the same time very withered, flabby, dry, peeling, and cool ; the conjunctiva bluish white, the lips and all visible mucous membranes almost as pale as death. Great dulness and apathy in every movement, general weakness and exhaustion, come on with vague pains in the joints, constant palpitations of the heart, with enormous intensity of its beating, returning upon the least movement, and frequently also pain in the region of the heart. The second sound of the heart is sometimes audible even at a distance of several paces; in auscultation, either both sounds are equally loud, or the first sound is short and weak, not clear, diffused, or combined with systolic, vesicular, whistling murmurs; the pulse is very frequent and small; there are murmurs in all the larger arteries, and a loud rushing is audible in the jugular vein, with a purring which is sensible to the touch. In individual, very rare cases, all the signs of an organic disease of the heart or aorta are met with. The patients complain of giddiness, frontal and temporal headaches, and rushing sounds in the ears; the respiration is frequent and short, and the respiratery murmurs weak ; after a few days dyspnon occurs; in many the chest is emphysematously enlarger. The urine is abundant, pale, and very rarely contains albumen. Besides these, constant hunger, singular appetites, occasional staius gastricus, with slight febrile movements, slimy coating of the tongue, and sensibility of the lower part of the abdomen, are exhibited. The spleen is occasionally a good deal enlarged, the liver frequently diminished in size. In short, a high degree of anæmia and hydramia is perceived. With indulgence and good fare, this state often lasts for years, in many cases its progress is very acute. But even with great care the individuals remain pallid, sickly, and miserable; slight acute diseases which make their appearance, are very serious, and at last dysentery carries off the patient. Only occasionally a patient recovers by a change of climate and all other conditions of life. Fatiguing labour and debilitating antiphlogistic treatment hasten the end. Or the patients die from diarrhor, general dropsy without albumen in the urine, \&c., in spite of all the iron and wine.

In the bodies we find, watery infiltration in various places, flabby pale muscles, great anamia of all parts, especially the brain, the lungs, the stomach, and the intestual mucous mem- 
brane; the substance of the heart, especially the inner layers of the muscles are very pale and even fatty; the heart is generally large and thick, hypertrophied and dilated, especially on the left side; the endocardium and the valres often irregular and thickened; the veins cmpty ; the heart contains small, soft, brown coagula with a little fibrine; but frequently both in the heart and in the larger veins, there is only a fluid of the colour of serum, with a few pale, large blood-corpuscles; the spleen and kidneys like fatty wax. The liver, and, more rarely, the spleen exhibit general uniform atrophy. All these circumstances usually make their appearance in Europe in persons suffering from chronic hremorrhage, as, for instance, in consequence of perforating ulceration of the stomach, althoigh dysentery and bilious typhoid often bring the melancholy scene to an end sooner.

Therapeutics.-Unacquainted with the real cause of this disease, Griesinger had alternately administered iron, quinine, and a Calcaria phosphorica, and frequently produced considerable relief but never a cure, in slight cases, whilst in serere cases he effected nothing. During one of lis last dissections in Cairo, howerer (17th April, 1852), a sudden light broke in tpon him on this subject, when he found the duodenum, the jejunum, and even the upper half of the ileum entirely filled with fresh, red blood, only coagulated here and there, and thuusands of Ancylostoma on the mucous membrane of the small intestine, each with its little ecchymosis resembling the bite of a leech. Atthough he thus left Egypt, and could collect no further clinical observations, he cried to the Arabian prosector, "You must now employ calomel and other anthelmintics against these Ancylostoma and the Distoma of the portal vein, in short, against the tropical chlorosis, as well as against hæmaturia, stone, dysentery, abscess of the liver, and all the undetermined diseases of tropical countries, perhaps even some of the tropical fevers, and inrestigate the latter illness itself, with reference to the most recent Helminthological discoreries." Abore all things: Griesinger praises calomel and oil of turpentine ì priori, the latter, indeed, especially for the Distoma of the portal vein, above all, for the Ancylostoma, as it certainly reaches the worms situated in the uppermost parts of the intestine; in substance, worms die in it very readily, and it also acts as a styptic upon the injurerl, bleeding vessels. This last remedy when mixed with castor oil, or with castor oil and a few grains of santonine, or the natron san- 
tonicum, to which vegetable purgatives are added, must prove particularly efficacious. None of oul colleagues working in the tropics shonld forget that tropical chlorosis is the consequence of the repeated, small intestinal bleedings, which scarcely betray themselves exterually, caused by intestinal worms, especially Ancylostoma.

\section{Filarice.}

With Dujardin the Filarice form the seventh genus of the first class "Nemutodes," or the first genus in the second section of the Nematoda (Nematodes ore rolundo, triangulari, ant cam aut sine papillis, sed sine lobis prominentibus; mares spiculis 2 incqualibus). Diesing refers to them as Genus XL of the Order VI (Nematoidea). This genus he has arranged in his system in the Sub-order II, Proctucha; Tribe III, Gamonematoidea; Section I, Hypophalli.

Diagnosis: Vermes albi, subfusci, aut rubri, corpore filiformi, elastico, cylindrico, ut plurimum longissimo, capite corpore continuo, inermi aut spinulis rectis et corneis (dentibus, seu papillis prominentibus Autorum) armato; ore terminali non labiato, vel labiato, rotundo, aut triangulari; resophago brevi, tubuloso, rectiore quam intestinum; ano terminali aut ante cauda apicem sito; cute lavi aut leviter oblique striatâ.

Mas: caudd plerumque obtusa, interdum membranam accessorian alosam exhibente; spiculis filiformibus in vagina tubulosa aut ligulaformi, ex Dujardino incequalibus, curvatis (?). Femina: vagina antrorsum, proxime ad os sita, plerumque duplici (Filaria rigida) aut multiplici (exc. quinqueloculari in Filaria labiata, Nathusius) ; ovulis ellipticis ant globosis, laceribus. Nunc ovi-nunc vivipare.

From the Gordii they are distingnished by their structure, mode of life, and the nature of the youngest brood, and also, according to Diesing, by the circumstance that they readily burst in water like other Nemutoda, which is not the case with the Gordii.

\section{Filarin medinensis.}

Pl. VIII, fig. 3 ; and Pl. VII, fig. 9.

Mares ommino ignoti aut potius ab auctoribus neglecti et omissi, 
quia ab minorem nagnitudinem minores efficiunt et molestias et dolores et vix unquam majores tunores; sed, uti Diesingius ipse enarrat, a Clellandio in 'Calcutta Journ. of Nat. Hist.' i, 359, Pl. X, fig. I, delineati.

Femince : corpore longissimo (ad 3 ulnas et aliquid supra) subalbo, filiformi, subcquali, secundum Dujardinum antrorsum, sed secundum D)iesingium, et quidem, quod ipse affirmare possum, retrorsum seusim attenuato, ad $1^{\prime \prime \prime}$ seu all $1-2 \frac{1}{2}$ mill. lato; ore orbiculari, spinulis 4 cruciatim oppositis; caudâ ad apicem uncinata, subacuta, in apice 0.065-0.082 mill. $=0.028-0.036^{\prime \prime \prime}$ Par.: $=0029-0.037^{\prime \prime \prime} V$. latâ, interdum in vermis ipsius cute ita "ffixâ, ut vix apicem liberum facere possis; vayinâ; ovulis; embryonibus $1^{\prime \prime}$ longis, vix $\frac{\frac{1}{4}^{\prime \prime \prime}}{4}$ latis. Species vivipara.

The Filaria medinensis, which was first placed by Gmelin amongst the true Helmintha, was first mentioned, according to the usual statements of authors, by the geographer and philosoplier Agatharchides of Cnidus, who was the teacher of Ptolemæus Alexander. It is to him, at least, that Plutarch refers in the ninth question of the eighth book of his 'Symposiacon' (Tabletalk) where he makes him narrate "that the people taken ill on the Red Sea suffered from many strange and unheard-of attacks,


edition of which I make use, it says only " amongst others little suakes') came out upon them, which gnawed away their legs and arms, and when touched again retracted themselves, coiled themselves up in the muscles, and there gave rise to the most insupportable pains; but that this evil has only been found then, and neitler before nor since amongst any other people." In this description the addition that the evil never occurred amongst any other people is especially accidental, and is certainly an addition of Plutarch's, who lived at a period in which the intercourse of the Greeks with the East, and especially with its more remote regions and the coasts of the Red Sea was so rare that the Greeks never came in contact with the countries in which the worm is endemic, and cousequently could neither see patients of the kind in these countries themselves, nor the worm brought into Greece by those who had visited those regions. Moreover, it is not clear, as only fragments of Agatharchides are extant, whether he had himself visited those regions and seen the disease or had only obtained a knowledge of it by hearsay in Egypt, on 
the southern and eastern borders of which the worm still oceurs. But however this may be, it is certain that Agatharchides knew very well that there was a disorder in those districts which owed its origin to a snake-like structure, which we now know as a worm, and indeed as Filaria medinensis. Many authors, led astray by the last addition "that these creatures lave never occurred anywhere else, or subsequently" have thought, certainly erroneously, that the narration of Agatharchides, quoted by Plutarch, was nothing but the altered tradition of the fiery serpents which the Lord sent upon the children of Israel during their stay in the neighbourhood of the Red Sea (Numbers xxi, 6). At the same time it was supposed either that this Mosaic narrative had been explained erroneously and arbitrarily by Agatharchides himself, or that it had come to lis ears in a mutilated form, by hearsay.

If we have thus ascertained that Agatharchides really intended the true Filaria medinensis, we are at once led to a repeated examination of that Mosaic passage, which has in fact rendered it not improbable to us that Moses is the first writer who has referred to our worm, and that he has really meant the Medina


before Seraphim it appears (to which M. Michaël called my attention) that a particular species of Nachasch (serpents) is referred to. All the translators (the Polyglott bible and the septuagint) have rendered both words by óp๕ıs, and in the parallel passages also (Book of Wisdom, xvi, 5 ; and 1 Cor. $x, 9$ ) we also read only ópacs. It is clear that the translators took no trouble about it, and only translated the word Nechaschim, but left the word Seraphim quite untranslated. Had they been

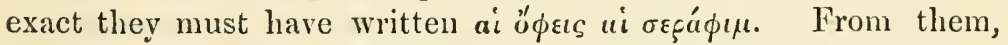
therefore, we learn nothing, and we must go back to the primary signification of the word Seraphim, which the commentators render by draco, serpentulus venenatus or comburentes dolores faciens. In itself, Seraphim, derived from the word Saraph, can signify nothing more than is, qui comburit, and it is clear that a species of animal is referred to which is distinguished by the inflammability of its bite, or generally by the inflammation which its presence causes. On this account Laborde thought that scorpions are referred to in this passage, an opinion which I cannot allow to pass, because in the first place the scorpions have nothing in common with the serpents in their exterual form or 
in their movements, but resemble the crabs and spiders; $2 \mathrm{~d}$, because the old Hebrews knew very well how to distinguish

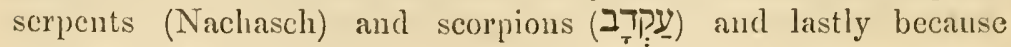
those bitten by scorpions quickly die; but although "much people" of the Israelites certainly died, yet a great number, who lookerl upon the brazen serpent, were saved.

Data as to the mode in which the Nechuschim Seraphim annoyed the Jews is to he found in the seventh verse, where it

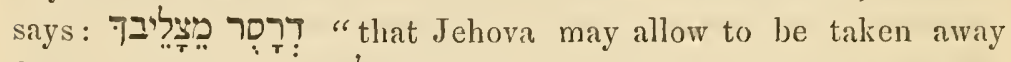
from upon us." "The על Mealeun literally indicates a disorder" occurring upon the Israelites, hut might also, according to M. Michael, indicate its lying upon them like a burden. Now it is certainly known that at the Cape, suakes creep in the night into the trowsers of the sleeping Boërs, and that scorpions also crawl into the clothes, but they do not trouble or wound man when lie does not strike, press, or otherwise irritate them. Moreover, when snakes inflict wounds, they do it withont remaining upon the person; come to him unseen, but not upon him. But if we understand the by literally, it suits the Filaria very well, as it occurs immediately beneath the skin and produces boils and tumours upon its surface. That in ancient times the Filaria was reckoned amongst the serpents on account of its suake-like form, is proved at once by the Greek name $\delta$ gakóvтเov $=$ dracunculus, that is to say, a species of snake, which had something fabulous and inexplicable alout it, which might certainly from its form be regarled as a serpent, but which from its nature could not pass as a snake with quite so much propriety. The inflammatory pain and swelling, which occurred with the breaking ont of the worm, are certainly very well expressed by Seraphim, the mortality amongst the Israelites is easily explained by their ignorance of the treatment, and the dangerous symptoms occurring in conseqnence of the breaking of the worm, which, according to the statements of some anthors may be immediately fatal. Thus, for example, Avenzoar expressly narrates, that, in his native country, "ager" in continenti post dolorem vehementem in parte affecta exortum moriatur." At the same time, we must not forget that the disorder being endemic in that place of sojourn made its appearance as an epidemic, as frequently occurs, and that endemic disorders raised to epidemics, always proceed with more dangerous symptoms than as cndemics. Hence the great mortality of the Israelites. 
Shortly after the death of Aaron, which took place on the first day of the fifth month, of the fortieth year after the Exodus from Egypt, and whilst the Israclites passed round the land of the Edomites, from Hor towards Oboth on the way from the sea Suple (which was probably that part of the Red Sea indicated on the maps as the Sinus Acnalites, or, in the present day, the Bay of Akaba), they were attacked by the fiery serpents. Consequently, both from the geographical position and the known observations which we possess upon the time of incubation of the worm, which lasts from two, three, six, to twelve months, this agrees very well with the explanation, that the Filaria medinensis is here referred to. On their long march from Egypt, which they had left in the neighbourhood of Atakeh and Suez, the Israelites had passed probably by Ayun Musa, upon the Asiatic territory, and thence moved towards the south as far as Mount Sinai, along the east eoast of that part of the Red Sea Sinus Heroopolites, which is now known as the Gulf of Suez. Here they turned again directly to the north, through the midst of the land, until at last they had arrived a certain distance to the north of the extreme apex of the Gulf of Aenala = Akaba, where the Erlomites compelled them to return towards the southeast. Only in the last portion of the way through the desert of Zin towards Mount IIor, but especially on the way from Hor towards Oboth, and rom the territories of the Edomites, for which jonrney they certainly required several months, did they come into the true district of the Medina-worm, namely, the central and eastern portion of Arabia Petrea, the plain which stretches away towards the coasts of the Bay of Aenala. This entire march from the wilderness of Zin to Oboth they would undoubtedly have passed over within the period of incubation of the Medinaworm (two months to one year). Here the Filcrice first broke up, with violent, infammatory pains. Thus then, with their further progress towards the north.east through Arabia Petræa, the Israclites contracted the Filarie which are still indigenous in Arabia Petraea, and this worm-province may consequently be of importanee and interest to the geographers in the determination of the course of travel in the fortictl year of the Israelites' wanderings. We are convineed that a careful investigation of these facts on the spot will completely confirm our opinion; and wo hereby thank M. Michaël for his assistance in the investigation of this question. 
As regards the cure, which Moses contrived, we can cxpect nothing else but that from its direction it must have been a theosophical, mystical one. "And Jehovah commanded him to make a Saraph, and he made a Nachasch Nechoseheth (a brazeı serpeut) which he commanded the Israelites to look upon, if they would live." This comes to the same thing as the mode of serpent-charming still in use in the Last, and, perhaps, the method still employed, if I am not mistaken, at the Cape of Good Hope, to drive away certain snakes by the sight of other serpents. It is possible that Moses had a similar idea, but also possible that another therapeutical signification lies hidden in the background. Thus, we may suppose either that Moses wished by the figure of the serpent to give warning against the perilous breaking of the worm, and to indicate that only those could become sound, who had extracted or got extracted a creature like the uninjured serpent, or it is an indication that in this case a brazen instrument, perhaps a sort of circumcising knife (which even then was formed of metal, whilst the Egyptians used kuives of flint) or a hot iron, which is still in use amongst the people in Abyssinia for opening the boils of Filarice, might be of use, and that, hy means of the brazen serpent, Moses desired to make his countrymen more patient under the operation.

I think, therefore, that there is great probability that the fiery serpents of Moses were the Filarie, and that Bartholin, the only commentator who has seemed to understand the Filarice thereby, is in the right. No importance is to be attached to Sennert's opinion that the fiery serpents fell upon the Jews from without, and did not grow in them, after what I have said above with regard to Mealenn. The worn may grow for a long time upon and in the individual, before it becomes large enough to produce pain, and break up with inflammation and dangerous symptoms.

If we return once more to Agratharchides, we find, in the first certain traces of acquaintance with the worm, after him, amongst the Arabian surgeons, who, according to Bremser, call it Ark, Aerk or Irk Almedini, which is rendered Vena seu Nervus medinensis by the Greek and Latin translators in the middle ages, who, having no opportunity of secing the worm, and as it was not introduced into Europe even by the crusades (because the crusaders at the utmost advanced to the neighbourhood of Jerusalem, and did not penetrate into the territory of the Filaria), 
disseminated all sorts of nonsensical opinions about it. Thus, some regarded it as a tumour and abscess from heated bloor, or a boil (Paré, Aldrovandi, Montanus and even Larrey), or as an apostheme (La Faye), an elongated vein (Gui de Cauliac), a corrupt nervous substance (Soranus, Pollux), as black bile (Tagentius), and as tumours and glands of the skin (Fielitz). The names Vena saniosa, by error in writing (printing?) Vena famosa, and further Vena meden, medeme, civilis, medinensis, cruris sive exiens, egrediens, mediana, aud Vena Eudimini, are all synonyms produced in this fashion. As I am unacquainted with the Arabic language, I songht for the Hebrew root analogous to the Arabic Ark, I found the word $P$ ע, which is the same as corroded or "to corrode, or gnaw away." The notion of colrosion obtained from this agreed very well with our worm, which is described by Agatharchicles as having such an action, and I therefore applied to Dr. Zenker, of Leipzig, with the inquiry whether the Ark almedini of Avenzoar and Rhases might not probably be translated "the Medinian gnawer, or id quod corrodit Medinenses," regard being had to the Hebrew Arak. Upon this inquiry I received the following communication, to use as I pleased. "As regards the signification of $I r k, A r k$ or Arak almedini, a certain judgment can only be given after an iuspection of the text, which, however, only exists in mannseript, and is not accessible to me. Your supposition, however, that it must be rendered "the Medinian biter or gnawer" is quite correct. The Arabic Arak $\approx$ \# namely, the flesh from the bone, hence Ark of the bones. The substantive (nomen actionis) of arak is ark or irk and signifies especially guawing, gnawing away, as an action, a signification which is very well adapted for the name of a worm. The explanation would be still more easy, if we read $\ddot{a}_{1}$ arek, with a long $a$. 'This would currespond with the Arabic participle (nomen ayentis), and would have to be rendered the gnawer or the gnawing one. The question is now, which of the two words stands in the Arabic text. The translation nervus medinensis leads us to conclude that it is $\ddot{3}$ - and corresponds with the vocillization irk, (rein)." In order to obtain information as to the mode of writing in the original text, I applied to my friend Dr. Hille, junr., well known as the editor of the Araban Oculist, who sent me the following kind answer. 
Unfortunately, in consequence of the revision of the royal library no origiual was at the command of my friend, and his numerous copies of Arabic manuscripts only relate to ocular subjects. According to Dr. Hille, however, our views may correspond with the rendering "the Medinian biter, or the Medinian bite," all translators, nevertheless, are against it. Avicenna and Rhazes say, "that the worm occurs everywhere, in the hands, in the sides, but especially on the lower part of the thighs." The vena, as the translators say, issues from the resicle, produced with violent pain and formation of abscess. Of the old translators, Christ. Godofr. Gruner, treats most circumstantially of our worm, and says: "alii eam (i.e., venam med.,) pro pedesellis habent, alii neyant." Moreover, it is not to be confounded vitibus seu tortura vena, which are varices of the crural vein, or with morbus bovinus, a common disease of cattle, regarded as a worm living on the skin, or with the measles of pigs. At the same time he places this disorder with the Diacunculus of the ancients. According to Dr. Hille, the following passage from Gruner, page 219, of the 'Morborum Antiquitates,' sectio II, $x$, removes the difficulty of the explanation of the word used in the Arabic text. "Sequitur inflammatio, tumor, abscessus vesicæ in modum elatus atque demum inde egreditur, Alsaharavio teste, vena admodum subtilis chordce, aut ut Albucasis expressit, quasi sit raclix planta aut animal, aut, secundum Avenzoar, aliquid ad similitudinem nervi, aut denique ex Avicennæ descriptione, quiddam rubeum, ad ingredinem declive et quasi ramus villi nervi." Thus Dr. Hille arrives at the conclusion that in the Arabic text it must mean, $=3=I r k=r a d i x$ $=v e n a=v a s$; that the worm is named from its superficial similarity to the root of a plant, a nerve, or a ressel, and that the Arabian surgeons themselves had false notions of the worm $I r k$.

For my part, I willingly admit that even the old Arabians may not have recognised the nature of the disease, with the exception of Albucasis, who possibly suspected that it was an animal. But before I can quite fall in with the opinion of my learned friend, I must remark, that the Arabian surgcons may have found the word already in use, and that the people might have given the thing in question its name from the root Ark = biting. That the word is also still employed by other peoples, which have either sprung from the Arabs or come in contact with them, is shown by the name of the worm in the 
interior of Africa, namely, Arkin, and I beg to call the attention of linguists to this. They may see whether the Arabic word in question does not consequently merit this vocalization rather than, Irk.

Besides, I have still to mention that Galen had a substantive Dracontiasis, in which it is not so much the agent as the action that furnishes the idea from which the word is named. According to this, the superscription in 'Rhazes,' lib. vii, cap. 24, may run, "Upon the Medinian gnawing, or Medinian gnawing disease."

The Arabic word halaluachalaid, which is also employed for the worm, has been rendered by Velsch: serpens pulposus seu musculosus medinensis, tele aranece in modum convolutus. The old Greeks, as already observed, called the worm Soakóntov', from which the Roman surgeons formed dracunculus tibiarum, and Galen the worm-disease, Diakontiasis. In Persia, the worm is called Pejunk, Naru, Farentit; on the African coast, Ikon; in the interior of Africa, according to 'Tuschek, it is called, according to the kind $h^{a} l i n g$, or $h^{\prime}$ alin, from $h^{a} l i$, a tumour or abscess; (which is the more plentiful and readily removed worm, $\frac{1}{4}-\frac{3^{\prime \prime \prime}}{4}$ in thickness, usually $l^{\prime}$ long, snow-white, tough, sinew-like, difficult to tear, inarticulate, with no distinction between the head and caudal extremity, but in other respects has the same position, produces the same phenomena on breaking through, and requires the same treatment), or "rkin, the more malignant form, which according to 'Tuschek's reports, is said, ridiculously enough, to root itself in the abdomen, extending its arms towards the periphery in the manner of the polypes, and when an arm is broken off anywhere, to come again on some other part of the body. The root of these African names is identical with the two abore-mentioned Arabic names, and both names are nothing but differences of degree. $H^{a}$ ling indicates worms oecurring singly in the human body, perhaps partly males, or immature, unimpregnated females; ${ }^{a} \cdot k i n$, adult, large females, which occur at the same time in several places. In India the worm is called Naramboo, or Nurapoo chalandy; in Bucharia, Irschata; by Kämpfer, it is called Dracunculus Persarum; by Linné, Meyer, and Jördens, Gordius medinensis, (which it is not at all, as our more exact knowledge of the anatomy of the Gordii has shown us, and as was known even to the older writers, such as Löffer and Lind, who never saw a Gordius in the water in the native districts of our worm, and to 
Pallas, who never saw so many Gordii as in the Russian Walder Lake, althongh a Filaria medinensis had never occurred amongst the inhabitants.) Amongst the Germans, it is known as the medina worm, the Guinea thread-worm (Guineischer Fadenwurm), the skin-worm (Haut-), leg-worm (Bein-), and Pharaoh's-worm (Pharaohswurm); the Guinea dragon (Guineische Drache); by Warenius it is called Sehnadernspuhwrm; by the Dutch, Huid-, Been-, traadworm, guineiscke Draakje; by the English, the Guinea hair-worm; in French, le Dragonneau, le ver de Guinée, le ver cutané, la Veine de Medine; by the Portuguese in America, culebrilla, (probably a diminutive of coluber); by the Swedes, Onda-Betet, Tagelmatk.

Besides the errors disseminated by translators with regard to the position of the worm, we have still to mention that many describe it as the larva of an insect; even Brera inquires "au heruca;" and Jacobson, of Copenhagen, regards it as an asexual germ-sac.

Our knowledge of the natural history of the worm is at present rery deficicut. It is of the thickness of packthread, its anterior extremity obtuse, the mouth circular, without lips, but beset with four hooks, or, more correctly, with four styles, as the weapons on the head of the Filaria form acute, straight spines; the vagina operis in the neighbourhood of the mouth, and the vagina and nterus are probably double, as in most Filaria. I have not yet examined the head myself.

The length of the worm varies from several inches to three yards. Statements of greater dimensions are probably founded in error. In such cases, several worms must hare been taken for one,

With regard to the Filarice, we find, in the 'Gazette Médicale de Paris,' No. 23, 1855 , p. 365 , the following report from the Proceedings of the Société de Biologie for March, 1855.

The Filaria medinensis removed by Malgaigne, on the 13th of July, 1854, from the lower part of the thigh of a man, was, according to Robin, still filled with eggs. Beneath the general integument of the worm, which forms a long, thin tube, there was found, at this period, no trace of other organs or intestincs, but only a very thin sheath on the inner surface of the former, which was filled with eggs, $i$. e., the uterus. The young contained in this were almost all rolled up together, or with the tail springing outwards. They lived for several days in water at the 
ordinary temperature, dried up, and moved again when moistened. 'The body is rather flat than cylindrical, 0.755 mill. in length, 0.026 in breadth, and 0.019 in thickness. The head, 0.010 mill. in breadth, is narrowed; the mouth exhibits thin, small, round warts, which are scarcely visible at this period of existence (as they are also represented by Birkmeyer, so that it is questionable whether we can speak, with Diesing, of four warts). Behind the mouth the body becomes enlarged, and diminishes gradually posteriorly, until it forms a distinct tail, $0.250 \mathrm{mill}$. long, very finely pointed, contractile, very flexible, but not curled, and very different from that of the adult individual, in which it is 1 centim. in length. After death, this tail quickly bends round at the level of the anus.

The whole surface of the worm and its tail exhibit the wellknown fine rings, placed at a uniform distance (about 0.003 mill.) apart. The thickness of the walls of the body is 0.007 mill., and surrounds the digestive apparatus. The substance of the body is homogeneous, finely granulated, and exhibits no trace of muscular fibres. The thick-walled, contractile, and rather straight œsophagus, which is rarely beset with varicose enlargements, and measures $0.179-0.183$ mill. in length, does not entirely fill the substance of the body, although it appears to do so, and the intestine does not adhere to the walls of the body, but between it and the latter there are fine, fatty granulations, floating freely.

The true intestinal canal originates from the cardia, where it is rather more inflated than the cardia, and is, throughout, like the body, somewhat flat. The substance of its wall is homogeneous, without striæe or fibres, but sprinkled with numerous granulations. From the cardia to the anus its length is $0.284-0.288$ mill., whilst the whole length of the alimentary canal, from the mouth to the anus amounts to $0.463-$ 0.467 mill. Behind the anus the intestine is produced into a small, pale, very contractile cæecum of 0.03 mill. in length, into which, however, the contents of the intestine do not enter, and which is followed by another portion of the body of the length of several hundredths of a millimeter, which contains a colourless fluid. The anus is transverse, $0.006-7$ mill. in breadth, surrounded.by a little ridge, or a prominent contractile lip, and allows the intestinal mass to escape.

The worm is indigenous only in the lot zone, and even when it is transported into colder climates, does not appear to propa-

[' See also Busk in 'Transactions of Microscopical Society.'-Trass.] 
gate itself further, there, or to have an infectious action upon the vicinity. But even in the hot zone it does not occur everywhere, but only in particular districts, like all the Helmintha, and is cutirely wanting in certain places in affected countries, as, for instance, in Gambia, Angola, Coulabah, \&c. Particularly notorious places are-Senegal, Gaboon, the Last Indies, Bomluay, the peninsula of India, Persia, Arabia Petrea, the coasts of the Red Sea (especially towards the south), the shores of the Ganges, the Caspian Sea, Upper Egypt, Abyssinia, Nubia (especially in Sennaar, Schendi, Skordofan, Darfu), and Guinea. In America, where it was introduced by Negro slaves, it had already become a native in Curaçoa, even in Jacquin's time. 'Throughout these regions it attacks aborigines and foreigners without distinction of country, or race.

The disorder frequently becomes an epidemic, according to Pruner, in years of heavy rain, and especially in marshy districts. It also appears to occur especially at certain seasons of the year. According to Bremser, it is particularly abundant in the East Indies from Norember to January (the rainy season), and in Upper Egypt, according to Bitharz, shortly after the regular inundations of the Nile.

The mode of production of the worm in the human body is still enveloped in obscurity. Although the opinions of those who supposer the worm to immigrate by means of bad water (Bernicr, Bruce, Nicbuhr to 'Tuschek; the negroes in Schendi, for which reason the water is strained through linen before drinking, or drawn up from a depth of eighteen fathoms in the sea [Arthus], or Gallandat, who says that those who drink no water in Guinca escape), are now being gradually abandoned, and the views of those authors are obsolete, who say that the worm is prodnced by the use of palm wine, Indian grain, and bread (Kaukiens), of certain fishes or of locusts (confusion with Gordius), or that the eggs and young are brought upon the body by the land wind and evening dew, or by rain and wind, they must nevertheless be referred to on account of their general diffusion. The most convincing proof in opposition to the assertion that the worm is introduced into the body by driuking water, was furnished by a companion of Jacquin, who, when in Curaçoa, did not drink a drop of water, which, as a lover of spirituous liquids, was not very hard upon him. But he was attacked by the worm, whilst Jacquin, who drank much water, remained free from it. A Dutch gencral in 
Angola ate and drank nothing but food and beverages brought with him from Europe, and yet he acquired the worm.

It is an important circumstance that English officers, who never went about with the feet and arms uncovered, remained free from the worm. Pruner even thinks that very probably the germ of the worm is an independent marsh animal, and at the same time speaks of a conversion of this animal by an alternation of generation (certainly ill understood), into a Dracunculus within the human borly. Forbes thinks he found the brood of the Dracunculus free in the red, ochreous mud of the drying marshes; a fact which certainly requires a closer investigation and confirmation. However, the aborigines think that it comes from the marsly grounds into the skin. The ordinary seat of the worm is the subcutaneous cellular tissue, especially of the extremities, and of these again especially the lower ones, round the ankle. It may, however, occur under the skin and muscles iu all other parts of the human body, even under the tongue. Thus, Kämpfer remored a living worm from the scrotum; Baillie saw it in a sac on the testicle; Peré on the head, neck, and body; Brijon under the skin on the eye-ball. M'Gregor grives the following table of 172 cases: 124 times in the feet, 33 times on the lower, 11 times on the upper part of the thigh, twice in the scrotum, and twice in the hands. Pruner found a specimen behind the liver, between the layers of the mesentery; the posterior portion was but little altered and readily recoginisable; the anterior portion reached down over the duodenum as far as the crecum, enreloped in a sort of cartilaginous capsule. Sometimes the worm lies coiled up in a small space, sometimes extended; and in the latter case, if it lies on the surface, feels like a varicose vessel. Thus, Peré saw it lying in a snakc-like form under the whole of the skin of the abdomen and a part of that of the chest; Kämpfer saw it come forth under the knee, and the great toe move painfully, as if by a sting, during the extraction of the worm; another worm broke through the leg with one end, its mirldle lay round the ankle, and its other end came out through the sole of the foot. Thus the scene changes according to its seat. These examples will suffice to give a clcar idea of the worm, of which, moreover, as many as twenty-eight, thirty, nay, even fifty specimens have been observel on one man.

Diagnosis and therapentics.-If the worm occurs in superficial 
places with a hard substratum, its growth is scen to take place with extraordinary rapidity, according to Pruner. From 4!" it becomes several inches long in a couple of days. It is then casily killed by poultices of boiled garlic, after which it is absorbed withont any injurious consequences, or when it lies quite on the surface, the latter is cut, and the worm pulled ont with a hook. The slave-dealers rub in eivet and musk at the first appearance of symptoms. Frequently, however, the worm produces no annoyance for a long time. Dampier and Iscrt lad already quitted the native district of the worm for $6-8$ montlis, and Wengler's patient for $4-6$ months, before the worm betrayed itself by any troublesome symptoms. According to others, this may last 12 15 months, and according to Kämpfer cven nntil the third year. At other times the patients become emaciated, notwithstanding a very good appetite, and freedom from ferer, and at last die of exhaustion. When the worm is realy to come ont, a small pustule appears at the point where it will break through, sometimes withont any preliminary annoyance, sometimes with uneasy sensations, lieadache, pain in the stomach, nausea, fever, and formation of resicles at the point of breaking through, inflammation, swelling, and suppuration for sereral days previously; and also, if the worm lies at a joint, with prevention of the use of the limb affected. In Drummond himself stiffness and slight pain in the biceps femoris first set in, withont preventing his walking; in a few days there was swelling without pain, and alteration of colour. A few dars afterwards a reddish swelling, with a black point in the centre, was formed an inch above the inside of the ankle; and at the same time he felt with his finger a firm, round, catgut-like, twisted substance under the skin. Tro days afterwards (about threc weeks after the first sensation of stifiness) Drummond awoke at night with sudden insupportable itching over the whole body, general febrile symptoms, violent colic, vomiting, and purgation; after which shivering without perspiration follower. In the mean time the swelling had burst, and in its place there appeared a hard white substance, but so deep that it could not be laid hold of, because the animal had buried itself deeper amongst the muscles in the night. Nothing more was now to be felt at the surface of the firm, catgut-like swelling. In the following night the neighbourhood of the ankle became inflamed, and on the second day afterwards walking was impossible. 'Three days afterwards Drummond passed a thread round the animal, and then a 
bloody ichorous discharge flowed for 6 - 7 weeks ont of the wound, which gradually healed up to a small point. At this time the worm again came forth, and was fastened with a thread, rolled upou a stick, and drawn out twice a day; in twenty days the extraction was completed. This last case illustrates the history of the worm very well. Trro or three lays after the formation of the resicles these open up, or are opened with a lancet, when matter, bloorl, or sanies, and two or three inclies of the anterior end of the worm come forth. This end is carefully pulled, when several iuclies more frequently follow. All this is coiled round a little roll of linen, a small stick, or a fragment of lead (Avenzonr, Rhazes), which, however, as even Paulıs Riginetus obscrved, is less advisable, and this is fastened over the wound with sticking plaster, and a compress. A cleft stick to fasten the worm into, aud Velsch's armonry of peculiar copper instruments, are of no use, according to Bremser. The extraction is repeated twice a day, until the worm is entirely wound out, which usually takes three or four, but in Africa generally several, montlis. The worm rarely comes away in the first operation; if several worms be present, it may probably be months before the wound, which is to be rreated as a simple tumour, heals up; but this generally takes place easily.

According to Löfler, M'Gregor, Indian surgeons, Bruce, and Peré also, when the worm is felt on the surface of the skin, it may be laid bare, by taking loold of a fold of skin with forceps, making an incision of several inclies long, down to the worm, and removing the worm in a loop, or wedging it into a bit of wood, and then pulling alternately now on the one side, now the other side of the worm; whilst, at the same time, the patient is always kept in a position in which the muscles are relaxed as much as possible. In this way only half the time is employed; according: to Peré, only a sitting of four liours.

But if the worm is seated in the fleshy parts, if the inflammation, swelling, and pain are great, if the worm resist dragging or hreaks off, further assistance from art is necessary. According to Pruner, who also reports that if the worm is not alssorbed or encysted, it is removed hy suppuration, the aborigines, in the latter case, apply cow-dung, open the tumour or vesicle with a liot iron, and sprinkle over it a regetable powder (Sattala). To administer internal anthelminthics I regard as alosurd; all that is to be clone is to combat the gencral febrile phonomena, hut in other respects 
to use local treatment. For this purpose the following applica. tions are particularly recommended: Soft poultices of the Alö̈ litturalis, as relaxing the skin and facilitating the creeping forth of the worn ; binding below the linb, with fomentations of laurel berries and oil (Aëtius); rubbing in of mercurials (Bajous), or when the worm comes away with great difficulty, with Tinct. Myrrh., Aloë, or Aqua vulneraria; or a poultice of onions and bread, boiled in milk (after which the worm is said to roll itself up into a coil, and, according to Bancroft, Griffith, and Hughes, may be easily removed by the arldition of a worm-mixture, which is also especially extolled by Hillary); or a poultice of the burnt leares of the cotton-tree, with Aonara oil; the pouring in of tobacco oil (Barere), and tobacco powder (Dampin), and the blowing in of tobacco smoke (Ludw. Frank). An assafœtida mixture internally, and oil of sesamum externally, have also been strongly recommended. That mercurial pills administered intermally, even until salivation is produced, are of no use, has already been stated by Gallandat. Nevertheless, corrosive sublimate given internally, and mercurial rubbings in, which, according to Löffler, are quite useless, play a great part. The passage of electrical shocks through the worm is useless. Isert ran about much in the water even after the opening. Kämpfer recommends cold douches or cataplasms, and also the application of roasted onions (popular remedy). Linschot recommends the application of butter, Leiter that of sprouting onions boiled in milk, and Löffler that of Linimentum rolatile with Laudan. liquid. But according to Paulus Egineta, and Bremser, the best remedies appear to be soft poultices, with the addition of aloes and roasted onions, which accelerate the suppuration.

Although at present I possess no personal experience on this subject, the most advisable process appears to me to be the following local one, to which bleedings might be added in case of rery violent inflammation.

To relax the skin, let it be rubbed on the spots attacked with an ointment of Belladonna and Digitalis; the patients should be put once or trice a day, for three quarters to one hour or longer, in a general tepid bath, or when the worm has its seat in one extremity, in a local bath of soap and water, or of common salt or sea salt, and attempts made in the bath at extracting the worm. If it be found that the worm comes away rery quickly by this process, the bath and the manipulation in it are repeated. In the 
interval, soft poultices with onions and aloes should be applied to the affected organ.

If, from any reason, no baths can be given, tepid injections of a solution of Natron samtonic. gr. iv-rj, at a time, or of a solution of conmon salt in water with a drop of oil of anise, or of a solution of this salt in a thoroughly strained infusion of anise or valerian, should be made through the wound and close to the worm by means of a syringe with a very fine capillary pipe; the extraction of the worm should be then attempted, and the extracted portion well fistened. The process of cure must he assisted in general by cutting the skin over the worm, in Löfler's method, and also by gentle rubbing and kueading of the places where the worm lias formed knots.

From the most ancient periods the tearing of the worm has been regarded as a very bad accident, although, as observation has shown, not for the reason stated by Dujardin, that the living brood disseminated in the wound immediately give origin to new Filarice. This takes place frequently in consequence of rongh pulling, but also in the most careful treatment. According to Peré and Kämpfer, the worm, when torn or cut emits a white juice, which must be seminal filaments or eggs, according to the sex, and as we only know the females correctly, probably the latter. If the patient does not usually die suddenly in consequence of this breaking, as Avenzoar says, mortification and death may casily follow in a slıort time (Bancroft, Chardin, Gallandat, \&c.), or shortening and deformities of the legs occur (Dubois), or especially lingering fistula, which only heal slowly and with violent pain after they have been opened (as, for example, in Bruce himself). The latter was mentioned by Rhazes, but Gallandat contradicted it, as the worm makes its way ont with remaining fragments, even by empirical treatment with cataplasms. According to the observations of most authors, such as Hemmersou, Lister, and Cramer, who lad themselves suffered from the worms, and whose worms had been broken away, violent swelling, fever, and slceplessness occurred, and were only cured when the worm was killed, which, as Gallandat, certainly incorrectly, states, is the most dangerous thing of all. However, the diagnosis must be carefully made, and great attention must be paid to distinguishing between mere furunculi and furmenli cansed by the Filaria. Incautions surgeons and umprofessional people may very probably have drawn out sinews and nerves under the idea that they were 
the rorms, from which, as a matter of course, violent nerrous attacks, contractions, stiflness of the limbs, \&c., must result. Bremser even upbraids Larrey with only having an ordinary furunculus before him, because the worm does not occur in Luwer Egypt. The latter statement is untrue, for Giriesinger and others have treated the worm in Cairo.

'The prophylaxis is at present unknown. It appears, however, to be most probable, that in the regions where the Filaria is endemic, its youngest brood may live free in the water, or in damp grass, or in the moist soil, and that the brood gets upon the naked parts of the body in wading through the rivers, pools, marshes, or tanks with naked feet, sleeping withont clothes upon the bare ground, or with the water which flows over the naked upper parts of the body, \&c., when carrying water-vessels upon the head or back. Pruner's observation also, that the Filuriu occurs especially in the feet of carnivorons aumais, such as dogs and gulls, and rarely or scarcely ever in those of the herbivora, is well worth consideration. Perhaps it may yet be proved that: besides the higher Carnivora, the water-birds and wading-birds are also attacked. We certainly know nothing further as to whether the immigration is comnected with a certain time of the day, as the young Gordii with the night, and whether any particular care must be taken in the morning, in the heat of the day, or at night. But however this may be, it is for the present advisable that every one, in the native country of the worm, should be on their guard against bathing, wading through streams with naked feet, with torn boots, with shoes over which the water rises, \&c.

It must also be mentioned, that as only females appear to have been found (except by Clelland), some people suppose that the migrating brood must be already impregnated before immigration.

The controversy as to whether or no the worm is so far infectious that it is transferred from a patient attacked by it to other people in his ricinity, is regarded as decided by Pruner, who says, that it is proved by numerous facts that even in those tropical regious where the worm is not endemic, an actual transfer from one man to another, or to dogs and horses, takes place. The clearest proof of this, on a large scale, is furnished by Bremser in the statement that, even in his time, the worm had become naturalised in Curaçoa by the importation of negro slaves. This leads necessarily to the prophylactic precept, that no one should 
use the same vesscls that are employed by the patient in bathing, washing, or washing the feet, and that great caution should be observed with the bandages of such patients. As regards the prevalence of infeetion with the worm at particular seasons of the year, people are aceustomed to seek the reason for this in certain conditions of climate and season, but as far as I know, they have entirely overlooked the causes which lie in the nature of the worm itself. The principal question to be cleared up here is, whether the maturity of the eggs, that is to say the development of the living embryos, like their parents, is not connected with particular seasons of the year and with certain months. In the mean time double caution is to be observed in the native country of the worm at the periods which have been found by general experience to be most dangerous for infection.

There are still the eases in which Filaria medinensis has been seen under the conjunctiva, which are deserving of particular consideration. Of these, that of Mongin in St. Domingo, and that of Bajon in Cayenne, are the most authentic. Mongin's patient complained for twenty-four hours of a violent pain without inflammation. A worm appeared to creep across her eye. When Mongin wished to seize this worm with the forceps, he observed that it was between the conjunctiva and the albuginea. If the cornea was approached from without, violent pain was produced. He then opened the conjunctiva and drew forth a worm $l_{i j}^{1}$ inches long, of the thickness of the E-string of a violin, thicker at one end than at the other, but punctured at both enrls. This case serves as a rule of action when the seat of the Filaria is in this plaee.

\section{Immature species of Filaria found in the human lens.}

Besides the Filaria medinensis a second speeies has been found in Europe in the human eye, which been mentioned by authors sometimes as Filaria oculi humani, and sometimes as Filuria lentis (Diesing). All my endeavour's to obtain the original specimens have been in vain. M. Jüngken, who had the eourtesy most readily to permit iny inquiries, informed me that he had handed over the specimens found in a first ease, to the well known deceased helminthologist, Von Nordmann, and given the Filuria found in a second case to another student of lielminthology. The Filarie of Von Ammon and Gescheidt, which Von Ammon 
most kindly wished to procure me a sight of, were also no longer to be found. Consequently I can only communicate what I find on this subject in literature. To what species this Filaria belongs, I do not know; it is probably a Enropean Filaria of the domestic animals (either the Filaria lachrymalis of horses and cattle, or the Filaria obtusa of the swallow, most probably the former species, from the size and the region in which it usually dwells).

Os orbiculare, inerme. Corpus breve subcynale, spiraliter involutum, extremitate caudali maris .... . ; femine clavata apice mucronata (?). Longit. $\frac{3}{4}-5 \frac{1^{\prime \prime \prime}}{2}$; crassit: vix $\frac{\mathrm{I}^{\prime \prime \prime}}{5}$. (Diesing.)

In one case of Jïngken and Nordmann, two fine and extremely delicate coils were perceived in the Morgagnian fluid of an extracted leus suffering from gray cataract; under the microscope these were found to be coiled Filarice. One, as stated, was injured; the other, minjured one, was of the same thickness throughout, perfectly filiform, $\frac{3^{\prime \prime \prime \prime}}{4}$ long, very thin, coiled up in a spiral, and dead. The intestine was distinct and simple, the mouth without visible papillæ, and dark corpuscles were deposited in convolutions round the intestine. The anus protruded in the form of a pad.

In a lens obscured by Cataracta viridis lenticularis, extracted from an aged woman, the same authors found a living Filaria, $5_{\frac{1}{2}}^{\prime \prime \prime}$ in length, and apparently moulting.

(The other, second case cited by Nordmann, which is mentioned by Larrey and Meckel, certainly relates to Mongin's Filuria medinensis under the conjunctiva mentioned under species 1.)

In the case operated on by Von Ammon, and observed by Gescheidt, the tolerably large lens was yellowish-brown, and rather pulpy externally, and furnished intermally with a hard, stellate, whitish-yellow nucleus; its fibres, which were arranged in regular strix, were distinct, entangled, and not unfrequently crossed. On the inside of the lens, three Filarice seated upon the lens were seen; of these, one lay more upon the surface, and was, as well as the second, about $2^{\prime \prime \prime}$ in length, and of a white colour; the third was scarcely $\frac{3^{\prime \prime \prime}}{4}$ in length. The two larger ones were females, according to Gesclicidt, but it is not said whether they were perfectly mature. They lay tolerably straight, with the tail a little bent inwards; only the anterior part of the body was slightly tortuous. The third, and smallest specimen, 
was more of a reddish-white colour, arranged in a spiral form, and Gescheidt leaves it undecided whether it was a nuale or a female. The worms were very thin, of the same thickiess throughout, more acute towards the head, and more clubbed towards the tail, but had always a thin, short, crooked point. The mouth was small, tolerably circular, withont papillæ (lips). 'The intestine was yellowish, straight, without curvature, and without dilatation, and opened into a simple, round orifice, without any prominence. The ovaries were delicate, spiral cylinders, rumning close to the intestinal canal, and, according to Gescheidt, opening at the same place as the amus. For my part, I cannot admit that proof is given that we have to do here with females and ovaries, or that the opening of the ovaries into the anns, as above described, could have taken place (a circumstance unknown in the females of Filarie, and indeed in all the females of nematode worms with which I am acquainted). They were undoubtedly quite immature animals, and the opening of this cylinder into the anus was certainly a mistake of Gescheidt's. The tubes terminated in blind extremities at both ends, as in the Trichine, which, indeed, as already remarked, are said to be produced from Filaria, and in the case of certain species of Trichince may really originate therefrom.

Progress.-The reaction comnected with the immigration and growth of the Filaria is probably but small in general, but such guests may very easily give the first tendency to cloudiness of the lens and cataracts. Their diagnosis in the living subject must be rendered possible by the assistance of the ocular mirror; their prognosis falls under that of cataract; their therapentics are those of cataracta lentis, with the limitation, however, that when these worms occur in the lens every one must consider that the extraction but never the mere depression of the lens is indicated; when situated in the cornea they are removed, like foreign bodies, by simple incision.

\section{Ascarides.}

These worms, described by Dujardin as the nineteenth genus of the Nemaloda, and as the fourth gemus in the fourth section (Ascaridia), are treated of by Diesing as Genus XX in Order VI of the Achathelmintha elastica, but the Oxyuri are also introduced into this genus. The true Ascarides stand, according to Diesing, 
in the Subdivision II, Euascurida, and these arain in Division I, Apterocephate (caput non alatum), and in their principal section A, Gymnoascaridae (corpus inerme). Dujardin, to whom I adhere here, and who has separated the Ascurides from the Oxyurides, describes the former as follows:

Ascarides: corpore albo aut subflavo, subcylindrico, utrinque attenuato, fusiformi, 4 striis longitudinalibus subalbis, opacis, linearibus, instructo; cute transverse striatâ, capitc tubus, valvulis (labiis) convexis aut semilunaribus, interne finestratis, asophago valde musculoso, cylindrico ant claveformi; ventriculo cavitatum tiangularum prabente.

Mas minor, quam femina; extremitate caudali aliquid curvata et involutâ, nunc nudâ, nunc membranâ alutâ duplici, aut duplici tuberculorum et papillarum ordine aut rarissime acetabulo instructá ; cauda breviore, obtusiore quam in feminis; spiculo aut pene duplice plus minusve longo et arcuato.

Femina cauda rectiore et longiore; vagina slmplici antrorsum sitâ; utero bi-aut multiloculari; ovariis filiformibus, longissimis, duplicibus ant multiplicibus; ovula elliptica aut globulosa, extus lavia. Species aut ovi-aut vivipare, plerumque in tubo intestinali viventes.

The only-species to be referred to here is,

\section{Ascaris lumbricoides.}

It is placed by Dujardin as the first species in his first subgenus. Ascarides verce (uteris 2 brachiis paralleliter ad caudam versus directis instructa), Sectio prinea: Ascarides resophago simplice aut cum aut sine ventriculo, sed sine appendicis pyloricis. With Diesing one species stands as above, A. Gymnoascuridce, c. corpus utrinque cequaliter attenuatum. 49. Ascaris lumbricoides, Limé. With the sole exceptions of Goeze, who calls the worm Ascaris gigas, and Zeder, who names it Fusuria lumbricoides, authors have retained the Linnean name Ascaris lumbricoiles for this worm.

Vermes albi aut rubro- pallidi, cylinarici, in extremitatibus attenuati, fusiformes, elastici; cute transverse subarticulata striis transversis 0.02 mill. inter se distantibus, ex duobus stratis composita, 4 lineis lateralibus longitudinalibus subalbis majoribus capite distincto, parvo $(0 \cdot 7$ mill. lato), tribus valvulis semilunaribus, prominentibus, ad margines hyalinis armato, interne denticulatum musculorum stratum ad galli jube modum prebente; cesophago 
musculoso, 6-8 mill. Ionyo, filiformi, trituetro, ventriculo claveformi $(0 \cdot 7$ mill. lato, $2-3$ mill. longo) parvulo, intestino simplici valvulis aut villis et epithelio polyedrico sparsim instructo.

Mas : 150 ad 170 mill. $=1$ ad $66^{\prime \prime \prime}$ long., 3.2 mill. lat., cauda aliquid depressa, conica, inflexa et curvata, spiculis 2 planis, sub. ensiformibus, fere rectis, 1.8 mill. ad $2 \cdot 12$ mill. longis, 0.18 ad 0.23 mill. latis. Oryano spermatico simplici, 1200 mill. lonyo, testiculo caco perparvo, retortiformi, funiculo spermatico albo-intumido, ductu ejuculatorio angustiore ad ani latus sese aperienti. Spermatozoidia globuliformia, granulosa, in fenince vagina muturescentia.

Femine : 200 ad 275 mill. et supra longa $=8$ ad 18" ; media in parie 4 ad $5 \cdot 5$ mill. lata; caudâ conicâ obtusấ; aut aliquid ante cande apicem sito (1 mill. circiter); vayinâ simplici ante corporis dimidium silä, ex maynitudine feminarum variabili (ex. c. 85 mill. pone caput in femina 245 mill, et 103 mill. in femina 214 mill. lomya); utero ab initio simplici, bipartita aut biloculari. Ovaria filiformia, sensim attenuata, retrorsum usinue ad anum, et antrorsum supra vaginam aliquantuhm pergentia. Totalis ubiusyue ovarii longitudo ad $44^{\prime \prime}$ Lips.

Ovula immatura subtriquetra, numero 4 ad 8 conglomerata, matura isolata, rotunda, ad 0.087 mill. lata, cum testâ tenui, lavi; in natura libera sensim embiyones evolventia.

As regards the head of this worm, we find it to be distinctly composed of three patpillie which ean uncloubtedly be spread out upon the intestine, in a broad, circular, sucker-like surfice in the sucking-act of the worm. 'Their moveability is shown not only by the lighter notelies at their base, which indicate that the papillae or lips move as it were in a sort of hinge, but also by the cock's-comb-like structures in their interior which are nothing but muscular fibres, connected by means of a thin stratum running through the hinge just described, with the general museular system of the body. Bremser has seen the opening and closing of these papilli, and described the mechanism. He even reports that at the moment of opening, he saw a little tube protrude from the centre, which is the true oral orifice. Wedl thinks this the cleft proboscis, which is everted from the oral aperture for the reception of nourishment. I cannot give the name of oral aperture to this everted eylinder; the true oral aperture is formed by the opened lips or papilla ; the small tubule in the centre represents the Introilus faucium. Its protrusion is perhaps as much an active one by its own 
muscular structure, as a passive one by the contraction of the general muscular system of the boty. As regards the four whitish streaks on the sides of the worm, of which two are broader than the others, I have already stated, that these streaks prove to be cylindrical cords, in the interior of which a sort of hollow canal is detecter, which appear to present almost dendritic diverticula. There is no doubt that these cords are hollow canals, and in fact the remains of the fat-canals. In Ascaris lumbricoides these cords may be recognised as hollow canals throughout the whole subsequent period of life. The peculiar dendritic appearance in the interior of this streak is ccrtainly due to the unequal contraction and the collapsing of the walls of these retrograding canals.

The males and females may be distinguished during life, even by their form and external appearance. The female has the abdomen slender, fusiformly pointed: the male is bent round like a hook, and sometimes exhibits, at a short distance from the tail, a pair of white, delicate, projecting hairs, which are the protruded penis. The female shows two; lut frequently, when one orary runs rather further back than the other, only one thick, white cord, usually somewhat thimmer posteriorly, which terminates about $\frac{3}{4}-1$ inch, or $1 \frac{1}{2}$ inch from the caudal extremity, and is surpassed posteriorly by a brown cord, the intestine. The male exhibits a simple, white, tubular sac, constantly becoming wider posteriorly, which reaches to the anus, lets nothing more be seen of a brown intestine, and may be traced nearly to the extremity of the tail, as it opens here with the anus. If the female be pressed upon the body, or allowed to swell in water, a prolapsus of thin tubes (ovaries) and a discharge of a milky mixture (eggs) takes place in the anterior half of the animal from the vaginal orifice. If a male be pressed, a milky juice (the seminal globules) flows out in the neighbourhood of the anus, without the occurrence of a rupture or prolapsus, which are only produced very late, if at all, when the male is laid in water.

There is an error of Werner's to be mentioned here, which Wedl quotes; he says the penis may swell up into a club, because it stands in comnection with a thick seminal duct. This could only be the case if the penis of our Ascaris were perforated, and seminal corpuscles could pass into it. That this is impossible I have already mentioned. The matter is very easily explained. In Werner's case, the apex and the base or root of the penis were still within the external orifice of the scxual organs, but the 
middle (end) had protruded in a hemispherical form through the sexual aperture.

Of the intestiual canal we have only to say, that its commenccment is whitish and muscular, and that the oesophagus, which is composed of thick layers of longitudinal and transverse muscles, passes rapidly and without any particular constriction, into the intestinal canal, which is thin-walled, coated with epithelium internally, and shines through of a brownish colonr, from the brown excrement. This intestine is also furuished with a muscular layer, which is connected by fine ramifications with the cutaneous muscles (longitudiual and circular layers).

Between the two layer's of the cutaneous muscles, which send fine, fungous excrescences towards the skin, vacuoles occur, which give issue to a pale-reddish, oily, albuminous substance, and this is the bearer of a peculiar odorous matter, which adheres to the Ascuris lumbricoides in spite of the most careful washing, is very distinct from that of human excrement, and in course of time communicates to the spirit in which such worms have been preserved this peculiar odour, which is possessed by no other entozoon. I can, however, state nothing more exact with regard to this matter.

The external integument, according to Czermak, consists of six layers. It is formed of bandlike transverse rings, which do not run back into one another, but are frequently cleft dichotomonsly, and, with few exceptions, are suddenly interrupted at those places which correspond with the lateral lines of the animal. Betwechi the outer layer and two layers of fibres crossing each other obliquely, and two laid at a right angle over each other, Czermak saw a sixth lomogeneous layer, exactly like the membrane of the so-called mother-vesicles of Echinococcus. It appears to contain the oily, reddish, strongly odoriferous fluid just referred to, which exhibits the following phenomena of refraction: the membrane is donbly refractive, and in such a mamer that the directions of oscillation, which cross each other at right angles, are parallel to the longitudinal and transverse axes of the animal. These observations are confirmed by Wedl, who makes the phenomena analogous to those secn in the substance of the lens.?

Symptoms, diagnosis, and prognosis of the Ascarilles.-Although I cantiot say that I agree entirely with the words of De Filippi, 
when he says, "l'osserruzione dimostra che ospitanti ed ospitati virono in perfetta armonia; gli uni non disturbano il regolare procedimento delle favi vitali negli altri;" I nevertheless express the opinion, that, as a general rule, in the case of Ascurides, the liost and his guests agree very well together, and give one another very little mutual trouble. Notwithstanding their size, the Ascarides, in themselves, when staying quietly in the intestine, and when they do not oceur in too great numbers, bring but little danger to the constitution. They probably do not live at all npon ready-formed juices, but, for the most part, upon unelaborated chyme. A good appetite is almost the whole injury they do, and thus they are much less noxious than, for example, the much smaller Ancylostoma. An abnormal aggregation of Ascurides in the intestine, and a very firm coiling of them amongst themselves into an inextricable knot, may cause mechìuical obstacles in the interior of the intestinal canal, which may degenerate from simple, temporary stoppage, especially after certain foods, with congestion towards the brain, and all sorts of reflex phenomena caused thereby, to actual ileus. This may be easily understood, when we know cases, for example, in which the body of a child harboured hetween 300 and 400 Ascurides, or in which 103 of these worms were expelled from a child. But in general these phenomena are extremely rare, and, when they do occur, are usually transitory. All kinds of disturbances and perversions in alimentation, such as flatulency and tendency to diarrhoas, are especially produced after certain articles of food, and frequently only occur after offences against proper diet. It is only the worms which have been disturbed in some way, which renders the doctor uecessary, whether the disturbances are produced by causes in or ont of the worms. Internal causes of agitation, that is to say, those which are seated in the worm itself, are perlaps only to be found in the sexual actions. But here we find curselves upon a field of which we are totally ignorant, as we do not know whether a periodical maturity connected with particular seasons, and a periodical seeking of the females by the males do or do not take place. The smallest Ascaris which I have seen, and which I still preserve as a microscopic preparation in my collection, I expelled from myself, at the end of July. It is the sexually immature rorm already mentioned, of about $l_{2}^{1}$ inch long. We must therefore quit this subject, by openly confessing that the canses of excitement to 
wandering and restlessness seated within the worm, are entirely unknown to us. Causes whose seat is external to this worm, are those whicli act disquietingly upon the worm from the intestine and in its interior, the first cause of which is sometimes to be songht in changer and irritating nourishment, as is the case, apparently epidemically, at the period of the great general clange of diet towards the spring, antumn, and winter, and sometimes in morbidly altered anatomical or functional conditions of the intestinal camal. If, then, the worm be disquieted by any causes, it begins to wander about in the intestine which it inliabits, producing all kinds of disorders, which may even lead to death. According to the irritability of the individual, the number of the wanderers, the place to which they have wandered, and lastly, according to the power of the worms themselves of asserting their vital activity, so varies the danger to which thesc wanderers give rise. The irritations which cause the worms to pass out per anum, are not only inmocent, but even curative. This is the case especially when the worm has been disquieted. Sudden, very watery diarhoeas carry it away mechanically, after swelliug it up, and destroying its adhesive power. We see this particularly in cholera. But if the worm passes to the gall-ducts, in which it can continue its life, say at least for some days, it may produce all kinds of hepatic disorders, as, for instance, catarrh of the gall-ducts, nay, even abscess, and phenomena which are otherwise the consequences of the incarceration of gall-stones. As the oil of turpentine in Durand's mixture is also salutary against this worm, in such cases a treatment analogous to that of gall-stones alone would be salutary. If the worm gets into the ductus pancreaticus, or the vermiform appendage, infiammation and obstruction of these parts, perityphlitides, \&c., may follow. If it passes into the air-passages it may become the cause of violent spasm of the laryux at the moment of its immigration, and, by a longer stay in the bronchire, of violent catarrh, of fits of conghing, nay, even of pneumonia, which either lead to death, or to a rapid cure, by removing the intruder by coughing and retehing. If the worn remains fixed in the stomach, or on the way from the stomach towards the mouth, or the outer masal aperture, it gives rise to disorders which are milder or more violent, and of longer or shorter duration, according to the condition in which it finds itself at the moment of its arrival. If it reaches the above-mentioned regions by simply waurlering 
forward, without being carried upwards by watery vomitings, and thus becoming more swelled, heary, motionless, and inactive, I lave repcatedly seen it produce the most unpleasaut disturbances, such as constant retehing, the most troublesome vomiting, irritation in the throat, with fever, and even delirium, and, after the evacuation of the worm, all disappear like a flash of lightning. In doubtful and suspicions cases, therefore, it should never be omitted to open the moutl of individuals suspeeted of worms when suddenly attacked by fever, to see whether there is a worm in the pharyux, which is immediately to be removed with the finger or the forceps. If, however, the worm arrives in the stomach, or in the portion of the alimentary eanal between this and the mouth or nose, in a dull and sickly state, without the faculty of moving itself, and without strength to enable it to adhere, the symptoms produeed by it are much gentler and more passire, as the worm is more easily remored as a dead foreign body. Besides in these normal prolongations or appendages of the intestinal canal, the worm ean also pass to other regions by pseudo-paths, through the extemal integument, or be met with in closed serous cavities of the body. Such places the worm reaches ouly when a breach (perforation) or an ulcer yielding to the least force, for example to mere adhesion, was ripe for perforation, occurred in the intestine, exactly as we see Ascarides and Trenice, with or without hooks, wander through the shot-wounds in the intestines of animals killed by sportsmen, into the abdominal cavity, the lungs, or out of the borly. The cause of such perforations, therefore, lies only in morbid ulcerating processes of the mucous membranes of the intestine, whicl are certainly mostly of a dyscratic nature (tubercular, cancroid, typhoid). They can only be caused by the worms, when these, being present in great numbers, have led to ileus, inflammation of the intestine, and adlesion of the intestine with partial mortification. The prognosis is the same as in all perforating ulcers of the intestiual canal. At the same time it is a further question, whether the perforation takes place before or after the occurrence of adhesion with neighbouring organs. Thus are produced the so-called worm-abscesses, in which the worm passes out through the general integument. At the same time, however, before this takes place the previous perforated wound may be already covered by exudation, and the worm occur completely shut off from the intestinal canal in a saceulated carity. 
In this case there is no formation of fistula. At other times the fistula may still be produced, or the worm may arrive in the bladder by vesieo-intestinal fistula, in the vagina by intestinovaginal fistulæ, or in the ovarics by ovarian fistulæ, and be found in these places on dissection, or pass ont from them. Listly, having got access to the free abdominal cavity, it may become encysted there, and form an encysted abscess; or it may reach the cavity of the pleura by adhesions of the intestine and diaphragm, and the formation of a communication in this way, or through abscesses of the liver which perforate towards the plenra, just as well as by penetrating wounds. The experienced will know, that the wanderings of the worms after the death of the patients, must be well distinguished from this. But the worm can never actively bore through the healthy intestine. For this it is rendered unfit by the structure of its head and its thin lips, which are certainly adapted for suction, but not for boring. I express this opinion without hesitation, although I stand again in opposition to the authority of Von Siebold and that of Mondière, who assert that the worms are able to force asunder the fibres of the intestine with their resistant heads, and agree exactly with Rudolphi, Bremser, Rokitansky, and Bamberger.

Finally, let us refer to the symptoms which are produced by the Ascarides whilst remaining within the intestine. Starting from the above points of view, we shall be in a position to comprehend the whole series of the direct mechanical and reflex symptoms; these are the phenomena of an ordinary catarrhal affection of the stomach and intestine, from its lowest to its highest degrees, with all its consequences upon the general health, the general alimentation and the nervous system. For the physiological practitioner it suffices for the prognosis and treatment which will always be introduced when a conviction is obtained of the presence of the worms by their passage ont. Amongst the reflex phenomena we have especially to mention, without. particular reference to the species of worm, the collection of water in the nonth, yawning, hiccough, and snuffing in the nose. Their presence is not to be denied, but the latter probably rather belongs to the issuing proglottides of Trenice and Oxyurides, which tickle the anus, than to the Ascarides living in the middle of the intestine. But in this case still more common observations must be made. It is very diflicult to say whether Ascarides can produce intestiual catarrhs, or whether they only 
find in them accidental favorable circumstances for thriving, maintain and increase them, and whether these eatarrhs may not still persist independently after the removal of all the worms, in spite of all subsequent treatment, supposed to strengthen the mucous membrane.

Lastly, many of the older authors, and, very recently, Zimmermann, liave attributed to the worms a prognostic and generally unfavorable import in certain febrile disorders of the intestine, especially in typhus. Zimmermann never saw the worms pass off in typhus before the seventh day. The passigc of the worm only furnishes a doubtful, indirect, prognostic indication. When it takes place in the latter period of typluns, and after the patient has fasted long, it indicates simply that the Ascarides which live upon the ehyme in the lumman intestine are hungry and pass off because they find nothing. The proof of this is the state of fulness or emptiness of the intestines of the worm. If it occurs in the early days of the typhus and with general symptoms of serious illuess and numerous diarrhœal stools, it indicates that the attack of typhus is a severe one, that the typhous ulcers may extend high up in the intestine, so that the acrid secretions reach, irritate, and even expel the Ascarides which live ligher up. That there must be a condition of the intestinal canal, which favours the thriving of the worms, is clear. Whether, as is commonly supposer, this consists in an accumulation of intestinal mucus is by no means ascertained. Hence the after treatment is for the present a purely empirical one.

Therapeutics.-1. Propliylaxis. - The first thing to be done by the surgeon in practice consists in destroying the eggs of the Ascarides whererer he meets with them, and expelling every female that he can get at. It was H. E. Richter's merit that he first ascertained that the eggs remain urinjured in sewage, \&c. Recently, Barry, Bischoff, and others, have proved that the proeess of segmentation of the eggs of Nematoida continues eren in very concentrated alkalies or salts. According to the experiments of Verloren and Richter, alrealy described, the eggs of Ascarides only attain their full maturity when free in nature (in water), and only undergo the process of segmentation in this situation. In the various species of Ascarides, the time necessary for this purpose may be different. For whilst, according to Verloren, this is completer in one species of Ascaris within a few weeks, the 
eggs of Ascaris lumbricoides require at least a period of $11-12$ months for the purpose. Even Richter's first statement spoke of such a period; according to a communication from him in January, 1857, embryos had then began to be formed in eggs which had been put into water by him in February, 1856, but they did not move. Eggs which I placed in water in July, 1856, do not yet show any trace of embryos.

But as to what becomes of the ready-formed embryos we know really nothing. Perhaps they get into our bodies with drinking water, and perhaps this is sufficient for their development, although the administrations of the brood reared by Richter, by myself to dogs, by Haubner to pigs, and also by Leuckart, led to no successful result. Perlaps, however', this is not sufficient, and a further migration through other animal bodies must precede, although this mode is not very probable.

2. Direct therapeutics. - From the immense number of remedies recommended as Vermifuga, we should have rather tedious work if they were all to be referred to here by name. If we wish to treat the anthelminthic remedies in accordance with the claims which physiological medicine makes upon us, we may adopt one of two ways, namely, we must either seek out remedies which quickly kill and poison the worms, withont attacking the organism of the host itself too severely, or, as we usually see those worms which apparently pass off spontaneously, come forth in a living state, we must endeavour to discover by practice what remedies there are especially, in consequence of which the worms begin particularly to experience the desire of wandering outwards.

1. Experiments for the discovery of remedies which poison and kill the worms quickly have aheady been made to a greater or less extent by Redi, Baglio, Andry, Leclerc, Torti, Coulet, Aruemann, and Chabert. I willingly admit that Bremser thinks it is not advisable to make use of human worms, which liave passed off spontaneonsly, or which have been found on dissection some time after death for these expcriments; but this, as wcll as his further objection, thist all round worms quickly die when remored from their natural place of abode, and especially in the open air, may be very easily answered. All that is necessary, namely, is to take intestinal worms from freshly-killed lrealthy domestic animals, $\log s$ or cats, and to put them into white of egge, mixed with the medicament to be tested, at a temperature equal to the normal heat of the intestine, or only a few degrees 
above or below it. In experiments performed in the summer, the ordinary temperature is sufficient, if the mixture be exchanged for one of fresh white of egg, before putridity occurs. In winter it is best to use the ordinary stove-heat, which does not exceed blood-heat. In this way I liave tested a great number of the vermifuges of the schools, and have arrived at the following results :

1. In fresh white of egy, changed at least once a day, the most different entozoa, when taken from healthy, freshly killed auimals, lived for days.

2. In normal saliva, I have seen Oxyuris vermicularis live more than a day, it being understood that the worm was prevented from drying by constant fresh additions of saliva.

3. Even in water round-worms can live a day or two, but their vital manifestations are so weak and sluggish, in consequence of mechanical turgescence, that they can only be detected by the aid of electricity, one of the finest tests of the presence of life in these worms.

4. Whey lehaves exactly like water;

5. Milk developes conditions analogons to the latter somewhat less rapidly.

To have as serviceable a menstruum as possible therefore for the experiments above indicated, employ white of egg or saliva.

According to my experiments up to this time, the following table may be arranged, as to the time in which round-worms died in white of egg, mixed with the various remedies.

1. Death took place in $1-2$ lours in white of egg mixed with creosote, and large doses of common salt ard corrosive sublimate.

2. Death took place in $2-5$ hours in white of egg mixed with petroleum, cajeput oil, oil of turpentine, mustard, weaker solutions of common salt and washed herring's milt.

3. Death took place in 5-15 hours in white of $\mathrm{egg}$ mixed with garlic, onions, laurel, cloves, wood vinegar, Rad. punic. granat., Tinct. gallarum, sulphate of soda (concentrated solution).

4. Death took place in 15-24 hours in white of egg mixed with camphor, anise, and infusions or decoctions of ginger, gentian, elm-bark, kousso, and hops.

5. Death took place after 24 hours in white of egg mixed with infusion or decoction of parsley, rue, milfoil, tansy, valerian, chamomile, wormwood, myrrh, quassia, oranges, calamus, ipeca- 
clianha, walnuts, china bark, willow bark, Spirea ulmaria, oak bark, dragon's blood, eatechu, kino; and also with the vinous extraet of oak bark (Radem.), assafoetida, gum ammoniac, Peruvian balsam, Roob Junip., Extr. Thujæ, Ol. Ricini, Ol. Chaberti, Aq. picis, creosote water (weak), Fuligo splendens, and sulphate of soda (in weak solution).

Lead, zine, ealomel, and copper, had no effect, as they lay undecomposed at the bottom of the glass.

Besides the remedies here enumerated, I have also tested the Semina Cina with their preparations. In a mixture of white of egr with evarsely powdered seeds, the worms live for days; and in a mixture of white of egg with a strong Infusum semin. Cina, with repeated additions of umboiled powder, they also lived for days. In a mixture of santonine with water and white of egg the worms lived for days, and also in white of egg with santonine and a little vinegar. At the same time, howerer, the almost total insolubility of the santonine was proved, by suspending a little linen bag, with shots and crystals of santonine in the fluid taken out of the stomach of a eat, and slightly diluted with water, at $80^{\circ} \mathrm{F} .\left(30^{\circ} \mathrm{R}.\right)$, without any formation of crystals of santonine in the fluid subsequently.

In white of eggrs mixed with castor oil and santonine, the worms died, aecording to my experiments, within an hour. Falek, who repeated this experiment, could not convinee himself of this, and I admit that the apotheeary's assistant, to whom I had left the wateling of the experiment, made a mistake in the regulation of the temperature, and allowed it to rise too high and too quickly.

Iu a mixture of white of egg with Natron santonicum dissolved in water, Ascarides lived more than twelve hours.

In order, now, in the second place, to try in practice which of those methods, which appeared to me to exert an influence upou the life of the worns, were best adapted for practical application, and at the same time to test the meehanical irritants, I made the following experiments with anthelminties upon living eats and dogs. I administered Stannum raspatum to living eats, and, on dissection, found Tenice and Ascarides quite lively in the intestine, but the canal itself much irritated, and numerous punetiform spots of extravasated blood, in consequence of the wounding of the intestine by the points of the tin filings. Exactly the same 
appearances followed the administration of an electuary of Dolichos muriens.

After administering the celebrated black protoxide of copper of Rademacher for four days, the worms remained uninjured in the intestine. On the contrary, when I administered castor oil with santonine for sereral consccutive days, Ascarides always passed off in abundance, but certainly with strong purging.

With this result, obtained by experiments, I now passed to the discovery of the remedy most to be recommender in practice, and was directed to the preparations of santonine, as is especially slown by the last experiment.

Before I describe my observations and mode of treatment, I must, from the fame which the Semina Cinæ lave especially enjoyed, even for ages, refer to these above all, as an introduction to santonine. It must be confessed that the old practitioners sometimes produced very definite results with their electuaries of cina. The best known formulaz of these cina-worm-electuaries are the following:

1. Bremser's.- R Seminum Cinæ vel Tanaceti rulgaris ruditer contusorum, 亏ss; Pulv. rad. Valerian., 5ij; Pulv. rad. Jalappæ, Эiss-ij; Tartar. vitriol., 亏̈iss-ij; Oxymel Squill., q. s. ut fiat Electuarium. M. D. S. A tea-spoonful to be taken two or three times a day.

After taking two spoonfuls daily for three to four days, more slime, and frequently also worms, pass off, as Bremser says, with a more abundant stool. If the worms do not pass off, Bremser either administers some more of the electuary twice, or gives one spoonful three times. If the first pot of electuary does not suffice for complete recovery, a second is taken, but, according to Bremser, watery stools must never be produced. He never allowed more than two potsful to be taken, and it did not matter to him whether worms did or did not pass duriny its use.

To relax the bowels once in the midst of the treatment, he administered a weak purgative, according to the following prescription: R Pulr. rad. Jalappæ, Эj ; Pulr. fol. Sennæ, $5^{\text {ss }}$; Tartar. vitriol., 3 j. M. f. pulv. divid. in iij vel iv part. æeq. D. S. Half a powder to be taken every half to two hours, until it operates.

If Bremser had leucophlegmatic individuals under him, he employed the Oleum Chaberti against relapses. This oil is prepared in the following way. One part of stinking hartshorn oil is mixed 
with three parts of oil of turpentine, and this mixture is left to stand four days; it is then distilled in the sand bath from a glass retort, until three fourths of it has passed, and this is put into bottles of about one ounce, which must be well closed. Of this Bremser administered two tea-spoonfuls in a mouthful of water, every morning and evening. With sickness, less at first. To those who could not bear it fasting, he gave it half an hour after breakfast.

2. Störck's much esteemed formula.-R Sem. Cin., 5ij; Rad. Valer. min. pulv., 5j; Rad. Jalapl. pulv., 3 ss; Oxymel. Squill., q. s, ut f. El. One tea-spoonful every three hours.

3. Selle's strengthening worm-electuary.- R Pulv. Sem. Cin., 5vj; Ferri sulf. cryst.; Extr. Chin. fusc. aa., 5ij ; Syrup. Cinnam., q. s. ut f. El. One tea-spoonful three times a day. This may be the best when an after-treatment is to be observed.


Valer. pulv., 5jss; Kali Tartar. depur., 5ij; Oxymel Squill, 5vj; Syrup. simpl. q. s. ut f. El. One tea-spoonful every $2-3$ hours.

Who amongst us, who is getting on towards his fortieth year, especially if he passed his youth in the country, and had the benefit of the advice of a doctor who was already in years, has not been furnished at least once, if not twice a year, with one of the electuaries just mentioned, for the suspicion that he might have worms? Who does not remember the joyful time when his mother or tutor came before him with the spoon lieaped up with worm-electuary in the one hand, and in the other the honoured birch, and compelled him, no matter whether with or without results, to swallow down the electuary, or at least to keep it in his mouth until their backs were turned, and he could volumtarily get rid of it, either with or without the help of his fingers? It was, therefore, an indispensable requisite to see whether it could not be contrived to administer the remedy in a more agreeable form. The method of sprinkling the remedy, coarsely pounded, upon bread, and spreading syrup or lioney over it, and administering $\mathfrak{3}^{\mathrm{ss}}$ - j several times a day in this manner, followed every third or fourth day by a gentle aperient, must always be the most advisable if the ciua seeds are to be cmployed at all. J. Clarus extols these cina-slices above all worm-electuaries.

Gradually, however, the cina seeds have been displaced by the preparations obtained from them, and, in my opinion, with justice. In practice we can only extol two of them,-santonine and santonatc of soda; all the rest are unnecessiry. 
1. Santonine the preparation of which according to Calloud (See 'Pharmac. Centralblatt.,' 1849, 413, and J. Clarus, 'Handbuch der speciellen Arzueimittellehre,' 1852, p. 333), is best effected by the employment of ammonia, must be tasteless, when pure, because it does not dissolve in the mouth; dissolved in alcohol it tastes bitter ; dissolves but little in warm water, but with ease in fatty oils. It is at the same time inodorous, and has a very slight acid reaction, combines readily with alkalies and becomes yellow in the light of the sun. When impure it still contains resins and essential oils, and is, consequently, nauseous to take.

It is the best plan to administer santonine simultaneously with fatty oils, in order to bring it into solution as readily as possible, and for this purpose I have preferred to give it sprinkled upon bread and butter or in the yolk of an egg with sugar, and afterwards to follow it every 3 - 4 days with a gentle purgative (Jalap or the Electuar. Linit. Pharmac. Saxon.), or to administer it, to those who can easily take oils, with castor oil (gr. jj-.jv with $\tilde{3} \mathrm{j}$ of oil in tea-spoonfuls, until purgative action sets in). In this way the remedy should be repeated, if possible, for some days, or every other day, so that soft stools should be repeated several times a day, rather than that actual purgative stools should be produced. The use of milk at the same time, perhaps even the employment of the santonine in butter-milk, may also be advisable, and butter-milk may be substituted as a purgative in worm-treatment especially with children. Amongst the santonine lozenges, those prepared from cocoa undeprived of oil are most deserving of praise.

Since the commencement of the administration of santonine, it has become, in consequence of certain subsidiary actions, a sulject of contest and strife, which is not yet concluded, and which, perhaps, never will be quite settled, because the remedy will possibly be displaced before the matter is ready for judgment by IIautz's preparation, to which we shall immediately refer. The most troublesome effects said to have been seen from this remedy are spasms and obstinate obstructions with tenesmus, nay even bloody stools, which are said to have been seen by some after comparatively small quantities (gr. ij-iv once or twice a day) of the remedy. For my part, with a careful employment of the remedy (gr. ij-iv with $5 \mathrm{j}$ of castor oil) I have never seen bad subsidiary actions, and when it is administered with castor oil, the more obstinate obstructions are also wanting. The most terrible symptom, to the unprofessional patient, is the yellow, or blue, 
or even green appearance of all objects. As it appears to me, the yellow is essentially the primitive colour, and all other colours lepend upon the objects, upon which the patient turus his eyes. With a cloudy sky, and when the patient turns his eye not towards the window, but towards the dimly-liglited back part of the room, he sees all objects pale yellow, as far as I could obscrve; and also when he looks at objects strongly illuminated by the sum. If the day be fine and the patient sits at the window, looking at the blue sky, he thinks he sees everything green. At the same time, in quick turning from blue objects or from the blue sky towards objects differently coloured or illuminated, the colour varies through green towards blue and yellow in many ways. I think I have observed these appearances of colour, when I have endeavoured to understand the complaints of the patients. Frightful as these appearances would be to the patient if his attention was not previously called to them, they disturb lim but little when we do not omit to inform him of them beforehand. The medical man lias nothing to fear from them, these phenomena pass away of themselves within a few hours.

The physiologists have attempted to account for this phenomenon, and it was supposed that there was a yellow coloration of the serum of the blood, such as we meet with in jaundice, especially as the urine acquires a similar yellow colour. Zimmermann, of Hanover, gave a young man eight grains of santonine from seven to eleven o'clock in the morning. Frequent tears in the eyes soon followed, but ceased about eleven o'clock, and yellow sight, which still persisted at half-past twelve, when some blood was taken from the patient, on account of the occurrence of congestion of the head. The serum was colourless, and remained so even when heated to $80^{\circ} \mathrm{F}$. $\left(30^{\circ} \mathrm{R}\right.$.), and on the addition of urine. All other attempts to find a colouring matter analogous to that of the bile have also been in vain, as far as $I \mathrm{know}$. The urine may even be red, or raspberry colour, which often gives great anxiety to the parents, as they regard it as bloody; it may retain this colour as long as it has an acid reaction, and only become orange-yellow afterwards, but the sclerotica never exhibits a yellow colour; the urine never presents the well known phenomena of alteration of colour by nitric acid, nor do otlier appearances of jaundice occur, such as white stools, of the colour of dog's exerement. The yellow pigment treated of here, which must be formed on its passage through the body, because santonine does 
not pass as such into the urine (Kletzinsky), must act quite differently from the pigment causing jaundice. Kletzinsliy thinks lie found that the yellow pigment which makes its appearance in the urine after the administration of santonine, belongs to the xanthine series of madder, without, however, finding a trace of it in santonine, even in that which had become yellow, reddish-brown, and finally dark brown, by lying. We must, thereforc, certainly for the present, suppose, with Zimmermaun, that the colour phenomena are actions which take place in the brain, which is certainly affected for a time by the use of santoune, by a transient alteration of the retina and the central extremities of the optic nerve.

That it is necessary to be cautious in the employment of santonine, follows as a matter of course, and I should never give more than eight grains in two days, divided into doses of two grains each, twice a day, and on the second day of its use administer an aperient.

One does not know, in fact, whether to join in the complaint of J. Clarus, that this remedy has not yet been admitted into the 'Pharmacopœia officinalis' of Saxony, as serious errors and mistakes certainly occur with regard to this remedy, and, at all events, the remedy now to be referred to is a much more inmocent medicine, and yet produces the same effects.

2. Natron santonicum.-Both H. E. Richter, who first sent me the remedy prepared by Hautz himself, and myself can testify to the excellent action of this medicine. We have nerer seen injurious subsidiary actions, and I have even administered doses of gr. viij- $x$ twice a day to adults. The remedy must be administered alone, as every acid readily decomposes it, and it must not be mixed with electuaries. If it is to be taken at the same time with an aperient, the simple Aqua laxat. Vienniens is to be preferred. I make use of the following method:-As it is usually children that are brought by the parents with complaints of their being troubled with worms, and I myself do not wish to keep them from school, even if the parents did not usually feel the same desire, I let the children take a powder of Natron santon., with sugar ( $2-5$ grains, according to age), on a Friday night, and repeat the same dose on Saturday morning (fasting) and evening, and again on Sunday morning. On Sunday, half an hour or an hour after the last powder, an aperient electuary (Elcct. lenitiv. mite or Londinense, according to circumstances) or 
the necessary quantity of jalap, is administered, so that several soft motions may follow. By this means the worms usually pass off alive, of course if any were there; or these remarkable guests wander forth subsequently singly, and without motions. In short, they wander out because we have made their dwellingplace disagreeable to them. It only matters to us that they go; whether living or dead signifies little to us.

I shall be excused from giving individual cases. I may just mention that I had to treat a woman in her fiftieth year who liad suffered for weeks with worm-vomiting and the most violent disorders, when she came to mc. The treatment immediately commenced in the above manner, ameliorated the symptoms almost on the spot after the first administration; some worms (of which I received four) passed off with the freces, and all suffering ceased. A fresh employment of the remedy in eight days, in order to see if any stragglers were left, furnished no more worms. The woman has since remained healthy.

Dr. Pockels, of Holzminden, who has observed a blackish coloration of the tongue after the administration of santonine, praises, as a remedy for Ascaris lumbricoides, the root of Aspidium filix mas, in conjunction with purgatives. Panna and the flowers of Kousso are also to be recommended. 


\section{APPENDIX BY TRANSLATOR.}

Appendix A.

Mr. Rainey's Researches on the Structure and Development of the Cysticercus cellulosæ in the Pig.

In the year 1855, Mr. Rainey presented to the Royal Society of London, a paper on the structure and development of the Cysticercus cellulose as constituting the "measled pork" of the London markets. An abstract of these researches was published in the 'Proceedings of the Royal Society' for December 13th, 1855. They were sufficiently important as dealing with a period in the history of the development of Cysticerci which had not been previously accurately observed. But since that time Mr. Rainey has renewed his labours; and on the 19th of March, 1857, he presented a more complete account of his researches to the Royal Society, which have been ordered to be printed, with Mr. Rainey's illustrations, in the 'Philosophical Transactions.' Through the kindness of Mr. Rainey, I am enabled to give those portions of his paper relative to the development of the Cysticercus, which, with the materials added by the author to the second edition of his work, will render this volume a complete authority on all that has been done in reference to the history of the Entozoa up to the time of its pullication.

\section{The Development of the Cysticercus cellulosæ.}

"The earliest indication of this species of Cysticercus, which admits of certain recognition as a form of cystic entozoon, is the presence of a collection of reniform corpuscles of about ${ }_{2} \frac{1}{656}$ th of an inch in length, and $\overline{8}_{800}^{1} 0$ th in breadth, mixed with very minute, highly refractive molecules 
of different sizes in the substance of a primary faseiculus of a muscular fibre, or between its sarcolemma and the sarcous elements.

"Though such a eollection of corpuscles has a moderately definite shape, being somewhat fusiform, yet it has not a complete investment. It soon, however, acquires a very distinct membranous covering, which is first apparent about its middle, and afterwards at its extremities. Its dimensions in this stage of its formation may be about $\frac{1}{150}$ th of an inch in length, and $\frac{1}{1500}$ th in breadth, but these are by no means regular. The external investment at first appears only as a bright line of homogeneous substance, best defined on the side next the sarcous matter. It soon, however, increases in thickness, and afterwards becomes converted into short fibres, which increase in size and distinctness as the animalcule grows larger. 'These fibres are peeuliar; there is nothing that I am acquainted with analogous to them. They have not the sharp and welldefined outline of true cilia, nor are they pointed like setæ, or curled like eirri. They have somewhat the nature of white fibrous tissue, their distinctness being impaired by acetic acid. They are of different lengths in the same entozoon, and generally longer, though not thicker, in the large than in the small ones. Their length averages about $\frac{1}{2} \frac{1}{10} \overline{0}$ th of an inch.

"The most remarkable circumstance eonnected with them is the great uniformity of their arrangement in different Cysticerci. They eover the whole of the outer surface of the investing nombrane, and on opposite sides of the same entozoon, their form, size, and direction are similar, so that the two halves taken longitudinally are in this respeet symmetrical. If the direetion of these fibres be examined alout midway between the two extremities of one of these animaleules, they will be seen to project from the surface at right angles with the axis of its body; but if traced each way from this point they will be observed gradually to ineline to this axis at an angle which keeps diminishing as they approach the two extremities, so that the fibres nearest to the two ends almost eoincide in their direction with that of the axis, and thus correspond in their situation to the barbs situated on each side of the extremity of an ordinary feather.

"As the first position of these animals is in the very substanee of a primary muscular fasciculus, it is obvious that the meehanical action of this apparatus will be to aid their longitudinal development whilst new cells are in progress of formation in their interior. For it is scarcely possible that the muscular fibrille by which they are surrounded, can, when in action, fail by their friction to urge the two extremitics onwards in opposite directions, whilst at the same time the fibres by which these entozoa are covered are in consequence of their direction preventing the separated ends from regaining their former position, and thus the two ends being always carried in opposite directions without the possibility of a eounter movement, a general elongation must ensue. This apparatus also, by splitting up the primary faseiculi, will serve a locomotive purpose and thus enable these animals to reach the cellular intervals between the museular fibres, where their further development will be completed. That such is the eflect of the fibres in question is eviclent on a careful inspection of some of the fasciculi in which these animalenles are contained, in which a separation of the fibrilla ean be seen to have been produced by the pointed ends of the entozoon; these fibrillie having been obviously turned out of their original course, and some directed to one side and 
some to the other. This explanation receives confirmation from the fact of those Cysticerci which are developer in the muscular parietes of the heart being of a different shape fron those formed elsewhere, although their structure in all other respects is precisely the same. These Cyst $i$ cerci, in the first or mermieular stage of their development, are very short and thick, and of an oval shape. Their locomotive fibres, though perfectly demonstrable, are very short, and in many instances imperfect.

"After these Cysticcrci have reached the spaees between the muscular fibres, their subsequent development is the same as in other situations, and the perfect animals formed in the heart cannot be distinguished from those formed in other muscles. I may also add, that, while in the vermicular stage, the Cysticerci developed in the short muscular fibres of the tongue, are of a shape resembling very much those of the heart.

"The investing membrane which has just been clescribed as covered with cilia, is entirely filled with corpuscles, all of one kind, remarkably characteristic, and differing only according to their states of development. The perfect cells are best seen in the middle of an entozoon, but their mode of formation, and the subsequent changes which they undergo, must be examined in those parts which are increasing most rapidly, as in the growing ends of an animalcule.

"The first appearance indicative of an increase in the length of an animalcule is a thinning of the investing membrane, and a separation or partial detachment of the cilia-like fibres at the growing end. Next, a clear space, of the form of the part which is about to be added, is perceptible a little in advance of this extremity, apparently the result of a very fine membranous protrusion. This contains numerous dark molecules of different forms and sizes mixed with granules more or less perfectly spherical: the most perfect of these globular bodies are those wbich are nearest to the perfectly formed part of the animalcule. 'These corpuscles, when completely formed, have a bright oily-looking aspect, and a diameter of about $\frac{1}{500}$ th of an inch.

"These corpuscles have the appearance of being formed by the coalescence of molecules which had existed in the clear space before any corpuscles were apparent, by which they are afterwards replaced. After a growing end has become thus filled with these globular bodies, the terminal menbrane becomes more and more distinct, and the cilia-like fibres are afterwards added, which are generally neither so regularly disposed, nor so distinct as on other parts of an entozoon. Next, these corpuscles lose their spherical form and become flattened, and lastly, they assume their characteristic elliptical or reniform figure before mentioned, which they retain as long as the entozoon remains in its primary muscular fasciculus. This shape, however, is not essential to these corpuseles, but merely results from the rounded form of the masses into which they are grouped together, each corpuscle, by its convexity, forming a segment of the cireular outline of its respective group. These corpuscles contain very fine dark granules, so variously disposed in different ones, as to present a variety of appearances, such as circular or oval spaces, which might be taken for nuclei or nucleoli. These collections of corpuscles make up nearly the whole of an animalcule, and they frequently give to it a lobulated and sometimes an obscurely annulose appearance.

"The cutozoa, as long as they remain in the primary fasciculi, retain all those characters which have so far been deseribed; but these character 
gradually disappear after they have broken away from the cavity of the sarcolemma, and gained access to the spaces between the muscular fibres.

"In this new situation they gradually lose their former membranous clothing studded with cilia-like fibres, which can occasionally be seen partially deprived of its corpuscular contents, though sufficiently perfect to admit of demonstration. The reniform corpuscles before aggregated together in circular groups now gradually lose their distinctness of outline, and imperfectly coalesce into confused ill-defined masses, having an oily aspect, so that, if in this state, one of these vermicules be crushed under the microscope, amorphous oily and granular matter will be seen to have escaped from it, similar to that contained in the ventral part of the adult animal. Here, too, the restraint to the lateral growth of these entozoa being very much diminished, their breadth increases rapidly, and they present globular projections extending out very irregularly from their sides, giving them an irregular figure. These projections gradually take on the form of those which were described on the ventral part of the perfect entozoon. The largest of the entozoa which $I$ have seen in this stage is about $\frac{1}{12}$ th of an inch in length and $\frac{1}{40}$ th in breadth.

"The next facts requiring especial notice are those connected with that stage of development which takes place after the animalcule has become surrounded by an adventitious cyst.

"The first indication of the formation of such a cyst is, the turgescency of the capillaries, or some of the smaller vessels in the vicinity of one or more entozoa. Granular bodies, exudation-corpuscles, and fibres of different shapes next make their appearance. These at first only partially obscure the entozoon, but afterwards completely conceal it. When the cyst is first formed, the animalcule can, by a good light and careful examination, be obscurely seen within it, and by dissection under the microscope it can be dislodged.

"The interior of a cyst being smaller than the animalcule contained therein, it naturally follows that during its growth one portion must be folded over another. By this means it is adlapted to the confined locality in which it is lodged during the period of its development. Hence the ventral portions of all Cysticerci are, when first taken from their cysts, very unuch plicated; but these plicse disappear after the ventral sac has become distended with the fluid brought into contact with its surface.

"Up to this point of the development of the Cysticercus, it is a simple cyst growing by the assimilation of fluid imbibed equally by every part of its surface, no one part differing sensibly in its structure from another. No portion of this surface presents any indication of incipient hooklets or suekers. There is nothing either on its surface or in its interior analogous to the structure of an ovum. Nor is there any other anatomical character which would raise its organization above that of a simple acephalocyst. However, this so exactly resembles in its structure that of the ventral portion of a perfect Cysticercus, that it is impossible to doubt their identity of character. Its size, too, is not much beneath that stage where the suckers and hooklets first begin to present obscure indications of the part they are about to occupy.

"The first indication of the addition of the neck with the suckers and hooklets to the ventral part of a Cysticcreus is the appearance about its centre of a slightly raised body, depressed in the middle, with longitudinal folds proceeding from each side of it towards the poles of the ventral cyst, 
appearing as if at this part the parietes of the latter had been drawn inwards. On two sides of this hollow there are dark transverse lines, rather more distinct on one side than on the other, indicating the commencement of the transverse rugie of the neck, mentioned in the description of this part in the perfect animal, in which the laminated earthy bodies are contained. About the central part of the cervical projection there is an ill-defined oval space, having a granular appearance, and containing some minute spherical particles of a dark colour, consisting apparently of a highly refractive material. In this condition of the entozoon there is nothing in this space which has the slightest resemblance to the parts which are there about to be developed, namely, the hooklets, suckers, and earthy concretions; and it is only by the comparison oi these obscure appearances with the other specimens in which the development of the hooklets is a little more advanced, that their true signification can be learned."

The author here proceeds to describe the development of the hooklets, and continues-

"From the ficts that have just been mentioned, the hooklets of the animalcule in question do not appear to be formed by cell-development. For by the most careful examination of these organs, both recent, and after the application of acids, I have not been able to distinguish anything which can be looked upon as a cell or cell-nucleus, calculated to give the idea of their being developed from previously existing cells, or in dependence of cells; but, on the contrary, all the various forms and characters which they present during the process of their formation simply indicate the coalescence of very minute spherules of an homogeneous material, exceeding the number of a complete set of hooklets, into small globular masses, and these again into larger pieces, and so on successively, until recognisable portions of hooklets come into view, which, coalescing, build up, as it were, an entire organ.

"It is worthy of remark, that if these structures had been produced directly from the metamorphosis of previously existing cells, the circumstances connected with their formation would have been the most favorable for observing both the original cells and the changes which they passed through; indeed, so much so, that is almost impossible that they could have escaped notice. First, because these parts are of such a size and degree of transparency as to admit of examination with the highest powers of the microscope without the necessity of disarranging them, or disturbing their position by manipulation. Secondly, because the material of which they are composed is so dissimilar in appearance to that forming the adjacent tissue, and so characteristic that it cannot be confounded with the structures in their immediate vicinity. Thirdly, because at one view, in a favorable specimen, hooklets can be seen in every stage of their formation, from the first grouping together of the masses of formative particles to the blending of them into perfect organs ; and lastly, because it is not as if a mere thread of tissue were formed amongst other threads, slightly differing in appearance, as fibres of elastic tissue, for instance, in a mass of connective tissue, but the objects referred to are perfect organs, which possess an arrangement of parts connected together with order and remarkable regularity. So that, under such 
circumstanees, if these organs had been preceded by nucleated cells, and the cells had been transformed into hooklets, neither these cells in their primitive state, nor in their several stages of transformation, could have eseaped detection.

"The parts next to be noticed are the suckers. Indications of these are visible as soon as the hooklets. They appear as four circular spaces, presenting a granular aspect about the size of perfectly-formed suckers. The two sets of fibres next make their appearance, the radiating and eircular, which have not at first the sharp outline which they afterwards acquire, but still appear obscurely granular. As the tissue of these organs possesses nothing charaeteristic like that of the parts just described, the progressive changes which they undergo during the different periods of their formation can be but imperfectly distinguished; and hence no further description of them will be necessary.

"It has been observed in respect to the two sets of organs above described that their size does not increase materially after once formed; exactly the reverse is the case in reference to the part called the neek, and the quantity, though not the size, of the laminated bodies, which increase in number as the cavity of the latter increases in size. These bodies appear as soon as the hooklets and suckers, and they are as large when first formed as afterwards, but there are indications of the transverse wrinkles of the neck before either hooklets or suckers can be distinguished. The neck afterwards continues to grow, so that its relative length in respect to the ventral portion is some indication of the age of a Cysticereus.

"It is probable that this part does not arrive at its full size until after" it has been protruded, which I have never seen to be the ease in any animalcules occurring in or between the muscular fibres, and which perhaps is not effected until the entozoa quit their confined loeality between the muscular fibres, and gain aecess to the free surface of a mueous membrane, there, as physiologists generally believe, to be further developed into a higher form of entozoon."

Appendix B.

On the occurrence of species of Distoma in the human body.

In addition to the cases in which species of Distoma have oeeurred in the human body, and mentioned by the author in the text, the following cases will, I make no doubt, be interesting to the reader.

Dr. Budd, in the second edition of his work on 'Diseases of the Liver,' gives the following case :

"A few years ago a single fluke was discovered by my colleague ( $\mathrm{Mr}$ Partridge) in the gall-bladder of a person who died in the Middlesex Hos- 
pital. Mr. Partridge was present at the examination of the body, and was struck with the appearance of the gall-bladder, which, instead of being stained by bile, as is usual, was perfectly white. He took the gallbladder away to make of it a preparation, to show the natural structnre, and on laying it open discovered the fluke. He presented the fluke to Professor Owen, who considered it to differ in no respect from the Distoma hepaticum of the sheep. The gall-bladder and cystic duct, which were perfeetly healthy, are preserved in the muscum of King's College."

I am not aware of any other recorded case of the occurrence of this parasite in the gall-bladder in English practice. The following case, however, communieated to me by my friend Professor Busk, appears to be an undoubted instance of the occurrence of Distoma hepaticum in the tissues of the human body. Mr. Busk's attention was first called to the case by Mr. Clapp, of Exeter, who detected the nature of the parasite when shown him by the surgeon in whose practice it had been met with. Mr. Busk satisficd himself that the creature was truly the Distoma hepaticum. The case occurred in the practice of Mr. Fox, of Topsham, Devonshire. The following are the particulars of the case as given by Mr. Fox :

"Mr. L - , æt. 39 years, of good eonstitution, and much marked with the smallpox, had been a sailor for twenty years, sailing to the West Indies, Mediterranean, South America, \&c. For the last eight years he has loaded to Cronstadt in the Baltic, and has also visited Amsterdam. About fourteen months since, whilst at Cronstadt, he pereeived a small "pimple" about three inches behind the ear. This gradually enlarged to the size of a small walnut. A solution of iodine was applied with a view to dispersing the swelling, but unsuccessfully. After sometime, "while at sea," it inflamed and burst, discharging a sero-sanguinolent fluid from two small orifices. It then healed up again, and after a time was refilled with a similar fluid. It was theu laid freely open, and dressed with dry lint. The next day, on examining the wound, I thought I saw something moving, and, on taking it out, found it was a Distoma. When the wound was dressed the following day, there appeared to be portions of another worm, but in so softened a state that $I$ conld not be quite certain of it. The eolour of these worms was very similar to that of the surface of the wound. The wound was afterwards dressed with Ung. Resinæ and lint, and healed very kindly, remaining sound ever since. The man is now at sea, and I have not heard of his having any more tumours of the same kind.

$$
\text { (Signed) }
$$

February $2 \mathrm{~d}, 3857$.

Citarles Fox, Topsham, Devon."

The following correspondence, which has been kindly placed at my disposal by Professor Busk, who received it from Professor 
Owen, relates to a case in which, although the evidence is not complete, the occurrence of Distoma hepaticum in the tissues is rendered probable:

Liverpool, Clarence Street, October 8th, 1856.

Dear Sir,-I beg to forward you a specimen of an Entozoon-one of six or seven which eseaped from an abseess of the scalp in achild. The particulars of the case are the following :

William Bridge, æt. 25 months, of pale complexion, rather emaciated, with some tunidity of the belly-otherwise healthy, appetite good. About two months ago his mother observed a swelling on the upper part of the occiput, the size of half-a-crown, which increased in six or eight days to about the circumference of an orange, when it spontaneously discharged a considerable quantity of pus. The abscess continued partially to refill and discharge itself at intervals for about three weeks, when, on the removal of the poultice and clearing away the pus, the mother observed on the napkin used for that purpose, several of the animals in question, but exhibiting no signs of life or movement.

I saw the child the following day for the first time, when the mother shorred me the entozoa. I examined the cavity of the abscess, but could discover no more of them. The part is now healing under the continued use of tre poultice.

The hild was never known to pass worms, which I have since looked for under the use of anthelmintic remedies. It was weaned when eighteen months of age ; its food since then has been chiefly farinaceous, of which potatoes have formed a considerable portion.

I have not at present been able to find any analogous case in the several medical works which I have consulted. As relates to the classification of the animal, you would regard it as a species of the order Trematoda, as it seens to bear much resemblance to the fluke entozoon found in the liver of sheep, \&c.

Any information in connection with the above, and especially as relates to the generation of entozoa in so singular a situation, which you may consider the case worthy of, will be particularly esteemed.

I am, yours truly and respectfully,

\section{Professor Owen, F.R.S.,}

J. Penn Harris.

\&c. \&c.

British Museum, October 10th, 1856.

Dear Sir,-The entozoon which you have forwarded to me is a fine specimen of the Distoma hepaticum, a species common in the gall-bladder and ducts of sheep, extremely rare in man, and then only so far as I know or can find recorded by direct observation of naturalists and anatomists, in the biliary or intestinal tract.

The value of the case is undoubtedly affected by your not being so fortunate as to witness the worm in, or its eseape from, the abscess.

I would not impugn the good faith of the mother, but rather inquire into and weigh the possibilities or probabilities of any dead fluke-worms having got accidentally into the material of the poultice or on the rag or eloth used for the purpose. 
How had the mother preserved the entozoa; and how did she show them?

How many have you preserved besides the one transmitted; and how many did you count or see?

Excuse these questions; but one must exhaust every vein of inquiry before falling back upon the hypothesis of the devclopment of the distoma hepticum beneath an infant's scalp.

I am, dear sir, yours truly,

\section{J. Penn Harris, Esq.}

Ricitard Owen.

Liverpool, October 26th, 1856.

Dear Sir,-I beg to offer you my best acknowledgments for your kind and suggestive reply to my letter enclosing the entozoon sent to you a short time since.

I have inquired more fully into the case, which has not, however, tended to strengthen the proof that the entozoa came from the abscess in the child's scalp.

The mother's statement, viz., that she wiped them from the back of the head on the removal of the poultice, is founded on very imperfect evidence, as on inquiry I find on the removal of the ponltice she washed the back of the head with flannel and soap, at the same time gently pressing the abscess to favour the escape of matter, which she did without observing any of the fluke-worms. She afterwards took a cloth to dry the part with, spreading it over the head and pressing lightly upon it; she then crumpled the cloth up without looking at its immer side, and placed it on the table. Abont five minutes after, her daughter, on removing the cloth from the table, observed on one of the upper folds five of the worms in question, and on unfolding the cloth a sixth adhering to one of its corners ; there was no pus about them. She immediately called the attention of her mother to them, who immediately (and not perhaps umnaturally) exclaimed "They must have come from the child's head;" she placed them in water, and afterwards put them into a pint bottle, which was of green glass and not over clean, as when she showed them to me they were mixed up with a soft, yellowish, shred-like material, which I did not examine closely, but hastily separated the worms and threw it away. I conclude the bottle must have contained some fungi which had escaped the mother's notice.

I find that on the morning the entozoa were seen the daughter had been to the butcher's and purchased a piece of beef, which she brought home about the time the mother commenced washing the child's head. I cannot, however, make out that the cloth in question and the meat ever came in contact, or the latter was ever placed on the table on which the cloth was.

I have since seen the butcher, who tells me that seldom a week passes that he has not livers in his shop containing fluke-worms, and sometimes in considerable quantities.

I have endeavoured to trace a connection between the visit of the girl to the butcher and the appearance of the fluke-worms on the cloth; but at present I have not been able satisfactorily to do so, though I think it probable their discovery will be found to have some such connection. 
The prejudice of the mother in believing the entozoa came from the child's head is such as to require great caution in receiving her statements. The above particulars I have obtained chiefly from the daughter, who is rather more trustworthy.

I ought, perhaps, to apologise for troubling you with the above detail, fearing that the interest of the case is such as not to justify engaging your valuable time and attention.

Permit me to repeat my best thanks for your prompt and generous cousideration of the case.

I remain, yours truly and respectfully,

Professor Owen,

J. Penn Harris.

\&c. \&c.

The following case, also related by Dr. Budd in the work above mentioned, appears to have presented a species of Distoma hitherto unique:

"In the winter of 1843 fourteen flukes were found by Mr. Busk in the duodenum of a Lascar who died in the Seamen's Hospital. There were none in the gall-bladder or gall-ducts. These flukes were much thicker and larger than those of the sheep, being from an inch and a half to near three inches in length. They resembled the Distoma hepaticum in shape, but were like the Distoma lanceolatum in structure; the double alimentary canal, as in the latter variety, being not branched, and the entire space between it towards the latter part of the body being occupied by a branched uterine tube."

Two specimens of this fluke are now in the Museum of King's College, and I have also one in my possession, presented me by Mr. Busk. This fluke differs from all the other species found in the human body, in its large size. It is not improbable that the ordinary habitat of this species is some of the lower animals inhabiting warmer climates, and that is was introduced into the system of the Lascar in the same way as Distoma hepaticum in other cases. In the absence of any other distinguishing name for this species, I have called it, after the name of its discoverer, Distoma Buskii. 


\section{Appendix C.}

\section{On Dactylius aculeatus, a worm inhabiting the human body, described by Mr. T. B. Curling, and Spiroptera hominis.}

Whilst the sheets of this translation were passing through the press, my attention was called to a case related by Mr. Curling, Surgeon to the London Hospital, in the twenty-second volume of the 'Medico-Clirurgical Transactions.' As the history of this case and the oecurrence of the animal seems to have escaped the attention of the author of this work, it seemed to me desirable, in order to render this volume as complete as possible on the subject of the entozon, to reproduce it here.

"Mlay 31st, 1839, I received from Mr. Drake, surgeon, of the Commercial Road, a number of small worms contained in urine, which had been voided a few hours previously by a little girl, his patient, accompanied with a request to know their nature. The following is the account he gave me of the case :

"The girl, who is five years of age, had enjoyed good health until June, 1837, when she had an attack of inflammation of the lungs in a sub-acute form, attended by a peculiar hollow cough, and a deranged state of the intestinal mucous membrane. She has been subject to this cough ever since; a slight cold or derangement of the bowels being sufficient to bring it on. She has likewise been occasionally troubled with the small ascarides. At the beginning of May she had an attack of measles, which left her weak and much emaciated. A troublesome cough remained, attended with fever of a remittent character, and her urine was highcoloured and scanty in quantity. Under mild antiphlogistic treatment the fever diminished, and the urine assumed a natural appearance.

"May 26th.--Some small worms were first observed in the urine this day, and for several succeeding days, on rising in the morning, she voided, from the urethra, seven or eight.

"June 1st.--Several Ascarides vermiculares were observed in her motions, but no worms were discovered in the urine this day or the following one. They were again observed, however, on June 3d; and several have occasionally passed since, in the morning.

"11th.--The cough has left her, and she is rapidly improving in health and strength. She has never suffered from any affection of the urinary organs.

"I found the urine in which the worms were contained high-coloured and slightly acid. It was observed that when first passed they floated separately in the urine, but in a short time they coalesced and coiled themselves up together in the form of a ball, at the bottom of the vessel, and it was with difficulty that they could be separated. When they were disturbed their motions were often very lively; and if allowed to remain in the urine they lived for two or three days. They were very transparent, so that the contents of the alimentary canal could easily be 
distinguished by the naked eye. On immersing them in spirits of wine they soon beeame white and opaque. They were of two sizes; the larger worms being more numerous than the smaller.

"A slight examination at once convinced me that these worms could not belong to any of the species of entozoa at present known to infest man; and, considering the period of the year, I was at first induced to imagine that they must be the larva of some insect. On placing one in the field of the microscope, I recognised a beautiful organization, and true nematoid structure; and, on referenee to Rudolphi's 'Synopsis Entozonrum,' and other works on this subject, I discovered that it was an entozoon which had not hitherto been described. Having received several of these worms from Mr. Drake, at different times, 1 have had an opportunity of making repeated examinations of them by the aid of the microscope, in which I have had the advantage of the kind assistance of Professor Owen and Mr. John Quekett. The animals, being alive and active, formed very interesting objects, as we could readily see and watch the curious actions taking place in their interior.

"The worm is of a light colour, cylindrical in its form, and annulated, and tapers slightly towards both the extremities, but chiefly towards the anterior, which is the smaller. The female measures about four-fifths of an inch in length; the male, as is the ease with most of the nematoid worms, is much smaller, being about two fifths of an inch long. They vary, however, a good deal in size, especially the males. The head of the worm is obtuse and truncated, and has an orbicular mouth. The mouth is generally not very apparent, and several worms were examined before I suceeeded in discovering it. The neck is distinctly annulated. 'The tail is obtuse and also annulated, but not so mueh so as the neck. The tegument is a delicate transparent structure, containing two layers of fibres, one circular and the other longitudinal, both of which I believe to be muscular. After the rupture of a worm which had been in dilute spirit, these fibres were seen with great distinctness projecting at the injured part. The tegument is armed with a number of sharp-pointed spines, arranged in clusters of three or four, and sometimes five, in longitudinal equi-clistant rows. The intervals between the spines in each row, measured by means of the micrometer, were found to vary from one fiftieth to one seventieth of an inch. With the exception of a small part of the body to be noticed presently, the tegument was completely defended by these spines, which were detected as near the head as the third ring, and also close to the extremity of the tail. It was generally observed that, at the anterior part of the body, the spines were directed posteriorly, whilst about the centre they projected outwards, and near the tail pointed towards the head. On examining the worm slightly compressed between two pieces of glass in the field of the microscope, I often obtained a lateral view of the spines attaehed to the sides of the animal, and $I$ could then very distinctly discern their motions, the animal having apparently the power of protruding and retracting them at pleasure. 'The spines are attached to the external tegument, into which, when retractel, they are received; and they appear to be moved by a number of fibres radiating outwards, in the substance of the tegument. The alimentary canal appeared, on some oceasions, of a light, yellow colour; on others, it presented a brownish hue. Upon examining a large female worm, the alimentary canal appeared to commence at the mouth, by three small 
convoluted tubes, which were shortly afterwards united into a single one. 'The single tube, after proceeding' for some distance in a tortuous course, became sacculated, and, enlarging as it descended, it terminated at the extremity of the tail in a trilobular aperture, the anus. On one occasion I saw very clearly the opening and closure of this orifice. The commencement of the alimentary canal by three tubes was not always apparent, and for some time I imagined that it began by a single tube. The motions of this canal were extremely beautiful. It moved freely in the interior of the animal, at one time becoming straight and at another time convoluted, as the body of the worm was extended or diminished. It also moved backwards and forwards in an extraordinary manner, and the sacculi were seen to close and dilate by a sort of peristaltic action. On each side of the alimentary canal, at its commencement, there is a series of lobulated bodies, the structure and office of which I could not make out. They were of a light colour, and accompanied the osophagus in its lively movements in the longitudinal direction. In several male worms a band was seen running along the centre of the intestinal canal, being lost near the anus.

"By the side of the alimentary canal, and sometimes crossing it obliquely, I observed in many instances, especially in the female worms, a distinct tube of a faint light colour, marked by transverse bands, which seemed to have independent motions, somewhat of a pulsating character. It was generally seen near the anterior part of the body, but it could be traced for some distance towards the posterior. The pulsating character of this tube was first determined by my friend Mr. Owen; the pulsations occurred at intervals of from eight to twelve seconds. This tube forms, in his opinion, the analogue of the dorsal artery of the amnelida. In several worms I could distinctly perceive two light-coloured vessels twining round the alimentary canal near the head, which gave off lateral branches, and afterwards, joining, formed a single trunk, which also sent off branches from its sides. Between the intestinal canal and external tegument I could distinguish, on numerous occasions, an extremely rapid eirculation of minute globules, which passed in two contrary directions, side by side, in a continuous stream. This was observed at intervals nearly the whole length of the animals, being frequently obscured by the movements of the digestive tube. I could also discern, near the tail, a number of globules passing slowly in longitudinal and transverse eurrents, and crossing the alimentary canal. ${ }^{1}$

"The structure of the female worm is much more complicated than that of the male. The vulva is situated near the anterior extremity, about one fifth of an inch from the head. It appears like a mamillated process, is somewhat opaque, and can be discemed by the unassisted eye. The animal swells at this part, the tegument is thicker, there are no spines, and, for a short distance above and below the vulva, the body is encircled by a series of regular, dark-coloured fibres. About mid-distanee between the head and vulva, and on opposite sides of the digestive tube, I inva-

The worm became so opaque after immersion in spirit, and decomposed so rapidly, that much of the beautiful organisation that I have described became lost to the observer shortly after deatl. I attempted to preserve some in salt and water, and in dilute vinegar, but without any better result. 
riably found, in the numerous microseopic examinations which I made of the female worms, two oval granular bodies or glands. Immediately below these oval bodies there are two slightly convoluted tubular processes. It was a long time before I could make out the structure of these proeesses; but after repeated investigation I found that each terminated at one end in a free extremity, of a bell shape and brownish red colour, which was beautifully fimbriated. This free extremity moved about in the interior of the animal in various directions with great freedom; and the difficulty of making out the structure of these boclies was chiefly owing to the diversity of shape and appearanee which under these circumstances they presented. They probably had some connection with the alimentary canal, as they accompanied it in its frequent movements in the longitudinal direction. From the other extremity of each of these bodies there appeared to proceed a small convoluted tube, and the two, after running together for a short distance along the digestive tube, joined the oviducts; but this junction was not very clearly seen. The oviducts consisted of two small tubes, which were distinctly traced commencing at the vulva, and then twining in a very tortuous manner around the alimentary canal, about as far as half way between the anus and vulva.

"I made many careful examinations of the smaller worms, but I could distinguish neither penis nor any genital apparatus whatever; though, in some of the specimens, I observed, near the anterior extremity, darkcoloured transverse lines, similar to those marked in the vicinity of the vulva in the fernale. Can these be young worms, the sexual organs of which have not yet been developed, or are they not animals of the male sex? There is certainly not sufficient evidence to warrant any positive conclusion; but, inasmuch as in most of the nematoid worms there is the same disparity in the sizes of the two sexes as in those of the worns in this case, and, with the exception of the dark lines just alluded to, as the smaller specinens exhibited no trace of the complicated structures remarked in the female, I have preferred considering them at present as belonging to the opposite sex.

"From the above description, those conversant with the structure of the entozoa will readily reeognise a true nematoid structure. These worms differ, however, from all the known genera of this class, not only in wanting the characters by which they are distinguished, but in possessing several peculiarities in structure, namely, a well-marked annulated body, an anal aperture of a labiated form, and a tegument armed throughout with spines. Referring, therefore, this entozoon to the order Nematoidea of Rudolphi, in which it would constitute a new genus, its character may be thus described:

"Genus Dactrudus. 1

"Corpus teres elasticum anmulatum et utrinque attenuatum, caput obtusum os arbiculare, anus trilabiatus.

"Dactrlius aculeates.

"Capite obtuso, toto corpore aculcorum serie multiplici armato, cauda obtusâ et annulatâ.

$H a b$. in Hominis vesicâ urinariâ.

1 From iastúdtoc, annulus. 
"Spines are found attaehed to the head in many different speeies of the entozoa; but the existence of these curious dermal processes on the body has been observed in only one worm of the nematoid class, the Strongy? us horridus, an animal found by Rudolphi in the asophagus of the waterhen. In this worm they consist of reflected hooklets, and are arranged in four longitudinal rows, but they are only continued for a short distance along the body, and, in the representation given of them, ${ }^{1}$ appear to be single instead of occurring in clusters, as in the dactylius acnleatus. Professor Owen, in speaking of these epidermie proeesses, which he considers serve as prehensile instruments to retain the proboscis and the worm in its position, remarks, - "When they are spread over the surface of the body they may have the additional function of aiding in the locomotion of the speeies, analogous to the spines which arm the segments of the œstrus, which passes its larva state, like any entozoon, in the interior of the stomach and intestines of a higher organized animal."'2

Two specimens of this worm, are preserved in the Museum of University College, and another in the Microscopic Cabinet of the Royal College of Surgeons of England.

As the notice of the rarer forms of Entozoa may lead to their more extensive observation, I am induced to add the following notice of the Spiroptera hominis from Professor Owen's article "Entozoa" in the "Cyclopedia of Anatomy and Physiology.'

"With respeet to the following parasite of the human body, the Spiroptera hominis, Rud., considerable obscurity prevails. A poor woman, who is still living in the workhouse of the parish of St. Sepulchre, London, has been subject, since the year $1806^{\circ}$ (when she was twenty-four years old), up to the present time, to retention of urine, aceompanied with distress and pain indicative of disease of the bladcler. The catheter has been employed from time to time during this long period to draw off the urine, and its application has been, and continues occasionally to be, followed by the extraction and subsequent discharge of worms, or vermiform substances, with numerous small granular bodies. The latter are of uniform size, resembling small grains of sand: those which we have examined, and which were preserved in spirit, present a subglobular, or irregularly flattened form; but when recently expelled, I am assured by my friend Dr. Arthur Farre, that they are perfectly spherical; they consist of an external smooth, firm, diaphanous coat, including a compact mass of brown and minutely granular substanee. The inner surface of the containing capsule presents, under the microscope, a regular, beautiful, and minute reticulation, produced by depressions or cells of a hexagonal form. These, therefore, we regard as ova, and not as fortuitous morbid productions. The vermiform substances are elongated bodies of a moderately firm, solid, lomogeneous texture, varying in length from four to eight inches; attenuated at both extremities; having the diameter of a line

1 'Entozoorum Historia Naturulis,' vol. i, tah. 3, figs. 8 and 9.

2 'Cyclopradia of Anatomy and Physiology,' Art. Entozoa, vol. ii, p. 127. 
half-way between the extremities and the middle part, where the body is contracted and abruptly bent upon itself. Some are irregularly trigonal, others tetragonal. In the three-sided specimens ove surface is broad, convex, and smooth; the other two are narrow and coneave, and separated by a narrow longitudinal groove, in which is sometimes lodged a filamentary brown concretion. In the tetragonal portions the broad smooth surface is divided into two parts by the rising of the middle part of the convexity into an angle. The most remarkable appearance in these ambiguous productions is the beautiful crenation of one of the angles or ridges betwcen the convex and concave facet; which, from its regularity and constancy, can hardly be accounted for on the theory of their nature and origin suggested by Rudolphi: "lymphamque in canatibus fistulosis coactam passimque compressam filum inæequale efformare crediderim.' On the other hand it is equally difficult to form any satisfactory notion of these substances as organized bodies growing by an inherent and independent vitality. We have not been able to observe a single example in which the substance had both extremities well defined and unbroken; these, on the contrary, are flattened, membranous, and more or less jagged and irregular. They present no trace of alimentary or generative orifices on any part of their exterior surface, nor any canals subservient to those functions, in the interior parenchyma. If subsequent observations on recently expelled specimens of these most curious and interesting productions should, however, establish their claims to be regarded as Entozoa, they will probably rank as a simple form of Sterelmintha.

"The existence of the Spiroptera hominis is founded on the observation of substances very different from the preceding productions. ${ }^{\$}$ The specimens so called were transmitted to Rudolphi, in a separate phial, at the same time with the ova and larger parenchymatous bodies above described, and are presumed to have been expelled from the same female under the same circumstances. They consisted of six small Nematoid worms of different sexes; the males were eight, the females ten lines in length, slender, white, highly elastic.

"The head truncated, and with one or two papilla; the mouth orbicular, the body attenuated at both extremities, but especially anteriorly. The tail in the female thicker, and with a short obtuse apex; that of the male more slender, and emitting a small mesial tubulus, probably the sheath of the penis : a dermal aliform production near the same extremity determines the reference of this Entozoon to the genus Spiroptera.

"There are no specimens of this Entozoon among the substances discharged from the urethra of the female, whose case is above alluded to, which are preserved in the Musenm of the College of Surgeons." 



\section{EXPLANATION OF THE PLATES.}

\section{PLATE (TAB.) I.}

Fig. 1. Vibriones, after Lebert.

" 2. Trichomonas vaginalis, after Donné.

" 3. Amæboid corpuscles, after Wagner and Lieberkühn.

$"$ 4. Colourless blood-corpuscles of man, after the same.

" 5. Egg $(a)$, and escaped embryos $(b, c)$, of Tania dispar from the frog, after Van Beneden. At $d$ the niddle hook for boring is dotted.

„ 6. Migration-passages of the brood of Tania Conurus in the brain of the sheep $(a)$, and a young Coenurus attached $(b)$.

" 6 (below). Shedding of the hooks of the migrated brood.

"7. Migration-passages of Tania serrata on the surface of the liver of the rabbit.

" 8. A suite of small Conuri.

"9. Diagraminatic representation of the development of Ceenurus and its hooks.

\section{PLATE (TAB.) II.}

1. Bothriocephalus latus.

2. Uterus and egg-sacs of the same.

3. External, and 4, internal organs of generation, magnified, after Eschricht.

5. Eggs, closed and with embryo escaping.

6. Cysticercus tenuicollis.

7. Head of the same, after Eschricht.

8. Hooks of the second row, after the same.

9. Ilooks of both rows, after the same.

10. Uteri of Tania ex Cysticerco tenuicolli.

11. Luschka's representation of the origin of the fluid of the caudal vesicle of Cysticerci.

\section{PLATE (TAB.) III.}

"1-3. Eggs and cmbryos of Tonia solium.

"4. Cysticercus cellulose in the flesh.

" 5. The same six weeks after feeding a pig with Tania solium.

" 6. The same in the retina of the human eyc, after Von Gräfe. 
Fig. 7. Head of Tenia solium with its rascular system, which probalbly anastomoses before and behind, as shown by the dotted line.

„8. Head of Trenia solinm in front.

" 9. Crown of hook-sacs on the head of Tania solium.

"10. Penis and uterus of the same magnified three times.

"11. Tania mediocanellata of Küclıenmeister.

,12. Uterus and penis of the same (magnified $1 \frac{1}{2}$ ).

"13. Egg of the same.

"14. Tape-worm from the Cape of Good Hope.

, 15. Uterus of the same.

, 16. Eggs of the same.

, 17. Echinococcus scolicipariens, Küchenmeister $=$ E. veterinorum.

$a$. With the stalk dependent and head drawn in.

b. Free, with the vascular system, after Wedl.

c. Hooks of the first row (magnified 400 times).

$d$. The same of the second row. The small free points indicate free moving Echinococci, those attached to the sides of the cyst are the scolices (natural size).

"18. Echinococcus altricipariers, Küchenmeister $=$ E. hominis (a cyst diminished).

a. Daugliter-resicles of natural size.

$a^{\prime}$. The same with Echinococci magnified.

$b$. The same with grand-daughter vesicle of natural size.

c. The same separated from its stalk in the urinary blarlder (of natual size).

d. Exhibits the further process of nesting.

e. Isolated free Echinococci.

$f$. Hooks of the first row (magnified 400 times).

$g$. The same of the second row.

The dots indicate the small Echinococci which swim freely in the fluid of the cyst. "19. A transverse incision through the walls of the mother-and daughter-resicles.

\section{PLATE (TAB.) IV.}

1. Tania Echinococcus scolicipariens magnified.

2-4. Hooks of the same of the first row, magnified 650 times.

5-6. The same of the second row.

, 7-8. The same deformed.

" 9. Egg of this Tania.

"10. Hooks of Echinococcus altricipariens magnified 650 times.

$a, c, d$. Hooks of the first row.

$b, e$. The same of the second row.

"11. Distoma heterophyes, after Bilharz.

12. Prickle of the penis of the same.

"13. Distoma in the eye, after Von Ammon.

"14. Distoma in eye.

"15. The same isolated.

The diagram represents the hooks of rarious tape- and cyst.worms, according to their relative size.

a. Total length.

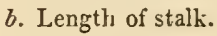


Fig. :5, c. Length of claw.

d. Total length of the lateral process, (spine, Dorn, Tap).

e. Breadth of the same.

$f$. Breadth of stalk.

I. Hooks (first and second rows) of Tania serrata and Cysticercuspisiformis.

II. Ditto of Trenia ex Cysticerco tenuicolli and of Cysticercus tenuicollis.

IIr. Ditto of Trenia solium and of Cysticercus cetlulose.

Iv. Ditto of T. litterata, Rudolphi, and of Cysticercus.

v. Ditto of T. crassiceps, Dujardin, and of Cysticercus.

vi. Ditto of T. crassiceps, Rudolphi, and of Cysticercus.

vir. Ditto of $T$. intermedia and of Cysticercus.

vi1. Ditto of Echinococcus scolicipariens.

Ix. Ditto of E. altricipariens.

\section{PLATE (TAB.) V.}

3. The parts $e^{t}$ and $h$ of the foregoing figure magnified.

a. Point of union of the yelk-sac.

b. Germ-stock (ovary).

c. Single yelk-cells (vitelline bodies), as they pass from $a$. size.

2. The same magnified twenty times.

$a$. Oral sucker.

$a^{\prime}, a^{\prime}$. Cut ends of the intestinal tube.

$f$. The ventral sucker.

$g, g, g$. Convolutions of the testes. uterus. ration. the vascular system has not becn clearly made out.

-6. Eggs of the Distoma in various stages of development.

7. Tip of the penis magnified.

8. Portion of the spinous membrane (magnified 500 times).

9. Development of the spermatozoa.

10. Peculiar vacuoles formed by muscular layers.

11. Distoma lanceolatum.

1. Distoma hepaticum, with the ramifications of the intestinal tube, twice ratural

$b, b, b, b$. Yelk-sacs which collect together in the lateral ducts, $b^{\prime}, b^{\prime}$, which communicate with a lenticular enlargement $c^{\prime}$, by a transverse branch from each side, $c$. The convoluted nterine duct, $d, d, d$, proceeds from $c^{\prime}$, becoming larger as it proceeds, and terminates in the narrow vagina, $e, e$.

$h$. The germ-stock lying behind $c^{\prime}$. Continuation of $g$, representing a vesicula seminalis interna, appearing to open into $h^{\prime}$, the commencement of the

$i, i$. Funiculi spermatici proceeding from a tube $k$ at the entrance of the sac of the penis, which is seen to communicate with the male organ of gene-

The red lines indicate the organ of excretion which forms behind a large efferent vessel which in the young Distoma is seen to contain small transparent globules. The connection between this organ and

a. Oral sucker, œsophagus, and blind double intestinal tube. 
Fig. 11, b. Water vascular-system and organ of cxcretion.

c, c. Yelk-sacs.

d. Horizontal efferent duct of the same.

e. Uterus.

$f$. Point at which the eggs become brown-red.

g. Vagina.

$h$. Ventral sucker.

$i, i$. Testes with efferent ducts.

k. Vesicula seminalis exterior (sac of penis, cirrhus-beutel).

l. Vesicula seminalis interior.

"12. Egg of this Disloma.

\section{PLATE (TAB.) VI.}

1. A male of Distoma hæmatobium grasping the female in a gynœcophoric canal.

$a$. Head of female projecting from the caul.

$b, c$. Tail of the same.

b. Spot where the two loranches of the divided intestinal tube unite.

c. Spot where the united hlind gut ends.

$d, d$. The body of the encloser female within the male.

$e$. The clink of the gynœcophoric canal closed.

$f$. The same somewhat open.

$g$. Base of the canal.

7. Seat of the male genitalia.

$i$. Oral sucker of the male.

$k$. Stoniach of the same.

2. Anterior portion of the body of the male of Distoma homatobium viewed from the ventral aspect.

a. Oral sucker.

b. Ventral sucker.

c. Dichotomous intestiual tube.

d. Sac of the penis.

e. Testes.

3. Anterior portion of the female.

a. Mouth.

b. Ventral sucker.

c. Opening of the oviducts.

d. Division of the intestinal tube.

e. Eggs in the oviducts.

$f$. Oviducts.

"4. Egg of the same from a calcified tubercle from the liver.

"5. Egg from an open vessel in the intestinal mucous meinbrane.

" 6. Egg with the living embryo.

, 7. Egg with the escaping embryo.

" 8-9. Free embryos.

, 10-12. Empty egg-shells.

,13. Yonng animal in larva-case.

"14. Young animal, a quarter of an hour after hatching. 
Fig. 15. The same, after the action of water.

" 16. A male Ancylostomum duodenale, of the natural size.

"17. The same, magnified, and seen laterally.

a. The long single penis.

b. Region of anus.

c. Opening of the two organs of secretion.

d. Lower broader portion of the organ of secretion, with a nucieus.

$e$. The convolution of the cysts.

"18. Female of Ancylostomum duodenale, of natural size.

"19. Lateral view of the same, largely magnified.
a. Oral aperture.
b. Anus.
c. Opening of both organs of secretion.
d. Vulva.

"20. Lateral view of the upper part of the body of Ancylostomum duodenale.

a. Lower portion of the ventral edge of the oral sucker.

b. Upper portion of the edge of the sucker, towards the back.

c. Muscular œesophagus.

d. Intestine.

$e$. Secretory organ of left side.

$f$. Opening of the secretory organs on the ventral side of the worm.

, 21. Posterior riew of the upper part of the body of the same worm. The dental apparatus is seen through the oral aperture above.

$a$, a. Lateral papillix.

"22. One of the four teeth from the oral aperture of the same worm.

"23. Anterior view of the same norm.

$a$. Lower arch of the oral aperture.

$b, b$. The lateral papillæ.

$c, c$. The two secretory organs.

$d, d$. Their nuclei.

e. Their openiugs.

"24. Lateral view of the posterior extremity of a male Ancylostomum duodenale.

a. The straight penis.

b. Dorsal sile.

c. Ventral side.

d. The middle single ray of the eleven parenchymatous rays projecting from the open caudal vesicle.

$e$. Region of the anus.

"25. Posterior view of the same.

a. The right flap of the caudal vesicle.

b. The middle single parenchymatous ray.

„, 26. Male of Oxyuris vermicularis, magnified 230 times.

a. Winglike appeudage to the mouth of the worm.

b. The pharynx, with club-shaped enlargement.

c. The head of the gullet, with a peculiar valvular apparatus in its intertos (a kind of gizzard).

d. Stounacl.

$e, e$. Intestinal canal. 
Fig. 26, $f$. Spermatic organ with the sperm-cells.

. 27. Egg, with perfect embryo.

. 28. A piece of the edge of the chitinous skeleton of the female, magnified 250 times.

. 29, 30. Eggs.

. 31. Female of Oxyuris vermicularis, magnified 40 times.

$a, b, c, d, e$, as in fig. 26.

$f$. Opening of the anus.

g. Opening of the vagina.

$h, h, h, h, h$. The organs preparing and carrying the eggs. They divide into an anterior and posterior branch, of which the first is seen at $k$.

.3 $3 a$. External termination of the vagina, with the eggs cscaping.

(Figs. 11-15 after Griesinger, the remaining figures, from 1-25, after Bilharz).

\section{PLATE (TAB.) VIY.}

. 1. The male of Trichocephalus dispar, magnified 120 times.

a. Month, with the papillæ.

$a^{\prime}$. Esophagus.

b. Convolutions of the intestines, or œsopliagus.

c. The two appendages on the anterior portion of the above.

d. Narrowing of the intestinal portion behind $c$.

$d^{\prime}$. The special stomach.

$d^{\prime \prime}$. Intestinal canal lined with epithelium (see fig. 8, $d$ ).

$d^{\prime \prime \prime}$. Opening of the intestinal tube and spermatic duct into a common cloaca, $e$. At this point there is a valve for the intestine, and another for the spermatic duct.

f. Spermatic duct.

g. Contraction and subsequent terminal expansion of the duct.

$h$. Opening of the spermatic cord into the cloaca.

i. A band which covers the penis and its sheath.

k. Penis.

1. End of the penis.

$m$. Radiating external copulative appendage attached to the end of the penis.

. 1. Trichocephalus dispar, of natural size.

., 2. Female of Trichocephalus dispar. The lower part of the body from the stomach

a. The stomach.

b. The intestine.

c. The anus.

d. The vagina.

$e$. Convolutions of the uterus.

The edges of this figure are notched, which is not the case in figure 1, but the notching is always present.

" 3. The external copulative appendage of the male (fig. 1, $m$ ), magnified.

4. Egg of Trichocephalus dispar, magnified 320 times.

5. Trichina spiralis in its capsule, after Luschka.

6. An isolated capsule with a pointed appendage. 
Fig. 7. An isolated Trichina spiralis, after Luschka.

a. The head.

b. The apparently articulated tube of the intestinal canal (œsophagus); it attains its greatest size at the point $b$, and is filled with elementary corpuscles.

$c$. Commencement of a blind tube in the posterior part of the animal, which encloses another tube containing dark granules $(d)$; these are perhaps the primordial elements of the subsequent generative organs.

e. The caudal extremity, witl, according to Luschka, a well-marked anus with three valves.

8. Trichina spiralis, dissected, after Luschka.

a. Expausion of the anterior part of the alimentary canal, imbedded in parcnchyma.

b. The same, free.

c. The funnel-shaped stomach, with two lateral vesicles or appendages.

d. Continnation of the intestine below, with epithelial (flat) cells in the wall.

e. The second tube of the lower half of the body (primordial generative structures). (Figures 5-8 after Luschka.)

PLATE (TAB.) VIII.

. 1 a. Male of Strongylus gigas, natural size, after Bremser.

" $1 b$. The head, somewhat magnified, after Bremser.

" I c. Female of the same, of the natural size, with the eggs somewhat magnified.

a. Head and oral aperture.

๖. Esophagus and stomach.

c. Intestinal canal.

d. Vagina and commencement of uterus.

$e, e$. The longitudinal line along its edges.

"2a. Filaria hominis bronclialis, after Trentler. This is the Strongylus longevaginatus of Diesing.

$2 b$. A somewhat magnified view of the posterior part of the body of the male, with the two projecting spicules.

3. Lower portion of the body of Filaria medinensis. The dark portion in the middle is the intestine terminating in the anus.

" $3 a$. Head of this worm with three papillæ, after Birkmeyer.

. 4. Male of Ascaris lumbricoides, of the natural size.

a. Esophagus.

b. Intestinal canal.

c. Spermatic duct.

d. Lateral longitudinal line. The spicules are seen at the end of the tail.

5. Female of the same worm, of natural size.

$a, b, d$. As in fig. 4 .

$e, e$. The two nterine cords which run down to within one inch of the end of the tail and anus, and open externally at the vagina.

"6. The mouth, with its thrce hyaline flaps and comb-like muscles, with the retortshaped excavated cntrance to the intestiual canal. 
Fig. 7. Mouth, with the flaps extended.

" 8. Caudal extremity of a young female, with the anus and the undulating toorhed lateral edges, and projections of these edges.

"9. The two sword-shaped spicules of the penis, magnified.

, 10. Epithelium from the uterus.

N.B. The remaining objects on this plate are described in the second volume of the Translation, and are explained in that volume. 


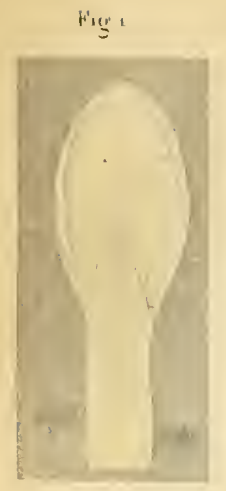

F IV

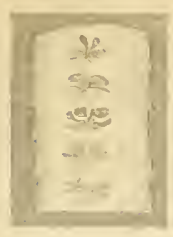

fing

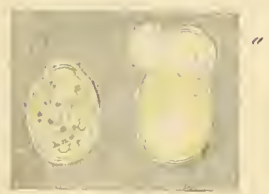

Frov

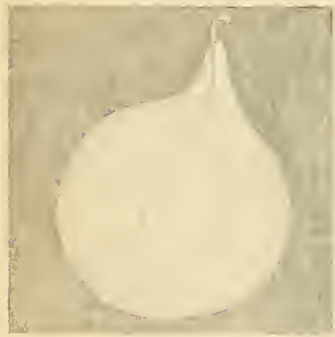

liaw

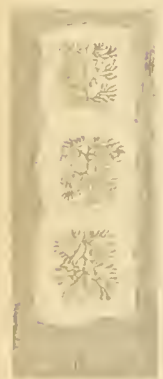

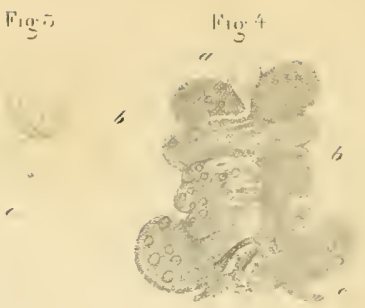

Figy





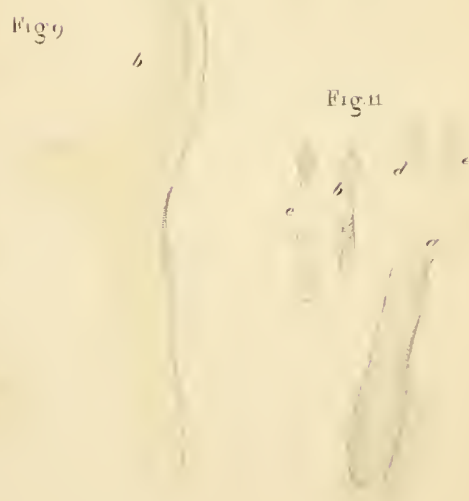

C Landel ar. 

Iab III


Fig

"g" $=8 x=0$
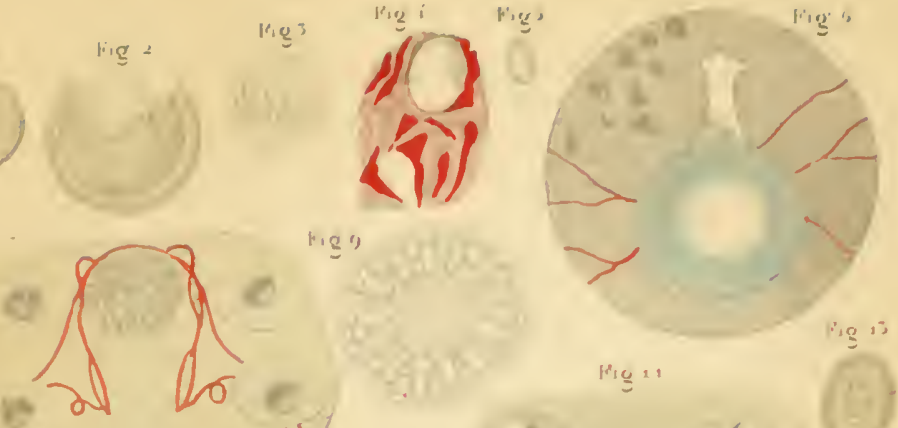

$\operatorname{Hig}=1$
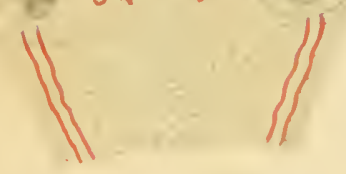

Fig 8



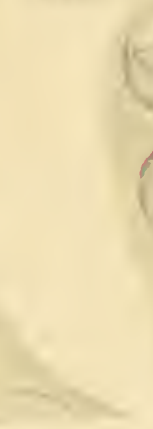

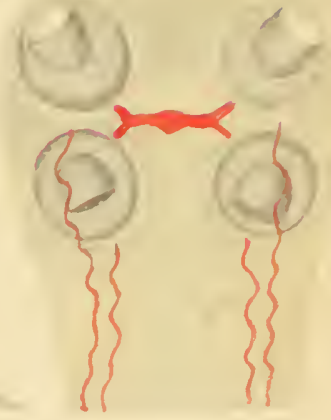

Fig is

Fig 19

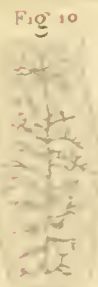

$-4 \sqrt{20}-$

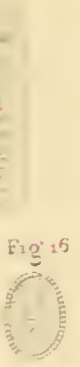

$\operatorname{rig}{ }_{1} \delta$
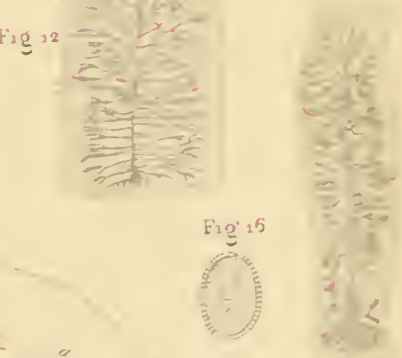

Pig 14

Treb IV

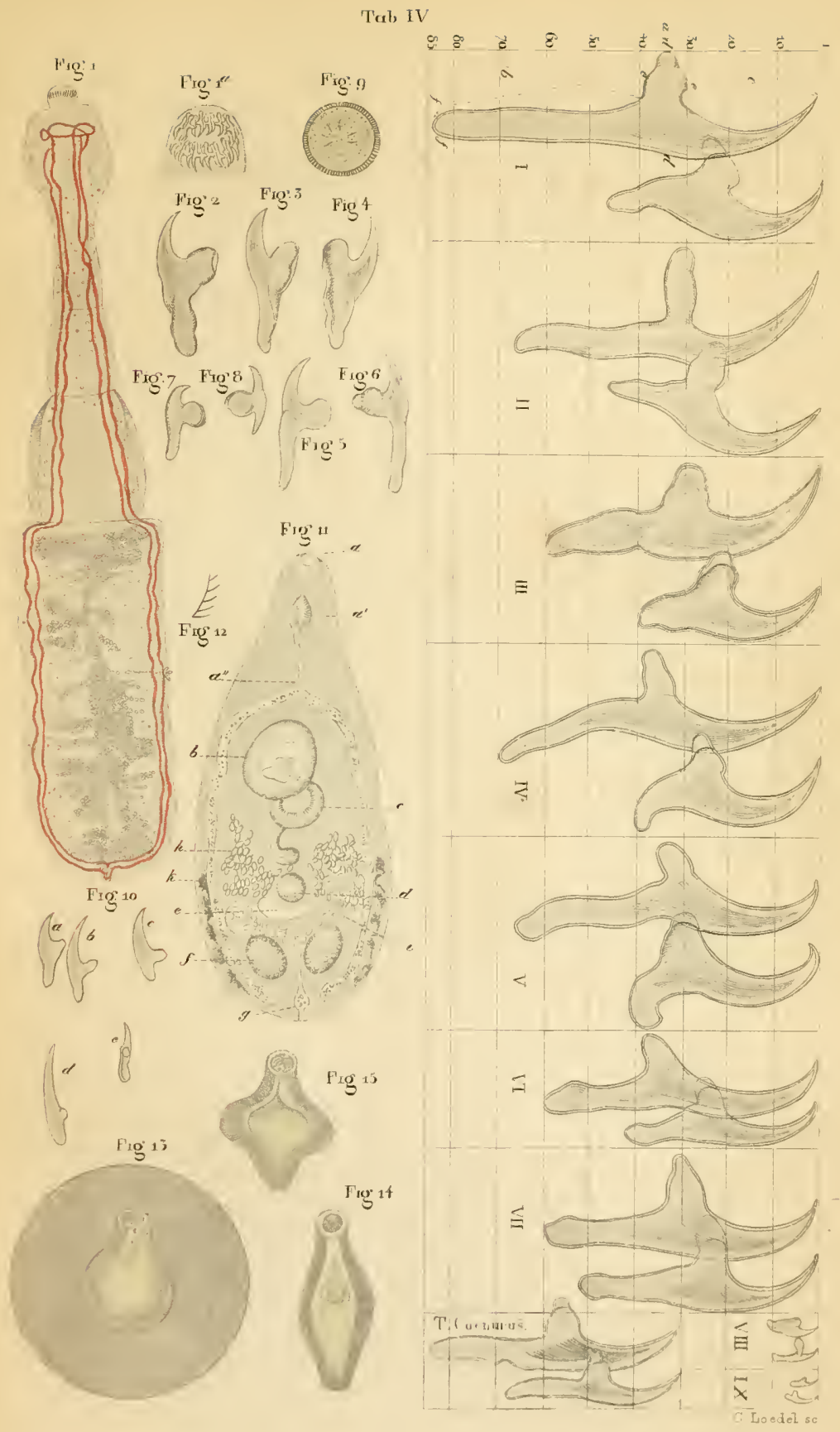



Fig. I.

Yip.
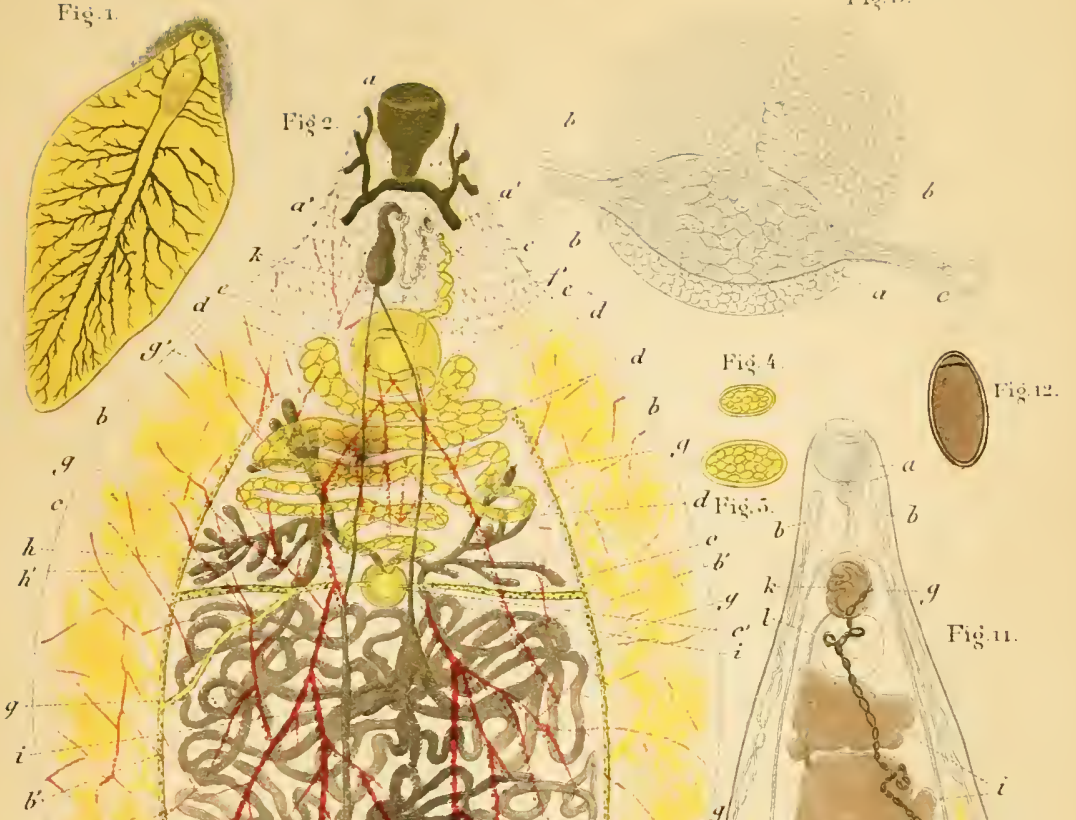

Fig. 9. $c$

tid 120



210
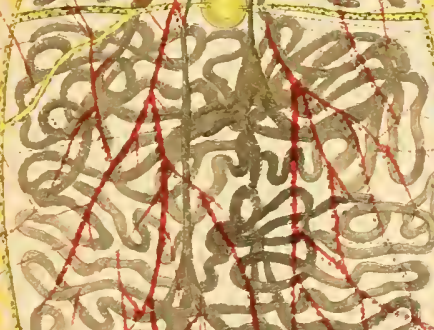

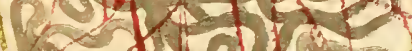

$-1,13,1$.

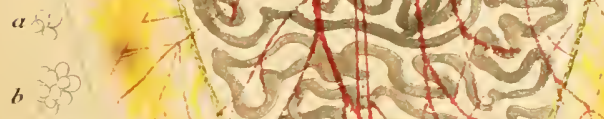

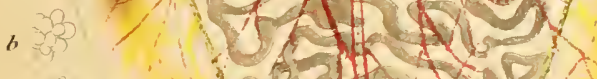



Iisi.

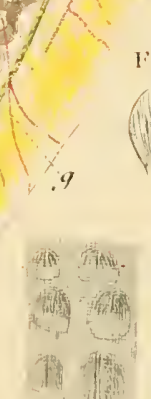

I'ig in
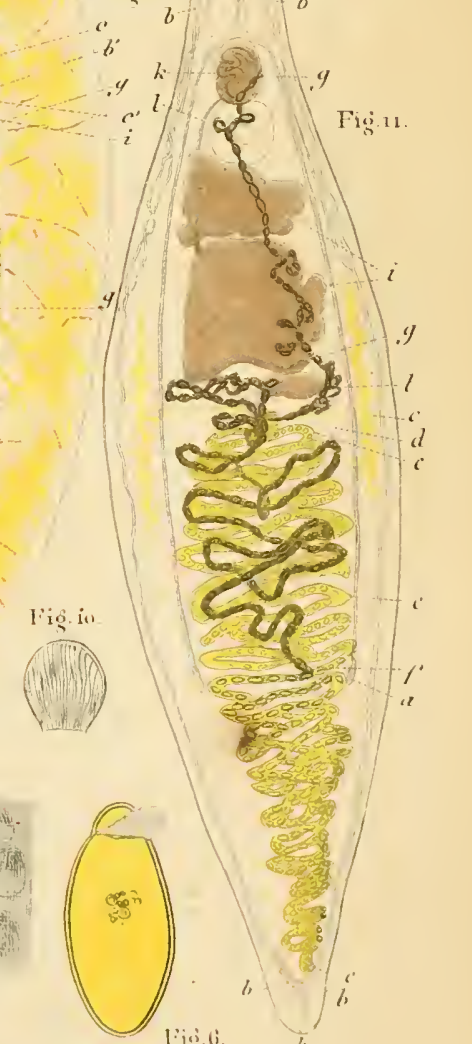

Tab.VI

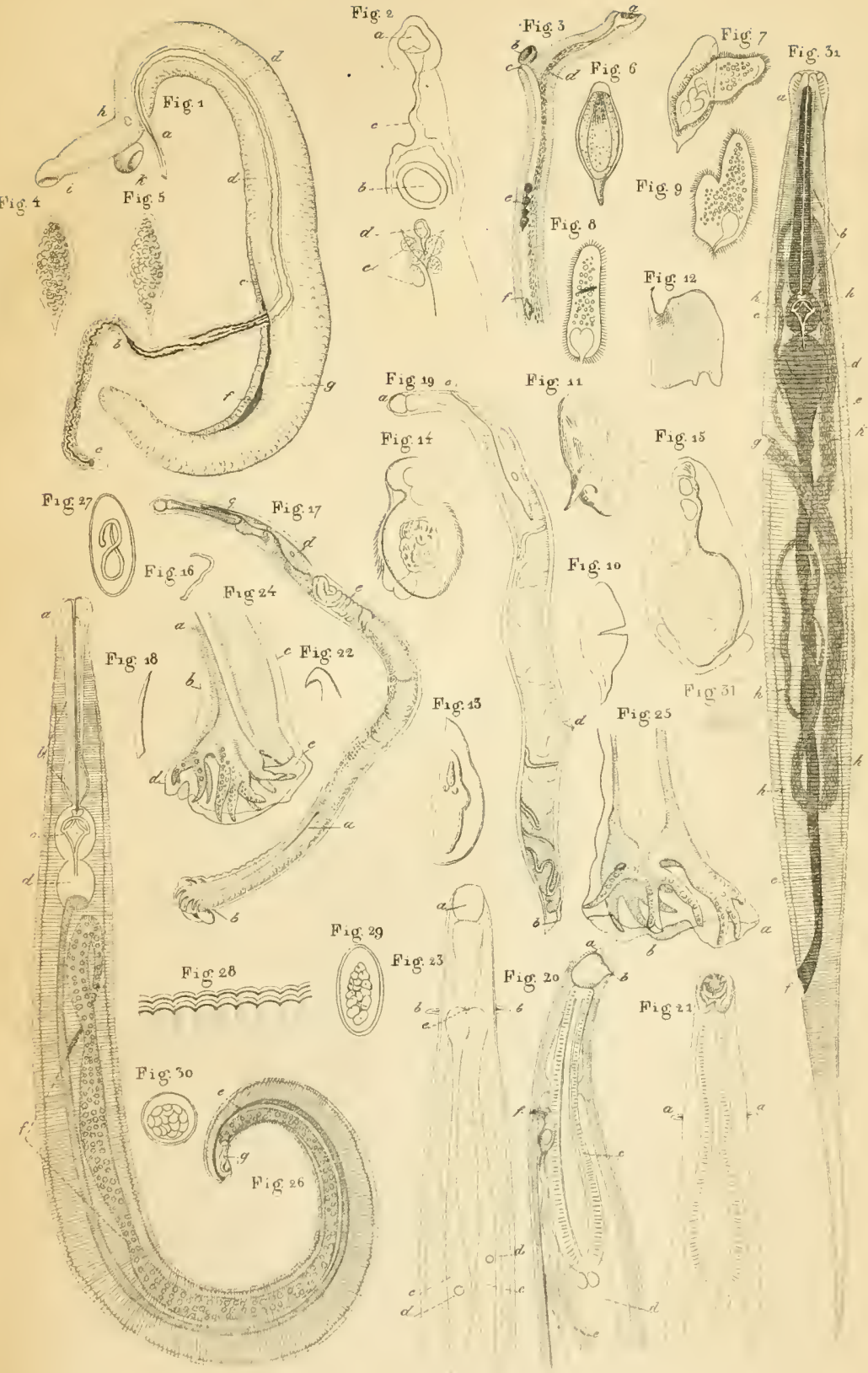


Tab.VIl .

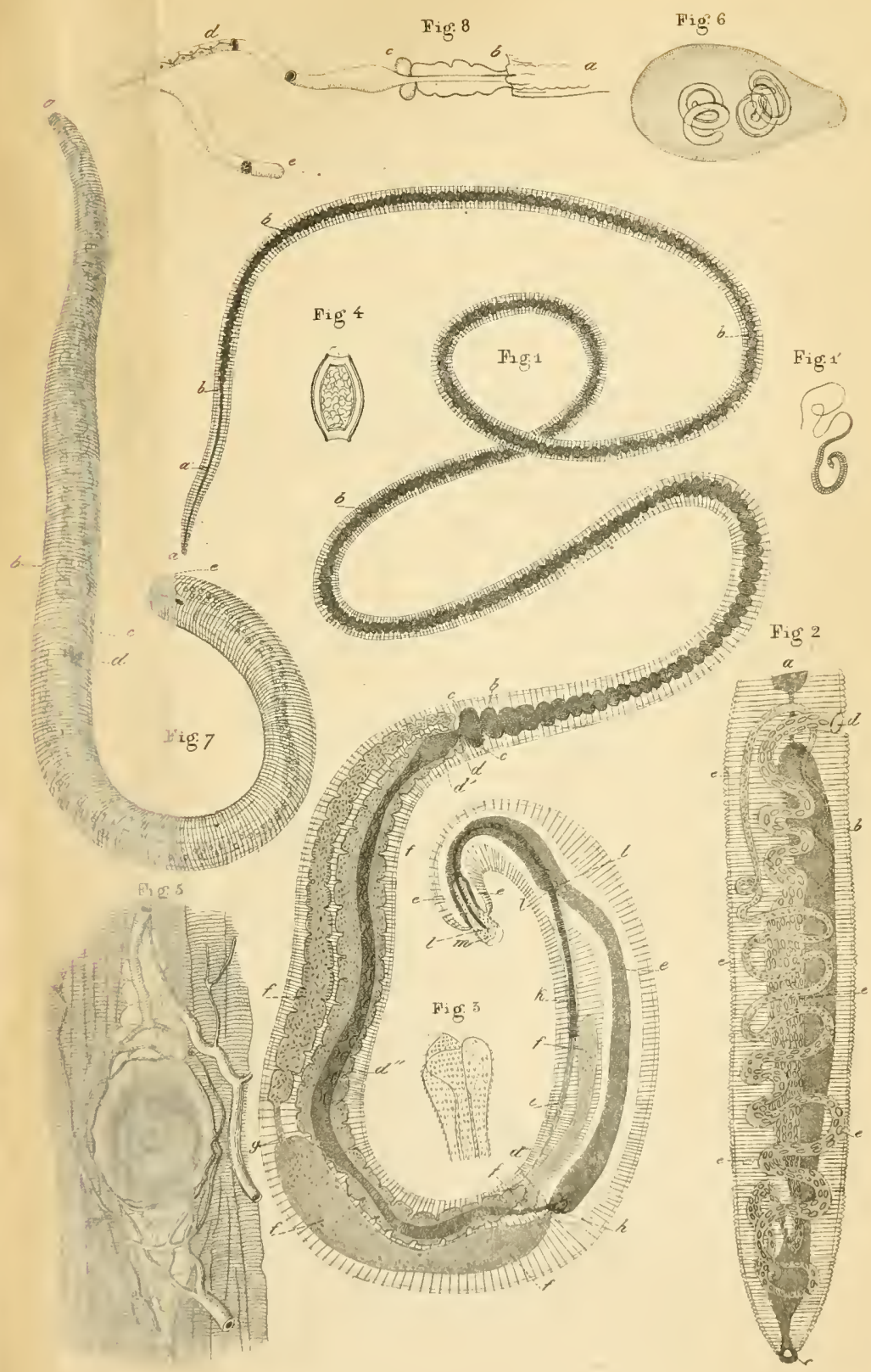



Tab. VIII

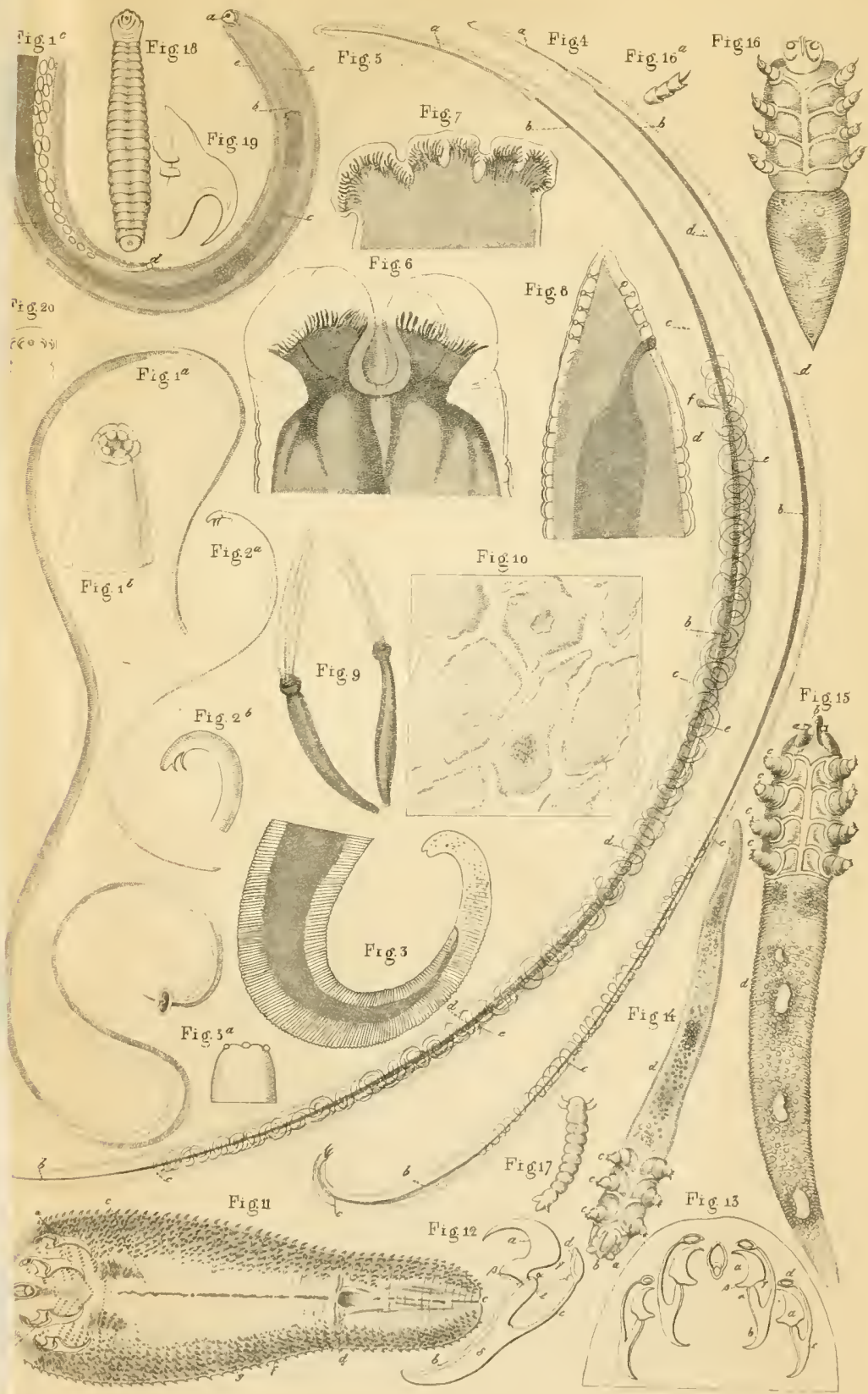




